Friedemann Tetsch

\title{
Raumwirkungen des Finanzsystems der Bundesrepublik Deutschland
}


Friedemann Tetsch

\section{Raumwirkungen des Finanzsystems der Bundesrepublik Deutschland}

ÜBER DEN AUTOR:

Geb. am 24.5.1948 in Rinteln/Weser, Abitur im Mai 1967 in Rinteln, nach der Wehrdienstzeit Studium der Volkswirtschaft in Kiel, Diplom-Prüfung im Wintersemester 1973/74, anschließend Mitarbeiter von Prof. Dr. W. Albers im Institut für Finanzwissenschaft der Universität Kiel, seit 1.11.1977 im Bundesministerium für Wirtschaft. 
Raumwirkungen des Finanzsystems

der Bundesrepublik Deutschland 


\title{
Finanzwissenschaftliche Schriften
}

\author{
Herausgegeben \\ von den Professoren
}

Albers, Krause-Junk, Littmann, Oberhauser, Pohmer, Schmidt

\section{Band 6}

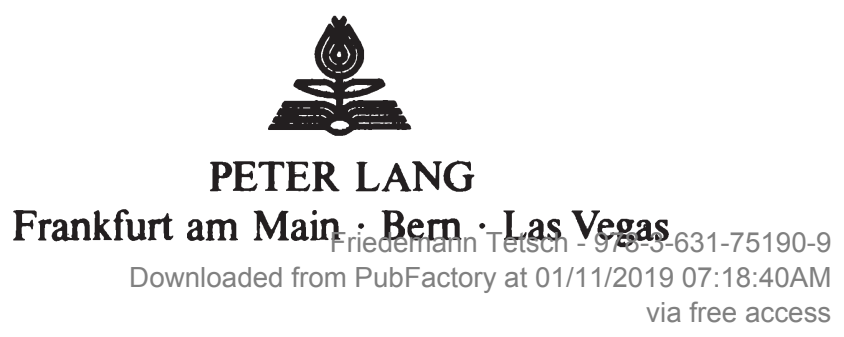


Friedemann Tetsch

\section{Raumwirkungen des Finanzsystems der Bundesrepublik Deutschland}

Eine Untersuchung der Auswirkungen der Finanzreform von 1969 auf die Einahmenposition der untergeordneten Gebietskörperschaften und ihrer regionalpolitischen Zieladäquanz

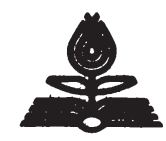

PETER LANG

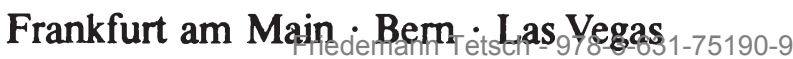


CIP-Kurztitelaufnahme der Deutschen Bibliothek

\section{Tetsch, Friedemann}

Raumwirkungen des Finanzsystems der Bundesrepublik Deutschland: e. Unters. d. Auswirkungen d. Finanzreform von 1969 auf d. Einnahmenposition d. untergeordneten Gebietskörperschaften $u$. ihrer regionalpolit. Zieladäquanz. - Frankfurt am Main, Bern, Las Vegas: Lang, 1978.

(Finanzwissenschaftliche Schriften; Bd. 6)

ISBN 3-261-02409-7

Open Access: The online version of this publication is published on www.peterlang.com and www.econstor.eu under the international Creative Commons License CC-BY 4.0. Learn more on how you can use and share this work: http://creativecommons. org/licenses/by/4.0.

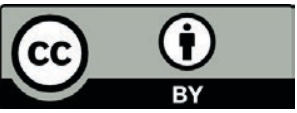

This book is available Open Access thanks to the kind support of ZBW - Leibniz-Informationszentrum Wirtschaft.

ISBN 3-261-02409-7

ISBN 978-3-631-75190-9 (eBook)

Auflage $200 \mathrm{Ex}$.

(C) Verlag Peter Lang GmbH, Frankfurt am Main 1978

Alle Rechte vorbehalten.

Nachdruck oder Vervielfältigung, auch auszugsweise, in allen Formen wie Mikrofilm, Xerographie, Mikrofiche, Mikrocard, Offset verboten.

Druck: Fotokop Wilhelm Weihert KG Darmstadt

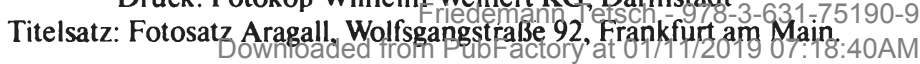


Meiner Frau Jutta,

ohne die diese Arbeit nicht zustande gekommen wäre 
Friedemann Tetsch - 978-3-631-75190-9

Downloaded from PubFactory at 01/11/2019 07:18:40AM

via free access 
Seite

1. TEIL: THEORETISCHE GRUNDLAGEN ........... 25

A. DIE ZIELE IN DER REGIONALPOLITIK ............ 25

I. Raumordnungspolitik und Regionalpolitik - Begriffsbe-

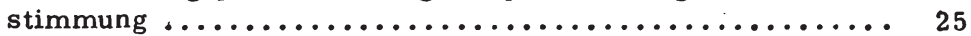

II. Zielsysteme der Raumordnungspolitik ............. 26

1. Das räumlich koordinierte Zielsystem ........... 26

2. Das räumlich unkoordinierte Zielsystem ........... 26

3. Das Verhältnis der beiden Zielsysteme zueinander ..... 27

III. Die regionalen Implikationen des gesamtwirtschaftlichen Zielsystems ............................ 28

1. Die regionalen Implikationen des Gerechtigkeitsziels .... 28

1.1. Inhalt des verteilungspolitischen Ziels der Regional-

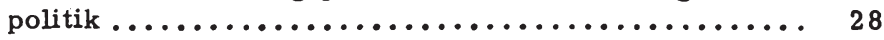

1.2. Produktwerte als Indikatoren des regionalen Wohlstandsniveaus ......................... 29

1.3. Stellenwert des verteilungspolitischen Ziels der

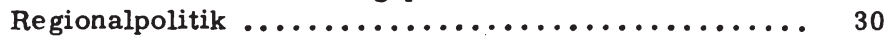

2. Die regionalen Implikationen des Wachstumsziels ...... 33

2.1. Inhalt des wachstumspolitischen Ziels der Regional-

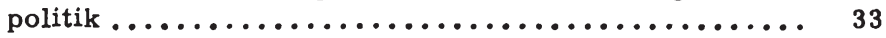

2.2. Zur Problematik des regionalen Entwicklungspoten-

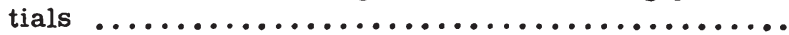

3. Die Beziehungen $\mathrm{zwischen} \mathrm{dem} \mathrm{wachstums-und} \mathrm{dem}$ verteilungspolitischen Ziel der Regionalpolitik....... 38

3.1. Zielkonflikt bei kurz- und mittelfristigem Planungs-

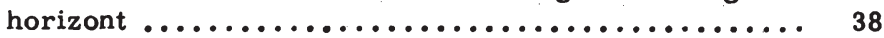

3.2. Zielharmonie bei längerfristigem Planungshorizont... 39

3. 3. Zielharmonie möglicherweise auch bei kurz- und mittelfristigem Planungshorizont ............. 41

4. Das langfristig wünschenswerte Ausmaß des interregionalen Einkommensausgleichs

5. Die regionalen Implikationen des Stabilitätsziels ....... 43

5.1. Inhalt des stabilitätspolitischen Ziels der Regional-

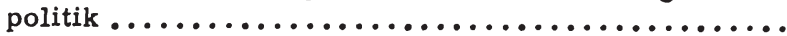


5.2. Stellenwert des stabilitätsorientierten Ziels der Regionalpolitik .................................. 44

IV. Die regionalpolitischen Ziele der Bundesregierung ......... 45

B. DER PROZESS DER RÄUMLICHEN DIFFERENZIERUNG . . . . 48

I. Das Prinzip der zirkulären, selbstverstärkenden Verursachung 48

II. Anfangsimpulse regionaler Wachstums - und Verdichtungs -

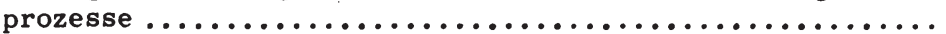

1. Die Bedeutung des Lagers als auslösender Faktor eines eigendynamischen, regional begrenzten Verdichtungs - und Wachstumsprozesses ....................... 49

2. Die Bedeutung der Lage ..................... 50

2.1. Die wirtschaftsgeographische Lage.............. 50

2. 2. Die Lage zur Hauptstadt ................... 51

2.3. Die Lage zum Verkehrssystem ................. 52

3. Ergebnis der vorstehenden Überlegungen ... . . . . . . . . . . . 54

III. Determinanten und Grenzen des kumulativen Prozesses der räumlichen Differenzierung..................... 55

1. Der Einfluß interner Effekte auf die Standortwahl ........ 56

1.1. Begriffsbestimmung .................... 56

1.2. Vorteil der Agglomeration - Möglichkeiten der Realisie rung interner Ersparnisse ................ 56

2. Der Einfluß externer Effekte auf die Standortwahl ........ 58

2.1. Begriffsbestimmung..................... 58

2.2. Vorteile der Agglomeration: Möglichkeiten der Ausnutzung positiver externer Effekte ............. 59

2.2.1. Vorteile des räumlichen Verbunds zwischen Lieferanten und Abnehmern ..................... 60

2.2.2. Die räumliche Verteilung des Angebots öffentlicher Leistungen ......................... 6

2.2.2.1. Ziel der Zentralregierung: Maximierung der Wähler-

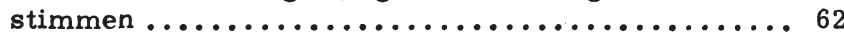

2.2.2.2. Raumwirtschaftliche Quasi-Neutralität .......... 63

2.2.3. Die räumliche Verteilung neuen technischen Wissens .. 64

2.2.3.1. Räumliche Verteilung der Erfindungen .......... 64

2.2.3.2. Räumliche Verteilung der Innovationen .......... 65

2.2.3.3. Răumliche Verteilung der Imitationen ........... 65 
2.2.4. Ergebnis der bisherigen Überlegungen ..........65 65

2.3. Agglomerationsnachteile: Negative externe Effekte.....66 66

2.3.1. Flächenknappheit ...................67

2. 3.2. Verschlechterung der Umweltbedingungen ........67

2.3.3. Institutionell-organisatorische Starrheiten .......668

2.3.4. Die Funktion der Agglomerationsnachteile als automatische Stabilisatoren des räumlichen Differenzierungsprozesses ....................668

2.4. Die ballungsfördernde Wirkung der Agglomerationseffekte ............................ 70

3. Erklärung der Beharrungskraft der einmal getroffenen

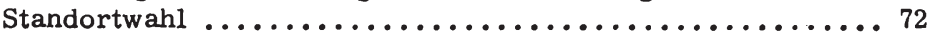

3.1. Die zeitliche Begrenzung des Planungszeitraums der

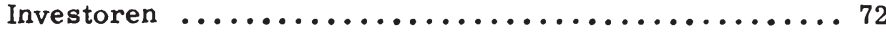

3.2. Die Anspruchsanpassungs-Theorie ............ 73

3. 3. Das Prinzip der kognitiven Dissonanz ............ 74

C. ANSATZPUNKT UND KONZEPTION EINER ZIELGERECHTEN

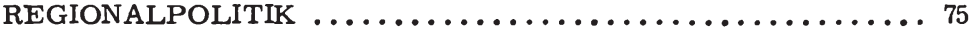

D. FINANZPOLITISCHE EINFLUSSMÖGLICHKEITEN DER ÖF FENTLICHEN HÄNDE AUF DIE RÄUMLICHE ORDNUNG DER WIRTSCHAFT $\ldots \ldots \ldots \ldots \ldots \ldots \ldots \ldots \ldots \ldots \ldots \ldots . \ldots \ldots$

I. Der Einfluß der Gemeinden auf die Raumstruktur ......... 79

1. Voraussetzungen der Modellbetrachtungen ............. 79

2. Die finanzpolitischen Aktionsparameter der Gemeinden .... 81

2.1. Gliederung des kommunalen Aktionsraumes .........81

2.2. Raumwirtschaftliche Einflußmöglichkeiten der Kommu nen durch Variation des Niveaus ihrer Aktivität bei unveränderter Struktur ihrer Einnahmen und Ausgaben ... 82

2.2.1. Senkung des Niveaus kommunaler Aktivität ....... 82

2.2.2. Erhöhung des Niveaus der kommunalen Aktivität .... 84

2.3. Raumwirtschaftliche Einflußmöglichkeiten der Kommu nen durch Variation der Struktur ihrer Einnahmen und Ausgaben bei unverändertem Niveau ihrer Aktivität . . . 87

2.3.1. Voraussetzungen der Modellbetrachtungen .......87

2. 3.2. Variation der Einnahmenstruktur .............88

2.3.2.1. Die angestrebte Standortwirkung........... 88 
2.3.2.2. Bestimmungsfaktoren der Wirksamkeit........ 88

2.3.2.2.1. Das Verhalten der anderen Kommunen ......... 88

2.3.2.2.2. Die Reaktion der privaten Haushalte ......... 89

2.3.2.2.3. Die Einschätzung der Dauerhaftigkeit der Standortvorteile durch die Investoren ............ 89

2.3.2.4. Das Steuerobjekt der Steuer, deren Tarif geändert werden soll .................... 90

2. 3. 3. Variation der Ausgabenstruktur .............. 91

2.3.3.1. Substitution von Sozialleistungen durch Subventionen • 91

2.3.3.2. Substitution haushaltsorientierter Infrastrukturleistungen durch unternehmensorientierte Infrastruk-

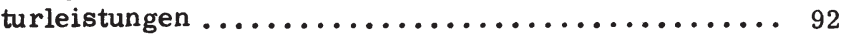

2.3.3.2.1. Die angestrebte Standortwirkung ........... 93

2.3.3.2.2. Bestimmungsfaktoren der Wirksamkeit ........ 94

2.3.3.2.2.1. Das Verhalten der anderen Kommunen ....... 94

2.3.3.2.2.2. Die Reaktion der privaten Haushalte.......... 94

2. 3. 3.2.2.3. Die Einschätzung der Dauerhaftigkeit der Standortvorteile durch die Investoren .......... 95

2.3.3.2.3. Die Basisfunktion der Infrastruktur $\ldots \ldots \ldots \ldots 96$

2. 3. 3. 3. Die Bedeutung der haushaltsorientierten Infrastruktur als Attrahierungsinstrument .............. 96

2.3.4. Empfehlungen für eine kommunale Attrahierungs -

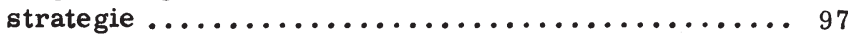

2.3.5. Die Bedeutung der Steuerkraft für die Attrahierungsmöglichkeiten der einzelnen Gemeinden ......... 98

2.3.5.1. Klärung der Voraussetzungen .............. 98

2.3.5.2. Der Einfluß der Steuerkraft auf die absolute Höhe der attraktivitätsfördernden Ausgaben ......... 98

2.3.5.3. Die raumwirtschaftlichen Effekte des regionalen

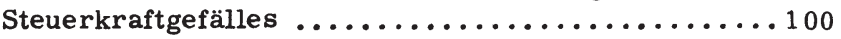

2. 3.5.4. Raumwirtschaftliche Wirkung des kommunalen Einnahmensystems unter Berücksichtigung der kommunalen Steuersatzdifferenzierung und Kreditauf nahmemöglichkeit ........................... 101

2.3.5.4.1. Regionale Unterschiede in der Steueranspannung . . 101 2.3.5.4.2. Die Möglichkeit der Kreditaufnahme .......... 101 
II. Finanzpolitische Einflußmöglichkeiten des Zentralstaates auf die Raumstruktur ........................... 102

1. Klärung der Voraussetzungen ................... 102

2. Raumwirtschaftliche Einflußmöglichkeiten des Zentralstaates durch einnahmen- und ausgabenpolitische Maßnahmen ... 103

2.1. Bei regional vollständig radizierter Aktivität . . . . . 103

2.2. Bei regional nicht radizierter Aktivität ........... 105

2.3. Raumwirtschaftliche Wirkungen der zentralstaatlichen Infrastrukturausgaben ................. 107

3. Raumwirtschaftliche Einflußmöglichkeiten durch Beeinflussung der Einnahmenposition der untergeordneten $\mathrm{Ge}$ bietskörperschaften ..................... 108

3.1. Die finanzausgleichspolitischen Maßnahmen ......... 109

3.2. Die Entscheidungsbefugnis des Zentralstaates ....... 110

III. Raumwirtschaftliche Einflußmöglichkeiten der Teilstaaten . . . . 111

IV. Grundsatzfragen zu den finanzausgleichspolitischen Einflußmöglichkeiten des Zentralstaates .................. 111

1. Rechtfertigung des föderalistischen Staatsaufbaus ........ 111

2. Die Eignung des örtlichen Aufkommens als Steuerverteilungskriterium .......................... 112

3. Möglichkeiten zur Vermeidung der regionalpolitisch unerwünschten Steuereinnahmenunterschiede . . . . . . . . . . . . . 114

3.1. Horizontale Ausgleichszahlungen ................ 114

3.2. Steuerverbund ......................... 114

3.2.1. Staatspolitische Beurteilung des Steuerverbunds ..... 115

3.2.2. Regionalpolitische Beurteilung des Steuerverbunds ...117

4. Der öffentliche Bedarf als Verteilungskriterium der Steuer-

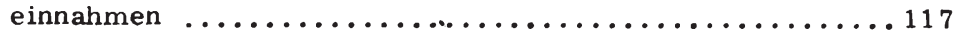

4.1. Die Popitz'sche Forderung nach einem "allgemeinen Ausgleich der öffentlichen Bedarfe und ihrer Deckung" .....118

4.2. Klärung des Begriffs "öffentlicher Bedarf" .......... 119

5. Überlegungen zur wünschenswerten Höhe der regionalen (lokalen) Pro-Kopf-Bedarfe und ihrer Deckung .......... 120

5.1. Die Ist-Ausgaben der Gemeinden als Indikator des kom-

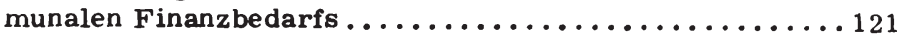

5.2. Anstieg der Nachfrage nach öffentlichen Leistungen mit zunehmender Gemeindegröße als Rechtfertigung der Staffelung der Pro-Kopf-Einnahmen ............. 121 
5.2.1. Höhere Nachfrage nach öffentlichen Leistungen zur Kompensation der Nachteile der Enge .......... 121

5.2.2. Abhängigkeit der Nachfrage nach öffentlichen Leistungen von dem regionalen Wohlstandsniveau und

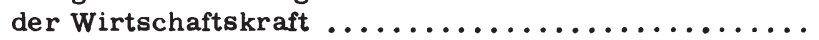

5.2.2.1. Die regionale Verteilung der Nachfrage nach haushaltsorientierten öffentlichen Leistungen ........ 122

5.2.2.2. Die regionale Verteilung der Nachfrage nach unternehmensorientierten öffentlichen Leistungen ..... 123

5.2.2.3. Räumliche Auswirkungen der Berücksichtigung lokaler (regionaler) Unterschiede in der Nachfrage nach öffentlichen Leistungen bei der horizontalen Einnahmenverteilung ................124

5. 3. Anstieg der Kosten der öfentlichen Leistungserstellung als Rechtfertigung der Staffelung des Bedarfs nach der

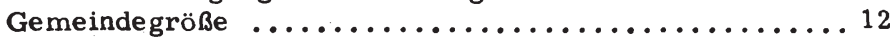

5. 3.1. Die Abhängigkeit der Kosten öffentlicher Leistungserstellung vom Agglomerationsgrad........... 125

5.3.2. Die räumlichen Auswirkungen der Berücksichtigung regionaler Unterschiede in den Kosten der öfentlichen Leistungserstellung bei der horizontalen Einnahmenverteilung ......................... 12

5. 3. 3. Methoden der Umsetzung der ballungsbedingten Kostensteigerungen öffentlicher Leistungserstellung in

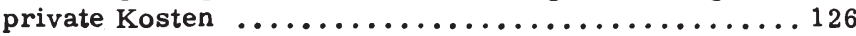

5.4. Angebot zentralörtlicher Leistungen als Rechtfertigung der Staffelung der Pro-Kopf-Einnahmen nach der Ge-

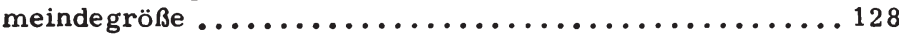

5.5. Methoden zur Abgeltung der Kosten zentralörtlicher Leistungserstellung ...................... 129

5.5.1. Pauschale Abgeltung durch Staffelung der Steuereinnahmen pro Kopf nach der Gemeindegröße ........ 129

5.5.2. Abgeltung der Netto-Ertrags-spillovers nach dem Äquivalenzprinzip (horizontale Kompensation) . . . . . 130

5. 5. 3. Abgeltung der Netto-Ertrags-spillovers durch Zahlungen der übergeordneten Gebietskörperschaften (vertikale Kompensation) ...................... 130

6. Grundlinien eines regionalpolitisch rationalen Systems der

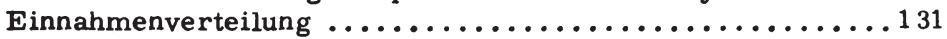

6.1. Der volkswirtschaftliche Finanzbedarf - Grundlage der Einnahmenverteilung....................... 131 
6.2. Regional (lokal) gleich hohe Pro-Kopf-Steuereinnahmen .............................. 132

6.3. Finanzzuweisungen - ein unentbehrliches Element der Einnahmenverteilung .................. 133

6.4. Die regionalpolitische Aufgabenteilung zwischen der Verteilung der Steuereinnahmen und der Verteilung der Zuweisungen $\ldots \ldots \ldots \ldots \ldots \ldots \ldots \ldots \ldots \ldots \ldots$

2. TEIL: EMPIRISCHE UNTERSUCHUNG DER AUSWIRKUNGEN DER FINANZREFORM VON 1969 AUF DIE EINNAHMEN POSITION DER UNTERGEORDNETEN GEBIETSKÖRPERSCHAFTEN DER BUNDESREPUBLIK DEUTSCHLAND

A. PROBLEMSTELLUNG UND BEGRIFFSKLÄRUNG . . . . . . . . 135

I. Der Finanzausgleich - Definition und Systematik .......... 135

1. Der passive Finanzausgleich ................. 135

2. Der aktive Finanzausgleich ................. 136

2.1. Die Verteilung der Steuerquellen ............. 137

2.2. Die Umverteilung der Steuererträge ............ 137

II. Abgrenzung der für die empirische Untersuchung relevanten Maßnahmen der Finanzreform ................... 138

B. DIE NEUREGELUNG DER HORIZONTALEN EINNAHMENVERTEILUNG AUF LÄNDEREBENE DURCH DIE FINANZREFORM VON 1969

I. Die Verteilung der Steuereinnahmen der Länder gemäß dem kassenmäßigen örtlichen Aufkommen im Vergleich zur tatsächlichen Verteilung der Ländersteuereinnahmen ........ 140

1. Die Neuordnung der vertikalen Steuerverteilung durch die

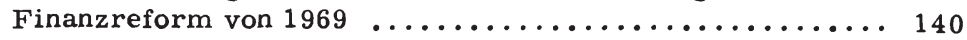

2. Die Regelung der horizontalen Steuerverteilung durch die Finanzreform von 1969

3. Die finanziellen Auswirkungen der Abweichung vom kassenmäßigen örtlichen Aufkommen als ausschließlichem Steuerverteilungskriterium im Rechnungsjahr 1974

3.1. Das methodische Vorgehen ................. 143

3.2. Interpretation der Ergebnisse ............... 145

3.3. Regionalpolitische Beurteilung der Ergebnisse ....... 146

II. Die Bereinigung des kassenmäßigen örtlichen Aufkommens von steuertechnisch bedingten Verzerrungen 
1. Die Notwendigkeit der Zerlegung der Lohnsteuer und der Körperschaftssteuer ..................... 147

2. Die Zerlegung der Lohngteuer im Rechnungsjahr 1974 ..... 149

2.1. Die Auswirkung der Zerlegung der Lohnsteuer auf die Einnahmenposition der einzelnen Länder im Rechnungsjahr

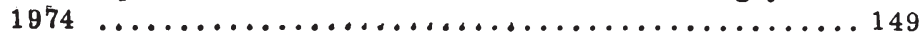

2.1.1. Das methodische Vorgehen .................. 149

2.1.2. Interpretation und Beurteilung der Ergebnisse ...... 152

2.1.8.1. Die Gesamtwirkung ................... 152

2.1.8.2. Die Wirkung auf eintelne Länder ............. 152

2.1،3.3. Der Nivellie rungseffekt ................. 152

2.2. Die Zusammensetzung der Zerlegungssalden der einzelnen Läder im Rechnungsjahr $1974 \ldots \ldots \ldots \ldots \ldots \ldots 3$

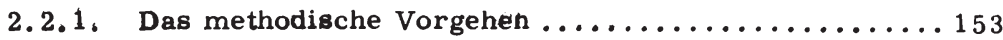

2.2.3. Interpretation und Beurtellung der Ergebnisse ...... 156

2.3. Die regionalpolitische Bedeutung der Zerlegung der

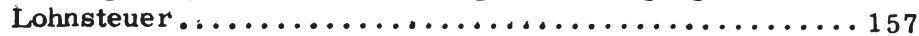

3. Die Zerlegung der Körperschaftsteuer im Jahr $1974 \ldots \ldots \ldots 158$

3.1. Die Auswirkung der Zerlegung der Körperschaftsteuer auf die Einnahmenposition der einzelnen Länder im Jahr

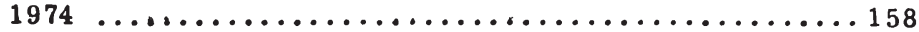

3.1.1. Das methodische Vorgehen ................. 158

3.1.2. Interpretation und Beurteilung der Ergebnisse ....... 158

3.1.2.1. Die Gesamtwirkung .................. 158

3.1.2.2. Die Wirkung auf einzelne Länder ............ 160

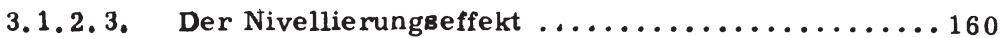

3.2. Die Zusammensetzung der Zerlegungssalden der einzelnen Länder im Rechnungsjahr $1974 \ldots \ldots \ldots \ldots 161$

III. Die Vertellung des Länderanteils an den Steuern vom Umsatz auf die einzelnen Länder im Rechnungsjahr $1974 \ldots \ldots \ldots \ldots \ldots 164$

1. Der Verteilungsmodus des Länderanteils an der Umsatz-

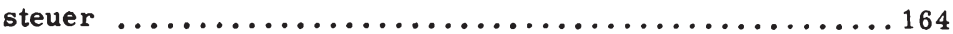

2. Die Auswirkung der Verteilung des Länderanteils an der Umsatzsteuer auf die Einnahmenposition der einzelnen Län-

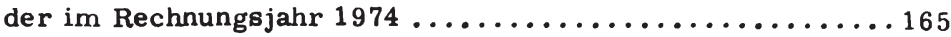

2.1. Das methodische Vorgehen ....................... 165 
2.2. Interpretation und Beurteilung der Ergebnisse ....... 165

2.2.1. Die Gesamtwirkung .................. 165

2.2.2. Die Wirkung auf einzelne Länder ........... 166

2.2.3. Der Nivellie rungseffekt ................. 166

3. Die Auswirkung der Verteilung von 25 Prozent des Länderanteils an der Umsatzsteuer an besonders steuerschwache Länder im Jahr $1974 \ldots \ldots \ldots \ldots \ldots \ldots \ldots$. . . . . . . . . 169

3.1. Das methodische Vorgehen ................ 169

3.2. Interpretation und Beurteilung der Ergebnisse ....... 169

IV. Zusammenfassung der bisher erzielten Ergebnisse ....... 170

V. Die Verteilung des Länderanteils an der Körperschaftsteuer und an der Kapitalertragsteuer auf die einzelnen Länder nach der Einwohnerzahl - ein Vorschlag zur Reform der horizontalen Steuerverteilung ......................... 172

1. Die Verteilung des Länderanteils an der Körperschaftsteuer auf die einzelnen Länder nach der Einwohnerzahl . . . . . . 172

1.1. Das methodische Vorgehen .................. 172

1.2. Interpretation und Beurteilung der Ergebnisse . . . . . . 175

2. Die Verteilung des Länderanteils an der Kapitalertragsteuer auf die einzelnen Länder nach ihrer Einwohnerzahl . . 175

2.1. Das methodische Vorgehen .................. 175

2.2. Interpretation und Beurteilung der Ergebnisse ....... 176

3. Die Auswirkung der Verteilung des Länderanteils an der Körperschaftsteuer und an der Kapitalertragsteuer nach der Einwohnerzahl auf die gesamten Steuereinnahmen der einzelnen Länder im Jahr $1974 \ldots \ldots \ldots \ldots \ldots \ldots \ldots \ldots \ldots$

3.1. Das methodische Vorgehen ................. 178

3.2. Interpretation und Beurteilung der Ergebnisse . . . . . 178

VI. Die Korrektur der horizontalen Steuerverteilung durch den

Länderfinanzausgleich ........................ 180

1. Die technische Durchführung des Länderfinanzausgleichs nach der Finanzreform von $1969 \ldots \ldots \ldots \ldots \ldots \ldots \ldots \ldots$

1.1. Die Systematik des Ausgleichsverfahrens .......... 181

1.2. Die Vorschriften zur Bemessung der Ausgleichszahlun-

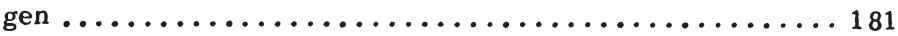

1.3. Die Berücksichtigung des lokalen Finanzbedarfs im Länderfinanzausgleich .................. 182 
2. Die Auswirkung des Länderfinanzausgleichs auf die Einnahmenposition der einzelnen Länder (ohne Gemeinden)

im Rechnungsjahr $1974 \ldots \ldots \ldots \ldots \ldots \ldots \ldots \ldots \ldots$.............. 184

2.1. Das methodische Vorgehen ................. 184

2.2. Interpretation und Beurteilung der Ergebnisse ........ 184

3. Die Auswirkung des Länderfinanzausgleichs auf die Einnahmenposition der einzelnen Länder und ihrer Gemeinden im Rechnungsjahr $1974 \ldots \ldots \ldots \ldots \ldots \ldots \ldots$. . . . . . . 186

3.1. Die Notwendigkeit der Einbeziehung der Gemeinden in die Untersuchung...................... 186

3.2. Interpretation und Beurteillung der Ergebnisse . . . . . 187

3.2.1. Der Nivellie rungseffekt des Länderfinanzausgleichs im Rechnungsjahr $1974 \ldots \ldots \ldots \ldots \ldots \ldots \ldots \ldots \ldots 187$

3.2.2. Das Finanzkraftgefälle zwischen den Ländern und ihren Gemeinden nach Durchführung des Länderfinanzausgleichs im Rechnungsjahr $1974 \ldots \ldots \ldots \ldots \ldots \ldots$

VII. Die Korrektur der horizontalen Steuerverteilung durch vertikale Ausgleichszahlungen...................... 190

1. Die Handhabung der vertikalen Ausgleichszahlungen in der Bundesrepublik Deutschland ................. 190

2. Die Auswirkung der Ergänzungszuweisungen des Bundes auf die Einnahmenposition der einzelnen Länder im Jahr 1974 . 190

2.1. Das methodische Vorgehen .................. 190

2.2. Interpretation und Beurteilung der Ergebnisse ........ 193

3. Der Umverteilungseffekt von vertikalen Ausgleichszahlun-

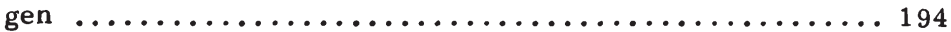

3.1. Der Umverteilungseffekt der Ergänzungszuweisungen im Rechnungsjahr 1974 .......................... 195

3.2. Der Umverteilungseffekt der vertikalen Ausgleichszahlungen im Rechnungsjahr 1969 ............... 195

VIII. Die Umverteilungswirksamkeit des Steuerverteilungssystems vor und nach der Finanzreform von 1969 ............. 197

1. Die Umverteilungswirksamkeit des Steuerverteilungssystems im letzten Jahr vor Inkraftreten der Finanzreform . . . . . 197

2. Die Umverteilungswirksamkeit des Steuerverteilungssystems nach der Finanzreform ................... 198

2.1. Methoden zur Berechnung der Umverteilungswirkung des Steuerverteilungssystems nach der Finanzreform ... 198 
2.1.1. Der erste Ansatz zur Ermittlung des Umverteilungs effektes des reformierten Steuerverteilungssystems . . 198

2.1.2. Der zweite Ansatz zur Ermittlung des Umverteilungseffekts des reformierten Steuerverteilungssystems . . . 202

2.2. Interpretation und Beurteilung der Ergebnisse . . . . . . . 202

IX. Die Verteilung der Zuschüsse des Bundes für Investitionen der Länder und ihrer Gemeinden im Jahr $1974 \ldots \ldots \ldots \ldots$. . . . . . . 204

1. Die regionale Verteilung der Investitionszuschüsse des Bundes gemäß dem kassenmäßigen örtlichen Steueraufkommen

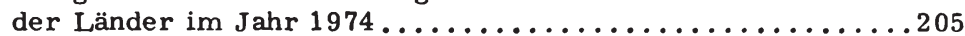

1.1. Die regionalpolitische Beurteilung dieser Vergleichsver-

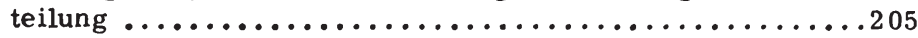

1.2. Interpretation und Beurteilung der Ergebnisse . . . . . . 207

2. Die regionale Verteilung der Investitionszuschüsse des Bundes gemäß dem Anteil der Länder am Bruttoinlandsprodukt

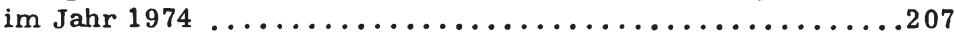

2.1. Die regionalpolitische Beurteilung dieser Vergleichsver-

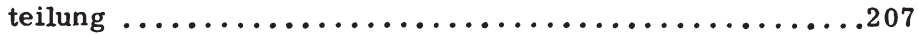

2.2. Interpretation und Beurteilung der Ergebnisse . . . . . . 209

3. Die regionale Verteilung der Investitionszuschüsse des Bundes gemäß der Einwohnerzahl der Länder im Jahre 1974. . . 210

3.1. Die regionalpolitische Beurteilung dieser Vergleichs-

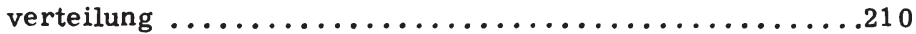

3.2. Interpretation und Beurteilung der Ergebnisse . . . . . .210

4. Die regionale Verteilung der Investitionszuschüsse des Bundes gemä $\beta$ den Grundsätzen des Bundesraumordnungspro-

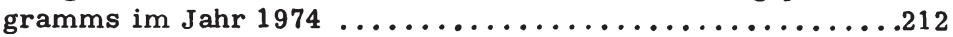

4.1. Die regionalpolitische Beurteilung dieser Vergleichsver-

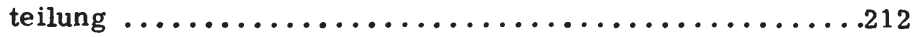

4.2. Interpretation und Beurteilung der Ergebnisse $\ldots \ldots \ldots .213$

X. Die Gesamtfinanzmasse der Länder und ihrer Gemeinden in der Bundesrepublik Deutschland im Jahre 1974 . . . . . . . . . . . 215

1. Die regionalpolitische Bedeutung der Gesamtfinanzmasse . . 215

2. Die Zusammensetzung der Gesamtfinanzmasse .........216

3. Die Berechnung der Gesamtfinanzmasse ............ 217

4. Interpretation und Beurteilung der Ergebnisse . . . . . . . 218

4.1. Die Streuung der Pro-Kopf-Einnahmen ............ 218 
4.2. Das regionale Gefälle in der Finanzkraft .......... 218

4. 3. Der Einfluß der horizontalen Einnahmenverteilung des Jahres 1974 auf die Raumstruktur .............220

C. DIE NEUORDNUNG DER HORIZONTALEN EINNAHMENVERTEILUNG AUF GEMEINDEEBENE DURCH DIE FINANZREFORM

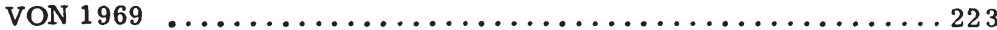

I. Das Gemeindesteuersystem vor der Finanzreform von $1969 \ldots 223$

II. Die Ziele der Gemeindefinanzreform von $1969 \ldots \ldots \ldots \ldots \ldots \ldots 25$

III. Die Maßnahmen der Gemeindefinanzreform von $1969 \ldots \ldots \ldots \ldots 227$

1. Die Beteiligung der Gemeinden am Aufkommen aus der Ein-

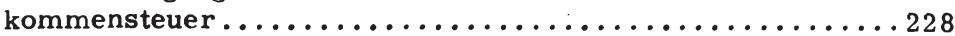

2. Die Beteiligung von Bund und Ländern am Gewerbesteueraufkommen der Gemeinden in Form einer Gewerbesteuer-

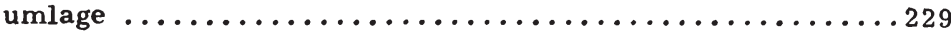

3. Die Aufhebung des Gewerbesteuerausgleichs zwischen Wohnund Betriebsgemeinden . . . . . . . . . . . . . 230

IV. Die Auswirkung der Gemeindefinanzreform von 1969 auf die vertikale Streuung der Steuerkraft der Gemeinden im Jahr 1974. 230

1. Die Veränderung der vertikalen Streuung der Steuerkraft der Gemeinden im Jahr 1974 durch die Gemeindefinanzre form unter Vernachlässigung des Gewerbesteuerausgleichs zwischen Wohn- und Betriebsgemeinden ............2 30

1.1. Das methodische Vorgehen .................230

1.2. Die Verstärkung der Finanzkraft der Gemeinden im Jahr 1974 durch die Gemeindefinanzreform ...........231

1.3. Die Abschwächung der Steuerkraftunterschiede zwischen den Gemeinden unterschiedlicher Größenklassen im Jahr 1974 durch die Gemeindefinanzreform von $1969 \ldots \ldots \ldots 232$

1.4. Die Umverteilung der Steuerkraft zwischen den Gemeinden unterschiedlicher Größe im Jahr 1974 durch die Gemeindefinanzreform von 1969

2. Die Veränderung der vertikalen Streuung der Steuerkraft der Gemeinden im Jahr 1974 durch die Gemeindefinanzreform unter Berücksichtigung des Gewerbesteuerausgleichs zwischen Wohn- und Betriebsgemeinden ............238

2.1. Der fiktive Gewerbesteuerausgleich zwischen Wohn - und Betriebsgemeinden im Jahr 1974.............238

2.1.1. Bestimmungsfaktoren des Volumens des Gewerbesteuerausgleichs zwischen Wohn- und Betriebsgemeinden 
2.1.2. Annahmen über Volumen und Struktur des fiktiven Gewerbesteuerausgleichs des Jahres 1974 . . . . . . . . 240

2.2. Die vertikale Verteilung der Steuerkraft der Gemeinden im Jahr 1974 ohne Gemeindefinanzreform von $1969 \ldots \ldots 241$

2.2.1. Die vertikale Streuung der kommunalen Steuerkraft im Jahr 1974 unter Berücksichtigung des Gewerbesteuer ausgleichs in der Variante $I \ldots \ldots \ldots \ldots \ldots \ldots \ldots . \ldots 242$

2.2.2. Die vertikale Streuung der kommunalen Steuerkraft im Jahr 1974 unter Berücksichtigung des fiktiven Gewerbesteuerausgleichs in der Variante II ...........242

2.3. Der Umverteilungs - und Nivellierungseffekt der Gemeinde finanzreform bei Berücksichtigung des fiktiven Gewerbesteuerausgleichs 1974 in der Variante I .............244

2.4. Der Umverteilungs - und Nivellierungseffekt der Gemeindefinanzreform bei Berücksichtigung des fiktiven Gewerbe steuerausgleichs 1974 in der Variante II ...........246

2.5. Zusammenfassung der Untersuchungsergebnisse ...... 246

2.6. Die regionalpolitische Beurteilung der Auswirkungen der Gemeindefinanzreform auf die vertikale Streuung der kommunalen Steuerkraft ....................248

3. Die Beteiligung der Gemeinden am Aufkommen aus der Umsatzsteuer - ein Vorschlag zur Reform des Gemeindesteuer -

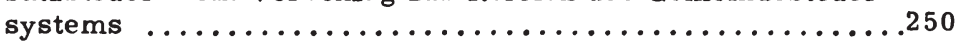

3.1. Die regionalpolitische wünschenswerte Neuordnung des kommunalen Steuersystems ................250

3.2. Der Umverteilungs - und Nivellierungseffekt einer Beteiligung der Gemeinden an der Umsatzsteuer gemäß ihrer

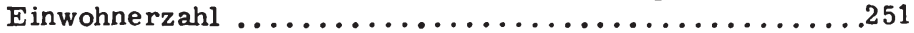

4. Zusammenfassung der Ergebnisse .253

V. Die Auswirkung der Gemeindefinanzreform von 1969 auf die horizontale Streuung der Steuerkraft der Gemeinden im Jahr

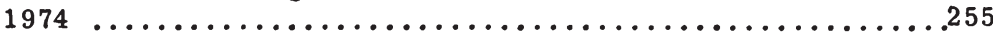

1. Der Einfluß der Gemeindefinanzreform von 1969 auf die Streuung der Steuerkraft der Gemeinden gleicher Größenklasse im

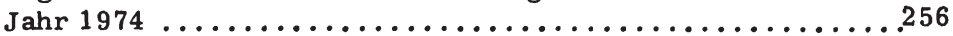

1.1. Das methodische Vorgehen ..................256

1.2. Interpretation und Beurteilung der Ergebnisse . . . . . . 259

2. Der Einfluß der Gemeindefinanzreform von 1969 auf die Streuung der kommunalen Steuerkraft der Landkreise und der kreis-

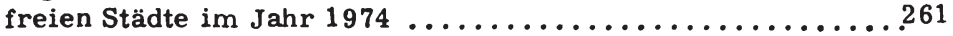


2.1. Das methodische Vorgehen................ 261

2.1.1. Die Berechnung der Streuungsmaße ........... 261

2.1.2. Relativierung der Untersuchungsergebnisse...... 263

2.2. Interpretation und Beurteilung der Ergebnisse ....... 264

VI. Die Aufstockung der kommunalen Steuerkraft durch Finanzzuweisungen von Bund und Ländern ............... 270

1. Die räumlichen Auswirkungen des Finanzausgleichs zwischen Ländern (Bund) und Gemeinden (Gemeindeverbänden) im Jahr 1974 ...........................

1.1. Die regionalpolitisch erwünschte Verteilung der Finanzzuweisungen von Bund und Ländern an Gemeinden und

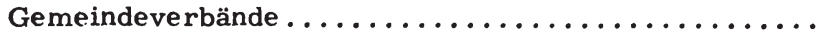

1.2. Das methodische Vorgehen .................. 272

1. 3. Interpretation und Beurteilung der Ergebnisse ....... 274

1.3.1. Die Verteilung der Finanzzuweisungen von Bund und Ländern auf die einzelnen Gemeindegrößenklassen

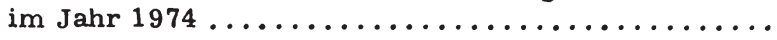

1.3.2. Die Verteilung der Finanzzuweisungen von Bund und Ländern auf die einzelnen Landkreise und kreisfreien Städte im Jahr $1974 \ldots \ldots \ldots \ldots \ldots \ldots \ldots \ldots \ldots \ldots$

1.3.2.1. Die räumlichen Auswirkungen des vertikalen Gemeindefinanzausgleichs in Hessen im Jahr 1974...

1.3.2.2. Die räumlichen Auswirkungen des vertikalen Gemeindefinanzausgleichs in Rheinland-Pfalz im Jahr 1974 .........................

1.3.2.3. Die räumlichen Auswirkungen des vertikalen Gemeindefinanzausgleichs in Nordrhein-Westfalen im Jahr 1974 ........................

1.3.2.4. Die räumlichen Auswirkungen des vertikalen Gemeindefinanzausgleichs in Bayern im Jahr 1974. .

1.3.2.5. Die răumlichen Auswirkungen des vertikalen Gemeindefinanzausgleichs in Niedersachsen im Jahr 1974

1.3.2.6. Die räumlichen Auswirkungen des vertikalen Gemeindefinanzausgleichs im Saarland im Jahr 1974

1.3.2.7. Die räumlichen Auswirkungen des vertikalen Gemeindefinanzausgleichs in Schleswig-Holstein im Jahr 1975 
1. 3. 3. Zusammenfassung der Ergebnisse .......... 308

2. Die räumlichen Auswirkungen der regionalen Verteilung der kommunalen Gesamteinnahmen im Jahr 1974 . . . . . 310

VII. Politische Schlußfolgerungen für das kommunale Einnahmen-

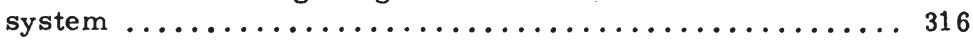

1. Eigene Steuereinnahmen als Bestandteil des kommunalen Einnahmensystems ..................... 317

2. Allgemeine Finanzzuweisungen als Bestandteil des kommunalen Einnahmensystems ................ 317

3. Spezielle Finanzzuweisungen als Bestandteil des kommunalen Einnahmensystems ........................ 319

4. Konzeptionen der Reform des kommunalen Einnahmen-

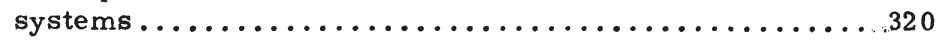

ANME RKUNGEN $\ldots \ldots \ldots \ldots \ldots \ldots \ldots \ldots \ldots \ldots \ldots \ldots \ldots \ldots$

LITERATURVERZEICHNIS .................. 373

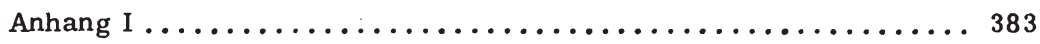


Friedemann Tetsch - 978-3-631-75190-9

Downloaded from PubFactory at 01/11/2019 07:18:40AM

via free access 
Seite

Tabelle 1 Auswirkung der Verteilungsvorschriften des Art. 107 Grundgesetz auf die Steuereinnahmen der einzelnen Länder der Bundesrepublik Deutschland im Jahre 1974 . . . . . . . . . . . . . . . . . . . . . . 144

Tabelle 2 Die Auswirkung der Zerlegung der Lohnsteuer auf die Einnahmenposition der einzelnen Länder im

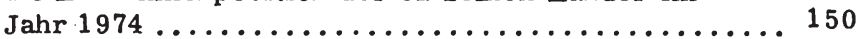

Tabelle 2 a Die Brutto-Zahlungen der Länder im Rahmen der Lohnsteuerzerlegung im Jahr $1974 \ldots \ldots \ldots \ldots \ldots \ldots 154$

Tabelle $2 \mathrm{~b}$ Die Netto-Zahlungen einiger ausgewählter Länder im Rahmen der Lohnsteuerzerlegung im Jahr 1974 . 155

Tabelle 3 Die Auswirkung der Zerlegung der Körperschaftsteuer auf die Einnahmenposition der einzelnen Länder im Jahr $1974 \ldots \ldots \ldots \ldots \ldots \ldots \ldots \ldots \ldots \ldots \ldots \ldots \ldots$

Tabelle 3 a Die Brutto-Zahlungen der Länder im Rahmen der Körperschaftsteuerzerlegung im Jahr $1974 \ldots \ldots \ldots 162$

Tabelle $3 \mathrm{~b}$ Die Netto-Zahlungen einiger ausgewählter Länder im Rahmen der Körperschaftsteuerzerlegung im Jahr $1974 \ldots \ldots \ldots \ldots \ldots \ldots \ldots \ldots \ldots \ldots \ldots \ldots \ldots \ldots \ldots$

Tabelle 4 Auswirkung der Verteilung des Länderanteils an den Steuern vom Umsatz gemäß $\$ 2$ des Gesetzes über den Finanzausgleich zwischen Bund und Ländern im Jahr $1974 \ldots \ldots \ldots \ldots \ldots \ldots \ldots \ldots \ldots \ldots \ldots \ldots \ldots \ldots \ldots$

Tabelle 4 a Auswirkung der Verteilung von 25 Prozent des Lănderanteils an der Umsatzsteuer in Form von Ergänzungsanteilen an besonders finanzschwache Länder im Jahr 1974 .........................

Tabelle 5 Die Variationskoeffizienten der Steuereinnahmen der Länder für das Rechnungsjahr $1974 \ldots \ldots \ldots \ldots \ldots . . \ldots 173$

Tabelle 6 Auswirkung der Verteilung des Länderanteils an der Körperschaftsteuer und an der Kapitalertragsteuer nach der Einwohnerzahl auf die gesamten Steuereinnahmen der einzelnen Länder im Jahr 1974 ........

Tabelle 6 a Die Verteilung des Länderanteils an der Körperschaftsteuer auf die einzelnen Länder nach der Einwohnerzahl für das Jahr $1974 \ldots \ldots \ldots \ldots \ldots \ldots \ldots \ldots \ldots \ldots \ldots$

Tabelle $6 \mathrm{~b}$ Die Verteilung des Länderanteils an den nicht veranlagten Steuern vom Ertrag (Kapitalertragsteuer) auf die einzelnen Länder nach der Einwohnerzahl für das Jahr 1974 
Tabelle 7 a Auswirkung des Länderfinanzausgleichs auf die Steuerkraft der einzelnen Länder im Rechnungs-

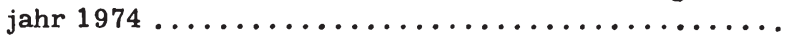

Tabelle $7 \mathrm{~b}$ Auswirkung des Länderfinanzausgleichs auf die Finanzkraft der einzelnen Länder und ihrer Gemeinden im Jahr $1974 \ldots \ldots \ldots \ldots \ldots \ldots \ldots \ldots \ldots$

Tabelle 8 a Auswirkung der Bundesergänzungszuweisungen auf die Finanzkraft der einzelnen Länder im Rechnungs -

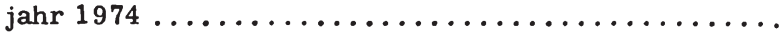

Tabelle $8 \mathrm{~b}$ Auswirkung der Bundesergänzungszuweisungen auf die Finanzkraft der einzelnen Länder und ihrer Gemeinden im Rechnungsjahr $1974 \ldots \ldots \ldots \ldots \ldots \ldots$. . . .

Tabelle $8 \mathrm{c}$ Der Umverteilungseffekt der Ergänzungszuweisungen des Bundes in den Rechnungsjahren 1969 und $1974 \ldots 196$

Tabelle 9 Steue rumverteilung $\mathrm{zwischen}$ den Bundesländern vor und nach der Finanzreform ................. 199

Tabelle 9 a Steuereinnahmen der Länder 1974 nach altem Recht (Stand 1969) ............................ 201

Tabelle 10 a Die Verteilung der Investitionszuschüsse des Bundes auf die einzelnen Länder gemäß ihrem kassenmäßigen örtlichen Aufkommen im Jahr 1974 ......... 206

Tabelle $10 \mathrm{~b}$ Die Verteilung der Investitionszuschüsse des Bundes auf die einzelnen Länder gemäß ihrem Anteil am Bruttoinlandsprodukt im Jahr $1974 \ldots \ldots \ldots \ldots \ldots \ldots$. . . .

Tabelle 10 c Die Verteilung der Investitionszuschüsse des Bundes auf die einzelnen Länder gemäß ihrer Einwohnerzahl im Jahr $1974 \ldots \ldots \ldots \ldots \ldots \ldots \ldots \ldots \ldots \ldots$

Tabelle $10 \mathrm{~d}$ Die Verteilung der Investitionszuschüsse des Bundes auf die einzelnen Länder gemäß den Grundsätzen des Bundesraumordnungsprogramms im Jahr $1974 \ldots .$. .

Tabelle 11 Die Gesamtfinanzmasse der Länder und ihrer Gemeinden im Jahr $1974 \ldots \ldots \ldots \ldots \ldots \ldots \ldots \ldots \ldots$

Tabelle 12 a Die Steuerkraft der Gemeinden der Bundesrepublik Deutschland nach Gemeindegrößenklassen im Jahr

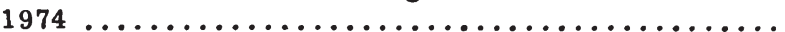

Tabelle 12 b Die vertikale Streuung der Steuerkraft der Gemeinden im Jahr $1974 \ldots \ldots \ldots \ldots \ldots \ldots \ldots \ldots$. . . . . . . . 234

Tabelle $12 \mathrm{c}$ Die Umverteilungswirkung der Gemeindefinanzreform für das Jahr 1974 ohne Berücksichtigung des Gewerbesteuerausgleichs .................236 
Tabelle 13 a Die vertikale Verteilung der Steuerkraft der Gemeinden im Jahr 1974 ohne Gemeindefinanzreform und unter Berücksichtigung des Gewerbesteueraus -

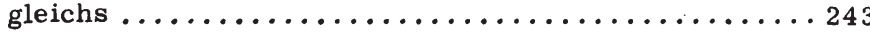

Tabelle $13 \mathrm{~b}$ Die Umverteilungswirkung der Gemeindefinanzreform für das Jahr 1974 unter Berücksichtigung des fiktiven Gewerbesteuerausgleichs 1974 in der Variante $I$................................. 245

Tabelle 13 c Die Umverteilungswirkung der Gemeindefinanzreform für das Jahr 1974 unter Berücksichtigung des fiktiven Gewerbesteuerausgleichs 1974 in der Varian-

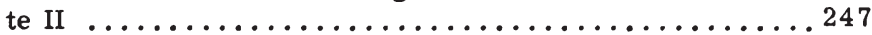

Tabelle 14 Die Beteiligung der Gemeinden an der Umsatzsteuer gemäß ihrer Einwohnerzahl für das Jahr $1974 \ldots \ldots \ldots 252$

Tabelle 15 Die Auswirkung der Gemeindefinanzreform auf die vertikale Streuung der gemeindlichen Steuerkraftwerte pro Einwohner im Jahr $1974 \ldots \ldots \ldots \ldots \ldots \ldots \ldots 254$

Tabelle 16 a Die Streuung der Steuerkraft der Gemeinden gleicher Größenklasse in Schleswig-Holstein in den Jahren 1974 und 1965

Tabelle 16 b Der Einfluß der Gemeindefinanzreform von 1969 auf die horizontale Streuung der Steuerkraft der Gemeinden gleicher Größenklassen in Schleswig-Holstein im

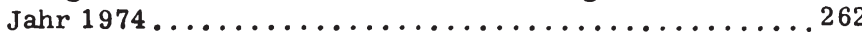

Tabelle 17 a Der Einfluß der Gemeindefinanzreform auf die horizontale Streuung der kommunalen Steuerkraft im Jahr 1974 auf der Ebene der Landkreise und der kreisfreien

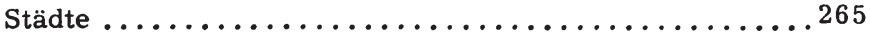

Tabelle $17 \mathrm{~b}$ 'Der Einfluß der Gemeindefinanzreform auf die horizontale Streuung der kommunalen Steuerkraft im Jahr 1974 auf der Ebene der Landkreise und der kreisfreien

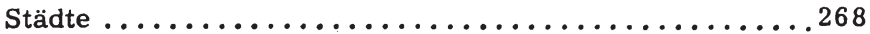

Tabelle 18 a Die Finanzkraft der krèisfreien Städte und der kreis angehörigen Gemeinden in Hessen im Jahr $1974 \ldots \ldots 276$

Tabelle $18 \mathrm{~b}$ Die Finanzkraft der kreisfreien Städte und der kreisangehörigen Gemeinden in Rheinland-Pfalz im Jahr 1974

Tabelle $18 \mathrm{c}$ Die Finanzkraft der kreisfreien Städte und der kreisangehörigen Gemeinden in Nordrhein-Westfalen im

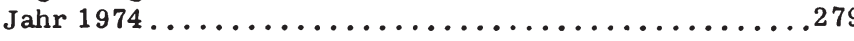

Tabelle $18 \mathrm{~d}$ Die Finanzkraft der kreisfreien Städte und der kreisangehörigen Gemeinden in Bayern im Jahr $1974 \ldots \ldots 280$ 
Tabelle 18 e Die Finanzkraft der kreisfreien Städte und der kreis angehörigen Gemeinden in Schleswig-Holstein im Jahr $1974 \ldots \ldots \ldots \ldots \ldots \ldots \ldots \ldots \ldots \ldots \ldots \ldots \ldots \ldots \ldots . \ldots \ldots \ldots$

Tabelle $18 \mathrm{f}$ Die Finanzkraft der Gemeinden des Saarlandes im Jahr $1974 \ldots \ldots \ldots \ldots \ldots \ldots \ldots \ldots \ldots \ldots \ldots \ldots \ldots . \ldots . \ldots 28$

Tabelle 19 a Die Finanzkraft der Gemeinden und Gemeindeverbände in Hessen im Jahr $1974 \ldots \ldots \ldots \ldots \ldots \ldots \ldots \ldots 286$

Tabelle $19 \mathrm{~b}$ Die Finanzkraft der Gemeinden und Gemeindeverbände in Rheinland-Pfalz im Jahr 1974 ............. 290

Tabelle $19 \mathrm{c}$ Die Finanzkraft der Gemeinden und Gemeindeverbände in Nordrhein-Westfalen im Jahr 1974 . . . . . . . . 294

Tabelle $19 \mathrm{~d}$ Die Finanzkraft der Gemeinden und Gemeindeverbände in Bayern im Jahr $1974 \ldots \ldots \ldots \ldots \ldots \ldots . \ldots 298$

Tabelle 19 e Die Finanzkraft der Gemeinden und Gemeindeverbände in Niedersachsen im Jahr 1974 . . . . . . . . . . . . 304

Tabelle $19 \mathrm{f}$ Die Finanzkraft der Gemeinden und Gemeindeverbände im Saarland im Jahr $1974 \ldots \ldots \ldots \ldots \ldots \ldots \ldots \ldots$

Tabelle $19 \mathrm{~g}$ Die Finanzkraft der Gemeinden und Gemeindeverbände in Schleswig-Holstein im Jahr 1975. . . . . . . . . . . 309

Tabelle 20 Die Verteilung der Finanzzuweisungen von Bund und Ländern und der Finanzkraft auf steuerstarke und steuerschwache Regionen im Jahr $1974 \ldots \ldots \ldots \ldots \ldots$ 


\section{TEIL: THEORETISCHE GRUNDLAGEN}

\section{A. DIE ZIELE IN DER REGIONALPOLITIK}

I. Raumordnungspolitik und Regionalpolitik - Begriffsbestimmung

Raumordnungspolitik ist darauf ausgerichtet, ein allgemein akzeptiertes gesellschaftspolitisches Leitbild der Ordnung des Raumes im umfassendsten Sinne zu verwirklichen. Sie umfaßt alle bewußt von staatlichen Institutionen ergriffenen Maßnahmen, um Räume bzw. Regionen gemäß dem gesellschafts politischen Leitbild oder Zielsystem zu gestalten, zu entwickeln und zu nutzen. (1) Die Beeinflussung der Raumstruktur mit raumordnungspolitischen Maßnahmen berücksichtigt nicht nur die ökonomischen, sondern auch die sozialen, kulturellen und ökologischen Aspekte der wünschenswerten Raumstruktur. (2) Da das angestrebte Zielsystem alle Teilbereiche des gesellschaftlichen Lebens umfaßt, entstammen die Instrumente der Raumordnungs politik (3) einer Vielzahl staatlicher Einzelpolitiken. "Raumordnungspolitik ist danach der Oberbegriff für alle staatliche Tätigkeit, die unmittelbar oder mittelbar auf den Raum Bezug nimmt." (4)

Im Gegensatz zu Brösse (5) wird Regionalpolitik oder regionale Wirtschafts politik hier als "ökonomischer Bereich der Raumordnungspolitik"(6) betrachtet. Sie zielt darauf ab, die aus dem umfassenden gesellschaftspolitischen Zielsystem abgeleitete wünschenswerte Raumstruktur mit Hilfe spezifisch wirtschaftspolitischer Instrumente zu realisieren. (7)

Im folgenden wird Regionalpolitik in einem noch engeren Sinne verstanden: Ihre Maßnahmen beschränken sich darauf, die "regionalen Implikationen"(8) der globalen Ziele der Wirtschaftspolitik anzustreben. Regionalpolitik ist also ein "Teilbe reich der staatlichen Wirtschaftspolitik, sie umfaßt neben bzw. ergänzend zu der globalen (nationalen) Wirtschaftspolitik alle Bestre bungen und Maßnahmen, die bewußt im Hinblick auf ihre räumlichen Auswirkungen ergriffen werden. "(9)

Zum Bereich der Regionalpolitik werden in dieser Arbeit nur die Maßnahmen gezählt, mit denen der Staat absichtsvoll die Raumstruktur beeinflus sen will. Nicht zur Regionalpolitik gehören solche Maßnahmen, die primär anderen als regionalpolitischen Zielèn dienen, von denen aber unbeabsichtigte und deshalb unkontrollierte Nebenwirkungen auf die Raumstruktur ausgehen. (10) Erst wenn die räumlichen Effekte dieser Maßnahmen von den staatlichen Entscheidungsträgern explizit berücksichtigt und dementsprechend diese Maßnahmen ergriffen, modifiziert oder unterlassen werden, können sie als regionalpolitische Instrumente bezeichnet werden.

Nachdem erläutert worden ist, was unter "Raumordnungspolitik" und "Regionalpolitik" in dieser Arbeit verstanden wird, soll anschließend das mit re gionalpolitischen Maßnahmen angestrebte Zielsystem abgeleitet und begründet werden. Damit soll die Präferenzstruktur des Verfassers offengelegt und das Verständnis der ziel- bzw. wertbezogenen Interpretation der Ergebnisse des empirischen Teils der Arbeit erleichtert werden. 


\section{Zielsysteme der Raumordnungspolitik}

Für die Raumordnungspolitik hat Brösse zwei Zielsysteme entwickelt, die in föderalistisch aufgebauten Staaten gleichzeitig auftreten: Das räumlich koordinierte Zielsystem und das räumlich unkoordinierte Zielsystem. (11)

\section{Das räumlich koordinierte Zielsystem}

Bei diesem handelt es sich um das Zielsystem einer gesamtwirtschaftlich orientierten Raumordnungspolitik. (12) Die Zielvorstellungen über die räumliche Entwicklung der einzelnen Teilräume werden von einer zentralen Entscheidungsinstanz aus gesamträumlichen bzw. gesamtgesellschaftlichen Zie len abgeleitet. Die für die einzelnen Regionen geltenden Ziele werden nach einheitlichen Kriterien bestimmt und stimmen die Interessen und Erfordernisse aller Teilräume zielgerecht, also optimal, aufeinander ab. Übergeordnete Aspekte drängen regionale Sonderinteressen zurück. (13)

In allgemeiner Formulierung besteht das Ziel der gesamtwirtschaftlich orientierten Raumordnungspolitik darin, die verfügbaren Ressourcen (14) so in die einzelnen Regionen zu lenken und dort zu nutzen, daß das gesamträumliche Optimum realisiert wird.

Das gesamträumliche Optimum wird durch die geltenden gesellschaftspolitischen Zielvorstellungen determiniert und kann durch eine Reihe von Unterzielen konkretisiert werden. Als wichtigste Unterziele führt Brösse auf:

- Integration der Regionen,

- Befriedigende Beschäftigungslage in allen Regionen,

- Stetiges und befriedigendes Wachstum im Gesamtraum,

- Befriedigende räumliche Zuordnung der wichtigsten Daseinsfunktionen (Wohnen, Arbeiten, Versorgung usw.),

- Angleichung der Niveaus der Regionen,

- Schutz von Natur, Landschaft und Umwelt. (15)

\section{Das räumlich unkoordinierte Zielsystem}

Das räumlich unkoordinierte Zielsystem wird von einer ausschließlich an regionalen Interessen orientierten Raumordnungspolitik angestrebt. Die konkreten Ziele der räumlichen Entwicklung einer Region werden von regionalen und/oder lokalen Entscheidungsinstanzen festgelegt. Übergeordnete gesamtstaatliche Zielvorstellungen und Interessen anderer Teilräume werden grundsätzlich nicht berücksichtigt.

Ziel der untergeordneten Entscheidungsinstanzen in allgemeiner Formulierung ist es, so viel Ressourcen wie möglich in die eigene Region zu lenken und dort optimal zu nutzen. Man kann auch sagen, daß der Vorteil der eigenen Region maximiert werden soll. Dabei versuchen die wirtschaftsstarken Regionen ihren Einkommensvorsprung gegenüber den "armen Regionen"(16) 
mindestens aufrecht zu erhalten (Erhaltung des Besitzstandes), während die wirtschaftsschwachen Regionen um eine Verringerung des Einkommensrückstands zu den "reichen Regionen" (16) (Verbesserung des Besitzstandes) bemüht sind. Um dieses "egoistische" Ziel zu verwirklichen, streben die untergeordneten Entscheidungsinstanzen im wesentlichen folgende Unterziele an:

- Vollbeschäftigung für die eigene Region,

- Stetiges und befriedigendes Wachstum in der eigenen Region,

- Konjunkturunabhängigkeit der regionalen Wirtschaftszweige,

- Steigerung der Attraktivität der eigenen Region,

- Schutz von Natur, Landschaft und Umwelt,

- Befriedigende räumliche Zuordnung der Daseinsfunktionen innerhalb der eigenen Region. (17)

\section{Das Verhältnis der beiden Zielsysteme zueinander}

Die gleichzeitige Existenz zweier unabhängig nebeneinanderstehender Zielsysteme der Raumordnungspolitik ist charakteristisch für föderalistisch auf gebaute Staaten. In ihnen wird die "Ausübung der staatlichen Befugnisse und die Erfüllung der staatlichen Aufgaben"(18) grundsätzlich regionalen Entscheidungsinstanzen zugewiesen. Außerdem erhalten lokale Entscheidungsinstanzen das Recht, "alle Angelegenheiten der örtlichen Gemeinschaft. . . in eigener Verantwortung zu regeln. (19) Unter der Voraussetzung dieser Aufgabenverteilung auf die verschiedenen bundesstaatlichen Ebenen muß den untergeordneten Gebietskörperschaften das Recht zugebilligt werden, die Ziele für die räumliche Entwicklung ihres Hoheitsgebiets selbst festzulegen. Da jedoch überregionale Gesichtspunkte bei der Bestimmung der spezifisch regionalen Ziele nicht berücksichtigt werden, drohen raumordnungspolitische Maßnahmen der untergeordneten Gebietskörperschaften bei ausschließlicher Orientierung an ihrem räumlich unkoordinierten Zielsystem gesamtstaatliche Ziele und Belange zu verletzen. Das Nebeneinander beider Zielsysteme der Raumordnungspolitik macht deshalb ihre Koordination erforderlich. "Das gesamträumliche Zielsystem darf demnach räumlich unkoordinierte Zielsysteme nicht ausschließen, sondern nur beeinflussen und in eine bestimmte Richtung lenken. "(20)

In dieser Arbeit wird u. a. danach gefragt, welche Möglichkeiten der Zentralstaat in einem Bundesstaat besitzt, um die Diskrepanz zwischen gesamtwirtschaftlich orientiertem Zielsystem und den räumlich unkoordinierten Zielsystemen zu verringern. Es geht bei diesem Problem in erster Linie darum, ob und wie der Zentralstaat mit Hilfe finanzpolitischer, insbesondere finanzausgleichspolitischer Maßnahmen die untergeordneten Entscheidungsträger dazu bewegen kann, überregionale Gesichtspunkte, Zielelemente des räumlich koordinierten Zielsystems, bei ihren raumwirksamen Entscheidungen zu beachten. Wenn in dieser Arbeit von raumordnungspolitischen bzw. regionalpolitischen Zielen gesprochen wird, sind damit immer die Teilziele eines räumlich koordinierten Zielsystems gemeint. 
III. Die regionalen Implikationen des gesamtwirtschaftlichen Zielsystems

Die wichtigsten Teilziele des räumlich koordinierten Zielsystems der Raumordnungspolitik sind aus dem Zielsystem der globalen Wirtschaftspolitik abgeleitet. Sie bilden das Zielsystem der Regionalpolitik, das damit ein Teil des raumordnungspolitischen Zielsystems ist. Als Oberziele der regionalpolitischen Ziele fungieren die wirtschaftspolitischen Ziele Gerechtigkeit, Wachstum und Stabilität. Die Ziele der Regionalpolitik stellen die "regionalen Implikationen"(21) dieser drei wirtschaftspolitischen Oberziele dar.

1. Die regionalen Implikationen des Gerechtigkeitsziels

1.1. Inhalt des verteilungspolitischen Ziels der Regionalpolitik

Aus dem Gerechtigkeitsziel als wirtschaftspolltisches Oberziel kann für die Regionalpolitik als erstes die Aufgabe abgeleitet werden, eine Vergrößerung der regionalen Einkommensunterschiede zu verhindern.

Zielt diese Forderung auf Konstanz der Einkommensrelationen zwischen den einzelnen Regionen ab, muß sie als Minimalforderung betrachtet werden. Sie bedeutet dann nämlich, daß gleiche Wachstumsraten des Pro-Kopf-Einkommens der Regionen angestrebt werden, was bei positiven Wachstumsraten zu einer Vergrößerung der absoluten Einkommensunterschiede pro Kopf zwischen den einzelnen Regionen führt.

Weitreichender ist diese Forderung, mittels regionalpolitischer Maßnahmen eine Verschärfung des interregionalen Einkommensgefälles zu vermeiden, wenn damit Konstanz der absoluten regionalen Einkommensunterschiede angestrebt wird. Dieses Ziel wird nur erreicht, wenn die Pro-Kopf-Einkommen der einzelnen Regionen prozentual umso stärker wachsen, je niedriger sie sind.

Über die Vermeidung größerer Einkommensunterschiede zwischen den einzelnen Teilräumen einer Volkswirtschaft hinaus kann aus dem Gerechtigkeitsziel gefolgert werden, die Regionalpolitik solle das interregionale Einkommensgefälle verringern. Auch hier sind die belden oben angesprochenen Aspekte zu beachten.

Hält man diese Forderung bereits für erfüllt, wenn sich infolge unterschiedlicher Wachstumsraten die Einkommensrelationen zwischen den Regionen zugunsten der ärmeren Regionen verbessern, kann damit immer noch eine Vergrößerung der absoluten Einkommensunterschiede einhergehen. (22)

Am weitesten geht die Forderung, die Regionalpolitik solle die absoluten Einkommensunterschiede verringern. Bei dieser Formulierung ist noch offen, wie weit die Annäherung der regionalen Einkommensniveaus gehen soll, ob vielleicht die regionalen Einkommensunterschiede vollständig beseitigt oder gar das interregionale Einkommensgefälle umgekehrt werden soll.

Wenn als Ziel der regionalen Strukturpolitik die "Vermeidung und Beseitigung 
extremer Disparitäten in der interregionalen Verteilung der durchschnittlichen Pro-Kopf-Realeinkommen"'(23) definiert wird, so wird in dieser Arbeit damit immer die Verringerung der absoluten Einkommensunterschiede zwischen den einzelnen Regionen, die tendenzielle Annäherung der regionalen Einkommensniveaus an den gesamträumlichen Durchschnitt, gemeint.

\subsection{Produktwerte als Indikatoren des regionalen Wohlstandsniveaus}

In der bisherigen Inhaltsbestimmung der regionalen Implikationen des $\mathrm{Ge}$ rechtigkeitsziels wird von der Verringerung regionaler Einkommensunterschiede gesprochen, wobei mit "regionalem Einkommen" die regionalen Inlandsproduktwerte oder Sozialproduktwerte pro Einwohner der Region zu verstehen sind. Diese Produktwerte einer Region, die zum Teil offiziellen Statistiken entnommen werden können (24), enthalten aber in der Regel nur die marktmäßig erzielten Leistungseinkommen der in der Region lebenden (Sozialprodukt) oder in ihr arbeitenden (Inlandsprodukt) Menschen. Andere Einkommensbestandteile können aber interregionale Unterschiede in den Leistungseinkommen abschwächen oder gar überkompensieren, so daß das durchschnittliche Leistungseinkommen einer Region nur ein unvollkommener Indikator für das regionale Einkommensniveau im Sinne von Wohlstandsniveau ist.

In einem umfassenden Indikator für das regionale Wohlstandsniveau müssen neben dem marktmäßigen Leistungseinkommen ( $\left.Y_{L}\right)$ auch die Transfereinkommen an die Einwohner der Region $\left(T_{r}\right)$ und die von ihnen entrichteten Steuern $(T)$, als negativer Posten, eingehen. Diese drei Faktoren ergeben zusammen das verfügbare monetäre Einkommen $\left(\mathrm{Y}_{\mathrm{m}}^{\mathrm{V}}\right)$. Dieses muß ergänzt werden um nichtmonetäre oder preislose Einkommensbestandteile (Ynm)(25), deren wichtigste Elemente die Güter- und Leistungserstellung der Regions einwohner für den Eigenverbrauch $\left(\mathrm{Pr}_{\mathrm{E}}\right)$, die von der öffentlichen Hand unentgeltlich angebotenen Güter - und Dienstleistungen ( $L_{0 ̈}$ ) sowie der Zustand der natürlichen Umwelt, kulturelle und soziale Atmosphäre und ähnliche Wohnortfaktoren $(U)$ sind. Das regionale verfügbare Gesamteinkommen $\left(Y^{V}\right)$ als Indikator des regionalen Wohlstandsniveaus besteht demnach aus folgenden Elementen:

$\mathrm{Y}^{\mathrm{V}}=\mathrm{Y}_{\mathrm{m}}^{\mathrm{V}}+\mathrm{Y}_{\mathrm{nm}}=\mathrm{Y}_{\mathrm{L}}+\mathrm{T}_{\mathrm{r}}-\mathrm{T}+\mathrm{Pr}_{\mathrm{E}}+\mathrm{L}_{\ddot{\mathrm{O}}}+\mathrm{U}$

Orientiert sich nun die Regionalpolitik an dieser umfassenden Einkommenskonzeption und strebt die Verringemung der absoluten regionalen Wohlstandsunterschiede an, so wird sie in starkem Maße inoperabel. Infolge der Erfas sungsschwierigkeiten der Einzelteile des regionalen verfügbaren Gesamteinkommens ist eine Analyse der aktuellen interregionalen Einkommensverteilung und die Prognose ihrer zukünftigen Entwicklung ebenso unmöglich wie die Erfolgskontrolle regionalpolitischer Maßnahmen. Die Erfassungsschwierigkeiten beginnen bereits bei der Ermittlung des verfügbaren monetären Einkommens der Regionen. Zwar lassen sich seine Bestandteile quantifizieren, doch reichen die gegenwärtig verfügbaren Statistiken nicht aus, um die regiona- 
le Verteilung der Transferzahlungen und Steuerzahlungen (Zahlungsinzidenz) zu erfassen. Bei den Bestandteilen des nichtmonetären Einkommens kommen zu den statistischen Mängeln noch die Schwierigkeiten der Quantifizierung, der Nutzenmessung.

Trotz der mit diesem umfassenden Einkommenskonzept verbundenen Schwierigkeiten darf sich die Regionalpolitik nicht ausschließlich auf die Verringerung regionaler Unterschiede im monetären Leistungseinkommen oder monetären verfügbaren Einkommen beschränken. Sie muß die räumliche Verteilung der nichtmonetären Einkommensbestandteile und die Möglichkeiten zu ihrer Beeinflussung deswegen beachten, weil diese Einkommensbestandteile als Element des regionalen Wohlstandsniveaus eine Determinante der interregionalen Faktorwanderungen sind und ihre Beeinflussung zur langfristigen Steigerung des regionalen Leistungseinkommens beitragen kann.

Die Bedeutung der nichtmonetären Bestandteile des regionalen Gesamteinkommens schlägt sich in der Forderung nieder, die Regionalpolitik solle die Einheitlichkeit der Lebensverhältnisse im Gesamtraum wahren (26) oder für gleichwertige Lebensbedingungen in allen Teilräumen sorgen. Diese Zielsetzung fordert, daß die "Versorgung mit privaten Gütern" interregional nicht allzu verschieden sein und eine "gleichwertige Versorgung mit Gütern und Diensten des öffentlichen Sektors"(27) herbeigeführt werden soll. Wenn im weiteren Verlauf dieser Arbeit die Verringerung der absoluten Einkommens unterschiede pro Kopf zwischen den Regionen als von der Regionalpolitik zu verfolgendes Ziel postuliert wird, ist dabei $\mathrm{zwar}$ in erster Linie an die Verringerung der regionalen Unterschiede hinsichtlich des monetären Leistungseinkommens gedacht. Gleichzeitig soll aber die Bedeutung der nichtmonetären Eînkommensbestandteile nicht unterschätzt werden. Vielmehr sollen diese in der obigen Formulierung des regionalpolitischen Ziels eingeschlossen sein.

1.3. Stellenwert des verteilungspolitischen Ziels der Regionalpolitik

Für die Notwendigkeit, die interregionalen Einkommensunterschiede zu verringern, können mehrere Gründe angeführt werden.

a) In hochentwickelten Volkswirtschaften werden die als Ergebnis des Marktprozesses entstehenden interpersonellen Einkommensunterschiede gemäß den gesellschaftlichen Wertvorstellungen als ungerechtfertigt hoch angesehen. Zu ihrer Verringerung werden redistributionspolitische Maßnahmen als notwendig erachtet.

Das interpersonelle Verteilungsproblem hat auch einen regionalen Aspekt, der nicht vernachlässigt werden darf. In der Regel verteilen sich nämlich die Bezieher unerwünscht niedriger Einkommen nicht gleichmäßig auf die gesamte Volkswirtschaft, sondern sind überproportional in schwachstrukturierten Regionen zu finden. Eine tendenzielle Nivellierung der interregionalen Einkommensverteilung führt damit in der Regel auch zu einem Abbau der interpersonellen Einkommensunterschiede im Gesamtraum. (28)

Die Verringerung interpersoneller Einkommensunterschiede über eine Ein- 
ebnung des interregionalen Wohlstandsgefälles hat sogar einen erheblichen Vorteil gegenüber globalen verteilungspolitischen Maßnahmen traditioneller Art. Die globale Verteilungspolitik versucht mit Transferzahlungen und Steuervergünstigungen das verfügbare monetäre Einkommen der Bezieher niedriger Einkommen zu erhöhen. Sie ist damit überwiegend symptomorientiert. Die verteilungsorientierte Regionalpolitik versucht dagegen, die Ursachen für die regionalen Unterschiede in den monetären Leistungseinkommen zu beseitigen. Sie ist ursachenorientiert.

Mit der Berücksichtigung des regionalen Aspektes des interpersonellen Verteilungsproblems wird das "'Recht auf angemessenes Einkommen' an irgendeinem Ort innerhalb der nationalen Volkswirtschaft" erweitert zu einem Recht auf angemessenes Einkommen innerhalb der angestammten Region, zu einem "Recht auf Heimat". (29)

Das Ziel des Abbaus interregionaler Einkommensunterschiede erhält damit den Charakter eines "Wertes an sich", eines "letzten" Ziels.

b) Dem regionalen Einkommensgefälle entspricht auch ein regionales $\mathrm{Be}$ schäftigungsgefälle (30), denn das niedrige Pro-Kopf-Einkommen strukturschwacher Regionen ist nicht allein auf die unterdurchschnittliche Produktivität der ansässigen Unternehmen und der von ihnen angebotenen Arbeitsplätze zurückzuführen. Ein weiterer Grund ist das quantitativ unzureichende Arbeitsplatzangebot und damit die hohe regionale Arbeitslosigkeit.

Die Einwohner der zurückgebliebenen Regionen können sich nicht damit abfinden, daß sie wegen der Zugehörigkeit zu ihrer Region schlechtere Beschäftigungs - und Einkommensmöglichkeiten und damit geringere Möglichkeiten zur Selbstverwirklichung haben sollen als die Einwohner anderer Regionen. Armut, Hoffnungslosigkeit, das Gefühl, vom Zentralstaat vernachlässigt zu werden, all das schlägt sich in politischem Radikalismus und Seperationsbestrebungen nieder. Die durch das regionale Einkommensgefälle ausgelösten sozialen Spannungen gefährden, wenn sie längerfristig bestehen bleiben, den Bestand der Wirtschafts - und Gesellschaftsordnung und die Einheit des Staates. $(31,32)$

Die tendenzielle Nivellierung der regionalen Einkommensverteilung wird damit zu einem Mittel, "Frieden und Sicherheit im Innern"(31) eines Staates zu sichern.

c) Ein dritter Aspekt stellt stärker ökonomische Überlegungen in den Vordergrund.

Die regional unterschiedlichen Beschäftigungs - und Verdienstmöglichkeiten sind die wohl entscheidende Determinante der Wanderungsbewegungen des Faktors Arbeit. Da sich die Chancen zur Einkommenserzielung am Gefälle der regionalen Pro-Kopf-Einkommen ablesen lassen, bestimmt dieses Gefälle Umfang und Richtung der Arbeitskräftewanderungen innerhalb, aber auch zwischen den Volkswirtschaften.

Von Befürwortern der passiven Sanierung wird die Abwanderung von Arbeits kräften aus einkommensschwachen Regionen positiv beurteilt, weil dadurch 
das regionale Einkommensniveau angehoben würde. Dabei wird jedoch übersehen, daß der Bevölkerungsverlust in der zurückgebliebenen Region einen kumulativen Proze $\beta$ auslösen kann. So wird durch eine Abwanderung nicht nur die Zahl der überschüssigen Arbeitskräfte, sondern auch die der Nachfrager verringert. Damit wird leicht die Existenzgrundlage für solche re gionsansässigen Unternehmen zerstört, die überwiegend für die regionale Nachfrage produzieren. Werden auch sie zur Abwanderung gezwungen, beeinträchtigt dies auch die Produktivität solcher Betriebe, die für über regionale Märkte produzieren. Hinzu kommt, daß jeder Wanderungsproze $\beta$ ein selektiver Vorgang (33) ist. In erster Linie verlassen die jüngeren und qualifizierteren Arbeitskräfte die Region. Den zurückbleibenden Unternehmen steht damit ein Arbeitspotential zur Verfügung, daß sich im Zeitverlauf qualitativ ständig verschlechtert. Die dadurch bewirkte relative oder absolute Produktivitätssenkung kann auch die Unternehmen zur Aufgabe des bisherigen Standorts zwingen, die vor Beginn der passiven Sanierung interregional wettbewerbsfähige Arbeitsplätze angeboten haben.

Auf der anderen Seite erhöht der Zustrom junger und qualifizierter Arbeits kräfte in hochentwickelte Regionen deren Anziehungskraft auf Unternehmen und kann damit eine Ausdehnung des Arbeitsplatzangebots in den stark verdichteten Räumen bewirken.

Aber auch, wenn die Arbeitskräftewanderungen keine kumulativen Tendenzen auslösen, können sie Probleme schaffen, die sie als unerwünscht erscheinen lassen. Diese Probleme lassen sich mit dem Begriff "soziale Zusatzkosten"(34) zusammenfassen und treten sowohl in den Abwanderungsgebieten als auch in den Zuwanderungsgebieten auf.

In den Abwanderungsgebieten droht "soziale Erosion". Die zurückbleibende Bevölkerung ist infolge ihrer einseitigen Struktur und der geringen Bevölke rungsdichte nicht mehr in der Lage, lebensfähige soziale Einheiten zu bilden. Es droht eine soziale und kulturelle Verödung, aus der ebenfalls kumulative Tendenzen hervorgehen können. Investiertes privates und öffentliches Kapital wird nicht mehr ausreichend ausgelastet und schließlich zerstört. Dies trifft insbesondere zu für Wohngebäude, Infrastruktureinrichtungen und Investitionen in die Landschaft, durch die die Naturlandschaft zur Kulturlandschaft wurde. (35)

In den Zuwanderungsgebieten verschärft der Bevölkerungsstrom aus den Abwanderungsgebieten alle Probleme, die sich aus den zunehmenden räumlichen Konzentrationen ökonomischer Aktivitäten ergeben: Die Umweltbelastung durch Lärm und Schmutz nimmt zu, die Überlastung der Infrastruktureinrichtungen wird immer bedrohlicher, die Leistungsfähigkeit der Faktoren Arbeit und Kapital beeinträchtigt, woraus sich auch eine Verletzung des wachstumspolitischen Ziels ergeben kann. (36)

Ein weiterer Aspekt der Arbeitskräftewanderung berührt das Gerechtigkeitsziel. Mit dem Bevölkerungsverlust ist für die Gebietskörperschaft der armen Region ein Ertrags-spillout (37) verbunden. Denn sie hat z. B. in Form von Ausgaben im Gesundheits - und Ausbildungswesen in "menschliches Kapital" (human capital) investiert, muß jedoch infolge des "body and brain drain" 
den Ertrag dieser Investition der reichen Region uberlassen. Die zurückgebliebene Region hat damit Aufwendungen geleistet, durch die die wirtschaftsstarke Region ihre Wirtschaftskraft weiter stärken kann.

Unter diesen Gesichtspunkten wird hier Cairncross u. a. zugestimmt, daß "Eindämmung der Wanderungen auf ein erträgliches Ausmaß" "ein zentrales Anliegen der Regionalpolitik"(38) sein sollte.

Dem verteilungspolitischen Ziel der Regionalpolitik wird in dieser Arbeit aus Gerechtigkeitserwägungen und wegen seiner Funktion zur Vermeidung sozialer Spannungen und unerwünschter Bevölkerungswanderungen die Priorität vor allen anderen Zielen der Regionalpolitik eingeräumt. Im Konfliktfall hätten demnach wachstumspolitische hinter verteilungspolitischen Erwägungen zurückzustehen. Es muß jedoch betont werden, daß dieser hohe Stellenwert des verteilungspolitischen Ziels orts - und zeitbedingt ist. Er ist also nicht unabhängig vom Entwicklungsstand der konkret betrachteten Volkswirtschaft. Mit zunehmender wirtschaftlicher Entwicklung verändern sich auch Struktur und Rangfolge der gesellschaftlichen Wertvorstellungen. Das Ziel des überwiegend quantitativ verstandenen Wachstums verliert immer mehr an Bedeutung gegenüber Fragen des qualitativen Wachstums und der Verteilung des Wohlstands (Qualität des Lebens). (39)

\section{Die regionalen Implikationen des Wachstumsziels}

\subsection{Inhalt des wachstumspolitischen Ziels der Regionalpolitik}

Als spezifisch ökonomisches Ziel wird der Regionalpolitik zugewiesen, für die räumliche Verteilung der Produktivkräfte zu sorgen, durch die das größtmögliche Sozialprodukt und/oder ein möglichst kräftiges Wachstum der Gesamtwirtschaft ermöglicht wird. Die Regionalpolitik soll also die Produktivkräfte interregional und intraregional so lenken, daß es zu einer Gleichheit der sozialen Grenzkosten der wirtschaftlichen Aktivitäten im Raum (40) kommt. Solange noch regionale Unterschiede in den sozialen Grenzkosten auftreten, lohnt es sich volkswirtschaftlich, Ressourcen vom Ort höherer Grenzkosten abzuziehen und an den Ort niedrigerer Grenzkosten zu lenken. Ein gegebenes Sozialprodukt kann dadurch zu niedrigeren (sozialen) Kosten erstellt werden (41) oder mit gegebenem Ressourceneinsatz kann ein größeres Sozialprodukt bzw. Wohlstandsniveau erreicht werden. (42) Giersch bezeichnet diese Frage als "das ökonomische Grundproblem der Regionalpolitik". (43)

Theoretisch ist damit die unter wachstumspolitischen Gesichtspunkten wünschenswerte räumliche Verteilung der Produktivkräfte eindeutig festgelegt. Doch bietet dieses wohlfahrtstheoretische Kriterium der wachstumsorientierten Regionalpolitik keine praktikable Entscheidungshilfe. Deswegen wird als Entscheidungskriterium für eine wachstumsoptimale räumliche Allokation der Ressourcen der Begriff des regionalen Entwicklungspotentials eingeführt. (44) Dieses Kriterium fordert, daß die öffentlichen Hände ihre regionalen Fördermittel zur Attrahierung privater mobiler Produktivkräfte in den 
Regionen einsetzen sollen, die das höchste regionale Entwicklungspotential aufweisen.

\subsection{Zur Problematik des regionalen Entwicklungspotentials}

Das regionale Entwicklungspotential kann vorläufig "als dasjenige Pro-KopfProdukt (Regionalprodukt) bezeichnet werden, das eine Region bei optimaler Nutzung aller ihr zur Verfügung stehenden Ressourcen erzielen kann". (45)

Dabei ist bedeutsam, daß bei dieser Definition von einer augenblicklich gegebenen Ressourcenausstattung der einzelnen Regionen ausgegangen wird. Der Begriff der "Ressource" wird außerordentlich umfassend verstanden:

- Unter einem gesellschaftlichen und organisatorischen Aspekt rechnen Biehl und Mitarbeiter die sozialen und politischen Rahmenbedingungen des gesellschaftlichen Lebens und der wirtschaftlichen Aktivitäten dazu.

- Unter einem quantitativen und qualitativen Blickwinkel gehören u. a. zu den "Ressourcen":

Die verfügbare Menge und Qualität des Bodens (z. B. Klima, Topographie, Bodenschätze, Flächen), das Arbeitskräftepotential als Bestand an ungelernten Arbeitskräften, das Ausbildungskapital einschließlich technischem und organisatorischem Wissen, die Infrastruktur, das private Sparkapital.

- Unter einem räumlichen Aspekt betrachten die Autoren u. a. die wirtschaftsgeographische Lage und den Agglomerationsgrad einer Region als "Ressource".

- Unter einem strukturellen Blickwinkel wird die sektorale und intrasektorale Wirtschaftsstruktur dazu ge rechnet. (46)

Die regionalen Entwicklungsmöglichkeiten, das für eine Region maximaì mögliche Pro-Kopf-Produkt, werden nun aber nicht von allen Ressourcen gleichermaßen begrenzt. Nur die Faktoren determinieren das regionale Entwicklungspotential, die immobil und unteilbar und deshalb regional gebunden und politisch gar nicht oder nur zu hohen Kosten erweitert werden können. Faktoren mit diesen Eigenschaften werden als Potentialfaktoren bezeichnet. (47)

Mobile und teilbare Faktoren können "ja grundsätzlich in jede Region attrahiert und mit den dort vorhandenen Potentialfaktoren kombiniert werden". (48) Sind die mobilen Faktoren augenblicklich nicht in einer Region vorhanden, wird dadurch das mögliche Regionalprodukt nicht beeinträchtigt. Deswegen wird "die jeweilige Ausstattung einer Region mit Ressourcen, die einen vergleichsweise hohen Potentialcharakter haben, als Indikator für die Größenordnung des potentiell erzielbaren Regionalprodukts und damit des regionalen Entwicklungspotentials"(48) aufgefaßt. Ob eine Ressource Potentialcharakter besitzt, hängt aber nicht nur von ihrer Art, sondern in erster Linie von dem zugrunde gelegten Zeithorizont ab. Bei kurzfristiger Betrachtung kann die Kapazität keiner Ressource verändert werden. Alle Ressourcen haben damit Potentialcharakter. Bei mittelfristiger Betrachtung sind Faktoren wie priva- 
tes Kapital und Arbeitskräfte bereits vergleichsweise mobil und teilbar. "Wird ein noch längerer Zeitraum gewählt, so daß etwa auch wesentliche Ände rungen in der relativen Infrastrukturausstattung auftreten und diese sich nicht nur in der Branchenstruktur, sondern auch in der sektoralen Wirtschaftsstruktur bemerkbar machen können, dann muß ein noch größerer Kreis von Ressourcen als mobil und auch teilbar und damit durch private und öffentliche Entscheidungen beeinflußbar betrachtet werden. "(49) Als Potentialfaktoren bleiben in längerfristiger Sicht dann nur noch

- "die gesellschaftlichen und politischen Rahmenbedingungen

- alle Teilfaktoren des Faktors Boden (z. B. Klima, Topographie, Bodenschätze, Flächen)

- die wirtschaftsgeographische Lage"150)

übrig.

Nach diesen Überlegungen läßt sich das regionale Entwicklungspotential nun endgültig definieren als dasjenige potentielle Pro-Kopf-Produkt (Regionalprodukt), das mit den bei dem gewählten Zeithorizont in einer Region verfügbaren Potentialfaktoren und bei optimaler Auslastung dieser Potentialfaktoren durch mobilere Faktoren erzielt werden kann. (51)

Im Grunde ist es gar nicht die bei unterstelltem Zeithorizont gegebene Ausstattung der Region mit Potentialfaktoren, die das regionale Entwicklungspotential determiniert. Entscheidend für das maximal mögliche Regionalprodukt ist vielmehr der knappste Potentialfaktor, der Potentialfaktor mit Engpaßcharakter. (52) Wird nun im Rahmen der Regionalpolitik für die wirtschaftsschwachen Regionen ein bestimmtes Mindest-Pro-Kopf-Einkommen als Ziel angestrebt, so kann die Differenz zwischen tatsächlicher und angestrebter Höhe des Regionalprodukts durch zwei Maßnahmengruppen verringert werden:

- Die in der Region verfügbaren Potentialfaktoren mit Engpaßcharakter werden stärker mit mobileren Faktoren, die aus anderen Regionen attrahiert oder in der betreffenden Region mobilisiert werden, kombiniert und damit ausgelastet. "Damit wird aber immer erst erreicht, daß tatsächliches Regionalprodukt und Entwicklungspotential zusammenfallen". (53)

- Ist damit das angestrebte regionale Einkommensniveau noch nicht erreicht, muß die Region besser mit Engpaßfaktoren ausgestattet werden. Dadurch steigt das Entwicklungspotential und durch Kombination mit komplementären, meist mobileren Faktoren auch das tatsächliche Einkommen in den Förderregionen. In diesem Sinne erfordert ein "Abbau der interregionalen Einkommensunterschiede.., daß die Ausstattung mit Potentialfaktoren verbessert wird". (54)

Für regionalpolitische $Z$ wecke erscheint Biehl und Mitarbeitern der mittelfristige Zeithorizont angemessen. In Abhängigkeit von dieser Zeitspanne ergeben sich zwei Gruppen von Ressourcen mit Potentialfaktorcharakter:

- Ressourcen, die sowohl mittel- als auch langfristig Potentialfaktorcharak- 
ter haben, nämlich die gesellschaftlichen und politischen Rahmenbedingungen, alle Teilfaktoren des Faktors Boden und die wirtschaftsgeographische Lage.

Diese auch langfristig gar nicht oder nur mit hohem Kostenaufwand manipulierbaren Faktoren sind in schwachverdichteten und einkommensschwachen Regionen in der Regel noch lange nicht ausgeschöpft. Sie besitzen dort also keinen Engpaßcharakter und begrenzen mittelfristig nicht das Entwicklungspotential dieser Räume.

In hochverdichteten Räumen sind diese Potentialfaktoren dagegen zum Teil bereits stark oder vollständig ausgelastet. Dies gilt besonders für das Naturraumpotential. "Für diese Regionen können also auch langfristige Potentialfaktoren im Einzelfall Engpaßcharakter haben". (55)

- Ressourcen, die nur mittelfristig Potentialfaktorcharakter haben, deren Kapazität langfristig dagegen durch politische Maßnahmen erweitert werden kann.

Dazu zählen:

a) das Arbeitskräftepotential (Zahl der unausgebildeten Arbeitskräfte)

b) die Infrastruktur

c) die Agglomeration (räumliche Konzentration von Bevölkerung und wirtschaftlicher Aktivität)

d) die sektorale Wirtschaftsstruktur.

Diese Faktoren können mittelfristig auch für schwachverdichtete Regionen Engpaßcharakter haben und damit das regionale Entwicklungspotential auch der einkommensschwachen Region begrenzen.

Die letzten vier Faktoren sind aber nur mittelfristig kaum zu verändern. Langfristig dagegen verlieren sie ihren Potentialfaktorcharakter. Tritt in einer Region bei einem dieser Faktoren ein Engpaß auf, durch den das regionale Entwicklungspotential begrenzt wird, kann durch eine verbesserte Aus stattung der Region mit diesem bisherigen Engpaßcharakter ein weiterer Anstieg des Regionalprodukts ermöglicht werden. (56) Das Regionalprodukt kann dann solange steigen, bis der ständige Zustrom komplementärer, mobiler Ressourcen einen anderen Potentialfaktor zum Engpaßfaktor werden läßt. Langfristig, und dieser Zeithorizont wird in dieser Arbeit gewählt, begrenzen nur die Potentialfaktoren "naturräumliche Bedingungen" und "gesellschaftliche Rahmenbedingungen" das maximal mögliche Pro-Kopf-Einkommen einer Region. Die Ausstattung der einzelnen Regionen mit mittel- und längerfristig mobilen Ressourcen und damit das regionale Wirtschaftswachs tum stoßen damit vor allem auf naturräumliche Grenzen, wie Bodenknappheit, Erschöpfung von Rohstofflägern, ungünstigen klimatischen Verhältnis sen usw., die nur unter sehr hohem Kostenaufwand (57) hinausgeschoben werden können. Insofern sind die Grenzen des Wachstums ein regionales Phänomen, das besonders in stark verdichteten Räumen auftritt.

Regionale Unterschiede im Entwicklungspotential, wie es hier verstanden wird, also Unterschiede im langfristig grundsätzlich möglichen Pro-Kopf- 
Produkt einer Region, beruhen ausschließlich auf einer unterschiedlichen Ausstattung der einzelnen Regionen mit langfristig kaum oder gar nicht zu verändernden Potentialfaktoren, also in erster Linie mit natürlichen Faktoren. Für westeuropäische und insbesondere deutsche Verhältnisse bedeutet dies, daß die Entwicklungspotentiale etwa gleichgroßer Regionen kaum gravierende Unterschiede aufweisen dürften. Die gesellschaftlichen Rahmenbedingungen weisen in einer Volkswirtschaft wie der deutschen nur geringfügige Unterschiede auf. Dasselbe gilt für die klimatischen Verhältnisse. Lediglich die Gestalt der Erdoberfläche (Topographie), die wirtschaftsgeographische Lage sowie die Existenz bzw. Nichtexistenz von Bodenschätzen begünstigen bzw. benacisteiligen einige Regionen und verursachen Unterschiede im langfristig grundsätzlich möglichen Regionalprodukt. Dabei verliert der Faktor "Bodenschätze" in einem rohstoffarmen Land wie der Bundesrepublik Deutschland, in dem zudem noch die meisten Vorkommen bereits ausgeschöpft sind, seine Bedeutung für Unterschiede im regionalen Entwicklungspotential. Als bedeutendster Faktor ist wohl die wirtschaftsgeographische Lage anzusehen, die sich solange als Nachteil für einzelne Regionen auswirkt, wie diese Regionen an der Peripherie eines durch Zollmauern abgegrenzten Wirtschafts gebietes liegen und die ökonomische Entfernung zum wirtschaftlichen Zentrum des Wirtschafts raumes nicht durch z. B. Infrastrukturmaßnahmen stark verringert wird. Für die Bundesrepublik Deutschland verliert aber auch dieser Faktor die Bedeutung, die er für die peripheren Regionen in wesentlich größeren Wirtschaftsräumen, z. B. für die Europäische Gemeinschaft oder im Weltmaßstab besitzt.

Aufgrund dieser Überlegungen wird in dieser Arbeit davon ausgegangen, daß etwa gleich große Regionen in der Bundesrepublik und auch in weiten Teilen Westeuropas langfristig in etwa gleich große regionale Pro-Kopf-Einkommen realisieren können. Regionale Unterschiede im tatsächlichen Pro-Kopf-Einkommen spiegeln dann unterschiedliche Auslastungsgrade der etwa gleich hohen regionalen Entwicklungspotentiale wider, die auf einer regional unterschiedlichen Ausstattung mit mobilen Ressourcen, vor allem öffentlichem und privatem Kapital, denen der Faktor Arbeit folgt, beruhen. Eine Verringerung der interregionalen Unterschiede im tatsächlichen Regionaleinkommen wäre durch eine verbesserte Ausstattung der einkommensschwachen Regionen mit mobilen Faktoren zu erreichen.

Nach der hier entwickelten Auffassung muß die von Giersch gestellte Frage nach dem regionalen Entwicklungspotential als Entscheidungskriterium für eine wachstumsoptimale Allokation der Ressourcen etwas anders gestellt werden. Es geht nicht mehr um die Frage nach der Region mit dem größten Entwicklungspotential. Alle Regionen haben ja langfristig relativ gleich groBe Entwicklungspotentiale, nur werden die grundsätzlich vorhandenen Entwicklungsmöglichkeiten in den einzelnen Regionen unterschiedlich stark ausgenutzt. Es stellt sich nun die Frage:

- In welcher Region läßt sich eine politisch erwünschte Einkommenserhöhung mit dem geringsten Ressourceneinsatz erreichen, bzw.

- in welcher Region läßt sich mit gegebenem Umfang öffentlicher Fördermittel der größte Einkommensanstieg realisieren? 
Es geht also um die Kosten einer höheren Auslastung des regionalen Entwicklungspotentials, wobei die Antwort auf diese Frage wieder von der politisch vorgegebenen Zeitspanne zur Realisierung des angestrebten Ziels abhängt.

3. Die Beziehungen $\mathrm{zwischen} \mathrm{dem} \mathrm{wachstums-} \mathrm{und} \mathrm{dem} \mathrm{verteilungspoliti-}$ schen Ziel der Regionalpolitik

Die Beantwortung der vorstehenden Frage ermöglicht auch eine Aussage über mögliche Zielkonflikte $\mathrm{zw}$ ischen dem verteilungspolitischen und dem wachs tumspolitischen Ziel der Regionalpolitik.

\subsection{Zielkonflikt bei kurz- und mittelfristigem Planungshorizont}

Die hier postulierte tendenzielle Gleichheit der regionalen Entwicklungspotentiale erscheint nur für einen langfristigen Zeithorizont plausibel. Wird ein mittelfristiger Zeithorizont zugrunde gelegt, z. B. eine Legislaturperiode, so muß man von der gegebenen Ausstattung der einzelnen Regionen mit Arbeitskräften und Infrastruktureinrichtungen und der gegebenen regionalen Wirtschaftsstruktur und räumlichen Konzentration ausgehen. Die Kapazität dieser Ressourcen kann auch mittelfristig nicht oder nur mit hohem Aufwand erweitert werden. Sie sind Potentialfaktoren, die das maximal mögliche Regionalprodukt determinieren.

Wird dieser mittelfristige Zeithorizont politisch vorgegeben, wird die Entscheidung über die regionale Verteilung staatlicher Fördermittel unter wachstumspolitischem Aspekt häufig zugunsten der einkommensstarken und relativ hochverdichteten Regionen ausfallen. In ihnen haben die vier mittelfristigen Potentialfaktoren bereits ein sehr hohes Niveau erreicht. Durch Einsatz einer gegebenen Summe von Fördermitteln kann der Staat in einem dieser Bereiche Engpässe abbauen und in relativ kurzer Zeit die Auslastung der übrigen Potentialfaktoren erhöhen. In dieser kurzen Zeitspanne ist es also möglich, mit den zur Verfügung stehenden Mitteln einen ansehnlichen Anstieg des Regionalprodukts zu erreichen.

Für einkommensschwache, deglomerierte Regionen kann sich die Sachlage genau entgegengesetzt darstellen. Infrastruktur, Agglomerationsgrad und sektorale Wirtschaftsstruktur befinden sich $u$. U. in einem so unbefriedigenden Zustand, daß das regionale Entwicklungspotential in mittelfristiger Sicht sehr niedrig ist. Durch die in der Region bereits vorhandenen mobilen Faktoren ist dieses geringe regionale Entwicklungspotential möglicherweise auch schon stark ausgelastet, stärker jedenfalls als das der hochverdichteten Region. (58) Soll nun das tatsächliche Regionalprodukt in dieser Region erhöht werden, müßte die Kapazität aller Potentialfaktoren mit Engpaßcharakter erhöht werd en. Ein Ausbau der gesamten regionalen Infrastruktur und eine gleichzeitige Erhöhung des Agglomerationsgrades und Verbesserung der sektoralen Wirtschaftsstruktur dieser Region ist aber mit den mittelfri- 
stig zur Verfügung stehenden Mitteln und in der vorgegebenen Zeitspanne von vielleicht vier Jahren oft gar nicht möglich. Würden jedoch die bereitstehenden Fördermittel quantitativ hierzu ausreichen, käme es erst nach langer Ausreifungs - und Anlaufzeit zu den erwünschten Entwicklungsimpulsen. Die Erträge dieser staatlichen Investitionen fielen nicht mehr innerhalb der mittelfristigen Planungsperiode an. Die durch das mittelfristige Entwicklungsprogramm des regionalpolitischen Entscheidungsträgers in der deglomerierten Region bewirkte Einkommenserhöhung ist dann geringer als die eines Einsatzes dieser Mittel in der hochverdichteten Region.

Aus wachstumspolitischen Gründen wäre eine Engpaßbeseitigung in den stark verdichteten Regionen wünschenswert, aus verteilungspolitischen Gründen müßte die einkommensschwache Region gefördert werden. Eine verteilungsorientierte Regionalpolitik kann demnach mit gesamtwirtschaftlichen Wachstumsverlusten verbunden sein.

Dieser mögliche Konflikt zwischen dem wachstumspolitischen und verteilungspolitischen Ziel der Regionalpolitik existiert aber bestenfalls kurz- und mittelfristig.

\subsection{Zielharmonie bei längerfristigem Planungshorizont}

Wird der Zeithorizont über die mittelfristige Zeitspanne ausgedehnt, gehen auch diejenigen Auswirkungen eines mit gegebenen Fördermitteln finanzierten Entwicklungsprogramms in das Entscheidungskalkül ein, die einen hohen Zeitbedarf haben. So ist z. B. damit zu rechnen, daß die Strategie der Engpaßbeseitigung in stark agglomerierten Regionen eine Arbeitskräftewanderung aus deglomerierten in die geförderten, stark agglomerierten Regionen induziert. Die damit verbundenen gesamtwirtschaftlich unerwünschten Effekte (soziale Zusatzkosten) (59) treten aber vielleicht erst "nach der nächsten Wahl" auf und gehen deshalb nicht in eine auf mittlere Zeitspannen beschränkte Nutzen-Kosten-Analyse von Förderprogrammen ein. Dasselbe gilt auch für positive externe Effekte eines Entwicklungsprogramms für zurückgebliebene Regionen. Die Maßnahmen zum Ausbau der Infrastruktur, Erhöhung des regionalen Agglomerationsgrades und/oder Verbesserung der sektoralen regionalen Wirtschaftsstruktur führen möglicherweise erst nach mehr als vier oder fünf Jahren zu erhöhter Investitionstätigkeit der bereits ansässigen Unternehmen und zur Ansiedlung neuer Unternehmen in der Förderregion. Diese erst langfristig eintretenden Attrahierungseffekte bzw. Entwicklungsimpulse gehen nicht in die auf mittlere Perioden beschränkte, sondern nur in die auf längerfristige Perioden bezogene Produktivität "optimal dimensionierter" Entwicklungs - bzw. Förderpläne (60) ein.

Schon wenn die von einmalig eingesetzten Fördermitteln bewirkte Einkommenserhöhung (Produktivität) betrachtet wird, kann die Ausdehnung des Zeithorizontes auch unter wachstumspolitischen Gesichtspunkten der Förderung zurückgebliebener Gebiete vor der Engpaßbeseitigung in stark agglomerierten Regionen den Vorrang geben. Der aus kurz-bzw. mittelfristiger Sicht existierende Zielkonflikt entfällt. 
Löst man sich von dem Gedanken, eine gegebene, einmalig eingesetzte Fördersumme solle hinsichtlich ihrer kurz-, mittel- und schließlich langfristig auftretenden positiven und negativen Auswirkungen für unterschiedlich agglomerierte Regionen beurteilt werden, erscheint die Förderung schwach agglomerierter Regionen noch stärker auch als wachstumspolitische Notwendigkeit.

Bei Zugrundelegung eines längerfristigen Zeithorizonts zeigt das hohe Regionalprodukt der stark agglomerierten Regionen an, daß ihr langfristiges Entwicklungspotential infolge ihrer hohen Ausstattung mit mobilen und teilbaren Faktoren bereits stark ausgelastet ist. Soll der Auslastungsgrad des Entwicklungspotentials und damit das tatsächliche Pro-Kopf-Produkt dieser Regionen weiter erhöht werden, indem die regionale Ausstattung mit privatem und öffentlichem Kapital und Arbeitskräften sowie der regionale Agglomerationsgrad erhöht werden, so stößt man damit sehr schnell an die Grenzen des Wachstums, die die naturräumlichen Potentialfaktoren setzen. Der Zustrom weiterer mobiler Faktoren in diese Regionen löst produktivitäts und wohlstandsmindernde Effekte (ballungsbedingte negative externe Effekte) aus, die einen Anstieg des regionalen Wohlstandsniveaus relativ niedrig ausfallen lassen oder vielleicht sogar zu einer Wohlstandsminderung führen. Die zunehmende Bodenknappheit, Umweltbelastung usw. bewirken, daß die gesamtwirtschaftliche Produktivität der zusätzlich in diesen Regionen eingesetzten mobilen Ressourcen sehr gering ist bzw. die sozialen Kosten einer angestrebten Erhöhung des regionalen Pro-Kopf-Einkommens ausgesprochen hoch sind. Ein weiteres Wachstum ist ab einem bestimmten Agglomerations grad überhaupt nur noch möglich, wenn ausschließlich Maßnahmen ergriffen werden, die gar keinen Bodenbedarf haben und die die Qualität der mobilen und immobilen Ressourcen verbessern. Es handelt sich dabei u. a. um eine intensivere Nutzung des Bodens (Bebauung in mehreren Ebenen), Maßnahmen zur Reinhaltung der Umwelt, Intensivierung der Forschung zwecks "Züchtung" des technischen Fortschritts, Rationalisierung der gesellschaftlichen und wirtschaftlichen Organisationsformen. Nur durch diese in hohem Maße kostenintensiven Maßnahmen läßt sich langfristig ein weiterer Anstieg des Wohlstandsniveaus der überoptimal agglomerierten Regionen erreichen.

Diese räumlichen Grenzen des Wachstums sind in schwach agglomerierten Regionen dagegen längst nicht erreicht. In ihnen sind z. B. noch genug Grund und Boden, Trinkwasser, saubere Umwelt usw. vorhanden. Mittelfristig wird zwar das mögliche Regionalprodukt durch infrastrukturelle Mängel, wachstumshemmende Wirtschaftsstruktur usw. begrenzt. Langfristig kann aber das Pro-Kopf-Einkommen bzw. das Wohlstandsniveau dieser Regionen mit niedrigem Auslastungsgrad ihres Entwicklungspotentials mit vergleichs weise niedrigem Ressourcenaufwand erhöht werden, indem die mittelfristigen Engpaßfaktoren beseitigt werden.

Zur Erhöhung des Auslastungsgrades des regionalen Entwicklungspotentials bzw. zur Anhebung des tatsächlichen Regionalprodukts in regional gleichem Ausmaß sind langfristig in den schwach agglomerierten Regionen weniger kostspielige Maßnahmen als in überoptimal agglomerierten Regionen erforderlich. Die Produktivität einer zur Verfügung stehenden Fördersumme ist 
in langfristiger Sicht in schwach agglomerierten Regionen größer als in stark agglomerierten, weil die naturräumlichen Grenzen des maximal möglichen Regionalprodukts in den zurückgebliebenen Regionen noch nicht durch enorm kostspielige Maßnahmen manipuliert, hinausgeschoben werden müssen.

Vieles deutet also darauf hin, daß bei langfristigem Zeithorizont nicht nur das verteilungspolitische, sondern auch das wachstumspolitische Ziel der Regionalpolitik eine Lenkung der mobilen Ressourcen in schwach agglomerierte einkommensschwache Regionen verlangt. (61)

3.3. Zielharmonie möglicherweise auch bei kurz- und mittelfristigem Planungshorizont

Aber auch in kurz- bzw. mittelfristiger Sicht kann sich diese Folgerung ergeben. Zwar mögen die hohe Infrastrukturausstattung, der Agglomerationsgrad und die sektorale Wirtschaftsstruktur in stark verdichteten Regionen auf mittlere Sicht einen stärkeren Einkommensanstieg, verstanden als Anstieg des regionalen Bruttoinlandsprodukts, versprechen, als es die Engpaßfaktoren in schwach verdichteten Räumen zulassen würden. Dabei muß aber beachtet werden, daß die regionalen Produktwerte und ihre Zuwachsraten auf der Basis der Volkswirtschaftlichen Gesamtrechnung berechnet werden. Soziale Zusatzkosten und soziale Zusatzerträge gehen in diese Werte nicht ein, die also eher die einzelwirtschaftlichen als die gesamtwirtschaftlichen Kosten widerspiegeln.

Die Produktwerte der stark agglomerierten Regionen und ihre Zuwachsraten werden von der Volkswirtschaftlichen Gesamtrechnung aus zwei Gründen zu hoch ausgewiesen:

- In das Regionalprodukt gehen auch solche Güter und Leistungen ein, die zur Beseitigung der negativen Folgen des Ballungsprozesses erstellt werden. Es handelt sich dabei um Güter und Leistungen, deren Inanspruchnahme nicht den Wohlstand der Einwohner jener Regionen erhöht, sondern eine ballungsbedingte Wohlstandsminderung verhindert. Zuwachsraten des Regionalprodukts, die auf die verstärkte Produktion solcher Güter und Leistungen zurückgehen, weisen eine Wohlstandssteigerung aus, die nicht vorliegt.

- Im Regionalprodukt werden die negativen externen Effekte (soziale Zusatzkosten), die im Verlaufe des Ballungsprozesses immer größere Bedeutung erlangen und das regionale Wohlstandsniveau senken, nicht als negative Posten erfaßt. Das Regionalprodukt ist deshalb nur ein unvollkommener Indikator für den regionalen Wohlstand.

Würde man die als erstes erwähnten Güter und Leistungen aus den regionalen Produktwerten der Ballungsregionen eliminieren und außerdem die ballungsbedingten sozialen Zusatzkosten von dem bereinigten Regionalprodukt bzw. seiner Zuwachsrate abziehen (können), könnten "trotz positiver VGR-Zuwachsraten die sozialen Nettoerträge [einer zunehmenden räumlichen Konzentration, F.T.], negativ werden, weil das Verdichtungsoptimum weit überschritten wurde." $(62)$ 
Auf der anderen Seite werden positive externe Effekte, die in zurückgeblie benen Räumen im Verlauf eines Verdichtungsprozesses entstehen, und dort das Wohlstandsniveau der Einwohner jener Regionen, nicht aber ihr monetäres Leistungseinkommen erhöhen, nicht von der Volkswirtschaftlichen Ge samtrechnung erfaßt. Relativ niedrige Zuwachsraten der Regionalprodukte jener Regionen spiegeln also nicht unbedingt die regionalen Wohlstandssteigerungen wider.

So ist es also in vielen Fällen der technischen Unzulänglichkeit der Regionalproduktberechnung zuzuschreiben, daß die Strategie der Engpaßbeseitigung in stark agglomerierten Regionen in kurz - und mittelfristiger Betrachtungs weise als wachstumsoptimal und eine bevorzugte Ressourcenlenkung in schwach agglomerierte Regionen mit dem wachstumspolitischen Ziel der Regionalpolitik zu kollidieren scheint. "Bei einer Bewertung des regionalen Wachstums zu sozialen Kosten und Erträgen" "werden aber auch die bisher bestehenden interregionalen Wohlstandsunterschiede verringert werden können, ohne daß auf gesamtwirtschaftliches Wachstum verzichtet werden muß"(63), und das auch bei mittelfristigem Zeithorizont.

Als Ergebnis der Überlegungen über die Beziehungen zwischen dem wachstums - und verteilungspolitischen Ziel der Regionalpolitik kann hier festgestellt werden: Je länger der gewählte Betrachtungszeitraum ist und je höher der Agglomerationsgrad der einkommensstarken Regionen und damit die Wahrscheinlichkeit, daß sie ihr Agglomerationsoptimum überschritten haben, desto geringer ist die Gefahr, daß ein Ausgleich interregionaler Wohlstandsunterschiede mit Wachstumsverlusten erkauft werden muß.

Sollte sich nach Abwägung aller hier diskutierten Gesichtspunkte bei der Lösung konkreter regionalpolitischer Probleme trotzdem ein Konflikt zwischen beiden Zielen herausstellen, besitzt das verteilungspolitische Ziel so viel Eigengewicht, daß ihm die Priorität vor dem wachstumspolitischen Ziel eingeräumt werden kann.

4. Das langfristig wünschenswerte Ausmaß des interregionalen Einkommens ausgleichs

Die Überlegungen zum regionalen Entwicklungspotential lassen auch eine Aussage zu, wie stark der Abbau interregionaler Einkommensunterschiede mittels Maßnahmen der verteilungsorientierten Regionalpolitik gehen sollte.

Wenn infolge relativ geringer Unterschiede der regionalen Ausstattung mit natürlichen, langfristigen Potentialfaktoren die regionalen Entwicklungs potentiale gleich groß sind und außerdem die staatlichen Entscheidungsträger über Instrumente verfügen, die zurückgebliebenen Regionen langfristig mit den mobilen Faktoren, die zur Auslastung ihrer Entwicklungspotentiale erforderlich sind, auszustatten, sollte die verteilungsorientierte Regionalpolitik langfristig auch einen vollständigen Ausgleich der regionalen ProKopf-Einkommen anstreben. 
Das Bemühen, die interregionalen Einkommensunterschiede vollständig aus zugleichen, würde langfristig auch zu einer tendenziellen Annäherung der Infrastrukturausstattungen, der Agglomerationsgrade und der sektoralen Wirtschaftsstrukturen der Regionen führen. Die durch starke Unterschiede in der regionalen $\mathrm{F}$ aktorausstattung gegebene Begründung für die interregionale Arbeitsteilung und damit für Unterschiede hinsichtlich der regionalen Branchenstruktur verlöre an Bedeutung. Die interregionale Arbeitsteilung fände nicht mehr so stark wie bisher in Form intersektoraler, sondern überwiegend in Form zwischenbetrieblicher Arbeitsteilung statt.

Das bedeutet aber nicht, daß es tatsächlich auch zu irgendeinem Zeitpunkt zu einem vollständigen Ausgleich der regionalen Branchenstrukturen und Einkommensunterschiede kommen muß oder wird. Da nämlich der technische Fortschritt nicht gleichmäßig und gleichzeitig im Raum entsteht (64), Pionierunternehmer regional unterschiedlich auftreten und auch die Anpassungsfähigkeit der Wirtschaftssubjekte an wachstumsbedingte Strukturwandlungen, ebenso wie diese selbst, immer $\mathrm{zwischen}$ den Regionen (und auch intraregional) Unterschiede aufweisen wird, ist eine völlige regionale Gleichheit ziemlich unwahrscheinlich. Die zweite Bedingung für komparative Kostenvorteile (65) einer Region, nämlich unterschiedlich hohe Produktivitäts vorsprünge $z$ wischen den Regionen bei der Produktion der einzelnen Güter, behielte ihre Gültigkeit. (66)

Es wird also immer einige Regionen geben, die an der Spitze der Einkommensentwicklung marschieren. Eine Regionalpolitik, die langfristig den vollständigen Ausgleich der regionalen Einkommensunterschiede anstrebt, sorgt aber dafür, daß

- alle Regionen die gleiche Chance haben, an der Spitze der Einkommensentwicklung zu marschieren,

- das regionale Wohlstandsgefälle, das sich tatsächlich einstellen wird, wesentlich geringer ist als das gegenwärtige,

- das regionale Wohlstandsgefälle nicht ständig in eine Richtung geht, also nicht einseitig ist, sondern daß sich die einzelnen Regionen in ihrer Führungsrolle im Entwicklungsprozeß ablösen können und werden.

\section{Die regionalen Implikationen des Stabilitätsziels}

\subsection{Inhalt des stabilitätspolitischen Ziels der Regionalpolitik}

Konjunkturelle Schwankungen und wachstumsbedingte Strukturwandlungen wirken sich auf die einzelnen Wirtschaftssektoren und -branchen in unterschiedlichem Ausmaß aus. Es treten gleichzeitig in einzelnen Wirtschafts zweigen Produktionsengpässe, in anderen Branchen Überkapazitäten auf, die zu verhindern bzw. zu beseitigen Aufgabe der sektoralen Strukturpolitik ist. (67) Dieser sektorale Aspekt der kurz- und langfristigen Wirtschaftsentwicklung muß um einen regionalen Aspekt ergänzt werden. Da die einzelnen Wirtschaftszweige nicht gleichmäßig im Wirtschaftsraum verteilt 
sind, sich also die regionalen Wirtschaftsstrukturen $\mathrm{z}$. T. e rheblich unterscheiden, schlagen sich die konjunkturellen und wachstumsbedingten Probleme auch in den einzelnen Regionen mit unterschiedlicher Stärke nieder.

Eine Aufgabe der Regionalpolitik besteht nun darin, diesen regionalen Aspekt der kurz- und langfristigen Wirtschaftsentwicklung zu berücksichtigen, die "konjunkturelle und strukturelle Anfälligkeit der regionalen Standort- und Produktionsstrukturen [zu reduzieren], um eine möglichst stabile Beschäfti gungs - und Einkommensentwicklung in der Gesamtwirtschaft zu sichern. "(68)

Eine auf dieses Ziel ausgerichtete (stabilitätsorientierte) Regionalpolitik muß $z$ weigleisig vorgehen. Bei gegebenen regionalen Wirtschaftsstrukturen, also kurz - und mittelfristig muß sie durch regional differenzierten Einsatz konjunkturpolitischer Maßnahmen unerwünschte regionale Unterschiede im $\mathrm{Be}$ schäftigungsniveau oder den Inflationsraten verhindern oder beseitigen. Globale Konjunkturpolitik und Regionalpolitik müssen also koordiniert werden. Langfristig ist dieser nachfrageorientierten Politik eine angebotsorientierte Politik vorzuziehen. Sie soll die Ursachen der regionalen Anfälligkeit, wie die Einseitigkeit der regionalen Branchenstruktur und den überproportionalen Anteil strukturschwacher Wirtschaftszweige, beseitigen. Dazu ist eine Koordination von sektoraler und regionaler Strukturpolitik erforderlich. (69)

Diese ursachenorientierte Politik zielt insbesondere darauf ab, durch eine Diversifikation der regionalen Branchenstrukt ur die Krisenanfälligkeit soge nannter monostrukturierter Regionen zu verringern. (70) Besonderes Gewicht sollte dabei die "Politik selektiver Angebotssteuerung" auf die Ansiedlung und Expansion solcher Wirtschaftszweige legen, die auf lange Sicht einer Nachfrage mit hoher Einkommenselastizität gegenüberstehen und damit der Region langfristig eine günstige Wettbewerbsposition verschaffen. (71)

\subsection{Stellenwert des stabilitätsorientierten Ziels der Regionalpolitik}

Eine vielseitige regionale Wirtschaftsstruktur dient, da sie die Krisenanfälligkeit der Region verringert, dem Ziel der sozialen Sicherheit. Darüberhinaus verhindert sie, daß Gebietskörperschaft und Einwohner einer Region in eine so große Abhängigkeit von dominierenden Unternehmen oder Branchen geraten, daß sie der Gefahr von Erpressungsversuchen ausgesetzt sind. Damit kann die stabilitätsorientierte Regionalpolitik die Bildung ökonomischer Machtstellungen verhindern helfen. Zudem bietet eine diversifizierte Wirtschaftsstruktur der ansässigen Bevölkerung eine Vielfalt von Arbeits -, Einkommens - und Lebensmöglichkeiten. Der Freiheitsspielraum der Menschen, verstanden als Möglichkeit, zwischen verschiedenen Alternativen zu wählen, wird erhöht.

Die Einseitigkeit der regionalen Wirtschaftsstruktur bringt noch einen weiteren Nachteil mit sich. Es besteht die Gefahr, daß der Wirtschaftsraum einseitig genutzt und damit einzelne langfristige Potentialfaktoren des Entwicklungspotentials zu Engpaßfaktoren werden. Die einseitige Inanspruchnahme z. B. des Grundwasserreservoirs, der Atmosphäre oder der Erdober- 
fläche durch regional dominierende Wirtschaftszweige kann dann leicht eine langfristige Erhöhung des regionalen Pro-Kopf-Produkts verhindern. (72)

Ist die stabilitätsorientierte Regionalpolitik darauf ausgerichtet, die sektorale Wirtschaftsstruktur bzw. Branchenstruktur einer strukturschwachen Region den wachstums bedingten Strukturwandlungen anzupassen, gestaltet sie damit einen mittelfristigen Potentialfaktor des regionalen Entwicklungspotentials, der häufig Engpaßcharakter hat. Durch Beseitigung dieses Engpasses ermöglicht sie langfristig einen weiteren Anstieg des Regionalprodukts und damit einen höheren Auslastungsgrad des langfristigen regionalen Entwicklungspotentials dieser einkommensschwachen Region. Sie dient damit zugleich den wachstums - und verteilungspolitischen Zielen der Regionalpolitik.

\section{Die regionalpolitischen Ziele der Bundesregierung}

Nachdem Inhalt, Bedeutung, Rangfolge und Beziehungen der wichtigsten Ziele der Regionalpolitik abgeleitet und bestimmt sind, soll im folgenden das regionalpolitische Zielsystem der Bundesregierung dargestellt werden. Damit kann gezeigt werden, ob es eine Diskrepanz zwischen dem Zielsystem der Bundesregierung und demjenigen gibt, das in dieser Arbeit der Beurteilung raumwirtschaftlicher Entwicklungen und räumlicher Auswirkungen finanzpolitischer Maßnahmen zugrundeliegt. Sollte eine Diskrepanz zwischen beiden Zielsystemen ermittelt werden, müßten die raumwirksamen Maßnahmen der drei staatlichen Ebenen auf ihre Zieladäquanz hinsichtlich beider Zielsysteme untersucht werden. Aber auch, wenn eine weitgehende Übereinstimmung zwischen beiden Zielsystemen festgestellt wird, ist die Darstellung der regionalpolitischen Ziele der Bundesregierung nicht überflüssig: Sie erlaubt eine Aussage darüber, ob und inwieweit konkrete finanzpolitische Maßnahmen solchen regionalpolitischen Zielen dienen oder diese verletzen, die explizit von der Bundesregierung angestrebt werden.

Das regionalpolitische Zielsystem der Bundesregierung findet sich im "Raumordnungsprogramm für die großräumige Entwicklung des Bundesgebietes (Bundesraumordnungsprogramm)" aus dem Jahr 1975. Darin werden "gleichwertige Lebensbedingungen in allen Teilräumen"(73) des Bundesgebietes als oberstes Ziel der raumbeeinflussenden Politik bezeichnet, denn sie stellen "eine wesentliche Grundlage der Chancengleichheit für alle Bürger"(73) dar. Um dieses Ziel zu erreichen, müssen "großräumige Disparitäten", d.h. regionale Unterschiede auf den Gebieten der Infrastruktur, der Umweltqualität und der regionalen Wirtschaftsstruktur abgebaut werden. (73)

Maßnahmen, die dem Abbau großräumiger Disparitäten in der Infrastrukturausstattung dienen, sollen schwerpunktmäßig in Teilräumen mit besonders großen infrastrukturellen "Ausstattungsdefiziten"(73) ergriffen werden. Innerhalb der Fördergebiete sollen die Mittel räumlich konzentriert in Entwicklungsschwerpunkten eingesetzt werden. Die regionale Wirtschaftsstruktur soll mit Vorrang in solchen Gebietseinheiten verbessert werden, die "in ihrer allgemeinen Entwicklung wesentlich zurückgeblieben sind oder zurückzublei ben drohen. .. "(73). 
Die vorrangige und verstärkte Mittelzuweisung an Regionen, die in ihrer Entwicklung am weitesten unter dem Bundesdurchschnitt liegen, soll Verdichtungstendenzen im ländlichen Raum auslösen und somit städtische Lebensformen auch in solchen Regionen ermöglichen. Beabsichtigt wird damit, "eine großräumige Abwanderung aus schwach strukturierten Räumen zu verhindern"(74) und einen regionalen Entwicklungsproze $\beta$ in Gang zu setzen, in dessen Verlauf das "Einkommensniveau als eine Voraussetzung für die Verbesserung der Lebensbedingungen in den betreffenden Gebietseinheiten"(75) angehoben wird. Außerdem fordert die Bundesregierung im Bundesraumordnungsprogramm, daß einer weiteren Zunahme des Arbeitsplatzangebots und der Einwohnerzahl in industriell stark entwickelten Regionen entgegengewirkt wird. Diese Entballungspolitik soll aber in erster Linie indirekt, d.h. "durch Maßnahmen, die hauptsächlich ländlichen und zurückgebliebenen Gebieten sowie dem Zonenrandgebiet zugute kommen"(76),durchgeführt werden. Bei kurzfristiger Betrachtungsweise besteht nach Auffassung der Bundesregierung ein Konflikt zwischen dem Ziel des Abbaus großräumiger Disparitäten und dem eines möglichst hohen gesamtwirtschaftlichen Wachstums. Denn eine Arbeitskräftewanderung aus schwachstrukturierten in stark verdichtete Gebiete würde den Beitrag der Arbeitskräfte zum Bruttoinlandsprodukt erhöhen. Bei längerfristiger Betrachtungsweise würden aber die negativen Auswirkungen der Abwanderung aus ländlichen Gebieten - unerwünschte Minderauslastung vorhandener Infrastruktureinrichtungen und soziale Erosion in den Abwanderungsgebieten, zunehmender Wachstumsdruck in den Zuwanderungsgebieten - stark zu Buche schlagen. Langfristig würde deshalb eine Förderung ländlicher Gebiete, durch die Arbeitskräftewanderungen in die Ballungsgebiete verhindert werden, einen "höheren sozialen Nutzen"(77) als die umgekehrte Strategie bringen und damit einen "Beitrag zum langfristigen und ausgewogenen Wirtschaftswachstum"( 77$)$ leisten.

Damit sind das regionalpolitische Zielsystem der Bundesregierung, ihre Ansicht über die Zielbeziehungen sowie die von ihr bevorzugte regionalpolitische Strategie skizziert. Es zeigt sich, daß sowohl das stabilitäts -, wachstums - und verteilungspolitische Ziel der Regionalpolitik im Zielsystem der Bundesregierung enthalten sind. Dabei mißt sie den regionalen Implikationen des Gerechtigkeitsziels eine überragende Bedeutung bei. Nicht nur in diesem Punkt besteht eine große Übereinstimmung zwischen dem regionalpolitischen Zielsystem der Bundesregierung und dem in dieser Arbeit entwickelten. So sieht auch die Bundesregierung keinen Konflikt zwischen dem wachstums - und dem verteilungspolitischen Ziel, wenn man eine langfristige Betrachtungsweise zugrundelegt. Die Verringerung interregionaler Einkommensunterschiede fördert danach langfristig auch das gesamtwirtschaftliche Wachstum.

Die von der Bundesregierung verfolgte Strategie zur Realisierung ihres Zielsystems läßt sich mit den Begriffen "dezentralisierte Konzentration"(78) oder "dezentrale Schwerpunktbildung"(79) umschreiben. Durch schwerpunktmäßig eingesetzte Maßnahmen zur Verbesserung der Infrastruktur und der Wirtschaftsstruktur in einkommensschwachen Regionen sollen die Abwanderung von Arbeitskräften aus diesen Gebieten (passive Sanierung) verhindert und 
die Zuwanderung von mobilen Faktoren in diese Gebiete erreicht werden. Man verspricht sich davon, daß ein regionaler Wachstumsproze $\beta$ induziert wird, in dessen Verlauf sich der Einkommensrückstand der ländlichen, schwach industrialisierten Regionen gegenüber den stark agglomerierten Regionen verringert. Als Begleiterscheinung dieser regionalen Wachstumsprozesse in ländlichen Gebieten erhofft sich die Bundesregierung eine Abschwächung des Verdichtungsprozesses in den stark agglomerierten Gebieten.

Das Zielsystem des Bundesraumordnungsprogramms ist nicht allein für die Bundesregierung und die ihr unterstehenden Bundesbehörden verbindlich. Vielmehr haben Bund und Länder "mit diesem Programm Zielvorstellungen für die langfristige Entwicklung gemeinsam erarbeitet. "(80) Das Programm ist "Grundlage einer offenen, zukunftsweisenden Kooperation $z$ wischen Bund und Ländern sowie zwischen den Ländern. "(80) Es fungiert als "gesamträumlicher und überfachlicher Orientierungsrahmen" $(80)$, durch den die räumlich unkoordinierten Zielsysteme der Länder auf das räumlich koordinierte Zielsystem des Bundes ausgerichtet werden sollen. Bund und Länder verpflichten sich ausdrücklich, ihre raumbedeutsamen Planungen und Maßnahmen den Zielaussagen und Schwerpunktbestimmungen des Programms anzupassen. (80) Damit erhalten die im Bundesraumordnungsprogramm aufgestellten Ziele auch für regionalpolitische Maßnahmen der Bundesländer eine relativ große Verbindlichkeit und eignen sich als Beurteilungsmaßstab der tatsächlich ergriffenen raumbedeutsamen Maßnahmen von Bund und Ländern. 


\section{B. DER PROZESS DER RÄUMLICHEN DIFFERENZIERUNG}

In diesem Kapitel wird untersucht, wie es im Verlauf des Industrialisierungsprozesses auf der einen Seite zur Herausbildung wirtschaftlicher Notstands - und Entleerungsgebiete, auf der anderen Seite zur Entstehung stark agglomerierter Wohlstandsregionen kommt. Der räumliche Differenzierungsprozeß wird also als räumliche Differenzierung des wirtschaftlichen Wachstumsprozesses verstanden. Entstehung, Verlauf und Grenzen von regional begrenzten Wachstumsprozessen sollen hier beschrieben und erklärt werden.

In der nachfolgenden Beschreibung des räumlichen Differenzierungsprozesses wird unterstellt, daß die Unternehmen tendenziell ihren Gewinn maximieren wollen. Gemäß dieser Zielsetzung wählen sie für ihre Investitionen den Standort, der ihnen den größtmöglichen Gewinn verspricht und verlassen ihn, wenn ein anderer Standort bessere Gewinnchancen in Aussicht stellt. "Investitionen [werden also] stets dort vorgenommen..., wo die Grenzleistungsfähigkeit des Kapitals vergleichsweise am höchsten ist. "(81) Auch die Arbeitskräfte versuchen, ihr Einkommen zu maximieren. Sie streben an die Orte eines möglichst großen Arbeitsplatzangebots (= große Nachfrage nach Arbeitskräften) und damit an die Orte, die günstige Einkommenschancen bieten. Der relativ immobile Faktor Arbeit folgt dem mobileren Faktor "nicht investiertes Kapital" zum Ort des mittelfristig immobilen Faktors "investiertes Kapital".

Eine Erweiterung der Zielfunktion um nichtmonetäre Einkommensbestandtei le ("preislose örtlich bedingte Nutzen", "preislose Einmaligkeiten") (82) zur Zielsetzung der Nutzenmaximierung, wie sie z. B. Lösch (83) vornimmt, oder ihre Modifizierung durch die Berücksichtigung von Informations- und Risikoproblemen (84) kann hier aus Einfachheitsgründen nicht vorgenommen werden. Sie sind aber als Determinanten der tatsächlichen Standortentscheidungen von Unternehmen und Arbeitnehmern ebenso zu beachten, wie z. B. regionale Gewinnunterschiede oder auch Elemente nicht-rationalen Verhaltens. (85)

I. Das Prinzip der zirkulären, selbstverstärkenden Verursachung

Der Prozeß regional differenzierten Wirtschaftswachstums kann mit Hilfe des Prinzips der zirkulären, selbstverstärkenden Verursachung (86) erklärt werden:

Das Ergebnis eines Prozesses (" abhängige Variable) wirkt verstärkend auf die Kausalfaktoren des Prozesses (- unabhängige Variable) zurück und bewirkt damit, daß der Prozeß weiterläuft. Die Auswirkungen (Folgen) eines Komplexes von Verursachungsfaktoren werden im Grunde selbst die Ursachen für zukünftige Entwicklungen. Wird ein solcher Prozeß erst einmal ausgelöst, setzt er sich kumulativ fort, bis er an "irgendwelche" Grenzen stößt.

Dieses Prinzip wird auf den Prozeß der räumlichen Differenzierung übertragen. Wird in einer Region "auf irgendeine Weise" ein regionaler Verdich- 
tungs - und Entwicklungsproze $\beta$ in Gang gesetzt, setzt dieser Proze $\beta$ aus sich selbst heraus Kräfte frei, die auf einen weiteren Anstieg von Agglomerationsgrad und regionalem Wohlstandsniveau hinwirken. Der Prozeß entwickelt Eigendynamik. Die zunehmende Verdichtung und Erhöhung des regionalen Wohlstandsniveaus werden selbst die Ursache für weiteres wirtschaftliches Wachstum und steigende Agglomeration in dieser Region. Erst wenn ein bestimmter Agglomerationsgrad erreicht oder überschritten wird, machen sich Gegenkräfte bemerkbar, die unter Umständen die kumulativen Tendenzen der räumlichen Konzentration und des Sozialproduktanstiegs brechen.

Die mit Absicht gewählten vagen Formulierungen in der Beschreibung des Prinzips der zirkulären, selbstverstärkenden Verursachung machen deutlich, daß dieses Prinzip nur dann befriedigend als Erklärungsinstrument regionaler Wachstums - und Verdichtungsprozesse dienen kann, wenn drei Fragen schlüssig beantwortet werden können:

- Welche Faktoren sind dafür verantwortlich, daß an einigen Orten im Raum Wachstums - und Verdichtungstendenzen ausgelöst werden, während andere Orte bzw. Regionen im Zustand der Quasi-Stagnation (87) verharren? Dies ist die Frage nach den Anfangsimpulsen bzw. der Initialzündung dieser regional begrenzten Prozesse.

- Welche Faktoren tragen und verstärken die einmal ausgelösten regionalen Wachstums - und Verdichtungsprozesse? Dies ist die Frage nach den Determinanten der Eigendynamik dieser Prozesse.

- Welche Faktoren begrenzen möglicherweise die kumulativen regionalen Wachstums - und Verdichtungsprozesse? Dies ist die Frage nach den Grenzen des regionalen Wachstums.

Im folgenden wird versucht, diese drei Fragen zu beantworten.

II. Anfangsimpulse regionaler Wachstums - und Verdichtungsprozesse

Lösch nennt fünf Ursachenkomplexe, die für die Bildung von Städten verantwortlich sind: Vorteile der Masse, der Mischung, der Lage, des Lagers und den Zufall. (88) Die Faktoren Lager, Lage und Zufall führen zu einer ungleichmäßigen Verteilung wirtschaftlicher Aktivitäten im Raum. Sie sind es, die primär regionale Konzentrations - und Wachstumsprozesse auslösen. Die Vorteile der Masse und der Mischung, die auch als Agglomerationsvorteile bezeichnet werden können, haben dagegen insbesondere für die Verstärkung einmal ausgelöster räumlicher Verdichtungsprozesse Bedeutung. Sie tragen in erster Linie die regionalen Wachstums- und Verdichtungsprozesse, bestimmen also ihre Eigendynamik.

1. Die Bedeutung des Lagers als auslösender Faktor eines eigendynamischen, regional begrenzten Verdichtungs - und Wachstumsprozesses

Der Begriff des Lagers umfaßt die Gesamtheit aller naturräumlichen Faktoren, mit denen ein Raum ausgestattet sein kann: Rohstoffvorkommen, Was- 
servorräte, Gestalt der Erdoberfläche, natürliche Verkehrswege wie schiffbare Flüsse, Furten, Bergpässe, klimatische Verhältnisse, Bodenqualität usw.

Die große Bedeutung dieser natürlichen'Faktoren als auslösende Elemente des räumlichen Differenzierungsprozesses (89) liegt darin, daß sie ungleichmäßig auf die einzelnen Regionen verteilt sind. "Praktisch. . haben in der Regel jene natürlichen Faktoren ein besonderes Gewicht, an deren Lager die Erzeugung notwendig gebunden ist: Ackerland, Bodenschätze, Täler, Häfen, Klima. Am wichtigsten sind davon wieder jene Faktoren, deren Vorkommen einerseits beschränkt und konzentriert ist, andererseits verhältnismäßig viel wirtschaftliche Tätigkeit bindet. "(90) In Regionen, die derart von der Natur begünstigt sind, können wirtschaftliche Aktivitäten entstehen und sich entfalten. Sie werden "von vornherein mit Wahrscheinlichkeit .. Angelpunkte des Standortsystems ... . Die anderen Erzeugungszentren, deren Standort nicht unbedingt an natürliche Lager gebunden ist, am extremsten die ihrem Wesen nach stark verbrauchsbestimmten, werden mehr oder weniger von jener ersten Konzentration angezogen, oder doch danach ausgerichtet. "(91)

\section{Die Bedeutung der Lage}

Drei Aspekte der "Lage" sollen hier kurz erörtert werden:

- die Lage im Wirtschaftsraum (wirtschaftsgeographische Lage)

- die Lage zur Hauptstadt

- die Lage zum Verkehrssystem.

\subsection{Die wirtschaftsgeographische Lage}

Die historische Zufälligkeit einer Grenzziehung zwischen zwei Staatsgebieten hat für den räumlichen Differenzierungsprozeß erhebliche Bedeutung. Sie bestimmt, ob eine Region bzw. ein Standort zentral oder peripher im Wirtschaftsgebiet liegt. Der raumdifferenzierende Einfluß einer politischen Grenze rührt daher, daß sie in der Regel auch Zoll-, Völker- und Verwaltungsgrenze ist. (92) Er ist umso größer, je geschlossener die Grenze ist, je stärker sie also grenzüberschreitende Güter- und Personenbewegungen verhindert.

Eine relativ geschlossene Grenze schreckt Unternehmen davon ab, sich in diesen peripheren Regionen anzusiedeln, denn sie haben "praktisch oft nur nach einer Seite hin einen Markt". (93) Bei gleicher Qualität der Verkehrsverbindungen können deshalb die peripher gelegenen Unternehmen nur einen wesentlich kleineren Absatz- und Bezugsmarkt erschließen, als wenn sie einen zentraler gelegenen Standort gewählt hätten. Wollen sie gleich große Marktgebiete erschließen wie Konkurrenten in zentraler gelegenen Standorten, müssen sie erheblich größere Entfernungen überwinden. Ökonomisch bedeutet dies für Unternehmen in peripher gelegenen Standorten: 
- Entweder ist das durch die Staatsgrenze eingeengte Marktgebiet kleiner als es für eine rentable Produktion notwendig wäre. Die Aufnahme der Produktion lohnt in diesem Fall überhaupt nicht.

- Oder die Größe des Marktgebietes erlaubt zwar eine rentable Produktion, verhindert aber, daß Skalenerträge und damit langfristig sinkende Grenzund Durchschnittskosten in dem Umfang realisiert werden können, wie dies die erheblich größeren Märkte um die zentraleren Standorte ermöglichen. In diesem $\mathrm{F}$ all ist die Produktion in peripheren Gebieten weniger lohnend als in den zentraleren Standorten und längerfristig nicht wettbewerbsfähig.

Relativ geschlossene Staatsgrenzen verhindern also, daß wirtschaftliche Aktivitäten im Wirtschaftsgebiet gleichmăßig entstehen und sich gleichmäßig entwickeln können. Sie bewirken eine Konzentration wirtschaftlicher Aktivitäten in zentralgelegenen Regionen und eine Entleerung der peripheren Regionen, die "Grenzöde". (94)

Verstärkt wird die Standortungunst der peripheren Gebiete noch, wenn z. B. aus strategischen Gründen, Dichte und Qualität der Verkehrsleistungen in den Grenzgebieten hinter denen der zentraleren Regionen zurückstehen.

Die Bedingung relativ geschlossener Staatsgrenzen kann für die vorindustrielle Epoche und die Phase des industriellen Aufschwungs in Westeuropa als gegeben unterstellt werden. Industrielle Impulse konnten deshalb schon aus diesem Grund nicht in allen Regionen gleichmäßig auftreten, sondern mußten sich konzentriert in zentral gelegenen Regionen auswirken. Aber auch in der Gegenwart läßt sich der raumdifferenzierende Effekt einer relativ geschlossenen Staatsgrenze beobachten, wie das von Voigt und Mitarbeitern untersuchte Beispiel des Zonenrandgebietes beweist. (95)

\subsection{Die Lage zur Hauptstadt}

Der raumdifferenzierende Einfluß der Hauptstadt (96) beruht auf den Vorteilen, die sie den in ihrer Nähe lebenden Wirtschaftssubjekten bietet. So haben Hauptstädte der vorindustriellen Epoche (Burgen, Fürstenresidenzen usw.) ihrer Umgebung z. B. Schutz vor fremden Angreifern und eine Reihe von Arbeits - und Verdienstmöglichkeiten geboten. Dazu kommt auch noch die Ausstrahlungskraft des häufig hochstehenden kulturellen Lebens an diesen Orten. Die Vorteile der Nähe zur Hauptstadt bewirken, daß am Sitz der politischen Herrscher Verdichtungstendenzen von Wohn - und Produktionsstätten auftreten und ein lokaler bzw. regionaler Entwicklungsproze $\beta$ ausgelöst werden kann.

Die Nähe zu Hauptstädten moderner Staaten erscheint u. a. aus folgenden Gründen lohnend:

- Häufig ist das gesamte Verkehrsnetz bzw. Kommunikationsnetz des Staates auf die Hauptstadt ausgerichtet, so daß Produzenten von der Haupt stadt aus den Staatsraum als Absatz- und Bezugsgebiet am kostengünstigsten erschließen können. 
- Zu Verwaltungsstellen kann ein engerer Kontakt gehalten werden, wodurch politische Entscheidungen beeinflußt werden können.

- Man erhofft sich einen größeren Anteil an öffentlichen Aufträgen, da die Marktkenntnis des öffentlichen Auftraggebers in der Regel mit zunehmender Entfernung von der Hauptstadt abnimmt.

"Seit ein so großer Teil des Volkseinkommens auch im Frieden von der öffentlichen Hand ausgegeben wird, bietet der Sitz der Verwaltung viele Standortvorteile. Selbstverwaltung der Länder und Gemeinden in allem, was nicht unbedingt zentral entschieden werden muß, wirkt darum auflokkernd. "(97) Mit diesen Überlegungen zur raumdifferenzierenden Wirkung, die vom Standort der Hauptstadt ausgeht, ist auch ein Grund aufgezeigt, warum die räumliche Konzentration wirtschaftlicher Aktivitäten in stark zentralistisch aufgebauten Ländern wie Frankreich wesentlich stärker ist als in Deutschland, das jahrhundertelang in beinahe unzählig viele Kleinstaaten zersplittert war. Außerdem können diese Überlegungen als eine raumwirtschaftliche Begründung der Notwendigkeit eines föderativ aufgebauten Staates aufgefaßt werden.

Die Lage der Hauptstadt bzw. Hauptstädte selbst kann von vielen Faktoren abhängen. Beispielhaft seien genannt:

- die zentrale Lage im Herrschaftsgebiet,

- die günstige Lage an natürlichen Verkehrswegen,

- verteidigungspolitische Erwägungen in Verbindung mit der Beschaffenheit der Erdoberfläche,

- landschaftliche Reize und damit persönliche Präferenzen des politischen Entscheidungsträgers,

- Rohstoffvorkommen und, darauf aufbauend, Konzentration von wirtschaftlichen Aktivitäten.

Die starke Orientierung, teilweise sogar Abhängigkeit des Standortes der Hauptstadt (eines Systems von Hauptstädten) an bzw. von naturräumlichen Faktoren und der Zentralität bewirkt, daß die raumdifferenzierenden Effekte des Lagers und der wirtschaftsgeographischen Lage verstärkt werden. Ist der Standort der Hauptstadt erst einmal durch politische Entscheidung festge legt, richten sich viele wirtschaftliche bzw. gesellschaftliche Aktivitäten auf ihn aus. Dadurch ist der Rahmen, in dem sich die Raumstruktur in der $\mathrm{Zu}$ kunft entwickeln wird, zu einem großen Teil bestimmt. (98)

\subsection{Die Lage zum Verkehrssystem}

Voigt und Mitarbeiter haben die Bedeutung des Verkehrssystems, insbesondere des Eisenbahnwesens, als auslösenden Faktor des räumlichen Differenzierungsprozesses herausgearbeitet. (99)

Vor Erfindung und Bau der Eisenbahn befindet sich das Verkehrssystem in Westeuropa in einem ausgesprochen schlechten Zustand. Die dadurch bedingten hohen Transportkosten engen die Absatzgebiete der einzelnen Produzenten 
stark ein und verhindern dadurch die Massenproduktion. Kostenungünstig produzierende Unternehmen werden durch Entfernung und hohe Transportkosten vor der Konkurrenz kostengünstiger produzierender Unternehmen ge schützt. Die Produktionsstätten sind noch relativ gleichmäßig auf alle Teilgebiete des Wirtschaftsraumes verteilt.

Durch den Bau der Eisenbahn wird diese Situation radikal verändert. Ihre Linienführung berührt nur wenige Regionen bzw. Orte, die dadurch gegenüber den anderen begünstigt werden. Der Anschluß an das Eisenbahnnetz bedeutet nämlich für die Produzenten an diesen Orten und Regionen eine erhebliche Senkung ihrer Transportkosten. Sie werden dadurch in die Lage versetzt, ihr Marktgebiet sowohl im Hinblick auf ihren Absatz als auch hinsichtlich des Bezugs von Vorleistungen auszuweiten und in die Marktgebiete ihrer nicht ans Eisenbahnnetz angeschlossenen Konkurrenten einzubrechen. (100) Der Eisenbahnanschluß verursacht also eine Erweiterung des Launhardtschen Trichters (101) des Produzenten. Die so zustandekommende Ausweitung des Absatzes ermöglicht interne Ersparnisse, die überwiegend auf Unteilbarkeiten der Produktionsanlagen und -verfahren beruhen. "Arbeitet ein größerer Betrieb mit niedrigeren Stückkosten als ein kleinerer, so kann das an sich schon kostengünstiger produzierende Unternehmen seine Vorrangstellung durch zusätzliche Investitionen ausbauen. Der begünstigte Unternehmer kann seine Absatzgebiete auf Kosten von immer mehr Unternehmen an entfernteren Orten ausdehnen, ... . Durch hinzuwachsende Nachfrage ergibt sich gleichzeitig wieder die Chance, weiterhin sinkende Grenzkostenverläufe auszunutzen. Hier ist die erste Phase eines kumulativen Prozesses zu erkennen." (102)

Die auf wenige Orte und Regionen begrenzte Verbesserung der Verkehrsverhältnisse verschafft also den dort ansässigen Produzenten Gewinnvorteile. Die ortsansässigen Unternehmen expandieren, ortsfremde Unternehmen aus nicht begünstigten Räumen werden attrahiert, weil sie sonst wettbewerbsunfähig werden. Damit ist an den durch das Eisenbahnnetz begünstigten Orten ein lokaler bzw. regionaler Verdichtungs - und Wachstumsproze $\beta$, in den benachteiligten Regionen ein Stagnations - oder Schrumpfungsproze $\beta$ in Gang gesetzt worden. Der einmal geschaffene Gewinnvorteil erlaubt den Produzenten in den begünstigten Orten bzw. Regionen, an der Spitze der wirtschaftlichen Entwicklung zu bleiben und ihren Abstand zu den Konkurrenten in Regionen ohne Eisenbahnanschluß ständig zu vergrößern.

Der Verdichtungs - und Entwicklungsprozeß in den begünstigten Regionen wird weiterhin dadurch verstärkt, daß in ihnen wirtschaftliche Aktivitäten entste hen, die bisher im gesamten Wirtschaftsgebiet noch nicht existierten. Erst die Verbesserung der Verkehrsverhältnisse ermöglicht die Erschließung aus reichend großer Marktgebiete, ohne die die Produktion vieler Güter und Dienstleistungen nicht rentabel wäre. Auch neue wirtschaftliche Aktivităten, die der Gesamtwirtschaft zuwachsen, konzentrieren sich also auf die durch das Verkehrssystem begünstigten Regionen.

Als weiterer raumdifferenzierender Effekt des Eisenbahnbaus ist der damit verbundene Nachfrageeffekt zu nennen. Die vom Eisenbahnbau bewirkten Ein- 
kommensströme fließen vor allem in die Region, in der die Investitionen vorgenommen werden, da in ihr viele Materiallieferanten und die Mehrzahl der Arbeitskräfte leben. Die Steigerung des regionalen Einkommensniveaus induziert eine Steigerung der Nachfrage, vor allem nach Konsumgütern, die eine hohe Einkommenselastizität besitzen. Zur Zeit des Eisenbahnbaus handelt es sich vor allem um Produkte des Ernährungs - und Textilgewerbes. Die von der Nachfragesteigerung besonders stark betroffenen Unternehmen in den begünstigten Regionen erweitern ihre Produktionskapazitäten, bieten neue Arbeitsplätze an und attrahieren Arbeitskräfte aus anderen Regionen.(103)

Der Anschluß an das Eisenbahnnetz begünstigt die davon betroffenen Orte und Regionen also sowohl von der Angebotsseite als auch von der Nachfrageseite her. Die so begünstigten Standorte werden zum Ausgangspunkt eines sich selbst nährenden Industrialisierungsprozesses.

Die Streckenführung der Eisenbahn begünstigt zu einem großen Teil solche Orte und Regionen, in denen bereits aufgrund ihrer zentralen Lage, Nähe zur Hauptstadt und/oder günstigen Ausstattung mit naturräumlichen Faktoren (Lager) regionale Wachstums - und Verdichtungsprozesse ausgelöst oder dazu günstige Voraussetzungen vorhanden sind. Dies wird deutlich, wenn man sich die wesentlichsten Bestimmungsfaktoren der Streckenführung der Eisenbahn vor Augen hält. Vor allem im Anfangsstadium der Erschließung des Raumes durch Eisenbahnen orientiert sich die Streckenführung vornehmlich an

- natürlichen Verkehrswegen, die nur geringe bautechnische Probleme aufwerfen;

- vorhandenen Rohstoffvorkommen und Verdichtungsräumen, da in ihnen die Nachfrage nach Massentransportleistungen am größten und die Auslastung der Transportkapazität am sichersten ist;

- der Hauptstadt bzw. dem System von Hauptstädten.

Damit erscheint auch die Streckenführung der Eisenbahn zu einem erheblichen Teil von naturräumlichen Faktoren bestimmt. Das Eisenbahnnetz ist aber zugleich ein Beispiel dafür, wie von einer staatlichen Einrichtung regional bzw. lokal begrenzte positive externe Effekte ausgehen können, die zu einer ungewollten und unkontrollierbaren, sich selbst verstärkenden räumlichen Differenzierung führen.

\section{Ergebnis der vorstehenden Überlegungen}

Abgesehen vom Zufall, über den keine systematischen Aussagen gemacht werden können, sind die naturräumlichen Faktoren des Lagers und der Lage als die Faktoren identifiziert worden, die den räumlichen Differenzierungs prozeß auslösen. Verfügt eine Region zufällig über entdeckte Rohstoffvorkommen, fruchtbare Böden, ist sie verkehrsmäßig leicht zu erschließen und mit lebensfreundlichem Klima gesegnet, liegt sie nahe dem Zentrum oder der Hauptstadt des Wirtschafts - bzw. Staatsgebietes und ist sie, weil z. B. eine oder mehrere der vorstehenden Bedingungen für sie erfüllt sind, an ein 
leistungsfähiges Eisenbahnnetz angeschlossen, besteht eine große Wahrscheinlichkeit, daß sie Ausgangspunkt eines eigendynamischen Verdichtungs und Wachstumsprozesses wird. (104) Dabei ist nicht erforderlich, daß eine Region alle diese Vorzüge aufweist. Entscheidend ist, daß sie aus dem Zusammenwirken ihrer Ausstattungsfaktoren ihren Einwohnern günstigere Einkommens - und Lebensmöglichkeiten bietet als andere Regionen.

Kommt ein regionaler Konzentrations - und Wachstumsproze $\beta$ überhaupt erst einmal zustande, ist auch die Wahrscheinlichkeit groß, daß er zu einem kumulativen Prozeß wird (104) und sich die regionalen Wohlstands - und Verdichtungsunterschiede verstärken, auch wenn die ursprünglich auslösenden Faktoren gar nicht mehr vorhanden oder bedeutend sind. Die Faktoren, die für diese kumulativen Tendenzen verantwortlich sind, werden im folgenden Kapitel erörtert.

Die Erklärung der Entstehung regionaler Verdichtungs- und Wachstumsprozesse ist nicht vollständig und kann nicht mehr als Plausibilität beanspruchen. Sie ist keine Erklärung der "Wirklichkeit im strengen Sinn ..., da sie ... die ganze Interdependenz der wirtschaftlichen Kräfte außer acht [läßt]. Doch ist es für eine erste Annäherung ... zweckmäßig, die wichtigsten, wenn auch nicht allein wirksamen Faktoren in den Mittelpunkt zu rücken. .... . Das Ergebnis ist nicht zwingend, aber doch wahrscheinlich. Solche beschränkten Faustregeln [für das Entstehen von Ballungen, F. T.] sind praktisch wichtiger als das wissenschaftlich genaue Betonen einer uferlosen Interdependenz."(105) Dies gilt auch für die folgende Erörterung der Bestimmungsfaktoren der Eigendynamik regionaler Konzentrationsprozesse und ihrer Grenzen.

III. Determinanten und Grenzen des kumulativen Prozesses der räumlichen Differenzierung

Im Verlauf der allgemeinen wirtschaftlichen Entwicklung verschiebt sich das Bedeutungsgewicht der einzelnen raumdifferenzierenden Faktoren. Die naturräumlichen Faktoren des Lagers und der Lage verlieren immer mehr Einfluß auf die Standortentscheidungen der Wirtschaftssubjekte zugunsten der gesellschaftlich bedingten, vom Industrialisierungsprozeß selbst geschaffenen Faktoren. (106) Diese Faktoren können mit den Begriffen "interne" und "externe" Effekte, "Agglomerationsvorteile bzw. -nachteile"(107) oder "Vorteile der Nähe" und "Nachteile der Enge"(108)bezeichnet werden.

Der "tendenzielle Bedeutungsrückgang" der naturräumlichen Faktoren drückt sich vor allem darin aus, daß der Anteil der sogenannten "footloose industries" an der gesamten Industrie immer größer wird. (109) Die zu diesen Industriezweigen gehörenden Unternehmen sind nicht dadurch gekennzeichnet, daß sie in ihrer Standortwahl völlig frei sind. Vielmehr sind sie nur von natürlichen Standortfaktoren relativ unabhängig. Für die Standortentscheidung dieser Unternehmen ist dagegen von ausschlaggebender Bedeutung, ob sie an einem bestimmten Ort interne und externe Ersparnisse realisieren können. Für hochentwickelte Volkswirtschaften kann desshalb von einer "Prädomi- 
nanz interner und externer Ersparnisse als raumdifferenzierende Faktoren"(110) gesprochen werden.

Diese relative Bedeutungsverschiebung $\mathrm{zw}$ ischen den Standortfaktoren darf aber nicht zu der Schlußfolgerung verleiten, sie werde quasi automatisch die von natürlichen Standortfaktoren geprägte Raumstruktur auflösen. Das dominierende Gewicht der internen und externen Effekte für die Standortentscheidung der Wirtschaftssubjekte verstärkt vielmehr die eingetretene räumliche Konzentration, denn stark verdichtete und hochentwickelte Regionen bieten umfangreichere Möglichkeiten zur Realisierung interner und externer Ersparnisse als stagnierende und dünn besiedelte Regionen. (111)

Im folgenden sollen diese ballungsverstärkenden Zusammenhänge näher erläutert werden.

1. Der Einfluß interner Effekte auf die Standortwahl

1.1. Begriffsbestimmung

Als interne Effekte werden die Auswirkungen wirtschaftlicher Aktivitäten be zeichnet, die sich unmittelbar in der Wirtschaftsrechnung des handelnden Wirtschaftssubjektes niederschlagen. Das einzelne Wirtschaftssubjekt verursacht für sich selbst positive oder negative Konsequenzen, die es bei der Entscheidung zwischen Handlungsalternativen berücksichtigt. Hier werden wegen ihrer überragenden Bedeutung als Standortfaktor nur die positiven internen Effekte (interne Ersparnisse) behandelt. Interne Ersparnisse können einem Unternehmen bei der Ausdehnung der eigenen Produktion entstehen und äußern sich in Form sinkender Durchschnittskosten. Ihre Ursache haben sie in technischen Unteilbarkeiten von Produktionsanlagen und -verfahren sowie in den Möglichkeiten, mit steigender Produktion die interne Arbeitsteilung zu verbessern. (112)

\subsection{Vorteil der Agglomeration - Möglichkeiten der Realisierung interner Ersparnisse}

Ein Standort, der durch seine natürliche Ausstattung anderen Standorten überlegen ist, entwickelt sich nicht nur zu einer räumlichen Konzentration des Angebots, sondern auch immer stärker zu einer räumlichen Konzentration der Nachfrage. Deswegen suchen Unternehmen, die nicht oder nur schwach von natürlichen Standortfaktoren abhängen ("footloose industries"), die Nähe der Agglomerationszentren. Diese bieten ihnen als Produktionsstandort aus zwei Gründen eine größere Möglichkeit, interne Ersparnisse zu realisieren als schwachagglomerierte Regionen:

a) Auch bei gleichen Produktionskosten in beiden Standorten ermöglicht der Standort im Agglomerationsgebiet ein preisgünstigeres Angebot als ein Standort in einer schwach agglomerierten Region. Das liegt daran, daß die größere räumliche Nähe zum Absatzmarkt Transport- und Informationskosten senkt. 
Infolge dieses Preisvorteils kann ein Unternehmen einen höheren mengenmäßigen Absatz realisieren, wenn es seinen Standort statt in schwachagglomerierten in stark verdichteten Regionen wählt. Höherer Absatz bedeutet aber langfristig auch die Möglichkeit, die Produktion zu erhöhen. Bestehende Kapazitäten können damit optimaler ausgelastet und/oder neue Produktions verfahren, die sich erst bei einer Mindestproduktionsmenge rentieren, eingesetzt werden. Damit kann eine Senkung der Durchschnittskosten (Skalenerträge) realisiert werden, was eine weitere Absatzerhöhung und Ausnutzung interner Ersparnisse ermöglicht.

Während für die Anfangsphase des Industrialisierungsprozesses die mit der Nähe zum Absatzmarkt verbundene Transportkostensenkung das ausschlaggebende Gewicht hat, treten mit zunehmender Entwicklung immer mehr andere Kostenfaktoren in den Vordergrund. (113) Beispielhaft seien hier folgende Vorteile der Nähe, aus denen sich interne Ersparnisse ergeben können, erwähnt:

- Die unmittelbare Nähe zum Absatzmarkt versetzt einen Anbieter in die Lage, schneller und kostengünstiger die Nachfrager über seine Angebote zu informieren (Werbungskosten), als er dies von einem Standort in einer schwachverdichteten Region aus könnte.

- Die Informationsbeschaffung über die Verbraucherpräferenzen, Bonität der Kunden usw. kostet den Anbieter weniger Zeit und Geld und ist zudem mit geringerem Risiko behaftet. Er kann somit schneller auf Verschiebungen der Nachfragestruktur reagieren, als wenn er seinen Standort in größerer Entfernung zur räumlichen Nachfragekonzentration gewählt hätte und insgesamt sein Geschäftsrisiko reduzieren.

- Im Agglomerationsgebiet ist der Absatzmarkt nicht nur größer, sondern auch differenzierter. Dies erlaubt unter Umständen eine Spezialisierung auf Produkte, bei deren Prouduktion man gegenüber anderen Produzenten komparative Kostenvorteile besitzt, aber in schwach verdichteten Regionen keine quantitativ ausreichende Nachfrage findet.

- Der Zeitbedarf für die Lieferung der nachgefragten Produkte ist für die Produzenten mit Standort im Verdichtungsgebiet geringer als mit Standort in ländlichen Randgebieten. Dies fällt besonders bei Gütern und Leistungen ins Gewicht, die kurzfristig geliefert werden müssen, wie z. B. Ersatzteile und Reparatur- bzw. Wartungsleistungen.

- Mit zunehmender Entfernung vom Nachfragezentrum nimmt für die dort ansässigen Nachfrager in der Regel die Markttransparenz ab. Am besten überblicken sie das Angebot in ihrer unmittelbaren Nähe. Deshalb ist auch die Wahrscheinlichkeit groß, daß Anbieter, die ihren Standort im oder beim Verbrauchszentrum wählen, einen größeren Anteil der Nachfrage gewinnen, als Konkurrenten in peripherer Lage. Dazu kann es auch dann kommen, wenn Preise, Produktqualitäten und/oder Lieferbedingungen der letzteren günstiger als die der ersteren, aber eben nicht bekannt sind.

Zusammenfassend kann man feststellen, daß "die Entfernung über ihre unmittelbaren Kosten hinaus bei allem Individuellen, bei allem, was Vertrauen 
und Vertrautheit voraussetzt, eine zum eigenen Schaden oft mißachtete Rolle"(114) spielt. Die räumliche Nähe zum Verbrauchszentrum verschafft dem Anbieter einen größeren Anteil an der Nachfrage und damit die Chance, gröBere interne Ersparnisse zu verwirklichen, als ihm an einem Standort in peripherer Lage möglich wäre.

b) Das Agglomerationsgebiet als Standort bietet nicht nur die Möglichkeit, die Transport- und Informationskosten zu senken. Hinzu kommen Produktionskostensenkungen, die als positive externe Effekte (115) aus der wirtschaftlichen Aktivität anderer Wirtschaftssubjekte resultieren.

Diese agglomerationsbedingten Kostensenkungen bzw. Gewinnerhöhungen er möglichen den begünstigten Produzenten, z. B. durch eine entsprechende Investitionstätigkeit oder einfache Preissenkung, ein qualitativ und preislich günstigeres Angebot zu erstellen als Konkurrenten außerhalb des Verdichtungsgebietes. Infolgedessen können sie ihren Absatz auf Kosten der nicht ortsansässigen Konkurrenten ausdehnen und erneut sinkende Durchschnitts kosten verwirklichen. Externe Ersparnisse werden so zur Ursache zukünftiger interner Ersparnisse.

Das es "praktisch ... oft schwierig oder sogar unmöglich [ist], externe Produktionseffekte technologischer und pekuniärer Art sowie Skaleneffekte zu unterscheiden"(116), fällt auch eine getrennte Untersuchung beider Faktorgruppen schwer. Bei der folgenden Erörterung der positiven externen Effekte als Agglomerationsvorteile werden deshalb auch Aspekte dargestellt, die man dem Bereich der internen Ersparnisse zuordnen kann und die in diesem Zusammenhang unter Umständen auch schon angesprochen worden sind.

\section{Der Einfluß externer Effekte auf die Standortwahl}

\subsection{Begriffsbestimmung}

Unter dem Begriff der "externen" Effekte werden Auswirkungen wirtschaft licher Aktivitäten zusammengefaßt, die sich nicht in den Wirtschaftsrechnungen der handelnden, diese Effekte verursachenden Wirtschaftssubjekte, sondern in den Wirtschafts rechnungen Dritter niederschlagen. Sie gehen deswegen nicht in das Entscheidungskalkül des Handelnden ein. Wenn externe Effekte vorliegen, hängt der Erwartungsparameter eines Wirtschaftssubjektes nicht nur von seinem eigenen Aktionsparameter, sondern auch von den Aktionsparametern anderer Wirtschaftssubjekte ab. "Externe Effekte spiegeln ganz allgemein die Sozialdeterminiertheit des Handelns der Wirtschaftseinheiten wider". (117)

Externe Effekte können sich einmal als direkte Interdependenzen technologischer oder psychologischer Art zwischen Produktions - und Nutzenfunktionen darstellen. Sie wirken dann außerhalb des Marktmechanismus, weswegen sie als "nicht marktmäßig bedingte externe Effekte"(118) bezeichnet werden. Zum anderen können sie durch den Marktmechanismus wirken. In diesem Fall hat die Marktaktion eines Wirtschaftssubjektes einen Preiseffekt zur 
Folge, der sich für andere Wirtschaftssubjekte in Form von Geldgewinnen oder -verlusten auswirkt. Dieser Fall der externen Effekte wird mit dem Begriff "monetäre" oder "pekuniäre" externe Effekte bezeichnet. (119)

Verursacht werden können externe Effekte von Unternehmen, privaten und öffentlichen Haushalten. Sie können sowohl Wirtschaftssubjekte des eigenen Sektors als auch der anderen beiden Sektoren betreffen. Liegen positive externe Effekte (externe Ersparnisse) vor, so wird dem Verursacher dieser Effekte nur ein Teil der von ihm erbrachten Leistung über den Markt entgolten. Sein privater Ertrag ist dann niedriger als der volkswirtschaftliche (soziale) Ertrag seiner Aktivität. In Höhe der positiven Differenz zwischen volkswirtschaftlichem Ertrag und privatem Ertrag liegt ein sozialer Zusatzertrag vor.

Im Fall negativer externer Effekte (externe Verluste) verursacht ein Wirtschaftssubjekt mit seiner Aktivität für andere Wirtschaftssubjekte Nachteile, für die es keinen Ausgleich zahlen muß. Die privaten Kosten der wirtschaftlichen Aktivität dieses Wirtschaftssubjekts sind in diesem Fall niedriger als die volkswirtschaftlichen Kosten. Es liegen soziale Zusatzkosten vor.

Als zwei Spezialfälle der externen Effekte stellen sich spezifisch öffentliche Güter und Spillover-Effekte dar.

Spezifisch öffentliche Güter sind dadurch gekennzeichnet, daß sie nicht oder nur zu sehr hohen Kosten nach dem Ausschlußprinzip angeboten werden können. Bei Nichtanwendbarkeit des Ausschlußprinzips erhält der Anbieter überhaupt kein Entgelt für seine Leistung oder sein Gut. Es fällt ein sozialer Zusatzertrag in voller Höhe des volkswirtschaftlichen Ertrages an. (120) Der Begriff der Spillover-Effekte bezeichnet positive und negative externe Effekte zwischen Gebietskörperschaften. Die Aktivitäten eines Gliedstaates oder einer Kommune stiften in vielen Fällen auch Einwohnern anderer Gebietskörperschaften unentgeltlich Nutzen oder aber beteiligen sie an den Kosten der öffentlichen Leistungserstellung, ohne ihnen dafür eine Gegenleistung zu bieten. (121)

2.2. Vorteile der Agglomeration: Möglichkeiten der Ausnutzung positiver externer Effekte

Positive externe Effekte oder Fühlungsvorteile entstehen, wenn sich

- Unternehmen derselben Branche (localization economies)

- Unternehmen verschiedener Branchen (urbanization economies)

an einem Ort bzw. in einer Region konzentrieren. (122) Diese Vorteile, die ein Unternehmen aus der Nachbarschaft zu anderen Unternehmen, allgemein: zu anderen Wirtschaftssubjekten, ziehen kann, lassen sich häufig nur schwer erfassen. (123) Sie weisen so vielfältige Formen auf, daß eine umfassende Darstellung nicht möglich ist. Deshalb sollen im folgenden nur drei Aspekte der Fühlungsvorteile behandelt werden, die als besonders bedeutend eingeschätzt werden: 
- die Vorteile des räumlichen Verbunds zwischen Lieferanten und Abnehmern;

- die vom Staat verursachten externen Ersparnisse und ihre räumliche Verteilung;

- der Einfluß von Verdichtungsgebieten auf die Entstehung und Verbreitung des technischen Fortschritts.

2.2.1. Vorteile des räumlichen Verbunds zwischen Lieferanten und Abnehmern

Mit zunehmender Spezialisierung eines Unternehmens steigt der Zwang, mit anderen Unternehmen zusammenzuarbeiten. Die nachgefragten Inputs müssen soweit wie möglich den spezifisch innerbetrieblichen Anforderungen entsprechen, um Produktivitätsminderungen zu vermeiden. Ebenso muß das eigene Endprodukt möglichst weitgehend den innerbetrieblichen Bedingungen des Abnehmerbetriebes angepaßt werden, wenn man nicht den Verlust des Abnehmers riskieren will.

Beispiele der zwischenbetrieblichen Zusammenarbeit sind unter anderem:

- Austausch von Informationen über die besonderen Produktionsbedingungen und Anforderungen des Marktpartners,

- gemeinsame Planung und Abstimmung des Produkts,

- Schulung des Bedienungspersonals des Abnehmerbetriebs, teilweise durch Einsatz in der Produktion des Produkts.

Je spezialisierter das Produkt ist, desto höher ist in der Regel auch der Wartungs - und Reparaturbedarf. Fachleute des Lieferanten und/oder Ersatzteile müssen schnell zur Verfügung stehen, um Produktionsunterbrechungen zu verhindern. Die Intensität der vertikalen Kooperation und Kommunikation ist eine wichtige Determinante der betrieblichen Produktivität und Wettbe werbsfähigkeit. "Die Existenz derartiger 'Kommunikationskanäle' und deren Funktionsfähigkeit zur Überwindung der 'ökonomischen Entfernung' ist der Standortfaktor, der mehr und mehr an die Stelle der reinen Transportkosten zur Überwindung der 'physischen Entfernung' getreten ist. "(124)

Agglomerationsgebiete bieten wesentlich mehr Möglichkeiten, schnell und zu niedrigen Kosten zu kommunizieren, als dünn besiedelte Regionen. Das liegt einmal an der größeren räumlichen Nähe zu tatsächlichen oder potentiellen Liefer- oder Abnehmerbetrieben. Zum anderen erlaubt die räumlich konzentrierte Nachfrage nach Kommunikationsleistungen eine höhere Auslastung, also eine höhere betriebswirtschaftliche Rentabilität eines hochgradig unteilbaren Kommunikationsnetzes, wodurch die Verdichtungsräume wesentlich besser mit leistungsfähigen "Kommunikationskanälen" als schwach agglomerierte Räume ausgestattet werden. Die geringeren Kommunikationskosten im weitesten Sinn machen die Agglomerationsgebiete als Standort attraktiv für alle Unternehmen, die auf intensive Kontakte zu vor- und nachgelagerten Unternehmen angewiesen sind. (125) 
Ein Spezialfall des räumlichen Verbunds hat heute für die Produktivität vieler Unternehmen besonders große Bedeutung: Die räumliche Nähe zwischen Unternehmen des sekundären und des tertiären Sektors. Unternehmen des sekundären Sektors sind in steigendem Maße auf das Leistungsangebot von Banken, Versicherungen, Wirtschaftsprüfern, Wartungsunternehmen, der öffentlichen Verwaltung usw. angewiesen. Steht ihnen kein quantitativ und/ oder qualitativ ausreichendes Dienstleistungsangebot zur Verfügung, müssen sie viele dieser Leistungen selbst erstellen, was meistens nur mit höhe ren Kosten möglich ist, da der Spezialisierungsvorteil entfällt.

Das Angebot moderner Dienstleistungen (126) konzentriert sich nun vorwiegend in den großen Verdichtungsräumen. Denn nur in zentralen Lagen mit einem großen Einzugsbereich ist eine hinreichende Auslastung der hochspezialisierten und häufig unteilbaren Angebotskapazitäten möglich.(127) Ein Angebot gehobener Dienstleistungen kommt u. U. überhaupt erst zustande, wenn eine bestimmte Mindestmenge nachgefragt wird und somit ein rentables Angebot erlaubt. (128)

Die höherwertige Ausstattung der Verdichtungsräume mit komplementären Betrieben des Dienstleistungssektors stellt einen der wichtigsten Vorteile der Agglomeration dar. Sie attrahiert, nicht zuletzt deswegen, weil Dienstleistungen so gut wie nicht transportfähig sind und deshalb am Ort ihrer Produktion verbraucht werden müssen, weitere Unternehmen des sekundären Sektors.

Wir haben es hier mit einer Wechselbeziehung zwischen sekundärem und tertiärem Sektor zu tun: Eine räumliche Konzentration von Industriebetrieben und damit ein gewisses Niveau regionaler bzw. lokaler Nachfrage nach Dienstleistungen ist erforderlich, damit überhaupt ein Angebot gehobener Dienstleistungen entsteht. Das Angebot gehobener Dienstleistungen entwickelt sich zu einem Standortvorteil erster Güte, wodurch eine Expansion des sekundären Sektors bewirkt wird. Die Nachfrage nach zentralen Gütern und Leistungen steigt weiter, die Rentabilität des vorhandenen Dienstleistungsangebots verbessert sich, neues Angebot wird induziert. Hierdurch erhöht sich wiederum die Attraktivität der zentralen Orte für standortsuchende Industriebetriebe. (129) Die räumliche Konzentration wirtschaftlicher Aktivitäten entwickelt aus sich selbst heraus kumulative Tendenzen.

\subsubsection{Die räumliche Verteilung des Angebots öffentlicher Leistungen}

Die vom Zentralstaat bzw. den untergeordneten Gebietskörperschaften errichtete Infrastruktur (130) gilt heute als die wichtigste Quelle externer Ersparnisse. "Das Vorhandensein einer quantitativ und qualitativ ausreichenden Infrastruktur kann ... als das entscheidende generelle Standorterfordernis der meisten Branchen angesehen werden. "(131)

Infrastruktureinrichtungen können vielfach nicht nach dem Ausschlußprinzip genutzt werden. Aber auch, wenn das Ausschlußprinzip grundsätzlich anwendbar ist, wird seine Anwendung häufig aus wirtschafts - und versorgungs - 
politischen Gründen abgelehnt. Der Charakter der Infrastrukturleistung als spezifisch öffentliches Gut, als meritorisches Gut oder als wirtschaftspolitisches Instrument veranlaßt den Staat, Infrastrukturleistungen den privaten Wirtschaftssubjekten überwiegend kostenlos zur Verfügung zu stellen. (132) Die staatliche Tätigkeit bringt privaten Wirtschaftssubjekten Vorteile, ohne daß sie dafür dem Verursacher ein kompensatorisches Entgelt zahlen müssen.

Die vom Staat geschaffene unentgeltliche Nutzungsmöglichkeit von Infrastruktureinrichtungen wirkt in zweifacher Weise als Standortvorteil:

- Sie erhöht die Produktivität bzw. senkt die Kosten der bereits ansässigen Unternehmen und erhöht so die Attraktivität des Standorts für standortsuchende Unternehmen. Sie ist damit unmittelbar produktions relevant.

- Sie ist zugleich auch mittelbar produktionsrelevant. Dieser Effekt beruht darauf, daß Infrastrukturleistungen den Wohn- und Freizeitwert eines Ortes erhöhen. Sie bestimmen damit als nichtmonetäre oder "psychische" Einkommen direkt das Wohlstandsniveau der Faktorbesitzer mit. Dadurch können insbesondere hochqualifizierte Arbeitskräfte am Ort gehalten oder attrahiert werden. (133)

Infrastruktureinrichtungen sind in den meisten Fällen räumlich immobil und ihr Output weist Dienstleistungscharakter (134) auf, kann also nur am Ort der Entstehung als Vorleistung oder Konsumgut genutzt werden. (135) Deswe gen ist die räumliche Verteilung der Infrastruktureinrichtungen entscheidend dafür, wie durch das staatliche Leistungsangebot der räumliche Differenzie rungsproze $\beta$ beeinflußt wird.

Parallel zum räumlichen Differenzierungsproze $\beta$ verläuft ein regional ungleichmäßiger Ausbau der Infrastruktur: Gebiete, die in der Entwicklung zurückgeblieben sind, weisen infrastrukturelle Mängel auf. Dagegen wird die Infrastruktur vorrangig dort ausgebaut, wo Wachstums - und Verdichtungs impulse einen kumulativen Proze $\beta$ in Gang gesetzt haben. (136) Die vom Staat verursachten externen Ersparnisse treten also konzentriert in Verdichtungs regionen auf und verstärken die Ballungs - und Entleerungstendenzen.

Die Ursachen für die regional ungleichmäßige Verteilung der Infrastruktureinrichtungen sind vielfältig und werden ausführlicher weiter unten erörtert. An dieser Stelle sollen nur zwei Einflußfaktoren aufgezeigt werden, die das räumliche Investitionsverhalten des Zentralstaates erklären können.

\subsubsection{Ziel der Zentralregierung: Maximierung der Wählerstimmen}

Bei diesem Erklärungsversuch wird davon ausgegangen, daß die Politiker in einer Demokratie nicht einem metaphysischen "Gemeinwohl" dienen wollen. Die Motive ihres Handelns sind vielmehr egoistischer Natur: Streben nach Macht, Prestige, Einkommen usw.. Diese Ziele können Politiker nur erreichen, wenn sie die Zustimmung der Mehrheit der Wähler für sich und ihre Politik gewinnen oder behalten. Um die für die Besetzung der politischen Machtpositionen entscheidenden Wahlen $\mathrm{zu}$ gewinnen, versuchen die 
Politiker in demokratischen Staaten, die Zahl der auf sie entfallenden Wählerstimmen zu maximieren.

Bietet das Wahlsystem die Chance des Machtwechsels, (137) so verhindert die Konkurrenz zwischen den Politikern um die Machtpositionen, daß das egoistischen Motiven folgende Verhalten des Politikers den sozialen Zweck seines Handelns, nämlich den Interessen der Bürger zu dienen, verletzt. So wie der Preismechanismus bei ausreichender Konkurrenz zwischen Produzenten die Anbieter dazu zwingt, ihr Angebot soweit wie möglich den Verbraucherwünschen anzupassen, so zwingt der Wahlstimmenmechanismus die Politiker, die Interessen der Wähler zu berücksichtigen. Nur der Politiker, dem das am besten gelingt, hat Wahlsiegchancen. (138)

Mit diesem Modell rationalen Verhaltens von Politikern bzw. Regierungen in demokratischen Staaten kann erklärt werden, warum stark verdichtete Regionen bei der Placierung von Infrastrukturprojekten begünstigt werden. In ihnen konzentriert sich das Wählerpotential. Entsteht der Eindruck, der Ballungsraum komme bei der Verteilung der Infrastruktureinrichtungen im Vergleich zu wirtschaftlichen Notstandsgebieten zu kurz, verliert die Regierung im Ballungsraum unter Umständen mehr Wählerstimmen, als sie in den "begünstigten" Gebieten gewinnt. Das Ziel, die Wählerstimmen zu maximieren, und so an der Macht zu bleiben, erzwingt also eine überproportionale Versorgung der Ballungs regionen mit Infrastrukturleistungen. (139, 140)

\subsubsection{Raumwirtschaftliche Quasi-Neutralität}

Finanzpolitische Maßnahmen des Staates waren und sind teilweise noch heute an dem Postulat einer "raumwirtschaftlichen Quasi-Neutralität" ausgerichtet. Aus dieser Forderung ergibt sich als ausgabepolitische Konsequenz, daß die öffentlichen Leistungen entsprechend den lokalen Bedarfen räumlich verteilt werden sollen. (141)

Für die räumliche Verteilung des öffentlichen Leistungsangebots ist also die aktuelle Nachfrage nach staatlichen Leistungen entscheidend. Ihr regionales bzw. lokales Volumen ist von der in der Vergangenheit abgelaufenen raumwirtschaftlichen Entwicklung abhängig und pro Einwohner um so größer, je höher der Agglomerationsgrad einer Region ist. Die in der Vergangenheit entstandene Raumstruktur wird als das Ergebnis der marktwirtschaftlichen Kräfte angesehen und deshalb als Datum hingenommen. Durch Beseitigung von Engpässen in der Infrastruktur soll erreicht werden, daß sich der spontan ablaufende raumwirtschaftliche Prozeß unbehindert entfalten kann.

Die Ausrichtung des öffentlichen Leistungsangebots an den lokalen Bedarfen scheint zugleich das Gebot der Sparsamkeit bei der Verwendung öffentlicher Mittel zu erfüllen. (142) Nur die Infrastruktureinrichtungen scheinen gerechtfertigt, die in befriedigendem Umfang ausgelastet sind. Dies ist aber bei großenteils unteilbaren Anlagen nur der Fall, wenn sie auf eine große örtliche Nachfrage nach ihren Leistungen stoßen. 
Die "Bedarfsorientie rung des räumlichen Ausgabeverhaltens"(143) des Staates, das aus dem Streben nach "raumwirtschaftlicher Quasi-Neutralität" und "privatwirtschaftlicher Quasi-Rentabilität" resultiert, verbessert die Standortqualität der Verdichtungsräume bzw. verhindert ihre Verschlechterung und verstärkt den räumlichen Diffe renzie rungsproze $\beta$.

\subsubsection{Die räumliche Verteilung neuen technischen Wissens}

Technischer Fortschritt oder neues technisches Wissen umfaßt alle in einer Periode ne"! realisierten Produktionsverfahren und neuen Produkte, auch wenn sie mit bisher bekannten Verfahren hergestellt worden sind. (144) Technischer Fortschritt entsteht in drei Stufen:

- Entwicklung neuen technischen Wissens (Erfindung oder Invention)

- Realisierung der Invention (Innovation)

- Annahme und Nachahmung des realisierten technischen Wissens (Adaption und Imitation)

Alle drei Stadien des technischen Fortschritts haben für seine räumliche Verteilung Bedeutung.

\subsubsection{Räumliche Verteilung der Erfindungen}

Die Entwicklung neuen technischen Wissens hängt von der "Höhe der Forschungsinputs (Kapital, Arbeit, bestehendes Wissen) und ... von einer Zu fallsgröße ab."(145) Vor Beginn des Industrialisierungsprozesses werden die Erfindungen überwiegend von Einzelerfindern gemacht. Der Zufall spielt für die Entstehung neuen technischen Wissens eine relativ große Rolle und sorgt für eine gleichmäßige Verteilung der Erfindungen im Raum. Mit zunehmender Industrialisierung nimmt der Zwang zur Entwicklung neuen technischen Wissens, vor allem durch die Veränderung der Faktormengenrelation und Konkurrenzverschärfung zu. Die Entwicklung des technischen Fortschritts wird immer systematischer durch Forschungsindustrien betrieben. Mit der Veränderung in der Organisation des technischen Fortschritts, der "Entpersönlichung der Erfingungs - und Neuerungstätigkeit" erhält die Höhe der Forschungsinputs das ausschlaggebende Gewicht für die regionale Verteilung der Erfindungen. (146)

Kapital, Arbeit und das in den Arbeitskräften und dem bereits investierten Kapital verkörperte technische Wissen konzentrieren sich auf die Regionen, in denen bereits kumulative Wachstums - und Verdichtungsprozesse interne und externe Ersparnisse ermöglicht haben. (147) Diese Räume haben die be sten Voraussetzungen, neues technisches Wissen zu entwickeln. Sie werden die Ausgangspunkte technischer Neuerungen.

Die interregionalen Unterschiede in der Entstehung des technischen Fortschritts werden aus zwei Gründen auch nicht durch interregionale Kommunikation eingeebnet: 
- Auch wenn die Bereitschaft des Erfinders zur Weitergabe seiner Erfindung besteht, wie im Fall der staatlichen Grundlagenforschung, sind die Voraussetzungen zur Aufnahme der neuen Erkenntnisse, nämlich ein hoher Stand technischen Wissens, vorzugsweise in den Agglomerationen gegeben.

- Im Falle der privaten Grundlagen- und Zweckforschung fehlt sogar grundsätzlich die Bereitschaft, neues technisches Wissen unentgeltlich weiterzugeben. (148)

\subsubsection{Räumliche Verteilung der Innovationen}

Auch die Chancen zur Realisierung des neuen technischen Wissens hängen von der gegebenen Raumstruktur ab und sind deshalb interregional ungleichmäßig verteilt. Sie sind konzentriert auf Regionen, die besondere Standorteigenschaften (Marktnähe, gute Infrastrukturausstattung, hoher Agglomerationsgrad usw.) aufweisen. Dort ansässige Unternehmen erzielen im Durchschnitt höhere Gewinne als Konkurrenten in schwächer agglomerierten Regionen. (149) Sie sind deshalb eher in der Lage, neue technische Produktionsverfahren, die häufig wegen ihrer Unteilbarkeit einen großen Kapitalaufwand und wegen des mit ihnen verbundenen Risikos überwiegend Selbstfinanzierung erfordern, einzuführen. (150)

\subsubsection{Räumliche Verteilung der Imitationen}

Das Stadium der Adaption und der Imitation ist durch ähnliche Zusammenhänge gekennzeichnet wie das der Innovation und der Invention. "Ein Nachvollzug oder eine bessere Ausführung der Innovation sind . . oft nicht möglich, weil den potentiellen Imitatoren nicht genügend finanzielle Mittel zur Verfügung stehen (zum Beispiel, wenn es sich um kleine Unternehmen handelt) und die Forschungsabteilungen für das spezielle Problem nicht genügend geistiges Kapital (vorgetane Arbeit) akkumuliert haben. "(151)

Auch die Möglichkeit der Aufnahme und des Nachvollzugs, die häufig den Adaptoren und Imitatoren selbst die Entwicklung neuer Verfahren und Produkte und die Ausnutzung interner Ersparnisse ermöglichen, sind also überwiegend auf die von der wirtschaftlichen Entwicklung begünstigten Regionen beschränkt.

\subsubsection{Ergebnis der bisherigen Überlegungen}

Der Ablauf des räumlichen Differenzierungsprozesses muß aus dem Zusammenwirken aller Standortfaktoren erklärt werden:

Naturräumliche Faktoren und historische Zufälligkeiten geben die auslösenden Entwicklungsimpulse (Initialzündung) für regionale Wachstums - und Ver dichtungsprozesse. Die räumliche Nähe zu anderen privaten Wirtschaftssub- 
jekten läßt externe Ersparnisse und in ihrer Folge auch interne Ersparnisse entstehen. Mit zunehmender Verdichtung steigt die Nachfrage der privaten Wirtschaftssubjekte nach öffentlichen Leistungen. Durch die nachfrageorientierte Begünstigung der Verdichtungsräume beim Auf - und Ausbau der Infrastruktur durch den Zentralstaat werden den privaten Wirtschaftssubjekten weitere Möglichkeiten zur Realisierung externer und interner Ersparnisse geboten. Hohe Gewinne, aufnahmefähige Märkte, hoher Stand verkörperten technischen Wissens, geistig mobile Einwohner, "soziale Atmosphäre" machen die Unternehmen dieser Regionen zu Vorreitern bei der Entstehung und Durchsetzung des technischen Fortschritts. Die interregionale Wettbe werbsfähigkeit der regionsansässigen Faktorbesitzer, das regionale Gewinnbzw. Einkommensgefälle und damit die Attraktivität der Region für ortsfremde $F$ aktoren werden weiter erhöht.

Daß dieser kumulative Proze $\beta$ nicht unbegrenzt weiterläuft, liegt an der Existenz der Faktoren, die auch bei langfristiger Betrachtungsweise für das regionale Entwicklungspotential Potentialfaktorcharakter haben:

- die gesellschaftlichen und politischen Rahmenbedingungen

- die Teilfaktoren des Faktors Boden

- die wirtschaftsgeographische Lage.(152)

Ihre Kapazität kann auch langfristig nicht oder nur zu hohen Kosten erweitert werden, so daß sie als Engpaßfaktoren die langfristigen regionalen Entwicklungspotentiale begrenzen. Je stärker das regionale Entwicklungspotential durch den regionalen Wachstums - und Verdichtungsproze $\beta$ ausgelastet ist, desto mehr Faktoren erschweren eine weitere regionale Verdichtung und Wohlstandssteigerung. Auf diese den räumlichen Differenzierungsproze $\beta$ begrenzenden Faktoren soll nun etwas näher eingegangen werden.

\subsection{Agglomerationsnachteile: Negative externe Effekte}

Der kumulative Wachstums - und Verdichtungsprozeß nimmt die "nicht-privaten Leistungsquellen" einer Region immer stärker in Anspruch und ersch öpft sie schließlich. (153) "Lokalisierte Faktoren" werden immer knapper, (154) der regionale Wachstums - und Verdichtungsprozeß stößt in immer mehr Bereichen an seine räumlichen Grenzen. Man kann die Agglomerationsnachteile auch als Resultat der Überlastung des Raumes und seiner natürlichen Eigenschaften bezeichnen.

Über die Nachteile der Enge kann ebenso wie über die Vorteile der Nähe "vom theoretischen Standpunkt aus sehr wenig Allgeme ines"(155) gesagt werden. Deshalb soll an einigen Beispielen verdeutlicht werden, wie die langfristigen Potentialfaktoren des regionalen Entwicklungspotentials die kumulativen Tendenzen des Verdichtungsprozesses bremsen und möglicherweise sogar brechen können. (156) 


\subsubsection{Flächenknappheit}

Ein Teilfaktor des Faktors Boden ist die Fläche, die mit zunehmender Ballung immer knapper wird. Die Flächenknappheit und die dadurch verursachte Bodenpreissteigerung haben $u . a$. folgende ballungsbremsenden Effekte:

- Sie bewirken, daß Unternehmen in Ballungsgebieten gar nicht oder nur zu hohen Kosten ihre Produktionsanlagen und/oder ihre Produktionskapazität erweitert können. Ihre Möglichkeiten, interne Ersparnisse zu realisieren, werden dadurch begrenzt. Langfristig können diese Unternehmen gegenüber Konkurrenten in schwächer agglomerierten Regionen wettbewerbsunfähig werden, wenn jene dank ausreichender Flächen ihre Produktions kapazität ständig erweitern, hohe interne Ersparnisse realisieren und einen immer größeren Anteil an der Nachfrage gewinnen.

- Flächenknappheit und Bodenpreissteigerungen in den Ballungsgebieten begrenzen auch die Kapazitätserweiterungen im Bereich der Infrastruktur. Die Gebietskörperschaften können schon aus Kostengründen beim Ausbau der Infrastruktur nicht mehr Schritt halten mit der Nachfrage nach Infrastrukturleistungen. Die zunehmend auftretenden Engpässe in der Infrastruktur beeinträchtigen die Produktivität der ortsansässigen Faktoren, denn die von der öffentlichen Hand gebotenen externen Ersparnisse verringern sich.

- Flächenknappheit und Bodenpreissteigerungen verdrängen das Wohnungsangebot aus dem Zentrum andie Peripherie des Ballungsraumes. Hohe Mieten und zeitraubende Arbeitswege verringern die Attraktivität der Region für Arbeitskräfte und werden in den Löhnen und lohnabhängigen Aufwendungen auf die Unternehmen weitergewälzt. (157)

Die Flächenknappheit kann als "eine Ursache und ein Initialpunkt der Erschließung der noch "unterentwickelten' ländlichen Gebiete" angesehen werden. "Die industrialisierten Regionen ... müssen wegen der Flächenknappheit ihre Produktionsfaktoren in anderen Regionen ... einsetzen, was zu einer Entwicklung dieser Räume und zu einer Angleichung der Niveaus im Gesamtraum führt." Dazu "bedarf es aber eines sehr hohen Entwicklungsniveaus verbunden mit einer sehr hohen Flächenbeanspruchung in den entwickelten Regionen. "(158)

\subsubsection{Verschlechterung der Umweltbedingungen}

Einen zweiten Teilfaktor des Faktors Boden kann man mit dem Begriff "Umweltbedingungen" umschreiben.

Einstmals freie Güter (159) werden mit zunehmender Auslastung des regionalen Entwicklungspotentials immer mehr zu knappen Gütern, deren Inanspruchnahme immer höhere Kosten verursacht. $\mathrm{Zu}$ den negativen Folgen eines regional begrenzten Wachstums - und Verdichtungsprozesses gehören unter diesem Gesichtspunkt: 
- die zunehmende Verschmutzung und Vergiftung von Luft und Wasser,

- die Lärmbelästigung,

- die Probleme der Müllbeseitigung.

- die Erschöpfung natürlicher Wasserreservoirs u. ä. .

Die durch den Ballungsproze $\beta$ bewirkte Aus - und Überlastung der natürlichen Umweltfaktoren wirkt direkt kostensteigernd auf die Unternehmen. Werden bestimmte Schwellenwerte überschritten, wirken sich diese Folgen der Verdichtung z. B. gesundheitsschädigend aus und werden als Belästigungen empfunden. Deshalb erteilt die öffentliche Hand den Verursachern immer mehr Auflagen, durch die die Umweltbeeinträchtigungen vermieden werden sollen. Die dadurch erzwungenen Maßnahmen sind für die Verursacher in der Regel äußerst kostenintensiv (z. B. Luftfilter, Rauchwaschanlagen oder unternehmenseigene Kläranlagen).

Gleichzeitig wird der Unternehmenssektor auf indirekte Weise durch die Nachteile der Enge negativ berührt. Die Bewältigung der ballungsbedingten Umweltprobleme durch die öffentliche Hand verursacht dieser hohe Kosten (Kläranlagen, Erschließung neuer Grundwasserreservoirs usw.), die in Form höherer Gebühren auch die Kosten der Unternehmen erhöhen. Lärmbelästigung, Umweltverschmutzung, räumliche Enge, Verkehrs-und Wohnungsengpässe, all dies beeinträchtigt Gesundheit, Lebensfreude, Leistungsfähigkeit und Leistungsbereitschaft der Arbeitskräfte (160) und wirkt sich negativ auf Kosten bzw. Produktivität der Unternehmen aus.

\subsubsection{Institutionell-organisatorische Starrheiten}

Aber auch die durch die anderen Potentialfaktoren gesetzten Grenzen machen sich im Verlauf des Verdichtungsprozesses bemerkbar. Hier sei nur die geringe Elastizität der gesellschaftlichen und politischen Rahmenbedingungen betont, die sich solange nicht nachteilig auswirkt, wie die gesellschaftlichen und politischen Institutionen nicht stark in Anspruch genommen werden.

So treten z. B. mit zunehmender Auslastung der Verwaltungskapazitäten im öffentlichen und privaten Sektor immer mehr organisatorisch-institutionelle Starrheiten auf (langwierige Antrags - und Genehmigungsverfahren, Kompetenzüberschneidungen u. ä.). Auch sie mindern die Produktivität der ortsansäs sigen Faktoren. Ähnliches gilt auch für die traditionellen Formen und Regeln des menschlichen Zusammenlebens, die mit steigender räumlicher Enge und fortschreitender Arbeitsteilung immer höherem Druck ausgesetzt sind und die Leistungsfähigkeit der Menschen beeinträchtigen können. (161)

2.3.4. Die Funktion der Agglomerationsnachteile als automatische Stabilisatoren des räumlichen Differenzierungsprozesses

Die starke Aus-bzw. Überlastung des Raumes, die sich in Nachteilen der Enge niederschlägt, verursacht bei den ortsansässigen Faktoren Kostener- 
höhungen bzw. Produktivitätsminderungen. Die interregionale Wettbewerbs fähigkeit der Standorte in den Ballungsgebieten und damit deren Attraktivität auf Faktoren wird beeinträchtigt. Sind die Agglomerationsnachteile stark genug, so kehrt sich das bisher zugunsten der Verdichtungsgebiete bestehende regionale Gewinngefälle zugunsten schwächer agglomerierter Regionen um. Faktoren aus den Ballungsgebieten weichen immer stärker in schwächer verdichtete Regionen aus, (162) der Zustrom ortsfremder Faktoren in die Ballungsgebiete schwächt sich ab. Auf diese Weise wirken die Agglomerationsnachteile als "automatische Stabilisatoren"(163) des räumlichen Differenzierungsprozesses.

Die stabilisierende Wirkung der Ballungsnachteile hängt von ihrer Merklichkeit ab. Sie müssen von den betroffenen Wirtschaftssubjekten in der Agglomeration in einer solchen Intensität gespürt werden, daß davon eine Verhaltensänderung, insbesondere ein Standortwechsel bewirkt wird. Die Merklichkeit der Ballungsnachteile ist nun umso geringer, je gleichmäßiger die negativen Auswirkungen der Ballung auf die Einwohner der Ballungsreglon verteilt werden. Muß eine Vielzahl von Wirtschaftssubjekten die Ballungskosten tragen, so werden sie vom einzelnen Betroffenen kaum als Belastung empfunden. Schlagen sich die Ballungskosten dagegen bei einer relativ geringen $\mathrm{Zahl}$ von Wirtschaftssubjekten nieder und insbesondere bei denen, die eine Schlüsselrolle im räumlichen Verdichtungsprozeß spielen, kann man eher eine Ausweichreaktion der Betroffenen und damit einen Stabilisierungseffekt erwarten.

Man kann nun davon ausgehen, daß der größte Teil der negativen Auswirkungen des Ballungsprozesses von der wirtschaftlichen Aktivität einer relativ geringen Anzahl von Wirtschaftssubjekten, den Unternehmen, verursacht wird. Würden sich Beeinträchtigungen der öffentlichen und privaten Haus halte und anderer Unternehmen voll in den Kostenrechnungen der verursachenden Betriebe niederschlagen, der Verursacher also diese Kosten tragen, würde die Rentabilität seines Standorts äußerst stark beeinträchtigt. Um dem Druck auf seine Rentabilität auszuweichen und seine Wettbewerbsfähigkeit wieder herzustellen, müßte er in solche Regionen abwandern, in denen infolge des geringeren Agglomerationsgrades seine wirtschaftliche Aktivität geringere negative Effekte auslöst.

Die Tatsache, daß der Preismechanismus bei der Zurechnung dieser Effekte auf den Verursacher versagt, diese Effekte also als negative externe Effekte in Erscheinung treten, schwächt nun die stabilisierende Wirkung der Agglomerationsnachteile ab. Sie werden nun nicht von den wenigen Verursachern, sondern von vielen Betroffenen, nämlich allen oder beinahe allen Wirtschaftssubjekten im Ballungsgebiet, zum Teil auch solchen außerhalb des Ballungsgebiets getragen. Diese gleichmäßige Verteilung der Ballungsnachteile führt dazu, daß das einzelne betroffene Wirtschaftssubjekt diese Nachteile oft gar nicht oder nur schwach als Belastung empfindet. Die geringe Spürbarkeit verhindert eine Verhaltensänderung, die erst zustande kommt, wenn die Belastung einen bestimmten Erträglichkeitspegel überschreitet. Für die Unternehmen wirkt sich die räumliche Enge nur insoweit aus, wie die durch ihre Standortentscheidungen verursachte Flächenknappheit, Infrastrukturengpässe, 
erhöhte Unfall- und Krankheitshäufigkeit usw. auf ihre privaten Kosten und Produktivität negativ zurückwirken. Das Verhalten der Unternehmen wird dadurch relativ schwach und erst bei sehr hohem Verdichtungsgrad beeinflußt.

Eine weitere Abschwächung der stabilisierenden Wirkung der Agglomerationsnachteile wird durch Maßnahmen der öffentlichen Hand bewirkt. Sie ist häufig bemüht, die Nachteile der Ballung für Unternehmen, die als Rückwirkungen ihrer eigenen Standortentscheidung angesehen werden können, abzuschwächen. Dies ist z. B. der Fall, wenn unter dem Postulat der "raumwirtschaftlichen Quasi-Neutralität" vorwiegend Engpässe in der Infrastruktur der Ballungsgebiete beseitigt werden oder in Ballungsgebieten Industrie gelände zu niedrigen Preisen angeboten wird. Auf diese Weise werden die Nachteile der Ballung für wenige Wirtschaftssubjekte verringert. Diese honorieren die spürbare Entlastung ihrer Kostenseite damit, daß sie auf die sonst vielleicht erforderliche Standortveränderung verzichten. Die Kosten dieser Maßnahmen dagegen werden auf viele Wirtschaftssubjekte, nämlich alle Steuerzahler der Region, wenn Spillover-Effekte vorliegen auch noch auf Steuerzahler anderer Regionen, verteilt. Bei jedem einzelnen wird diese zusätzliche Belastung in aller Regel nur so schwach spürbar, daß er daraufhin nicht seinen Wohnort wechselt oder anderswie die ihm auferlegte Belastung auf die Unternehmen zu überwälzen versucht. (164)

Diese Abschwächung der stabilisierenden Wirkung der Agglomerationsnachteile beruht also darauf, "daß gerade die Leistungen der öffentlichen Wirtschaft und der Verwaltung in sehr unterschiedlichem Maße von den einzelnen Standortteilnehmern bei - unter sozialen Gesichtspunkten - gleichmäßi ger Kostenverteilung durch die Praxis der Besteuerung in Anspruch genommen werden"(165) und deshalb auch in unterschiedlichem Ausmaß das Verhalten der davon Betroffenen beeinflussen.

\subsection{Die ballungsfördernde Wirkung der Agglomerationseffekte}

Die Agglomerationsvor- und -nachteile haben im Verlauf des Verdichtungs prozesses ein unterschiedliches Gewicht. Agglomerationsvorteile treten von Beginn des räumlichen Konzentrationsprozesses an auf, Nachteile der Agglomeration werden dagegen erst in einem fortgeschrittenen Stadium des Ballungsprozesses spürbar. Wirtschaftliche Aktivitäten führen nämlich erst dann zu Schäden bei anderen Wirtschaftssubjekten und beeinträchtigen deren Produktivität oder Wohlfahrt, wenn sie einen bestimmten Schwellenwert überschritten haben. Existenz und Ausmaß der negativen Ballungseffekte sind also vom Agglomerationsgrad abhängig. (166)

In den Anfangsstadien des Verdichtungsprozesses bringt eine Zunahme der räumlichen Konzentration wirtschaftlicher Aktivitäten den Wirtschaftssubjekten mehr Vor- als Nachteile. Die sozialen Durchschnittskosten der Produktion sinken mit steigendem Agglomerationsgrad, da immer mehr Möglichkeiten entstehen, interne und externe Ersparnisse zu nutzen, ohne daß sich bereits die Nachteile der Enge wesentlich bemerkbar machen. 
Mit zunehmender Auslastung des regionalen Entwicklungspotentials treten jedoch immer stärker die negativen Auswirkungen der räumlichen Enge in den Vordergrund. Die Nachteile, die eine weitere Verdichtung mit sich bringt, übersteigen schließlich ab einem bestimmten Agglomerationsgrad die zusätzlichen Vorteile der Agglomeration. (167) Jenseits dieses "Agglomerationsoptimums" steigen die sozialen Durchschnittskosten der Produktion des Standorts bei weiterer Verdichtung.

Bei diesen Überlegungen wird unterstellt, daß die sozialen Kosten (private Kosten + soziale Zusatzkosten) der Produktion an einem Standort einen er tragsgesetzlichen Verlauf aufweisen und die sozialen Durchschnitts - und Grenzkostenkurve u-förmig verlaufen. (168) Die Unterstellung eines u-förmigen Verlaufs der sozialen Durchschnittskosten-Kurve begründet die Vermutung, daß die im Verlauf des Ballungsprozesses immer gewichtiger werdenden Nachteile der Enge den Konzentrationsprozeß, "das Wachstum der Städte", automatisch bremsen. (169) Diese Wirkung wird jedoch nur dann eintreten, wenn auch die privaten Kosten der Produktion an einem Standort $u$-förmig verlaufen. Davon kann man jedoch nicht einfach ausgehen. Die Annahme eines u-förmigen Verlaufs der Durchschnittskosten-Kurve gilt "nur bei Bewertung zu gesamtwirtschaftlichen, nicht aber auch notwendigerweise zu einzelwirtschaftlichen Kosten und Erträgen. "(1 70)

Für die Standortwahl oder Investitionsentscheidung des Unternehmers sind nur die Kosten und Erträge entscheidend, die in die einzelwirtschaftliche Wirtschafts rechnung eingehen. Die einzelwirtschaftliche Entscheidung wird also nur durch die privaten Kosten und Erträge, nicht aber durch die gesamten, d.h. die sozialen Kosten und Erträge, die eine wirtschaftliche Aktivität verursacht, bestimmt.(171) Die Unvollständigkeit der privaten Standortkalku lation hat ihre Ursache in der Unfähigkeit des Preismechanismus, alle Aus wirkungen einer wirtschaftlichen Aktivität dem Verursacher vollständig zu zurechnen. Sie ist ein wichtiger Erklärungsfaktor des räumlichen Differenzierungsprozesses:(172)

In der Wirtschafts rechnung des Unternehmens schlagen sich die Vorteile der Agglomeration vollständig als Kostensenkung bzw. Produktivitätserhöhung nieder. Sie gehen deshalb in das Entscheidungskalkül des standortsuchenden Unternehmers ein. Dagegen wird bei der Standortentscheidung nicht berücksichtigt, ob und in welchem Ausmaß andere Wirtschaftssubjekte durch die Entscheidung zugunsten der Agglomeration als Standort negativ betroffen werden, denn diese negativen Effekte wirken sich für den Verursacher nicht kostensteigernd aus, sie sind externe Kosten.

Die aus der Unvollkommenheit des Preismechanismus (173) resultierende Möglichkeit, die Vorteile der Ballung unentgeltlich, also ohne Kompensationszahlung für den oder die Verursacher, zu nutzen, verstärkt einmal entstandene Ballungstendenzen. Die Möglichkeit, Kosten der eigenen Aktivität zu vermeiden und anderen Wirtschaftssubjekten anzulasten, schwächt die deglomerative Wirkung der mit zunehmendem Agglomerationsgrad steigenden Ballungsnachteile (174) ab und verhindert 
so eine wirksame automatische Stabilisierung des Ballungsprozesses. Die durch die Standortentscheidung einer relativ geringen Anzahl von Wirtschaftssubjekten verursachten Ballungsnachteile werden auf eine Vielzahl von Wirtschaftssubjekten verteilt, so daß ihr verhaltensändernder Einfluß relativ schwach ist.

"Das Gegenstück zu diesem Fall übermäßiger Ballung infolge mangelnder Berücksichtigung der 'externen Kosten' ist die unzureichende Entwicklung anderer Gebiete infolge unzureichender Abgeltung der 'externen Erträge'. Industriebetriebe, die sich in rein agrarischen Gebieten niederlassen wollen, kommen nicht in den unentgeltlichen Genuß von Fühlungsvorteilen; aber sie würden nachfolgenden Betrieben Fühlungsvorteile bieten, für die sie jedoch kein Entgelt erwarten können. Des halb kommt der Industrialisierungsproze $\beta$ in reinen Agrarregionen so schwer in Gang. "(175)

Der Tatbestand, daß die Vorteile und die Nachteile einer räumlichen Konzentration wirtschaftlicher Aktivitäten nicht oder nur unvollständig ihren Verursachern zugerechnet werden können, ist die wohl entscheidende Ursache der Eigendynamik eines einmal in Gang gesetzten Prozesses räumlicher Differenzierung. Standorte in schwach agglomerierten Regionen erscheinen deswegen betriebswirtschaftlich unrentabel, während Standorte in Agglomerationsgebieten betriebswirtschaftlich auch dann noch lohnend sind, wenn das Festhalten an ihnen volkswirtschaftlich längst schon mit Wohlstandsverlusten verbunden ist.

\section{Erklärung der Beharrungskraft der einmal getroffenen Standortwahl}

Auch wenn sich die Agglomerationsnachteile in spürbarem Maße gewinnmindernd für die Unternehmen in den Ballungsregionen auswirken und damit auch die betriebswirtschaftliche Rentabilität der Standorte gefährden, gibt es eine Reihe von Gründen für die Vermutung, daß sie nicht genug Kraft besitzen, einmal entstandene Raumstrukturen wieder aufzulösen.

\subsection{Die zeitliche Begrenzung des Planungszeitraums der Investoren}

Miksch hat dargestellt, daß die mit jeder Standortwahl verbundenen Investitionen wenigstens auf relativ kurze Sicht räumlich nicht "übertragbar" oder "einschmelzbar" sind. Dies liegt an dem relativ kurzen Planungszeitraum, den viele Investoren schon infolge ihrer eigenen begrenzten Lebensdauer ihren Entscheidungen zugrunde legen. Auf der Basis des gegebenen Zeithorizonts erscheinen dann die Kosten des Standortwechsels in Form von Kapitalzerstörung am alten Standort und hohen Erstinvestitionen und Mühen am neuen Standort nicht lohnend. Am alten Standort wird solange wie möglich festgehalten. (176) Aber "im long run setzt sich dann doch die neue Standortverteilung durch, wenn auch vielleicht mit mancherlei Verzögerungen, Hemmungen und Abirrungen. "(177) 


\subsection{Die Anspruchsanpassungs-Theorie}

Doch auch auf lange Sicht kann nicht unbedingt eine Anpassung der Standortstruktur an neue Bedingungen auf der Angebots - und/oder Nachfrageseite erwartet werden. Überlegungen, die eine langfristige Beharrungskraft der einmal entstandenen Raumstruktur plausibel erscheinen lassen, liefert die sogenannte Anspruchsanpassungs-Theorie. (178) Sie kritisiert die Auffassung der traditionellen Theorie, derzufolge der Unternehmer mit seiner Standortwahl seinen Gewinn zu maximieren versuche. Vielmehr strebe der Unternehmer ein befriedigendes Gewinniveau an, wobei sein subjektives Anspruchsniveau bestimme, was als "befriedigend" betrachtet wird.

Kernpunkt dieser Theorie ist die Analyse des Informations - und Entscheidungsprozesses, durch den der Unternehmer aus der Vielzahl der ihm zur Verfügung stehenden Handlungsalternativen diejenige auswählt, die ihm das angestrebte Gewinniveau zu realisieren verspricht. Die Informationsgewinnung über die Eignung der einzelnen Handlungsalternativen hinsichtlich der Realisierung des "befriedigenden" Gewinns erfordert einen großen Aufwand an Zeit und Geld, bereitet Mühe und ist mit großen Unsicherheiten behaftet. Deswegen wird der Unternehmer nicht Informationen über alle Handlungs alternativen gleichzeitig gewinnen wollen. Er wird sich auf diejenigen beschränken, die er mit den geringsten Zeit - und Geldkosten und mit der größten Sicherheit gewinnen kann. Ist unter den zuerst untersuchten Handlungsalternativen keine enthalten, die ihm den angestrebten Gewinn verspricht, wird er die Informationsgewinnung intensivieren und so weitere Handlungsalternativen in sein Entscheidungskalkül einbeziehen. Der Informations- und Entscheidungsproze $\beta$ wird dann abgebrochen, wenn er eine Handlungsalternative gefunden hat, von deren Anwendung er den "zufriedenstellenden" $\mathrm{Ge}$ winn erwarten kann. Ob dann unter den nichtberücksichtigten Handlungsalternativen eine vorhanden ist, die noch größeren Gewinn ermöglicht, spielt für den Unternehmer keine Rolle mehr. "Es ist dann .. die Wahrscheinlichkeit sehr groß, daß in dieser so eng begrenzten Menge berücksichtigter Handlungsalternativen weder die privatwirtschaftlich noch die volkswirtschaftlich optimale Alternative enthalten ist. "(179)

Die Intensität des Alternativenvergleichs hängt außer vom individuellen Anspruchsniveau vor allem von den Kosten der Informationsgewinnung und dem Risiko der Informationen ab. Kosten und Risiko sind umso größer, je weiter sich der Unternehmer aus seinem bisherigen Betätigungsfeld und von seinem bisherigen Standort entfernt. "Hieraus erklärt sich .. zu einem nicht unerheblichen Teil die Beharrungskraft eines einmal gewählten Standortes: Erst wenn sich alle anderen Aktionsparameter der Unternehmung (z. B. Preispolitik, Veränderung des Produktionsprogramms etc.) als ungeeignet zur Verbesserung des bisherigen Standortes erwiesen haben, wird der Standort selbst in Frage gestellt. Bei der Suche nach einem neuen geeigneten Standort werden dann aus dem gleichen Grunde wieder die in der Nähe des augenblicklichen Sitzes der Unternehmung bzw. die im Erfahrungsbereich des Unternehmers ... liegenden möglichen Standorte bevorzugt analysiert. "(180) 


\subsection{Das Prinzip der kognitiven Dissonanz}

Neben dieser quantitativen Begrenzung spielt auch eine qualitative Begrenzung des Informationsprozesses für die Erklärung der Beharrungskraft der Raumstruktur eine Rolle. Diese qualitative Begrenzung kann mit dem Prinzip der kognitiven Dissonanz (181) begründet werden: Die Menschen neigen dazu, zwischen ihren Zielen und Wünschen auf der einen Seite, und ihren Handlungen und deren Auswirkungen auf der anderen Seite eine Übereinstimmung herbeizuführen. Führt eine ergriffene Handlungsalternative nicht zu dem erwarteten Ergebnis, versucht man die aufgetretene Dissonanz zwischen tatsächlichem und erwünschtem Ergebnis zu verringern. Der psychologische Prozeß, in dem versucht wird, die Dissonanz herabzumindern, durchläuft mehrere Stadien:

- Informationen, die daraufhinweisen, daß die Entscheidung zugunsten einer bestimmten Handlungsalternative falsch war, will man so lange wie möglich nicht wahrhaben (selektive Informationsauswahl).

- Wenn die Dissonanz nicht mehr zu verleugnen ist, bemüht man sich, sie als vorübergehend zu betrachten.

- Sprechen die das Wirtschaftssubjekt erreichenden Informationen dafür, daß die Dissonanz eher dauerhaft ist, wird durch alle möglichen Rechtfertigungen die einmal getroffene Entscheidung verteidigt.

- Wird die Dissonanz schließlich als immer unbefriedigender empfunden, wird in vielen Fällen, häufig unbewußt, das Anspruchsniveau bzw. die Zielfunktion an die realisierbaren Zielwerte angepaßt. Die andere Möglichkeit, die eingetretene Dissonanz abzubauen, nämlich die ursprüngliche Entscheidung bewußt zu korrigieren, verlangt das Eingeständnis eines Entscheidungsfehlers und wird nur in wenigen Fällen ergriffen.

Auch wenn also ein Unternehmer nachträglich feststellen sollte, daß seine getroffene Standortwahl nicht den erhofften Gewinn erbracht hat, wird er seine Standortwahl nicht einfach korrigieren. Es ist eher zu erwarten, daß er sein Anspruchsniveau auf das realisierbare Gewinniveau herabsenkt, und so seinen Standort "verteidigt". Aus einem solchen Unternehmerverhalten kann "wieder eine A-priori-Präferenz für den einmal gewählten Standort und damit e ine weitere Ursache für die erhebliche Beharrungskraft der einmal getroffenen Standortwahl abgeleitet werden. "(182)

Verschlechtern die Nachteile der Agglomeration im Verlauf des regionalen Wachstums - und Verdichtungsprozesses die Gewinnsituation der ansässigen Unternehmen so stark, daß ein regionales Gewinngefälle zugunsten schwächer agglomerierter Regionen entsteht, kann davon keine automatische Auflösung der Verdichtungsschwerpunkte erwartet werden. Der kurze Planungs zeitraum der privaten Investoren, die Kosten der Informationsgewinnung und die Unsicherheit der Informationen sowie psychologisch erklärbare Hemmnisse verhindern häufig die Aufgabe eines Standortes, auch wenn er bei ausschließlicher Gewinnorientierung längst nicht mehr haltbar wäre. 


\section{ANSATZPUNKT UND KONZEPTION EINER ZIELGERECHTEN REGIONALPOLITIK}

Die Überlegungen des vorhergehenden Kapitels relativieren die Annahme, derzufolge die Unternehmer ihr Kapital ständig an den Orten investieren, an denen sie den größtmöglichen Geldgewinn realisieren können. Als weiterer Einwand gegen diese Annahme muß bedacht werden, daß die Unternehmer gleichzeitig auch Konsumenten sind und, wenn überhaupt, nicht ihr monetäres Einkommen, sondern ihren Gesamtnutzen unter Einschluß nichtmonetärer Einkommensbestandteile maximieren wollen. (183) Nun ist aber einerseits der realisierte Geldgewinn die wohl wichtigste Determinante des Gesamtnutzens eines Unternehmers. Zum anderen kann davon ausgegangen werden, daß die Kosten der Informationsgewinnung sowie die Unsicherheit der Informationen über Standorteigenschaften langfristig sinken und an Bedeutung verlieren werden. (184) Aus diesen Gründen wird daran festgehalten, daß das nicht investierte Kapital sehr mobil ist und tendenziell an den Ort des höchsten Realertrags strebt. (185) Entscheidend für die Standortwahl der Investoren und somit auch für die regionale Verteilung der Produktivkräfte sind in erster Linie die regionalen Gewinnunterschiede bzw. die regionalen Unterschiede im Verhältnis zwischen Reallohn und Arbeitsproduktivität. (186)

Das Reallohn-Arbeitsproduktivitäts-Verhältnis ist die entscheidende Determinante des Beschäftigungsniveaus eines Betriebs, einer Region oder einer ganzen Volkswirtschaft. Je größer das Reallohn-Arbeitsproduktivitäts-Verhältnis einer Region im Verhältnis zu demjenigen in den anderen Regionen ist, desto niedriger ist das Beschäftigungsniveau in dieser Region. Die bereits ansässigen Unternehmen erzielen infolge des bei gegebener regionaler Produktivität zu hohen Reallohnniveaus geringere Gewinne als Konkurrenten in anderen Regionen. Sie können deshalb auf längere Sicht nicht im gleichen Ausmaß wie ihre Konkurrenten produktivitätserhöhende, technischen Fortschritt verkörpernde Maßnahmen durchführen und verlieren immer stärker ihre Konkurrenzfähigkeit. Das Arbeitsplatzangebot in den Regionen mit überdurchschnittlich hohem Verhältnis von Reallohn zu Arbeitsproduktivität geht zurück. Für standortsuchende Unternehmer scheidet eine solche Region von vornherein als möglicher Standort aus, so daß der Rückgang des Arbeits platzangebots auch nicht durch Kapitalimport ausgeglichen werden kann. In dieser Region entsteht regionale Arbeitslosigkeit, die man als Mindestlohnarbeitslosigkeit bezeichnen kann. (187)

Regionen, in denen die Lohnquote unterdurchschnittlich hoch ist, bieten dagegen den ansässigen Unternehmen gute Chancen, ihre Kapazitäten zu erweitern, langfristig Produktivitätsfortschritte zu erzielen und so ihre Wettbewerbsfähigkeit auszubauen. Bereits ansässige Unternehmen expandieren, neue Unternehmen werden attrahiert, wodurch das regionale Arbeitsplatzangebot steigt.

Die regionale Arbeitslosigkeit auf der einen und das Überangebot an Arbeitsplätzen auf der anderen Seite bewirken eine Abwanderung von Arbeitskräften aus den Regionen mit hohem in die Regionen mit niedrigem Reallohn-Arbeitsproduktivitäts-Verhältnis. Der mobilste Teil des relativ immobilen Faktors 
Arbeit folgt dem wesentlich mobileren Faktor "nicht investiertes Kapital" an die Orte der hohen Realerträge des Kapitals. (187)

Arbeitskräftewanderungen werden also nicht in erster Linie von regionalen Unterschieden in den Reallohnsätzen bestimmt, sondern vielmehr von regionalen Unterschieden im Arbeitsplatzangebot und damit von regionalen Unterschieden in den Möglichkeiten der Einkommenserzielung. (188) Ein regionales Reallohngefälle kann sogar der Grund dafür sein, daß Arbeitskräfte zur Abwanderung aus den Regionen mit hohem in die Region mit niedrigerem Reallohnsatz gezwungen werden. Diese Situation tritt ein, wenn den regionalen Reallohnunterschieden nicht im selben Ausmaß Produktivitätsunterschie de zugunsten der Region mit höherem Reallohn entsprechen.

Regionale Unterschiede in den Reallohn-Arbeitsproduktivitäts-Verhältnis sen kommen dadurch zustande, daß die regionalen Produktivitätsgefälle von den regionalen Reallohngefällen abweichen. Das regionale Gefälle der Arbeitsproduktivität verläuft parallel zum regionalen Gefälle der Agglomerationsgrade. (189) Die Vorteile der räumlichen Konzentration: Vorteile des engen räumlichen Verbunds, umfangreiches und differenziertes Angebot öffentlicher Leistungen, gute Chancen zur Durchsetzung neuen technischen Wissens, erhöhen die Produktivität des Faktors Arbeit und verschaffen den stark verdichteten Regionen einen Produktivitätsvorsprung gegenüber den schwach verdichteten Regionen.

Im vorhergehenden Kapitel werden die Agglomerationsvorteile als Ursache des regionalen Gewinngefälles zugunsten der stark agglomerierten Regionen bezeichnet. Diese Auffassung ist aber nur zutreffend, wenn die agglomerationsbedingten Produktivitätsunterschiede größer sind als die regionalen Reallohnunterschiede. Davon kann man aber realistischerweise ausgehen.

Die Verhandlungen zwischen Arbeitgebern und Gewerkschaften über die Höhe der Nominallohnsätze stehen unter dem Diktat der Forderung: "Gleicher Lohn für gleiche Arbeit". Mit diesem Postulat sind aber regionale Nominallohnunterschiede und, bei geringen regionalen Preisniveauunterschieden, damit auch regionale Reallohnunterschiede im Ausmaß der regionalen Produktivitätsunterschiede nicht vereinbar. (190) Bei kurzfristig, vielleicht auch mittelfristig gegebener regionaler Arbeitsproduktivitätsentwicklung bestimmt die gewerkschaftliche Lohnpolitik das regionale Beschäftigungsniveau. Setzt sie in allen Teilen der Volkswirtschaft ohne Rücksicht auf regionale Produktivitätsunterschiede gleich hohe Nominallohnsätze durch, sorgt sie dafür, daß das interregionale Produktivitätsgefälle zu einem interregionalen Gewinngefälle wird. Die Regionen mit weit unterdurchschnittlichem Niveau der Arbeitsproduktivität, die schwach agglomeriert und häufig peripher gelegen sind, verlieren Kapital und Arbeitskräfte und werden immer mehr zu wirtschaftlichen Notstandsgebieten. Regionen, die dank ihres hohen Agglomerationsgrades und ihrer zentralen Lage eine überdurchschnittlich hohe Arbeitsproduktivität aufweisen, attrahieren immer mehr Faktoren, bleiben weiterhin Zuwanderungsregionen. Bei gegebenem regionalen Produktivitätsgefälle sind die Reallöhne in den Agglomerationen zu niedrig, in den Deglomerationsgebieten zu hoch, um die Ballungstendenzen zu bremsen und eine ausgeglichenere Entwicklung der einzelnen Regionen einzuleiten. 
Die gewerkschaftliche Lohnpolitik erweist sich damit als ein nicht zu unterschätzender Bestimmungsfaktor des räumlichen Differenzierungsprozesses. Sie kann zu einem auslösenden Faktor eines langfristigen Wachstums - und Verdichtungsprozesses in einer zurückgebliebenen Region werden. Dazu ist es erforderlich, daß sie Reallohnunterschiede gegenüber den Ballungs gebie ten zuläßt, die größer als die Produktivitätsunterschiede gegenüber jenen Wohlstandsregionen sind. Dadurch wird die zurückgebliebene Region für viele Unternehmen als Standort attraktiver als die Agglomeration. Bereits ansässige Unternehmen brauchen nicht mehr abzuwandern, um wettbewerbsfähig zu bleiben, sondern können infolge ihrer verbesserten Wettbewerbs fähigkeit ihren Absatz ausdehnen. Die sich bildende und ständig verstärkende Verdichtung wirtschaftlicher Aktivitäten schafft immer mehr Möglichkeiten für ansässige Unternehmen, interne und externe Ersparnisse zu nutzen. Die lohnpolitische Zurückhaltung hat eine langfristige Produktivitätssteigerung ausgelöst, die nun auch Reallohnsteigerungen ohne Gefahr für die regionale Wettbewerbsfähigkeit und das regionale Beschäftigungsniveau ermöglicht.

Seine entscheidende Bedeutung für die unternehmerische Standortwahl macht das Reallohn-Arbeitsproduktivitäts-Verhältnis in den einzelnen Regionen zum wichtigsten Ansatzpunkt für regionalpolitische Maßnahmen des Staates.

Aufgabe der staatlichen Regionalpolitik ist es, die "Ursachen der Rückständigkeit von Regionen, nämlich die Angebotsbedingungen"(191), in den Griff zu bekommen. Dabei ist für den Erfolg der "angebotsorientierten Regionalpolitik"(192) nicht entscheidend, daß sie die Angebotsbedingungen in zurückgebliebenen Regionen schlechthin verbessert, sondern daß sie die Angebotsbedingungen dort im Vergleich zu anderen Regionen, insbesondere den Ballungsregionen, verbessert. Um dies zu erreichen, muß das Reallohn-Arbeitsproduktivitäts -Verhältnis gleichzeitig in beiden Regionstypen beeinflußt werden. In den Regionen, deren Verdichtung und Wachstum gebremst werden soll, wird ein Anstieg des Reallohns im Vergleich zur Arbeitsproduktivität angestrebt. Dagegen soll sich die Rentabilität der Standorte in wirtschaftlichen Notstands gebieten dadurch verbessern, daß dort die Arbeitsproduktivität schneller wächst als der Reallohn. (193)

Regionalpolitische Maßnahmen können sowohl beim jeweiligen Reallohn- als auch beim jeweiligen Produktivitätsniveau einer Region ansetzen. Doch scheidet eine Einflußnahme des Staates auf das Reallohnniveau über eine Beeinflussung des Nominallohnniveaus infolge der geltenden Tarifautonomie in der Bundes republik und den anderen Mitgliedsländern der Europäischen Gemeinschaft weitgehend aus.(194) Zur Beeinflussung der regionalen Angebotsbedingungen und Gewinnsituationen stehen dem Staat langfristig in erster Linie nur produktivitätsbeeinflussende Maßnahmen zur Verfügung.

Diese Maßnahmen können in zwei Gruppen unterteilt werden:

- Bei der ersten Gruppe handelt es sich um jene Maßnahmen, durch die eine weitere Erhöhung der privatwirtschaftlichen Produktivität der Arbeits plätze in den Ballungsgebieten verhindert oder gebremst werden soll. Der Maßnahmenkatalog umfaßt überwiegend Unterlassungen: Alle Eingriffe, die die produktivitätsmindernde Wirkung der Agglomerationsnachteile ab- 
schwächen oder beseitigen, sollen unterlassen werden. Ballungsnachteile sollen soweit wie möglich in pekuniäre Kosten transformiert und ihren Verursachern angelastet werden, damit sie einen spürbaren Druck auf die Rentabilität der Standorte in den Agglomerationen ausüben.

- Der zweite Maßnahmenkomplex betrifft die Angebotsbedingungen in den zurückgebliebenen Regionen und zielt auf eine Steigerung der regionalen Produktivität im Verhältnis zum Reallohn ab. Als entwicklungspolitische Strategie hat sich das Konzept der regionalen Schwerpunktbildung (195) oder der dezentralisierten Konzentration (196) durchgesetzt. Es basiert auf der Erkenntnis, daß die Qualität eines Standorts entscheidend von seinem Angebot externer Ersparnisse abhängt. Nur wenn eine zurückgebliebene Region vergleichbare Möglichkeiten zur Realisierung externer Ersparnisse wie eine stark agglomerierte Region bietet, können in ihr neue Unternehmen angesiedelt oder bereits ansässige Unternehmen gehalten werden. Die Bildung und Verstärkung regionaler Verdichtungsschwerpunkte scheint also eine notwendige Voraussetzung für einen dauerhaften, sich selbst tragenden regionalen Wachstumsproze $\beta$ zu sein.

Regionale Verdichtungsschwerpunkte lassen sich mit vertretbarem Aufwand nur bilden und/oder entwickeln, wenn die knappen öffentlichen Fördermittel massiv in wenigen ausgewählten Orten eingesetzt werden. (197)

Die verfolgte Konzeption ist eine "Verbindung des Entwicklungspolkonzepts mit dem Zentrale-Orte-Konzept zu einem Konzept der 'Wachstumszentren"". (198) Einerseits strebt die regionale Entwicklungspolitik die Konzentration eines umfangreichen und differenzierten Angebots öffentlicher und privater Dienstleistungen im regionalen Schwerpunkt an. Andererseits wird die Ansiedlung und Expansion solcher Unternehmen gefördert, die vor- und nachgelagerte Unternehmen attrahieren und so zur Bildung eines Industriekomplexes beitragen, der seinen Mitgliedern vielfältige Fühlungsvorteile bietet.

Diese Politik der aktiven Sanierung will durch eine Verbesserung der regionalen Angebotsbedingungen in den wirtschaftlichen Notstandsgebieten erreichen, daß der Faktor Kapital zum Faktor Arbeit wandert. Auf diese Weise wird in den Notstandsgebieten das Arbeitsplatzangebot erweitert und diversifiziert, wodurch eine weitere Abwanderung von Arbeitskräften in die Ballungsgebiete verhindert wird.

Im nächsten Hauptteil der Arbeit wird nun untersucht, über welche grundsätzlichen Möglichkeiten der Zentralstaat und die nachgeordneten Gebietskörperschaften verfügen, um eine solche Politik zu betreiben. Dabei können hier nur die Möglichkeiten und ihre Erfolgschancen diskutiert werden, mit Hilfe finanzpolitischer Maßnahmenkomplexe die räumliche Ordnung der Wirtschaft $\mathrm{zu}$ beeinflussen. 
D. FINANZPOLITISCHE EINFLUSSMÖGLICHKEITEN DER ÖFFENTLICHEN HÄNDE AUF DIE RÄUMLICHE ORDNUNG DER WIRTSCHAFT

I. Der Einfluß der Gemeinden auf die Raumstruktur

1. Voraussetzungen der Modellbetrachtungen

Auf der ersten Stufe der Überlegungen über finanzpolitische Einflußmöglichkeiten der öffentlichen Hände auf die regionale Verteilung der Ressourcen wird die Existenz übergeordneter Gebietskörperschaften vernachlässigt. Gefragt wird lediglich nach den Raumwirkungen des kommunalen Finanzsystems, worunter die Beeinflussung der lokalen Standortqualitäten und der Anziehungskraft auf Ressourcen durch einnahmen - und ausgabenpolitische Entscheidungen kommunaler Gebietskörperschaften verstanden wird. (199) Dabei sollen folgende Annahmen gelten:

a) Die Gemeinden besitzen sowohl auf der Einnahmen- als auch auf der Ausgabenseite vollständige oder weitgehende Finanzautonomie. Entweder können sie selbständig entscheiden, welche Einnahmequellen sie in welchem Ausmaß ausschöpfen wollen. Das kommunale Einnahmesystem ist als ungebundenes Trennsystem ausgestaltet. (200) Oder die den Gemeinden zustehenden Einnahmequellen sind festgelegt, dann steht ihnen das Ausmaß ihrer Inanspruchnahme frei. In diesem zweiten $F$ all liegt ein gebundenes Trennsystem (200) vor. Diese unbegrenzte oder begrenzte Einnahmenhoheit wird durch eine vollständige Ausgabenhoheit ergänzt. Die Gemeinden können nach eigenem Ermessen über ihre eigenen Einnahmen verfügen.

b) Die Einnahmen der Gemeinden bestehen ausschließlich aus Steuern. Eine Finanzierung der Ausgaben durch Kredite ist ausgeschlossen.

c) Die Aktivität der Gemeinden ist örtlich vollständig radizierbar. Die örtliche Radizierbarkeit besitzt drei Aspekte:

- Die den einzelnen Gemeinden zufließenden Steuereinnahmen werden ausschließlich von Einwohnern der jeweiligen Gemeinde gezahlt und getragen. Eine regionale Steuerüberwälzung findet also nicht statt.

- Das Leistungsangebot der einzelnen Gemeinden kommt nur Einwohnern der anbietenden Gemeinde zugute. Es treten also keine Ertrags-Spillovers auf.

- Die einzelnen Gemeinden beziehen die zur Erstellung ihres Leistungs angebots erforderlichen Inputs ausschließlich von ortsansässigen Wirtschaftssubjekten. Von der Kommune werden also nur ortsansässige Arbeitskräfte beschäftigt und Aufträge nur an ortsansässige Unternehmen vergeben. (201)

d) Die Kommunen betreiben eine "aktive Standortpolitik"(202). Sie versuchen bewußt Einfluß auf die Standortentscheidungen der Wirtschaftssubjekte zu nehmen, indem sie die Standortqualitäten am Ort im Verhältnis zu anderen Gemeinden verbessern. Ihr raumwirtschaftliches $\mathrm{Ziel}$ besteht darin, soviel 
Ressourcen wie möglich in die eigene Region zu lenken, um "die ökonomi sche Lage der eigenen Region zu verbessern"(203) bzw. "die Vorteile der eigenen Region zu maximieren"(204). Die Kommunen streben also nicht die gesamtwirtschaftlich erwünschte Raumstruktur an, sondern verfolgen räumlich unkoordinierte Zielsysteme. (205)

Der "Vorteil der eigenen Region" wird von der Gemeinde überwiegend unter fiskalisch-deckungspolitischen Gesichtspunkten betrachtet. Ihre Finanzpolitik ist auf die Attrahierung potenter Steuerzahler ausgerichtet und dient damit der Einnahmenerzielung. Die "partielle Einnahmenorientierung der Ausgabenpolitik" der Gemeinden scheint ein Wesensmerkmal der kommunalen Finanzautonomie zu sein. (206)

Die Adressaten und damit die konkrete Strategie dieser einnahmenorientierten Attrahierungspolitik werden durch die Ausgestaltung des kommunalen Steuersystems determiniert. (207) Hängt z. B. die Höhe der kommunalen Steuerkraft (208) in erster Linie von der Einkommensteuerleistung der Gemeindebürger $a b$, wird sich die kommunale Finanzpolitik stark um eine Attrahierung gutverdienender Arbeitskräfte bemühen. (209) Ein Interes se an der Ansiedlung von Gewerbebetrieben besteht dann nur insoweit, als ein ausreichendes Arbeitsplatzangebot ein wichtiger Wohnfaktor für Bezieher hoher Einkommen sein kann. Dagegen steht die Ansiedlung von Gewerbebetrieben dann im Mittelpunkt finanzpolitischer Maßnahmen der Gemeinden, wenn der größte Teil der kommunalen Steuereinnahmen von Ge werbebetrieben aufgebracht wird. (210)

Wenn man eine eindeutige Aussage darüber treffen will, welche Art von Ressourcen die Gemeinden mit Hilfe ihrer finanzpolitischen Aktionsparameter attrahieren wollen, muß man also ein bestimmtes kommunales Steuersystem unterstellen. Deswegen wird hier in Übereinstimmung mit der Situation in der Bundesrepublik Deutschland angenommen, daß der Hauptpfeiler des kommunalen Steuersystems durch eine Gewerbesteuer gebildet wird. Diese Annahme entspricht uneingeschränkt der Situation in der BRD bis zur Gemeindefinanzreform von 1969.(211) Die Beteiligung der Gemeinden an der Einkommensteuer bei gleichzeitiger Abtretung eines Teils der Gewerbesteuer an Bund und Länder hat das Interesse der Gemeinden an der Ansiedlung von Gewerbebetrieben abgeschwächt. Doch ist auch weiterhin die Abhängigkeit der kommunalen Steuerkraft von Zahl und Rentabilität der Gewerbebetriebe am Ort sehr groß. (211) Darüber hinaus ist das gewerbliche Arbeitsplatzangebot einer Gemeinde ein wichtiger Wohnortfaktor und bestimmt so Zahl und Einkommensteuerleistung der Gemeindeeinwohner mit. Aus diesen beiden Gründen kann die Attrahierung von Gewerbebetrieben und die Förderung der bereits ansässigen $\mathrm{Be}-$ triebe auch nach der Gemeindefinanzreform als das dominierende raumwirtschaftliche (Unter-)Ziel der kommunalen Finanzpolitik angesehen werden.

Um dieses Ziel zu erreichen, versuchen die einzelnen Gemeinden, das lokale Reallohn-Arbeitsproduktivitäts-Verhältnis bzw, die lokale Erlös Kosten-Relation im Verhältnis zu anderen Gemeinden zu verbessern. Auf 
diese Weise soll wenigstens für einige Unternehmen ein regionales Gewinngefälle geschaffen werden, durch das eine Zuwanderung von Kapital und Arbeitskräften induziert und eine Abwanderung bereits ansässiger Faktoren verhindert wird. (212)

Im nächsten Abschnitt wird nun analysiert, welche Möglichkeiten die einzelnen Gemeinden grundsätzlich besitzen, mit finanzpolitischen Mitteln die Investitionsentscheidungen der Unternehmen zu ihren Gunsten zu beeinflussen. Dabei interessiert besonders die Wirksamkeit und damit die Attrahierungskraft der einzelnen finanzpolitischen Instrumente. Für eine regionalpolitische Beurteilung der Raumwirkungen des kommunalen Finanzsystems ist weiterhin entscheidend zu wissen, inwieweit der Einsatz der einzelnen Attrahierungsmaßnahmen allen Gemeinden gleichermaßen oder nur einigen wenigen faktisch möglich ist.

\section{Die finanzpolitischen Aktionsparameter der Gemeinden}

\subsection{Gliederung des kommunalen Aktionsraumes}

Das regionalpolitische Instrumentarium wird in der Literatur uberwiegend in drei Gruppen zusammengefaßt, für die hier einige alternative Bezeichnungen aufgeführt werden:

- Instrumente der befehlenden (213) bzw. der normativen (214) Raumordnungspolitik, Zwangsmittel (215) oder Ge- und Verbote (direct controls) (216);

- Instrumente der ankurbelnden (213) bzw. der aktivierenden (214) Raumordnungspolitik, Anreiz-, Abschreckungs-, Anpassungs- und Gestaltungsmittel (215) oder finanzielle Maßnahmen (finanzielle incentives) (216);

- Instrumente der empfehlenden (213) bzw. der informierenden (214) Raumordnungspolitik, Maßnahmen der Kommunikation und Information (215).

Die Instrumente aller drei Maßnahmenkomplexe zielen darauf ab, die privaten Wirtschaftssubjekte $z u$ einem Verhalten $z u$ bewegen, das den Zielvorstellungen des regionalpolitischen Entscheidungsträgers entspricht. Dabei unterscheiden sich die Ge - und Verbote von den finanziellen Maßnahmen vor allem in der "Direktheit des Eingriffes"(217), also in der "Unmittelbarkeit bzw. Mittelbarkeit, in der eine Verhaltensänderung bewirkt wird. "(217) Während mit Maßnahmen der ersten Gruppe den privaten Wirtschaftssubjekten vielfach ein bestimmtes Verhalten zwingend vorgeschrieben wird, bleibt ihnen bei den Maßnahmen der zweiten Gruppe in der Regel die Entscheidungsfreiheit, ob sie die angebotenen finanziellen Anreize annehmen oder ablehnen.

Nur die Instrumente dieser zweiten Gruppe, die spezifisch finanzpolitische Instrumente sind, werden anschließend untersucht. Sie werden weiterhin unterteilt in

- einnahmen- und ausgabenpolitische Maßnahmen,

- haushalts - und unternehmensorientierte Maßnahmen. 
Mit der Unterscheidung von haushalts - und unternehmensorientierten Maßnahmen wird unterstellt, daß verschiedene, in sich relativ homogene Gruppen von Wirtschaftssubjekten auf die von regionalpolitischen Entscheidungs trägern gesetzten finanziellen Anreize in unterschiedlicher Weise reagieren, (218) so daß durch selektiven Instrumenteneinsatz das Verhalten gerade derjenigen Wirtschaftssubjekte beeinflußt werden kann, deren Aktivitäten für die regionale Entwicklung als besonders wichtig angesehen werden. Nun bereitet zwar die Unterteilung in haushaltsorientierte und unternehmensorientierte Maßnahmen, insbesondere auf dem Gebiet der Infrastrukturleistungen "statistisch-empirisch fast unüberwindliche Schwierigkeiten. In der Theorie darf aber davon ausgegangen werden, daß über die Zuordnung eindeutig entschieden werden kann." $(219,220)$

Als Ergebnis dieser Vorüberlegungen ergibt sich folgende Gliederung des finanzpolitischen Aktionsraumes der Gemeinden zur Beeinflussung der Raumstruktur:(221)

Auf der Einnahmenseite:

- Steuern von Haushalten

- Steuern von Unternehmen
Auf der Ausgabenseite:

(a) unmittelbare Zahlungen (222)

- an Haushalte

- an Unternehmen

(b) Angebot öffentlicher Leistungen (223)

- an Haushalte (224)

- an Unternehmen.

Zur Verbesserung ihrer Standortqualität und damit zur Erhöhung ihrer Attraktionskraft auf mobile Faktoren, insbesondere den Faktor Kapital, können die Gemeinden die finanzpolitischen Aktionsparameter grundsätzlich sowohl quantitativ als auch strukturell variieren.(225) Diese grundsätzlichen Möglichkeiten werden anschließend beschrieben und hinsichtlich ihrer Wirksamkeit beurteilt.

2.2. Raumwirtschaftliche Einflußmöglichkeiten der Kommunen durch Variation des Niveaus ihrer Aktivität bei unveränderter Struktur ihrer Einnahmen und Ausgaben

2.2.1. Senkung des Niveaus kommunaler Aktivität

Für die folgenden Überlegungen wird angenommen, daß die Gemeinden ausschließlich Steuern von Unternehmen erheben und die ihnen zufließenden Steue reinnahmen für die Erstellung eines Leistungsangebots verwenden, das ausschließlich den Unternehmen zugute kommt. Außerdem wird unterstellt, daß bei gleicher Steueranspannung alle Gemeinden gleich hohe Steuereinnahmen pro Kopf erzielen.

Durch eine Senkung der Steuerbelastung unter das Niveau der Steueranspannung in anderen Kommunen kann eine Gemeinde nun versuchen, attrahierend auf ortsfremde Unternehmen zu wirken und die Expansionsmöglichkeiten bereits ansässiger Unternehmen zu verbessern. Das von der Gemeinde zu ihren 
Gunsten geschaffene regionale Steuerlastgefälle dient also als Instrument zur Erhöhung der lokalen Wirtschafts - und Steuerkraft.

Isoliert betrachtet verbessert die Steuersenkung die Gewinnsituation der tatsächlich oder potentiell in der Gemeinde produzierenden Betriebe. Die von der Steuersenkung bewirkte Kostensenkung kann zu zwei Reaktionen der Unternehmen führen:

- Die Kostensenkung kann in Form niedrigerer Preise an die Käufer der Produkte weitergegeben werden. Dieser Preiseffekt zieht in der Regel einen Mengeneffekt nach sich. Der Anstieg der nachgefragten Menge (bei gleichem oder vergrößertem Absatzgebiet) führt langfristig zu einer Produktionserhöhung, ermöglicht interne Ersparnisse und somit indirekt eine Gewinnsteigerung.

- Die begünstigten Unternehmen verzichten auf eine Preissenkung im Ausmaß der Steuersenkung. Ihr Gewinn steigt damit infolge der Steuersenkung unmittelbar, wodurch ihnen in der Zukunft eine verstärkte"Entwicklung und Anwendung technischer und organisatorischer Neuerungen und damit weitere Kostensenkungen möglich werden. (226)

Beide Effekte des regionalen Steuerlastgefälles erhöhen die Wettbewerbsfähigkeit der ansässigen Unternehmen im Vergleich zu Unternehmen in Gemeinden mit höherer Steuerbelastung. Bereits ansässige Unternehmen expandieren stärker, als dies ohne Steuersenkung der Fall gewesen wäre, für standortsuchende Unternehmen wird die Gemeinde attraktiver.

Mit der Senkung der Steuerbelastung durch die Gemeinde ist aber nicht nur eine kostenmäßige Entlastung der Unternehmen, sondern auch gleichzeitig ein Rückgang der Steuereinnahmen der Gemeinden verbunden. (227)

Zwar könnte man vermuten, daß die Expansion der ansässigen und die Zuwanderung neuer Unternehmen infolge der Steuersatzsenkung zu einem Anstieg der Steuerbemessungsgrundlagen in der Gemeinde führt. Doch weist dieser Förder - oder Mengeneffekt der Steuersatzsenkung einen hohen Zeitbedarf auf. Der Ausfall von Steuereinnahmen infolge der Steuersatzsenkung (bei unveränderten Bemessungsgrundlagen) wird nicht sofort kompensiert durch einen Anstieg der Steuerbemessungsgrundlagen (bei nun niedrigerem Steuersatz).

Der aus diesem Zusammenhang resultierende Rückgang der kommunalen Steuereinnahmen zwingt die Gemeinde, ihr Angebot von Vorleistungen für die private Produktion einzuschränken. (228) Öffentliche Inputs müssen durch private Inputs ersetzt werden, wodurch die Unternehmen wieder kostenmäßig belastet werden. Die Nettowirkung aus der Senkung der Steuerbelastung und der Verringerung des öffentlichen Leistungsangebots auf die Kosten- bzw. Gewinnsituation der Unternehmen entscheidet, ob diese von den Gemeinden angewandte Attrahierungsstrategie Erfolg hat. Nur wenn die Kostensenkung infolge der Steuersatzsenkung von den Unternehmen höher eingeschätzt wird als die Kostensteigerung infolge des Ausfalls öffentlicher Leistungen, wird diese Gemeinde für Investoren attraktiver. 
Schränkt die Kommune dagegen Aktivitäten ein, die bisher mit positiven externen Ersparnissen (229) für den Unternehmenssektor verbunden waren, liegt also eine kos tenmäßige Präferenz für die öffentliche Produktion der Vorleistungen vor, stellt sich zwangsläufig eine Verschlechterung der Standortverhältnisse ein. Bei der Mehrzahl öffentlicher Leistungen zugunsten der Unternehmen ist aber wohl die Wahrscheinlichkeit groß, daß positive externe Ersparnisse vorliegen. Deshalb muß man diese Strategie der Kommunen als wenig erfolgversprechend betrachten, die lokale Wirtschafts - und damit auch Steuerkraft zu stärken.

\subsubsection{Erhöhung des Niveaus der kommunalen Aktivität}

Eine Kommune kann auch mit der entgegengesetzten Strategie versuchen, zusätzliche Ressourcen in die eigene Region zu lenken. In diesem Fall soll eine Anhebung des Steuersatzes Steuermehreinnahmen bewirken, mit denen das Angebot öffentlicher Leistungen zugunsten der Unternehmen erhöht werden kann. (230)

Während bei der ersten Strategie Attrahierungseffekte von der relativ geringen Steuerbelastung erwartet werden (und ein Rückgang der Steuereinnahmen aus der Sicht der Gemeinde unerwünscht ist), erhofft man sich bei die ser Strategie Attrahierungs - und Fördereffekte von dem im Verhältnis zu anderen Gemeinden größeren Angebot unternehmensorientierter kommunaler Leistungen. Aber auch in diesem Fall muß der Nettoeffekt von erhöhter Steuerbelastung, die zur Finanzierung des quantitativ und/oder qualitativ verbesserten Leistungsangebots erforderlich ist, und gestiegenem Leistungs angebot der Gemeinden auf die Gewinnsituation der Unternehmen betrachtet werden. Nur aus diesem Nettoeffekt lassen sich Rückschlüsse auf die Erfolgsaussichten dieser Strategie ziehen.

Der Erhöhung der individuellen Steuerbelastung folgt in der Regel eine Erhöhung des öffentlichen Leistungsangebots erst mit einiger zeitlicher Verzögerung. Außerdem besteht für das einzelne Unternehmen eine erhebliche Unsicherheit darüber, in welchem Ausmaß es vom erhöhten Leistungsangebot profitiert. So treten zuerst fast ausschließlich die negativen Standortwirkungen der Steuersatzerhöhung ein, so daß sich diese Strategie erst ein$\mathrm{mal}$ in einer Verschlechterung der Gewinnsituation und der Gewinnaussichten ortsansässiger und potentieller Investoren auswirkt:

- entweder unmittelbar, wenn eine Steuerüberwälzung auf die Abnehmer nicht durchgeführt wird oder nicht gelingt,

- oder mittelbar, weil infolge der Steuerüberwälzung ein regionales Preisgefälle entsteht, das zu sinkendem Absatz, eingeschränktem Absatzgebiet und verringerten Möglichkeiten zur Ausnutzung interner Ersparnisse führt. (231)

Dadurch werden wenigstens temporär die Standortqualität der Gemeinde und ihre Attraktionskraft auf Investoren vermindert. Tendenziell werden ansäs sige Unternehmen zur Abwanderung in Gemeinden mit niedrigerer Steuerbe- 
lastung gezwungen und die Zuwanderung neuer Unternehmen verhindert.

Setzt der Absatzrückgang der ansässigen Betriebe und/oder ihre Ausweichreaktion in Form der Abwanderung zeitlich unmittelbar nach Anhebung der individuellen Steuerbelastung und in großem Ausmaß ein, kommt es zu einer Verringe rung der lokalen Steuerbemessungsgrundlagen, durch die der Effekt der Tarifänderung auf die Steuereinnahmen möglicherweise überkompensiert wird. Statt der erhofften Steuermehreinnahmen sinkt infolge der Steuersatzerhöhung das Steueraufkommen. Das mit dieser Strategie angestrebte Ziel, durch ein verbessertes öffentliches Leistungsangebot attrahierend $\mathrm{zu}$ wirken, kann nicht erreicht werden. Vielmehr muß das Leistungsangebot sogar noch eingeschränkt werden.

Positiver muß diese Strategie dagegen beurteilt werden, wenn der Absatzrückgang und die Abwanderung der ortsansässigen Betriebe zeitlich verzögert eintreten und nicht so stark sind, daß trotz höherer Steuerbelastung die Steuereinnahmen sinken. Dieser Fall muß wohl als der realistischere betrachtet werden, denn die geringe Mobilität des "bereits investierten Kapitals". Verlagerungen von Betrieben sind gewöhnlich mit hohen Kapitalverlusten verbunden, (232) verhindert eine sofortige und starke Abwanderung ortsansässiger Betriebe. Es kommt deswegen infolge der Steuersatzerhöhung zu einem Anstieg der Steuereinnahmen, so daß zusätzliche öffentliche Leistungen zugunsten der Unternehmen finanziert werḍen können.

Mit den zusätzlich angebotenen öffentlichen Leistungen kann die Gemeinde die Verschlechterung der Standortbedingungen, die aus der höheren Steuerbelastung resultiert, nur dann überkompensieren, wenn sie solche Leistungen zusätzlich anbietet, die die privaten Unternehmen nur zu wesentlich höheren Kosten selbst erstellen könnten. Denn in diesem Fall ist ja die Kostenentlastung durch zusätzliche öffentliche Leistungen für die Unternehmen größer, als wenn sie die ihnen abverlangten zusätzlichen Steuermittel selbst zur Produktion der entsprechenden Vorleistungen verwendet hätten.

Die Gemeinde wird also durch diese Strategie nur dann für Investoren attraktiver,

- wenn das am Ort bereits investierte Kapital relativ immobil ist und deshalb die Steuersatzerhöhung überhaupt zu Steuermehreinnahmen führt, und

- wenn die Steuermehreinnahmen für zusätzliche öfentliche Leistungen verwendet werden, deren Produktion von der Kommune kostengünstiger als von den privaten Unternehmen durchgeführt werden kann.

Als weitere entscheidende Bedingung, die auch für die Strategie der Niveausenkung kommunaler Aktivität gilt, kommt hinzu, daß alle anderen Kommunen, mit denen die betrachtete Gemeinde im Attrahierungswettbewerb steht, das Niveau ihrer Aktivität unverändert lassen. (233)

Während eine Reduzierung der kommunalen Aktivität mit großer Wahrscheinlichkeit die Standortbedingungen in der Gemeinde eher verschlechtert als verbessert, hat also eine Gemeinde mit einer Ausdehnung ihrer Aktivität eine größere Chance, sich im Attrahierungswettbewerb der Gemeinden Vorteile zu verschaffen. 
Abschließend soll die eingangs gemachte Bedingung, daß ausschließlich Unternehmen Steuern zahlen und nur sie die kommunalen Leistungen in Anspruch nehmen, aufgehoben werden. Als ein anderér Extremfall wäre auch denkbar, daß die Kommunen nur von den privaten Haushalten Steuern erheben, die damit finanzierten öffentlichen Leistungen aber ganz oder überwiegend zugunsten der Unternehmen anbieten. Wir legen also unserer Betrachtung eine andere Ausgaben- und Einnahmenstruktur als bisher zugrunde, lassen aber diese neue Struktur bei einer Veränderung des Niveaus der kommunalen Aktivität wie im vorstehenden Fall konstant. Eine Erhöhung der Aktivität einer Gemeinde scheint nun auf den ersten Blick die Standortbedingungen für Gewerbebetriebe wesentlich stärker zu verbessern, als dies im vorstehenden $\mathrm{Fall}$ möglich ist, erhalten doch die Unternehmen zusätzliche kostensenkende Vorleistungen, ohne kostenmäßig durch die Steuererhöhung belastet zu werden. Ob eine solche Strategie den von der Gemeinde erwünschten Erfolg bringt, hängt vor allem ab:

- Vom Verhalten der anderen Gemeinden;

Es bestimmt, ob durch die erhöhte Aktivität der betrachteten Kommune zugunsten der in ihr ansässigen Gewerbebetriebe überhaupt ein regionales Leistungsgefälle entsteht.

- Vom Verhalten der zusätzlich belasteten Haushalte;

Davon hängt $a b$, ob ein regionales Leistungsgefälle, sollte es überhaupt zustande kommen, nur vorübergehend oder längerfristig eine Kostensenkung für die Unternehmen bewirkt.

- Von der Einschätzung der Längerfristigkeit der geschaffenen Standortvor teile durch die standortsuchenden Investoren.

Sie entscheidet darüber, ob die von der Kommune geschaffenen Standortvorteile zusätzliche Investitionen bereits ansässiger und ortsfremder Unternehmen am Ort induzieren.

Nur wenn alle drei Bedingungen gleichzeitig erfüllt sind, kann eine Gemeinde hoffen, daß durch ihre Aktivität ein lokaler Verdichtungs - und Wachstums proze $\beta$ ausgelöst wird. Dabei ergibt sich die Bedeutung der dritten Bedingung aus folgender Vermutung: $\mathrm{Ob}$ bereits ansässige Unternehmen in einer Region Erweiterungsinvestitionen durchführen und neue Unternehmen zur Ansiedlung in dieser Region bereit sind, "hängt davon ab, wie Unternehmer und Arbeitnehmer langfristig (234) die Entwicklungschancen des Unternehmens bzw. die Ausgestaltungsmöglichkeiten des Privatlebens einschätzen. "(235) Nur wenn die Einschätzung dieser langfristigen Entwicklungsmöglichkeiten in einer Region positiver ausfällt als für andere Regionen, kann die erwünschte Standortentscheidung des Unternehmers erwartet werden.

Auf diese Zusammenhänge wird näher eingegangen, wenn die Variation der Einnahmen- und Ausgabenstruktur und die Bestimmungsfaktoren ihrer Wirksamkeit diskutiert werden. 
2.3. Raumwirtschaftliche Einflußmöglichkeiten der Kommunen durch

Variation der Struktur ihrer Einnahmen und Ausgaben bei unverändertem Niveau ihrer Aktivität

2.3.1. Voraussetzungen der Modellbetrachtungen

Im folgenden wird untersucht, ob und gegebenenfalls wie die einzelnen Ge meinden durch eine Variation ihrer Budgetstruktur die Standortverteilung beeinflussen können. Dabei wird von folgenden Voraussetzungen ausgegangen:

In der Ausgangssituation

- existieren zwischen den Gemeinden keine Steuerbelastungsunterschiede,

- weisen alle Gemeinden dasselbe Einnahmen- und Ausgabenniveau auf,

- sind ihre Einnahmen- und Ausgabenstruktur völlig identisch.

Mit diesen Annahmen wird unterstellt, daß im Ausgangszustand alle Gemeinden aus den einzelnen Steuerarten auch absolut gleich hohe Einnahmen pro Einwohner erzielen und für die einzelnen Verwendungszwecke absolut gleich hohe Beträge pro Einwohner ausgeben. Daraus resultiert, daß die Raumwirkungen der einzelnen Kommunen im Ausgangsstadium identisch sind.

- Bei einer Verschiebung der Struktur der Einnahmen oder Ausgaben bleibt das Niveau der kommunalen Aktivität unverändert. (236)

Erhöht nun eine Kommune das relative Gewicht der Ausgaben für einen bestimmten Verwendungszweck, so steigt damit zugleich der absolute Ausgabenbetrag für diesen Verwendungszweck, während die für andere Zwecke verwendeten Mittel absolut sinken. Gleichzeitig verursacht die Gemeinde damit auch interlokale Unterschiede in der absoluten Höhe der Pro-KopfBeträge, die für die einzelnen Zwecke eingesetzt werden.

Entsprechendes gilt, wenn eine Gemeinde den Anteil einer bestimmten Einnahmenart an den Gesamteinnahmen verändert. Zwischen den einzelnen Gemeinden entstehen dadurch Unterschiede in der absoluten steuerlichen Belastung der einzelnen Gruppen von Wirtschaftssubjekten.

Eine Gemeinde, die aktiv die lokale Wirtschafts - und Steuerkraft erhöhen will, strebt die "optimale" Steuer- und Ausgabenstruktur an. Sie versucht, die Steuerlast so auf die verschiedenen Gruppen von Wirtschaftssubjekten und die Steuereinnahmen so auf die verschiedenen Verwendungszwecke zu verteilen, daß von der gewählten Zusammensetzung ihres Budgets die größtmögliche Attraktionskraft auf mobile Faktoren ausgeht. (237)

Hier werden drei mögliche Strategien der Gemeinden auf ihre Wirksamkeit als Attrahierungsinstrument untersucht:

- Senkung der Steuerbelastung für die Unternehmen bei gleichzeitiger Erhöhung der Steuerbelastung für die Haushalte,

- Erhöhung der Transferzahlungen an Unternehmen bei gleichzeitiger Verringerung der Transferzahlungen an Haushalte,

- Erhöhung des kommunalen Leistungsangebots zugunsten der Unternehmen bei gleichzeitiger Einschränkung des haushaltsorientierten Leistungsangebots. 


\subsubsection{Variation der Einnahmenstruktur}

\subsubsection{Die angestrebte Standortwirkung}

Eine Gemeinde kann versuchen, durch eine Variation ihrer Steuerstruktur ihre Attraktionskraft auf Investoren zu erhöhen. Dazu müßte sie die steuer liche Belastung der Unternehmen reduzieren und zum Ausgleich des Steuerausfalls die Steuerbelastung der Haushalte erhöhen. Diese Verschiebung der kommunalen Steuerstruktur bewirkt, daß die einzelnen Unternehmen in der betrachteten Gemeinde steuerlich schwächer belastet werden als die Unternehmen in allen anderen Gemeinden. (238) Von diesem regionalen Steuerbelastungsgefälle verspricht sich die Gemeinde eine Belebung der Investitionstätigkeit ortsansässiger und ortsfremder Investoren, durch die die lokale Konzentration wirtschaftlicher Aktivitäten erhöht würde. Im Verlauf des so induzierten räumlichen Verdichtungsprozesses könnten dann für die privaten Wirtschaftssubjekte verstärkt Möglichkeiten zur Ausnutzung externer und interner Ersparnisse (Agglomerationsvorteile) entstehen, (239) durch die die Produktivität der ansässigen bzw. neu angesiedelten Betriebe gesteigert und ihre Gewinnsituation verbessert würde. Auf diese Weise könnte ein sich selbst tragender lokaler Wachstumsproze $\beta$ in Gang gesetzt werden, in dessen Verlauf die örtliche Steuerkraft stiege und die anfänglich gewährten steuerlichen Vergünstigungen für die Unternehmen überflüssig würden. (240)

\subsubsection{Bestimmungsfaktoren der Wirksamkeit}

\subsection{Das Verhalten der anderen Kommunen}

Reagieren die anderen Kommunen auf diese unternehmensfreundliche Steuerreform der betrachteten Gemeinde gleichgerichtet, also mit einer Anpas sung ihrer Steuerstruktur, so entsteht überhaupt kein Steuerbelastungsgefälle zugunsten der autonom handelnden Gemeinde. Ihr ist es damit auch nicht ge lungen, wenigstens für einige Unternehmen ein regionales Gewinngefälle herbeizuführen, durch das die Investitionskraft der örtlichen Unternehmen ge stärkt und Gewerbebetriebe attrahiert werden könnten.

$\mathrm{Ob}$ ein solches Parallelverhalten aller oder der meisten Kommunen als Reaktion auf eine steuerliche Entlastung der Unternehmen und gleichzeitig höherer Steuerbelastung der Haushalte in einer Gemeinde eintreten wird, muß wohl im jeweiligen konkreten Fall empirisch geprüft werden. Immerhin kann festgestellt werden, daß ein solches Verhalten der Kommunen in der Realität anzutreffen ist (241) und auch relativ plausibel erscheint. Es kann jedenfalls nicht einfach mit dem Hinweis auf die unterstellte Finanzautonomie der Gemeinden als unwahrscheinlich abgetan werden. (242) 


\subsection{Die Reaktion der privaten Haushalte}

Kommt es überhaupt zu einem regionalen Steuerbelastungsgefälle, weil sich die Gemeinden nicht gleichgerichtet verhalten, entscheiden die Reaktionen der steuerlich stärker belasteten Haushalte, ob der so entstehende Kostenvorteil für die Unternehmen über eine längere Zeit bestehen bleibt. Die Verlage rung der Steuerlast von den Unternehmen auf die Haushalte verringert ja das verfügbare Einkommen der Haushalte. Die Haushalte können deshalb in die Gemeinden abwandern, in denen die Steuerbelastung für sie niedriger als am bisherigen Wohnort ist. Um die Arbeitskräfte am Ort zu halten, müßten in diesem Fall die Unternehmen als Ausgleich für den Verlust an Nettoeinkommen ihren Arbeitskräften höhere Bruttoentgelte zahlen. Damit hätte auf der Kostenseite der Unternehmen lediglich eine Substitution zweier Kostenfaktoren stattgefunden. Die Standortbedingungen in der Gemeinde mit niedrigerer Steuerbelastung der Unternehmen wären nicht oder nur geringfügig verbessert. (243)

Diese Reaktion kommt aber nur zustande, wenn die Arbeitskräfte eine hohe regionale Mobilität aufweisen, (244) die nicht einfach als gegeben unterstellt werden darf. Vielmehr sprechen Beobachtung und Plausibilität für eine recht geringe regionale Mobilität des Faktors Arbeit. Die Abwanderung an den Ort geringerer steuerlicher Belastung ist für die Arbeitskräfte u.a. mit der Aufgabe vertrauter Lebensverhältnisse, möglicherweise dem Verkauf von Grundund Hausbesitz, teilweise mit erheblichen Umzugskosten und dem Risiko der Arbeitsplatzsuche verbunden. Die regionalen Steuerbelastungsunterschiede müssen schon sehr groß sein, bei gleichzeitig geringen regionalen Unterschieden im Arbeitsplatzangebot und in der Versorgung mit öffentlichen Gütern, wenn ein Nichtunternehmer Kosten und Mühen eines Wohnortwechsels auf sich nehmen soll. Da man also eine relativ geringe regionale Mobilität der Nichtunternehmer unterstellen muß, (245) wird die erhöhte Steuerbelastung der Haushalte kaum in Form höherer Löhne auf die Unternehmen überwälzt.

Senkt eine Gemeinde die Steuerbelastung der in ihr ansässigen Unternehmen bei gleichzeitiger Erhöhung der Steuerbelastung der Haushalte, wird die so für die Unternehmen bewirkte Kostensenkung nicht oder nur geringfügig durch einen Anstieg der Arbeitskosten kompensiert, so daß die Verbesserung der Standortbedingungen längerfristig bestehen bleiben könnte. (246)

2.3.2.2.3. Die Einschätzung der Dauerhaftigkeit der Standortvorteile durch die Investoren

Aber auch, wenn infolge der geringen regionalen Mobilität der Arbeitskräfte die steuerlich bedingte Verbesserung der Gewinnsituation über eine längere Zeitspanne bestehen bleiben könnte, liegt damit noch keine hinreichende $\mathrm{Be}-$ dingung für eine erhöhte Investitionstätigkeit am Ort der niedrigeren Steuerbelastung der Unternehmen vor. Ob es zu dem erwünschten Kapitalzustrom in die Gemeinde kommt, hängt vielmehr entscheidend davon $a b$, ob die stand- 
ortsuchenden Investoren die von der Kommune geschaffenen Standortvorteile als irreversibel ansehen. Dies ist dann der Fall, wenn eine Gemeinde die von ihr geschaffenen Standortvorteile nicht kurzfristig und jederzeit nach eigenem Ermessen wieder aufheben kann. Da die Standortentscheidung "in der Regel auf lange Sicht getroffen wird, werden steuerliche Erwägungen .. nur dann eine wichtige Rolle spielen, wenn man annehmen kann, daß das derzeitige Belastungsgefälle auch auf lange Sicht bestehen bleibt. "(247)

Gerade aber steuerpolitische Maßnahmen sind in hohem Maße reversibel. Für den standortsuchenden Investor ist es ausgesprochen ungewi $\beta$, wie lange der durch steuerpolitische Maßnahmen geschaffene Standortvorteil bestehen bleibt. (248) Dies ist der Grund, weswegen "sich die steuerlichen Unterschiede auf Standortwahl und/oder -verlegung nur wenig auswirken dürften. "(249)

\subsection{Das Steuerobjekt der Steuer, deren Tarif geändert werden soll}

Nehmen wir an, daß die steuerlichen Standortvorteile von den Investoren als relativ irreversibel eingeschätzt werden. Dann bestimmt ein weiterer Faktor die Wirksamkeit einer Steuersatzsenkung, nämlich das Steuerobjekt der Steuer, deren Tarif geändert wird.

In der Regel haben alle Betriebe bestimmte Kostenelemente vorzuweisen. Deshalb entlastet die Steuersatzsenkung einer Steuer, die an diese Kostenelemente anknüpft, alle ansässigen Betriebe, auch diejenigen, die sich gerade in der Gemeinde angesiedelt haben. Demgegenüber entlastet eine Tarifänderung von gewinnabhängigen Steuern nur die Betriebe, die überhaupt einen Gewinn erzielen. (250) Gerade bei Neugründungen von Betrieben mu $\beta$ man aber häufig davon ausgehen, daß in der Anlaufzeit Verluste entstehen. Diese Unternehmen müssen sich dann erst aus eigener Kraft in die Gewinnzone bringen, bevor sie vom regionalen Steuerlastgefälle profitieren. (251) In der Zwischenzeit können sie aber bereits in solche Liquiditätsschwierigkeiten geraten, daß sie sich aus Furcht davor gar nicht erst zur Ansiedlung bereit finden oder wieder zur Abwanderung gezwungen sehen, auch wenn sie sich auf lange Sicht von diesem Standort Gewinnvorteile versprechen. Eine lokale Konzentration wirtschaftlicher Aktivitäten, in deren Verlauf externe und interne Ersparnisse anfallen und die Steuervergünstigungen überflüssig machen, kommt dann gar nicht erst zustande.

Die Gefahr gleich'gerichteten Verhaltens anderer Kommunen, mögliche Ausweichreaktionen der Haushalte, der Einfluß des Steuerobjekts, besonders aber die hohe Reversibilität steuerpolitischer Entscheidungen lassen es ziemlich unwahrscheinlich erscheinen, daß eine Gemeinde mit einer steuerlichen Entlastung der Unternehmen und gleichzeitiger steuerlicher Mehrbelastung der Haushalte mobile Ressourcen attrahieren kann. Steuerliche Vergünstigungen für Unternehmen werden bei der Standortentscheidung der Investoren in der Regel nur zwischen sonst gleichwertigen Standorten den Ausschlag geben. Ihnen kommt deshalb im Rahmen der kommunalen Attrahierungspolitik bestenfalls eine "subsidiäre Funktion"(252) zu. 


\subsubsection{Variation der Ausgabenstruktur}

"Bei gleicher Höhe der Pro-Kopf-Ausgaben in den Regionen (Ländern) [bzw. Gemeinden, F. T.] kann die Ausgabenstruktur auf private Haushalte und Unternehmen anziehend oder abstoßend wirken."(253) Dabei hat die einzelne Kommune vor allem zwei grundsätzliche Möglichkeiten, die Standortbedingungen für Gewerbebetriebe im Vergleich zu anderen Kommunen zu verbessern:

- Transferzahlungen an Haushalte (Sozialleistungen) werden verringert, die an Unternehmen (Subventionen) im selben Ausmaß erhöht. (254)

- Kommunale Leistungen zugunsten der Haushalte werden eingeschränkt, so daß Finanzmittel frei werden, mit denen das Angebot kommunaler Leistungen zugunsten der Unternehmen ausgeweitet werden kann.

Die Wirksamkeit dieser ausgabenpolitischen Maßnahmen als Instrumente der kommunalen Attrahierungspolitik wird anschließend untersucht.

\subsubsection{Substitution von Sozialleistungen durch Subventionen}

Um die Wirksamkeit dieser ausgabenpolitischen Maßnahmen zu beurteilen, müssen im wesentlichen dieselben Überlegungen angestellt werden wie zur Frage der Wirksamkeit der Strukturänderung auf der Einnahmenseite:

- Ebenso wie mit der steuerlichen Entlastung von Unternehmen versucht die Gemeinde durch zusätzliche Transferzahlungen an Unternehmen "korrespondierende Investitionen privater Unternehmungen und der öffentlichen Hand [zu] induzieren und damit neue Quellen für externe Kostenersparnisse [zu] erschließen. "(255) Es sollen also auf indirektem Wege verstärkt Möglichkeiten zur Ausnutzung externer und interner Ersparnisse in der Gemeinde und damit die Basis für einen sich selbst tragenden Wachstumsprozeß geschaffen werden, in dessen Verlauf die Subventionie rung der Unternehmen überflüssig wird.

- Auch bei dieser Strategie muß die Gemeinde befürchten, daß sich die anderen Gemeinden gleichgerichtet verhalten und daß die Arbeitskräfte, deren verfügbares Einkommen infolge der Kürzung der Sozialleistungen gesunken ist, in andere Gemeinden abwandern. Beide Reaktionen verhindern, daß den Unternehmen überhaupt und dazu noch längerfristige Standortvorteile von der Gemeinde geboten werden können. Doch läßt die weiter unten diskutierte Beziehung (256) zwischen Steuerkraft und Ausgabenstruktur einer Gemeinde vermuten, daß vielen Gemeinden ein gleichgerichtetes Verhalten infolge mangelnder Finanzkraft nicht möglich ist, auch wenn es ihnen zur Erhaltung ihrer Wettbewerbsfähigkeit wünschens wert erscheint. Außerdem kann bei Empfängern von Sozialleistungen, die häufig den unteren Einkommens - und Bildungsschichten angehören, eine besonders geringe regionale Mobilität angenommen werden. Aus diesen beiden Gründen hat eine Gemeinde eine reelle Chance, durch zusätzliche Subventionen bei gleichzeitig verminderten Sozialleistungen ihre Standortqualität auch längerfristig im Vergleich zu anderen Gemeinden zu verbessern. 
- Die Reversibilität dieser ausgabenpolitischen Vergünstigung ist eher noch höher als die der steuerpolitischen Vergünstigung einzuschätzen. Einmal werden Subventionen in Form direkter Zahlungen an Unternehmen (offene Subventionen) regelmäßiger auf ihre Berechtigung überprüft als Subventionen in Form steuerlicher Vergünstigungen (verdeckte Subventionen) $(257,258)$. Zum anderen ist bei der Kürzung von offenen Subventionen in der Regel mit weniger Widerstand der Betroffenen und der Öffentlichkeit zu rechnen. Werden nämlich steuerliche Vergünstigungen aufgehoben, erscheint dies den Betroffenen und der Öffentlichkeit häufig als zusätzliche Belastung in Form einer Steuererhöhung. Dagegen wird eine Kürzung direkter Zahlungen an Unternehmen oft nur als Wegfall von Vergünstigungen empfunden und kann der Öffentlichkeit nicht als zusätzliche Belastung glaubhaft gemacht wenden. Offene Subventionen sind also beherrschbarer als verdeckte Subventionen.

Der hohe Grad der Reversibilität dieser ausgabenpolitischen Vergünstigung macht es unwahrscheinlich, daß Investoren ihre Standortentscheidung überwiegend an regionalen Unterschieden hinsichtlich offener Subventionen ausrichten, auch wenn dadurch ein regionales Kosten-bzw. Gewinngefälle verursacht wird.

- Im Gegensatz zu den steuerlichen Vergünstigungen ist die Wirksamkeit der offenen Subventionen nicht an die Existenz von Gewinnen gebunden. Lediglich aus diesem Grund könnte man diesem Instrument eine größere Eignung als Instrument der Attrahierungspolitik der Gemeinden zubilligen.

Substituiert eine Gemeinde Transferzahlungen an Haushalte durch Transferzahlungen an Unternehmen und gewährt sie damit den ortsansässigen Unternehmen absolut höhere offene Subventionen als andere Gemeinden, (259) kann sie nicht ohne weiteres erwarten, auf diese Weise einen stärkeren Einfluß auf die Standortentscheidung der Investoren auszuüben als mit der entsprechenden steuerpolitischen Strategie. Die absolut höheren offenen Subventionen werden ebenso wie eine niedrigere Steuerbelastung, wenn überhaupt, nur dann bei der Investitionsentscheidung eines Investors den Ausschlag zugunsten der betreffenden Gemeinde geben, wenn sich alle übrigen Standortbe dingungen nicht wesentlich gegenüber alternativen Standorten unterscheiden. Allein durch höhere Subventionen jedenfalls wird eine Kommune kaum die Raumstruktur zu ihren Gunsten beeinflussen können. (260)

2.3.3.2. Substitution haushaltsorientierter Infrastrukturleistungen durch unternehmensorientie rte Infrastrukturleistungen

Die Untersuchung über die Determinanten des räumlichen Differenzierungsprozesses hat gezeigt, daß sich mit zunehmender wirtschaftlicher Entwicklung und Arbeitsteilung die Standortentscheidungen der privaten Investoren immer stärker an der regionalen Verteilung der Möglichkeiten, externe und interne Ersparnisse auszunutzen, orientieren.(261) Für die sogenannten "footloose industries" sind die externen und internen Ersparnisse bereits "die entscheidenden Standorteigenschaften"(262) geworden. Diese notwen- 
digen Standorterfordernisse und Bedingungen eines sich selbst tragenden Wachstumsprozesses können die einzelnen Gemeinden einmal in indirekter Weise beeinflussen. Diese Möglichkeit ist im Zusammenhang mit den beiden subventionspolitischen Strategien dargestellt und als wenig erfolgversprechend beurteilt worden. Zum anderen können die Kommunen in direkter Weise für externe und interne Ersparnismöglichkeiten sorgen, denn ihre Investitionen in die Infrastruktur sind eine "wesentliche Quelle der so entscheidenden externen Effekte".(263)

\subsection{Die angestrebte Standortwirkung}

Die beiden wichtigsten der vielfältigen Wirkungen von Infrastrukturmaßnahmen (264), der indirekte Produktivitätseffekt und der direkte Wohlstands effekt, stehen hier im Mittelpunkt des Interesses.

Der indirekte Produktivitätseffekt mißt "die externen Effekte, welche durch eine Investition zugunsten anderer Bereiche oder Unternehmungen geschaffen werden und sich dort in Kostensenkungen beziehungsweise Produktivitätssteigerungen auswirken, ohne daß der Investor dafür entschädigt wird. Der indirekte Produktivitätseffekt ist der mit den melsten Infrastrukturinvestitionen beabsichtigte Zweck. "(265) Dieser Effekt geht von Leistungen der unternehmensorientie rten Infrastruktur (Produktivinfrastruktur) aus. Diese Leistungen werden den Unternehmen von der öffentlichen Hand unentgeltlich oder zu nicht kostendeckenden Preisen zur Verfügung gestellt und substituieren Vorleistungen, die sonst von den Produzenten selbst erstellt werden müßten.

"Der direkte Wohlstandseffekt .. besteht darin, daß gewisse Investitionen ... Kapitalgüter schaffen, welche von privaten Haushalten unmittelbar genutzt werden können. "(266) Dieser Effekt ist mit Leistungen der haushalts orientierten Infrastruktur (Konsumtivinfrastruktur) verbunden. Ihre Leistungen haben Konsumgutcharakter und stellen einen Bestimmungsfaktor des nicht-monetären Haushaltseinkommens dar. (267)

Diese unterschiedlichen Wirkungen der Infrastruktur kann sich eine Kommune zunutze machen, wenn sie Gewerbebetriebe attrahieren will. $\mathrm{Zu}$ diesem Zweck müßte sie ihr Angebot an haushaltsorientierten Leistungen reduzieren. Mit den freiwerdenden Ressourcen könnte sie dann ihr Angebot an Infrastrukturleistungen zugunsten der Unternehmen erhöhen, so daß sie den ansässigen Unternehmen absolut mehr kostensenkende Vorleistungen bietet als andere Gemeinden. Bei gegebener örtlicher Nachfrage nach unternehmensorientierten Infrastrukturleistungen schafft die Gemeinde damit einen Infrastrukturüberschuß. Sie hofft, dadurch so viel wirtschaftliche Aktivitäten zu attrahieren und in der Region zur Entfaltung zu bringen, daß die aktuelle Nachfrage nach Infrastrukturleistungen auf das Niveau des vorhandenen Angebots steigt, (268) die lokale Steuerkraft erhöht wird und so in der Zukunft einen Ausbau auch der haushaltsorientierten Infrastruktur erlaubt. Dieser Anreizeffekt könnte dadurch zustande kommen, daß die Ausdehnung des infrastrukturellen Leistungsangebots den betroffenen Unternehmen Preissenkungen erlaubt und ihre Gewinne erhöht. Es tritt "eine Verbesserung der Wettbewerbs- 
bedingungen gegenüber Konkurrenten [ein], die sich im erhöhten Absatz, Senkung der Stückkosten durch Mehrproduktion und Mehrabsatz, besseren Möglichkeiten der Selbstfinanzierung und damit zur Forschung nach technischem Fortschritt äußern kann. "(269, 270) Der erhoffte Attrahierungseffekt soll also bei dieser Strategie von einem regionalen Leistungsgefälle ausgehen.

\subsection{Bestimmungsfaktoren der Wirksamkeit}

Die Wirksamkeit dieser ausgabenpolitischen Attrahierungsstrategie hängt in erster Linie wieder von den Faktoren ab, die im Zusammenhang mit der Variation der Einnahmenstruktur diskutiert worden sind.

\subsection{Das Verhalten der anderen Kommunen}

Eine Parallelreaktion der anderen Kommunen würde verhindern, daß die autonom handelnde Gemeinde überhaupt absolut mehr unternehmensorientierte Infrastrukturleistungen als andere Kommunen anbieten und so ein regionales Leistungsgefälle zu ihren Gunsten schaffen kann. Die Ausdehnung des Leistungsangebots zugunsten der Unternehmen würde somit auch nicht die Standortqualität dieser Gemeinde im Vergleich zu den anderen Gemeinden verbessern.

Doch ist ein solches Parallelverhalten der übrigen Kommunen wesentlich unwahrscheinlicher als im Fall der steuerpolitischen Attrahierungsstrategie. Einmal kann man davon ausgehen, daß die Transparenz einer Steuerstrukturänderung für die Gemeinden größer ist als diejenige einer Verschiebung des Infrastrukturleistungsangebots. Wenn die Mehrzahl der Gemeinden gar nicht bemerkt, daß eine einzelne Gemeinde ihr unternehmensorientiertes Leistungs angebot erhöht, können sie sich aber auch nicht gleichgerichtet verhalten.

Aber auch, wenn die Kommunen gleichermaßen gut über steuerpolitische wie über ausgabenpolitische Attrahierungsmaßnahmen einer einzelnen Gemeinde informiert sind, scheint vielen Kommunen eine Anpassung ihres Leistungsangebots an das der autonom handelnden Gemeinde unmöglich. Dieser Tatbestand resultiert aus der Abhängigkeit der Ausgabenstruktur einer Gemeinde von der absoluten Höhe ihrer Steuerkraft. Dieser Zusammenhang wird weiter unten eingehender diskutiert. (271)

\subsection{Die Reaktion der privaten Haushalte}

Die Reduzierung des haushaltsorientierten Infrastrukturleistungsangebots bedeutet für die Haushalte eine Verringerung ihres verfügbaren Realeinkommens. (272) Reagieren sie darauf mit einer Verlagerung ihres Wohnsitzes in Gemeinden mit größerem Angebot haushaltsorientierter Leistungen, werden die Unternehmen zu Kompensationszahlungen in Form höherer Bruttoarbeits entgelte gezwungen. Ihre Kostensituation hätte sich damit kaum oder gar nicht im Verhältnis zu anderen Standorten verbessert. 
Nun kommt aber eine solche Überwälzung nur bei hoher regionaler Mobilität des Faktors Arbeit zustande. Die Diskussion im Zusammenhang mit den beiden subventionspolitischen Attrahierungsstrategien hat jedoch gezeigt, daß eine Reihe von Gründen für die Vermutung einer recht geringen regionalen Mobilität der Arbeitskräfte spricht.

Im Zusammenhang mit der Einschränkung des haushaltsorientierten Leistungsangebots durch eine Kommune kommt noch ein weiterer Faktor hinzu, der eine Abwanderung und Überwälzung der Nutzeneinbuße in Form höherer Bruttoarbeitsentgelte unwahrscheinlich macht: Die "'Geldillusion' der Haushalte in Bezug auf ihr verfügbares Realeinkommen [dürfte] bei Ausgabenänderungen beträchtlich stärker sein .. als bei Steueränderungen. "(273) Eine Steuererhöhung schlägt sich für den Haushalt am Ende der Wirtschaftsperiode sichtbar in einer Verringerung seines verfügbaren Geldeinkommens nieder. Dagegen ist die Nutzeneinbuße infolge verringerten Leistungsangebots für ihn in der Regel unmerklich. Wird sie aber nicht oder nur unvollständig wahrgenommen, kann auch keine Ausweichreaktion erfolgen.

Soweit Überwälzungsprozesse unbeachtet bleiben oder nicht eintreten, können also "relative Standortpräferenzen für diejenigen Kommunen abgeleitet werden, die vergleichsweise mehr als andere Gemeinden Vorleistungen an die Industrie als an die Endnachfrage abgeben".(274)

\subsection{Die Einschätzung der Dauerhaftigkeit der Standortvorteile durch die Investoren}

Investoren werden nur dann bereit sein, in einer Gemeinde $\mathrm{zu}$ investieren, wenn sie die langfristigen Entwicklungsmöglichkeiten ihres Unternehmens in dieser Gemeinde günstiger einschätzen als in anderen Gemeinden. Deshalb ist für den Erfolg einer Attrahierungsstrategie entscheidend, ob die Investoren die von der Gemeinde geschaffenen Standortvorteile als langfristig, als relativ irreversibel einschätzen. Bei Standortvorteilen in Form höherer (offener und verdeckter) Subventionen ist es für die Investoren höchst ungewiß, wie lange dieser Standortvorteil bestehen bleibt, denn die Gemeinde kann die zusätzlichen Vergünstigungen jederzeit wieder rückgängig machen. Anders verhält es sich dagegen mit Standortvorteilen, die durch einen Aus bau der unternehmensorientierten Infrastruktur entstehen. Sie können nicht ohne weiteres, wenn sie einmal geschaffen worden sind, wieder aufgehoben werden. "Vorleistungen in Form von Investitionen der Öffentlichen Hand, deren Nutznießer Unternehmungen sind, bleiben während der gesamten Lebensdauer [der Infrastrukturinvestition, F.T.] wirksam, so daß sie in dieser Hinsicht 'standortwirksamer' sind"(275) als subventionspolitische Vergünstigungen.

Die geringe Wahrscheinlichkeit von gleichgerichtetem Verhalten aller übrigen Kommunen und von Ausweichreaktionen der Haushalte begründet die Vermutung, daß eine Gemeinde dauerhafte Standortvorteile schaffen kann, wenn sie absolut mehr unternehmensorientierte Infrastrukturleistungen pro Einwohner anbietet als andere Gemeinden. Der hohe Grad an Irreversibilităt 
der so geschaffenen Standortvorteile sorgt dafür, daß diese Standortvorteile in die Standortkalkulation der Investoren eingehen und sich ihre Standortentscheidung stärker an regionalen Unterschieden im unternehmensorientierten Leistungsangebot orientiert als z. B. an regionalen Unterschieden in der Steuerbelastung.

\subsection{Die Basisfunktion der Infrastruktur .}

Bei der Überlegung, welchem finanzpolitischen Instrument die größte Attraktionskraft und damit im Rahmen einer Attrahierungspolitik der Vorrang einzuräumen ist, muß noch ein weiterer Gesichtspunkt berücksichtigt werden. Ohne eine Mindestausstattung mit bestimmten Infrastruktureinrichtungen ist eine wirtschaftliche Betätigung an einem Ort entweder gar nicht oder nur zu so hohen Kosten möglich, daß sie sich nicht lohnt. Infrastruktur ist eine notwendige Voraussetzung wirtschaftlicher Aktivitäten. In diesem Sinne hat die Infrastruktur eine Grundlagen- $(276)$ bzw. Basisfunktion (277) für die wirtschaftliche Entwicklung einer Region zu erfüllen. Erst wenn die erforderlichen infrastrukturellen Voraussetzungen für ökonomische Aktivitäten geschaffen sind, kann eine Gemeinde an den Einsatz anderer finanzpolitischer Attrahierungsinstrumente denken. (278)

\subsubsection{Die Bedeutung der haushaltsorientierten Infrastruktur als Attrahie rungsinstrument}

Mit ihrer Basisfunktion und großen Wirksamkeit kann der Vorrang der unternehmensorientierten Infrastrukturmaßnahmen gegenüber allen anderen finanzpolitischen Attrahierungsmaßnahmen der Gemeinden begrüdet werden. Nun entwickelt sich aber die Verfügbarkeit von Arbeitskräften, insbesondere solchen mit hoher Qualifikation, an einem Ort zu einem immer bedeutenderen Standortfaktor. Zugleich hängt die Wohnortwahl sowohl der Unternehmerals auch der Nichtunternehmerhaushalte außer von den Einkommenserzie lungsmöglichkeiten am Ort auch sehr stark vom lokalen Angebot an Infrastrukturleistungen ab. (279) Deshalb werden auch haushaltsorientierte Infrastrukturmaßnahmen ein wichtiges Instrument der kommunalen Attrahierungs politik. (280)

Doch sind nicht alle haushaltsorientierten Infrastrukturleistungen gleichermaßen als Instrument der kommunalen Attrahierungspolitik wirksam. Im wesentlichen werden nur solche Leistungen als Attrahierungsinstrument geeignet sein, die Wirtschaftssubjekten zugute kommen, die sich des Wohlstandseffekts dieser Leistungen bewußt sind und zugleich eine hohe regionale Mobilität aufweisen. Eine Erhöhung der Infrastrukturleistungen zugunsten der Haushalte von Rentnern oder einkommensschwachen Arbeitnehmern wird folglich so gut wie gar nicht die Standortqualität einer Gemeinde verbessern. (281) Wird im folgenden davon ausgegangen, daß "Infrastruktureinrichtungen ... sowohl als unmittelbar wie als mittelbar produktionsrelevante Ressourcen auch 
strategische Größen im regionalen Wettbewerb um knappe mobile Produktions faktoren"(282) und damit "die entscheidende Methode einer regionalen Entwicklungspolitik"(283) sind, so bezieht sich diese Aussage nicht auf alle Infrastrukturmaßnahmen. Sie gilt in erster Linie für alle unternehmensorientierten und solche haushaltsorientierten Leistungen, die in erheblichem Maße die Wohnortwahl der Unternehmer und hochqualifizierten Arbeitnehmer bestimmen.

\subsubsection{Empfehlungen für eine kommunale Attrahierungsstrategie}

Aus den bisherigen Überlegungen ergibt sich in groben Zügen folgende Empfehlung für eine kommunale Attrahierungsstrategie:

Eine Gemeinde, die ihre Wirtschafts- und Steuerkraft im Vergleich zu anderen Kommunen erhöhen will, muß versuchen, absolut mehr Infrastruktur leistungen zugunsten der Unternehmen und der Haushalte der oberen Statusschichten anzubieten als andere Kommunen. Dieses verstärkte Leistungs angebot kann sie im wesentlichen finanzieren (284)

- durch Einschränkung der Transferzahlungen und Leistungsabgabe an immobile Haushalte (bei konstantem Niveau ihrer Aktivität),

- durch schwerpunktmäßige Verwendung der wachstumsbedingten Steuer mehreinnahmen für die attraktivitätsfördernden Ausgaben (bei unveränderter Steuerbelastung) und

- durch stärkere Steuerbelastung der ortsansässigen Haushalte und Verwendung der zusätzlichen Steuereinnahmen überwiegend für den Ausbau der attrahierend wirkenden Teile der Infrastruktur (Niveau - und Strukturvariation). $(285,286)$

Subsidiär und simultan zu dieser Infrastrukturpolitik sollten die Gemeinden den Unternehmen Starthilfen in Form offener oder verdeckter Subventionen gewähren. Diese haben vor allem die Aufgabe, Liquiditätsschwierigkeiten zu vermeiden, die neuangesiedelten Betrieben durch Verluste in der Anlaufphase entstehen und die Ansiedlung verhindern oder die Einstellung der neuaufgenommenen Produktion erzwingen können. Diese Subventionen kann man auch als finanzielle Abgeltung der positiven externen Effekte, die von den sich ansiedelnden Betrieben nachfolgenden Betrieben verursacht werden, begründen. $(287,288)$

Anschließend ist nun zu untersuchen, wovon die absolute Höhe der Ausgaben einer Kommune für die oben aufgeführten attraktivitätsfördernden Infrastrukturleistungen abhängt. Von dieser Determinante wird damit bestimmt, ob alle oder nur bestimmte Gemeinden eine wirksame Attrahierungspolitik betreiben können. 
2.3.5. Die Bedeutung der Steuerkraft für die Attrahierungsmöglichkeiten der einzelnen Gemeinden

\subsubsection{Klärung der Voraussetzungen}

Bisher wurden gleich hohe Pro-Kopf-Einnahmen und Pro-Kopf-Ausgaben für alle Gemeinden unterstellt. Unter dieser Annahme besitzt diejenige Gemeinde Vorteile im Attrahierungswettbewerb um mobile Ressourcen, die von allen Gemeinden den größten Anteil ihrer Pro-Kopf-Ausgaben für Infrastrukturleistungen verwendet und damit absolut höhere Infrastrukturleistungen anbietet als alle anderen Gemeinden. (289) Die absolute Höhe der Pro-KopfAusgaben für attrahierend wirkende Leistungen und damit das regionale Leistungsgefälle (290) hängen unter den gemachten Voraussetzungen ausschließlich von den autonomen politischen Entscheidungen der einzelnen Kommunen ab.

In der Realität hängt die Attraktionskraft der einzelnen Kommune von zwei Faktoren, einem objektiven und einem subjektiven, ab: Die finanzielle Ausstattung einer Gemeinde bestimmt als objektiver Faktor, welche Möglichkeiten eine Gemeinde überhaupt besitzt, attrahierend zu wirken. (291) Von ihrer politischen Entscheidung hängt es dann ab, wie sie die ihr gegebenen Möglichkeiten tatsächlich nutzt. (292)

Um den Einfluß der finanziellen Ausstattung einer Kommune auf ihre Attrahierungsmöglichkeiten isoliert aufzeigen zu können, wird davon ausgegangen, daß zwischen den Gemeinden keine Unterschiede in der Steueranspannung bestehen. Außerdem wird auch weiterhin die Möglichkeit der Kreditfinanzierung ausgeschlossen. Damit bestimmt allein die kommunale Steuerkraft, in welcher absoluten Höhe eine Gemeinde pro Einwohner Ausgaben für attraktivitätsfördernde Zwecke leisten kann.

2.3.5.2. Der Einfluß der Steuerkraft auf die absolute Höhe der attraktivitätsfördernden Ausgaben

Die absolute Höhe der Steuerkraft einer Gemeinde determiniert in zweifacher Weise die absolute Höhe der Ausgaben einer Gemeinde für attraktivitätsför dernde Zwecke:

- Bei gleicher Ausgabenstruktur aller Gemeinden ist die absolute Höhe der Infrastrukturausgaben umso größer, je höher die lokale Steuerkraft ist. Parallel zum regionalen Steuerkraftgefälle verläuft also auch ein Gefälle im kommunalen Leistungsangebot.

- Je größer die lokale Steuerkraft ist, desto größer kann der Anteil der attraktivitätsfördernden Ausgaben, also insbesondere der Infrastrukturausgaben, an den Gesamtausgaben sein.

Diesen Zusammenhang zwischen Ausgabenstruktur und absoluter Höhe der Steuerkraft kann man folgendermaßen erklären: 
Jede Gemeinde hat, unabhängig von ihrer Größe und Steuerkraft, bestimmte Mindestleistungen für ihre Bürger zu erbringen. Durch dieses Minimum an öffentlicher Aktivität schafft die Gemeinde die Voraussetzungen für das Zusammenleben von Menschen an einem Ort und sichert allen Gemeindebürgern das kulturelle Existenzminimum. Das Volumen dieser Pflichtaufgaben ist relativ unantastbar. (293) Zur Erfüllung dieser Aufgaben entsprechend bestimmter Mindeststandards werden alle Gemeinden in etwa gleich hohe ProKopf-Beträge aufwenden müssen. (294) Erst wenn die einzelne Gemeinde diese primär haushaltsorientierten Leistungen in befriedigender Weise erbracht hat, kann sie die ihr noch verbleibenden Finanzie rungsmittel nach eigenem Ermessen für freie Aufgaben einsetzen. Nur dieser Mobilitätsanteil an den Steuereinnahmen, der als "kommunalstrategisch verwendbare Finanzreserve" $^{\prime \prime 295) ~ z u ~ v e r s t e h e n ~ i s t, ~ s t e h t ~ a l s o ~ d e r ~ G e m e i n d e ~ f u ̈ r ~ Z w e c k e ~ z u r ~ V e r-~}$ fügung, von denen sie eine attrahierende Wirkung auf mobile Ressourcen erwartet. (296)

Besitzt nun eine Gemeinde eine sehr niedrige Steuerkraft, so reichen die ihr zufließenden Steue reinnahmen möglicherweise noch nicht einmal aus, um ihre Pflichtaufgaben in befriedigender Weise zu erfüllen. Sie wird deshalb gar keine oder nur geringfügige Leistungen zugunsten des Unternehmenssektors finanzieren können. (297) Auch etwaige wachstumsbedingte Steuermehreinnahmen wird sie schwergewichtig dafür einsetzen müssen, ihre Pflichtaufgaben entsprechend den allgemeinen Standards zu erfüllen.

Gemeinden mit hoher Steuerkraft können dagegen die Steuereinnahmen, die diesen zur Erfüllung der Pflichtaufgaben erforderlichen Sockelbetrag übersteigen, in vollem Umfang für attraktivitätsfördernde Zwecke ausgeben. Je höher die kommunale Steuerkraft ist, desto größer sind absolut und relativ die Ausgaben für diese freien Aufgaben. Die Ausgabenstruktur einer Gemeinde ist also eine Funktion der absoluten Höhe ihrer Steuerkraft. (298, 299)

Damit ergibt sich folgendes Ergebnis:

"Je höher das Steueraufkommen pro Einwohner einer Gemeinde ist, desto mehr Ausgaben pro Einwohner kann sie tätigen, und umso größer ist auch die Wahrscheinlichkeit, daß sie eine bessere Infra-Struktur anzubieten vermag [als Gemeinden mit niedrigerer Steuerkraft, F.T.]. Das bedeutet aber auch: Je höher das örtliche Steueraufkommen pro Kopf ist, desto eher wird eine Gemeinde in der Lage sein, neue Industrien zu attrahieren, die wiederum potentielle Steuerzahler darstellen. "(300)

Die Steuerkraft "bestimmt ... die ausgabenpolitischen Freiheitsgrade (über den Mobilitätsanteil) und damit die Intensität kommunaler Attrahierungs maßnahmen". (301) Sie ist "ein unmittelbarer Gradmesser für die wirtschafts fördernde Aktivität der Gemeinden"(302) (genauer: für die Möglichkeiten zu wirtschaftsfördernden Aktivitäten), "der wichtigste Anhaltspunkt für den möglichen Umfang der Bereitstellung öffentlicher Leistungen"(303) durch die Kommunen.

Aufgrund dieser Zusammenhänge wird in dieser Arbeit davon ausgegangen, daß die wichtigsten raumwirtschaftlichen Wirkungen der Aktivität der öffent- 
lichen Hände, außer von der regionalen Verteilung der staatlichen Ausgaben, von den regionalen Steuerkraftunterschieden ausgehen. (304) Dies ist auch der Grund, weshalb im empirischen Teil der Arbeit vorrangig danach gefragt wird, wie sich die finanzausgleichspolitischen Regelungen in der BRD und insbesondere ihre Modifizierung durch die Finanzreform von 1969 auf die Pro-Kopf-Steue reinnahmen der untergeordneten Gebietskörperschaften (bei einheitlicher Steueranspannung) und damit auf das regionale Steuerkraftgefälle auswirken.

2.3.5.3. Die raumwirtschaftlichen Effekte des regionalen Steuerkraftgefälles

Regionale Steuerkraftunterschiede kommen durch regionale Unterschiede in der Höhe der Bemessungsgrundlage der Steuer, die der Gemeinde in Ertrags hoheit zusteht, zustande. Da eine Gemeinde mit hoher Steuerkraft eine stärkere Attraktionskraft auf die Wirtschaftssubjekte, die den steuerlichen Tatbestand aufweisen, ausüben kann als eine steuerschwache Gemeinde, wirken Steuerkraftunterschiede auf eine räumliche Konzentration der Steuerbemessungsgrundlage und damit auf eine Verschärfung der regionalen Unterschiede in der Steuerbemessungsgrundlage hin. Dem Steuerkraftgefälle wohnt somit die Tendenz inne, sich selbst zu verstärken. Wir haben ein weiteres Beispiel für das Prinzip der zirkulären Verursachung vorliegen. (305)

Welchen konkreten Einfluß ein gegebenes Steuerkraftgefälle auf die Raumstruktur ausübt, hängt vom Steuerobjekt der kommunalen Steuer ab. Hier gehen wir davon aus, daß sich das Steuersystem der untergeordneten Gebietskörperschaften ausschließlich oder doch überwiegend aus einkommens - bzw. ertragsabhängigen Steuern zusammensetzt, so daß die Gemeinden (oder Teilstaaten) allein aus fiskalischen Gründen ein Interesse an der Expansion ihres gewerblichen Sektors haben.

Unter dieser Voraussetzung ist die kommunale Steuerkraft eine positive Funktion der lokalen Wirtschaftskraft (306), wobei je nach konkreter Ausgestaltung der einzelnen Steuern die regionalen Steuerkraftunterschiede von den regionalen Wirtschaftskraftunterschieden abweichen können. Das regionale Steuerkraftgefälle verstärkt damit die Wohlstandsunterschiede zwischen den Regionen, wodurch die Ursache für noch größere regionale Steuerkraftunterschiede in der Zukunft geschaffen ist. (307)

In diesem Zusammenhang drückt sich der ballungsfördernde Effekt eines Steuerverteilungssystems, das zu einer Parallelität von regionalem Steuerkraftgefälle und regionalem Wohlstandsgefälle führt, aus. Das auf einkommensabhängigen Steuern beruhende kommunale Steuersystem ist damit als ein Faktor identifiziert, der dazu beiträgt, daß der von naturräumlichen Faktoren der Lage und des Lagers ausgelöste räumliche Differenzierungs prozeß sich selbstverstärkende Tendenzen entwickelt. "Hat sich im Laufe der geschichtlichen Entwicklung also - gleichgültig aus welchen Ursachen ein Wohlstandsgefälle zwischen verschiedenen Gebieten herausgebildet, dann wird sich auf Grund dieser Zusammenhänge der Abstand zwischen reichen und armen Gebietskörperschaften immer weiter vergrößern; man spricht 
in diesem Sinne zutreffend von einem 'Gesetz der wachsenden Diskrepanz'."(308)

Das relative Gewicht der kommunalen Infrastrukturinvestitionen (309) läßt vermuten, daß dieser raumwirtschaftliche Effekt des kommunalen Steuersystems in seiner Bedeutung für die Eigendynamik des räumlichen Differenzierungsprozesses eher vor als nach dem raumwirtschaftlichen Effekt des zentralstaatlichen Investitionsverhaltens (310) rangiert.

2.3.5.4. Raumwirtschaftliche Wirkung des kommunalen Einnahmensystems (311) unter Berücksichtigung der kommunalen Steuersatzdifferenzierung und Kreditaufnahmemöglichkeit

Die raumwirtschaftlichen Wirkungen des kommunalen, aus einkommensabhängigen Steuern bestehenden Finanzsystems wurden bisher gleichgesetzt mit den raumwirtschaftlichen Wirkungen, die vom regionalen Steuerkraftge fälle ausgehen. Muß die Aussage über die ballungsfördernde Wirkung des kommunalen Einnahmensystems modifiziert werden, wenn a) regionale Unterschiede in der Steueranspannung und b) die Möglichkeit der Kreditaufnah me durch Kommunen zugelassen werden?

\subsection{Regionale Unterschiede in der Steueranspannung}

Die Überlegungen zur Niveauvariation kommunaler Aktivität (312) haben gezeigt, daß eine Erhöhung des kommunalen Leistungsangebots, die mit Hilfe einer Steuersatzerhöhung finanziert wird, als Attrahierungsinstrument für alle Gemeinden relativ unwirksam ist. Dazu kommt, daß infolge des $\mathrm{Zu}$ sammenhangs zwischen absoluter Höhe der Steuerkraft und der Ausgabenstruktur (313) nur die bereits steuerstarken Gemeinden in der Lage sein dürften, die zusätzlichen Steuereinnahmen überwiegend für attraktivitätsför dernde Ausgaben zu verwenden. Würden die Kommunen das Instrument der Steuersatzdifferenzierung einsetzen, wäre also eher eine Verstärkung der Ballungstendenzen zu erwarten als eine Abschwächung.

Da auch die Gemeinden in der Bundesrepublik dieses Instrument so gut wie gar nicht als Attrahierungsinstrument einsetzen, wie die geringe Streuung der Hebesätze der Gewerbesteuer zeigt, (314) kann der Einfluß der Steuersatzdifferenzierung auf die Raumstruktur hier weitgehend vernachlässigt werden.

\subsection{Die Möglichkeit der Kreditaufnahme}

Durch Aufnahme von Krediten können die Gemeinden ihren finanziellen Spielraum für freie Aufgaben und somit ihre Möglichkeiten zur Attrahierung von Gewerbebetrieben ausweiten, ohne daß gleichzeitig der Vorteil besserer Leistungen mehr oder weniger durch den Nachteil höherer Steuern kompensiert 
wird. (315) Die Kreditaufnahme scheint also ein Instrument zu sein, mit dem steuerschwache Gemeinden ihren steuerkraftbedingten Nachteil im Attrahierungswettbewerb verringern können.

Ob eine Gemeinde jedoch überhaupt einen Kredit bekommt und in welcher Höhe ihr dieser gegebenenfalls gewährt wird, hängt wiederum sehr stark von der absoluten Höhe ihrer Steuerkraft ab. Sowohl der Kreditgeber als auch die kommunale Aufsichtsbehörde, die in der Bundesrepublik den Gemeinden die Kreditaufnahme genehmigen muß, richten ihre Entscheidung danach, ob die laufenden Einnahmen der Gemeinde, also im wesentlichen ihre Steuereinnahmen, eine sichere Tilgung und Verzinsung des Kredits gewährleisten. (316) Das führt dazu, daß "die Verschuldungsmöglichkeit eine ähnliche Streuung aufweist"(317) wie die Steuerkraft.

Je höher also die Steuerkraft einer Gemeinde ist, desto leichter wird sie einen Kredit erhalten und desto größer ist der Pro-Kopf-Betrag des ihr maximal möglichen Kredits. Wird den Gemeinden die Kreditfinanzierung ermöglicht, muß tendenziell mit einer Vergrößerung der absoluten Einnahmenunterschiede zwischen den Gemeinden gerechnet werden, wodurch die vom regionalen Steuerkraftgefälle ausgehenden Wirkungen auf die Raumstruktur noch verstärkt werden.

Werden die eingangs gemachten Bedingungen aufgehoben, kann man keinesfalls damit rechnen, daß die regionalpolitisch unerwünschten Effekte des regionalen Steuerkraftgefälles abgeschwächt werden. Die Möglichkeiten der Steuersatzdifferenzierung und der Kreditfinanzierung wirken eher in dieselbe Richtung wie das regionale Steuerkraftgefälle. Deshalb kann auch die raumwirtschaftliche Wirkung des kommunalen Einnahmensystems, soweit von Zuweisungen der übergeordneten Gebietskörperschaften abgesehen wird, mit den raumwirtschaftlichen Wirkungen des regionalen Steuerkraftgefälles gleichgesetzt werden.

II. Finanzpolitische Einflußmöglichkeiten des Zentralstaates auf die Raumstruktur

\section{Klärung der Voraussetzungen}

Nachdem der finanzpolitische Aktionsraum der Gemeinden zur Attrahierung von Gewerbebetrieben untersucht worden ist, wird in diesem Abschnitt danach gefragt, mit welchen Aktionsparametern der Zentralstaat mobile Ressourcen in ausgewählte Regionen lenken kann. Dabei wird unterstellt, daß der Zentralstaat, ebenso wie die Gemeinden, mit seinen finanzpolitischen Entscheidungen vor allem auf die Standortentscheidungen der privaten Unternehmen einzuwirken versucht. Während jedoch die Gemeinden in erster Linie aus fiskalischen Gründen an der Gewerbeattrahierung interessiert sind, sieht der Zentralstaat hierin die wirksamste Möglichkeit, erwünschte regionale Entwicklungen einzuleiten und unerwünschte Entwicklungen zu bremsen. Damit wird eine "Theorie der regionalen Wirtschaftsentwicklung zugrunde gelegt ..., die den Unternehmer als den Faktor ansieht, auf den sich die 
regionale Entwicklung in einem marktwirtschaftlich orientierten Systen langfristig stützen muß". (318)

Welche Region(en) der Zentralstaat als Standort für Gewerbebetriebe für wünschenswert hält und deshalb zu Fördergebieten erklärt, hängt von seiner konkreten regionalpolitischen Zielfunktion ab. Für die vorliegende Fragestellung ist jedoch dieses Auswahlproblem irrelevant. Denn hier geht es ausschließlich darum, die grundsätzlichen Möglichkeiten des Zentralstaates zur Beeinflussung der Raumstruktur zu ermitteln. Dabei wird angenommen, daß die Finanzautonomie der Gemeinden durch die Aktivität des Zentralstaates (Bundes) nicht eingeschränkt wird.

Der Bereich der finanzpolitischen Aktionsparameter des Zentralstaates zur Beeinflussung der Standortverteilung wird unterteilt in:

- einnahmen- und ausgabenpolitische Maßnahmen,

- Maßnahmen, durch die die Einnahmenposition der untergeordneten Gebietskörperschaften beeinflußt wird. (319)

Der Komplex der einnahmen- und ausgabenpolitischen Maßnahmen wird in zwei Schritten untersucht:

- Zuerst wird unterstellt, daß die Aktivität des Zentralstaates regional vollständig radiziert ist. (320)

- Diese Annahme wird im zweiten Schritt aufgehoben, so daß der Fntzugseffekt durch Bundessteuern und der Zuführungseffekt durch Ausgaben des Zentralstaates in jeder einzelnen Region voneinander abweichen können.

2. Raumwirtschaftliche Einflußmöglichkeiten des Zentralstaates durch einnahmen - und ausgabenpolitische Maßnahmen

2.1. Bei regional vollständig radizierter Aktivität

Diese Annahme besagt, daß der Zentralstaat die ihm aus einer Region zuflieBenden Steuereinnahmen in voller Höhe wieder in Form von Staats ausgaben in die entsprechende Region zurückfließen läßt. Die regionale Verteilung der Bundesausgaben entspricht also der Verteilung der regionalen Steueraufkommen. Der Saldo von Entzugseffekt durch Bundessteuern und Zuführungseffekt durch Bundesausgaben ist somit in jeder Region null. Außerdem bezieht der Zentralstaat die Vorleistungen, die er zur Erstellung eines Leistungsange bots benötigt, jeweils in der Region, in der er die entsprechenden Leistungen anbietet.

Unter dieser Voraussetzung verfügt der Zentralstaat grundsätzlich über dieselben Aktionsparameter wie die Gemeinden, um mobile Ressourcen in bestimmte Regionen zu lenken. Auch für die Wirksamkeit der einzelnen Lenkungsinstrumente gelten im wesentlichen die im vorhergehenden Kapitel angestellten Überlegungen.

Die Wirksamkeit der zentralstaatlichen Regionalpolitik hängt entscheidend 
davon ab, ob es ihm überhaupt gelingt, die Standortqualität der entsprechenden Regionen im Vergleich zu den übrigen dauerhaft zu verbessern. Desweiteren ist erforderlich, daß die vom Zentralstaat geschaffenen Standortvorteile von den standortsuchenden Investoren als dauerhaft eingeschätzt werden. Nur wenn beide Bedingungen gemeinsam erfüllt sind, kann der Zentralstaat gemäß seinem regionalpolitischen Zielsystem die Standortentscheidungen der privaten Investoren beeinflussen.

$\mathrm{Da}$ das Problem des Parallelverhaltens nur dann relevant ist, wenn mehrere Gebietskörperschaften um mobile Ressourcen konkurrieren und auch im Fall der zentralstaatlichen Regionalpolitik von einer relativ geringen regionalen Mobilität des Faktors Arbeit ausgegangen werden muß, kann der Zentralstaat wohl mit Hilfe aller drei oben dargestellten Strategien dauerhafte Standortvorteile in einzelnen Regionen schaffen. Durch steuerliche Entlastung der regionsansässigen Unternehmen entsteht ein regionales Steuerbelastungsgefälle, durch überdurchschnittlich hohe Transferzahlungen und Infrastrukturleistungen zugunsten der regionsansässigen Unternehmen ein regionales Leistungsgefälle, das grundsätzlich über einen längeren Zeitraum bestehen bleiben kann. Nur hinsichtlich ihrer Reversibilität unterscheiden sich die Standortvorteile, die durch die einzelnen Attrahierungsstrategien verursacht werden. Die relativ hohe Irreversibilität infrastruktureller Standortvorteile macht unte rnehmensorientierte Infrastrukturmaßnahmen zum wirksamsten regionalpolitischen Lenkungsinstrument des Zentralstaates.

Will also der Zentralstaat einer bestimmten Region Standortvorteile verschaffen und so mobile Ressourcen in diese Region attrahieren, muß er in dieser Region über einen längeren Zeitraum absolut höhere Pro-Kopf-Ausgaben für Infrastruktureinrichtungen als in den übrigen Regionen leisten. Die absolute Höhe der Pro-Kopf-Ausgaben für die Infrastruktur in den einzelnen Regionen kann als Indikator für den raumwirtschaftlichen Einfluß des Zentralstaates angesehen werden.

Um die Richtung des raumwirtschaftlichen Einflusses des Zentralstaates zu ermitteln, muß untersucht werden, von welchen Faktoren unter der gemachten Annahme regional vollständig radizierter Aktivität des Zentralstaates die absolute Höhe seiner Infrastrukturausgaben in den einzelnen Regionen abhängt. Als entscheidende Determinanten müssen das regionale Steueraufkommen pro Kopf und das regionale Wohlstandsniveau pro Kopf angesehen werden:

- Bei gleicher Struktur der Bundesausgaben in allen Regionen sind die dem Bund aus dem regionalen Steueraufkommen für Infrastrukturmaßnahmen zur Verfügung stehenden Einnahmen pro Kopf umso größer, je größer das regionale Steueraufkommen ist.

- Die Struktur der Bundesausgaben in den einzelnen Regionen hängt tendenziell vom regionalen Wohlstandsniveau ab. Je reicher die Einwohner einer Region sind, desto niedriger wird der Pro-Kopf-Betrag sein, den der Zentralstaat aus sozialpolitischen Gründen, nämlich zur Sicherung des Existenzminimums vieler Haushalte bzw. zur Erhaltung strukturschwacher Betriebe und Arbeitsplätze, in Form von Transferzahlungen in eine Region zurückfließen lassen muß. Ein großer Teil des Aufkommens an Bun- 
dessteliern aus reichen Regionen kann deshalb in Form attraktivitätsfördernder Ausgaben in diese Regionen zurückfließen, während das Steuer aufkommen aus armen Regionen vom Bund überwiegend für sozialpolitisch motivierte und wenig attraktivitätsfördernde Zwecke verwendet werden muß.

Ist das regionale Aufkommen der Bundessteuern positiv mit dem regionalen Wohlstandsniveau korreliert, so bewirken diese beiden Zusammenhänge, daß der Zentralstaat bei regional vollständig radizierter Aktivität in den Regionen mit dem höchsten Wohlstandsniveau absolut höhere Ausgaben pro Kopf für attraktivitätsfördernde Zwecke leisten kann als in ärmeren Regionen. Parallel zum regionalen Wohlstandsgefälle entsteht somit ein regionales Gefälle im Angebot zentralstaatlicher Infrastrukturleistungen, durch das einmal entstandene regionale Wohlstandsunterschiede immer weiter verstärkt werden (Gesetz der wachsenden Diskrepanz).

Als Zwischenergebnis kann somit festgehalten werden: Wenn der Zentralstaat seine Ausgaben regional so verteilt, daß bei gegebenen regionalen Aufkommen an Bundessteuern in keiner Region ein positiver oder negativer Saldo zwischen Entzugs - und Zuführungseffekt (Null-Saldo) entsteht, wirkt er keineswegs raumneutral. Vielmehr würde ein solches Ausgabeverhalten des Zentralstaates mit großer Wahrscheinlichkeit den ablaufenden räumlichen Differenzierungsprozeß verstärken. Als Indikator für die Stärke der ballungsfördernden Wirkung der zentralstaatlichen Aktivität können die Unterschiede in der absoluten Höhe der regionalen Pro-Kopf-Ausgaben des Bundes dienen, da von ihnen das Ausmaß des regionalen Leistungsgefälles determiniert wird.

\subsection{Bei regional nicht radizierter Aktivität}

Im Fall regional vollständig radizierter Aktivität bestimmt das regionale Aufkommen an Bundessteuern den Umfang zentralstaatlicher Aktivität in jeder Region. Die Unterschiede im regionalen Steueraufkommen pro Kopf entscheiden über Richtung und Stärke des raumwirtschaftlichen Einflusses des Bundes. Nachdem die Entscheidung zugunsten eines bestimmten Steuersystems gefallen ist, bleibt dem Bund kaum noch ein Spielraum, die Raumstruktur nach freiem Ermessen zu beeinflussen. In diesem Sinne kann von einer Determiniertheit der raumwirtschaftlichen Wirkung des Zentralstaats durch das herrschende Steuersystem gesprochen werden. Sie wird beseitigt, wenn die Annahme der regional vollständig radizierten Aktivität wegfällt.

In der Realität ist die zentralstaatliche Aktivität so gut wie nie regional vollständig radiziert. (321) Die vom Zentralstaat in eine Region fließenden monetären und realen Leistungsströme weichen in der Regel vom Beitrag der Region zur Finanzierung dieser Leistungsströme ab. Ebenso bezieht der Zentralstaat die zur Erstellung seines Leistungsangebots erforderlichen Inputs nicht nur aus der Region, der sein Leistungsangebot zugute kommt. "Der prinzipielle Unterschied zu dem System [ausschließlich, F. T. ] kommunaler Finanzhoheit besteht bei zentralstaatlicher Politik in der Unabhängigkeit der regionalen öffentlichen Ausgaben sowie der mit ihnen verbundenen Leistungs - 
aufnahmen und -abgaben von dem regionalen Steueraufkommen. "(322)

Bei gegebenem Steuersystem und damit gegebenen regionalen Steueraufkommen kann der Zentralstaat durch die regionale Verteilung seiner Ausgaben in jeder Region den von ihm gewünschten Saldo von Zuführungs - und Entzugs effekt seiner Aktivität herbeiführen und so auf die regionale Entwicklung Einfluß zu nehmen versuchen. Der Zentralstaat verfügt damit "über grundsätz lich andere Parameter als eine Kommune".(323) Seine ausgabenpolitischen Einflußmöglichkeiten auf die Raumstruktur sind damit noch größer als die der Gemeinden.

Die zusätzlichen raumwirtschaftlichen Einflußmöglichkeiten des Zentralstaates, die aus der Unabhängigkeit seiner regionalen Ausgaben von den regionalen Steueraufkommen resultieren, können besonders gut verdeutlicht werden, wenn man vom Zustand regional vollständig radizierter Aktivität aus geht. Es sei nun angenommen, daß der Zentralstaat den reichen Regionen weniger Mittel zuführt, als er ihnen in Form von Steuern entzogen hat. Durch diese Mittelkürzung wird der Pro-Kopf-Betrag, den der Zentralstaat in den einzelnen Regionen zur Existenzsicherung der Wirtschaftssubjekte aufwenden muß, nicht beeinträchtigt. Die Kürzung wirkt sich lediglich auf die finanzielle Manövriermasse aus, so daß der Bund in den reichen Regionen überwiegend die Ausgaben für attraktivitätsfördernde Zwecke reduzieren wird.

Das Äquivalent zu den negativen Salden von Zuführungs - und Entzugseffekt in den reichen Regionen sind die positiven Salden in den Regionen mit unterdurchschnittlich hohem Wohlstandsniveau und Steueraufkommen pro Kopf. Gewährt der Bund ihnen mehr Ausgaben, als ihrem regionalen Steueraufkommen entspricht, besteht kaum ein Grund, weswegen die sozialpolitisch motivierten Bundesausgaben in diesen Regionen ansteigen sollten. Vielmehr kann und wird der größte Teil dieser zusätzlichen Bundesmittel für freie Aufgaben, insbesondere den Ausbau der regionalen Infrastruktur, eingesetzt werden.

Die Erhöhung der Bundesausgaben pro Kopf in den armen Regionen über und die Senkung der Bundesausgaben pro Kopf in den reichen Regionen unter das Niveau der regionalen Steueraufkommen, schwächt das regionale Ausgabenund Leistungsgefälle ab, das im Fall regional vollständig radizierter Aktivität besteht. Ist jedoch die regionale Umverteilung zugunsten der steuerschwachen Regionen quantitativ gering, bleibt das regionale Leistungsgefälle weiterhin, wenn auch abgeschwächt, bestehen. Trotz der positiven Salden in den armen Regionen geht von der zentralstaatlichen Aktivität ein ballungsfördernder Effekt aus. Die Abweichung der regionalen Bundesausgaben von den regionalen Steueraufkommen hat lediglich bewirkt, daß der ballungsfördernde Effekt der zentralstaatlichen Aktivität schwächer ist als bei einer regionalen Verteilung der Bundesausgaben gemäß den regionalen Steueraufkommen. Auf einen ballungshemmenden Effekt der zentralstaatlichen Aktivität kann erst dann geschlossen werden, wenn der Bund in den reichen Regionen nur noch geringere Pro-Kopf-Beträge für attraktivitätsfördernde $Z w e c k e$ verwendet als in den armen Regionen. 
An Vorzeichen und Höhe der Salden von Zuführungs - und Entzugseffekt der zentralstaatlichen Aktivität in den einzelnen Regionen kann also nicht ohne weiteres abgelesen werden, ob der Zentralstaat Ballungstendenzen verstärkt oder abschwächt. Diese Salden sind nicht als Indikatoren des raumwirtschaftlichen Einflusses des Zentralstaates geeignet. Um ihn abschätzen zu können, muß vielmehr in erster Linie die absolute Höhe der Pro-Kopf-Ausgaben des Zentralstaates in den einzelnen Regionen und ihre Struktur ermittelt werden.

2.3. Raumwirtschaftliche Wirkungen der zentralstaatlichen Infrastrukturausgaben

Das wirksamste ausgabenpolitische Lenkungsinstrument des Zentralstaates sind seine Infrastrukturausgaben. Da nicht mehr regional radizierte Aktivität unterstellt wird, müssen die raumwirtschaftlichen Wirkungen der zentralstaatlichen Infrastrukturausgaben unter zwei Gesichtspunkten betrachtet werden, die hier als Nutzen- und als Zahlungsinzidenz (324) bezeichnet werden:

- Die Infrastrukturausgaben dienen dem Zentralstaat zur Erstellung seines Angebots an Infrastrukturleistungen. Durch die regionale Verteilung seiner Infrastrukturleistungen verschafft er einzelnen Regionen Vorzugspositionen im Attrahierungswettbewerb um mobile Ressourcen und bewirkt regional ungleiche Entwicklungschancen. Dieser raumwirtschaftliche Effekt des infrastrukturellen Leistungsangebots (Nutzeninzidenz) ergibt sich primär aus der regionalen Verteilung der Infrastrukturprojekte (formale Nutzeninzidenz). Die bewußte Placierung der Infrastrukturprojekte ist ein wichtiges Instrument des Zentralstaates zur Beeinflussung der regionalen Entwicklung. (325) Die regionale Verteilung der Infrastrukturprojekte gibt aber noch kein vollständiges Bild der regionalen Verteilung des Nutzens aus Infrastruktureinrichtungen. Einmal muß bedacht werden, daß auch Einwohner anderer Regionen die Leistungen eines Infrastrukturprojektes in Anspruch nehmen können (Ertrags-spillovers). Zum anderen muß ermittelt werden, in welchem Ausmaß das Angebot von Infrastruktur leistungen in einer Region bereits ansässige Faktoren interregional wettbewerbsfähiger macht, regionsfremde Ressourcen attrahiert und auf diese Weise einen regionalen Entwicklungsproze $\beta$ induziert (effektive Nutzeninzidenz).

- Infrastrukturausgaben sind das monetäre Äquivalent zu Gütern und Leistungen, die der Zentralstaat vom privaten Sektor bezieht und zur Erstellung seines Leistungsangebots einsetzt. Mit der regionalen Verteilung seiner Vorleistungskäufe besitzt der Zentralstaat ein weiteres Instrument, mit dem er in den einzelnen Regionen Möglichkeiten zur Erzielung von Arbeitseinkommen und Gewinnen sowie zur Realisierung interner Ersparnisse schaffen kann (Zahlungsinzidenz). Die regionale Verteilung der InputKäufe bedeutet "eine regionale Verteilung von zusätzlichen bzw. 'vorenthaltenen' Vorteilen für die dort ansässigen Unternehmer".(326) Mit der bewußten Placierung seiner Aufträge (formale Zahlungsinzidenz) besitzt 
der Zentralstaat eln zusätzliches Instrument, mit dem er erheblichen Einfluß auf die regionalen Wachstumsprozesse ausüben kann. (327) Um die raumwirtschaftlichen Wirkungen der Input-Käufe vollständig zu erfassen (effektive Zahlungsinzidenz), müssen auch die Folgewirkungen (328) ermittelt werden, die von der Vergabe derr Aufträge und von den Zahlungsströmen, die den einzelnen Regionen zufließen, ausgehen.

Die Überlegungen über die Einflußmöglichkeiten des Zentralstaates auf die Raumstruktur könneh in folgenden Thesen zusammengefaßt werden:

- Der raumwirtschaftliche Einfluß des Zentralstaates resultiert in erster Linie aus der regionalen Verteilung seiner Infrastrukturleistungen (Outputs) und der regionalen Verteilung seiner Vorleistungskäufe (Inputs).

- Die regionale Verteilung der zentralstaatlichen Outputs und Inputs hängt primär von der regionalen Verteilung der Infrastrukturprojekte und der regionalen Placierung der Aufträge ab.

- Die raumwirtschaftliche Wirkung der Projekt- und Auftragsverteilung kann zwar durch etwaige Ertrags-spillovers und finanzielle Abflüsse in andere Regionen in Form von Vorleistungskäufen der Auftragsnehmer und Konsumgüterkäufen der begünstigten Einkommensbezieher modifiziert, aber kaum aufgehoben werden.

- Deshalb sind die regionale Placierung der Infrastrukturprojekte und die regionale Placierung der Auftrăge die wirksamsten raumwirtschaftlichen Lenkungsinstrumente des Zentralstaates aus dem Bereich der Finanzpolitik.

- Der Zentralstaat kann einer Region Standortvorteile verschaffen, indem er in dieser Region absolut höhere Infrastrukturleistungen pro Einwohner anbietet und/oder absolut höhere Aufträge pro Einwohner in diese Region fließen läßt als in andere Regionen.

- Der Begünstigung einer Region durch überdurchschnittlich hohe Infrastrukturleistungen kann eine Benachteiligung durch unterdurchschnittlich hohe Aufträge pro Einwohner gegenüberstehen. Der raumwirtschaftliche Einfluß des Zentralstaates ergibt sich als Nettoeffekt der regionalen Verteilung seiner Leistungen und Aufträge. (329) Sowohl das vom Zentralstaat geschaffene regionale Leistungsgefälle als auch das regionale Auftragsgefälle bestimmen Richtung und Intensität seines Einflusses auf die Raumstruktur.

3. Raumwirtschaftliche Einflußmöglichkeiten durch Beeinflussung der Einnahmenposition der untergeordneten Gebietskörperschaften

Der regionalpolitische Handlungsspielraum der untergeordneten Gebietskörperschaften (Länder und Gemeinden) wird durch die absolute Höhe ihrer Steuerkraft determiniert. Die regionalen Unterschiede in der Steuerkraft entscheiden über Richtung und Stärke der raumwirtschaftlichen Effekte, die von der finanzpolitischen Aktivität der untergeordneten Gebietskörpe rschaf ten ausgehen. (330) Deshalb ist die Verteilung der Finanzierungsmittel, die 
den untergeordneten Ebenen im Föderativstaat zustehen, auf die einzelnen Mitglieder dieser Ebenen ein entscheidender Aktionsparameter zur Beeinflussung der Raumstruktur. (331)

\subsection{Die finanzausgleichspolitischen Maßnahmen}

Dem Zentralstaat steht eine Reihe von Maßnahmen zur Verfügung, mit denen er die Verteilung der Einnahmen auf die einzelnen untergeordneten Gebiets körperschaften steuern kann. Ihm ist es grundsätzlich möglich, diejenige regionale Streuung der Steuerkraft zu realisieren, die am wirksamsten zur Erreichung seiner regionalpolitischen Zielvorstellungen beizutragen scheint. Bei diesen Maßnahmen handelt es sich im wesentlichen um folgende (332):

- Ausstattung der untergeordneten Gebietskörperschaften mit Steuern, die ihnen in Ertragshoheit, also gemäß dem örtlichen Aufkommen, (333) zu stehen.

Die regionale Streuung des örtlichen Aufkommens einer einzelnen Steuer gleicht niemals derjenigen der anderen Steuern. Deshalb werden mit der Auswahl der "eigenen" Steuern der untergeordneten Gebietskörperschaften gleichzeitig auch Richtung und Stärke des regionalen Steuerkraftgefälles festgelegt.

- Beteiligung der untergeordneten Gebietskörperschaften an Gemeinschafts steuern (334) und Verteilung der einer Ebene zustehenden Steuereinnahmen auf die einzelnen Mitglieder der Ebene nach anderen Kriterien als dem des örtlichen Aufkommens.

Durch entsprechende Wahl des Verteilungskriteriums kann der Zentralstaat die von ihm gewünschte regionale Streuung der Steuereinnahmen pro Kopf realisieren.

- Regelungen, die dem Ausgleich unerwünschter Steuerkraftunterschiede dienen.

Der Zentralstaat kann auf direktem Wege unerwünschte Steuerkraftunterschiede abschwächen, indem er Ausgleichszahlungen an steuerschwache Gebietskörperschaften der untergeordneten Ebene leistet (vertikaler Steuerkraftausgleich). Außerdem kann er durch gesetzliche Bestimmungen beeinflussen, in welcher Richtung und in welchem Ausmaß untergeordnete Gebietskörperschaften Ausgleichszahlungen an Körperschaften derselben Ebene zu leisten haben (horizontaler Steuerkraftausgleich).

- Zuweisungen des Zentralstaates an untergeordnete Gebietskörperschaften, die nicht primär dem Ausgleich von regionalen Steuerkraftunterschieden dienen.

Durch sie kann der Zentralstaat gezielt den Mobilitätsanteil der Einnahmen einzelner Gebietskörperschaften erhöhen und ihnen attraktivitäts fördernde Ausgaben ermöglichen. 


\subsection{Die Entscheidungsbefugnis des Zentralstaates}

Diese hier grob skizzierten Maßnahmen des Zentralstaates, mit denen er die Einnahmenposition der untergeordneten Gebietskörperschaften direkt und die Raumstruktur indirekt beeinflussen kann, unterscheiden sich nicht unwesentlich von seinen weiter oben diskutierten regionalpolitischen Instrumenten. Diese Unterschiede ergeben sich aus den Eigenarten des föderalistischen Staatsaufbaus.

Der Föderalismus ist nicht schon dann verwirklicht, wenn den untergeordneten Gebietskörperschaften ihre Eigenständigkeit in der Verfassung garantiert ist. (335) Materiell ist vielmehr erforderlich, daß sie einen Rechtsanspruch auf eigene Einnahmen besitzen, so daß sie relativ langfristig disponieren können. Außerdem darf es nicht im'freien Ermessen des Zentralstaates ste hen, die finanzielle Ausstattung der untergeordneten Gebietskörperschaften zu verändern. (336) Finanzausgleichspolitische Entscheidungen sollten deshalb im Föderativstaat nur mit Zustimmung der betroffenen untergeordneten Gebietskörperschaften getroffen werden. Sie werden in der Regel im Wege der politischen Auseinandersetzung zwischen Bund, Ländern und Gemeinden gefunden und stellen einen politischen Kompromiß dar. (337, 338)

Wenn diese materiellen Voraussetzungen des Föderalismus erfüllt sind, unterliegen diese regionalpolitisch so bedeutsamen Maßnahmen also weder der alleinigen Entscheidungsbefugnis des Zentralstaates, noch können sie von ihm so flexibel eingesetzt werden wie seine übrigen finanzpolitischen Instrumente. Trotzdem werden sie hier als regionalpolitische Aktionsparameter des Zentralstaates betrachtet. Denn zum einen werden Änderungen im System der Einnahmenverteilung häufig von ihm initiert, zum anderen haben seine Vorstellungen über die wünschenswerte Mittelverteilung oft ein solches politisches Gewicht, daß die untergeordneten Gebietskörperschaften lediglich Details, nicht aber die Konzeption abändern können.

Diese finanzausgleichspolitischen Maßnahmen des Zentralstaates stehen im weiteren Verlauf dieser Arbeit im Mittelpunkt der Überlegungen. Zuerst wird versucht, einige Grundsatzfragen zu diesem Maßnahmenkomplex zu klären. Es geht vor allem um die Frage, ob das örtliche Aufkommen einer Steuer als Verteilungskriterium der Steuereinnahmen geeignet ist, um die regionalpolitische Beurteilung des Steuerverbunds, um Probleme des öffentlichen Bedarfs und seiner Staffelung nach der Gemeindegröße sowie um die regionalpolitische Aufgabe von Zuweisungen des Zentralstaates an die untergeordneten Gebietskörperschaften. Die Diskussion dieser Probleme erleichtert das Verständnis des sich anschließenden empirischen Teils. In ihm werden konkrete Maßnahmen aus diesem Bereich der raumwirtschaftlichen Einflußmöglichkeiten des Zentralstaates untersucht. Es wird gezeigt, in welcher Richtung und in welchem Ausmaß die von der Bundesregierung im $\mathrm{Zu}$ sammenwirken mit den Ländern und Gemeinden im Rahmen der Finanzreform von 1969 geschaffenen Regelungen die Einnahmenposition der einzelnen untergeordneten Gebietskörperschaften gegenüber dem Zustand vor der Reform verändert haben. 
Bevor jedoch auf diese Fragen näher eingegangen wird, muß noch der Vollständigkeit halber auf die raumwirtschaftlichen Einflußmöglichkeiten der Teilstaaten eines Föderativstaates eingegangen werden.

III. Raumwirtschaftliche Einflußmöglichkeiten der Teilstaaten

Entsprechend ihrer Stellung als Mittelinstanz im föderativ aufgebauten Staat müssen die raumwirtschaftlichen Einflußmöglichkeiten der Teilstaaten (Länder) unter zwei Aspekten gesehen werden:

- Auf der einen Seite versucht jeder Teilstaat, den Vorteil der eigenen Region zu maximieren. Er steht mit allen anderen Teilstaaten im Attrahierungswettbewerb um potente Steuerzahler. Alle Aussagen über die Attrahierungsmöglichkeiten und ihre Bestimmungsfaktoren, die für die Gemeinden gemacht wurden (339), gelten auch für die Länder. (340) Unterschiede in den Pro-Kopf-Steuereinnahmen zwischen den Ländern, die positiv mit den Wirtschaftskraftunterschieden zwischen den Ländern korreliert sind, verstärken die regionalen Wohlstandsunterschiede und die bereits ablaufenden Ballungstendenzen. (341)

- Auf der anderen Seite hat jeder Teilstaat eine Vorstellung über die wünschenswerte räumliche Verteilung der Ressourcen innerhalb der eigenen Grenzen. Während er in interregionaler Hinsicht ein räumlich unkoordinier tes Zielsystem (342) verfolgt, strebt er in intraregionaler Hinsicht ein räumlich koordiniertes Zielsystem (342) an. Zur Realisierung des letzteren stehen dem einzelnen Teilstaat grundsätzlich dieselben Instrumente zur Verfügung, die auch der Zentralstaat zur Erreichung seines regionalpolitischen Zielsystems einsetzen kann. Das einzelne Land kann also insbesondere durch die Verteilung seiner Infrastrukturprojekte und seiner Aufträge auf die einzelnen Teilregionen und durch die Beeinflussung der Einnahmenpositionen seiner Gemeinden die Standortverteilung innerhalb der Ländergrenzen beeinflussen.

IV. Grundsatzfragen zu den finanzausgleichspolitischen Einflußmöglichkeiten des Zentralstaates

1. Rechtfertigung des föderalistischen Staatsaufbaus

Der Föderativstaat ist durch eine mehrstufige Gliederung des öffentlichen Sektors charakterisiert. Neben den Organen des Zentralstaates stehen die Organe der Teilstaaten und die Gemeinden. Das Verhältnis zwischen den drei bundesstaatlichen Ebenen kann nicht mit den Begriffen "Über - und Unterordnung", sondern eher mit "Zusammenarbeit" und "prinzipielle Gleichberechtigung" umschrieben werden. Innerhalb des ihnen zugewiesenen Aufgabenbereichs können die Gebietskörperschaften der unteren Ebenen eigenständig entscheiden und handeln. (343) 
Die Eigenständigkeit der untergeordneten (344) Gebietskörperschaften erscheint vor allem aus folgenden Gründen staatspolitisch wünschenswert:

- Die im Föderativstaat nebeneinander existierenden eigenständigen Willensbildungszentren kontrollieren sich gegenseitig. Einseitige und extreme Standpunkte können sich deshalb kaum durchsetzen. Die Verteilung der Macht auf eine Reihe eigenständiger Willensbildungszentren verhindert Machtmißbrauch und ist somit "eine wesentliche Sicherung für den freiheitlichen und sozialen Rechtsstaat". (345, '346) Die Rechtfertigung des Föderalismus als "zusätzliches, besonders wirksames System der Gewaltenteilung"(347) setzt sich immer stärker durch.

- Das Nebeneinander eigenständiger Willensbildungszentren gibt dem einzelnen Bürger die Gelegenheit, an mehreren Stellen des Staatsaufbaus seine politischen Vorstellungen zu Gehör zu bringen. Er kann dadurch vermehrt und leichter die politischen Entscheidungen beeinflussen. (348) Der föderative Staatsaufbau ist also ein Instrument, durch das die $\mathrm{Zu}$ stimmung der Bürger (Konsensus) zum politischen System gesichert werden kann.

- Die Entscheidungsinstanzen der unteren Ebenen können besser als die zentralen Instanzen die individuellen Bedürfnisse nach öffentlichen Leistungen erkennen und die zu ihrer Befriedigung geeigneten Maßnahmen ermitteln. "Lokal differenzierte Bedürfnisse ... stellen den eigentlichen Grund für die Existenz lokaler Gebietskörperschaften dar. "(349, 350) Die Eigenständigkeit der untergeordneten Gebietskörperschaften dient also dazu, Niveau und Struktur des Angebots öffentlicher Leistungen soweit wie möglich mit Niveau und Struktur der Nachfrage nach öffentlichen Leistungen in Übereinklang zu bringen. Der föderalistische Staatsaufbau soll "eine ungewollte Meritorisierung beim Angebot öffentlicher Güter" $r^{\prime \prime}(351)$ verhindern.

Wenn grundsätzlich Einigkeit besteht, daß den untergeordneten Gebietskör perschaften in einem bestimmten Umfang Eigenständigkeit zugebilligt werden sollte, entsteht die Notwendigkeit, sie mit Einnahmen auszustatten, die sie nach eigenem Ermessen verwenden können. Nach welchen Kriterien sollten die eigenen Einnahmen der untergeordneten Gebietskörperschaften auf die einzelnen Mitglieder der beiden unteren Ebenen verteilt werden, ohne daß es zu Konflikten mit den zugrundegelegten regionalpolitischen Zielen kommt? Diese Frage wird anschließend untersucht.

2. Die Eignung des örtlichen Aufkommens als Steuerverteilungskriterium

Bis zur Finanzreform von 1969 "galt [es] als Glaubenssatz, daß die Länder zum Zeichen ihrer Steuerhoheit primär das in ihrem Bereich anfallende (örtliche) Aufkommen der Ländersteuern oder Steueranteile zu beanspruchen hätten". (352) Die Beteiligung an den der eigenen Ebene zustehenden Steuereinnahmen gemäß dem örtlichen Aufkommen erschien den einzelnen Gebiets körperschaften, insbesondere den finanzstarken, sozusagen als ihr "natur- 
liches" Recht. Diese Ansicht soll hier nicht näher auf ihre Berechtigung hin geprüft werden, denn man gerät dabei leicht in eine Diskusaion, in der Werturteil gegen Werturteil steht. (353)

Die Eignung des örtlichen Aufkommens als Steuerverteilungskriterium soll vielmehr mit Hilfe eines wirkungsorientierten Ansatzes beurteilt werden. $\mathrm{Zu}$ diesem Zweck werden die räumlichen Auswirkungen, die von einer Steuerverteilung gemäß dem örtlichen Aufkommen außgehen, mit dem zugrundegelegten regionalpolitischen Zielsystem (354) konfrontiert. Muß erwartet werden, daß eine Verteilung der Steuereinnahmen gemäß dem örtlichen Aufkommen die räumliche Konzentration wirtschaftlicher Aktivitäten verstärkt, wird das örtliche Aufkommen als Steuerverteilungskriterium regionalpolitısch negativ beurteilt.

Die Auswirkungen dieser Steuerverteilungamethode auf den Verlauf des räumlichen Differenzierungsprozesses sind bereits explizit dargestellt worden, (355) so daß man sich an dieser Stelle auf eine kurze Zusammenfassung der Ergebnisse beschränken kann:

Bei jeder Steuer, die in den westeuropäischen Staaten erhoben wird und/oder die den wichtigsten Anforderungen an ein rationales Steuersystem genügt (356), ist die steuerliche Bemessungsgrundlage regional ungleichmäßig verteilt. Deshalb treten sowohl zwischen den Gemeinden als auch zwischen den Regionen Unterschiede im Pro-Kopf-Aufkommen auf, $(357,358)$ Die interlokale und interregionale Streuung der örtlichen Aufkommen (pro Kopf) ist zum einen für die Regionalpolitik unkontrollierbar. Zum anderen verlaufen bel den wichtigsten Steuern die regionalen Unterschiede im örtlichen Aufkommen parallel zu den Unterschieden in der regionalen Wirtschaftskraft, wobei teilweise die ersteren größer als die letzteren sind, (359)

Bei einer Verteilung der Steuereinnahmen auf die untergeordneten Gebietskörperschaften gemäß deren örtlichem Aufkommen entsteht deshalb ein regionales Leistungsgefälle zugunsten der Regionen, depen Wirtschaftskraft und Agglomerationsgrad bereits überdurchschnittlioh hoch sind. Die regionalen Wohlstandsunterschiede werden dadurch vergrößert, die Ballungstendenzen verstärkt.

Aus regionalpolitischer Sicht ist deshalb die steuerliche Autonomie der untergeordneten Gebietskörperschaften "eine ziemlich zweifelhafte Errungenschaft" $(360)$. Wird für sie die Ertragshoheit über die ihnen zustehenden Steuern gefordert, so dient dies allein "der Auffechterhaltung einer dureh die natürlichen Steuerkraftunterschịede bedingten Differenzierung der Leistungskraft der einzelnen Lände $r^{\prime \prime}(361)$ und Gemeinden.

Wegen dieser regionalpolitisch unerwünschten Wirkungen wird hier eịne ausschließlich nach dem örtlichen Aufkommen vorgenommene Steuerverteilung auf die untergeordneten Gebietşörperschaften obgelehnt. Damit werden zugleich Steuerverteilungssysteme verworfen, die assehließlich aus dem Trennsystem (362) oder dem Mischsystem (362) (radizierter Steuerverbund (363)) bestehen. 
3. Möglichkeiten zur Vermeidung der regionalpolitisch unerwünschten Steuereinnahmenunterschiede

3.1. Horizontale Ausgleichszahlungen

Wird dieser Weg gewählt, erhalten die untergeordneten Gebietskörperschaften in einem ersten Schritt ihre Steuereinnahmen gemäß dem örtlichen Aufkommen (z. B. gebundenes Trennsystem oder Mischsystem in Form des Quotensystems). Diese primäre Einnahmenverteilung wird in einem zweiten Schritt durch Ausgleichszahlungen der finanzstarken an die finanzschwachen Gebietskörperschaften derselben Ebene korrigiert (horizontaler Finanzaus gleich).

Aus föderalistischer Sicht mag diese Methode der Steuerverteilung vielleicht erwünscht erscheinen. Aus regionalpolitischer Sicht müssen dagegen einige Bedenken angemeldet werden. Gegen sie spricht, "daß sie zu der Vorstellung verleitet, die horizontalen Finanzausgleichsleistungen seien 'Opfer' der finanzstärkeren Länder [bzw. Gemeinden, F.T.], denen ein Teil der eigentlich ihnen zustehenden Steuerkraft zugunsten anderer Länder [bzw. Gemeinden, F. T. ] entzogen wird. "(364) Diese Vorstellung resultiert insbesondere aus der Tatsache, daß die ausgleichspflichtigen Gebietskörperschaften Einnahmen hergeben müssen, die sich bereits in ihren Kassen und damit in ihrer Verfügungsgewalt befinden. Die interregionale Umverteilung, gemessen an der Verteilung nach dem örtlichen Aufkommen, liegt vollständig of fen. Sie stößt nicht zuletzt wegen ihrer großen Merklichkeit auf erheblichen Widerstand der ausgleichspflichtigen Gebietskörperschaften. "Bei dieser Methode werden im allgemeinen gewisse Unterschiede in der regionalen Finanzkraft bestehenbleiben, da die steuerstarken Länder [bzw. Gemeinden, F.T.] nicht bereit sein dürften, zugunsten der steuerschwachen Länder [bzw. Gemeinden, F.T.] auf so viele Steuereinnahmen zu verzichten, daß eine völlige Nivellierung der Steuerkraft eintritt."(365)

Die Wahrscheinlichkeit, daß auch nach Durchführung eines horizontalen Finanzausgleichs Unterschiede in derLeistungskraft der untergeordneten Gebietskörperschaften bestehen bleiben, die regionalpolitisch nicht akzeptabel sind, ist relativ groß. (366) Deshalb wird hier auch die Steuerverteilung nach dem örtlichen Aufkommen mit nachträglicher Korrektur durch einen horizontalen Finanzausgleich unter regionalpolitischer Zielsetzung als nicht geeignetes Steuerverteilungssystem angesehen.

\subsection{Steuerverbund}

Bei dieser Methode werden die Steuereinnahmen, die einer untergeordneten Ebene zustehen, nach anderen Maßstäben als dem des örtlichen Aufkommens auf die einzelnen Mitglieder der jeweiligen Ebene verteilt. Durch Verwendung gesetzlich festgelegter Bedarfsmaßstäbe als Steuerverteilungskriterium wird gleichzeitig mit der Verteilung der Steuereinnahmen auf die verschiedenen bundesstaatlichen Ebenen (vertikaler Finanzausgleich) ein horizontaler Aus - 
gleichseffekt erzielt. Ausgleichszahlungen zwischen Gebietskörperschaften derselben Ebene können auf diese Weise überflüssig gemacht werden.

Eine ausführliche Diskussion aller Vor- und Nachteile des Steuerverbunds im Vergleich zum Trennsystem kann hier nicht durchgeführt werden. (367) Bevor jedoch die Eignung des Steuerverbunds als Steuerverteilungssystem unter regionalpolitischer Zielsetzung beurteilt wird, muß geklärt werden, ob gegen dieses Steuerverteilungssystem aus föderalistischer Sicht grundsätzlich Bedenken erhoben werden müssen, die seine Anwendung ausschließen.

\subsubsection{Staatspolitische Beurteilung des Steuerverbunds}

Der Wissenschaftliche Beirat beim Bundesministerium der Finanzen und Zeitel lehnen den Steuerverbund $a b$, weil sie durch ihn die Eigenständigkeit der untergeordneten Gebietskörperschaften bedroht sehen. So betont der Wissenschaftliche Beirat, daß der Steuerverbund die untergeordneten Geб̆ietskörperschaften "in eine unerwünschte Abhängigkeit von der Steuerpolitik der übergeordneten Gebietskörperschaften"( 368 ) bringt. Dieses sachlich zutreffende Argument muß jedoch relativiert werden:

- Die Einnahmen der untergeordneten Gebietskörperschaften sind immer dann von der Steuerpolitik der übergeordneten Gebietskörperschaften abhängig, wenn ihnen keine Gesetzgebungsbefugnis über die Steuern, deren Ertrag ihnen zufließt, zusteht. Vollständige Unabhängigkeit von der Steuerpolitik der übergeordneten Gebietskörperschaften liegt nur beim freien Trennsystem vor, das jedoch aus stichhaltigen wirtschaftspolitischen Gründen abzulehnen ist. (369) Auch beim gebundenen Trennsystem oder Mischsystem in der Form des Quotensystems sind die Einnahmen der untergeordneten Gebietskörperschaften von steuerpolitischen Maßnahmen des Zentralstaates abhängig. (370) Mitwirkungsrechte an der Steuergesetzgebung, die den untergeordneten Gebietskörperschaften bei diesen beiden Steuerverteilungsmethoden möglicherweise eingeräumt sind, können ihnen grundsätzlich in gleicher Weise auch bei einer Anwendung des Steuerverbundes gewährt werden, wie dies in der Bundesrepublik in Art. 105, Abs. 3 des Grundgesetzes auch geschehen ist. (371) Die Ablösung dieser Steuerverteilungssysteme durch einen Steuerverbund bringt also die untergeordneten Gebietskörperschaften nicht automatisch in eine größere Abhängigkeit von der Steue rpolitik des Zentralstaats.

- Das Problem der Abhängigkeit von der Steuerpolitik der übergeordneten Gebietskörperschaften ist relativ irrelevant, wenn man bedenkt, daß die Einnahmen der untergeordneten Gebietskörperschaften grundsätzlich von den politischen Aktivitäten der übergeordneten Gebietskörperschaften beeinflußt werden. Die Beziehung zwischen zentralstaatlicher Politik und Einnahmenentwicklung der untergeordneten Gebietskörperschaften ist be sonders im Fall der bundesstaatlichen Konjunkturpolitik offensichtlich. Eine etwaige Unabhängigkeit der untergeordneten Gebietskörperschaften von der Steuerpolitik des Zentralstaates ändert an diesem allgemeinen Sachve rhalt nichts. 
Während das Argument des Wissenschaftlichen Beirats zwar sachlich richtig, m. E. aber relativ unbedeutend ist, kann der Meinung Zeitels inhaltlich nicht zugestimmt werden. Seiner Meinung nach ist "wohl kaum ernstlich zu bestreiten, daß mit einem Ausbau des Steuerverbundes ein Verlust an individueller Dispositionsmöglichkeit gegenüber der Verfügbarkeit über eigene Einnahmen verbunden ist. "( 372$)$

Die untergeordneten Gebietskörperschaften können grundsätzlich auf der Einnahmenseite (Steuerhoheit) und auf der Ausgabenseite (Ausgabenhoheit) über Dispositionsmöglichkeiten verfügen. Steuerhoheit verlangt die Gesetzgebungs befugnis über die Steuerquellen, deren Ertrag einem zusteht. Wird für die untergeordneten Gebietskörperschaften Steuerhoheit gefordert, spricht man sich damit für das freie Trennsystem aus.

Für die Bundesrepublik Deutschland wird ein freies Trennsystem als Steuerverteilungssystem aus einer Reihe von wirtschaftspolitischen Gründen (Besteuerung nach dem Prinzip der Leistungsfähigkeit, Verteilungs - und konjunkturpolitische Effizienz der zentralstaatlichen Steuerpolitik) abgelehnt. Deshalb besitzen in der BRD die Bundesländer so gut wie gar keine und die Gemeinden nur eine eingeschränkte Steuerhoheit. (373) Die Einführung eines Steuerverbundes würde die Dispositionsmöglichkeiten der untergeordneten Gebietskörperschaften auf der Einnahmenseite also gar nicht oder nur geringfügig einschränken.

Wenn den untergeordneten Gebietskörperschaften die Steuerhoheit versagt wird, bedeutet dies jedoch nicht, daß sie auch keine Ausgabenhoheit besitzen. Ausgabenhoheit läßt sich auch ohne Einnahmen- bzw. Steuerhoheit verwirklichen. (374) Sie besteht in diesem Fall zwar nicht mehr hinsichtlich des Niveaus, aber doch hinsichtlich der Struktur der Ausgaben. Ob die untergeordneten Gebietskörperschaften die ihnen zustehenden Einnahmen nach eigenem Ermessen verwenden können, hängt nicht vom Verteilungsschlüssel der Verbundmasse (örtliches Aufkommen oder Bedarfsmaßstäbe) ab. Entscheidend dafür sind vielmehr die finanzverfassungsrechtlichen Regelungen über die Aufgabenkompetenzen der untergeordneten Gebietskörperschaften. Die Einnahmen aus dem Steuerverbund sind also für die untergeordneten Gebiets körperschaften ebenso eigene Einnahmen, wie ihre Einnahmen aus dem Trennoder Mischsystem.

"Der originäre Anspruch auf das im eigenen Bereich kassenmäßig angefallene Steueraufkommen kann ... nicht als Attribut der Staatsqualität [der Bundes länder, F. T. ] betrachtet werden. "(375) Vielmehr ist für "die Eigenstaatlichkeit der Länder [und für die Eigenständigkeit der Gemeinden, F. T. ] . entscheidend, daß ihre Finanzausstattung nicht vom Ermessen der Bundesbehörden abhängt und daß ihre gesetzlichen Steue rbeteiligungsansprüche nicht ohne Zustimmung des Bundesrates zu ihrem Nachteil geändert werden können. "( 376,377$)$

Aus föderalistischer Sicht darf man wohl den Steuerverbund nicht wesentlich anders beurteilen als die Kombination von gebundenem Trennsystem und horizontalem Finanzausgleich. Welches Steuerverteilungssystem aus regionalpolitischer Sicht vorzuziehen ist, hängt davon ab, ob sie sich hinsichtlich ihrer räumlichen Auswirkungen unterscheiden. 


\subsubsection{Regionalpolitische Beurteilung des Steuerverbunds}

Grundsätzlich kann durch die Wahl geeigneter Verteilungsschlüssel eine Verteilung der Steuereinnahmen auf die einzelnen Länder bzw. Gemeinden realisiert werden, durch die unerwünschte räumliche Entwicklungen gebremst, ja sogar erwünschte Entwicklungen eingeleitet werden können. Doch auch bei dieser Steuerverteilungsmethode ist mit dem Widerstand derjenigen Gebietskörperschaften zu rechnen, die weniger Steuereinnahmen erhalten, als ihrem örtlichen Aufkommen entspricht. Auch in diesem Fall werden sich also regionale Steuerkraftunterschiede zugunsten der Wohlstandsregionen nicht vermeiden lassen. Die Frage ist nur, ob mit dieser Methode ein stärkerer horizontaler Ausgleichseffekt erzielt werden kann als mit horizontalen Ausgleichszahlungen? Diese Frage kann allgemein nur schwer entschieden werden. (378) Es kann lediglich vermutet werden, daß der Widerstand der finanzstarken Gebietskörperschaften gegen die in den vertikalen Finanzausgleich eingebaute Steuerkraftnivellierung geringer sein wird als bei nachträglicher Umverteilung von Steuereinnahmen. Diese Vermutung stützt sich vor allem darauf, daß die durch bedarfsorientierte Verteilungskriterien bewirkte Umverteilung in ihrer Höhe weniger offensichtlich und daher für die finanzstarken Gebietskörperschaften weniger merklich ist. Davon kann man wohl ausgehen, weil bei der Entscheidung über den Verteilungsschlüssel die in der Zukunft liegenden Umverteilungswirkungen nur mit Schwierigkeiten abgeschätzt werden können. Auch eine Ex-post-Berechnung der Umverteilungswirkung ist nicht in jedem Fall möglich und verursacht große Kosten und Mühen. Die einzelnen Gebietskörperschaften treten "nicht unmittelbar als Gebende und Nehmende"(379) auf, so daß ihnen nicht jedes Jahr von Neuem vor Augen geführt wird, in welcher Höhe sie auf Steuereinnahmen verzichten müssen, die sie bei einer Verteilung ausschließlich nach dem örtlichen Aufkommen erhalten hätten. Das Unbehagen der finanzstarken Gebietskörperschaften über die zu ihren Lasten gehende Umverteilung wird somit, im Gegensatz zur Lösung des horizontalen Finanzausgleichs, nicht jährlich erneuert oder gar verstärkt. Man kann also bei dieser Steuerverteilungsmethode eine gewisse "Umverteilungsillusion" vermuten. (380)

Die Wahrscheinlichkeit, daß die untergeordneten Gebietskörperschaften das Ausmaß der Umverteilung von Steuereinnahmen nicht vollständig erkennen, kann wohl als relativ groß eingeschätzt werden. Deshalb kann man von einem Steuerverbund mit gesetzlich festgelegten, bedarfsorientierten Verteilungsschlüsseln erwarten, daß durch ihn in der Regel ein größerer horizontaler Ausgleichseffekt erzielt werden kann als durch die Kombination von gebundenem Trennsystem und horizontalem Finanzausgleich. Dies ist der Hauptgrund, weswegen in dieser Arbeit dem Steuerverbund vor allen anderen Steuerverteilungssystemen der Vorzug gegeben wird. (381)

\section{Der öffentliche Bedarf als Verteilungskriterium der Steuereinnahmen}

Die einer untergeordneten Ebene zustehenden Einnahmen, also ihr Anteil an der Verbundmasse, sollen auf die einzelnen Mitglieder dieser Ebene nach 
gesetzlich festgelegten Bedarfsmaßstäben verteilt werden. Einige mit diesen Bedarfsmaßstäben verbundene Probleme sollen in diesem Abschnitt näher untersucht werden.

4.1. Die Popitz'sche Forderung nach einem "allgemeinen Ausgleich der öffentlichen Bedarfe und ihrer Deckung"

Die traditionelle Finanzwissenschaft hat, ausgehend von Popitz, einen "allgemeinen Ausgleich der öffentlichen Bedarfe und ihrer Deckung"(382) gefordert. Die Verteilung der öffentlichen Einnahmen auf die einzelnen Gebiets körperschaften sollte "der Bedingung eines allseitigen Einklanges von öffentlichen Bedarfen und ihrer Deckung genügen ... . Das zweite Gos se n sche Gesetz wurde so zur Generalklausel, mit der der Finanzausgleich allgemein und die Konstruktion gewisser Verteilungsschlüssel insbesondere ihre Motivierung erhielten. "(383)

Dieses Postulat verlangt eine Verteilung der öffentlichen Einnahmen auf die einzelnen Gebietskörperschaften, bei der die letzte in jeder Gebietskörperschaft eingesetzte Geldeinheit den jeweiligen Gemeindebürgern überall den gleichen Nutzen stiftet. (384) Die optimale Einnahmenverteilung liegt also vor, wenn regionale Gleichheit der Grenznutzen aus öffentlicher Aktivität erreicht ist. Durch eine weitere Umverteilung der Einnahmen zwischen den einzelnen Gebietskörperschaften kann dann der für die Gesamtheit aus der öffentlichen Aktivität anfallende Nutzen nicht mehr erhöht werden. Die Mittelverteilung, die das zweite Gossensche Gesetz erfüllt, bewirkt also, daß der Gesamtnutzen aus der öffentlichen Aktivität maximiert wird. So sehr die ses Verteilungskriterium auch theoretisch überzeugen mag, so wenig eignet es sich jedoch als Entscheidungshilfe für die konkrete Verteilung einer gegebenen Verbundmasse. Die regionale Gleichheit der Grenznutzen aus öffentlicher Aktivität läßt sich durch die Verteilung der öffentlichen Einnahmen nämlich nur dann erreichen, wenn der Nutzen aus öffentlicher Aktivität drei wesentliche Bedingungen erfüllt:

- er muß quantifizierbar sein,

- er muß individuell zurechenbar sein,

- er muß interpersonell vergleichbar sein.

In der Realität ist keine dieser drei Bedingungen für die Anwendbarkeit dieses nutzentheoretischen Verteilungskriteriums erfüllt. (385) Das Postulat vom "allgemeinen Ausgleich der öffentlichen Bedarfe und ihrer Deckung" erweist sich damit als materiell inhaltsleer, besitzt also Leerformelcharakter. "Durch den auf den öffentlichen Sektor übertragenen zweiten Gos s e n schen Satz kann .. jede Finanzausgleichsoperation - einschließlich jener der vollständigen Enthaltsamkeit - motiviert werden. Anders ausgedrückt: Die Formel vom Ausgleich der öffentlichen Bedarfe und ihrer Deckung hilft keinen Deut in den Bemühungen weiter, einen optimalen Verteilungsschlüs sel der Finanzausgleichsmassen zu gewinnen. "(386)

Da eine objektive Bedarfsermittlung so gut wie unmöglich ist, wird die Fest- 
legung der öffentlichen Bedarfe der einzelnen Gebietskörperschaften immer eine politische Entscheidung sein. (387) Die konkrete Höhe der Finanzmittel, die den einzelnen Gebietskörperschaften zugewiesen werden, hängt von der Interpretation dessen, was "öffentlicher Bedarf" genannt wird, ab. Damit beeinflußt die konkrete Interpretation des "öffentlichen Bedarfs" auch die Raumstruktur. Die große regionalpolitische Bedeutung sowie die Unschärfe des Begriffs des "öffentlichen Bedarfs" machen es erforderlich, ihn etwas eingehender zu untersuchen.

\subsection{Klärung des Begriffs "öffentlicher Bedarf"}

Unter "Bedarf" wird "die im Markte tatsächlich auftretende Nachfrage"(388) verstanden. Dementsprechend kann mit dem Begriff des "öffentlichen Bedarfs" die Nachfrage der privaten Wirtschaftssubjekte nach Leistungen der öffentlichen Hände bezeichnet werden. Die öffentlichen Bedarfe entspringen also den individuellen Bedürfnissen der Wirtschaftssubjekte. "Zur Deckung der öffentlichen Bedarfe erstellen die Kommunen Leistungen verschiedener Art, die von den lokalen Industrien und/oder den Haushalten aufgenommen werden. "(389) Um dieses Leistungsangebot erstellen zu können, benötigen die öffentlichen Hände Finanzierungsmittel. Die Summe der Finanzierungsmittel, die sie benötigen, um die innen gegebenen Aufgaben in einer bestimmten Periode in befriedigendem Umfang zu erfüllen, wird "Finanzbedarf" der jeweiligen Gebietskörperschaft genannt. Wenn im folgenden der Begriff "Bedarf" verwendet wird, ist damit nicht die Nachfrage der privaten Wirtschafts subjekte nach öffentlichen Leistungen, sondern der von den einzelnen Gebietskörperschaften zur Durchführung ihrer Aufgaben benötigte Finanzbedarf gemeint.

Die Höhe des Finanzbedarfs einer Gebietskörperschaft hängt von Art und Umfang der Aufgaben, die sie zu erfüllen hat, ab. Dabei bestimmen die von den einzelnen Gebietskörperschaften verfolgten Ziele, welche Aufgaben und damit Ausgaben als unbedingt notwendig erscheinen. Zwei unterschiedliche Interpretation des Bedarfs kann man unterscheiden:

- den "lokalen" Bedarf

Der Kreis der als notwendig erachteten Aufgaben und Ausgaben kann aus der Sicht der einzelnen untergeordneten Gebietskörperschaft gesehen und von ihr nach eigenem Ermessen festgesetzt werden. Die Summe der Finanzierungsmittel, die zur Realisierung der Aufgaben aus der Sicht der untergeordneten Gebietskörperschaft erforderlich ist, wird als "lokaler" Bedarf bezeichnet. Der lokale Bedarf wird im wesentlichen durch die aktuelle, kaufkräftige Nachfrage der Einwohner der untergeordneten Gebietskörperschaften nach öffentlichen Leistungen bestimmt. Er "berechnet sich aus den Bedürfnissen des lokalen oder regionalen Bereiches"(390) und wird den effektiven Kosten der öffentlichen Leistungserstellung gleichgesetzt.

- den "volkswirtschaftlichen" Bedarf 
In welchem Umfang Aktivität und Ausgaben einer untergeordneten Gebietskörperschaft wünschenswert sind, kann nicht nur von ihr selbst, sondern auch aus übergeordneter, gesamtwirtschaftlicher Sicht beurteilt werden. In diesem $\mathrm{F}$ all entscheiden die Ziele eines räumlich koordinier ten Zielsystems die Höhe des Finanzbedarfs, der den einzelnen untergeordneten Gebietskörperschaften zugebilligt wird. Dieser aus gesamtwirtschaftlichen Gründen wünschenswerte Finanzbedarf wird volkswirtschaftlicher Bedarf einer untergeordneten Gebietskörperschaft genannt. Er wird so festgelegt, daß die Aktivität der untergeordneten Gebietskörperschaften möglichst zur Realisierung der gesamtwirtschaftlichen Ziele beiträgt. (391)

Der lokale Bedarf einer untergeordneten Gebietskörperschaft weicht in der Regel von ihrem volkswirtschaftlichen Bedarf ab. (392) Diese Diskrepanz zwischen beiden Bedarfsarten beruht darauf, daß eine untergeordnete Gebietskörperschaft nur selten Ziele anstrebt (räumlich unkoordiniertes Zielsystem), die sich mit den wirtschaftspolitischen Zielvorstellungen der übergeordneten Gebietskörperschaft(en) decken (räumlich koordiniertes Zielsystem).

Bevor eine gegebene Verbundmasse auf die einzelnen Mitglieder einer untergeordneten Ebene des Bundesstaates verteilt werden kann, muß eine Grundsatzentscheidung darüber getroffen werden, an welcher Bedarfsart sich die Mittelverteilung zu orientieren hat. Zugleich muß eine Vorstellung über die wünschenswerte Höhe interregionaler bzw. interlokaler Unterschiede des Pro-Kopf-Bedarfs bestehen.

5. Überlegungen zur wünschenswerten Höhe der regionalen (lokalen) ProKopf-Bedarfe und ihrer Deckung

Aus einer Reihe von Gründen kann man vermuten, daß der Pro-Kopf-Finanzbedarf der untergeordneten Gebietskörperschaften umso größer ist, je höher ihr Agglomerationsgrad und ihr Wohlstandsniveau sind:

- Die Finanzstatistiken belegen, daß mit wachsender Einwohnerzahl die Ausgaben der Gemeinden pro Kopf ansteigen. Schließt man von der Höhe der kommunalen Ist-Ausgaben auf den Finanzbedarf, müssen den Gemeinden mit zunehmender Einwohnerzahl auch steigende Pro-Kopf-Einnahmen zugewiesen werden.

- Je größer eine Gemeinde ist, desto mehr und qualitativ bessere Leistungen fragen ihre Einwohner nach. Folglich muß eine Gemeinde mit steigender Einwohnerzahl mehr und bessere Leistungen pro Einwohner anbieten und benötigt deshalb höhere Pro-Kopf-Einnahmen als kleinere Gemeinden.

- Je größer eine Gemeinde ist, desto höher sind die Kosten, die bei Erstellung einer Einheit der öffentlichen Leistungen anfallen. Um quantitativ und qualitativ dieselben Leistungen pro Kopf wie kleinere Gemeinden anbieten zu können, benötigen große Gemeinden also höhere Pro-Kopf-Einnahmen. 
- Größere Gemeinden übernehmen für ihr Umland in der Regel eine Dienstleistungsfunktion. Sie bieten als zentrale Orte Leistungen an, die auch von Einwohnern umliegender Gemeinden in Anspruch genommen werden. In dem Ausmaß, in dem zentralörtliche Dienste an Einwohner anderer Gemeinden kostenlos oder zu nicht kostendeckenden Preisen abgegeben werden, wird der Haushalt der zentralen (großen) Gemeinden belastet. Zum Ausgleich dieser Belastung müssen die größeren Gemeinden höhere ProKopf-Einnahmen als kleinere Gemeinden erhalten.

Diese in der Literatur am häufigsten diskutierten Rechtfertigungen für eine Staffelung des Finanzbedarfs und damit für eine Staffelung der Pro-Kopf-Einnahmen nach der Gemeindegröße (393) werden anschließend auf ihre Stichhaltigkeit und ihre räumlichen Auswirkungen geprüft. Die Analyse führt zugleich zu einer Entscheidung zugunsten einer der beiden Bedarfsarten als Grundlage der Steuerverteilung.

5.1. Die Ist-Ausgaben der Gemeinden als Indikator des kommunalen Finanzbedarfs

Von den Ist-Ausgaben der untergeordneten Gebietskörperschaften kann weder auf ihren lokalen, noch auf ihren volkswirtschaftlichen Bedarf geschlossen werden. Die Höhe der Ist-Ausgaben der Länder und Gemeinden wird langfristig von ihren verfügbaren Steuereinnahmen und damit von finanzausgleichspolitischen Entscheidungen bestimmt. Die "mit steigender Gemeindegrößenklasse zunehmenden tatsächlichen Ausgaben [sind also] zunächst nur Folge der Anerkennung eines höheren 'Finanzbedarfs', nicht aber ein Beweis dafür."(394) "In ihnen spiegeln sich demnach Mangel und Überfluß mindestens in dem gleichen Umfang wider wie der Bedarf."(395)

5.2. Anstieg der Nachfrage nach öffentlichen Leistungen mit zunehmender Gemeindegröße als Rechtfertigung der Staffelung der Pro-Kopf-Einnahmen

Für die Vermutung, daß die Nachfrage nach öffentlichen Leistungen pro Einwohner mit zunehmender Gemeindegröße ansteigt, lassen sich im wesentlichen zwei Gründe anführen.

\subsubsection{Höhere Nachfrage nach öffentlichen Leistungen zur Kompensation} der Nachteile der Enge

Überschreitet eine Gemeinde bzw. Region einen bestimmten Agglomerations grad (Agglomerationsoptimum), schlagen die Vorteile der Nähe in Nachteile der Enge um. Die Nachteile der Enge führen direkt zu einer Kostenerhöhung bei den privaten Wirtschaftssubjekten. (396) Um diesen ballungsbedingten Kostenanstieg zu kompensieren, fragen die Einwohner der Ballungsgebiete mehr öffentliche Leistungen nach als Einwohner ländlicher Regionen. Da die größe- 
ren Gemeinden zur Kompensation der Ballungsnachteile mehr Leistungen pro Einwohner anbieten müssen als kleinere Gemeinden, benötigen sie auch höhere Pro-Kopf-Einnahmen.

Die stark agglomerierten Gemeinden haben also zweifellos einen höheren lokalen Finanzbedarf als die kleineren Gemeinden. Die Frage ist nur, ob der ballungsbedingte Mehrbedarf bei der Verteilung der Einnahmen berücksichtigt werden sollte. Geschieht dies nämlich, werden die stark agglomerierten Gemeinden finanziell in die Lage versetzt, die Wirkung der Ballungs nachteile als automatische Stabilisatoren des räumlichen Differenzierungs prozesses (397) außer Kraft zu setzen. "Die Anerkennung eines besonderen öffentlichen Bedarfs in hochagglomerierten Räumen bedeutet nichts anderes als den Verzicht auf die bestmögliche räumliche Struktur. "(398)

Aus regionalpolitischen Gründen wird hier die Berücksichtigung des ballungsbedingten Mehrbedarfs der großen Gemeinden bei der Einnahmenverteilung abgelehnt. Damit ist auch eine erste Entscheidung zugunsten des volkswirtschaftlichen und gegen den lokalen Bedarf als Grundlage der Einnahmenverteilung gefallen.

5.2.2. Abhängigkeit der Nachfrage nach öffentlichen Leistungen von dem regionalen Wohlstandsniveau und der Wirtschaftskraft

5.2.2.1. Die regionale Verteilung der Nachfrage nach haushaltsorientierten öffentlichen Leistungen

Man kann vermuten, daß öffentliche Leistungen superiore Bedürfnisse befriedigen. Viele öffentliche Leistungen werden von den privaten Wirtschafts subjekten erst dann als wünschenswert empfunden und nachgefragt, wenn ihr Einkommen ein bestimmtes Mindestniveau erreicht hat und die Befriedigung elementarer Lebensbedürfnisse erlaubt. Mit zunehmendem individuellen Wohlstand werden dementsprechend Leistungen, die von den öffentlichen Händen erbracht werden müssen, in der Präferenzskala der privaten Wirtschafts subjekte einen immer höheren Rang einnehmen und deshalb immer stärker nachgefragt. Diese Vorstellung, daß die Struktur der Nachfrage der privaten Wirtschaftssubjekte nach Gütern und Dienstleistungen einkommensabhängig ist und mit steigendem Einkommen der Anteil der öffentlichen (und privaten) Dienstleistungen an der Gesamtnachfrage zunimmt, steht wohl auch hinter der These von Popitz (399), daß die Einwohner der großen Gemeinden höhere Lebensansprüche haben als die Einwohner der ländlichen Gebiete. (400)

Die These von den unterschiedlichen Lebensansprüchen der Bevölkerung von Stadt und Land ist in der Gegenwart stark umstritten. So vertritt z. B. Haller den Standpunkt, daß die heutige Massengesellschaft durch eine "immer weiter zunehmende Gleichförmigkeit der Lebensansprüche und Präferenzen" gekennzeichnet sei. "Man erstrebt überall wenigstens einen befriedigenden bis guten Stand der Bedürfnisbefriedigung, will nirgends zurückbleiben. Auch vom Staat erwartet man, unabhängig davon, in welchem Gliedstaat man wohnt, 
gleichmäßig gute Leistungen auf allen Gebieten, die für die private Bedürfnisbefriedigung wichtig sind. ... Die Präferenzskalen der Bürger dürften auch in dieser Richtung weitgehend nivelliert sein in dem Sinne, daß man in allen Sparten ziemlich hohe Ansprüche stellt. "(401) Littmann klassifiziert die Auffassungen, daß Einwohner kleiner Gemeinden nicht im selben Ausmaß wie Einwohner großer Gemeinden das Bedürfnis haben, öffentliche Einrichtungen zu nutzen, als "historische Relikte überholter politischer Wertungen". (402) Vielmehr "existieren zahlreiche öffentliche Bedarfe, deren Höhe pro Kopf schlechthin unabhängig von der Einwohnerzahl der Gemeinden ist." (402)

Beide Autoren bestreiten also grundsätzlich, daß die Einwohner großer Gemeinden pro Kopf höhere öffentliche Leistungen nachfragen als die Einwohner kleiner Gemeinden, wenn man von der Nachfrage nach öffentlichen Leistungen zur Kompensation der Ballungsnachteile absieht. Stimmt man dieser Auffassung zu, läßt sich eine Staffelung auch des lokalen Finanzbedarfs nach der Gemeindegröße nicht mehr rechtfertigen. Aus Gründen der Gleichbehandlung und Gerechtigkeit müssen dann alle Gemeinden unabhängig von ihrer Größe finanziell so ausgestattet werden, daß sie pro Einwohner dasselbe Leistungsvolumen anbieten können.

Ob man tatsächlich eine so weitgehende regionale Unterschiedslosigkeit der Nachfrage nach öffentlichen Leistungen unterstellen darf, kann nur schwer eindeutig beantwortet werden. Eine Entscheidung für oder gegen diese These wird immer zu einem großen Teil auf Werturteilen beruhen. Doch kann vielleicht soviel vermutet werden: Je geringer die regionalen Wohlstandsunterschiede sind und je besser die Einwohner der einzelnen Gemeinden oder Regionen über die Lebensbedingungen in anderen Gemeinden bzw. Regionen Bescheid wissen, desto weniger werden die Ansprüche der Bürger an das öffentliche Leistungsangebot regional voneinander abweichen. Die These von der Unterschiedslosigkeit der Lebensansprüche wird deshalb eher für die Bundesrepublik als für den Wirtschaftsraum der Europäischen Gemeinschaften zutreffen.

5.2.2.2. Die regionale Verteilung der Nachfrage nach unternehmensorientierten öffentlichen Leistungen

Die bisherigen Überlegungen beziehen sich ausschließlich auf haushaltsorientierte Leistungen. Untersuchen wir nun kurz, ob man unterstellen kann, daß die Nachfrage nach unternehmensorientierten Leistungen regional Niveauunterschiede aufweist, auch wenn man von den nachgefragten Leistungen absieht, die zur Kompensation der Ballungsnachteile dienen? Es leuchtet wohl unmittelbar ein, daß auch ohne die spezifisch ballungsbedingte Nachfrage in den Gemeinden bzw. Regionen, in denen sich die Gewerbebetriebe konzentrieren, pro Einwohner mehr unternehmensorientierte Leistungen nachgefragt werden als in Regionen mit geringem oder gar keinem Industriebesatz. Für die Nachfrage nach unternehmensorientierten Leistungen der öffentlichen Hände kann man eine positive Korrelation mit der regionalen Wirtschaftskraft unterstellen. 
Realistischerweise muß also angenommen werden, daß in großen Gemeinden auch dann, wenn Nachteile der Enge noch nicht kompensiert werden müssen, mehr öffentliche Leistungen nachgefragt werden als in kleinen Gemeinden. Dies gilt entweder ausschließlich für unternehmensorientierte oder, wenn man die Auffassung Hallers und Littmanns nicht voll teilt, auch für haushaltsorientierte öffentliche Leistungen. Inwieweit sollten nun diese regionalen Nachfrageunterschiede in regionale Einnahmenunterschiede umgesetzt werden?

5.2.2.3. Räumliche Auswirkungen der Berücksichtigung lokaler (regionaler) Unterschiede in der Nachfrage nach öffentlichen Leistungen bei der horizontalen Einnahmenverteilung

Wenn die untergeordneten Gebietskörperschaften die örtliche Nachfrage nach öffentlichen Leistungen befriedigen sollen, benötigen die Gemeinden mit hoher Wirtschaftskraft höhere Pro-Kopf-Einnahmen als wirtschaftsschwächere Gemeinden. Da in der Regel die Wirtschaftskraft der Gemeinden mit ihrer Größe zunimmt, kann so eine Staffelung des lokalen Finanzbedarfs nach der Gemeindegröße begründet werden. (403)

Dient der lokale Finanzbedarf als Steuerverteilungskriterium, entstehen ein regionales Einnahmen- und Leistungsgefälle zugunsten der großen Gemeinden. Durch überdurchschnittliche öffentliche Leistungen pro Einwohner in den Ballungsregionen wird die interregionale Konkurrenzfähigkeit der dort ansässigen Wirtschaftssubjekte weiter erhöht und die Abwanderung der mobilsten Faktoren aus den ländlichen (Entleerungs-)Gebieten verstärkt. Orientiert sich die Einnahmenverteilung ausschließlich oder überwiegend an der aktuellen örtlichen Nachfrage nach öffentlichen Leistungen, fließen die Einnahmen schwergewichtig dorthin, wo bereits eine hohe Konzentration wirtschaftlicher Aktivitäten vorzufinden ist. Die räumlichen Konzentrationstendenzen und regionalen Wohlstandsunterschiede werden verstärkt. $(404,405)$

Wegen dieser ballungsfördernden Wirkung muß aus regionalpolitischer Sicht abgelehnt werden, daß die aktuelle Nachfrage nach öffentlichen Leistungen und damit der lokale Finanzbedarf als Maßstab der Steuerverteilung verwendet wird. Regionalpolitisch erwünscht wäre dagegen, wenn man bei der Einnahmenverteilung mindestens von gleichen Pro-Kopf-Bedarfen ausgeht und dementsprechend die Gemeinden bzw. Regionen mit gleich hohen Einnahmen pro Kopf ausstattet. Auf diese Weise kann zwar noch kein sich selbst tragender Wachstumsproze $\beta$ in den Rückstandsgebieten induziert werden. Immerhin besteht aber doch die Chance, daß die Tätigkeit der öffentlichen Hände die regionalen Einkommensdiskrepanzen nicht noch weiter verschärft.

Wie die vorstehenden Überlegungen zeigen, spielt es für die Frage der wünschenswerten Höhe der Pro-Kopf-Bedarfe bzw. Pro-Kopf-Einnahmen im Grunde gar keine Rolle, ob man regionale Unterschiede in der Nachfrage nach öffentlichen Leistungen unterstellt oder nicht. Im einen $F$ all verbietet sich aus Gerechtigkeitsgründen, im anderen $\mathrm{F}$ all aus regionalpolitischen Gründen eine Staffelung des Finanzbedarfs nach der Gemeindegröße bzw. nach dem Agglomerationsgrad. 
5.3. Anstieg der Kosten der öffentlichen Leistungserstellung als Rechtfertigung der Staffelung des Bedarfs nach der Gemeindegröße

5. 3.1. Die Abhängigkeit der Kosten öffentlicher Leistungserstellung vom Agglomerationsgrad

Bisher haben wir unterstellt, daß die Kosten der öfentlichen Leistungserstellung pro Outputeinheit vom Agglomerationsgrad unabhängig sind. Das öffentliche Leistungsangebot wird danach im selben Umfang erhöht, in dem die öffentlichen Ausgaben steigen. Dies Annahme einer Parallelität von öffentlichem Leistungsangebot und öffentlichen Ausgaben ist realitätsfern und wird hier deshalb aufgegeben. Durch Beobachtung erscheint die Annahme gerechtfertigt, daß die Kostenkurve der öffentlichen Leistungserstellung pro Outputeinheit $\mathrm{u}$-förmig verläuft.

Die Kosten der Erstellung einer Einheit der öffentlichen Leistungen sind in sehr schwach (unteroptimal) und in sehr stark (überoptimal) agglomerierten Gemeinden (Regionen) höher als in optimal agglomerierten Gemeinden (Regionen). (406) In diesem Zusammenhang zwischen Kosten der öffentlichen Leistungserstellung und Agglomerationsgrad kommt zum Ausdruck, daß sich Deglomerations - und Agglomerationsnachteile nicht nur direkt im privaten Sektor, sondern auch im öffentlichen Sektor auswirken.

Erhalten nun alle Gemeinden gleich hohe Pro-Kopf-Einnahmen, so können die sehr kleinen und die sehr großen Gemeinden weniger öfentliche Leistungen pro Einwohner anbieten als die optimaler agglomerierten Gemeinden. Für die Einwohner der ersten beiden Gemeindegruppen würden sich die Deglomerations-bzw. Agglomerationsnachteile indirekt, und zwar auf dem Wege des geringeren Leistungsangebots ihrer Kommunen, bemerkbar machen. (407) Um das gleiche Leistungsangebot pro Kopf wie die optimal agglomerierten Gemeinden erstellen zu können, brauchen die nicht optimal agglomerierten Gemeinden höhere Pro-Kopf-Einnahmen. Auch wenn man aus den oben angegebenen Gründen für regional gleich hohe öffentliche Leistungen plädiert, kann also eine Abstufung des Finanzbedarfs nach der Gemeindegröße begründet werden. Ob die Bedarfsunterschiede, die mit den regionalen Unterschieden in den Kosten der öffentlichen Leistungserstellung gerechtfertigt werden können, bei der Einnahmenverteilung berücksichtigt werden sollten, wird wieder nach den räumlichen Auswirkungen einer solchen Einnahmenstaffelung beurteilt.

5.3.2. Die räumlichen Auswirkungen der Berücksichtigung regionaler Unterschiede in den Kosten der öffentlichen Leistungserstellung bei der horizontalen Einnahmenverteilung

Betrachten wir zuerst den Mehrbedarf der kleinen Gemeinden (ländlichen Regionen), der zur Kompensation der Nachteile der Weite dient. Wird er bei der Einnahmenverteilung nicht berücksichtigt, spüren die Einwohner dieser Gebiete die Deglomerationsnachteile nicht nur direkt in Form fehlender 
Fühlungsvorteile, sondern auch indirekt in Form eines unterdurchschnittlichen Leistungsangebots ihrer Gebietskörperschaft. Dadurch wird die Standortunterlegenheit dieser Regionen zementiert und die Abwanderung mobiler Faktoren gefördert. Wenn man die Entwicklungschancen der ländlichen Gebiete nicht zerstören und langfristig in ihnen sich selbst tragende Wachstumsprozesse auslösen will, sollte man ihnen mindestens im Ausmaß der deglomerationsbedingten Kostensteigerung höhere Pro-Kopf-Einnahmen als stärker agglomerierten Regionen zuweisen. Auf diese Weise könnte die regionalpolitisch negativ zu beurteilende Wirkung der Deglomeration auf das Leistungsangebot des öffentlichen Sektors kompensiert werden, so daß die ländlichen Gebiete wenigstens nicht weniger Leistungen pro Einwohner anbieten müssen als stärker verdichtete Gebiete. Allerdings müßte überlegt werden, ob sich nicht Finanzzuweisungen von übergeordneten Gebietskörperschaften zu diesem Zweck besser eignen als eine entsprechende Staffelung der Steuereinnahmen.

Zum entgegengesetzten Ergebnis kommt man beim Mehrbedarf, der für die großen Gemeinden mit ballungsbedingten Kostensteigerungen der öffentlichen Leistungserstellung begründet werden kann. Wird er bei der Einnahmenverteilung berücksichtigt, so setzt man die automatischen Stabilisatoren des räumlichen Ballungsprozesses außer Kraft. (408) Es wird verhindert, daß sich die Nachteile der Enge auch auf indirektem Weg, über eine Einschränkung des öffentlichen Leistungsangebots, in den Wirtschaftsrechnungen der Einwohner der Ballungsgebiete bemerkbar machen und so die Standortqualität der überoptimal agglomerierten Gemeinden verschlechtern. (409) Höhere Pro-Kopf-Einnahmen für die großen Gemeinden, mit denen die ballungsbedingten Kostensteigerungen kompensiert werden können, verhindern also, daß die Ballungstendenzen automatisch gebremst werden.

Aus regionalpolitischer Sicht ist vielmehr wünschenswert, daß sich die Nachteile der Enge sowohl direkt als auch indirekt in den Wirtschafts rechnungen der Einwohner der Ballungsgebiete niederschlagen und ihre Standortentscheidung beeinflussen. (410) Auch dann, "wenn mit zunehmender Gemeindegröße ein überproportionales Ansteigen der Kosten für die Deckung des 'Normalbedarfs' nachweisbar sein sollte, [ist] ein Ausgleich nicht gerechtfertigt, da im Interesse einer optimalen Faktorkombination steigende Sozialkosten als. Standortnachteil bemerkbar bleiben und nicht durch ausgleichspolitische Maßnahmen in ihrer Wirkung abgeschwächt oder kompensiert werden sollen. "(411)

5.3.3. Methoden der Umsetzung der ballungsbedingten Kostensteigerungen öffentlicher Leistungserstellung in private Kosten

Um die Nachteile der Enge für die privaten Wirtschaftssubjekte spürbar und transparent zu machen, bieten sich zwei Wege an.

- Alle Gebietskörperschaften erhalten unabhängig von ihrer Größe dense1ben Einnahmenbetrag pro Einwohner zugewiesen (Lösung 1). Überdurchschnittlich hohe, ballungsbedingte Kosten der Leistungserstellung in gro- 
Ben Gemeinden wirken sich in einem unterdurchschnittlichen Leistungsangebot aus. Die Nachteile der Agglomeration werden auf diese Weise in private Kosten transformiert und müssen bei den Standortentscheidungen der privaten Wirtschaftssubjekte beachtet werden.

- Alle Gemeinden sollen unabhängig von ihrer Größe gleich hohe öffentliche Leistungen pro Einwohner anbieten. Das setzt voraus, daß die großen Gemeinden höhere Pro-Kopf-Ausgaben als die kleineren Gemeinden tätigen. Die kommunalen Ausgaben werden durch örtlich vollständig radizierte Steuern, die den Kommunen in Ertragshoheit zugewiesen sind, finanziert. Um das reale Leistungsangebot trotz ballungsbedingter Kostensteigerungen aufrecht zu halten, müssen die überoptimal agglomerierten Gemeinden die Steuerbelastung ihrer Einwohner anheben (Lösung 2). Während bei der ersten Lösung unterdurchschnittliche kommunale Leistungen den privaten Wirtschaftssubjekten die Agglomerationsnachteile eines Standortes signalisieren, geschieht dies bei dieser zweiten Lösung durch die überdurchschnittliche Steuerbelastung. (412)

Littmann hält beide Alternativen für "konsequente Schemata einer rationalen kommunalen Finanzpolitik", (413) sieht sie jedoch nicht als gleichwertig an. Denn die zweite Lösung genügt seiner Meinung "besser dem Postulat der Selbstverantwortlichkeit der unteren politischen Instanzen, das dem föderativen Prinzip a priori zu eigen ist". (413) Dagegen setzt die erste Lösung "einen streng zentralistischen Staatsaufbau voraus und läßt die kommunalen Willensträger praeter propter zu Auftragsempfängern staatlicher Maßnahmen werden. "(413)

Dieser Standpunkt kann nicht ohne weiteres geteilt werden. Wie schon gezeigt, bedeutet die Einbeziehung untergeordneter Gebietskörperschaften in einen Steuerverbund (Lösung 1) nicht, daß sie automatisch zu Befehlsempfängern des Zentralstaates werden. (414) Die von Littmann präferierte Alternative 2 sichert den untergeordneten Gebietskörperschaften bestenfalls einen höheren Grad an Einnahmenhoheit, aber keinesfalls einen höheren Grad an Ausgabenautonomie als die erste Lösung. Allein mit dem größeren Ausmaß an Einnahmenhoheit für die untergeordneten Gebietskörperschaften kann aber eine Überlegenheit der zweiten Alternative über die erste m. E. nicht begründet werden. Dagegen muß man bedenken, daß die Agglomerationsnachteile durch Lösung 2 nur unter einer Bedingung vollständig in private Kosten transformiert werden: Die örtlichen Aufkommen der Steuern, die den Kommunen in Ertragshoheit zugewiesen sind, dürfen bei gleicher Steueranspannung sowohl zwischen Gemeinden gleicher als auch zwischen Gemeinden unterschiedlicher Größe nicht im geringsten streuen. (415) Sobald nämlich die großen Gemeinden bei gleicher Steueranspannung höhere Steuereinnahmen pro Kopf als kleinere Gemeinden erzielen, können sie die ballungsbedingten Kostensteigerungen kompensieren, ohne ihre Einwohner überdurchschnittlich steuerlich belasten zu müssen. Wenn man verteilungspolitisch indiskutable Kopfsteuern vernachlässigt, kann man sich kaum Steuern vorstellen, deren Aufkommen pro Kopf bei gleicher Steueranspannung regional überhaupt nicht streut. Auch Littmann entwickelt als konkreten Vorschlag zur zweiten Alternative ein kommunales Steuersystem, daß "nicht die idealen Eigenschaften aufweist, räum- 
liche Streuungen in den Steuerobjekten völlig auszuschließen. Schon aus diesem Grunde sind Finanzausgleichsmaßnahmen nicht zu entbehren. "(416)

Da bei Lösung 2 in jedem Fall ein nachträglicher Steuerkraftausgleich erfor derlich ist, muß man sie als komplizierter und verwaltungsmäßig aufwendiger einschätzen als die erste Alternative. Zudem muß befürchtet werden, daß infolge politischer Widerstände kein vollständiger Steuerkraftausgleich erreicht wird, (417) so daß durch den Steuersatzmechanismus die Ballungsnachteile weniger vollständig in private Kosten transformiert werden als durch den Leistungsmechanismus der ersten Lösung. Deshalb wird hier dafür plädiert, alle Kommunen unabhängig von ihrer Größe mit gleich hohen Pro-KopfEinnahmen auszustatten, so daß sich die ballungsbedingten Unterschiede in den Kosten öfentlicher Leistungserstellung in regional unterschiedlichen Leistungsangeboten pro Einwohner niederschlagen.

5.4. Angebot zentralörtlicher Leistungen als Rechtfertigung der Staffelung der Pro-Kopf-Einnahmen nach der Gemeindegröße

Soweit dieser Grund "für das Ansteigen des Finanzbedarfs verantwortlich ist, entspricht eine Zunahme der Steuerkraft mit wachsender Gemeindegrößenklasse lediglich der Aufgabenverteilung auf kleine und große Gemeinden. "(418) Die Berücksichtigung des Finanzbedarfs, der auf das Leistungsangebot einer Gemeinde zugunsten der Einwohner anderer Gemeinden zurückzuführen ist, erscheint auch mit den angestrebten regionalpolitischen Zielen vereinbar. Doch erfordert auch diese Rechtfertigung einer Staffelung der Pro-Kopf-Einnahmen nach der Gemeindegröße eine kritische Anmerkung.

Es ist zu bedenken, daß die großen Gemeinden durch ihr Umland nicht nur finanziell belastet, sondern auch finanziell entlastet werden. Nicht nur zentrale Orte übernehmen eine Versorgungsfunktion für ihr Umland. Auch das Umland übernimmt Funktionen für die Bewohner der zentralen Orte. (419) Die weniger stark agglomerierten Umlandgemeinden müssen z. B., häufig auch gegen ihren Willen, Flächen bereitstellen, die der Ver- und Entsorgung der Städte und der Naherholung der Stadtbewohner dienen. Dadurch können u. U. die wirtschaftlichen Entwicklungsmöglichkeiten der Umlandgemeinden eingeschränkt werden. Einwohner der Städte nutzen ebenso Infrastruktureinrichtungen der Umlandgemeinden, wie deren Einwohner die Einrichtungen der Städte in Anspruch nehmen. Den Ertrags-spillouts der zentralen Orte stehen also auch Ertrags-spillins (420) gegenüber, durch die ihr Budget entlastet und das der Umlandgemeinden belastet wird. Die Ausstattung der großen (zentralen) Gemeinden mit überdurchschnittlichen Pro-Kopf-Einnahmen ist regionalpolitisch nur dann akzeptabel, wenn die großen Gemeinden im Nettoeffekt durch ihr Umland finanziell belastet werden, und sie darf auch nur im Umfang der Netto-Belastung vorgenommen werden.

Kommt man nach Abwägen aller Argumente oder auch nur aufgrund "tägliche[r] Erfahrung" zu der Ansicht, "daß im Durchschnitt die größeren Gemeinden relativ höhere öffentliche Leistungen an die Einwohner kleinerer Gemeinden abgeben als umgekehrt", (421) muß die Frage entschieden wer- 
den, auf welche Weise diese zusätzlichen Kosten der größeren Gemeinden abgegolten werden sollen.

5.5. Methoden zur Abgeltung der Kosten zentralörtlicher Leistungserstellung

5.5.1. Pauschale Abgeltung durch Staffelung der Steuereinnahmen pro Kopf nach der Gemeindegröße

Um die großen Gemeinden für die Kosten zu entschädigen, die durch die Abgabe von öffentlichen Leistungen an Einwohner anderer Gemeinden entstehen, kann man sie mit höheren Pro-Kopf-Einnahmen als die kleinen Gemeinden ausstatten. Zwei technische Verfahren bieten sich dazu an. Entweder werden den Gemeinden Steuerquellen in Ertragshoheit zugewiesen, deren örtliches Aufkommen pro Einwohner mit der Gemeindegrößenklasse zunimmt. Oder sie erhalten aus der Steuerverbundmasse Einnahmen, die nicht nach der tatsächlichen, sondern nach einer "veredelten" Einwohnerzahl bemessen werden. Zur Berechnung der "veredelten" Einwohnerzahlen werden die tatsächlichen Einwohnerzahlen der Gemeinden umso stärker gewichtet, je größer die Gemeinden sind.

Gegen diese pauschale Abgeltung der zentralörtlichen Ertragsspillovers müssen aus regionalpolitischer Sicht schwerwiegende Bedenken erhoben werden. Sie kann nicht die vielfältigen Interdependenzen zwischen den Städten als zentralen Orten und ihrem Umland auch nur annäherungsweise berücksichtigen. Städte der gleichen Größenordnung nehmen im System der zenţralen Orte unterschiedliche Stellungen ein und werden durch ihre Beziehungen zum Umland in unterschiedlichem Ausmaß be- oder entlastet. Die "Kosten überörtlicher Funktion sind viel zu ungleichmäßig innerhalb der Gemeindegrößenklas sen verteilt, als daß sie durch einen Gemeindegrößenansatz abgegolten werden könnten. Es lassen sich in jeder Gemeindegröße Orte mit sehr hohem und Orte mit sehr niedrigem Steueraufwand für Bürger anderer Gemeinden nennen. "(422) Allein aus der Größe einer Gemeinde kann man also nicht auf die Höhe der Netto-Ertrags-spillouts schließen.

Werden die Netto-Ertrags-spillouts pauschal abgegolten, läßt sioh eine Überund Unterdotierung einzelner Gemeinden nicht vermeiden. Einige Gemeinden erhalten mehr Finanzmittel, als zum Ausgleich der Kostenbelastung aus ihrem Angebot zugunsten der Einwohner anderer Gemeinden erforderlich ist. Sie können für ihre Einwohner zusätzliche Leistungen anbieten und so ihre Attraktivität für mobile Ressourcen erhöhen. Die unterdotierten Kommunen dagegen werden gezwungen, ihr Leistungsangebot für die eigenen Einwohner einzuschränken.

Die Methode der pauschalen Abgeltung von Spillover-Effekten durch die Staffelung der Steuereinnahmen nach der Gemeindegröße erweist sich also als zu undifferenziert und als zu starr. Die durch sie zustandekommende Einnahmenverteilung beeinflußt die Raumstruktur in unerwünschter und unkontrollierbarer Weise. Sie ist deshalb für die Abgeltung von Spillover-Effekten denkbar ungeeignet. (423) 
5.5.2. Abgeltung der Netto-Ertrags-spillovers nach dem Äquivalenzprinzip (horizontale Kompensation)

Eine zweite Möglichkeit, Ertrags-spillouts abzugelten, besteht darin, die Kosten der Erstellung zentraler Dienste nach dem Äquivalenzprinzip auf die Nutznießer dieser Leistungen umzulegen. Dies kann einmal in der Weise geschehen, daß der zentrale Ort unmittelbar von den einzelnen Empfängern der zentralörtlichen Leistung entsprechend ihrer Inanspruchnahme der Leistung einen Finanziemungsbeitrag verlangt (individuelle kostenmäßige Äquivalenz). In diesem Fall wird das Angebot zentralörtlicher Leistungen über einen Gebührenhaushalt finanziert. Die zweite Möglichkeit zur horizontalen Kompensation besteht darin, die Gemeinden, deren Einwohner Einrichtungen des zentralen Ortes nutzen, entsprechend ihrem Anteil an der zentralörtlichen Leistungsabgabe an den Kosten der Leistungserstellung zu beteiligen (gruppenmäßige kostenmäßige Äquivalenz). Die Finanzierung des zentralörtlichen Leistungsangebots erfolgt dann durch Verwaltungskostenbeiträge der begünstigten Gemeinden.

Beide Abgeltungsverfahren lassen sich nur dann anwenden, wenn

- die Kosten der Erstellung zentralörtlicher Leistungen einschließlich der Gemeinkosten ermittelt werden können,

- die von den Einwohnern der umliegenden Gemeinden in Anspruch genommenen Leistungen entweder den begünstigten Individuen oder den begünstigten Gemeinden zugerechnet werden können und

- die zurechenbaren Leistungen quantifiziert und vergleichbar gemacht werden können. (424)

Für die Mehrzahl der zentralörtlichen Leistungen werden diese Bedingungen nicht zutreffen. Für einige dieser Leistungen werden dagegen die Probleme der Kostenermittlung, der Zurechenbarkeit und der Quantifizierung wenigstens so weit lösbar sein, daß schematische, aber für die Beteiligten doch einsichtige Ausgleichsverfahren gefunden werden können. Aber auch dann ist nicht gesichert, daß auf dem Wege der horizontalen Kompensation ein befriedigender Ausgleich der zentralörtlichen Kostenbelastung zustande kommt. Denn ein "grundlegendes Problem der horizontalen Kompensation liegt .. darin, daß die Gebietskörperschaft, welche Zahlungen wünscht, diese oft nicht erzwingen kann und deshalb von Anfang an auf den guten Willen des Partners angewiesen bleibt."(425)

Weil mit dieser Abgeltungsmethode nicht nur Messungs-, sondern auch große Zurechnungsprobleme verbunden sind und ein Ausgleich nur auf freiwilliger Basis erreicht werden kann, wird man auf diesem Wege wohl nur einen kleinen Teil der Netto-Ertrags-spillouts der zentralen (großen) Gemeinden abgelten können.

5. 5. 3. Abgeltung der Netto-Ertrags-spillovers durch Zahlungen der übergeordneten Gebietskörperschaften (vertikale Kompensation)

Damit man Netto-Ertrags-spillouts zentraler Gemeinden ausgleichen kann, 
müssen die Spillover-Effekte identifizierbar und meßbar sein. Sind diese Grundvoraussetzungen annähernd erfüllt, können die übergeordneten $\mathrm{Ge}$ bietskörperschaften durch Finanzzuweisungen an die zentralen Orte die tatsächlich auftretenden Spillover-Effekte weitgehend ausgleichen. Gemeinden, für die hohe Netto-Ertrags-spillouts festgestellt werden, erhalten höhere Zuweisungen als Gemeinden derselben oder auch einer darüber liegenden Größenklasse, für die niedrigere Kostenbelastungen durch das Umland vorliegen. So kann eine regionale Verteilung der Pro-Kopf-Einnahmen realisiert werden, die den lokalen Unterschieden im zentralörtlichen Finanzbedarf pro Kopf weitgehend entspricht. Die Gefahr einer Über- und Unterdotierung mit den daraus resultierenden unerwünschten und unkontrollierbaren Raumwirkungen kann in hohem Maße verringert werden. Der Abgeltung von SpilloverEffekten durch Zuweisungen der übergeordneten Gebietskörperschaften ist deshalb der Vorzug vor der pauschalen Abgeltung durch einen GemeindegröBenansatz zu geben. (426)

Vertikale Zahlungen sind auch geeignet, solche zentralörtlichen Lëistungen zu finanzieren, die nicht individuell oder gruppenmäßig zurechenbar oder zu deren Finanzierung die begünstigten Umlandgemeinden freiwillig nicht bereit sind. In dieser Hinsicht sind also vertikale Kompensationszahlungen auch den horizontalen Kompensationszahlungen überlegen. (427)

6. Grundlinien eines regionalpolitisch rationalen Systems der Einnahmenverteilung

Aus den Überlegungen zur wünschenswerten Höhe der Pro-Kopf-Bedarfe und ihrer Deckung werden in groben Zügen die Grundlinien eines Systems der Einnahmenverteilung sichtbar, das mit den angestrebten regionalpolitischen Zielen (428) vereinbar ist.

6.1. Der volkswirtschaftliche Finanzbedarf - Grundlage der Einnahmenverteilung

Die aktuelle Nachfrage nach öffentlichen Leistungen in den einzelnen untergeordneten Gebietskörperschaften ist das Ergebnis der raumwirtschaftlichen Prozesse der Vergangenheit. Verwendet man die lokalen Finanzbedarfe, die durch die aktuelle, marktwirksame Nachfrage nach öffentlichen Leistungen determiniert werden, als Grundlage der Verteilung der Einnahmen auf die einzelnen Mitglieder der unteren bundesstaatlichen Ebenen, so wird die bestehende Raumstruktur konserviert. Die aktuelle Nachfrage nach öffentlichen Leistungen an einem Ort darf jedoch keinesfalls als quasi-naturgesetzliche Größe, sondern muß als politisch beeinflußbar aufgefaßt werden. Die Gebietskörperschaften können durch ihre Aktivität latent vorhandene Nachfrage in aktuelle, marktwirksame Nachfrage nach öffentlichen Leistungen umwandeln. Deshalb sollte die Höhe der Pro-Kopf-Bedarfe der untergeordneten Gebietskörperschaften durch die angestrebten wirtschaftspolitischen, insbesondere die angestrebten regionalpolitischen Ziele bestimmt werden. 
Der jeweilige Finanzbedarf muß so festgelegt werden, daß als Ergebnis der am Bedarf orientierten Einnahmenverteilung die erwünschte Raumstruktur soweit wie möglich realisiert wird. Grundlage der Verteilung der Einnahmen auf die einzelnen untergeordneten Gebietskörperschaften muß also der volkswirtschaftliche Finanzbedarf sein. (429)

Damit wird die Einnahmenverteilung aus ihrer traditionellen fiskalisch-dekkungspolitischen Orientierung gelöst und bewußt als Instrument der Regionalpolitik betrachtet. (430) Die Betonung und vor allem Beachtung ihres Instrumentalcharakters ist deshalb wichtig, weil es keine raumneutrale Finanzpolitik gibt. (431) Jede finanzpolitische Entscheidung der öffentlichen Hände beeinflußt beabsichtigt oder unbeabsichtigt die Raumstruktur. Da dies insbesondere für Entscheidungen über die Einnahmenverteilung gilt, kommt es darauf an, unkontrollierte und deshalb häufig zielinkonforme räumliche Wirkungen des Einnahmenverteilungssystems zu vermeiden.

\subsection{Regional (lokal) gleich hohe Pro-Kopf-Steuereinnahmen}

Die Orientierung am volkswirtschaftlichen Finanzbedarf der einzelnen untergeordneten Gebietskörperschaften führt zu folgenden Postulaten:

a) Regionale Unterschiede in der Nachfrage nach öffentlichen Leistungen dürfen bei der Verteilung der Einnahmen nicht berücksichtigt werden.

b) Regionale Unterschiede in den Kosten der öffentlichen Leistungserstellung müssen sich in den privaten Kosten der ansässigen Wirtschaftssubjekte niederschlagen.

c) Die Kostenbelastung zentraler Orte infolge der Abgabe von Leistungen an Einwohner anderer Gemeinden rechtfertigt höhere Einnahmen pro Kopf. Die Abgeltung der Netto-Ertrags-spillouts sollte jedoch nicht pauschal durch eine Staffelung der Steuereinnahmen nach der Gemeindegröße (Gemeindegrößenansatz) vorgenommen werden.

d) Aus den Postulaten a) - c) folgt, daß alle untergeordneten Gebietskörperschaften (Länder und Gemeinden), unabhängig von ihrer Größe und Wirtschaftskraft, gleich hohe Pro-Kopf-Steuereinnahmen erhalten sollten. Praktisch kann dieses Ziel am einfachsten durch ein Gesamt- oder Teilsteuerverbundsystem erreicht werden, bei dem die einer unteren Ebene zustehenden Steuereinnahmen nach der tatsächlichen Einwohnerzahl auf die einzelnen Mitglieder der Ebene verteilt werden. (432)

e) Damit wird hier "eine Aufgaben- und Ausgabenautonomie der Gemeinden, sowohl was das Volumen an Ausgaben pro Kopf der Gemeindemitglieder, als auch was die Struktur der Gemeindeausgaben anlangt", (433) wie sie der Wissenschaftliche Beirat beim Bundesministerium der Finanzen befürwortet, abgelehnt. (434) Bei der hier vorgeschlagenen Lösung des horizontalen Steuerverteilungsproblems bleibt den untergeordneten Gebietskörperschaften keine Möglichkeit, das Niveau ihrer Aktivität zu bestimmen. Hinsichtlich der Verwendung der ihnen zufließenden Einnahmen 
besitzen sie jedoch Ermessensfreiheit, so daß die Struktur der Ausgaben Aktionsparameter der untergeordneten Gebietskörperschaften bleibt.

6.3. Finanzzuweisungen - ein unentbehrliches Element der Einnahmenverteilung

Aus einer Reihe von Gründen sind Zuweisungen der übergeordneten Gebiets körperschaften an die untergeordneten erforderlich:

a) Mit Zuwsisungen an untergeordnete Gebietskörperschaften müssen NettoErtrags-spillouts, die mit der Aktivität einzelner untergeordneter Gebiets körperschaften verbunden sind, abgegolten werden. (435) Diese Zuweisungen haben also eine "Abgeltungsfunktion". (436) Dabei sind die Zuweisungen so zu bemessen, daß den großen (zentralen) Gemeinden eher zu wenig als zu viel der Kostenbelastung durch Einwohner anderer Gemeinden ausgeglichen wird. Durch diese tendenzielle Unterdotierung werden sie dazu gezwungen, ihr Leistungsangebot für die eigenen Einwohner zu senken, wodurch sich die Standortqualitäten der Städte verschlechtern würden. Der Ballungsproze $\beta$ kann auf diese Weise gebremst werden. (437)

b) Zuweisungen an ländliche Gemeinden (Regionen) sollen verhindern, daß die entsprechenden Gebietskörperschaften wegen der deglomerationsbe dingten überdurchschnittlich hohen Kosten der öffentlichen Leistungserstellung nur unterdurchschnittliche Leistungen anbieten können. Diese Zuweisungen haben damit eine Kompensationsfunktion. (438)

c) Zuweisungen an schwach agglomerierte und wirtschaftsschwache Gemeinden (Regionen) sollen diese Gebietskörperschaften finanziell befähigen, ihr infrastrukturelles Defizit gegenüber den agglomerierten Wohlstandsregionen aufzuholen. Diese Zuweisungen dienen also zur Befriedigung des Nachholbedarfs einiger Gemeinden und Teilstaaten. (439)

d) Die unter Punkt c) genannten Zuweisungen ermöglichen den zurückgebliebenen Gebietskörperschaften bestenfalls, ihre Ausstattung mit Infrastruktureinrichtungen langfristig auf ein Niveau anzuheben, das mit demjenigen der Ballungsgebiete vergleichbar ist. Ob allein dadurch bereits mobile Ressourcen aus den Ballungsgebieten abgezogen werden, hängt vor allem von dem dort bereits erreichten Agglomerationsgrad und der Spürbarkeit der Agglomerationsnachteile ab. Um in den Ballungsgebieten ein weiteres überproportionales Wachstum zu verhindern oder wenigstens zu verlangsamen und gleichzeitig in den zurückgebliebenen Regionen sich selbst tragende Wachstumsprozesse auszulösen, sind u. U. Zuweisungen erforderlich, die über diejenigen zur Befriedigung des Nachholbedarfs hinausgehen. Diese Zuweisungen dienen also zur Realisierung der angestrebten räumlichen Entwicklung. Ihre regionalpolitische Funktion kann auch.als Initiativ- oder Ankurbelungsfunktion bezeichnet werden. (440)

e) Aus den unter den Punkten b) - d) angeführten Gründen müssen die wirtschaftsschwachen Regionen pro Einwohner höhere Zuweisungen von den übergeordneten Gebietskörperschaften erhalten als die wirtschaftsstarken, hochverdichteten Regionen. 
6.4. Die regionalpolitische Aufgabenteilung zwischen der Verteilung der Steuereinnahmen und der Verteilung der Zuweisungen

Die Ausführungen über die Einnahmenverteilung lassen eine regionalpolitische Aufgabenteilung zwischen der Verteilung der Steuereinnahmen und der Verteilung der Zuweisungen auf die untergeordneten Gebietskörperschaften erkennen.

Durch die Verteilung der den untergeordneten Gebietskörperschaften zustehenden Steuereinnahmen soll die "Normalfinanzausstattung" der einzelnen Teilstaaten bzw. Gemeinden erreicht werden. Es wird davon ausgegangen, daß die einzelnen untergeordneten Gebietskörperschaften unabhängig von GröBe und Wirtschaftskraft ein bestimmtes Mindestangebot an öffentlichen Leistungen pro Einwohner in gleicher Höhe erstellen müssen oder sollten. Die konkrete Verteilung der Steuereinnahmen zur Finanzierung dieses regional unterschiedslosen Mindestangebots muß so vorgenommen werden, daß unerwünschte räumliche Entwicklungen verhindert (441) und erwünschte räumliche Entwicklungen sich frei entfalten können. (442) Die horizontale Steuerverteilung (443) übernimmt damit eine mehr passive regionalpolitische Rolle: Sie soll die räumliche Entwicklung indirekt beeinflussen, indem sie dafür sorgt, daß sich die automatischen Stabilisatoren des räumlichen Differenzie rungsprozesses voll auswirken können.

Die Verteilung der Zuweisungen übernimmt dagegen eine mehr aktive regionalpolitische Rolle. Die Zuweisungen sollen regional und sachlich so verteilt werden, daß erwünschte räumliche Entwicklungen induziert und verstärkt werden. (444) Hier handelt es sich um einen direkten Einfluß auf die Raumstruktur. Die Verteilung der Zuweisungen wird immer zu regionalen und lokalen Einnahmenunterschieden führen. Das regionale Einnahmengefälle ist jedoch nicht zufällig oder unkontrolliert, sondern am regionalpolitischen Zielsystem orientiert. Es muß immer dann überprüft werden, wenn angestrebte Ziele erreicht sind oder an Bedeutung verloren haben.

Eine Verteilung der Einnahmen auf die einzelnen Mitglieder der unteren bundesstaatlichen Ebenen, die den vorstehenden Postulaten genügt, kann aus regionalpolitischer Sicht als ideale horizontale Einnahmenverteilung bezeichnet werden. Sie ist aber weder kurzfristig, noch in einem Schritt realisierbar, was auch angesichts der damit verbundenen Übergangsschwierigkeiten gar nicht wünschenswert sein kann. Die geringe Realisierungschance mindert aber wohl nicht den Wert, den die Vorstellung von einer idealen horizontalen Einnahmenverteilung besitzt. Sie kann als Fixpunkt dienen, an dem gemessen wird, ob konkrete finanzausgleichspolitische Maßnahmen in die regionalpolitisch gew ünschte Richtung führen und kann somit auch die finanzausgleichs politische Entscheidung erleichtern. In dieser Arbeit wird sie deshalb als Maßstab zur Beurteilung der konkreten finanzausgleichspolitischen Maßnahmen der Finanz reform von 1969 verwendet. 
2. TEIL: EMPIRISCHE UNTERSUCHUNG DER AUSWIRKUNGEN DER FINANZREFORM VON 1969 AUF DIE EINNAHMENPOSITION DER UNTERGEORDNETEN GEBIETSKÖRPERSCHAFTEN DER BUNDESREPUBLIK DEUTSCHLAND

\section{A. PROBLEMSTELLUNG UND BEGRIFFSKLÄRUNG}

Im letzten Kapitel sind die regionalpolitische Bedeutung des Finanzausgleichs, die Möglichkeiten des Zentralstaats zur Beeinflussung der Einnahmenposition der einzelnen untergeordneten Gebietskörperschaften und einige Grundsatz fragen zu diesem finanz - und regionalpolitischen Maßnahmenkomplex erörtert worden. (1) Damit sind die wichtigsten theoretischen Grundlagen für die nachfolgende empirische Untersuchung gelegt. Im Mittelpunkt der empirischen Untersuchung stehen einige bedeutende finanzausgleichspolitische Entscheidungen, die der Bundesgesetzgeber im Rahmen der Finanzreform von 1969 gefällt hat. Die Auswirkungen dieser Entscheidungen werden überwiegend danach beurteilt, ob sie mit dem oben abgeleiteten und auch von der Bundesregierung im Bundesraumordnungsprogramm vertretenen regionalpolitischen Zielsystem (2) vereinbar sind.

\section{Der Finanzausgleich - Definition und Systematik}

Die Finanzreform von 1969 umfaßt eine Neuordnung des Finanzausgleichs zwischen den drei bundesstaatlichen Ebenen in der Bundesrepublik Deutschland. Auf diese Weise sollte das "Kernstück der Finanzverfassung im Bundesstaat"(3) "den Anforderungen der Wirtschafts - und Finanzpolitik in einem hochindustrialisierten Sozialstaat" (4) angepaßt werden.

"Unter Finanzausgleich versteht man die Aufteilung der öffentlichen Aufgaben und der zu ihrer Finanzierung notwendigen Einnahmen auf die Gebietskörperschaften eines Staatsverbandes. "(5)

Der Finanzausgleich muß also in

- Regelungen der Aufgabenverteilung (passiver Finanzausgleich) und in

- Regelungen der Einnahmenverteilung (aktiver Finanzausgleich)

unterteilt werden. (6)

\section{Der passive Finanzausgleich}

Bei der Regelung des passiven Finanzausgleichs, dem "der logische Primat bei der Ordnung des Finanzausgleichs"(7) zustehen sollte, müssen drei Fragenkreise geklärt werden:

- Die Verteilung der Gesetzgebungskompetenz;

Hierbei geht es um die Frage, welche Gebietskörperschaft(en) das Recht 
besitzt (besitzen), die einzelnen öffentlichen Aufgaben gesetzlich zu regeln.

- Die Verteilung der Verwaltungszuständigkeit;

Im Bundesstaat muß festgelegt werden, welche Gebietskörperschaft(en) die einzelnen öffentlichen Aufgaben verwaltungsmäßig durchzuführen hat (haben), unabhängig davon, ob ihr (ihnen) die Gesetzgebungskompetenz zugeordnet ist.

- Die Verteilung der Finanzierungszuständigkeit.

Bei der Frage der Lastenabgrenzung geht es darum, welche Gebietskörperschaft(en) die Kosten der Aufgabenerfüllung zu tragen hat (haben). Die Kosten der Aufgabenerfüllung können einmal der (den) Gebietskörperschaft(en) zugewiesen werden, die das Recht der gesetzlichen Ausgestaltung der Aufgabenerfüllung (Gesetzgebungskompetenz) besitzt (besitzen). Oder aber die "Ausgabenverantwortung [fällt] der Gebietskörperschaft. . [zu], der die Ausführung der Aufgabe obliegt."(8) Wird die Verteilung der Finanzie rungszuständigkeit nach diesem Grundsatz "der Konnexität von Aufgabenerfüllung und Kostentragung"(9) geregelt, "folgt die Finanzverantwortung der Verwal tungszuständigkeit. "(10)

Die Regelung dieser drei Problemkreise hat unter einem vertikalen und unter einem horizontalen Aspekt zu erfolgen. Als erstes müssen die einzelnen Zuständigkeiten den verschiedenen Ebenen des Bundesstaates zugewiesen werden (vertikale Aufgabenverteilung). Sodann muß entschieden werden, wie die den einzelnen Ebenen zustehenden Zuständigkeiten auf die Mitglieder der einzelnen Ebenen verteilt werden sollen (horizontale Aufgabenverteilung). Dieser letzte Aspekt ist besonders im Zusammenhang mit der Verteilung der Finanzierungszuständigkeit bedeutsam, da die finanzielle Belastung durch die Erfüllung einer bestimmten Aufgabe zwischen den Aufgabenträgern derselben Stufe erhebliche Unterschiede aufweisen kann. (11)

Für den passiven Finanzausgleich ergibt sich somit folgendes Gliederungsschema:

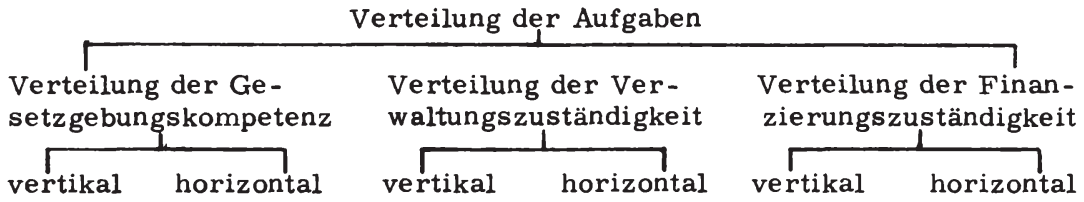

\section{Der aktive Finanzausgleich}

Nachdem die politische Entscheidung über die Verteilung der Aufgaben, insbesondere über die Verteilung der Kostenlast getroffen ist, kann der aktive Finanzausgleich sinnvoll geregelt werden. Die Verteilung der Steuereinnahmen, "das zentrale Problem des Finanzausgleichs"(12), wird unterteilt in 
- die Verteilung der Steuerquellen (originäre Steuerverteilung) und

- die Umverteilung der Steuererträge (Korrektur der originären Steuerverteilung).

\subsection{Die Verteilung der Steuerquellen}

Mit der Verteilung der Steuerquellen auf die Gebietskörperschaften im Bundesstaat sind wiederum drei Problemkreise verbunden, die einer klaren Regelung bedürfen:

- Die Verteilung der Steuergesetzgebungskompetenz;

Es muß geklärt werden, welcher Gebietskörperschaft das Recht zusteht, die Steuergesetze zu beschließen und damit über die Art der Steuerque1len und das Ausmaß ihrer Inanspruchnahme zu entscheiden. Mit der Verteilung der Steuergesetzgebungskompetenz wird die Frage der Finanzautonomie auf der Einnahmenseite (Steuerhoheit) einer Gebietskörperschaft geregelt.

- Die Verteilung der Verwaltungshoheit;

Weiterhin muß festgelegt werden, welche Gebietskörperschaften für die verwaltungsmäßige Erhebung der Steuern zuständig sein sollen und auf diese Weise die in den Steuergesetzen verbleibenden Ermessensspielräume ausnutzen können.

- Die Verteilung der Ertragshoheit.

Bei diesem Problemkreis geht es um die Frage, wie die Einnahmen aus den einzelnen Steuerquellen auf die einzelnen Gebietskörperschaften aufgeteilt werden. Die Entscheidung darüber bestimmt, welchen finanziellen Spielraum die einzelnen Gebietskörperschaften zur Erfüllung der ihnen zugewiesenen Aufgaben erhalten.

Alle drei bei der Verteilung der Steuerquellen anfallenden Problemkreise weisen wieder einen vertikalen und einen horizontalen Aspekt auf. Besonders bedeutsam sind diese beiden Aspekte im Zusammenhang mit der Verteilung der Ertragshoheit. Einmal muß entschieden werden, in welchem Umfang die einzelnen bundesstaatlichen Ebenen mit'Steuereinnahmen zur Finanzierung ihrer Aufgaben ausgestattet werden sollen. (13) Ist diese Entscheidung getroffen, müssen die Kriterien bestimmt werden, nach denen die einer Ebene zustehenden Steuereinnahmen auf die einzelnen Mitglieder der jeweiligen Ebene verteilt werden. (14)

\subsection{Die Umverteilung der Steuererträge}

Weicht die aus der Verteilung der Steuerquellen resultierende originäre Steuerverteilung von der politisch wünschenswerten Verteilung der Steuereinnahmen $a b$, muß sie nachträglich korrigiert werden. Dazu muß geregelt werden 
- welcher Gebietskörperschaft das Recht zusteht, die gesetzliche Regelung der Steuerumverteilung vorzunehmen (Gesetzgebungsbefugnis),

- welche Gebietskörperschaft die Steuerumverteilung verwaltungsmäßig durchführt (Verwaltungszuständigkeit) und

- welcher Gebietskörperschaft bereits vereinnahmte Steuereinnahmen entzogen werden und welcher Gebietskörperschaft die entsprechenden Mittel zufließen (Ertragshoheit).

Eine vertikal vollzogene Steuerumverteilung liegt vor, wenn eine Gebietskör perschaftsebene einen Teil der Steuereinnahmen, die ihr nach der Regelung der Verteilung der Steuerquellen zustehen, an eine andere bundesstaatliche Ebene abtritt. Werden durch die Aufbringung oder Verteilung der Umverteilungsmasse die Steuerkraftunterschiede zwischen den Gebietskörperschaften der gebenden oder der empfangenden Ebene verringert, ist in die vertikale Steuerumverteilung ein horizontaler Ausgleichseffekt eingebaut. Die Steuerumverteilung wird horizontal durchgeführt, wenn Gebietskörperschaften einer Ebene des Bundesstaates Steuereinnahmen, die nach der Verteilung der Steuerquellen eigentlich ihnen gehören, anderen Gebietskörperschaften derselben Ebene überweisen.

Für den aktiven Finanzausgleich ergibt sich somit folgendes Gliederungsschema:

Verteilung der Einnahmen

1. Verteilung der Steuerquellen Verteilung der

a) Gesetzgebungskompetenz vertikal horizontal

b) Verwaltungshoheit vertikal horizontal

c) Ertragshoheit vertikal horizontal
2. Umverteilung der Steuererträge

Verteilung der

a) Gesetzgebungskompetenz vertikal horizontal

b) Verwaltungshoheit vertikal horizontal

c) Ertragshoheit vertikal horizontal

II. Abgrenzung der für die empirische Untersuchung relevanten Maßnahmen der Finanzreform

Mit der Finanzreform von 1969 (15) hat der Bundesgesetzgeber sowohl eine Neuordnung der bundesstaatlichen Aufgabenverteilung als auch der Verteilung der Steuerquellen und der Umverteilung der Steuererträge beschlossen. Dabei sind Fragen aus allen drei Problemkreisen, also der Gesetzgebungskompetenz, der Verwaltungszuständigkeit und der Finanzierungszuständigkeit bzw. der Ertragshoheit mehr oder weniger umfassend neu ge regelt worden. Eine detaillierte Darstellung und Beurteilung aller Bestimmungen der Finanzreform ist hier aus Platzgründen nicht möglich und auch nicht erforderlich, da dazu bereits eine umfangreiche Literatur existiert. (16) 
In die empirische Untersuchung werden nur die Maßnahmen der Finanzre form einbezogen, die auf die Einnahmenposition der einzelnen untergeordneten Gebietskörperschaften Einfluß ausüben und somit eine große regionalpolitische Relevanz besitzen. Gegenstand der empirischen Untersuchung ist also ausschließlich die Neuordnung des aktiven Finanzausgleichs durch die Finanzreform von 1969.

Von allen Bestimmungen der Finanzreform aus diesem Bereich des Finanzausgleichs bleiben weiterhin diejenigen unberücksichtigt, die die Fragen der Gesetzgebungs - und Verwaltungshoheit über die Steuereinnahmen betreffen. Untersucht werden also nur die Maßnahmen der Finanzreform, die den Problemkreis der Ertragshoheit über Steuereinnahmen, sowohl im Hinblick auf die Verteilung der Steuerquellen als auch im Hinblick auf die Umverteilung der Steuererträge, neu ordnen.

Die hier untersuchten Maßnahmen der Finanzreform regeln

- die Verteilung der Steuereinnahmen auf die Ebene des Bundes, der Länder und der Gemeinden und

- die Verteilung der Steuereinnahmen, die einer Ebene zustehen, auf die einzelnen Mitglieder der jeweiligen Ebene.

Will man die Auswirkungen der Finanzreform auf die vertikale Steuerverteilung beurteilen, muß man danach fragen, ob die einer einzelnen Ebene zugewiesenen Steuereinnahmen vom Niveau her ausreichen, um den Mitgliedern dieser Ebene in ihrer Gesamtheit finanziell die Erfüllung der ihnen zugewiesenen Aufgaben zu ermöglichen. Die Beantwortung dieser Frage verlangt u. a. eine klare Vorstellung über die Rangordnung der Aufgaben der einzelnen Ebenen, über den Umfang, in dem diese in einer bestimmten Zeitspanne erfüllt werden sollen und über den dazu erforderlichen Mittelaufwand. Das Niveauproblem der Steuerverteilung ist zu einem großen Teil nur durch eine politische Entscheidung zu lösen. Zudem ist es regionalpolitisch von nur zweitrangiger Bedeutung. Deshalb wird in dieser Arbeit nicht geprüft, ob die Finanzreform zu einer "besseren" vertikalen Steuerverteilung in der Bundes republik geführt hat.

Regionalpolitisch ungleich interessanter und bedeutender ist vielmehr die Frage, welcher Einfluß von den relevanten Bestimmungen der Finanzreform auf die horizontale Verteilung der Steuereinnahmen ausgeht. In welche Richtung und in welchem Ausmaß verändern die Maßnahmen der Finanzreform von 1969 das regionale Steuerkraft - und Leistungs gefälle

- auf der Ebene der Länder,

- auf der Ebene der Gemeinden,

und wie sind etwaige Verschiebungen der regionalen Steuerkraftgefälle im Hinblick auf das oben abgeleitete Zielsystem der Regionalpolitik zu beurteilen? Dieses Strukturproblem der Steuerverteilung steht im Mittelpunkt der folgenden empirischen Untersuchung. (17) Sie wird entsprechend dieser Fragestellung in zwei Teile untergliedert. Im ersten Teil wird analysiert, in welcher Weise sich die Finanzreform auf die Einnahmenposition der einzelnen Bundesländer auswirkt. Der zweite Teil ist den Auswirkungen der Finanzreform auf die Finanzsituation der Gemeinden gewidmet. 


\section{B. DIE NEUREGELUNG DER HORIZONTALEN EINNAHMENVERTEILUNG AUF LÄNDEREBENE DURCH DIE FINANZREFORM VON 1969}

Der Prozeß der Verteilung der Steuereinnahmen auf die einzelnen Bundes länder vollzieht sich analytisch in mehreren Stufen:

- Die den Ländern nach der Regelung der vertikalen Steuerverteilung insgesamt zustehenden Steuereinnahmen werden gemäß dem kassenmäßigen örtlichen Aufkommen auf die einzelnen Bundesländer verteilt.

- Das kassenmäßige örtliche Aufkommen wird entsprechend der Landes zugehörigkeit der Steuerzahler zerlegt. Als Ergebnis der Zerlegung er gibt sich eine horizontale Steuerverteilung gemäß dem tatsächlichen, von steuertechnisch bedingten Verzerrungen bereinigten örtlichen Aufkommen.

- Ein Teil der den Ländern zustehenden Steuereinnahmen wird nach anderen Kriterien als dem des örtlichen Aufkommens auf die einzelnen Länder verteilt. Auf diese Weise wird mit der vertikalen Steuerverteilung gleichzeitig ein horizontaler Umverteilungseffekt bewirkt.

- Die Verteilung der Steuereinnahmen auf die einzelnen Länder, die aus dieser Konstruktion des Steuerverteilungssystems hervorgeht, wird nachträglich durch horizontale Ausgleichszahlungen korrigiert.

- Die horizontale Umverteilung der Steuererträge wird ergänzt durch vertikale Ausgleichszahlungen. Der Bund weist einigen Ländern aus den eigentlich ihm zustehenden Steuereinnahmen Mittel zu, die ausschließlich dem Abbau von Finanzkraftunterschieden zwischen den Ländern dienen und deswegen ohne Zweckbindung vergeben werden.

- Darüberhinaus gewährt der Bund den Ländern (und ihren Gemeinden) zweckgebundene Zuweisungen, deren Aufgabe in der Durchsetzung spezieller wirtschaftspolitischer Ziele besteht. Mit diesen vertikalen Finanzaus gleichszahlungen ist $\mathrm{zwar}$ primär kein horizontaler Umverteilungseffekt beabsichtigt, tatsächlich geht aber von ihnen ein starker Einfluß auf die Finanzkraftunterschiede zwischen den Ländern aus.

Diese sechs Stufen der Verteilung der Steuereinnahmen auf die einzelnen Länder dienen als Gliederung des ersten Teils der empirischen Untersuchung.

I. Die Verteilung der Steuereinnahmen der Länder gemäß dem kassenmäßigen örtlichen Aufkommen im Vergleich zur tatsächlichen Verteilung der Ländersteuereinnahmen

1. Die Neuordnung der vertikalen Steuerverteilung durch die Finanzreform von 1969

Bis zum Inkraftreten der Finanzreform am 1.1.1970 herrschte im Steuerverteilungssystem der Bundesrepublik Deutschland das gebundene Trennsystem vor. Bund und Länder verfügten über Steuerquellen, an deren Ertrag die jeweils andere Ebene nicht beteiligt war. Lediglich das Aufkommen 
der Einkommen - und das der Körperschaftsteuer standen Bund und Ländern gemeinsam zu (Gemeinschaftsteuer). Die Beteiligungsquote der beiden Ebenen am Aufkommen dieser beiden Gemeinschaftsteuern wurde durch Bundesgesetz, das der Zustimmung des Bundesrates bedurfte, festgesetzt. Durch Änderungen der Beteiligungsquoten sollte die Entwicklung der Einnahmen der Entwicklung des Finanzbedarfs der einzelnen Ebenen angepaßt werden. (18) Als Kriterium für die Verteilung der den Ländern insgesamt zustehenden Steuereinnahmen auf die einzelnen Länder sah das Grundgesetz ausschließlich das örtliche Aufkommen vor. Dies galt sowohl für die Steuern, die den Ländern nach dem gebundenen Trennsystem zugewiesen wurden (Landessteuern) als auch für die Verteilung des Länderanteils an der Einkommen- und Körperschaftsteuer. (19)

Die Finanzreform von 1969 führte zu einer umfassenden Neuordnung der Aufteilung der Steuerquellen auf Bund und Länder. Seit dem 1.1.1970 ist der Bereich der Gemeinschaftsteuern stark erweitert. Das Aufkommen folgender Steuern steht seitdem Bund und Ländern gemeinsam zu:(20)

- der Lohnsteuer und der veranlagten Einkommensteuer,

- der Körperschaftsteuer und der nicht veranlagten Steuer vom Ertrag (Kapitalertragsteuer),

- der Gewerbesteuerumlage,

- der Umsatzsteuer (einschließlich Einfuhrumsatzsteuer).

Vom Aufkommen der Einkommensteuer, der Körperschaftsteuer, der Kapitalertragsteuer und der Gewerbesteuerumlage erhalten Bund und Länder einen festen Anteil von je 50 Prozent. (21) Dagegen wird das Aufkommen der Umsatzsteuer nach einem variablen Beteiligungsverhältnis, das in einem zustimmungsbedürftigen Bundesgesetz festgelegt wird; aufgeteilt. "Die Funktion des Ausgleichsventils wurde von der Einkommen- und Körperschaftsteuer auf die Umsatzsteuer übertragen. "(22)

Neben den Einnahmen aus den Gemeinschaftsteuern verfügen die Länder auch nach der Finanzreform über Steuerquellen, deren Ertrag ausschließlich in ihre eigenen Kassen fließt. Die Finanzreform hat jedoch die Kapitalverkehrsteuern (23), die Versicherungssteuer und die Wechselsteuer aus dem Bereich der Landessteuern ausgegliedert und in die Ertragshoheit des Bundes gestellt. "Für die Überleitung auf den Bund sprechen die überregionale Belastungswirkung dieser Steuern und deren unterschiedliches Aufkommen, das weder zur Wirtschaftskraft noch zum Finanzbedarf der einzelnen Länder in Beziehung steht. "(24)

2. Die Regelung der horizontalen Steuerverteilung durch die Finanzreform von 1969

Die Frage, nach welchen Kriterien die den Ländern insgesamt zustehenden Steuereinnahmen auf die einzelnen Länder verteilt werden sollten, war während der gesamten Diskussion der Finanzreformvorschläge heftig umstritten. Sie entwickelte sich "zu einem der Kernpunkte der Auseinandersetzungen"(25). 
Vor der Finanzreform diente ausschließlich das örtliche Aufkommen als Steuerverteilungskriterium. Artikel 107 des Grundgesetzes d.a.F. enthielt lediglich eine Kann-Vorschrift über die Abgrenzung und Zerlegung des örtlichen Aufkommens einzelner Steuern oder Steueranteile. (26) Da durch die Finanzreform auch die Finanzkraftunterschiede zwischen den Bundesländern abgeschwächt werden sollten (27), schlug die Bundesregierung in ihrem Finanzreformprogramm vom 19.7.1967 vor, den Artikel 107 des Grundgesetzes zu ergänzen. In Form einer Kann-Vorschrift sollte grundsätzlich die Möglichkeit eröffnet werden, durch ein zustimmungsbedürftiges Bundesgesetz "für einen Teil des gemeinsamen Steueraufkommens [aus der Einkommensteuer, der Körperschaftsteuer und der Umsatzsteuer einschließlich der Einfuhrumsatzsteuer, F.T.] eine Verteilung nach anderen Maßstäben als dem örtlichen Aufkommen"(28) vorzunehmen. Dabei ließ die Bundesregierung keinen Zweifel daran, daß sie von den Möglichkeiten der Zerlegung und der Verteilung nach "anderen" Maßstäben bei den Gemeinschaftsteuern Gebrauch machen wollte.

Dieses Finanzreformprogramm wurde eingehend in der sogenannten Bund/Länder-Arbeitsgruppe zur Finanzreform beraten. Aufgabe dieser Arbeitsgruppe war es, "politische Grundfragen der Reform vorweg zwischen Bund und Ländern zu diskutieren und eine weitestgehende Annäherung der unterschiedlichen Standpunkte zu erreichen. "(29) "Die Bundesregierung hat die Anregungen der Länder sorgfältig geprüft und ihr Finanzreformprogramm auf Grund der Gespräche überarbeitet. "(30) Das Ergebnis dieser Gespräche bestand darin, daß die Bundesregierung die Kann-Vorschrift über die Verteilung der Steuereinnahmen auf die Länder nach anderen Maßstäben als dem des örtlichen Aufkommens wieder aus ihrem Entwurf eines Artikels 107 GG strich. Der "Entwurf eines ... Gesetzes zur Änderung und Ergänzung des Grundge setzes (Finanzreformgesetz)" vom 30.4.1968 sieht dementsprechend als einziges Verteilungskriterium für das Aufkommen der Landessteuern und für den Länderanteil an den Gemeinschaftsteuern das örtliche Aufkommen vor. Der Vorschlag eines Artikels 107 GG enthält lediglich eine Kann-Vorschrift über die Zerlegung des örtlichen Aufkommens (31), durch die erhebungs technisch bedingte Verzerrungen des örtlichen Aufkommens bereinigt werden sollten. (32)

Diese außerparlamentarische Einigung zwischen Bundesregierung und den Bundesländern wurde jedoch vom Bundestag nicht akzeptiert. Der Bundestag sprach sich "für eine grundlegende Änderung aus. Danach sollte die verfassungsrechtliche Vorschrift über die Aufteilung des Länderanteils an den Gemeinschaftsteuern nach dem Grundsatz des örtlichen Aufkommens beseitigt werden. Die Aufteilung sollte durch zustimmungsbedürftiges Gesetz in der Weise erfolgen, daß in einem Zuge - also ohne ergänzenden horizontalen Finanzausgleich - die Steuern unter Berücksichtigung von Bedarfsgesichts punkten angemessen aufgeteilt werden. Demgemäß sollte Art. 107 des Grundgesetzes ersatzlos entfallen.

Diese Regelung (33) wurde von den finanzschwachen Ländern begrüßt, fand aber nicht die erforderliche Zustimmung der Mehrheit des Bundesrates. "(34) 
Zur Überbrückung des tiefen Gegensatzes zwischen Bundestag und Bundesrat unterbreitete der Bundesminister der Finanzen einen Kompromißvor-

schlag. Dieser sah vor, den Länderanteil an

- der Körperschaftsteuer

- der nicht veranlagten Einkommensteuer (Kapitalertragsteuer) und

- der Umsatzsteuer

nach der Einwohnerzahl, den Länderanteil an

- der Lohnsteuer und

- der veranlagten Einkommensteuer

nach dem örtlichen Aufkommen ohne Zerlegung auf die einzelnen Länder auf zuteilen. Für die Landessteuern sollte der Grundsatz des örtlichen Aufkommens beibehalten werden. Auch dieser Reformvorschlag scheiterte am Widerspruch der finanzstarken Bundesländer, denen als einziges finanzschwaches Bundesland Bayern zur Seite stand. (35)

Bundestag und Bundesrat einigten sich schließlich im Vermittlungsausschuß darauf, daß nur der Länderanteil an der Umsatzsteuer nach der Einwohnerzahl auf die einzelnen Länder verteilt wird. Darüberhinaus wird verfassungs rechtlich die Möglichkeit geschaffen, maximal 25 Prozent des Länderanteils an der Umsatzsteuer in Form von Ergänzungsanteilen vorweg an die besonders finanzschwachen Länder zu verteilen. Von dieser Kann-Vorschrift wird im Gesetz über den Finanzausgleich zwischen Bund und Ländern vom 28. 8.1969 Gebrauch gemacht. Die Länderanteile an den übrigen Gemeinschaftsteuern werden dagegen ebenso wie die Landessteuern den einzelnen Ländern gemäß ihrem örtlichen Aufkommen zugewiesen. Allerdings schreibt die Neufassung von Art. $107 \mathrm{GG}$ zwingend eine Zerlegung des Lohnsteuer - und des Körperschaftsteueraufkommens vor. (36)

3. Die finanziellen Auswirkungen der Abweichung vom kassenmäßigen örtlichen Aufkommen als ausschließlichem Steuerverteilungskriterium im Rechnungsjahr 1974

Im vorhergehenden Abschnitt sind die gegensätzlichen Standpunkte im Streit um die Verteilungskriterien der Ländersteuereinnahmen und der schließlich erreichte Kompromiß skizziert worden. Anschließend wird nun untersucht, wie sich dieser Kompromiß im Untersuchungsjahr 1974 auf die Einnahmenposition der einzelnen Länder auswirkt.

\subsection{Das methodische Vorgehen}

Um die Auswirkungen der Verteilungsvorschriften des Art. 107 GG zu ermitteln, wird in Tabelle 1 die tatsächliche horizontale Verteilung der den Ländern insgesamt zustehenden Steuereinnahmen (Spalte 6) mit einer fiktiven Steuerverteilung (Spalte 2) verglichen. Diese fiktive Steuerverteilung würde sich ergeben, wenn die Steuereinnahmen der Länder im Jahr 1974 ausschließ- 
Tabelle 1 Auswirkung der Verteilungsvorschriften des Art. 107 Grundgesetz auf die Steuereinnahmen der einzelnen Länder der Bundesrepublik Deutschland in Jahre 1974

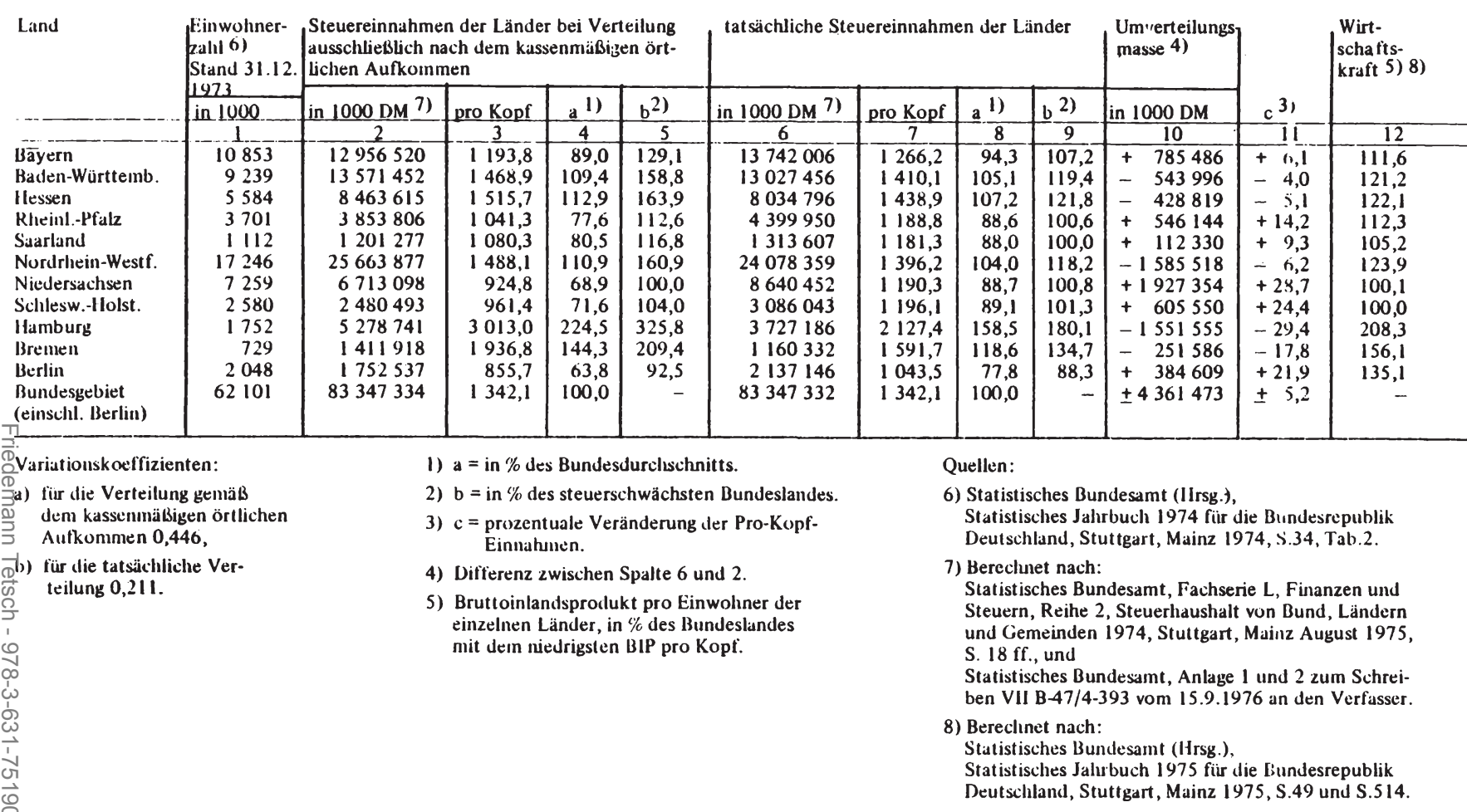


lich gemäß dem kassenmäßigen örtlichen Aufkommen auf die einzelnen Länder verteilt worden wären. Als kassenmäßiges örtliches Aufkommen ist die Summe der Steuereinnahmen zu verstehen, die die Finanzkassen der einzelnen Länder einnehmen, ohne Rücksicht auf die Landeszugehörigkeit der Steuerpflichtigen. Das kassenmäßige örtliche Aufkommen eines einzelnen Landes wird ermittelt, indem

- sein Gesamtaufkommen aus den Landessteuern,

- $43 \%$ seines Lohnsteueraufkommens vor der Zerlegung,

- $43 \%$ seines Aufkommens aus der veranlagten Einkommensteuer,

- 50 \% seines Aufkommens aus der nicht veranlagten Einkommensteuer (Kapitale rtragsteuer),

- $50 \%$ seines Körperschaftsteueraufkommens vor der Zerlegung,

- $50 \%$ der von seinen Gemeinden aufgebrachten Gewerbesteuerumlage und

- $37 \%$ seines Umsatzsteueraufkommens (einschl. Einfuhrumsatzsteuer)

addiert werden. (37)

Die Differenz zwischen den tatsächlichen und den fiktiven Steuereinnahmen jedes einzelnen Landes ergibt die in Spalte 10 aufgeführte Umverteilungs masse. Sie gibt an, in welchem Umfang die Einnahmenposition der einzelnen Länder dadurch verändert wird, daß die Neufassung des Art. 107 GG eine Abweichung vom kassenmäßigen örtlichen Aufkommen als alleinigem Steuerverteilungskriterium ermöglicht.

\subsection{Interpretation der Ergebnisse}

Betrachten wir zuerst die Verteilung der Ländersteuereinnahmen gemäß dem kassenmäßigen örtlichen Aufkommen. Hervorstechendstes Merkmal dieser fiktiven Verteilung sind die großen Unterschiede in den Pro-Kopf-Steuereinnahmen zwischen den einzelnen Ländern. Während der Pro-Kopf-Wert des Stadtstaates Hamburg 224, $5 \%$ des Bundesdurchschnitts erreicht, beträgt derjenige Berlins lediglich 63,8\% des Bundesdurchschnitts (Spalte 4). Der Variationskoeffizient als Streuungsmaß (38) der Verteilung des kassenmäßigen örtlichen Aufkommens pro Kopf weist einen Wert von 0,466 auf.

Das Ausmaß des regionalen Steuerkraftgefälles, das sich bei ausschließlicher Anwendung des kassenmäßigen örtlichen Aufkommens als Steuerverteilungskriterium einstellen würde, wird durch die Werte in Spalte 5 verdeutlicht. Danach könnten Hamburg, als steuerstärkstes Bundesland, und Hessen, als steuerstärkster Flächenstaat, über Steuereinnahmen pro Einwohner verfügen, die rund $326 \%$ bzw. $164 \%$ derjenigen betragen, die das steuerschwächste Bundesland Niedersachsen zur Erfüllung seiner Aufgaben einsetzen könnte.

Die Anwendung der in Art. 107 GG verankerten Verteilungsvorschriften - Zerlegung der Lohn- und Körperschaftsteuer und Verteilung des Länderanteils an der Umsatzsteuer gemäß $₫ 2$ des Gesetzes über den Finanzausgleich zwischen Bund und Ländern - führt zu einer erheblichen Abschwächung der Steuerkraftunterschiede zwischen den Ländern. Alle Länder, deren kassenmäßiges örtliches Aufkommen unter dem Bundesdurchschnitt liegt, verbessern ihre 
Einnahmenposition. Das Umgekehrte gilt für die Länder mit überdurchschnittlich hohen Pro-Kopf-Werten des kassenmäßigen örtlichen Aufkommens (Spalte 8). Dadurch sinkt der Variationskoeffizient der Pro-Kopf-Steuereinnahmen auf einen Wert von 0,211 .

Die beiden hier untersuchten Reformmaßnahmen bewirken, daß die steuerschwachen Länder Bayern, Rheinland-Pfalz, Saarland, Niedersachsen, Schleswig-Holstein und Berlin insgesamt 4, 36 Mrd. DM mehr Steuereinnahmen erhalten, als ihnen bei einer Verteilung gemäß dem kassenmäßigen örtlichen Aufkommen zugewiesen worden wäre (Spalte 10). Damit werden im Rechnungsjahr 1974 rund 5,2\% der gesamten Steuereinnahmen der Länder allein durch die Zerlegung der Lohn- und Körperschaftsteuer und die vom örtlichen Aufkommen gelöste Verteilung des Länderanteils an der Umsatzsteuer umverteilt. Hierin schlägt sich finanzwirtschaftlich das Ergebnis der politischen Auseinandersetzungen um die Verteilungskriterien der Ländersteuereinnahmen (39) nieder.

Von den Umverteilungsmaßnahmen nach Art. 107 GG profitieren am stärksten die beiden Länder Niedersachsen und Schleswig-Holstein. Ihre Pro-KopfEinnahmen steigen um 28,7\% bzw. 24,4\%. Den stärksten Verzicht auf Steuereinnahmen, die von den Finanzkassen in ihrem Hoheitsgebiet vereinnahmt worden sind, müssen die beiden Hansestädte leisten. Ihre tatsächlichen Steuereinnahmen pro Kopf liegen um 29,4\% bzw. 17, $8 \%$ unter denjenigen, die sie bei einer Steuerverteilung gemäß dem kassenmäßigen örtlichen Auf kommen erhalten hätten (Spalte 11).

\subsection{Regionalpolitische Beurteilung der Ergebnisse}

Bei einer Verteilung der Ländersteuereinnahmen gemäß dem kassenmäßigen örtlichen Aufkommen entsteht ein regionales Steuerkraftgefälle (Spalte 5), das parallel zum regionalen Wirtschaftskraftgefälle (Spalte 12) verläuft und außerdem wesentlich stärker als dieses ist. Eine solche Steuerverteilung würde die Wirtschaftskraftunterschiede $z$ wischen den Ländern vergrößern und Ballungstendenzen in den wirtschaftsstarken und stark agglomerierten Ländern fördern. (40)

Die Reformmaßnahmen des Art. 107 GG schwächen das regionale Steuerkraftgefälle ab. Sie wirken damit in die regionalpolitisch erwünschte Richtung. Doch trotz des beachtlichen Umfangs der Umverteilungsmasse reichen die Zerlegung der Lohn- und Körperschaftsteuer und die vom kassenmäßigen örtlichen Aufkommen gelöste Verteilung des Länderanteils an der Umsatzsteuer nicht aus, das Steuerkraftgefälle zwischen den Ländern vollständig oder in regionalpolitisch akzeptablem Aus maß abzubauen. Die tatsächliche horizontale Steuerverteilung läßt drei Ländergruppen erkennen:

- Bei der ersten Gruppe handelt es sich um Länder mit extrem hoher Steuerkraft. Zu ihr gehören Hamburg und Bremen, deren Steuerkraft rund $80 \%$ bzw. $35 \%$ über derjenigen des steuerschwächsten Bundeslandes (Saarland) liegt. 
- Die zweite Gruppe bilden Länder, deren Steuerkraft rund $20 \%$ über derjenigen des Saarlandes liegt. Hierzu zählen Baden-Württemberg, Hessen und Nordrhein-Westfalen.

- die dritte Gruppe bilden die steuerschwachen Länder Rheinland-Pfalz, Saarland, Niedersachsen und Schleswig-Holstein. Sie weisen eine etwa gleich hohe Steuerkraft (88\% - $89 \%$ des Bundesdurchschnitts) auf. (41)

Auch nach Durchführung der in Art. 107 GG verankerten Reformmaßnahmen verbleibt also ein Steuerkraftgefälle zwischen den Ländern, das parallel zum Wirtschaftskraftgefälle verläuft. Die Steuerkraftunterschiede zwischen den Ländern sind zwar geringer als die Wirtschaftskraftunterschiede, sie betragen aber zwischen der Gruppe der steuerschwachen und der Gruppe der steuerstarken Länder immer noch 20 Prozent und mehr. (42) Damit sind aber die wirtschafts - und steuerstarken Länder weiterhin in der Lage, ein quantitativ und qualitativ wesentlich besseres Leistungsangebot zu erstellen als die wirtschafts - und steuerschwachen Länder. Als Ergebnis der horizontalen Steuerverteilung entsteht also ein regionales Gefalle im Angebot öffentli cher Leistungen zugunsten der bereits stark industrialisierten und agglomerierten Länder, durch das der räumliche Differenzierungsprozeß verstärkt wird. Die hier untersuchten Reformmaßnahmen schwächen zwar den ballungsfördernden Effekt des horizontalen Steuerverteilungssystems, wie er sich bei einer Verteilung ausschließlich nach dem kassenmäßigen örtlichen Aufkommen ergeben würde, ab, beseitigen ihn aber nicht.

Will man diese regionalpolitisch unerwünschte Wirkung der horizontalen Steuerverteilung verringern oder ganz vermeiden, sind auch nach der Zerlegung der Lohn- und Körperschaftsteuer sowie der vom kassenmäßigen örtlichen Aufkommen gelösten Verteilung des Länderanteils an der Umsatzsteuer weitere Ausgleichsmaßnahmen erforderlich. Bevor diese jedoch hier behandelt werden, sollen die einzelnen Reformmaßnahmen, deren Gesamtwirkung in Tabelle 1 ermittelt worden ist, eingehender untersucht werden. Dabei wird die in Spalte 10 ausgewiesene Umverteilungsmasse erklärt, indem sie ihren drei Ursachen:

- der Zerlegung der Lohnsteuer,

- der Zerlegung der Körperschaftsteuer und

- der Verteilung des Länderanteils an der Umsatzsteuer gemäß $₫ 2$ des Gesetzes über den Finanzausgleich zwischen Bund und Ländern

zugeordnet wird.

II. Die Bereinigung des kassenmäßigen örtlichen Aufkommens von steuertechnisch bedingten Verzerrungen

1. Die Notwendigkeit der Zerlegung der Lohnsteuer und der Körperschaftsteuer

In der Bundesrepublik wird die veranlagte Einkommensteuer an das für den Wohnsitz des Steuerpflichtigen zuständige Finanzamt entrichtet. Dagegen 
wird die Lohnsteuer vom Arbeitgeber des Steuerpflichtigen an das Finanzamt des Arbeitsortes des Lohnsteuerpflichtigen abgeführt. Steuergläubiger für die Körperschaftsteuer ist das Finanzamt am Ort des Unternehmenssitzes.

Diese steuertechnischen Regelungen erhalten eine große finanzwirtschaftliche und regionalpolitische Bedeutung, wenn der Länderanteil an der Einkommen- und Körperschaftsteuer nach dem Grundsatz des kassenmäßigen örtlichen Aufkommens auf die einzelnen Länder verteilt wird. Arbeitet nämlich ein Lohnsteuerpflichtiger außerhalb seines Wohnsitzlandes, kommt seine Steuerleistung in voller Höhe dem Land zugute, in dem sich sein Arbeitsplatz befindet. Sein Wohnsitzland geht leer aus, obwohl es den Lohnsteuerpflichtigen und seine Familie mit öffentlichen Leistungen versorgen muß. Hinzu kommt noch, daß der Lohnsteuerjahresausgleich beim Wohnsitzfinanzamt geltend gemacht werden muß. Das Land, in dem sich der Wohnsitz des Lohnsteue rpflichtigen befindet, muß im Lohnsteuerjahresausgleich Steuern erstatten, die ein anderes Bundesland kassiert und ausgegeben hat. Dasselbe gilt, wenn ein Unternehmen mit Betrieben in mehreren Bundesländern eine zentrale Lohnabrechnung durchführt. Die Lohnsteuern aller Beschäftigten dieses Unternehmens fließen dann in die Kassen des Landes, in dem die zentrale Lohnabrechnung vorgenommen wird, in der Regel also in die Kassen des Sitzlandes des Unternehmens. Die Länder, in denen das besteuerte Einkommen erzielt wird und die Arbeitskräfte als Bürger Kosten verursachen, gehen leer aus. Bei der Körperschaftsteuer ergeben sich diese Wirkungen dann, wenn ein Unternehmen in der Rechtsform einer Kapitalgesellschaft Betriebsstätten in mehreren Bundesländern besitzt. Obwohl der Unternehmensgewinn von Betrieben in mehreren Ländern erwirtschaftet wird, erhält nur das Land, in dem sich der Unternehmenssitz befindet, die Steuern auf den Gesamtgewinn.

Der quantitative Einfluß dieser steuertechnischen Regelungen auf die Höhe des kassenmäßigen örtlichen Aufkommens ist umso größer, je stärker die Arbeitsplätze im Raum konzentriert und je mehr Unternehmen mit anderen fusioniert sind. Bei dem in der BRD schon vor 1970 erreichten hohen Grad an räumlicher und unternehmensmäßiger Konzentration bedeutet dies, daß ein nicht $\mathrm{zu}$ vernachlässigender Teil der Steuerkraftunterschiede $\mathrm{zwischen}$ den Ländern vor der Finanzreform nicht von ökonomischen Tatbeständen, sondern von steuertechnischen Regelungen bestimmt war. Das kassenmäßige örtliche Aufkommen eines Landes war und ist kein brauchbares Spiegelbild der steuerlichen Leistungsfähigkeit der Wirtschaftssubjekte eines Landes. Dient es trotzdem als Steuerverteilungskriterium, werden dadurch die Länder begünstigt, in denen u. a. wegen ihrer verkehrsgünstigen, zentralen Lage bereits eine starke Konzentration wirtschaftlicher Aktivitäten stattgefunden hat. Länder mit geringer Anziehungskraft auf Unternehmensleitungen und Betriebe dagegen werden benachteiligt. Dies war die Situation bis zur Finanzreform von 1969.(43)

Um diese steuertechnisch bedingte Begünstigung einzelner, in der Regel steuerstarker Länder zu beseitigen, hat der Bundesgesetzgeber im Rahmen der Finanzreform die Zerlegung der Lohnsteuer und der Körperschaftsteuer 
obligatorisch vorgeschrieben. In Verbindung mit dem Zerlegungsgesetz vom 25.2.1971 schreibt die Zerlegungsvorschrift des Art. 107 GG vor, daß das kassenmäßige örtliche Aufkommen der einzelnen Länder aus der Lohnsteuer und aus der Körperschaftsteuer nach der Landeszugehörigkeit der Steuerpflichtigen zu zerlegen ist. Die vereinnahmten Lohnsteuern von Arbeitskräften, die ihren Wohnsitz in einem anderen Bundesland haben, sind an das entsprechende Wohnsitzland zu überweisen. Die Körperschaftsteuer eines Unternehmens mit Betriebsstätten in mehreren Bundesländern ist entsprechend dem Anteil der einzelnen Betriebsstätten am Gesamtgewinn auf die Länder der Produktionsorte aufzuteilen. (44)

Auf diese Weise werden die "Abweichungen des regionalen Steueraufkommens von der wahren Steuerkraft der Länder"(45) beseitigt, wird das kassenmäßige örtliche Aufkommen in das örtliche Aufkommen umgewandelt.

2. Die Zerlegung der Lohnsteuer im Rechnungsjahr 1974

2.1. Die Auswirkung der Zerlegung der Lohnsteuer auf die Einnahmenposition der einzelnen Länder im Rechnungsjahr 1974

2.1.1. Das methodische Vorgehen

Tabelle 2 zeigt, in welcher Höhe Lohnsteuereinnahmen zwischen den Ländern dadurch umgeschichtet werden, daß vom Verteilungskriterium des kas senmäßigen Aufkommens durch die Zerlegung der Lohnsteuer abgegangen wird. Diese hier als Umverteilungsmasse bezeichnete Umschichtung von Lohnsteuereinnahmen (Spalte 8) wird ermittelt, indem die tatsächliche Verteilung der Lohnsteuereinnahmen (Spalte 5) einer fiktiven Verteilung der Lohnsteuereinnahmen (Spalte 2) gegenüber gestellt wird.

Die fiktive Verteilung gibt an, welche Lohnsteuereinnahmen den einzelnen Ländern 1974 zugeflossen wären, wenn keine Zerlegung erfolgt wäre. In diesem Fall hätten sich die Lohnsteuereinnahmen der einzelnen Länder auf $43 \%$ ihres kassenmäßigen örtlichen Lohnsteueraufkommens belaufen. Die tatsächlichen Lohnsteuereinnahmen der einzelnen Länder betragen $43 \%$ des von steuertechnisch bedingten Verzerrungen bereinigten örtlichen Aufkommens an Lohnsteuern. Von diesen tatsächlichen Lohnsteuereinnahmen der einzelnen Länder müssen die fiktiven Lohnsteuereinnahmen abgezogen werden, will man die Umverteilungsmasse (Spalte 8) erhalten. Diese Differenz zwischen den Länderanteilen an der Lohnsteuer nach der Zerlegung und den Länderanteilen vor der Zerlegung gibt die finanziellen Auswirkungen der Lohnsteuerzerlegung an.

Da die Gemeinden eines Landes in Höhe von $14 \%$ am örtlichen Lohnsteueraufkommen des Landes nach der Zerlegung beteiligt werden, (46) wirkt sich die Zerlegungsvorschrift des Art. $107 \mathrm{GG}$ auch auf die Einnahmenposition der Gemeinden aus. Deshalb ist auch ihr Lohnsteueranteil nach der Zerlegung mit demjenigen verglichen worden, den sie ohne Lohnsteuerzerlegung e rhalten hätten. 
Tabelle 2 Die Auswirkung der Zerlegung der Lohnsteuer auf die Einnahmenposition der einzelnen Länder im Jahr 1974

\begin{tabular}{|c|c|c|c|c|}
\hline \multirow[t]{3}{*}{ Land } & \multicolumn{4}{|c|}{ Lohnsteueraufkommen vor der Zerlegung 1 ) } \\
\hline & \multirow{2}{*}{$\begin{array}{l}\text { örtl. Gesamt- } \\
\text { aufkommen } \\
\text { in } 1000 \mathrm{DM}\end{array}$} & \multicolumn{3}{|c|}{\begin{tabular}{|l|} 
Länder- und Gemeindeanteil \\
\end{tabular}} \\
\hline & & in $1000 \mathrm{DM}$ & pro Kopf & $\begin{array}{l}\text { in \% d. Bundes- } \\
\text { durchschnitts }\end{array}$ \\
\hline & 1 & 2 & 3 & 4. \\
\hline $\begin{array}{l}\text { Bayern } \\
\text { Gemeinden }\end{array}$ & 11049369 & $\begin{array}{l}4751229 \\
1546912\end{array}$ & $\begin{array}{l}437,8 \\
142,5\end{array}$ & 87,9 \\
\hline $\begin{array}{l}\text { Baden-Württ. } \\
\text { Gemeinden }\end{array}$ & 11720954 & $\begin{array}{l}5040010 \\
1640934 \\
\end{array}$ & $\begin{array}{l}545,5 \\
177,6 \\
\end{array}$ & 109,5 \\
\hline $\begin{array}{l}\text { Hessen } \\
\text { Gemeinden }\end{array}$ & 7355770 & $\begin{array}{l}3162981 \\
1029808 \\
\end{array}$ & $\begin{array}{l}566,4 \\
184,4\end{array}$ & 113,7 \\
\hline $\begin{array}{l}\text { Rheinl.-Pfalz } \\
\text { Gemeinden }\end{array}$ & 3130788 & $\begin{array}{r}1346239 \\
438310 \\
\end{array}$ & $\begin{array}{l}363,8 \\
118,4 \\
\end{array}$ & 73,0 \\
\hline $\begin{array}{l}\text { Saarland } \\
\text { Gemeinden }\end{array}$ & 1083441 & $\begin{array}{l}465880 \\
151682 \\
\end{array}$ & $\begin{array}{l}419,0 \\
136,4 \\
\end{array}$ & 84,3 \\
\hline $\begin{array}{l}\text { Nordrh.-Westf. } \\
\text { Gemeinden }\end{array}$ & 21754181 & $\begin{array}{l}9354298 \\
3045585 \\
\end{array}$ & $\begin{array}{l}542,4 \\
176,6 \\
\end{array}$ & 108,9 \\
\hline $\begin{array}{l}\text { Niedersachsen } \\
\text { Gemeinden }\end{array}$ & 6810379 & $\begin{array}{r}2928463 \\
953453\end{array}$ & $\begin{array}{l}403,4 \\
131,3\end{array}$ & 81,0 \\
\hline $\begin{array}{l}\text { Schlesw.-Holst. } \\
\text { Gemeinden }\end{array}$ & 2319886 & $\begin{array}{l}997551 \\
324784 \\
\end{array}$ & $\begin{array}{l}386,6 \\
125,9 \\
\end{array}$ & 77,6 \\
\hline $\begin{array}{l}\text { Hamburg } \\
\text { Gemeinden }\end{array}$ & 4199532 & $\begin{array}{r}1805799 \\
587935\end{array}$ & $\begin{array}{r}1030,7 \\
335,6\end{array}$ & 206,8 \\
\hline $\begin{array}{l}\text { Bremen } \\
\text { Gemeinden }\end{array}$ & 1208183 & $\begin{array}{l}519519 \\
169146 \\
\end{array}$ & $\begin{array}{l}712,6 \\
232,0 \\
\end{array}$ & 143,0 \\
\hline $\begin{array}{l}\text { Berlin } \\
\text { Gemeinden }\end{array}$ & 1327760 & $\begin{array}{l}570937 \\
185886 \\
\end{array}$ & $\begin{array}{r}278,8 \\
90,8 \\
\end{array}$ & 55,9 \\
\hline $\begin{array}{l}\text { Bundesgebiet } \\
\text { Gemeinden }\end{array}$ & 71960242 & $\begin{array}{l}30942904 \\
10074434\end{array}$ & $\begin{array}{l}498,3 \\
162,2\end{array}$ & 100,0 \\
\hline
\end{tabular}

\section{Variationskceffizienten:}

a) für die Verteilung des Lohnsteueraufkommens vor der Zerlegung 0,399,

b) für die Verteilung des Lohnsteueraufkommens nach der Zerlegung 0,246.
Quellen:

1) Berechnet nach:

Statistisches Bundesamt, Fachserie L,

Finanzen und Steuern, Reihe 2, Steuerhaus-

halt von Bund, Ländern und Gemeinden 1974,

Stuttgart, Mainz August 1975, S. 18 und S. 19. 


\begin{tabular}{|c|c|c|c|c|}
\hline \multicolumn{3}{|c|}{ Lohnsteueraufkommen nach der Zerlegung ${ }^{2)}$} & \multirow{3}{*}{$\begin{array}{l}\text { U mverteilungs- } \\
\text { masse } \\
=\text { Differenz zwischen } \\
\text { Spalte } 5 \mathrm{u} .2 \\
\text { in } 1000 \mathrm{DM}\end{array}$} & \multirow{3}{*}{$\begin{array}{l}\text { prozentuale } \\
\text { Veränderung } \\
\text { der Pro-Kopf- } \\
\text { einnahmen }\end{array}$} \\
\hline \multicolumn{3}{|c|}{ Länder- und Gemeindenanteil } & & \\
\hline in $1000 \mathrm{DM}$ & pro Kopf & $\begin{array}{l}\text { in \% d. Bundes- } \\
\text { durchschnitts }\end{array}$ & & \\
\hline 5 & 6 & 7 & 8 & 9 \\
\hline 4905682 & 452,0 & \multirow{2}{*}{90,7} & +154453 & \multirow{2}{*}{$+3,2$} \\
\hline 1597199 & 147,2 & & 50287 & \\
\hline 4852452 & 525,2 & \multirow{2}{*}{105,4} & -187558 & \multirow{2}{*}{$-3,7$} \\
\hline 1579868 & 171,0 & & 61066 & \\
\hline 3100801 & 555,3 & \multirow{2}{*}{111,5} & - $\quad 62180$ & \multirow{2}{*}{$-1,9$} \\
\hline 1009563 & 180,8 & & 20245 & \\
\hline 1597490 & 431,7 & \multirow{2}{*}{86,6} & +251251 & \multirow{2}{*}{$+18,7$} \\
\hline 520113 & 140,6 & & 81803 & \\
\hline 471210 & 423,8 & \multirow{2}{*}{85,1} & 5330 & \multirow{2}{*}{$+1,2$} \\
\hline 153417 & 138,0 & & 1735 & \\
\hline 9056474 & 525,1 & \multirow{2}{*}{105,4} & - 297824 & \multirow{2}{*}{$-3,2$} \\
\hline 2948619 & 171,0 & & - 96966 & \\
\hline 3222126 & 443,9 & \multirow{2}{*}{89,1} & +293663 & \multirow{2}{*}{$+10,0$} \\
\hline 1049064 & 144,5 & & 95611 & \\
\hline 1245972 & 482,9 & \multirow{2}{*}{96,9} & +248421 & \multirow{2}{*}{$+25,0$} \\
\hline 405665 & 157,2 & & +80881 & \\
\hline 1415653 & 808,0 & \multirow{2}{*}{162,2} & -390146 & \multirow{2}{*}{$-21,6$} \\
\hline 460910 & 263,0 & & 127025 & \\
\hline 447656 & 614,0 & \multirow{2}{*}{123,2} & 71863 & \multirow{2}{*}{$-13,6$} \\
\hline 145748 & 199,9 & & 23398 & \\
\hline 627388 & 306,3 & \multirow{2}{*}{61,5} & 56451 & \multirow{2}{*}{$+9,8$} \\
\hline 204266 & 99,8 & & 18380 & \\
\hline 30942904 & 498,3 & \multirow{2}{*}{100,0} & \pm 1009569 & \multirow{2}{*}{ $\pm 3,3$} \\
\hline 10074434 & 162,2 & & \pm 328697 & \\
\hline
\end{tabular}

2) Berechnet nach:

Statistisches Bundesamt, Anlage 2 zum Schreiben

VII B-47/4-393 vom 15.9.1976 an den Verfasser. 


\subsubsection{Interpretation und Beurteilung der Ergebnisse}

\subsubsection{Die Gesamtwirkung}

Dank der Zerlegung erhalten die Länder Bayern, Rheinland-Pfalz, Saarland, Niedersachsen, Schleswig-Holstein und Berlin im Jahr 1974 insgesamt rund 1 Mrd. DM, ihre Gemeinden rund 330 Mill. DM mehr Lohnsteuereinnahmen, als ihnen bei einer Verteilung des Länder-(Gemeinde-)Anteils ausschließlich nach dem kassenmäßigen örtlichen Aufkommen zugeflossen wäre. Damit werden durch die Lohnsteuerzerlegung rund 3,3\% der den Ländern und ihren Gemeinden insgesamt zustehenden Lohnsteuereinnahmen umverteilt.

Es muß noch einmal betont werden, daß es sich bei dieser Umverteilung nicht um eine Begünstigung der oben genannten sechs Länder handelt, durch die regionale Steuerkraftunterschiede verringert werden sollen. Vielmehr dient die Lohnsteuerzerlegung dazu, eine auf den erwähnten steuertechnischen Regelungen beruhende Benachteiligung jener sechs Länder, die 1974 ein Ausmaß von 1, $34 \mathrm{Mrd}$. DM erreicht hätte, zu vermeiden.

\subsubsection{Die Wirkung auf einzelne Länder}

Obwohl die Umverteilungsmasse mit 3,3\% des Länderanteils an der Lohnsteuer relativ gering ist, wirkt sich die Lohnsteuerzerlegung auf die Einnahmenposition einzelner Länder recht erheblich aus. So liegen die Lohnsteuereinnahmen der Länder Schleswig-Holstein und Rheinland-Pfalz um $25 \%$ bzw. 18, 7 \% über denen, die sie ohne Zerlegung erhalten hätten (Spalte 9). Von allen Ländern profitieren damit diese beiden Länder von der Lohnsteuerzerlegung am stärksten. Die stärkste Einbuße an Lohnsteuereinnahmen, die bereits von ihren Finanzkassen vereinnahmt waren, müssen die beiden Stadtstaaten Hamburg und Bremen hinnehmen. Ihre Lohnsteuereinnahmen nach der Zerlegung liegen $21,6 \%$ bzw. 13,6 \% unter ihrem Länderanteil am kassenmäßigen örtlichen Aufkommen.

\subsubsection{Der Nivellie rungseffekt}

Mit der Zerlegung der Lohnsteuer wird zwar primär bezweckt, steuertechnisch bedingte Verzerrungen des örtlichen Aufkommens zu vermeiden. Doch geht von ihr auch ein erheblicher Nivellierungseffekt auf die Steuerkraftunterschiede zwischen den Ländern aus. Alle Länder, deren kassenmäßiges örtliches Aufkommen unter dem Bundesdurchschnitt liegt (Spalte 4), erhalten dank der Zerlegung mehr Lohnsteuereinnahmen, als sie sonst bekommen hätten. Dadurch nähern sich ihre Lohnsteuereinnahmen pro Kopf von unten dem Bundesdurchschnitt an (Spalte 7). Alle vor der Zerlegung lohnsteuerstarken Länder müssen einen Teil der Lohnsteuereinnahmen, die ihre Finanzkassen vereinnahmt haben, an lohnsteuerschwache Länder abführen. Ihre Lohnsteuereinnahmen pro Kopf nähern sich damit von oben dem Bundesdurchschnitt an. Die Zerlegung bewirkt insgesamt, daß der Variationskoeffizient 
der Lohnsteuerverteilung vor der Zerlegung mit einem Wert von 0, 399 auf einen Wert nach der Zerlegung von 0,246 fällt. Allerdings führt die Zerlegung der Lohnsteuer nicht dazu, daß ein vor der Zerlegung lohnsteuerstar kes Land zu einem lohnsteuerschwachen Land wird und umgekehrt.

\subsection{Die Zusammensetzung der Zerlegungssalden der einzelnen Länder im Rechnungsjahr 1974}

In einer etwas tiefergehenden Untersuchung wird nun die Struktur der Zerlegungssalden der einzelnen Länder ermittelt. Damit wird aufgezeigt, an wen die einzelnen Länder Zerlegungszahlungen zu leisten haben und von wem sie Zerlegungszahlungen erhalten. An der Herkunft der von einem Land empfangenen Zerlegungszahlungen wird deutlich, welche Länder von den oben erwähnten steuertechnischen Regelungen auf Kosten des betrachtenden Landes 1974 ohne Lohnsteuerzerlegung profitiert hätten und mit großer Wahrscheinlichkeit vor 1970 von ihnen profitiert haben. (47) Die Ermittlung der Bestimmungsorte von Zerlegungszahlungen eines Landes gibt darüber Auskunft, auf Kosten welcher Länder das betrachtete Land 1974 ohne Lohnsteuerzerlegung begünstigt worden wäre und wohl bis 1970 begünstigt worden ist. (47) Darüberhinaus erlauben diese Daten auch einen flüchtigen Einblick in Richtung und Ausmaß von Ländergrenzen überschreitenden Arbeitskräftebewegungen und Unternehmensverflechtungen.

\subsubsection{Das methodische Vorgehen}

Herkunft und Bestimmungsort der Zerlegungszahlungen der einzelnen Länder lassen sich den Tabellen $2 \mathrm{a}$ und $2 \mathrm{~b}$ entnehmen. Tabelle $2 \mathrm{a}$ enthält die Bruttozahlungen der einzelnen Länder im Rahmen der Zerlegung der Lohnsteuer. In den Zeilen der Tabelle werden die Zerlegungszahlungen aufgeführt, die das betreffende Land an die anderen Länder zu leisten hat. Ihre Summe erscheint mit negativem Vorzeichen in den Feldern auf der Diagonalen der Tabelle. (48) Die Zahlungen, die die einzelnen Länder brutto empfangen, stehen in den Spalten der Tabelle 2a. Ihre Summe wird von der mit negativem Vorzeichen versehenen Summe der zu leistenden Zahlungen abgesetzt. Als Ergebnis erhält man den Zerlegungssaldo des betrachteten Landes (unterste Zeile). Ist das Vorzeichen des Zerlegungssaldos negativ, hat das jeweilige Land insgesamt mehr Lohnsteuern an andere Länder abzuführen, als es von diesen erhält. Bei positivem Vorzeichen gilt das Umgekehrte. (49)

Aus Tabelle 2a geht Tabelle $2 b$ hervor. Sie weist die Zahlungen aus, die die einzelnen Länder netto von den einzelnen anderen Ländern empfangen (positives Vorzeichen) oder an jene netto zu leisten haben (negatives Vorzeichen). Allerdings werden in Tabelle $2 b$ die Netto-Zahlungen nur für jene sechs Länder ermittelt, deren Einnahmenposition von der Lohnsteuerzerlegung am stärksten beeinflußt wird (vergl. Tabelle 2, Spalte 9). Diese Länder sind in der Kopfzeile von Tabelle 2b aufgeführt. 
Tabelle 2a Die Brutto-Zahlungen der Länder im Rahmen der Lohnsteuerzerlegung im Jahr 1974 (in 1000 DM)

\begin{tabular}{|c|c|c|c|c|c|c|c|c|c|c|c|}
\hline von an & $\begin{array}{l}\text { Nordrhein- } \\
\text { Westfalen }\end{array}$ & Bayern & $\begin{array}{l}\text { Baden- } \\
\text { Württemb. }\end{array}$ & $\begin{array}{l}\text { Nieder- } \\
\text { sachsen }\end{array}$ & Hessen & $\begin{array}{l}\text { Rheinland } \\
\text { Pfalz }\end{array}$ & $\begin{array}{l}\text { Schleswig } \\
\text { Holstein }\end{array}$ & Saarland & Hamburg & Bremen & Berlin \\
\hline $\begin{array}{l}\text { Nordrhein- } \\
\text { Westfalen }\end{array}$ & -1343368 & 232770 & 106378 & 303995 & 141142 & 252784 & 96589 & 23712 & 79620 & 30891 & 75487 \\
\hline Bayern & 103091 & -456823 & 99665 & 65856 & 54181 & 39888 & 28839 & 8619 & 24419 & 6740 & 25524 \\
\hline $\begin{array}{l}\text { Baden- } \\
\text { Württemberg }\end{array}$ & 106661 & 263721 & -837472 & 52365 & 141509 & 176986 & 23325 & 16644 & 24380 & 8322 & 23559 \\
\hline Niedersachsen & 114414 & 41203 & 20363 & -431889 & 89532 & 16685 & 41203 & 2247 & 33848 & 61021 & 11373 \\
\hline HEssen & 109380 . & 153074 & 66864 & 73190 & -724985 & 220967 & 23686 & 18610 & 28761 & 9121 & 21332 \\
\hline $\begin{array}{l}\text { Rheinland- } \\
\text { Priglz }\end{array}$ & 28521 & 20507 & 41796 & 11459 & 49544 & -188989 & 4915 & 20976 & 4258 & 1941 & 5072 \\
\hline 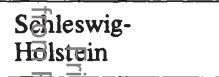 & 30506 & 20485 & 6635 & 63843 & 5623 & 7099 & -242460 & 1067 & 94095 & 8908 & 4199 \\
\hline Sब్తarland & 5731 & 2969 & 2264 & 1484 & 2043 & 66133 & 520 & -82640 & 726 & 455 & 314 \\
\hline Hogsmburg & 89534 & 70426 & 30447 & 299523 & 70714 & 17176 & 611536 & 3402 & -1245923 & 35360 & 17806 \\
\hline Bremen & 18183 & 9845 & 4796 & 274415 & 5151 & 4229 & 11647 & 725 & 10270 & -342957 & 3697 \\
\hline Be्flin & 21271 & 24338 & 10941 & 21203 & 19043 & 3399 & 8325 & 850 & 6493 & 1686 & -117548 \\
\hline $\begin{array}{l}\text { emprangene Zah- } \\
\text { luñgépin (brutto) }\end{array}$ & 627292 & 839329 & 390150 & 1167333 & 578482 & 805346 & 850585 & 96852 & 306870 & 164445 & 188363 \\
\hline Zetleigungs- & $-\quad 716074$ & +382514 & -447322 & +735444 & -146504 & +616358 & +608124 & +14212 & 939055 & -178511 & +70815 \\
\hline
\end{tabular}
$\overrightarrow{\mathrm{D}} \mathrm{V} \omega$

กิQjifille: Berechnet nach

$\overbrace{0}{ }_{0}$ Bundesministerium der Finanzen, Schnellbrief an die Finanzminister (Finanzsenatoren) der Länder, betr.

Zerlegung der Lohnsteuer und Körperschaftsteuer für das I. - IV. Vierteljahr 1974, Bonn, April 1974,

Juli 1974, Oktober 1974, Januar 1975 
Tabelle 2b Die Netto-Zahlungen einiger ausgewählter Länder im Rahmen der Lohnsteuerzerlegung im Jahr 1974 (in 1000 DM)

\begin{tabular}{|c|c|c|c|c|c|c|}
\hline & Hamburg & Bremen & $\begin{array}{l}\text { Rheinland- } \\
\text { Pfalz }\end{array}$ & $\begin{array}{l}\text { Schleswig- } \\
\text { Holstein }\end{array}$ & $\begin{array}{l}\text { Nieder- } \\
\text { sachsen }\end{array}$ & Berlin \\
\hline $\begin{array}{l}\text { Nordrhein- } \\
\text { Westfalen }\end{array}$ & $\begin{array}{r}79620 \\
-\quad 89534 \\
-\quad 9914\end{array}$ & $\begin{array}{r}30891 \\
-\quad 18183 \\
+\quad 12708 \\
(7,1)\end{array}$ & $\begin{array}{r}252784 \\
-\quad 28521 \\
+224263 \\
(36,4)\end{array}$ & $\begin{array}{r}96589 \\
-30506 \\
+\quad 66083 \\
(10,9)\end{array}$ & $\begin{array}{r}303995 \\
-114414 \\
+189581 \\
(25,7)\end{array}$ & $\begin{array}{r}75487 \\
-21271 \\
+54216 \\
(76,6)\end{array}$ \\
\hline Bayern & $\begin{array}{r}24419 \\
-\quad 70426 \\
-\quad 46007 \\
(4,9)\end{array}$ & $\begin{array}{r}6740 \\
-\quad 9845 \\
-\quad 3105\end{array}$ & $\begin{array}{r}39888 \\
-\quad 20507 \\
+19381\end{array}$ & $\begin{array}{r}28839 \\
-\quad 20485 \\
+\quad 8354\end{array}$ & $\begin{array}{r}65856 \\
-\quad 41203 \\
+\quad 24653 \\
(3,4)\end{array}$ & $\begin{array}{r}25524 \\
-24338 \\
+1186\end{array}$ \\
\hline $\begin{array}{l}\text { Baden- } \\
\text { Württemberg }\end{array}$ & $\begin{array}{r}24380 \\
-\quad 30447 \\
-\quad 6067\end{array}$ & $\begin{array}{r}8322 \\
-\quad 4796 \\
+\quad 3526\end{array}$ & $\begin{array}{r}176986 \\
-\quad 41796 \\
+135190 \\
(21,9)\end{array}$ & $\begin{array}{r}23325 \\
-\quad 6635 \\
+16690 \\
(2,7)\end{array}$ & $\begin{array}{r}52365 \\
-\quad 20363 \\
+\quad 32002 \\
(4,4)\end{array}$ & $\begin{array}{r}23559 \\
-10941 \\
+12618 \\
(17,8)\end{array}$ \\
\hline $\begin{array}{l}\text { Nieder- } \\
\text { sachsen }\end{array}$ & $\begin{array}{r}33848 \\
-299523 \\
-265675 \\
(28,3)\end{array}$ & $\begin{array}{r}61021 \\
-274415 \\
-213394 \\
(119,5)\end{array}$ & $\begin{array}{r}16685 \\
-\quad 11459 \\
+5226\end{array}$ & $\begin{array}{r}41203 \\
-\quad 63843 \\
-22640 \\
(3,7)\end{array}$ & - & $\begin{array}{r}11373 \\
-21203 \\
-\quad 9830 \\
(14,0)\end{array}$ \\
\hline Hessen & $\begin{array}{r}28761 \\
-\quad 70714 \\
-\quad 41953 \\
(4,5)\end{array}$ & $\begin{array}{r}9121 \\
-\quad 5151 \\
+\quad 3970\end{array}$ & $\begin{array}{r}220967 \\
-\quad 49544 \\
+171423 \\
(27,8)\end{array}$ & $\begin{array}{r}23686 \\
-\quad 5623 \\
+\quad 18063 \\
(3,0)\end{array}$ & $\begin{array}{r}73190 \\
-\quad 89532 \\
-\quad 16342 \\
(2,2)\end{array}$ & $\begin{array}{r}21332 \\
-19043 \\
+2289\end{array}$ \\
\hline $\begin{array}{l}\text { Rheinland- } \\
\text { Pfalz }\end{array}$ & $\begin{array}{r}4258 \\
-\quad 17176 \\
-12918\end{array}$ & $\begin{array}{r}1941 \\
-\quad 4229 \\
-\quad 2288\end{array}$ & - & $\begin{array}{r}4915 \\
-\quad 7099 \\
-\quad 2184\end{array}$ & $\begin{array}{r}11459 \\
-\quad 16685 \\
-\quad 5226\end{array}$ & $\begin{array}{r}5072 \\
-\quad 3399 \\
+\quad 1673\end{array}$ \\
\hline $\begin{array}{l}\text { Schleswig- } \\
\text { Holstein }\end{array}$ & $\begin{array}{r}94095 \\
-611536 \\
-517441 \\
(55,1)\end{array}$ & $\begin{array}{r}8908 \\
-\quad 11647 \\
-\quad 2739\end{array}$ & $\begin{array}{r}7099 \\
-\quad 4915 \\
+\quad 2184\end{array}$ & - & $\begin{array}{r}63843 \\
-\quad 41203 \\
+22640 \\
(3,1)\end{array}$ & $\begin{array}{r}4199 \\
-\quad 8325 \\
-\quad 4126 \\
(5,8)\end{array}$ \\
\hline Saarland & $\begin{array}{r}726 \\
-\quad 3402 \\
-\quad 2676\end{array}$ & $\begin{array}{r}455 \\
-\quad 725 \\
-\quad 270\end{array}$ & $\begin{array}{r}66133 \\
-\quad 20976 \\
+45157 \\
(7,3)\end{array}$ & $\begin{array}{r}520 \\
-\quad 1067 \\
-\quad 547\end{array}$ & $\begin{array}{r}1484 \\
-\quad 2247 \\
-\quad 763\end{array}$ & $\begin{array}{r}314 \\
-\quad 850 \\
-\quad 536\end{array}$ \\
\hline Hamburg & - & $\begin{array}{r}35360 \\
-\quad 10270 \\
+\quad 25090 \\
(14,1)\end{array}$ & $\begin{array}{r}17176 \\
-\quad 4258 \\
+\quad 12918\end{array}$ & $\begin{array}{r}611536 \\
-\quad 94095 \\
+517441 \\
(85,1)\end{array}$ & $\begin{array}{r}299523 \\
-\quad 33848 \\
+265675 \\
(36,1)\end{array}$ & $\begin{array}{r}17806 \\
-\quad 6493 \\
+11313 \\
(16,0)\end{array}$ \\
\hline Bremen & $\begin{array}{r}10270 \\
-\quad 35360 \\
-\quad 25090 \\
(2,7)\end{array}$ & - & $\begin{array}{r}4229 \\
-\quad 1941 \\
+\quad 2288\end{array}$ & $\begin{array}{r}11647 \\
-\quad 8908 \\
+2739\end{array}$ & $\begin{array}{r}274415 \\
-\quad 61021 \\
+213394 \\
(29,0)\end{array}$ & $\begin{array}{r}3697 \\
-\quad 1686 \\
+\quad 2011\end{array}$ \\
\hline Berlin & $\begin{array}{r}6493 \\
-\quad 17806 \\
-\quad 11313\end{array}$ & $\begin{array}{r}1686 \\
-\quad 3697 \\
-\quad 2011\end{array}$ & $\begin{array}{r}3399 \\
-\quad 5072 \\
-\quad 1673\end{array}$ & $\begin{array}{r}8325 \\
-\quad 4199 \\
+\quad 4126\end{array}$ & $\begin{array}{r}21203 \\
-\quad 11373 \\
+\quad 9830\end{array}$ & - \\
\hline insgesamt & $\begin{array}{r}-939055 \\
(100,0)\end{array}$ & $\begin{array}{r}-178511 \\
(100,0)\end{array}$ & $\begin{array}{r}+616358 \\
(100,0)\end{array}$ & $\begin{array}{r}+608124 \\
(100,0)\end{array}$ & $\begin{array}{r}+735444 \\
(100,0)\end{array}$ & $\begin{array}{r}+70815 \\
(100,0)\end{array}$ \\
\hline
\end{tabular}


Die Zerlegungszahlungen zwischen jedem einzelnen dieser sechs Länder und allen anderen Ländern sind in den Feldern der Spalten von Tabelle $2 \mathrm{~b}$ eingetragen. Die erste $Z$ ahl in jedem Feld gibt noch einmal den empfangenen, die zweite Zahl (negatives Vorzeichen) den zu leistenden Zerlegungsbetrag an. Die dritte Zahl ist als Summe der beiden ersten die hier interessierende Netto-Zerlegungszahlung. Die Summe dieser Netto-Zahlungen ergibt wieder den gesamten Zerlegungssaldo des jeweiligen Landes (letzte Zeile). Als vierte $\mathrm{Z}$ ahl ist in Klammern der Anteil der einzelnen Netto-Zahlungen am gesamten Zerlegungssaldo in die Felder der Spalten eingetragen. (50)

\subsubsection{Interpretation und Beurteilung der Ergebnisse}

Um den Umfang dieser Arbeit nicht ungebührlich auszuweiten, kann hier keine erschöpfende Interpretation der Tabelle $2 b$ vorgelegt werden. Vielmehr werden nur einige herausragende Ergebnisse aufgeführt.

Der Stadtstaat Hamburg weist von allen Bundesländern mit - 939 Mill. DM den (absolut) größten Zerlegungssaldo auf. Zudem ist der Zerlegungssaldo Hamburgs gegenüber allen anderen Ländern negativ. Ohne Zerlegung der Lohnsteuer wäre also Hamburg 1974 am stärksten von allen Ländern und gegenüber allen anderen Ländern durch die oben erwähnten steuertechnischen Re gelungen begünstigt worden. Daß diese Begünstigung Hamburgs seit dem 1.1.1970 mit der Zerlegung der Lohnsteuer aufgehoben ist, kommt besonders seinen Nachbarländern Schleswig-Holstein und Niedersachsen zugute. Diese beiden Länder erhalten im Rahmen der Lohnsteuerzerlegung von Hamburg netto 517,4 Mill. DM bzw. 265,7 Mill. DM zugewiesen, weil in dieser Höhe von ihren Einwohnern Lohnsteuern an die Finanzämter Hamburgs gezahlt worden sind. Diese Zerlegungssalden sind ein Spiegelbild der Verpflechtung Hamburgs mit seinem Umland und machen deutlich, in welchem Ausma $\beta$ Arbeitskräfte mit Wohnsitz in Schleswig-Holstein bzw. Niedersachsen zu ihren Arbeitsplätzen in Hamburg pendeln. Sie lassen zugleich den Umfang ahnen, in dem Hamburg vor 1970 an der Steuerleistung der Einwohner dieser beiden Länder partizipierte und damit die Einwohner seines Umlandes direkt an den Kosten seiner Leistungserstellung beteiligte (Kosten-spillout)(51).

Schleswig-Holstein ist das Land, das am stärksten von der Lohnsteuerzerlegung profitiert. Außer dem Zerlegungssaldo gegenüber Hamburg weist es noch zwei weitere interessante Zerlegungssalden auf. So erhält SchleswigHolstein von Nordrhein-Westfalen netto Zerlegungszahlungen in Höhe von 66, 1 Mill. DM. Dies ist mit 10,9\% des gesamten Zerlegungssaldos der zweitgrößte Saldo Schleswig-Holsteins gegenüber einem einzelnen Land. Dieser Saldo ist nicht mehr damit zu erklären, daß Arbeitskräfte mit Wohnsitz in Schleswig-Holstein in Nordrhein-Westfalen arbeiten und dort Lohnsteuern zahlen. Vielmehr muß es eine Reihe von Unternehmen mit Sitz in NordrheinWestfalen geben, die in Schleswig-Holstein Zweigbetriebe unterhalten und ihre Betriebsangehörigen zentral vom Unternehmenssitz aus entlohnen. Der zweite interessante Zerlegungssaldo Schleswig-Holsteins besteht gegenüber Niedersachsen. Dieses ist das einzige Land, an das Schleswig-Holstein in 
quantitativ beachtenswertem Maße Netto-Zahlungen zu leisten hat. Daraus kann man schließen, daß die relativ wirtschaftsstarken Regionen im Süden Schleswig-Holsteins, vor allem der Kreis Storman, einer recht großen Anzahl von lohnsteuerpflichtigen Arbeitskräften aus dem wirtschaftsschwachen Norden Niedersachsens Arbeitsplätze bieten.

\subsection{Die regionalpolitische Bedeutung der Zerlegung der Lohnsteuer}

Die Zerlegung der Lohnsteuer besitzt in allen Fällen ein finanziell bedeutendes Gewicht, in denen funktionale Wirtschaftsräume mit hohem Verflechtungsgrad durch Ländergrenzen zerschnitten werden. In der Bundesrepublik Deutschland trifft dies im wesentlichen für fünf Ballungszentren mit ihrem Einzugsbereich zu:

- Der Wirtschaftsraum Hamburg erstreckt sich auf die Bundesländer Hamburg (Zentrum), Niedersachsen und Schleswig-Holstein (Einzugsbereich).

- Der Wirtschaftsraum Bremen umfaßt die Hansestadt Bremen und ihr niedersächsisches Umland.

- Der Wirtschafts raum Mittelrhein mit seinem Zentrum in Nordrhein-Westfalen ist eng mit Randgebieten des Landes Rheinland-Pfalz verflochten.

- Teile des Einzugsgebietes des Ballungsraumes Rhein/Main, dessen Zentrum in Hessen liegt, gehören zum Land Rheinland-Pfalz.

- Der Wirtschaftsraum Rhein/Neckar teilt sich auf die Länder Baden-Württemberg und Rheinland-Pfalz.

Dementsprechend weisen die Länder Schleswig-Holstein und Niedersachsen gegenüber Hamburg, das Land Niedersachsen gegenüber Bremen und das Land Rheinland-Pfalz gegenüber Nordrhein-Westfalen, Hessen und BadenWürttemberg hohe positive Zerlegungssalden auf, die sich 1974 insgesamt auf rund 1,5 Mrd. DM belaufen.

Ohne Lohnsteue rzerlegung wären den Ländern Hamburg, Bremen, NordrheinWestfalen, Hessen und Baden-Württemberg, in denen sich die Zentren dieser fünf Ballungsregionen befinden, Lohnsteuern in Höhe dieser rund 1, 5 Mrd. DM von Einwohnern ihrer Nachbarländer zugeflossen. Davon hätten sie nach Abzug des Bundesanteils $57 \%$ zur freien Verfügung behalten können. Einwohner ihrer ländlichen Nachbarländer hätten also 1974 in Höhe von etwa 855 Mill. DM einen direkten Beitrag zu ihren Steuereinnahmen und damit zu den Kosten ihrer Leistungserstellung geleistet. Durch diesen Kosten-spillout wäre es den begünstigten Ländern möglich, ihre Attraktivität im allgemeinen und die des jeweiligen Ballungszentrums im besonderen noch stärker auszubauen, als es ihnen schon bei einer Verteilung der Lohnsteuer gemäß dem bereinigten örtlichen Aufkommen möglich ist. Das Steuerverteilungssystem enthielte hiermit in Form erhebungstechnischer Regelungen eine weitere Quelle, aus der ballungsverstärkende Tendenzen gespeist würden. Diese regionalpolitisch unerwünschte Alimentierung der wirtschaftsstarken Länder und ihrer Ballungs zentren durch ihre ländlichen Nachbarländer wird durch die Zerlegung der 
Lohnsteuer seit 1970 verhindert. Dies ist die regionalpolitische Bedeutung der Lohnsteuerzerlegung. (52)

3. Die Zerlegung der Körperschaftsteuer im Jahr 1974

3.1. Die Auswirkung der Zerlegung der Körperschaftsteuer auf die Einnahmenposition der einzelnen Länder im Jahr 1974

3.1.1. Das methodische Vorgehen

Die Auswirkung der Zerlegung der Körperschaftsteuer auf die Einnahmenposition der einzelnen Länder wird in Tabelle 3 nach demselben Verfahren wie im Fall der Lohnsteuerzerlegung ermittelt. Der tatsächlichen Verteilung des Länderanteils an der Körperschaftsteuer (Spalte 6) wird eine fiktive Verteilung (Spalte 2) gegenübergestellt. Diese gibt die Körperschaftsteuereinnahmen der einzelnen Länder an, die sie bei einer Verteilung des Länderanteils an der Körperschaftsteuer gemäß dem kassenmäßigen örtlichen Aufkommen erhalten hätten. An der Differenz zwischen der tatsächlichen und der fiktiven Verteilung läßt sich wieder die finanzielle Auswirkung der Zerlegungsvorschrift ablesen (Sp. 10).

\subsubsection{Interpretation und Beurteilung der Ergebnisse}

\subsubsection{Die Gesamtwirkung}

Die Zerlegung der Körperschaftsteuer sorgt dafür, daß 1974 rund 280 Mill. DM, das sind 5,4\% des Länderanteils an der Körperschaftsteuer, gegenüber einer Verteilung gemäß dem kassenmäßigen örtlichen Aufkommen umver teilt werden. Im Fall der Lohnsteuer profitieren alle lohnsteuerschwachen Länder von der Zerlegung, während alle lohnsteuerstarken Länder Einnahmen einbüßen. Bei der Körperschaftsteuer verhält es sich etwas anders. Nur drei Bundesländer, nämlich die körperschaftsteuerstarken Länder, Hamburg, Baden-Württemberg und Hessen müssen im Rahmen der Körperschaftsteuerzerlegung Netto-Zahlungen an die anderen Länder leisten. Diese drei Länder, die durch ihre zentrale und verkehrsgünstige Lage im Wirtschafts raum der Europäischen Gemeinschaft und durch ihre hohe Wirtschaftskraft gekennzeichnet sind, beherbergen also als Sitzland besonders viele und/oder besonders gewinnträchtige körperschaftsteuerpflichtige Unternehmen mit Zweigbetrieben in anderen Bundesländern. Ohne Zerlegung der Körperschaftsteuer wären sie $1974 \mathrm{im}$ Umfang von $280 \mathrm{Mill}$. DM durch die steuertechnische Bestimmung, derzufolge die Körperschaftsteuer an das Finanzamt am Sitzort der Unternehmung abzuführen ist, begünstigt worden. Es wäre damit diesen schon stark agglomerierten Ländern ermöglicht worden, Wirtschafts subjekte anderer Bundesländer direkt an den Kosten ihrer Leistungserstellung (Kosten-spillout) zu beteiligen. 
Tabelle 3 Die Auswirkung der Zerlegung der Körperschaftsteuer auf die Einnahmenposition der einzelnen Länder im Jahr 1974

\begin{tabular}{|c|c|c|c|c|c|c|c|c|c|c|c|}
\hline \multirow[t]{2}{*}{ Land } & \multicolumn{5}{|c|}{$\begin{array}{l}\text { Körperschaftsteueraufkommen vor der } \\
\text { Zerlegung } 2\end{array}$} & \multicolumn{4}{|c|}{$\begin{array}{l}\text { Körperschaftsteueraufkommen nach } \\
\text { der Zerlegung } 3\end{array}$} & \multirow{2}{*}{$\begin{array}{l}\text { Umverteilungs- } \\
\text { masse }=\text { Uiffe- } \\
\text { renz zwischen } \\
\text { Sp. } 6 \text { u. Sp. } 2 \\
\text { in } 1000 \mathrm{DM}\end{array}$} & \multirow{2}{*}{$\begin{array}{l}\text { prozentuale } \\
\text { Veränderung } \\
\text { d. Pro-Kopf- } \\
\text { Aufkommens }\end{array}$} \\
\hline & $\begin{array}{l}\text { örtl.Gesamt- } \\
\text { aufkommen } \\
\text { in } 1000 \mathrm{DM}\end{array}$ & $\begin{array}{l}\text { Länderan- } \\
\text { teil } \\
\text { in } 1000 \mathrm{DM}\end{array}$ & $\begin{array}{l}\text { pro } \\
\text { Kopf }\end{array}$ & $a^{1}$ & $b^{1}$ & $\begin{array}{l}\text { Länderan- } \\
\text { teil } \\
\text { in } 1000 \mathrm{DM}\end{array}$ & $\begin{array}{l}\text { pro } \\
\text { Kopf }\end{array}$ & $\mathrm{a}^{1}$ & $b^{1}$ & & \\
\hline & 1 & 2 & 3 & 4 & 5 & 6 & 7 & 8 & 9 & 10 & 11 \\
\hline Bayern & 1463981 & 731991 & 67,4 & 80,4 & 257,3 & 779150 & 71,8 & 85,7 & 189,9 & +47159 & $+6,5$ \\
\hline Baden-Württemb. & 2130171 & 1065085 & 115,3 & 137,6 & 440,0 & 959472 & 103,9 & 124,0 & 274,9 & -105613 & $-\quad 9,9$ \\
\hline Hessen & 1406284 & 703142 & 125,9 & 150,2 & 480,5 & 643666 & 115,3 & 137,6 & 305,0 & -59476 & $-\quad 8,4$ \\
\hline Rß̊ำinl.-Pfalz & 578949 & 289475 & 78,2 & 93,3 & 298,5 & 327973 & 88,6 & 105,7 & 234,4 & +38498 & $+13,3$ \\
\hline Såarland & 151689 & 75844 & 68,2 & 81,4 & 260,3 & 86626 & 77,9 & 93,0 & 206,1 & +10782 & $+14,2$ \\
\hline Nördxh.-Westf. & 3171152 & 1585576 & 91,8 & 109,5 & 350,4 & 1610179 & 93,4 & 111,5 & 247,1 & +24603 & $+1,7$ \\
\hline Nied $\frac{1}{2}$ sachsen & 379841 & 189920 & 26,2 & 31,3 & 100,0 & 274417 & 37,8 & 45,1 & 100,0 & +84497 & $+44,3$ \\
\hline Schles. & 219291 & 109646 & 42,5 & 50,7 & 162,2 & 138980 & 53,9 & 64,3 & 142,6 & +29334 & $+26,8$ \\
\hline Hä̀mburg & 714414 & 357207 & 203,9 & 243,3 & 778,2 & 242548 & 138,4 & 165,2 & 366,1 & -114659 & $-32,1$ \\
\hline Briemen & 137425 & 68712 & 94,3 & 112,5 & 359,9 & 85628 & 117,5 & 140,2 & 310,8 & +16916 & $+24,6$ \\
\hline Bêtlin & 50180 & 25090 & 12,3 & 14,7 & 46,9 & 53050 & 25,9 & 30,9 & 68,5 & +27960 & $+110,6$ \\
\hline $\begin{array}{l}\text { Bugidesgebiet } \\
\text { (einsehl.Berlin) }\end{array}$ & 10403377 & 5201688 & 83,8 & 100,0 & - & 5201688 & 83,8 & 100,0 & - & \pm 279749 & $\pm \quad 5,4$ \\
\hline
\end{tabular}
aे $\overrightarrow{\vec{C}}$ Variationskoeffizienten:

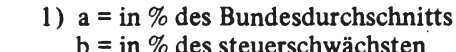

(u) Prürtlie Verteilung des Körperschaft-

Steùeraufkommens vor der

zeriegung 0,602,

b) für die Verteilung des Körperschaft-

steueraufkommens nach der

Zerlegung 0,397. Bundeslandes

Quellen:

2) Berechnet nach:

Statistisches Bundesamt, Fachserie L, Finanzen und Steuern, Reihe 2, Steuerhaushalt von Bund, Ländern und Gemeinden 1974, Stuttgart, Mainz August 1975, S. 18 und 19.

3) Berechnet nach:

Statistisches Bundesamt, Anlage 2 zum Schreiben VII B-47/4-393 vom 15.9.1976 an den Verfasser. 
Neben den körperschaftsteuerschwachen Ländern erhalten auch die vor der Zerlegung körperschaftsteuerstarken Länder Bremen und Nordrhein-Westfalen Netto-Zahlungen von Hamburg, Baden-Württemberg und Hessen. Bremen und Nordrhein-Westfalen erweisen sich damit mehr als Standort für Betriebsstätten, denn als Standort für den Sitz von körperschaftsteuerpflich tigen Unternehmen als attraktiv.

\subsubsection{Die Wirkung auf einzelne Länder}

Von den Ländern, die als Sitzland von Kapitalgesellschaften bevorzugt werden, büßt Hamburg im Jahr 1974 durch die Zerlegung am stärksten Körperschaftsteuereinnahmen ein (Spalte 11). Seine Körperschaftsteuereinnahmen nach der Zerlegung liegen 32,1\% unter denen vor der Zerlegung. Aber auch Baden-Württemberg und Hessen müssen mit 9,9\% bzw $8,4 \%$ eine spürbare Verschlechterung ihrer Einnahmen aus der Körperschaftsteuer hinnehmen.

Die Zerlegung der Körperschaftsteuer vermeidet eine steuertechnisch bedingte Benachteiligung insbesondere der Länder Berlin, Niedersachsen und Schleswig-Holstein. Ihre Einnahmen aus der Körperschaftsteuer steigen dank der Zerlegung um $110,6 \%, 44,3 \%$ bzw. $26,8 \%$. Ins gesamt entfallen auf diese drei Länder rund $50 \%$ der gesamten Umverteilungsmasse. Berlin, Niedersachsen und Schleswig-Holstein genießen aber anscheinend nicht nur als Sitzland bei vielen Kapitalgesellschaften eine geringe Wertschätzung. Vielmehr scheinen sich viele Kapitalgesellschaften auch zu scheuen, in diesen drei Ländern Betriebsstätten zu gründen. Darauf weist die Tatsache hin, daß Berlin auch nach der Zerlegung mit 30,9\%, Niedersachsen mit 45, $1 \%$ und Schleswig-Holstein mit 64, $3 \%$ des Bundesdurchschnitts (Spalte 8) mit Abstand die körperschaftsteuerschwächsten Länder sind.

\subsubsection{Der Nivellie rungseffekt}

Das kassenmäßige örtliche Aufkommen der Körperschaftsteuer streut sehr stark zwischen den Ländern. Während Hamburgs Pro-Kopf-Aufkommen 243, $4 \%$ des Bundesdurchschnitts beträgt, werden von den Finanzkassen Niedersachsens nur $31,3 \%$, von denen Berlins sogar nur 14, $7 \%$ der bundesdurchschnittlichen Pro-Kopf-Einnahmen aus der Körperschaftsteuer vereinnahmt (Spalte 4). Damit beträgt das kassenmäßige örtliche Aufkommen Hamburgs rund $780 \%$ desjenigen Niedersachsens. Ohne Zerlegung würde sich ein Körperschaftsteuerkraftgefälle ergeben, das erheblich größer als das Lohnsteuerkraftgefälle ohne Zerlegung ist. Dies wird durch die Variationskoeffizienten bestätigt: Für das kassenmäßige örtliche Aufkommen der Körperschaftsteuer beträgt er 0,602 gegenüber 0,399 für das Lohnsteueraufkommen vor der Zerlegung.

Ohne Zerlegung würden mit Ausnahme Berlins alle wirtschaftsstarken Länder weit überdurchschnittliche, alle wirtschaftschwachen Länder weit unter- 
durchschnittliche Einnahmen aus der Körperschaftsteuer erhalten. Bei einer Verteilung des Länderanteils an der Körperschaftsteuer nach dem kassenmäßigen örtlichen Aufkommen käme es also zu einem ausgesprochen starken regionalen Steuerkraftgefälle, das parallel zum regionalen Wirtachafts kraftgefälle verläuft. Die regionalen Steuerkraft- und Wirtschaftskraftunterschiede würden dadurch verstärkt. (53)

Die Zerlegung der Körperschaftsteuer dient zwar in erster Linie dazu, das örtliche Aufkommen der Körperschaftsteuer von steuertechnisch bedingten Verzerrungen zu bereinigen. Doch geht von ihr als Nebeneffekt auch eine beträchtliche Abschwächung der Unterschiede im Körperschaftsteueraufkommen der Länder aus. Alle körperschaftsteuerschwachen Länder erhaiten zum Teil erheblich höhere Körperschaftsteuereinnahmen, als sie ohne Zerlegung bekommen hätten, wodurch sich ihr Rückstand zum Bundesdurchschnitt verringert. Ein vor der Zerlegung körperschaftsteuerschwaches Land, nämlich Rheinland-Pfalz, wird durch die Zerlegung sogar zu einem körperschaftsteuerstarken Land (Spalte 8).

Außer den körperschaftsteuerschwachen Ländern erhalten aber auch $z$ wei schon vor der Zerlegung körperschaftsteuerstarke Länder, nämlich Bremen und Nordrhein-Westfalen, Netto-Zahlungen. Dadurch wird der Nivellierungseffekt der Körperschaftsteuerzerlegung wieder abgeschwächt. Immerhin verringert sich der Variationskoeffizient für die Verteilung des Länderanteils an der Körperschaftsteuer durch die Zerlegung von 0,602 auf 0,397. Damit entspricht er aber erst demjenigen der Verteilung der Lohnsteuer vor der Zerlegung.

Der Nivellierungseffekt der Zerlegung reicht jedoch nicht aus, um das Körperschaftsteuerkraftgefälle zwischen den Ländern auf ein regionalpolitisch akzeptables Ausmaß zu reduzieren. Bei den meisten Ländern weichen die Pro-Kopf-Einnahmen aus der Körperschaftsteuer sogar noch stärker vom Bundesdurchschnitt ab als ihre Wirtschaftskraft. Nach der Zerlegung stehen Hamburg, Bremen und Hessen mehr als dreimal so hohe Pro-Kopf-Einnahmen aus der Körperschaftsteuer zur Verfügung wie dem körperschaftsteuerschwächsten Bundesland Niedersachsen (Spalte 9). Während der Variations koeffizient für die Landessteuern 0,239, für den Länderanteil an der Lohnsteuer nach der Zerlegung 0,246 und für die gesamten Steuereinnahmen der Länder 0,211 beträgt, weist er für den Länderanteil an der Körperschaftsteuer nach der Zerlegung einen Wert von 0,397 auf.

Die horizontale Verteilung des Länderanteils an der Körperschaftsteuer ist eine wichtige Ursache dafür, daß auch nach Anwendung der Verteilungsvorschriften des Art. 107 GG in der Fassung vom 12.5.1969 zwischen den Ländern Steuerkraftunterschiede bestehen, die ein ballungsförderndes Leistungsgefälle zugunsten der wirtschaftsstarken Länder verursachen. (54)

\subsection{Die Zusammensetzung der Zerlegungssalden der einzelnen Länder im Rechnungsjahr 1974}

Wie die Lohnsteuerzerlegung wird auch die Zerlegung der Körperschaftsteuer einer weitergehenden Untersuchung unterzogen. Dies geschieht mit den Tabel- 
Tabelle 3a Die Brutto-Zahlungen der Länder im Rahmen der Körperschaftsteuerzerlegung im Jahr 1974 (in 1000 DM)

\begin{tabular}{|c|c|c|c|c|c|c|c|c|c|c|c|}
\hline von & $\begin{array}{l}\text { ivorarnein- } \\
\text { Westfalen }\end{array}$ & Bayern & $\begin{array}{l}\text { Baden- } \\
\text { Württemb. }\end{array}$ & $\begin{array}{l}\text { Nieaer- } \\
\text { sachsen }\end{array}$ & Hessen & $\begin{array}{l}\text { Rheinl.- } \\
\text { Pfalz }\end{array}$ & $\begin{array}{l}\text { Schlesw.- } \\
\text { Holstein }\end{array}$ & Saarland & Hamburg & Bremen & Berlin \\
\hline $\begin{array}{l}\text { Nordrhein- } \\
\text { Westfalen }\end{array}$ & -323325 & 58883 & 45424 & 52221 & 55596 & 28008 & 13433 & 6961 & 38840 & 10840 & 16119 \\
\hline Bayern & 47284 & -221099 & 45252 & 18515 & 29265 & 11019 & 4704 & 5397 & 9857 & 4252 & 45555 \\
\hline $\begin{array}{l}\text { Baden- } \\
\text { Württemberg }\end{array}$ & 54708 & 77212 & -299257 & 30305 & 37028 & 45936 & 1746 & 4744 & 17411 & 7902 & 22266 \\
\hline $\begin{array}{l}\text { Nieder- } \\
\text { sagchsen }\end{array}$ & 8420 & $-\quad 1100$ & $-\quad 1061$ & -33476 & 20215 & 1654 & 1550 & - & 2954 & 82 & 926 \\
\hline हुessen & 136394 & 58440 & 26136 & 47846 & -328062 & 29773 & 2300 & 2129 & 8792 & 1958 & 14295 \\
\hline $\begin{array}{l}\text { Rheinland- } \\
\text { Pralz }\end{array}$ & 24232 & 3478 & 11597 & 814 & 6159 & -55909 & 4096 & 455 & 4662 & 216 & 200 \\
\hline $\begin{array}{l}\text { Schleswig- } \\
\text { Holstein }\end{array}$ & 1149 & - & 32 & - & 350 & 356 & -4679 & - & 2781 & 10 & - \\
\hline Saa & 597 & - & 165 & - & - & - & - & $-\quad 762$ & - & - & - \\
\hline firmburg & 82625 & 38541 & 31519 & 56308 & 19283 & 6013 & 21195 & 58 & -279505 & 16450 & 7512 \\
\hline Bremen & 628 & 210 & 164 & 14370 & 90 & 249 & 122 & - & 2639 & -21410 & 2939 \\
\hline Berpin & 23743 & 7361 & 6149 & 6119 & 7042 & 872 & 1187 & 284 & 4529 & 1558 & -58844 \\
\hline $\begin{array}{l}\text { empiangene Zah- } \\
\text { (ungen (brutto) }\end{array}$ & 379780 & 243025 & 165377 & 226498 & 175028 & 123880 & 50333 & 20028 & 92465 & 43104 & 109812 \\
\hline Zerregungssaldo & +56455 & +21927 & -133879 & +193022 & -153034 & +67970 & +45654 & +19266 & -187040 & +21692 & +50968 \\
\hline
\end{tabular}

(1)

Ouelle: Berechnet nach

D $D$ Bundesministerium der Finanzen, Schnellbrief an die Finanzminister (Finanzsenatoren) der Länder, betr. Zerlegung der Lohnsteuer und Körperschaftsteuer für das I.-IV. Vierteljahr 1974, Bonn, April 1974, Juli 1974, Oktober 1974, Januar 1975. 
Tabelle 3b Die Netto-Zahlungen einiger ausgewählter Länder im Rahmen der Körperschaftsteuerzerlegung im Jahr 1974 (in 1000 DM)

\begin{tabular}{|c|c|c|c|c|c|c|}
\hline & Hamburg & $\begin{array}{l}\text { Baden- } \\
\text { Württemb. }\end{array}$ & Berlin & $\begin{array}{l}\text { Nieder- } \\
\text { sachsen }\end{array}$ & \begin{tabular}{|l} 
Schleswig- \\
Holstein
\end{tabular} & Hessen \\
\hline $\begin{array}{l}\text { Nordrhein- } \\
\text { Westfalen }\end{array}$ & $\begin{array}{r}38840 \\
-\quad 82625 \\
-\quad 43785 \\
(23,4)\end{array}$ & $\begin{array}{r}45424 \\
-\quad 54708 \\
-\quad 9284\end{array}$ & $\begin{array}{r}16119 \\
-23743 \\
-\quad 7624 \\
(15,0)\end{array}$ & $\begin{array}{r}52221 \\
-\quad 8420 \\
+43801 \\
(22,7)\end{array}$ & $\begin{array}{r}13433 \\
-\quad 1149 \\
+12284 \\
(26,9)\end{array}$ & $\begin{array}{r}55596 \\
-136394 \\
-\quad 80798 \\
(52,8)\end{array}$ \\
\hline Bayern & $\begin{array}{r}9857 \\
-\quad 38541 \\
-\quad 28684 \\
(15,3)\end{array}$ & $\begin{array}{r}45252 \\
-\quad 77212 \\
-31960 \\
(23,9)\end{array}$ & $\begin{array}{r}45555 \\
-\quad 7361 \\
+38194 \\
(74,9)\end{array}$ & $\begin{array}{r}18515 \\
+\quad 1100 \\
+\quad 19615 \\
(10,2)\end{array}$ & $\begin{array}{r}4704 \\
- \\
+4704 \\
(10,3)\end{array}$ & $\begin{array}{r}29265 \\
-\quad 58440 \\
-\quad 29175 \\
(19,1)\end{array}$ \\
\hline $\begin{array}{l}\text { Baden- } \\
\text { Württemberg }\end{array}$ & $\begin{array}{r}17411 \\
-\quad 31519 \\
-\quad 14108 \\
(7,5)\end{array}$ & - & $\begin{array}{r}22266 \\
-\quad 6149 \\
+16117 \\
(31,6)\end{array}$ & $\begin{array}{r}30305 \\
+\quad 1061 \\
+\quad 31366 \\
(16,2)\end{array}$ & $\begin{array}{r}1746 \\
-\quad 32 \\
+1714\end{array}$ & $\begin{array}{r}37028 \\
-\quad 26136 \\
+\quad 10892\end{array}$ \\
\hline $\begin{array}{l}\text { Nieder- } \\
\text { sachsen }\end{array}$ & $\begin{array}{r}2954 \\
-\quad 56308 \\
-53354 \\
\quad(28,5)\end{array}$ & $\begin{array}{r}-\quad 1061 \\
-\quad 30305 \\
-31366 \\
(23,4)\end{array}$ & $\begin{array}{r}926 \\
-\quad 6119 \\
-5193 \\
(10,2)\end{array}$ & - & $\begin{array}{r}1550 \\
+1550\end{array}$ & $\begin{array}{r}20215 \\
-\quad 47846 \\
-\quad 27631 \\
(18,1)\end{array}$ \\
\hline Hessen & $\begin{array}{r}8792 \\
-\quad 19283 \\
-10491\end{array}$ & $\begin{array}{r}26136 \\
-\quad 37028 \\
-10892 \\
(8,1)\end{array}$ & $\begin{array}{r}14295 \\
-\quad 7042 \\
+7253 \\
(14,2)\end{array}$ & $\begin{array}{r}47846 \\
-\quad 20215 \\
+27631 \\
(14,3)\end{array}$ & $\begin{array}{r}2300 \\
-\quad 350 \\
+1950\end{array}$ & - \\
\hline $\begin{array}{l}\text { Rheinland } \\
\text { Pfalz }\end{array}$ & $\begin{array}{r}4662 \\
=\quad 6013 \\
-\quad 1351\end{array}$ & $\begin{array}{r}11597 \\
-\quad 45936 \\
-\quad 34339 \\
(25,6)\end{array}$ & $\begin{array}{r}200 \\
-\quad 872 \\
-\quad 672\end{array}$ & $\begin{array}{r}814 \\
-\quad 1654 \\
-\quad 840\end{array}$ & $\begin{array}{r}4096 \\
-\quad 356 \\
+3740 \\
(8,2)\end{array}$ & $\begin{array}{r}6159 \\
-\quad 29773 \\
-\quad 23614 \\
(15,4)\end{array}$ \\
\hline $\begin{array}{l}\text { Schleswig- } \\
\text { Holstein }\end{array}$ & $\begin{array}{r}2781 \\
-\quad 21195 \\
-18414 \\
(9,8)\end{array}$ & $\begin{array}{r}32 \\
-\quad 1746 \\
-\quad 1714\end{array}$ & $\begin{array}{l}-\overline{1} 187 \\
-1187\end{array}$ & $\begin{array}{r}-\overline{1550} \\
-\quad 1550\end{array}$ & - & $\begin{array}{r}350 \\
-\quad 2300 \\
-1950\end{array}$ \\
\hline Saarland & $=\quad-58$ & $\begin{array}{r}165 \\
-\quad 4744 \\
-\quad 4579\end{array}$ & $\begin{array}{l}- \\
=-284 \\
-\quad 284\end{array}$ & - & - & $=\frac{-}{2129}$ \\
\hline Hamburg & - & $\begin{array}{r}31519 \\
-\quad 17411 \\
+\quad 14108 \\
(10,5)\end{array}$ & $\begin{array}{r}7512 \\
-\quad 4529 \\
+2983\end{array}$ & $\begin{array}{r}56308 \\
-\quad 2954 \\
+\quad 53354 \\
(27,6)\end{array}$ & $\begin{array}{r}21195 \\
-\quad 2781 \\
+18414 \\
(40,3)\end{array}$ & $\begin{array}{r}19283 \\
-\quad 8792 \\
+10491\end{array}$ \\
\hline Bremen & $\begin{array}{r}2639 \\
-\quad 16450 \\
-\quad 13811 \\
(7,4)\end{array}$ & $\begin{array}{r}164 \\
-\quad 7902 \\
-\quad 7738\end{array}$ & $\begin{array}{r}2939 \\
-\quad 1558 \\
+1381\end{array}$ & $\begin{array}{r}14370 \\
+\quad 82 \\
+\quad 14452 \\
(7,5)\end{array}$ & $\begin{array}{r}122 \\
-\quad 10 \\
+\quad 112\end{array}$ & $\begin{array}{r}90 \\
-\quad 1958 \\
-\quad 1868\end{array}$ \\
\hline Berlin & $\begin{array}{r}4529 \\
-\quad 7512 \\
-\quad 2983\end{array}$ & $\begin{array}{r}6149 \\
-\quad 22266 \\
-\quad 16117 \\
(12,0)\end{array}$ & - & $\begin{array}{r}6119 \\
-\quad 926 \\
+5193\end{array}$ & $\begin{array}{r}1187 \\
-\quad 1187\end{array}$ & $\begin{array}{r}7042 \\
-\quad 14295 \\
-\quad 7253\end{array}$ \\
\hline insgesamt & $\begin{array}{r}-187039 \\
(100,0)\end{array}$ & $\begin{array}{r}-133881 \\
(100,0)\end{array}$ & Friet 50,968 n & etstch 1939303 & $31+7556559$ & $\begin{array}{r}-153035 \\
(100,0)\end{array}$ \\
\hline
\end{tabular}


len $3 a$ und $3 b$, die nach demselben Muster wie die Tabellen 2a und $2 b$ aufgebaut sind. Alles, was zum Aufbau jener Tabellen gesagt wurde, gilt entsprechend auch für die Tabellen $3 a$ und $3 b$.

Die Ta bellen 3a und $3 b$ gliedern die Zerlegungssalden der einzelnen Länder in ihre Bestandteile auf und runden so das mit Tabelle 3 gewonnene Bild ab. Mit der Ermittlung der Herkunft und des Bestimmungsortes der Zahlungen im Rahmen der Körperschaftsteuerzerlegung wird ein Aspekt der interregionalen Verflechtung von Kapitalgesellschaften beleuchtet. Da damit aber keine grundlegend neuen Erkenntnisse gewonnen, sondern lediglich die Ergebnisse der Tabelle 3 ergänzt und differenziert werden, wird hier keine weitere Interpretation vorgenommen. Sie bleibt dem interessierten Leser vorbehalten.

III. Die Verteilung des Länderanteils an den Steuern vom Umsatz (55) auf die einzelnen Länder im Rechnungsjahr 1974

1. Der Verteilungsmodus des Länderanteils an der Umsatzsteuer

Im vorigen Abschnitt ist mit der Bereinigung des örtlichen Aufkommens von steuertechnisch bedingten Verzerrungen die zweite Stufe des Prozesses der Steuerverteilung auf die einzelnen Länder untersucht worden. Die Zerlegung der Lohnsteuer und Körperschaftsteuer erklärt einen Teil der Diskrepanz zwischen tatsächlichen Steuereinnahmen der Länder und ihrem kassenmäßigen örtlichen Aufkommen, die in Tabelle 1 ausgewiesen wird. Die Verteilung des Länderanteils an der Umsatzsteuer ist vollständig vom kassenmäßigen örtlichen Aufkommen oder vom be reinigten örtlichen Aufkommen als Verteilungskriterium gelöst. Deshalb wird sie hier als dritte Stufe des Prozesses der horizontalen Steuerverteilung betrachtet. (56)

Die Verteilung des Länderanteils an der Umsatzsteuer wird durch eine besondere Verteilungsvorschrift geregelt, die in $\$ 2$ des Gesetzes über den Finanzausgle'ich zwischen Bund und Ländern vom 28.8.1969 (BGBl. I S. 1432 ff.) (57) in Zusammenhang mit Art. 107, Abs. 1 GG festgelegt ist. Die Verteilungsvorschrift bestimmt (58):

- An $75 \%$ des Länderanteils an der Umsatzsteuer werden die einzelnen Länder gemäß ihrer Einwohnerzahl beteiligt. Als Verteilungskriterium für $3 / 4$ des Länderanteils dient also ein gesetzlich festgelegter, objektiver Bedarfsmaßstab.

- Aus den verbleibenden $25 \%$ des Länderanteils an der Umsatzsteuer erhalten die Länder, deren Einnahmen aus den Landessteuern und den Gemeinschaftsteuern ohne Umsatzsteuer (59) unter dem Bundesdurchschnitt liegen, sogenannte Ergänzungsanteile. Sie werden in Höhe der Differenz zwischen tatsächlichen Einnahmen der steuerschwachen Länder aus den Landessteuern und den Geme inschaftsteuern ohne Umsatzsteuer und $92 \%$ des Bundesdurchschnitts dieser Einnahmen gewährt. Die Auffüllung der Steuereinnahmen auf $92 \%$ des Bundesdurchschnitts in Form der Ergänzungs anteile dient also dem Abbau von Steuerkraftunterschieden zwischen den Ländern. 
Den steuerschwachen Ländern wird außerdem garantiert, daß sie aus die sen $25 \%$ des Länderanteils mindestens soviel Einnahmen erhalten, wie sie bei einer Verteilung auch dieser $25 \%$ nach der Einwohnerzahl bekommen hätten. Ist der Ergänzungsanteil eines Landes kleiner als der ihm nach der Einwohnerzahl zustehende Anteil, wird die Differenz in Form einer Garantiezuweisung ausgeglichen.

Verbleibt von den $25 \%$ des Länderanteils an der Umsatzsteuer nach Überweisung der Ergänzungsanteile und der Garantiezuweisungen noch ein Rest, so wird dieser auf die steuerstarken Länder nach ihrer Einwohnerzahl aufgeteilt.

In den nächsten beiden Abschnitten werden die finanziellen Auswirkungen dieser Verteilungsvorschrift für den Länderanteil an der Umsatzsteuer untersucht. Zuerst wird festgestellt, in welchem Ausmaß die Verteilungsvorschrift insgesamt die Einnahmenposition der einzelnen Länder gegenüber einer Verteilung nach dem kassenmäßigen örtlichen Aufkommen verändert. AnschlieBend wird die ermittelte Umverteilungsmasse auf ihre beiden Ursachen, die Verteilung nach der Einwohnerzahl und die Verteilung von $25 \%$ des Länderanteils in Form von Ergänzungsanteilen, zurückgeführt.

2. Die Auswirkung der Verteilung des Länderanteils an der Umsatzsteuer auf die Einnahmenposition der einzelnen Länder im Rechnungsjahr 1974

\subsection{Das methodische Vorgehen}

Tabelle 4 gibt Auskunft über die Umverteilung von Steuereinnahmen zwischen den Ländern, die 1974 durch die in $\$ 2$ des Finanzausgleichsgesetzes festge legte Verteilungsvorschrift für den Länderanteil an der Umsatzsteuer bewirkt wird. Als Ausgangsverteilung, an der der Umverteilungseffekt dieser Maßnahme der Finanzreform gemessen wird, dient wieder die Verteilung gemäß dem kassenmäßigen örtlichen Aufkommen (60) (Spalte 2). Diese fiktive Verteilung wird von der tatsächlichen Verteilung des Länderanteils an der Umsatzsteuer (Spalte 5) abgezogen. Die Differenz zwischen beiden Verteilungen (Spalte 8) gibt den Umverteilungseffekt dieser Maßnahme der Finanzreform an.

\subsection{Interpretation und Beurteilung der Ergebnisse}

2.2.1. Die Gesamtwirkung

Im Gegensatz zur Zerlegung der Lohnsteuer und der Körperschaftsteuer dient die Verteilung des Länderanteils an der Umsatzsteuer ausschließlich zum Ausgleich der Finanzkraftunterschiede und damit der Umverteilung von Steuereinnahmen zwischen den Ländern. Die bewußte Ausgestaltung dieser Maßnahme der Finanzreform als Umverteilungsinstrument wirkt sich positiv auf die Höhe der bewirkten Umverteilung von Steuereinnahmen zwischen den Ländern aus. 
Im Rechnungsjahr 1974 erhalten alle steuerschwachen Bundesländer insge samt 3,1 Mrd. DM mehr Einnahmen aus der Umsatzsteuer, als ihnen bei einer Verteilung nach dem kassenmäßigen örtlichen Aufkommen zustehen würde. Alle steuerstarken Länder verlieren in diesem Umfang Steuereinnahmen, die von umsatzsteuerpflichtigen Wirtschaftssubjekten an ihre Finanzämter abgeführt wurden. Damit sorgt die vom örtlichen Aufkommen als Steuerverteilungskriterium vollständig gelöste Verteilungsvorschrift des $\$ 2$ des Finanzausgleichsgesetzes dafür, daß 16,4 \% des Länderanteils an der Umsatzsteuer zwischen den steuerstarken und den steuerschwachen Ländern umverteilt werden.

\subsubsection{Die Wirkung auf einzelne Länder}

Entsprechend dem großen Umfang der Umverteilungsmasse wirkt sich die Verteilungsvorschrift des Länderanteils an der Umsatzsteuer ausgesprochen stark auf die Einnahmenposition der einzelnen Länder aus (Spalte 9).

Von den steuerstarken Ländern müssen Hamburg und Bremen den stärksten Verlust an bereits vereinnahmten Umsatzsteuereinnahmen hinnehmen. Gegenüber einer Verteilung des Länderanteils nach dem kassenmäßigen örtlichen Aufkommen verringern sich Hamburgs Umsatzsteuereinnahmen durch die Reformmaßnahme um 67,6 \% und Bremens um 48,4\%. Von den steuerschwachen Ländern profitieren Niedersachsen, Berlin und Schleswig-Holstein mit Abstand am stärksten. Ihre Umsatzsteuereinnahmen pro Kopf steigen im Vergleich zu einer Verteilung nach dem kassenmäßigen örtlichen Aufkommen um $133,6 \%, 93,8 \%$ bzw. $71,2 \%$.

\subsubsection{Der Nivellierungseffekt}

Bei einer Verteilung des Länderanteils an der Umsatzsteuer gemäß dem kassenmäßigen örtlichen Aufkommen würden alle Länder, die hinsichtlich der übrigen Ländersteuereinnahmen bereits steuerstark sind, weit überdurchschnittliche Umsatzsteuereinnahmen erhalten. An der Spitze dieser Länder steht Hamburg, dessen kassenmäßiges örtliches Umsatzsteueraufkommen $289,9 \%$ des Bundesdurchschnitts beträgt (Spalte 4). Alle auch sonst steuerschwachen Länder weisen ein weit unterdurchschnittliches kassenmäßiges örtliches Umsatzsteueraufkommen pro Kopf auf. (61) Niedersachsen und Berlin stehen dabei mit 52,4\% bzw. 51,3\% des Bundesdurchschnitts an letzter Stelle der umsatzsteuerschwachen Länder. Diese großen Steuerkraftunter schiede schlagen sich auch im Variationskoeffizienten für das kassenmäßige örtliche Umsatzsteueraufkommen nieder. Er beträgt 0,678 (62). Damit ist die Streuung des kassenmäßigen örtlichen Aufkommens der Umsatzsteuer noch größer als die des Körperschaftsteueraufkommens vor der Zerlegung.

Die spezielle Verteilungsvorschrift für den Länderanteil an der Umsatzsteuer verhindert, daß es zu diesem regionalpolitisch höchst unerwünschten Steuerkraftgefälle zugunsten der wirtschaftsstarken Länder kommt. Sie begnügt sich 
nicht nur mit einer Abschwächung des aus der Verteilung nach dem kassenmäßigen örtlichen Aufkommen hervorgehenden Steuerkraftgefälles, sondern kehrt dieses zugunsten der steuer - und wirtschaftsschwachen Bundesländer um. Nach der Verteilung des Länderanteils gemä $\beta \S 2$ des Finanzausgleichsgesetzes stehen im Jahr 1974 die beiden sonst steuerschwachen Länder Saarland und Niedersachsen an der Spitze aller Länder. Die ihnen zugewiesenen Umsatzsteuereinnahmen betragen $127,6 \%$ bzw. 122, $4 \%$ des Bundesdurchschnitts (Spalte 7). Die übrigen steuerschwachen Länder erhalten Umsatzsteuereinnahmen in Höhe des Bundesdurchschnitts, die steuerstarken Länder dagegen nur in Höhe von 94 - $95 \%$ des Bundesdurchschnitts. Der Variations koeffizient der Umsatzsteuereinnahmen nach der Verteilung gemä $\$ 2$ des Finanzausgleichsgesetzes hat einen Wert von 0,114 . Der Wert des Variationskoeffizienten muß in diesem Fall anders beurteilt werden als z. B. im Fall der Lohnsteuerzerlegung. Solange auch nach der Steuerverteilung alle steuerund wirtschaftsstarken Länder überdurchschnittliche, alle steuer - und wirtschaftsschwachen Länder unterdurchschnittliche Steuereinnahmen pro Kopf aufweisen, muß die horizontale Steuerverteilung aus regionalpolitischer Sicht umso ungünstiger beurteilt werden, je größer der Variationskoeffizient ist. Durch die Verteilung des Länderanteils an der Umsatzsteuer gemä $§ 2$ des Finanzausgleichsgesetzes entsteht aber die umgekehrte Situation, nämlich ein Umsatzsteuerkraftgefälle zugunsten der insgesamt steuer - und wirtschafts schwachen Länder. Von ihm gehen umso stärkere Gegenkräfte zum Ballungsprozeß aus, je größer die Einnahmenunterschiede zugunsten der wirtschaftsschwachen Länder sind. In diesem Fall ist demnach ein großer Wert des Variationskoeffizienten regionalpolitisch positiver als ein kleiner Wert zu beurteilen. (63)

Für die mit $₫ 2$ des Finanzausgleichsgesetzes konkretisierte Maßnahme der Finanzreform ergibt sich somit aus regionalpolitischer Sicht folgende $\mathrm{Be}-$ urteilung:

Sie wirkt nicht nur in die regionalpolitisch erwünschte Richtung, sondern ist auch quantitativ wirkungsvoll. Die Zerlegung der Lohnsteuer und der Körperschaftsteuer schwächt lediglich den ballungsfördernden Effekt ab, der von der Verteilung dieser Steuern gemäß dem kassenmäßigen örtlichen Aufkommen ausgehen würde. Die Zerlegung beseitigt diesen Effekt aber nicht. Dagegen sorgt die Verteilungsvorschrift für den Länderanteil an der Umsatzsteuer für eine horizontale Steuerverteilung, die den Ballungstendenzen entgegenwirkt. Durch sie werden also die einzelnen Länder so mit Umsatzsteuereinnahmen ausgestattet, daß die aus der Verteilung der übrigen Ländersteuereinnahmen zugunsten der wirtschaftsstarken Länder entstehenden Steuerkraftunterschiede abgeschwächt werden. Damit kompensiert sie einen Teil der ballungsfördernden Wirkungen, die von der horizontalen Verteilung der übrigen Ländersteuereinnahmen ausgehen. Sie besitzt damit von allen Maßnahmen der Finanzreform die größte regionalpolitische Wirksamkeit. 
Tabelle 4 Auswirkung der Verteilung des Länderanteils an den Steuern vom Umsatz ${ }^{1}$ gemäß $\S 2$ des Gesetzes über den Finanzausgleich zwischen Bund und Ländern im Jahr 1974

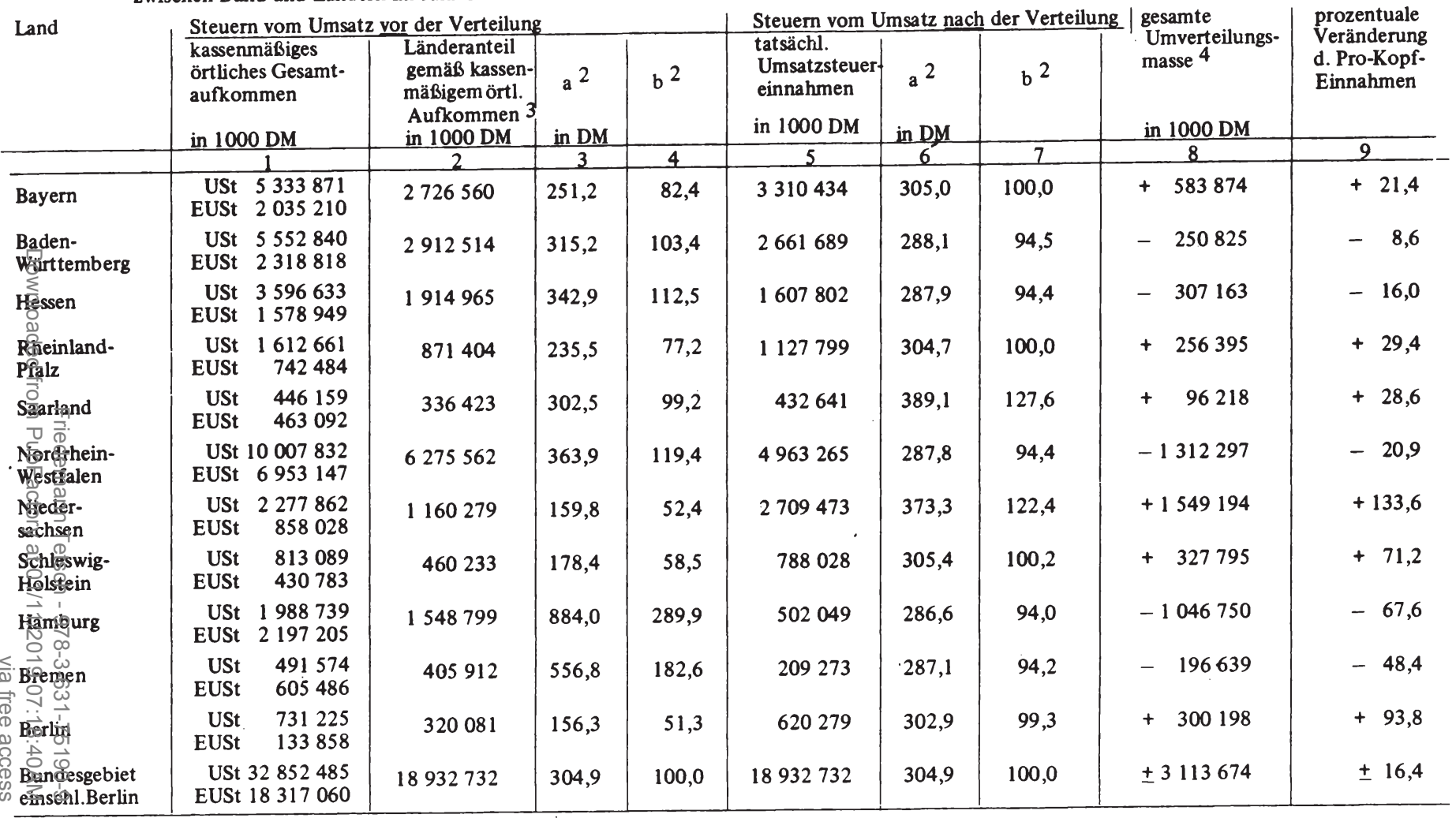

\section{1) Mehrwertsteuer una Einfuhrumsatzsteuer \\ 2) $\mathrm{a}=$ pro Kopf}

$\mathrm{b}=$ in \% des Bundesdurchschnitts
3) $37 \%$ des kassenmäßigen örtlichen Gesamtaufkommens

4) Differenz zwischen Spalte 5 und Spalte 2
Quelle: Berechnet nach

Statistisches Bundesamt, Fachserie L, Finanzen und

Steuern, Reihe 2, Steuerhaushalt von Bund, Ländern

und Gemeinden 1974, a.a.O., S. 18 - 21; und

Statistisches Bundesamt, Anlage 1 zum Schreiben VII

B-47/4-393 vom 15.9.1976 an den Verfasser. 
3. Die Auswirkung der Verteilung von 25 Prozent des Länderanteils an der Umsatzsteuer an besonders steuerschwache Länder im Jahr 1974

\subsection{Das methodische Vorgehen}

Die Verteilung des Länderanteils an der Umsatzsteuer führt deswegen zu einer Umverteilung von Steuereinnahmen zwischen den steuerstarken und den steuerschwachen Ländern in Höhe von 3,1 Mrd. DM, weil

- $75 \%$ des Länderanteils nach der Einwohnerzahl an alle Länder und

- $25 \%$ des Länderanteils in Form von Ergänzungsanteilen an besonders steuerschwache Länder

verteilt werden.

In Tabelle $4 \mathrm{a}$ wird ermittelt, in welchem Umfang diese beiden Verteilungskriterien als Ursache für den Umverteilungseffekt angesehen werden müssen. $\mathrm{Zu}$ diesem Zweck ist errechnet worden, in welcher Höhe die einzelnen Länder im Jahr 1974 Umsatzsteuereinnahmen erhalten hätten, wenn der gesamte Länderanteil an der Umsatzsteuer nach der Einwohnerzahl aufgeteilt worden wäre (Spalte 2). Zwischen diesen fiktiven Umsatzsteuereinnahmen der einzelnen Länder und ihrem kassenmäßigen örtlichen Aufkommen ist die Differenz gebildet worden (Spalte 4). Sie gibt den Umverteilungseffekt an, der bei ausschließlicher Verteilung des Länderanteils nach der Einwohnerzahl aufgetreten wäre. Um den Umverteilungseffekt, der von der besonderen Verteilung von $25 \%$ des Länderanteils ausgeht, zu ermitteln, müssen die Steuereinnahmen bei Verteilung nach der Einwohnerzahl (Spalte 2) von den tatsächlichen Umsatzsteuereinnahmen (Spalte 1) abgezogen werden. Die sich so in Spalte 3 ergebende Umverteilungsmasse ist darauf zurückzuführen, daß ein Teil des Länderanteils an der Umsatzsteuer nach einem anderen Maßstab als dem der Einwohnerzahl auf die einzelnen Länder verteilt wird.

Die Summe der beiden Umverteilungsmassen in Tabelle 4 a ergibt den gesamten Umverteilungseffekt der horizontalen Verteilung des Länderanteils an der Umsatzsteuer, wie er in Tabelle 4, Spalte 8 ausgewiesen wird.

\subsection{Interpretation und Beurteilung der Ergebnisse}

Durch die Verteilung des Länderanteils an der Umsatzsteuer gemäß $₫ 2$ des Finanzausgleichsgesetzes erhalten die steuerschwachen Länder rund 3,1 Mrd. DM mehr Steuereinnahmen als bei einer Verteilung gemäß dem kassenmäßigen örtlichen Aufkommen. Etwa 80 \% dieses Umverteilungseffektes be ruhen auf der Verteilung des Länderanteils nach der Einwohnerzahl. Wäre nämlich der gesamte Länderanteil nach der Einwohnerzahl verteilt worden, wären rund 2, 5 Mrd. DM, das sind 13, $3 \%$ des Länderanteils, zugunsten der steuerschwachen Länder umverteilt worden (Spalte 4). $20 \%$ des gesamten Umverteilungseffektes sind der Verteilung von einem Viertel des Länderanteils in Form von Ergänzungsanteilen zu verdanken. Diese Vorschrift bewirkt damit, daß die steuerschwachen Länder 1974 rund 600 Mill. DM mehr Umsatz- 
steuereinnahmen erhalten, als ihnen bei ausschließlicher Verteilung des Länderanteils nach der Einwohnerzahl zugestanden hätten.

Diese zusätzliche Umverteilung kommt im Grunde nur zwei steuerschwachen Ländern, nämlich Niedersachsen und dem Saarland, zugute (Spalte 3). Für das Saarland haben die Ergänzungsanteile eine besonders große Bedeutung. Ohne sie hätte es nur geringfügig mehr Umsatzsteuereinnahmen erhalten, als seinem kassenmäßigen örtlichen Aufkommen entspricht.

Allein durch die Verteilung eines Viertels des Länderanteils in Form von Ergänzungsanteilen werden 3,1 \% des Länderanteils umverteilt. Dieser Umverteilungseffekt entspricht dem der Lohnsteuerzerlegung $(3,3 \%)$, der allerdings im Fall der Lohnsteuerzerlegung nur mit einem erheblich größeren Verwaltungsaufwand erreicht werden kann.

\section{Zusammenfassung der bisher erzielten Ergebnisse}

Mit Tabelle 1 ist gezeigt worden, daß die steuerschwachen Länder durch die horizontale Steuerverteilung gemäß Art. 107, Abs. 1 GG in der Fassung vom 12.5.1969 auf Kosten der steuerstarken Länder rund 4,36 Mrd. DM mehr Steuereinnahmen erhalten, als sie bei Verteilung der den Ländern insgesamt zustehenden Steuereinnahmen gemäß dem kassenmäßigen örtlichen Aufkommen bekommen hätten. Die Abschnitte II. und III. mit den Tabellen 2, 3 und 4 dienen dem Zweck, diese Umverteilungsmasse zu erklären. Sie haben zu folgenden Ergebnis geführt.

Umverteilungsmasse (netto) insgesamt

(in $1000 \mathrm{DM}$ )

$$
\text { : } 4.361 .473=100,0 \%
$$

Umverteilungsmasse durch

a) Zerlegung der Lohnsteuer

$$
\text { 1.009.569 }=23,1 \%
$$

b) Zerlegung der Körperschaftsteuer (brutto) : 279.749

Nach Abzug der positiven Zerlegungsbeträge von Bremen und NordrheinWestfalen in Höhe von 16.916

$$
+\frac{24.603}{41.519} \quad 238.230=5,5 \%
$$

c) Verteilung der Umsatzsteuer gemäß $§ 2$ des Finanzausgleichsgesetzes

$$
\text { : } 3.113 .674=71,4 \% \text {. }
$$

Die bisher untersuchten Maßnahmen der Finanzreform - Zerlegung der Lohnsteuer, Zerlegung der Körperschaftsteuer und Verteilung der Umsatzsteuer gemäß $§ 2$ des Finanzausgleichsgesetzes - üben einen zum Teil beträchtlichen Umverteilungseffekt und Nivellierungseffekt aus. Der Umverteilungs effekt gibt die Summe der Abweichungen der tatsächlichen Steuereinnahmen der einzelnen Länder von ihrem jeweiligen kassenmäßigen örtlichen Aufkom- 
Tabelle 4a Auswirkung der Verteilung von 25 Prozent des Länderanteils an der Umsatzsteuer in Form von Ergänzungsanteilen an besonders finanzschwache Länder im Jahr 1974

\begin{tabular}{|c|c|c|c|c|}
\hline \multirow[t]{3}{*}{ Land } & $\begin{array}{l}\text { Länderanteil bei } \\
\text { Verteilung gemäß } \\
\text { § } 2 \text { des Finanzaus- } \\
\text { gleichsgesetzes } 1\end{array}$ & $\begin{array}{l}\text { Länderanteil bei } \\
\text { ausschließlicher } \\
\text { Verteilung nach der } \\
\text { Einwohnerzahl } 2\end{array}$ & $\begin{array}{l}\text { Umverteilungs- } \\
\text { masse I } 3\end{array}$ & $\begin{array}{l}\text { Umverteilungs- } \\
\text { masse II } 4\end{array}$ \\
\hline & in $1000 \mathrm{DM}$ & in $1000 \mathrm{DM}$ & in $1000 \mathrm{DM}$ & in $1000 \mathrm{DM}$ \\
\hline & 1 & 2 & 3 & 4 \\
\hline Bayern & 3310434 & 3308754 & +1680 & $+\quad 582194$ \\
\hline Baden-Württemb. & 2661689 & 2816694 & -155005 & 95820 \\
\hline Hessen & 1607802 & 1702394 & - 94592 & $-\quad 212571$ \\
\hline Rheinland-Pfalz & 1127799 & 1128324 & 525 & $+\quad 256920$ \\
\hline Saarland & 432641 & 339015 & +93626 & $+\quad 2592$ \\
\hline Nordrhein-Westf. & 4963265 & 5257788 & -294523 & -1017774 \\
\hline Niedersachsen & 2709473 & 2213051 & +496422 & +1052772 \\
\hline Schleswig-Holstein & 788028 & 786565 & +1463 & +326332 \\
\hline Hamburg & 502049 & 534132 & -32083 & -1014667 \\
\hline Bremen & 209273 & 222250 & -12977 & -183662 \\
\hline Berlin & 620279 & 624374 & $-\quad 4095$ & +304293 \\
\hline $\begin{array}{l}\text { Bundesgebiet } \\
\text { (einschl.Berlin) }\end{array}$ & 18932732 & 18933341 & $\begin{array}{l}+593191 \\
-593800\end{array}$ & $\begin{array}{l}+2525103 \\
-2524494\end{array}$ \\
\hline
\end{tabular}

1) siehe Spalte 5 in Tabelle 4.

2) Einwohnerzahl des jeweiligen Landes, multipliziert mit dem durchschnittlichen Umsatzsteueraufkommen pro Kopf in Höhe von DM 304,87.

3) Umverteilungsmasse durch Gewährung von Ergänzungsanteilen an besonders steuerschwache Länder $=$ Differenz $z$ wischen Spalte 1 und Spalte 2 .

4) Umverteilungsmasse durch Verteilung nach der Einwohnerzahl $=$ Differenz zwischen Spalte 2 in Tabelle 4a und Spalte 2 in Tabelle 4. 
men an und wird in Prozent der jeweiligen Ländersteuereinnahmen gemessen. Er kann sowohl zu einer Verstärkung als auch zu einer Abschwächung der Steuerkraftunterschiede futhren. Die Wirkung der Verteilungsvorschriften auf die Streuung der Pro-Kopf-Steuereinnahmen wird durch den Nivellierungseffekt gemessen. Der Verglelch des Variationskoeffizienten des kassenmäßigen örtlichen Aufkommens einer Ländersteuer mit dem Variationskoeffizienten der tatsächlichen Einnahmen aus dieser Ländersteuer zeigt, ob die horizontale Steuerverteilung die Steuerkraftunterschiede zwischen den Ländern abgeschwächt oder verstärkt hat. Die Verringerung der Streuung der Pro-Kopf-Einnahmen ist regionalpolitisch positiv zu beurteilen, wenn die Gruppe der wirtschaftsstarken mit der Gruppe der steuerstarken Länder auf der einen Seite und die Gruppe der wirtschaftsschwachen mit der Gruppe der steuerschwachen Länder auf der anderen Seite identisch sind.

Der Umverteilungseffekt und der Nivellierungseffekt der bisher untersuchten Finanzreformmaßnahmen sind in Tabelle 5 zusammengestellt. Zugleich sind die Variationskoeffizienten aller weiteren Ländersteuereinnahmen vor und nach der Steuerverteilung angegeben. Die Zusammenstellung der Variationskoeffizienten aller Ländersteuern nach der Verteilung hilft die Steuern zu identifizieren, die das auch nach der Finanzreform von 1969 bestehende regionalpolitisch unerwünschte Steuerkraftgefälle zugunsten der wirtschaftsstarken Länder (64) verursachen und bestimmen.

V. Die Verteilung des Länderanteils an der Körperschaftsteuer und an der Kapitalertragsteuer auf die einzelnen Länder nach der Einwohnerzahl ein Vorschlag zur Reform der horizontalen Steuerverteilung

Die Übersicht über die Variationskoeffizienten der einzelnen Ländersteuern (Tabelle 5) zeigt, daß die Einnahmen der Länder aus der Körperschaftsteuer und der Kapitalertragsteuer von allen Ländersteuereinnahmen nach der Verteilung die größte Streuung aufweisen. Sie tragen wesentlich dazu bei, daß auch nach der Steuerverteilung ein ballungsförderndes Steuerkraftgefälle besteht. (65) Deshalb wird anschließend untersucht, wie sich eine Verteilung des Länderanteils an der Körperschaftsteuer und der Kapitalertragsteuer auf die Einnahmenposition der einzelnen Länder ausgewirkt hätte, wenn sie nicht nach dem örtlichen Aufkommen, sondern nach der Einwohnerzahl vorgenommen worden wäre. Dies schlug der Bundesminister der Finanzen in den Auseinandersetzungen über die Verteilungskriterien der Länderanteile an den Gemeinschaftsteuern im Verlauf der Finanzreformdiskussion vor. (66)

1. Die Verteilung des Länderanteils an der Körperschaftsteuer auf die einzelnen Länder nach der Einwohnerzahl

1.1. Das methodische Vorgehen

Der Umverteilungseffekt einer Verteilung des Länderanteils an der Körperschaftsteuer auf die einzelnen Länder nach ihrer Einwohnerzahl wird in Ta- 
Tabelle 5 Die Variationskoeffizienten der Steuereinnahmen der Länder für das Rechnungsjahr 1974

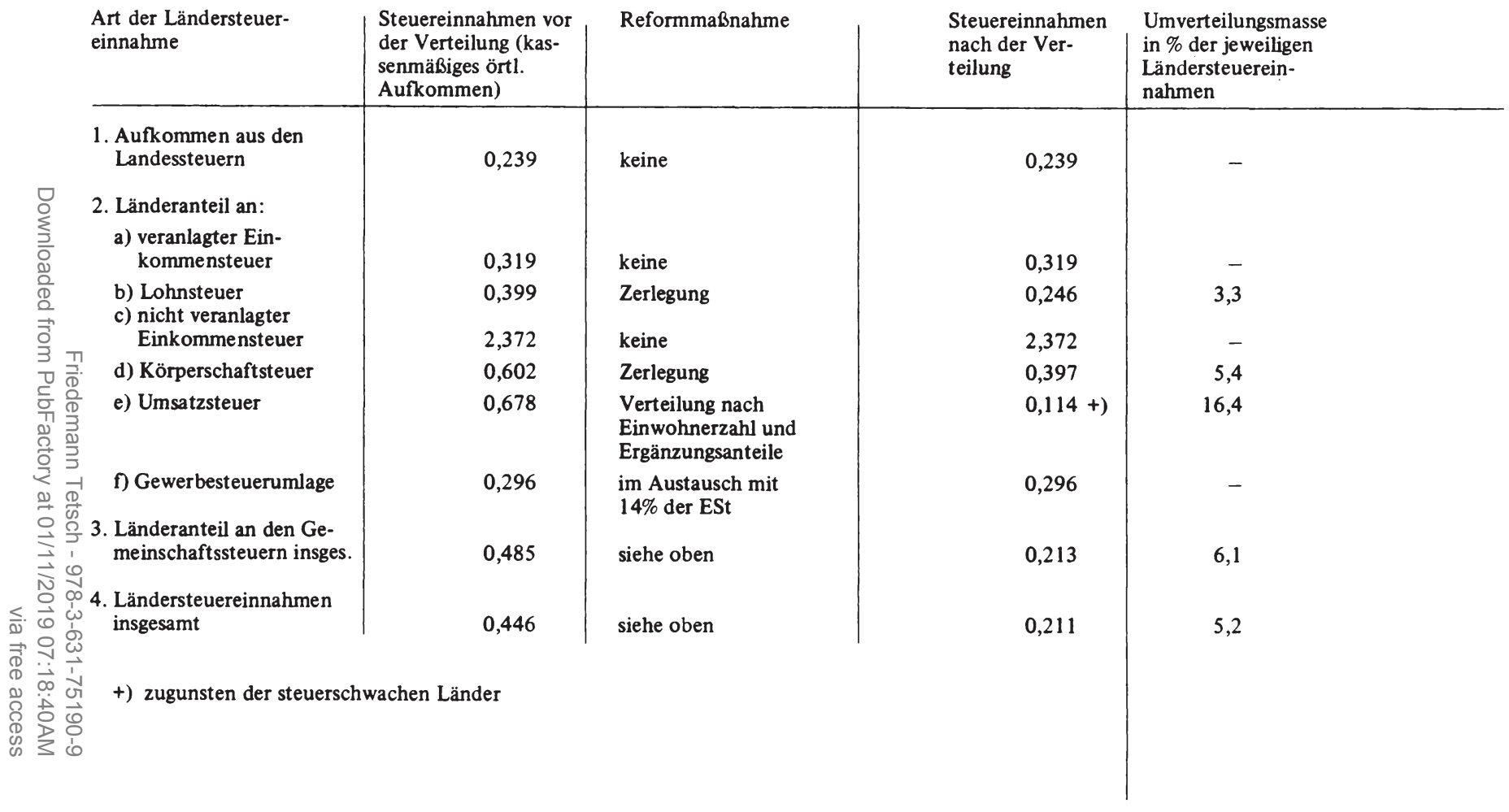


Tabelle 6a Die Verteilung des Länderanteils an der Körperschaftsteuer auf die einzelnen Länder nach der Einwohnerzahl für das Jahr 1974 (in 1000 DM)

\begin{tabular}{|c|c|c|c|c|c|}
\hline Land & $\begin{array}{l}\text { Länderanteil gemäß } \\
\text { kassenmäßigem ört- } \\
\text { lichem Aufkommen }\end{array}$ & $\begin{array}{l}\text { Länderanteil nach der } \\
\text { Zerlegung }^{2}\end{array}$ & $\begin{array}{l}\text { Länderanteil bei } \\
\text { Verteilung nach } \\
\text { der Einwohnerzahl } 3\end{array}$ & $\begin{array}{l}\text { Umverteilungs- } \\
\text { masse } 14\end{array}$ & $\begin{array}{l}\text { Umverteilungs- } \\
\text { masse II } 5\end{array}$ \\
\hline & 1 & 2 & 3 & 4 & 5 \\
\hline Bayern & 731991 & 779150 & 909481 & +177490 & +130331 \\
\hline Baden-Württemb. & 1065085 & 959472 & 774228 & -290857 & -185244 \\
\hline Hessen & 703142 & 643666 & 467939 & -235203 & -175727 \\
\hline Rheinland-Pfalz & 289475 & 327973 & 310144 & +20669 & $-\quad 17829$ \\
\hline Saarland & 75844 & 86626 & 93186 & +17342 & +6560 \\
\hline Nordrh.-Westf. & 1585576 & 1610179 & 1445215 & -140361 & -164964 \\
\hline Niedersachsen & 189920 & 274417 & 608304 & +418384 & +333887 \\
\hline Schlesw.-Holst. & 109646 & 138980 & 216204 & +106558 & +77224 \\
\hline Hamburg & 357207 & 242548 & 146818 & 210389 & 95730 \\
\hline Bremen & 68712 & 85628 & 61090 & $-\quad 7622$ & -24538 \\
\hline Berlin & 25090 & 53050 & 171622 & +146532 & +118572 \\
\hline $\begin{array}{l}\text { Bundesgebiet } \\
\text { (einschl. Berlin) }\end{array}$ & 5201688 & 52016886 & 52042316 & $\begin{array}{l}+8869757 \\
-8844327\end{array}$ & $\begin{array}{l}+6665748 \\
-6640328\end{array}$ \\
\hline
\end{tabular}

1) siehe Spalte 2, Tabelle 3

2) siehe Spalte 6, Tabelle 3

3) durchschnittliches Körperschaftsteueraufkommen in Höhe von 83,8 DM multipliziert mit der Einwohnerzahl des jeweiligen Landes
4) Umverteilungseffekt gegenüber der Verteilung gemäß dem kassenmäßigen örtlichen Aufkommen (Differenz zwischen Spalte 3 und 1)

5) Umverteilungseffekt gegenüber der Verteilung gemäß dem bereinigten örtlichen Aufkommen (Differenz zwischen Spalte 3 und 2)

6) Differenz $=2543$

7) Differenz $=2543$

8) Differenz $=2542$ 
belle 6a ermittelt. Dazu werden drei Verteilungen des Länderanteils aufgeführt:

- die Verteilung gemäß dem kassenmäßigen örtlichen Aufkommen (Spalte 1),

- die tatsächliche Verteilung, also die Verteilung gemäß dem bereinigten örtlichen Aufkommen (Spalte 2) und

- die Verteilung nach der Einwohnerzahl (Spalte 3).

Die Differenz zwischen der fiktiven Verteilung des Länderanteils an der Körperschaftsteuer gemäß der Einwohnerzahl und der ebenfalls fiktiven Verteilung gemäß dem kassenmäßigen örtlichen Aufkommen ergibt die Umverteilungsmasse I. Sie gibt an, in welchem Umfang zwischen den Ländern Kör perschaftsteuereinnahmen umverteilt werden, wenn statt des kassenmäßigen örtlichen Aufkommens die Einwohnerzahl der einzelnen Länder als Verteilungskriterium verwendet wird.

Die Differenz zwischen der fiktiven Verteilung nach der Einwohnerzahl und der tatsächlichen Verteilung ergibt die Umverteilungsmasse II. Im Ausmaß der Umverteilungsbeträge der Spalte 5 würden sich die Körperschaftsteuereinnahmen der einzelnen Länder verändern, wenn 1974 statt der Zerlegung der Körperschaftsteuer eine Verteilung nach der Einwohnerzahl durchgeführt worden wäre. Die durch die Zerlegung bewirkte Umverteilung (Tabelle 3, Spalte 10) und die Umverteilungsmasse II (Verteilung nach Einwohnerzahl gegenüber Verteilung nach Zerlegung) bilden zusammen die Umverteilungsmasse I (Verteilung nach Einwohnerzahl gegenüber Verteilung gemäß kassenmäßigem örtlichen Aufkommen).

\subsection{Interpretation und Beurteilung der Ergebnisse}

Bei einer Verteilung des Länderanteils an der Körperschaftsteuer gemä $\beta$ der Einwohnerzahl würden im Jahr 1974 alle steuerschwachen Länder auf Kosten aller steuerstarken Länder insgesamt rund 885 Mill. DM mehr Körperschaftsteuereinnahmen als bei einer Verteilung gemäß dem kassenmäßigen örtlichen Aufkommen erhalten (Spalte 4). Während durch die Zerlegung der Körperschaftsteuer nur 5, $4 \%$ des Länderanteils umverteilt werden, beträgt der Umverteilungseffekt der Verteilung nach der Einwohnerzahl rund $17 \%$ des Länderanteils an der Körperschaftsteuer.

Gegenüber dem geltenden Rechtszustand (Verteilung nach Zerlegung) würden den steuerschwachen Ländern 1974 rund 665 Mill. DM zusätzliche Körperschaftsteuereinnahmen auf Kosten der steuerstarken Länder zugewiesen werden. (67) Die Ablösung der Zerlegung durch eine Verteilung nach der Einwohnerzahl würde rund $13 \%$ des. Länderanteils zugunsten der steuerschwachen Länder umverteilen.

2. Die Verteilung des Länderanteils an der Kapitalertragsteuer auf die einzelnen Länder nach ihrer Einwohnerzahl

2.1. Das methodische Vorgehen

Tabelle $6 \mathrm{~b}$ gibt den Umverteilungseffekt an, der mit einer Verteilung des 
Länderanteils an der Kapitalertragsteuer nach der Einwohnerzahl im Jahr 1974 verbunden wäre (Spalte 3). Er ergibt sich als Differenz zwischen der Verteilung nach der Einwohnerzahl (Spalte 2) und der tatsächlichen Verteilung (Spalte 1).

Außerdem sind für jedes Land zwei Anteilsquotienten (68) berechnet worden. Der Anteilsquotient in bezug auf das Bruttoinlandsprodukt setzt den Anteil des einzelnen Landes am Länderanteil an der Kapitalertragsteuer mit dem Anteil des Landes am Bruttoinlandsprodukt der BRD in Beziehung (Spalte 7). Der Anteilsquotient in bezug auf die Einwohnerzahl ist das Verhältnis des Anteils des einzelnen Landes am Länderanteil an der Kapitalertragsteuer und des Anteils an der Einwohnerzahl der BRD (Spalte 8). Dieser Anteilsquotient ist mit der bisher verwendeten Meßziffer "in \% des Bundescurchschnitts" identisch. Die Anteilsquotienten zeigen an, ob und wie stark die regionale Verteilung der Kapitalertragsteuereinnahmen von der regionalen Verteilung der jeweiligen Bezugsgröße abweicht. Sie charakterisieren die horizontale Steuerverteilung und erlauben ihre Beurteilung unter verschiedenen Aspekten.

\subsection{Interpretation und Beurteilung der Ergebnisse}

Bei einer Reihe von inländischen Kapitalerträgen "wird die Einkommensteuer durch Abzug vom Kapitalertrag"(69) erhoben. "Der Schuldner der Kapitalerträge haftet .. für die Einbehaltung und Abführung der Kapitalertragsteuer. "(70)

Dieses Quellenabzugsverfahren führt dazu, daß die Kapitalertragsteuer dem Finanzamt, das für den Sitzort des Schuldners der Kapitalerträge zuständig ist, zufließt. Da in der BRD keine Zerlegung der Kapitalertragsteuer nach der Landeszugehörigkeit des Steuerpflichtigen (Gläubiger der Kapitale rträge) durchgeführt wird, erhält das Land, in dem sich der Sitz des Schuldners des Kapitalertrags befindet, diese Steuer in voller Höhe zugewiesen. Aus diesem Grund konzentriert sich das kassenmäßige örtliche Aufkommen aus der Kapitalertragsteuer in den Bundesländern, die als Sitzland von Unternehmen bevorzugt werden. Die Wohnsitzländer der Gläubiger der Kapitalerträge und damit der Steuerpflichtigen gehen leer aus.

Durch diese steuertechnische Regelung werden 1974 nur Hamburg und Hessen begünstigt. Gemessen an ihrem Anteil am Bruttoinlandsprodukt erhalten sie weit überproportionale Einnahmen aus der Kapitalertragsteuer (Spalte 7). Alle anderen Länder vereinnahmen erheblich weniger, als ihrem Anteil am Bruttoinlandsprodukt entspricht. Noch ungünstiger sieht die horizontale Verteilung des Länderanteils an der Kapitalertragsteuer aus, wenn man die regionale Verteilung der Bevölkerung als Beurteilungsmaßstab heranzieht. In diesem Fall erhält Hamburg 8,6-mal höhere Kapitalertragsteuereinnahmen, als ihm nach seiner Einwohnerzahl zusteht. Hessens Einnahmen aus dieser Quelle betragen $224 \%$ der durchschnittlichen Kapitalertragsteuereinnahmen, während die steuerschwachen Länder Niedersachsen und Schleswig-Holstein nur rund $20 \%$ der Einnahmen erhalten, die ihnen nach ihrer Einwohnerzahl zustehen. 
Tabelle $6 \mathrm{~b}$ Die Verteilung des Länderanteils an den nicht veranlagten Steuern vom Ertrag (Kapitalertragsteuer) auf die einzeinen Länder nach der Einwohnerzahl für das Jahr 1974

\begin{tabular}{|c|c|c|c|c|c|c|c|c|}
\hline Land & $\begin{array}{l}\text { Länderanteil an } \\
\text { nicht veranl.Steu- } \\
\text { ern v.Ertrag 4) } \\
\text { in } 1000 \text { DM }\end{array}$ & $\begin{array}{l}\text { Verteilung nach } \\
\text { der Einwohner- } \\
\text { zahl 1) } \\
\text { in } 1000 \mathrm{DM}\end{array}$ & $\begin{array}{l}\text { Umverteilungs- } \\
\text { masse } \\
=\text { Diff. Sp. } 2 \text { u. } 1\end{array}$ & $a^{2)}$ & $\left.b^{2)} 5\right)$ & $c^{2)}$ & $\mathrm{AQ}_{1}{ }^{3)}$ & $\mathrm{AQ}_{2}{ }^{3)}$ \\
\hline & 1 & \begin{tabular}{|l|}
2 \\
\end{tabular} & 3 & 4 & 5 & 6 & 7 & 8 \\
\hline Bayern & 97285 & 224874 & +127589 & $.7,56$ & 1632 & 17,48 & 0,4632 & 0,4325 \\
\hline Baden-Württemberg & 153518 & 191432 & +37914 & 11,93 & 15,10 & 14,88 & 0,7901 & 0,8017 \\
\hline Hessen & 258641 & 115700 & -142941 & 20,10 & 9,19 & 8,99 & 2,1872 & 2,2358 \\
\hline Rheinland-Pfalz & 35492 & 76685 & +41193 & 2,76 & 5,60 & 5,96 & 0,4929 & 0,4631 \\
\hline Saarland & 9311 & 23041 & +13730 & 0,72 & 1,57 & 1,79 & 0,4586 & 0,4022 \\
\hline Nordrh.-Westf. & 337337 & 357337 & +20000 & 26,21 & 28,79 & 27,77 & 0,9104 & 0,9438 \\
\hline Niedersachsen & 32437 & 150406 & +117969 & 2,52 & 9,81 & 11,69 & 0,2569 & 0,2156 \\
\hline Schteswig-Holstein & 10787 & 53458 & +42671 & 0,84 & 3,48 & 4,15 & 0,2414 & 0,2024 \\
\hline Hamburg & 312211 & 36301 & -275910 & 24,26 & 4,90 & 2,82 & 4,9510 & 8,6028 \\
\hline Bremen & 9542 & 15105 & +5563 & 0,74 & 1,53 & 1,17 & 0,4837 & 0,6325 \\
\hline Berlin & 30470 & 42435 & +11965 & 2,37 & 3,70 & 3,30 & 0,6405 & 0,7182 \\
\hline $\begin{array}{l}\text { Bundesgebiet ein- } \\
\text { schl. Berlin }\end{array}$ & 1287031 & 1286774 & $\begin{array}{l}+418594 \\
-418851\end{array}$ & 100,01 & 99,99 & 100,00 & 1,0000 & 1,0000 \\
\hline
\end{tabular}

1) 20,72 DM, multipliziert mit der Einwohnerzahl des jeweiligen Landes

2) a = Anteil am Länderanteil an den nicht veranlagten Steuern vom Ertrag

$\mathrm{b}=$ Anteil am Bruttoinlandsprodukt

$c=$ Anteil an der Einwohnerzahl

3) $\mathrm{AQ}_{1}=$ Anteilsquotient in bezug auf das BIP 1974

$\mathrm{AQ}_{2}=$ Anteilsquotient in bezug auf die Einwohnerzahl
Quellen:

4) Berechnet nach:

Statistisches Bundesamt, Fachserie L, Finanzen und Steuern, Reihe 2,

Steuerhaushalt von iund, Ländern und Gemeinden 1974, a.a.O., S. 18 f.

5) Berechnet nach:

Statistisches Bundesamt (Hrsg.), Statistisches Jahrbuch 1975 für die Bundesrepublik Deutschland, Stuttgart, Mainz 1975, S. 514. 
Diese große Streuung des kassenmäßigen örtlichen Aufkommens aus der Kapitalertragsteuer macht eine Verteilung des Länderanteils nach einem anderen Maßstab als dem des kassenmäßigen örtlichen Aufkommens dringend erforderlich.

Eine Verteilung des Länderanteils an der Kapitalertragsteuer nach der Einwohnerzahl hätte 1974 Hamburg und Hessen Steuereinnahmen in Höhe von 418 Mill. DM entzogen (Spalte 3). Etwa $32 \%$ des gesamten Länderanteils wären dadurch umverteilt worden. Von dieser Umverteilungsmasse gehen 63, 5 Mill. DM an die übrigen steuerstarken Länder, 355 Mill. DM an die steuerschwachen Länder. Dieser steuerkraftnivellierend wirkende Teil der Umverteilungsmasse ist damit noch erheblich größer als die Umverteilungs masse infolge der Körperschaftsteuerzerlegung. (71)

3. Die Auswirkung der Verteilung des Länderanteils an der Körperschaftsteuer und an der Kapitalertragsteuer nach der Einwohnerzahl auf die gesamten Steuereinnahmen der einzelnen Länder im Jahr 1974

\subsection{Das methodische Vorgehen}

Tabelle 6 enthält die Steuereinnahmen, die die einzelnen Länder 1974 erhalten hätten, wenn der Länderanteil an der Körperschaftsteuer nicht nach dem bereinigten und der Länderanteil an der Kapitalertragsteuer nicht nach dem kassenmäßigen örtlichen Aufkommen, sondern nach der Einwohnerzahl verteilt worden wären. Sie ergeben sich, indem aus den gesamten Steuereinnahmen der einzelnen Länder (Tabelle 1, Spalte 6) die Einnahmen aus der Körperschaftsteuer nach der Zerlegung (Tabelle 3, Spalte 6) und aus der Kapitalertragsteuer (Tabelle $6 \mathrm{~b}$, Spalte 1 ) herausgerechnet und die Einnahmen aus beiden Steuern bei einer Verteilung nach der Einwohnerzahl (Tabelle 6a, Spalte 3 und Tabelle $6 \mathrm{~b}$, Spalte 2) hinzugerechnet werden.

\subsection{Interpretation und Beurteilung der Ergebnisse}

Tabelle 6 ermöglicht einen Vergleich des 1974 tatsächlich existierenden Steuerkraftgefälles (Spalte 5) und demjenigen, das sich bei Verwirklichung des hier untersuchten Reformvorschlags ergeben würde (Spalte 4). Der Vergleich zeigt, daß eine Verteilung des Länderanteils an der Körperschaftsteuer und an der Kapitalertragsteuer gemäß der Einwohnerzahl das bei derzeitigem Recht existierende Steuerkraftgefälle abschwächen würde. Insbesondere würde sich der Steuerkraftvorsprung der Länder Hamburg und Hessen verringern. Der Variationskoeffizient der Verteilung nach Verwirklichung des Reformvorschlags beträgt 0,159 ge genüber 0,211 bei geltendem Recht.

Doch auch nach Verwirklichung dieses Reformvorschlags würden noch beträchtliche Steuerkraftunterschiede zwischen den Ländern bestehen. Den steuer - und wirtschaftsstarken Ländern stehen mindestens 15 Prozent (72) mehr Steuereinnahmen pro Einwohner als den beiden steuerschwächsten Bun- 
Tabelle 6 Auswirkung der Verteilung des Länderanteils an der Körperschaftsteuer und an der Kapitalertragsteuer nach der Einwohnerzahl auf die gesamten Steuereinnahmen der einzelnen Länder im Jahr 1974

\begin{tabular}{|c|c|c|c|c|c|}
\hline \multirow[t]{2}{*}{ Land } & \multicolumn{4}{|c|}{$\begin{array}{l}\text { Steuereinnahmen der Länder bei Verteilung des Länder- } \\
\text { anteils an der Körperschaftsteuer und an der Kapital- } \\
\text { ertragsteuer nach der Einwohnerzahl }\end{array}$} & \multirow{2}{*}{$\begin{array}{l}\text { tatsächl. Steuer- } \\
\text { einnahmen in \% des } \\
\text { steuerschwächsten } \\
\text { Bundeslandes } 2\end{array}$} \\
\hline & in $1000 \mathrm{DM}$ & pro Kopf & $a^{1}$ & $b^{1}$ & \\
\hline & 1 & 2 & 3 & -4 & 5 \\
\hline Bayern & 13999926 & 1290,0 & 96,1 & 107,9 & 107,2 \\
\hline Baden-Württemb. & 12880126 & 1394,1 & 103,9 & 116,6 & 119,4 \\
\hline Hessen & 7716128 & 1381,8 & 103,0 & 115,6 & 121,8 \\
\hline Rheinland-Pfalz & 4423314 & 1195,2 & 89,0 & 100,0 & 100,6 \\
\hline Saarland & 1333897 & 1199,5 & 89,4 & 100,4 & 100,0 \\
\hline Nordrh. Westf. & 23933395 & 1387,8 & 103,4 & 116,1 & 118,2 \\
\hline Niedersachsen & 9092308 & 1252,6 & 93,3 & 104,8 & 100,8 \\
\hline Schlesw.-Holst. & 3205938 & 1242,6 & 92,6 & 104,0 & 101,3 \\
\hline Hamburg & 3355546 & 1915,3 & 142,7 & 160,2 & 180,1 \\
\hline Bremen & 1141357 & 1565,6 & 116,6 & 131,0 & 134,7 \\
\hline Berlin & 2267683 & 1107,3 & 82,5 & 92,6 & 88,3 \\
\hline $\begin{array}{l}\text { Bundesgebiet } \\
\text { (einschl. Berlin) }\end{array}$ & 83349618 & 1342,2 & 100,0 & - & - \\
\hline
\end{tabular}

Variationskoeffizient: 0,159

1) $\mathrm{a}=$ in $\%$ des Bundesdurchschnitts

$\mathrm{b}=$ in $\%$ des steuerschwächsten Bundeslandes

2) siehe Tabelle 1 , Spalte 8 . 
desländern Rheinland-Pfalz und Saarland und mindestens 10 Prozent (72) mehr Steuereinnahmen pro Einwohner als Niedersachsen und Schleswig-Holstein zur Verfügung. Die Realisierung des Reformvorschlags würde also nicht verhindern, daß ein Steuerkraftgefälle zugunsten der wirtschaftsstarken Länder in einem regionalpolitisch unerwünschten Ausmaß bestehen bleibt. Auch nach Durchführung dieser Reformmaßnahme würde die horizontale Steuerverteilung ein regionales Gefälle im öffentlichen Leistungsangebot zu gunsten der bereits wirtschaftsstarken Länder verursachen, von dem sich selbst verstärkende Tendenzen ausgehen. Diese wären jedoch schwächer als ohne Verwirklichung des hier untersuchten Reformvorschlags. Wenn die Verteilung des Länderanteils an der Körperschaftsteuer und an der Kapitalertragsteuer nach der Einwohnerzahl aus regionalpolitischer Sicht auch nicht ausreichend ist, um ballungsfördernde Wirkungen des Steuerverteilungssystems ganz zu vermeiden, so stellt sie doch einen wichtigen Schritt in die erwünschte Richtung dar. Zudem hat sie den Vorteil, den rekurrenten Anschluß an die bisherige horizontale Steuerverteilung zu gewährleisten.

VI. Die Korrektur der horizontalen Steuerverteilung durch den Länderfinanzausgleich

Der Prozeß der Verteilung der den Ländern insgesamt zustehenden Steuereinnahmen ist bisher in drei Stufen zerlegt worden. Auf die Verteilung der Ländersteuereinnahmen gemäß dem kassenmäßigen örtlichen Aufkommen folgen als zweite und dritte Stufe die Zerlegung der Lohn- und Körperschaftsteuer sowie die Verteilung des Länderanteils an der Umsatzsteuer gemäß $\$ 2$ des Finanzausgleichsgesetzes. Als Ergebnis dieser Konstruktion des Steuerverteilungssystems ergibt sich für das Jahr 1974 eine horizontale Steuerverteilung, die durch Steuerkraftunterschiede in Höhe von 20 Prozent und mehr zugunsten der wirtschafts - und steuerstarken Bundesländer gekennzeichnet ist. (73) Steuerkraftunterschiede in einem solchen Ausmaß bedingen Unterschiede' im öffentlichen Leistungsangebot pro Einwohner zwischen den Ländern, wodurch ein wichtiger Aspekt des Grundsatzes der Einheitlichkeit der Lebensverhältnisse im Bundesgebiet verletzt wird. Deshalb sind weitere Maßnahmen zum Abbau der Steuerkraftunterschiede zwischen den Ländern erforderlich. Sie werden in der Bundesrepublik in Form horizontaler Aus gleichszahlungen auf Länderebene (Länderfinanzausgleich) ergriffen. Diese vierte Stufe des Steuerverteilungsprozesses wird im folgenden kurz dargestellt und auf ihre finanziellen Auswirkungen untersucht.

1. Die technische Durchführung des Länderfinanzausgleichs nach der Finanzreform von 1969

Artikel 107, Abs. 2 des Grundgesetzes schreibt einen angemessenen Ausgleich der Finanzkraftunterschiede $z$ wischen den Ländern vor und bezieht gleichzeitig die Gemeinden der Länder in diesen Ausgleich ein. Die technische Durchführung des horizontalen Länderfinanzausgleichs wird im einzelnen 
durch das Gesetz über den Finanzausgleich zwischen Bund und Ländern vom 28. August 1969 (74) geregelt. Dieses Gesetz "paßt den Länderfinanzaus gleich unter grundsätzlicher Beibehaltung der bisherigen Systematik an die neue Steuerverteilung an und verfolgt die Intensivierung des Finanzausgleichs". (75)

\subsection{Die Systematik des Ausgleichsverfahrens}

Das Finanzausgleichsgesetz schreibt vor, daß für jedes Land (76) eine Steuerkraftmeßzahl und eine Ausgleichsmeßzahl ermittelt werden müssen. Die Steuerkraftmeßzahl ist die Summe der Steuereinnahmen des Landes und der Steuereinnahmen seiner Gemeinden. Für die letzteren wird eine bundeseinheitliche Steueranspannung zugrunde gelegt. Die Ausgleichsmeßzahl ergibt sich als Summe der getrennt berechneten Meßzahlen zum Ausgleich der Ländersteuereinnahmen und zum Ausgleich der Gemeindesteuereinnahmen. Die beiden Ausgleichsmeßzahlen werden ermittelt, indem die bundesdurchschnittlichen Einnahmen aus den Ländersteuern bzw. Gemeindesteuern mit der Einwohnerzahl der Länder bzw. ihrer Gemeinden multipliziert werden. Bei der Ermittlung der Ausgleichsmeßzahl für die Ländersteuereinnahmen werden grundsätzlich die tatsächlichen Einwohnerzahlen der Länder, bei der Berechnung der Ausgleichsmeßzahl für die Gemeindesteuereinnahmen dagegen ver edelte Einwohnerzahlen der Gemeinden verwendet.

Länder, deren Steuerkraftmeßzahl kleiner als ihre Ausgleichsmeßzahl ist, erhalten als ausgleichsberechtigte Länder Ausgleichszuweisungen. Liegt dagegen die Steuerkraftmeßzahl über der Ausgleichsmeßzahl, so ist das betreffende Land ausgleichspflichtig und hat Ausgleichsbeiträge an die ausgleichs berechtigten Länder zu leisten. (77)

\subsection{Die Vorschriften zur Bemessung der Ausgleichszahlungen}

Kernstück der Neuordnung des Länderfinanzausgleichs im Zuge der Finanzreform ist die Vorschrift über die Bemessung der Ausgleichszahlungen. Danach werden die Ausgleichszuweisungen $(Z)$ nach folgendem Verfahren berechnet:

Liegt die Steuerkraftmeßzahl (S) eines Landes unter $92 \%$ ihrer Ausgleichsmeßzahl (A), wird diesem Land die Differenz zwischen seiner Steuerkraftmeßzahl und $92 \%$ seiner Ausgleichsmeßzahl vollständig und die Differenz zwischen $92 \%$ und $100 \%$ der Ausgleichsmeßzahl zu 37,5\% ausgeglichen.

Bei einer Steuerkraftmeßzahl zwischen $92 \%$ und $100 \%$ der Ausgleichsmeßzahl beträgt die Ausgleichszuweisung 37,5\% der Differenz zwischen Steuerkraftmeßzahl und Ausgleichsmeßzahl. (78) Damit werden den ausgleichsbe rechtigten Ländern Steuereinnahmen in Höhe von $95 \%$ ihrer Ausgleichsmeßzahl garantiert.

Für die Berechnung der Ausgleichsbeiträge (B) gilt: 
Die Steuerkraft, die zwischen $100 \%$ und $102 \%$ der Ausgleichsmeßzahl liegt, geht nicht in die Bemessungsgrundlage der Ausgleichsbeiträge ein.

Liegt die Steuerkraftmeßzahl eines Landes zwischen $102 \%$ und $110 \%$ seiner Ausgleichsmeßzahl, hat es $70 \%$ der Differenz zwischen seiner Steuerkraftmeßzahl und $102 \%$ seiner Ausgleichsmeßzahl als Ausgleichsbeitrag abzuführen.

Übersteigt die Steuerkraftmeßzahl $110 \%$ der Ausgleichsmeßzahl, beläuft sich der Ausgleichsbeitrag auf $70 \%$ der Differenz zwischen $102 \%$ und $110 \%$ der Ausgleichsmeßzahl und auf $100 \%$ der Differenz zwischen Steuerkraftmeßzahl und $110 \%$ der Ausgleichsmeßzahl. (79)

Nach Durchführung des Länderfinanzausgleichs beträgt demnach die Steuerkraft aller ausgleichspflichtigen Länder zwischen $102 \%$ und 104, $4 \%$ (80) ihrer Ausgleichsmeßzahl.

Die hier aufgeführten Vorschriften über die Bemessung der Ausgleichszuweisungen und der Ausgleichsbeiträge im Länderfinanzausgleich (81) garantieren also, daß nach Durchführung des Länderfinanzausgleichs die Finanzkraft jedes einzelnen Landes mindestens $95 \%$, höchstens aber 104, 4 \% seiner Ausgleichsmeßzahl beträgt. Damit versprechen sie einen weitgehenden Abbau der Finanzkraftunterschiede $z$ wischen den Ländern.

1.3. Die Berücksichtigung des lokalen Finanzbedarfs im Länderfinanzaus gleich

Der Länderfinanzausgleich ist grundsätzlich als Steuerkraftausgleich konzipiert. Doch enthält er auch einige Bestimmungen, durch die Belastungs - und damit Finanzbedarfsunterschiede zwischen den Ländern und ihren Gemeinden berücksichtigt werden sollen. Diese Bedarfselemente haben starken Einflu $\beta$ auf die Intensität des Finanzkraftausgleichs, so daß ohne ihre Kenntnis das Ergebnis des Länderfinanzausgleichs nicht verstanden werden kann.

Diese Bedarfselemente sind eingebaut

- in die Berechnung der Steuerkraftmeßzahl für die Ländersteuern (82);

Von den Ist-Steuereinnahmen der Länder Bremen, Hamburg, Niedersachsen, Saarland, Schleswig-Holstein und Rheinland-Pfalz werden feste Beträge (in unterschiedlicher Höhe) abgezogen. Durch diese künstliche Verringerung ihrer Steuerkraftmeßzahl sollen die Hafenlasten bzw. "übermäßige" Belastungen dieser Länder pauschal abgegolten werden.

- in die Berechnung der Ausgleichsmeßzahl für die Ländersteuern (83);

Die Meßzahl zum Ausgleich der Ländersteuereinnahmen wird für die Flächenstaaten durch Multiplikation der bundesdurchschnittlichen Einnahmen aus den Ländersteuern mit der tatsächlichen Einwohnerzahl der jeweiligen Länder ermittelt. Dagegen werden die Einwohnerzahlen der beiden Stadtstaaten Hamburg und Bremen mit $135 \%$ gewichtet. Ihre Ausgleichsmeßzahl wird dadurch künstlich erhöht, so daß sie niedrigere Ausgleichs - 
beiträge leisten müssen als bei Ansatz ihrer tatsächlichen Einwohnerzahlen.

- in die Berechnung der Steuerkraftmeßzahl für die Gemeindesteuern (84);

Für die Gemeinden der einzelnen Länder werden für jede einzelne Realsteuerart die Steuerkraftwerte (Grundbetrag, multipliziert mit einem bundeseinheitlichen Hebesatz) e rrechnet. Diese Steuerkraftwerte werden dann mit einem bundeseinheitlichen Prozentsatz so gekürzt, daß ihre Summe genau $50 \%$ der Ist-Steuereinnahmen aller Gemeinden beträgt.

Dieser halbe Ansatz der Gemeindesteuereinnahmen begünstigt die Länder, deren Gemeinden eine überdurchschnittliche Steuerkraft aufweisen, insbesondere Hamburg und Bremen. Denn die Differenz zwischen ihrer Steuerkraftmeßzahl und ihrer Ausgleichsmeßzahl fällt geringer aus als bei vollem Ansatz der Gemeindesteuereinnahmen, wodurch sie geringere Ausgleichsbeiträge zu leisten haben.

- in die Berechnung der Ausgleichsmeßzahl für die Gemeindesteuern (85).

Die Meßzahl zum Ausgleich der Gemeindesteuereinnahmen wird nicht mit Hilfe der tatsächlichen, sondern mit Hilfe von "veredelten" Einwohnerzahlen der Gemeinden berechnet. Die veredelten Einwohnerzahlen ergeben sich dadurch, daß die tatsächlichen Einwohnerzahlen der einzelnen Gemeinden umso stärker gewichtet werden, je größer die Gemeinde ist.

Konkret sieht der Gemeindegrößenansatz folgendermaßen aus :

tatsächliche angerechnete (ver-

Einw. -Zahl

$$
5.000
$$

500.000

1.000 .000

2.000. 000

edelte) Einw. -Zahl

$$
5.000
$$

593.500

1.218 .500

2. 518.500 veredelte Einw. Zahl in \% der tatsächl. EZ

$$
\begin{aligned}
& 100,0 \\
& 118,7 \\
& 121,9 \\
& 125,9 .
\end{aligned}
$$

Außerdem werden die Einwohnerwerte "im Interesse einer stärkeren Berücksichtigung der mit Verdichtungsräumen verbundenen Belastungen für Gemeinden ab 500.000 Einwohner durch prozentuale Zuschläge je nach Einwohnerdichte ergänzt ( 2 v. H. bei 1.500 bis 2.000 Einwohner je qkm, bis $6 \mathrm{v} . \mathrm{H}$. bei mehr als 3.000 Einwohner je qkm). "(86)

Durch die Anwendung dieser veredelten Einwohnerzahlen werden die Ausgleichsmeßzahlen für die Gemeindesteuern der stark agglomerierten Länder künstlich erhöht, so daß sie niedrigere Ausgleichsbeiträge zu leisten haben als bei Anwendung der tatsächlichen Einwohnerzahlen. Auch hiervon profitieren besonders stark Bremen und Hamburg.

Das Finanzausgleichsgesetz enthält also eine Reihe von Bestimmungen, durch die Unterschiede im lokalen Finanzbedarf der Länder und ihrer Gemeinden berücksichtigt und pauschal abgegolten werden. Dabei wird unterstellt, daß der lokale Finanzbedarf pro Einwohner mit steigendem Agglomerationsgrad zunimmt. (87) Die Berücksichtigung des ballungsbedingten lokalen Finanzbedarfs bewirkt, daß stark agglomerierte und steuerstarke Länder niedrigere 
Steuerkraftmeßzahlen und höhere Ausgleichsmeßzahlen aufweisen und dementsprechend niedrigere Ausgleichsbeiträge leisten, als ohne Einbau dieser Bedarfselemente in den Länderfinanzausgleich. Dank dieser Regelungen ver bleiben den stark agglomerierten Gebietskörperschaften also Steuereinnahmen, mit denen sie ballungsbedingte Kostensteigerungen bei der Erstellung ihres Leistungsangebots auffangen und/oder die der Kompensation der Ballungsnachteile dienende Nachfrage der privaten Wirtschaftssubjekte nach ö fentlichen Leistungen befriedigen können. (88) Damit wirkt die gegenwärtige Ausgestaltung des Länderfinanzausgleichs zwar nicht unmittelbar ballungsfördernd. Sie verhindert jedoch, daß sich die Ballungsnachteile in den stark agglomerierten Ländern als automatische Stabilisatoren des räumlichen Differenzie rungsprozesses vollständig auswirken können.

2. Die Auswirkung des Länderfinanzausgleichs auf die Einnahmenposition der einzelnen Länder (ohne Gemeinden) im Rechnungsjahr 1974

\subsection{Das methodische Vorgehen}

Tabelle 7a zeigt, in welchem Ausmaß die horizontalen Ausgleichszahlungen auf Länderebene die Einnahmenposition der einzelnen Länder beeinflussen. Die Ausgleichszahlungen im Rahmen des Länderfinanzausgleichs werden in Spalte 5 aufgeführt. Sie werden den Steuereinnahmen der Länder, die das Resultat der horizontalen Steuerverteilung gemäß den Verteilungsvorschrif ten des Art. 107, Abs. 1 des Grundgesetzes sind (Spalte 2), hinzugerechnet. Das Ergebnis des Länderfinanzausgleichs, die Finanzkraft der Länder (ohne Gemeinden) nach Durchführung des Länderfinanzausgleichs steht in Spalte 7.

\subsection{Interpretation und Beurteilung der Ergebnisse}

Im Rechnungsjahr 1974 beträgt die im Rahmen des Länderfinanzausgleichs umverteilte Finanzmasse rund 1,85 Mrd. DM. Sie wird von den steuerstarken Ländern Hamburg, Baden-Württemberg, Hessen und Nordrhein-Westfalen aufgebracht. Auf der Empfängerseite steht neben den steuerschwachen Ländern als einziges steuerstarkes Land Bremen.

Das primäre Ziel des Länderfinanzausgleichs ist die Steuerkraftnivellierung. Spalte 9 zeigt, daß sich alle steuerschwachen Länder von unten dem Bundesdurchschnitt annähern. Lediglich durch die Ausgleichszuweisung an Bremen in Höhe von immerhin 66, 3 Mill. DM wird der Nivellierungseffekt des Länderfinanzausgleichs abgeschwächt. Wie der Vergleich der Variationskoeffizienten zeigt - für die Finanzkraft vor dem Länderfinanzausgleich beträgt der Variationskoeffizient 0,207 , für die Finanzkraft nach dem Länderfinanzausgleich 0,155 - ist er aber immer noch beachtlich. Die Steuerkraftnivellierung geht jedoch nicht soweit, wie die Vorschriften über die Bemessung der Ausgleichszahlungen vermuten lassen. (89) Trotz der Garantie von Steuereinnahmen in Höhe von $95 \%$ der Ausgleichsmeßzahl erreicht das steuerschwächste Land Rheinland-Pfalz auch nach dem Länderfinanzausgleich nur 93,6\% der bundesdurchschnittlichen Finanzkraft.

184 
Tabelle 7a Auswirkung des Länderfinanzausgleichs auf die Steuerkraft der einzelnen Länder im Rechnungsjahr 1974

\begin{tabular}{|c|c|c|c|c|c|c|c|c|c|c|c|}
\hline Lind & $\begin{array}{l}\text { Einwoluner } \\
\text { am 30.6.746 }\end{array}$ & $\begin{array}{l}\text { Steuereinnal } \\
\text { yor Länderfi }\end{array}$ & $\begin{array}{l}\text { n der Länd } \\
\text { zzausgleich. }\end{array}$ & & $\begin{array}{l}\text { Länderfinanz } \\
\text { (LFA) }\end{array}$ & gleich & $\begin{array}{l}\text { Finanzkraft } \\
\text { Länderfüzan }\end{array}$ & $\begin{array}{l}\text { Länder na } \\
\text { sgleich }\end{array}$ & & & \\
\hline - & in $10 \underline{0} \underline{0}$ & in $1000 \mathrm{DM}$ & pro Kopf & 1 & in $1000 \mathrm{DM}$ & pro Kopf & in $1000 \mathrm{DM}$ & pro Kopf & a 1 & $b^{1}$ & c 1 \\
\hline$-\ldots \quad \ldots$ & 1 & 2 & 3 & 4 & 5 & 6 & 7 & 8 & 9 & 10 & 11 \\
\hline Bayern & 10848 & 13742006 & 1266,8 & 93,6 & 266300 & $+24,5$ & 14008306 & 1291,3 & 95,4 & 101,9 & $+1,9$ \\
\hline Baden-Württemb. & 9238 & 13027456 & 1410,2 & 104,2 & 614100 & $--66,5$ & 12413356 & 1343,7 & 99,2 & 106,0 & - 4,7 \\
\hline llessen & 5580 & 8034796 & 1439,9 & 106,4 & 264800 & $-\quad 47,5$ & 7769996 & 1392,5 & 102,8 & 109,9 & $-3,3$ \\
\hline Rheinland-Pfalz & 3696 & 4399950 & 1190,5 & 88,0 & 284100 & $+76,9$ & 4684050 & 1267,3 & 93,6 & 100,0 & $+6,5$ \\
\hline Saurland & 1108 & 1313607 & 1185,6 & 87,6 & 194100 & $+175,2$ & 1507707 & 1360,7 & 100,5 & 107,4 & $+14,8$ \\
\hline Nordrh.-Westf. & 17225 & 24078359 & I 397,9 & 103,3 & 565100 & $-32,8$ & 23513259 & 1365,1 & 100,8 & 107,7 & $-2,3$ \\
\hline Niedersachsen & 7262 & 8640452 & 1189,8 & 87,9 & 752200 & $+103,6$ & 9392652 & 1293,4 & 95,5 & 102,1 & $+8,7$ \\
\hline Schlesw.-Holst. & 2582 & 3086043 & 1195,2 & 88,3 & $\begin{array}{r}1100 \\
+\quad 329400\end{array}$ & $+127,1$ & 3414343 & 1322,4 & 97,7 & 104,3 & $+10,6$ \\
\hline Hanburg & 1742 & 3727186 & 2139,6 & 158,1 & $-\quad 396300$ & $-227,5$ & 3330886 & 1912,1 & 141,2 & 150,9 & $-10,6$ \\
\hline Bremen & 726 & 1160332 & 1598,3 & 118,1 & $+\quad 66300$ & $+91,3$ & 1226632 & 1689,6 & 124,8 & 133,3 & $+5,7$ \\
\hline $\begin{array}{l}\text { Bundesgebiet } \\
\text { (ohne Berlin) }\end{array}$ & 60007 & $81210186^{4}$ & 1353,3 & 100,0 & $\begin{array}{l}+1892400^{5} \\
-1841400^{5}\end{array}$ & - & $81261187^{4}$ & 1354,2 & 100,0 & - & - \\
\hline
\end{tabular}

Variationskoef fizienten:

a) Finanzkrafi vor Länderfinanzausgleich 0,207

b) Finanzkraft nach L.ändertinanzausgleich 0,155

1) $a=$ in \% des Bundesturchschnitts

$\mathrm{b}=$ in \% de's finanzschwäclisten Bundeslandes

$c=$ prozentuale Veränderung der Steuereinnahmen durch den Ländertinanzausgleich.

2) siehe Tabelle 1, Spalce 5 .

3) Sunme Spalte 2 und 5.

4) Differenz: 51001

5) Dilterenz: 51000
Quellen:

6) Statistisches Bundesamt, Finanzen und Steuern, Reihe 9, Realsteuervergleich 1974, Stuttgart, Mainz, Dezember 1975, S. 21.

7) Berechnet nach:

Bundesministeriun der Finanzen, Die Ausgaben und Einnahmen der Länder für das Rechnungsjahr 1974, Ubersicht I zu VA 2-FV 4036 - 1/75. 
Noch stärker ist die Diskrepanz zwischen erwartetem und tatsächlichem Nivellierungseffekt des Länderfinanzausgleichs im Fall der beiden Stadtstaaten Hamburg und Bremen. Hamburgs Einnahmenposition verschlechtert sich zwar infolge des Länderfinanzausgleichs um 10,6 \% (Spalte 11). Doch liegt seine Finanzkraft nach dem Länderfinanzausgleich mit 141,2 \% des Bundesdurchschnitts noch weit über dem Niveau, das die Bemessungsvorschrift für die Ausgleichsbeiträge erwarten läßt. Bremens Einnahmenposition verbes sert sich sogar um 5,7\%, so daß Bremens Finanzkraft von $118,1 \%$ des Bundesdurchschnitts auf 124, $8 \%$ ansteigt. Der Länderfinanzausgleich verstärkt in diesem $\mathrm{F}$ all also den Steuerkraftvorsprung eines steuer - und wirtschafts starken Bundeslandes und wirkt damit unmittelbar ballungsfördernd. Dies ist die regionalpolitisch bedenklichste Wirkung des Länderfinanzausgleichs.

Diese unerwartet günstige Einnahmenposition verdanken die beiden Stadtstaaten der Tatsache, daß in die Berechnung der Steuerkraft- und der Ausgleichsmeßzahl Bedarfselemente zugunsten der stark agglomerierten Länder eingehen. Die Daten der Spalte 9 stützen die oben geäußerte Vermutung, daß die Berücksichtigung eines mit steigendem Agglomerationsgrad wachsenden lokalen Finanzbedarfs pro Kopf im Rahmen des Länderfinanzausgleichs in erster Linie die beiden Stadtstaaten Hamburg und Bremen begünstigt und sich regionalpolitisch höchst negativ auswirkt.

3. Die Auswirkung des Länderfinanzausgleichs auf die Einnahmenposition der einzelnen Länder und ihrer Gemeinden im Rechnungsjahr 1974

3.1. Die Notwendigkeit der Einbeziehung der Gemeinden in die Untersuchung

Die Ergebnisse der Tabelle 7a erlauben noch keine umfassende und abschlieBende regionalpolitische Beurteilung der finanziellen Auswirkungen des Länderfinanzausgleichs. Denn die in Tabelle 7a durchgeführte Untersuchung ist insofern unvollständig, als sie die Einnahmenposition der Gemeinden der einzelnen Länder außer acht läßt.

Der Länderfinanzausgleich vollzieht sich zwar ausschließlich auf Länder ebene, doch sind auch die Gemeinden in den Länderfinanzausgleich einbezogen: Ihr Finanzbedarf und ihre Finanzkraft sind im Rahmen des Länderfinanzausgleichs zu berücksichtigen (90) und werden auch tatsächlich zur Berechnung der Ausgleichszahlungen herangezogen. (91) Demnach dient ein Teil der Ausgleichszahlungen dem Ausgleich der Finanzkraftunterschiede $z$ wischen den Ländern. Mit dem anderen Teil sollen dagegen die von Land zu Land be stehenden Finanzkraftunterschiede der Gemeinden abgeschwächt werden. Dieser Gemeindeanteil an den Ausgleichszahlungen im Rahmen des Länderfinanzausgleichs schlägt sich konkret in den vertikalen Ausgleichszahlungen zwischen den einzelnen Ländern und ihren Gemeinden im Rahmen des Gemeindefinanzausgleichs nieder:

- Die Gemeinden der ausgleichspflichtigen Länder erhalten von ihren Ländern Zuweisungen, die um den von den Gemeinden zu finanzierenden Teil der Länderfinanzausgleichsbeiträge gekürzt werden. (92) 
- Die Gemeinden der ausgleichsberechtigten Länder empfangen von ihren Ländern Zuweisungen, die aus eigenen Leistungen ihrer Länder und dem Gemeindeanteil an den Ausgleichszuweisungen aus dem Länderfinanzaus gleich bestehen. (93)

Die Ausgleichszahlungen im horizontalen Länderfinanzausgleich berühren also sowohl die Einnahmenposition der Länder als auch die ihrer Gemeinden. Will man die Gesamtwirkung des Länderfinanzausgleichs ermitteln, muß man die Finanzkraft der Länder und die ihrer Gemeinden vor und nach Durchführung des Länderfinanzausgle $\overline{i c h s}$ miteinander vergleichen. Dies geschieht in Tabelle $7 \mathrm{~b}$.

3.2. Interpretation und Beurteilung der Ergebnisse

3.2.1. Der Nivellierungseffekt des Länderfinanzausgleichs im Rechnungsjahr 1974

Mit der Einbeziehung der Steuerkraft der Gemeinden in die Untersuchung verstärken sich die Finanzkraftunterschiede $z$ wischen den Ländern. Mit Ausnahme von Hessen liegt die Finanzkraft aller Länder und ihrer Gemeinden vor Länderfinanzausgleich weiter vom Bundesdurchschnitt entfernt (Spalte 4) als ohne Einbeziehung der Gemeinden (Tabelle 7a, Spalte 4). Der Variationskoeffizient steigt mit der Einbeziehung der Gemeinden von 0,207 auf einen Wert von 0,219 .

Infolge des Länderfinanzausgleichs verringert sich die Streuung der Finanzkraft der Länder und ihrer Gemeinden. Der Variationskoeffizient sinkt von 0,219 auf 0,174 . Doch sind die Finanzkraftunterschiede zwischen den Ländern einschließlich ihrer Gemeinden nach dem Länderfinanzausgleich zum Teil erheblich größer, als sie bei Vernachlässigung der Steuerkraft der Gemeinden in Tabelle 7a ausgewiesen werden. Nur ein steuerschwaches Bundesland, nämlich Schleswig-Holstein, weist nach dem Länderfinanzausgleich eine Finanzkraft von mehr als $95 \%$ des Bundesdurchschnitts auf (Spalte 8). Alle anderen steuerschwachen Länder liegen mit ihrer Finanzkraft nach dem Länderfinanzausgleich zwischen $92 \%$ und $95 \%$ des Bundesdurchschnitts. Die Garantie von Steuereinnahmen in Höhe von $95 \%$ der Ausgleichs meßzahl ist also keineswegs gleichbedeutend mit einer Garantie von Steuereinnahmen in Höhe von $95 \%$ der bundesdurchschnittlichen Finanzkraft, was auf die bedarfsorientierten Vorschriften über die Ermittlung der Steuerkraftund Ausgleichsmeßzahlen zurückzuführen ist.

Die regionalpolitisch unerwünschten Wirkungen dieser bedarfsorientierten Vorschriften werden, wie in Tabelle $7 \mathrm{a}$, wieder besonders deutlich im Fall der beiden steuerstärksten Länder Hamburg und Bremen. Nach dem Länderfinanzausgleich liegt die Finanzkraft Hamburgs um 46, $3 \%$, diejenige Bremens um 26,0 \% über der bundesdurchschnittlichen Finanzkraft. Bei Einbeziehung der kommunalen Steuerkraft in die Untersuchung ist demnach der Finanzkraftvorsprung der beiden Stadtstaaten gegenüber den anderen Bundesländern 
Tabelle 7b Auswirkung des Länderfinanzausgleichs auf die Finanzkraft der einzelnen Länder und ihrer Gemeinden im Jahr 1974

\begin{tabular}{|c|c|c|c|c|c|c|c|c|c|c|}
\hline \multirow[t]{3}{*}{ Land } & \multirow{2}{*}{ 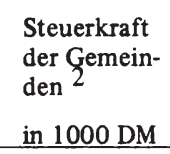 } & \multicolumn{4}{|c|}{ Finanzkraft vor Länderfinanzausgleich ${ }^{3}$} & \multicolumn{5}{|c|}{ Finanzkraft nach Länderfinanzausgleich 5} \\
\hline & & in $1000 \mathrm{DM}$ & pro Kopf 4 & $\mathrm{a}^{1}$ & $\mathrm{~b}^{1}$ & in $1000 \mathrm{DM}$ & pro Kopf ${ }^{4}$ & $\mathrm{a}^{1}$ & $b^{1}$ & $c^{1}$ \\
\hline & 1 & 2 & 3 & 4 & 5 & 6 & 7 & 8 & 9 & 10 \\
\hline Bayern & 3956700 & 17698706 & $1.631,5$ & 93,1 & 109,9 & 17965006 & $1.656,1$ & 94,4 & 102,6 & $+1,5$ \\
\hline Baden-Württemberg & 3976682 & 17004138 & $1.840,7$ & 105,1 & 124,0 & 16390038 & $1.774,2$ & 101,2 & 110,0 & $-3,6$ \\
\hline Hessen & 2302643 & 10337439 & $1.852,6$ & 105,7 & 124,8 & 10072639 & $1.805,1$ & 103,0 & 111,9 & $-2,6$ \\
\hline Rheinland-Pfalz & 1279407 & 5679357 & $1.536,6$ & 87,7 & 103,5 & 5963457 & $1.613,5$ & 92,0 & 100,0 & $+5,0$ \\
\hline Saarland & 331414 & 1645021 & $1.484,7$ & 84,7 & 100,0 & 1839121 & $1.659,9$ & 94,7 & 102,9 & $+11,8$ \\
\hline Nordrhein-Westf. & 7332166 & 31410525 & $1.823,5$ & 104,1 & 122,8 & 30845425 & $1.790,7$ & 102,1 & 111,0 & $-1,8$ \\
\hline Niedersachsen & 2355212 & 10995664 & $1.514,1$ & 86,4 & 102,0 & 11747864 & $1.617,7$ & 92,3 & 100,3 & $+6,8$ \\
\hline Schlesw.-Holstein & 889809 & 3975852 & $1.539,8$ & 87,9 & 103,7 & 4304152 & $1.667,0$ & 95,1 & 103,3 & $+8,3$ \\
\hline Hamburg & 1135801 & 4862987 & $2.791,6$ & 159,3 & 188,0 & 4466687 & $2.564,1$ & 146,3 & 158,9 & $-8,1$ \\
\hline Bremen & 376830 & 1537162 & $2.117,3$ & 120,8 & 142,6 & 1603462 & $2.208,6$ & 126,0 & 136,9 & $+4,3$ \\
\hline $\begin{array}{l}\text { Bundesgebiet } \\
\text { (ghne Berlin) } \\
\text { g) }\end{array}$ & 23936664 & 105146851 & $1.752,2$ & 100,0 & - & 105197851 & $1.753,1$ & 100,0 & 108,7 & - \\
\hline
\end{tabular}

Valriationskoeffizienten:

a蛋 Finanzkraft vor Länderfinanzausgleich: 0,219

b) Finanzkraft nach Länderfinanzausgleich: 0,174

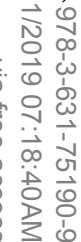

1) $\mathrm{a}=$ in $\%$ des Bundesdurchschnitts

$\mathrm{b}=$ in \% des finanzschwächsten Bundeslandes

$\mathrm{c}=$ prozentuale Veränderung der Pro-Kopf-Einnahmen.

2) Realsteuerkraft ./. Gewerbesteuerumlage + Gemeindeanteil an der Einkommensteuer. Berechnet nach:

Statistisches Bundesamt, Finanzen und Steuern, Reihe 9, Realsteuervergleich 1974, Stuttgart, Mainz, Dezember 1975, Seite 21 und 24.

3) Steuereinnahmen der Länder vor dem Länderfinanzausgleich (s. Tab. 1, Sp. 5) + Steuerkraft der Gemeinden.

4) Einwohnerzahlen Stand 30.6.1974.

5) Einnahmen aus Spalte 2 plus/minus horizontale Ausgleichszahlungen zwischen den Ländern (s. Tab. 7a, Sp. 5) 
noch größer, als er von Tabelle 7a ausgewiesen wird. Wenn das Finanzaus gleichsgesetz den steuerstarken Ländern nur Steuereinnahmen in Höhe von maximal 104, 4 \% ihrer Ausgleichsmeßzahl beläßt, (94) so besagt diese Vorschrift noch nichts über den tatsächlichen Abbau der Steuerkraftunterschie de durch den Länderfinanzausgleich. Vielmehr wird diese Vorschrift durch die konkrete Berechnung der Steuerkraft- und Ausgleichsmeßzahlen in so starkem Maße unterlaufen, daß das steuerstarke Bremen seinen Finanzkraftvorsprung gegenüber dem Bundesdurchschnitt sogar noch von 20,8\% auf $26,0 \%$ ausdehnen kann.

3.2.2. Das Finanzkraftgefälle zwischen den Ländern und ihren Gemeinden nach Durchführung des Länderfinanzausgleichs im Rechnungsjahr 1974

Nach dem Länderfinanzausgleich können die Länder einschließlich ihrer Gemeinden nach der Finanzkraft in vier Gruppen untergliedert werden:

- Die beiden Stadtstaaten Hamburg und Bremen verfügen über rund $59 \%$ bzw. $37 \%$ mehr Steuereinnahmen pro Einwohner, als den finanzschwächsten Bundesländern zur Erfüllung der kommunalen und staatlichen Aufgaben zur Verfügung stehen (Spalte 10).

- Mit weitem Abstand folgen die finanzstarken Flächenstaaten. Ihr Finanzkraftvorsprung gegenüber den finanzschwächsten Ländern beträgt $10-12 \%$.

- Eine Gruppe der finanzschwachen Länder liegt etwa drei Prozent über den finanzschwächsten Bundesländern. Dank des Länderfinanzausgleichs gehören Schleswig-Holstein und Saarland zu dieser Gruppe und stehen von allen finanzschwachen Ländern am günstigsten da.

- Rheinland-Pfalz und Niedersachsen weisen von allen Ländern die geringste Finanzkraft je Einwohner auf.

Auch dieses Steuerkraftgefälle versetzt die wirtschafts - und steuerstarken Länder finanziell in die Lage, etwaige ballungsbedingte Kostensteigerungen der öffentlichen Leistungserstellung zu kompensieren und ihren Wirtschaftssubjekten mehr öffentliche Leistungen pro Kopf zu bieten, als es die finanzschwachen Länder vermögen. Besonders negativ muß aus regionalpolitischer Sicht der Einfluß des Länderfinanzausgleichs auf die Einnahmenposition von Hamburg und Bremen beurteilt werden. Den sowieso schon wirtschafts- und steuerstärksten Ländern wird ein so großer finanzieller Handlungsspielraum gelassen, ja sogar noch verschafft, daß sie auch weiterhin eine größere Attraktionskraft auf mobile Ressourcen entfalten können als alle anderen Länder der Bundesrepublik. Deshalb verhindert auch die horizontale Steuerverteilung nach Durchführung des Länderfinanzausgleichs nicht nur, daß sich die automatischen Stabilisatoren der regionalen Wachstums - und Ballungs prozesse frei entfalten können. Vielmehr gehen von ihr unmittelbar ballungsfördernde Tendenzen aus. (95) 
VII. Die Korrektur der horizontalen Steuerverteilung durch vertikale Ausgleichszahlungen

1. Die Handhabung der vertikalen Ausgleichszahlungen in der Bundesrepublik Deutschland

Wenn auch die ergriffenen Maßnahmen der horizontalen Umverteilung der Steuererträge (96) nicht ausreichen, um die Steuerkraftunterschiede zwischen den Ländern auf ein akzeptables Maß zu beschränken und eine Intensivierung des horizontalen Finanzausgleichs am Widerstand der ausgleichspflichtigen Länder scheitert, bietet sich die Möglichkeit der vertikal durchgeführten Steuerumverteilung an. Diese Möglichkeit ist im Grundgesetz in Art. 107, Abs. 2, Satz 3 verankert und wird geit 1967 (97) vom Bund wahrgenommen. Der Bund gewährt den leistungsschwachen Ländern seitdem "Zuweisungen zur ergänzenden Deckung ihres allgemeinen Finanzbedarfs (Ergänzungszuweisungen). "(98) Er entspricht damit "dem ausdrücklichen Wunsch der Länder. Den ausgleichspflichtigen Ländern wurden mit dieser vertikalen Lösung Auseinandersetzungen untereinander darüber erspart, in welcher Höhe jedes von ihnen an der Aufbringung einer solchen zusätzlichen Finanzkraftverstär kung der leistungsschwachen Länder zu beteiligen wäre. "(99)

Bis einschließlich 1973 gewährte der Bund seine Ergänzungszuweisungen in Form eines für jedes Jahr feststehenden Betrages. Seit 1974 erhalten die finanzschwachen Länder Ergänzungszuweisungen in Höhe von 1,5\% des Aufkommens aus der Umsatzsteuer. (100) Die Ergänzungszuweisungen des Bundes an die finanzschwachen Länder dienen im Gegensatz zu den weiter unten analysierten Investitionszuweisungen des Bundes an die Länder ausschlie $\beta$ lich der Nivellierung der Finanzkraftunterschiede zwischen den Ländern und werden deshalb auch ohne $Z$ weckbindung vergeben. Die Verteilung dieser vertikalen Ausgleichszahlungen kann als die fünfte Stufe des Steuerverteilungsprozesses in der Bundesrepublik angesehen werden.

2. Die Auswirkung der Ergänzungszuweisungen des Bundes auf die Einnahmenposition der einzelnen Länder im Jahr 1974

2.1. Das methodische Vorgehen

Mit den Tabellen 8a und 8b wird der Nivellierungseffekt der Ergänzungszuweisungen des Bundes an die Länder für das Jahr 1974 ermittelt. Dabei wird analog zur Untersuchung des horizontalen Länderfinanzausgleichs verfahren. In Tabelle 8a bleibt die Steuerkraft der Gemeinden unberücksichtigt. Die Ergänzungszuweisungen werden der Finanzkraft der Länder nach dem Länderfinanzausgleich hinzugerechnet. Es entsteht die Einnahmenposition der einzelnen Länder nach der horizontal und vertikal vollzogenen Steuerumverteilung. In Tabelle $8 \mathrm{~b}$ werden die Gemeinden in die Untersuchung einbezogen. Die Finanzkraft der Länder und ihrer Gemeinden ergibt zusammen mit den Ergänzungszuweisungen die Steu ereinnahmen, die den jeweiligen Ländern und ihren Gemeinden nach der horizontalen und vertikalen Umverteilung der Steuer- 
Tabelle 8a Auswirkung der Bundesergänzungszuweisungen auf die Finanzkraft der einzelnen Länder im Rechnungsjahr 1974

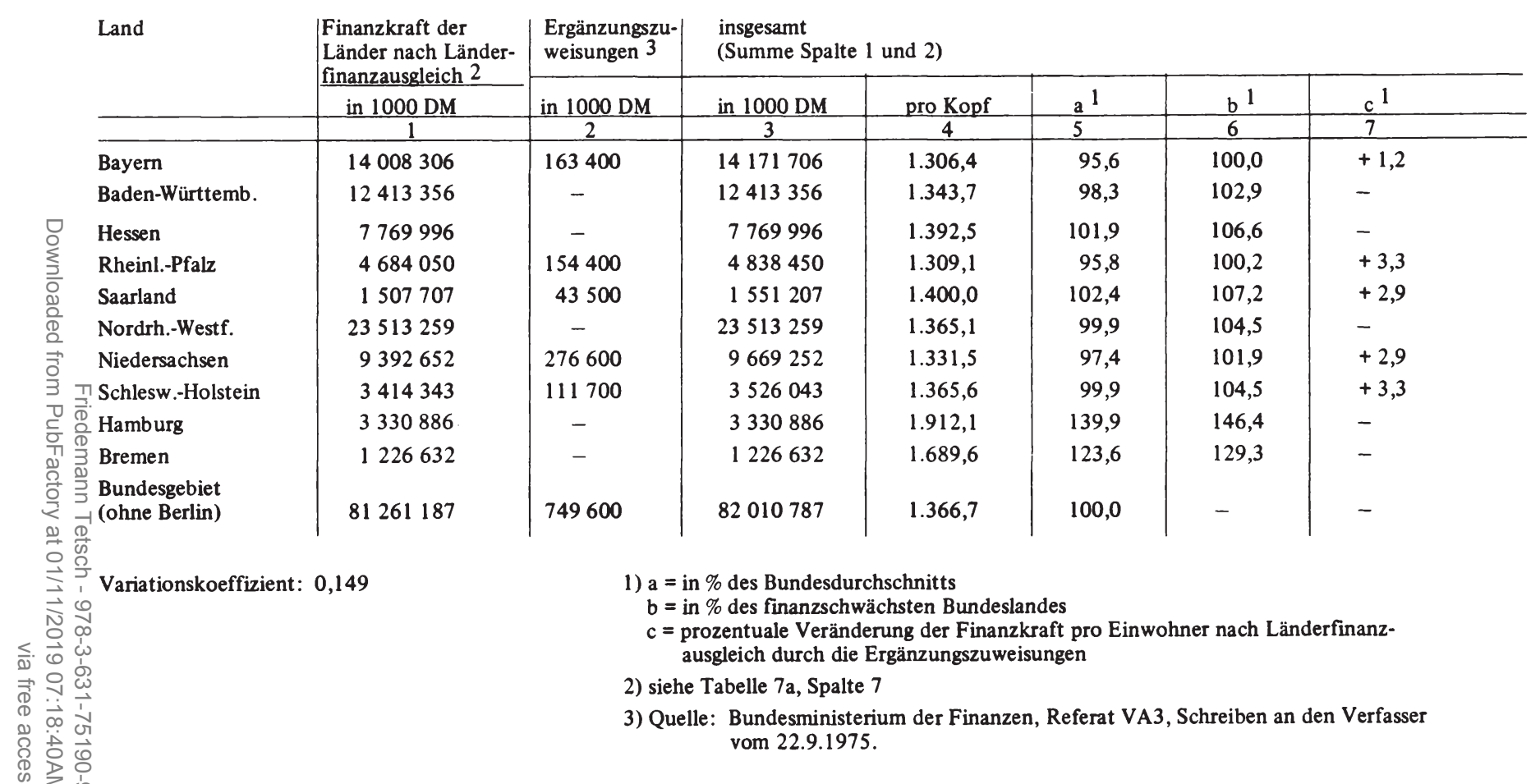


Tabelle $8 \mathrm{~b}$ Auswirkung der Bundesergänzungszuweisungen auf die Finanzkraft der einzelnen Länder und ihrer Gemeinden im Rechnungsjahr 1974

\begin{tabular}{|c|c|c|c|c|c|c|c|}
\hline \multirow[t]{3}{*}{ Land } & \multirow{3}{*}{$\begin{array}{l}\text { Finanzkraft der } \\
\text { Länder u.Gemein- } \\
\text { den nach Länderfi- } \\
\text { nanzausgleich } 2 \\
\text { in } 1000 \mathrm{DM} \\
\end{array}$} & \multirow{3}{*}{\begin{tabular}{|}
$\begin{array}{l}\text { Ergänzungszu- } \\
\text { weisungen } 3\end{array}$ \\
in $1000 \mathrm{DM}$ \\
\end{tabular}} & \multicolumn{5}{|c|}{$\begin{array}{l}\text { insgesamt } \\
\text { (Summe Spalte } 1 \text { und 2) }\end{array}$} \\
\hline & & & & & & & \\
\hline & & & in $1000 \mathrm{DM}$ & pro Kopf & $a^{1}$ & $\mathrm{~b}^{1}$ & $c^{1}$ \\
\hline & 1 & \begin{tabular}{|c|}
2 \\
\end{tabular} & 3 & 4 & 5 & 6 & 7 \\
\hline Bayern & 17965006 & 163400 & 18128406 & $1.671,1$ & 94,6 & 101,0 & $+0,9$ \\
\hline Baden-Württemberg & 16390038 & - & 16390038 & $1.774,2$ & 100,5 & 107,2 & - \\
\hline Hessen & 10072639 & - & 10072639 & $1.805,1$ & 102,2 & 109,0 & - \\
\hline Rheinland-Pfalz & 5963457 & 154400 & 6117857 & $1.655,3$ & 93,8 & 100,0 & $+2,6$ \\
\hline Saarland & 1839121 & 43500 & 1882621 & $1.699,1$ & 96,2 & 102,6 & $+2,4$ \\
\hline Nordrhein-Westf. & 30845425 & - & 30845425 & $1.790,7$ & 101,4 & 108,2 & - \\
\hline Niedersachsen & 11747864 & 276600 & 12024464 & $1.655,8$ & 93,8 & 100,0 & $+2,4$ \\
\hline Schlesw.-Holstein & 4304152 & 111700 & 4415852 & $1.710,2$ & 96,9 & 103,3 & $+2,6$ \\
\hline Hamburg & 4466687 & - & 4466687 & $2.564,1$ & 145,2 & 154,9 & - \\
\hline Bremen & 1603462 & - & 1603462 & $2.208,6$ & 125,1 & 133,4 & - \\
\hline $\begin{array}{l}\text { Bundesgebiet } \\
\text { (ohne Berlin) }\end{array}$ & 105197851 & 749600 & 105947451 & $1.765,6$ & 100,0 & - & - \\
\hline
\end{tabular}

Variationskoeffizient: 0,168

1) $\mathrm{a}=$ in $\%$ des Bundesdurchschnitts

$\mathrm{b}=$ in \% des finanzschwächsten Bundeslandes

$\mathrm{c}=$ prozentuale Veränderung der Finanzkraft pro Einwohner nach Länderfinanzausgleich durch die Ergänzungszuweisungen

2) siehe Tabelle $7 \mathrm{~b}$, Spalte 6

3) Quelle: Bundesministerium der Finanzen, Referat VA3, Schreiben an den Verfasser vom 22.9.1975. 
einnahmen zur Verfügung stehen. Die Einnahmenverteilung aus Tabelle $8 \mathrm{~b}$ kann insofern als "endgültige" horizontale Steuerverteilung bezeichnet werden, als keine weiteren Maßnahmen mit dem spezifischen Ziel der Finanzkraftnivellierung mehr ergriffen werden. Die Interpretation und Beurteilung der Ergebnisse beschränkt sich auf diese "endgültige" Verteilung der Steuereinnahmen der Tabelle $8 b$.

\subsection{Interpretation und Beurteilung der Ergebnisse}

Im Rechnungsjahr 1974 gewährt der Bund den finanzschwachen Ländern Ergänzungszuweisungen in Höhe von insgesamt 750 Mill. DM (Tabelle 8b, Spalte 2). Durch sie steigt die Finanzkraft von vier finanzschwachen Ländern und ihrer Gemeinden um 2,4\%-2,6\%, lediglich diejenige von Bayern und seiner Gemeinden erhöht sich nur um 0,9\% (Spalte 7). Der von den Ergänzungszuweisungen bewirkte Nivellierungseffekt ist relativ gering. Der Variationskoeffizient für die Finanzkraft der Länder und ihrer Gemeinden beträgt vor der Gewährung der Ergänzungszuweisungen 0,174 und fällt durch sie auf 0,168 .

Auch nach der vertikalen Umverteilung der Steuererträge existiert in der Bundesrepublik ein Finanzkraftgefälle zugunsten der wirtschafts - und steuer starken Länder. Die Ergänzungszuweisungen des Bundes haben also an der Richtung des Steuerkraftgefälles nichts geändert, haben es jedoch weiter abgeschwächt. Das Finanzkraftgefälle, das nach Durchführung aller dem Ziel der Steuerkraftnivellie rung dienenden Maßnahmen bestehen bleibt, hat folgende Gestalt (Spalte 6):

- Die beiden Stadtstaaten Hamburg und Bremen haben $55 \%$ bzw. $33 \%$ mehr Steuereinnahmen pro Einwohner zur Erfüllung der kommunalen und staatlichen Aufgaben zur Verfügung als die finanzschwächsten Bundesländer.

- Der Finanzkraftvorsprung der drei finanzstarken Flächenländer gegenüber den finanzschwächsten Ländern beträgt 7 - $9 \%$.

- Rheinland-Pfalz, Niedersachsen und Bayern sind die finanzschwächsten Länder. Die ihnen pro Einwohner zugewiesenen Steuereinnahmen liegen noch um etwa $3 \%$ unter denen von Schleswig-Holstein und dem Saarland.

Dieses "endgültige" Finanzkraftgefälle zugunsten der wirtschafts - und steuerstarken Länder ist nur unwesentlich geringer als dasjenige vor Durchführung der vertikalen Steuerumverteilung. Deshalb fällt seine regionalpolitische $\mathrm{Be}-$ urteilung auch nicht anders als im Fall des Finanzkraftgefälles nach dem Länderfinanzausgleich aus:

Dank ihres Finanzkraftvorsprungs sind die wirtschaftsstarken und stark agglomerierten Länder finanziell in der Lage, ballungsbedingte Kostensteigerungen bei ihrer Leistungserstellung aufzufangen. Sie können also auch dann den in ihnen ansässigen Wirtschaftssubjekten mindestens ebenso hohe Leistungen pro Kopf anbieten wie die schwach agglomerierten Länder, wenn ihre öffentliche Leistungserstellung höhere Kosten pro Outputeinheit erfordert. 
Das "endgültige" Finanzkraftgefälle schwächt auf diese Weise die automatischen Stabilisatoren des räumlichen Differenzierungsprozesses und konserviert die bestehenden regionalen Unterschiede in der Wirtschaftskraft. (101)

Wenigstens für die Stadtstaaten kann man darüberhinaus annehmen, daß ihr Finanzkraftvorsprung für ein höheres Leistungsangebot pro Einwohner ausreicht, als es den anderen Ländern möglich ist. Die "endgültige" Steuerver teilung auf die einzelnen Länder und ihre Gemeinden bewirkt also auch unmittelbar ballungsfördernde Tendenzen.

Die durch die Finanzreform geschaffenen oder modifizierten Maßnahmen zum Ausgleich der Steuerkraftunterschiede zwischen den Ländern (und ihren Gemeinden) haben zwar aus regionalpolitischer Sicht in die gewünschte Richtung geführt. Doch reicht ihr Nivellierungseffekt nicht aus, um eine horizontale Steuerverteilung zu realisieren, von der keine unerwünschten Wirkungen auf die Raumstruktur ausgehen.

Zur Beurteilung dieses Ergebnisses der Finanzreform von 1969 muß noch ein weiterer Aspekt herangezogen werden. Die insgesamt erreichte Steuerkraftnivellierung resultiert aus der Zerlegung der Lohnsteuer und der Körperschaftsteuer, der Verteilung des Länderanteils an der Umsatzsteuer nach der Einwohnerzahl und in Form von Ergänzungsanteilen, dem horizontalen Länderfinanzausgleich und schließlich der Gewährung von Ergänzungszuweisungen durch den Bund. Sie wird mit einem enormen Verwaltungsaufwand erkauft. Dagegen könnte derselbe Nivellierungseffekt mit weitaus geringerem Verwaltungsaufwand erreicht werden, wenn ein größerer Teil des Länderanteils am Aufkommen aus den Gemeinschaftsteuern (Verbundmasse) als heute nach gesetzlich festgelegten, objektiven Bedarfsmaßstäben, insbesondere nach der tatsächlichen Einwohnerzahl, auf die einzelnen Länder verteilt würde. Auch aus diesem Grund kann die mit der Finanzreform von 1969 geschaffene Steuerverteilung auf die einzelnen Länder nur als ein Übergangsstadium zu einer zielgerechteren horizontalen Steuerverteilung betrachtet werden.

\section{Der Umverteilungseffekt von vertikalen Ausgleichszahlungen}

Üblicherweise werden die Ergänzungszuweisungen des Bundes an die Länder zu den Zahlungen im Rahmen des horizontalen Länderfinanzausgleichs hinzuge rechnet und bilden mit ihnen zusammen die Umverteilungsmasse. Damit werden die Ergänzungszuweisungen in vollem Umfang als umverteilungswirksam angesehen. Diese Auffassung wird hier nicht geteilt. Vielmehr müssen die Ergänzungszuweisungen als erhöhte Beteiligung der Länder am Aufkommen aller oder einer bestimmten Gemeinschaftsteuer verstanden werden. (102) Durch die Ergänzungszuweisungen des Bundes kommt dann nur in dem Ausmaß eine Umverteilung von Steuereinnahmen zustande, in dem die tatsächlich den einzelnen Ländern gewährten Zuweisungen von dem Betrag abweichen, den sie bei einer Verteilung dieser zusätzlichen Steuereinnahmen gemäß dem kassenmäßigen örtlichen.Aufkommen erhalten hätten. 
3.1. Der Umverteilungseffekt der Ergänzungszuweisungen im Rechnungs jahr 1974

Entsprechend dieser Überlegung werden die Ergänzungszuweisungen des Bundes im Jahr 1974, die in Höhe von 1,5\% des Umsatzsteueraufkommens ge währt wurden, als Erhöhung des Länderanteils an der Umsatzsteuer um 1, 5 Prozentpunkte betrachtet. Die Umverteilungswirkung der Ergänzungszuweisungen besteht deshalb aus zwei Komponenten:

- Bei einer Verteilung dieser 1,5\% des Umsatzsteueraufkommens auf die einzelnen Länder gemäß ihrer Einwohnerzahl wäre gegenüber einer Verteilung gemäß dem kassenmäßigen örtlichen Aufkommen eine Umverteilung von Steuereinnahmen zustande gekommen.

- Tatsächlich wird aber dieser zusätzliche Länderanteil an der Umsatzsteuer nicht nach der Einwohnerzahl verteilt. Im Ausmaß der Abweichung der tatsächlichen Verteilung von derjenigen gemäß der Einwohnerzahl werden noch einmal Steuereinnahmen umverteilt.

Der gesamte Umverteilungseffekt der Ergänzungszuweisungen des Bundes im Rechnungsjahr 1974 wird in Tabelle 8c (Spalte 10) ausgewiesen. Er ergibt sich als Differenz $\mathrm{z}$ wischen der tatsächlichen Verteilung von 1,5\% des Umsatzsteueraufkommens in Form der Ergänzungszuweisungen (Spalte 9) und der Verteilung dieses zusätzlichen Länderanteils an der Umsatzsteuer gemäß dem kassenmäßigen örtlichen Aufkommen der einzelnen Länder (Spalte 7). Zusätzlich ist in Spalte 8 die Verteilung dieser zusätzlichen Umsatzsteuereinnahmen der Länder nach ihrer Einwohnerzahl angegeben. Die Verteilung von $1,5 \%$ des Umsatzsteueraufkommens auf die Länder in Form von Ergänzungszuweisungen verschafft den finanzschwachen Ländern auf Kosten der finanzstarken insgesamt rund 526 Mill. DM mehr Steuereinnahmen, als sie bei einer Verteilung gemäß dem kassenmäßigen örtlichen Aufkommen erhalten hätten. Etwa $70 \%$ der für Ergänzungszuweisungen zur Verfügung stehenden Finanzmasse in Höhe von 750 Mill. DM wirken damit umverteilend. Ein Vergleich der Werte der Spalte 7 und 8 zeigt überdies, daß dieser Umverteilungseffekt überwiegend darauf beruht, daß dieser zusätzliche Länderanteil an der Umsatzsteuer nicht nach der Einwohnerzahl, sondern nach dem Kriterium der Finanzschwäche ('Bedürftigkeit") auf die Länder verteilt wird.

3.2. Der Umverteilungseffekt der vertikalen Ausgleichszahlungen im Rech"nungsjahr 1969

Dieselbe Überlegung wie oben gilt für die vom Bund im letzten Jahr vor der Finanzreform gewährten Ergänzungs - und Sonderzuweisungen in Höhe von insgesamt $240 \mathrm{Mill}$. DM. In Höhe dieses Betrages hat der Bund die Länder im Jahr 1969 zusätzlich am Gesamtaufkommen aus den beiden Gemeinschaftsteuern vor der Finanzreform, also am Aufkommen aus der Einkommensteuer und aus der Körperschaftsteuer, beteiligt. Nur die Abweichung zwischen den tatsächlichen Zuweisungen an die einzelnen Länder (Spalte 4) und dem Betrag, den die einzelnen Länder bei einer Verteilung des zusätzlichen 
Tahelle 8c Der Uinverteilungseffekt der Ergänzungszuweisungen des Bundes in den Rechnungsjalıren 1969 und 1974

\begin{tabular}{|c|c|c|c|c|c|c|c|c|c|c|}
\hline \multirow{3}{*}{ Land } & \multicolumn{4}{|c|}{1969} & \multirow{3}{*}{$\begin{array}{l}\text { Umverteilungs- } \\
\text { masse } 5\end{array}$} & \multicolumn{5}{|c|}{1974} \\
\hline & \multirow{2}{*}{\multicolumn{2}{|c|}{$\begin{array}{l}\text { Länderanteil an der } \\
\text { Eink.-steuer u. Kör- } \\
\text { persch.-steuer } 1\end{array}$}} & \multirow{2}{*}{\multicolumn{2}{|c|}{\begin{tabular}{|l|l|} 
Ergänzungszuweisungen usw. \\
fiktive Ver- \\
tcilung
\end{tabular}}} & & \multirow{2}{*}{$\begin{array}{l}\text { Anteil am } \\
\text { Umsatzst.- } \\
\text { Aufkom- } \\
\text { men } 6\end{array}$} & \multicolumn{3}{|c|}{ Itgänzungszuweisungen } & \multirow{2}{*}{$\begin{array}{l}\text { Umvertejlungs- } \\
\text { masse }\end{array}$} \\
\hline & & & & & & & $\begin{array}{l}\text { Verteilung gem. } \\
\text { kassenm.örtl. } 7\end{array}$ & $\begin{array}{l}\text { Verteil.gem. } \\
\text { Einwohner- }\end{array}$ & $\mid \begin{array}{l}\text { tatsächil. } \\
\text { Verteilung }\end{array}$ & \\
\hline & in 1000 . & in $\frac{2}{2}$ & in $1000 \mathrm{DM}$ & in $1000 \mathrm{DM}$ & in $1000 \mathrm{DM}$ & in $\frac{\%}{6}$ & in $1000 \mathrm{DM}$ & in 1000 DM & in $1000 \mathrm{DM}$ & in $1000 \mathrm{DM}$ \\
\hline Bayern & 5596227 & 15,55 & 37320 & 40000 & +2680 & 14,65 & 109816 & 135663 & 163400 & +53.584 \\
\hline Baden-Württemb. & 6167693 & 17,14 & 41136 & - & -41136 & 15,65 & 117312 & 115488 & - & 117312 \\
\hline Hessen & 4046149 & 11,24 & 26976 & - & -26976 & 10,29 & 77134 & 69800 & - & 771.34 \\
\hline Rheinl. Pfalz & 1611164 & 4,48 & 10752 & 48000 & +37248 & 4,68 & 35081 & 46263 & 154400 & +119319 \\
\hline Saarland & 415906 & 1,16 & 2784 & 33000 & +30216 & 1,81 & 13568 & 13900 & 43500 & +29932 \\
\hline Nordrh.-Westf. & 10884373 & 30,25 & 72600 & - & -72600 & 33,72 & 252765 & 215575 & - & ‥ 252765 \\
\hline Niedersachsen & 3252929 & 9,04 & 21696 & 83000 & +61304 & 6,23 & 46700 & 90738 & 276600 & +229900 \\
\hline Schlesw.-Ilolsı. & 1072134 & 2,99 & 7176 & 36000 & +28824 & 2,47 & 18515 & 32250 & 111700 & +93185 \\
\hline Hamburg & 2337696 & 6,50 & 15600 & -- & -15600 & 8,32 & 62367 & 21900 & - & 62367 \\
\hline Bremen & 601044 & 1,67 & 4008 & - & $-\quad 4008$ & 2,18 & 16341 & 9113 & - & -16341 \\
\hline $\begin{array}{l}\text { Bundesgebiet } \\
\text { (ohne Berlin) }\end{array}$ & 35985315 & $|100,02|$ & 240048 & 240000 & $\begin{array}{l}+160272 \\
-160320\end{array}$ & 100.00 & 749599 & 750690 & 749600 & $\begin{array}{l}+525920 \\
-525919\end{array}$ \\
\hline
\end{tabular}

1) Berechnet nach:

Statistisches Bundesamt, Finanzen und Steuern, Steuerhaushalt von Bund, Ländern uıd Gemeinden, 4. Vierteljahr und Jahr 1969. Seite 30 und 31.

2) Ergänzung'zuweisungen und Sonderzuweisungen für Strukturmaßnahmen. 3) Verteilung von 240 Mill. DM gemä $B$ den Prozentsätzen aus Spalte 2.

4) Quelle: Finanzbericht 1969, a.a.O., S. 357.

5) Differenz, zwischen Spalte 4 und 3.
6) Berechnet nach Tabelle 4, Spalte 2 .

7) Verteilung von 749,6 Mill. DM gemäß den Prozentsätzen aus Spalle 6.

8) Ergänzungszuweisungen pro Einwolıner des Bundesgchicts (=12.5 DM). multipliziert mit der Einwohnerzahl des jeweiligen Landes (Stand 31.12.1973).

9) Siehe Tabelle $8 \mathbf{a}$.

10) Differenz zwischen Spalte 9 und 7 . 
Länderanteils in Höhe von 240 Mill. DM gemäß dem kassenmäßigen örtli chen Aufkommen der Einkommen- und Körperschaftsteuer (Spalte 3) erhalten hätten, gibt die Umverteilung von Steuereinnahmen durch die Gewährung der Ergänzungszuweisungen (Spalte 5) an. Gegenüber einer Verteilung gemäß dem kassenmäßigen örtlichen Aufkommen bringt 1969 die Verteilung dieses zusätzlichen Länderanteils an den Gemeinschaftsteuern in Form von Ergänzungszuweisungen den finanzschwachen Ländern auf Kosten der finanzstarken einen Gewinn von 160 Mill. DM. Durch die Gewährung von Ergänzungs zuweisungen werden 1969 rund $67 \%$ des zusätzlichen Länderanteils umverteilt.

VIII. Die Umverteilungswirksamkeit des Steuerverteilungssystems vor und nach der Finanzreform von 1969

Im letzten Abschnitt ist die fünfte Stufe des Prozesses der Verteilung der Steuereinnahmen auf die einzelnen Länder in der Bundesrepublik Deutschland untersucht worden. Die Gewährung von Ergänzungszuweisungen ist die letzte finanzausgleichspolitische Maßnahme, die primär oder ausschließlich zum Zwecke der Nivellierung der Steuerkraftunterschiede zwischen den Ländern ergriffen wird. Deswegen wird hier auch die Verteilung der Steuereinnahmen auf die einzelnen Länder, die nach der Gewährung der Ergänzungszuweisungen erreicht wird, als "endgültige" horizontale Steuerverteilung be zeichnet. Damit ist ein Stand der Untersuchung erreicht, bei dem die Frage geklärt werden kann, ob durch die Finanzreform von 1969 die Umverteilungs wirksamkeit des Steuerverteilungssystems gesteigert worden ist.

Um die Umverteilungswirksamkeit des Steuerverteilungssystems festzustellen, muß die vom Steuerverteilungssystem $z$ wischen den Ländern umverteilte Finanzmasse ermittelt und $z u$ den Ländersteuereinnahmen vor der Umverteilung in Beziehung gesetzt werden. Die dazu erforderlichen Berechnungen werden für die beiden Rechnungsjahre 1969 und 1974 in den Tabellen 9 und 9 a durchgeführt.

1. Die Umverteilungswirksamkeit des Steuerverteilungssystems im letzten Jahr vor Inkrafttreten der Finanzreform

Vor der Finanzreform von 1969 wurden die den Ländern insgesamt zustehenden Steuereinnahmen ausschließlich nach dem kassenmäßigen örtlichen Aufkommen auf die einzelnen Länder verteilt. Diese originäre Steuerverteilung wurde nachträglich durch horizontale und vertikale Ausgleichszahlungen korrigiert. So resultierte der gesamte Umverteilungseffekt des Steuerverteilungssystems vor der Finanzreform

- aus dem horizontalen Länderfinanzausgleich und

- aus der Gewährung von Ergänzungszuweisungen und Sonderzuweisungen des Bundes an einzelne Länder. 
Die von diesen beiden finanzausgleichspolitischen Maßnahmen bewirkte Umverteilung von Steuereinnahmen zwischen den Ländern wird in Tabelle 9 in den Spalten 1 und 2 angegeben. Die Zahlungen im Rahmen des horizontalen Länderfinanzausgleichs und der Umverteilungseffekt der Ergänzungszuweisungen ergeben zusammen die Umverteilungswirkung des Steuerverteilungs systems vor der Finanzreform (Spalte 3 ).

Im letzten Jahr vor Inkrafttreten der Finanzreform werden durch diese beiden finanzausgleichspolitischen Maßnahmen rund 2,6 Mrd. DM zugunsten der finanzschwachen Länder umverteilt. Diese Umverteilungsmasse macht 5,6\% der gesamten Steuereinnahmen der Länder (ohne Gemeinden) aus.

2. Die Umverteilungswirksamkeit des Steuerverteilungssystems nach der Finanzreform

2.1. Methoden zur Berechnung der Umverteilungswirkung des Steuerverteilungssystems nach der Finanzreform

Für die Berechnung der Umverteilungswirkung des Steuerverteilungssystems nach der Finanzreform werden zwei verschiedene Ansätze gewählt, die einer eingehenderen Erläuterung bedürfen.

\subsubsection{Der erste Ansatz zur Ermittlung des Umverteilungseffektes des reformierten Steuerverteilungssystems}

Mit diesem Ansatz wird die in Spalte 8 der Tabelle 9 als Umverteilungsmas se I bezeichnete Umverteilungswirkung des reformierten Steuerverteilungs systems bestimmt. Die Umverteilungsmasse I setzt sich aus drei Bestandteilen zusammen:

- der Differenz zwischen den tatsächlichen Steuereinnahmen der Länder im Jahr 1974 vor Durchführung des Länderfinanzausgleichs und den Steuereinnahmen, die die Länder bei unveränderten Vorschriften über die Verteilung der Steuerquellen und über die Verteilungskriterien der Ländersteuereinnahmen erhalten hätten (Spalte 5);

- den Zahlungen im Rahmen des horizontalen Länderfinanzausgleichs des Jahres 1974 (Spalte 6);

- der Umverteilungswirkung der Ergänzungszuweisungen des Jahres 1974 (Spalte 7).

Während die letzten beiden Komponenten der Umverteilungsmasse I bereits in vorstehenden Tabellen diskutiert worden sind, (103) muß die erste Komponente neu berechnet werden. Dabei wird von der Überlegung ausgegangen, daß im Zuge der Finanzreform

- eine Neuverteilung der Steuerquellen auf die bundesstaatlichen Ebenen vorgenommen worden ist, wodurch sich die Zusammensetzung der Länder- 
Tahelle 9 Steuerumverteilung zwischen den Bundesländern vor und nach der Finanzreform

\begin{tabular}{|c|c|c|c|c|c|c|c|c|c|c|c|c|c|}
\hline \multirow{3}{*}{ Land } & \multicolumn{4}{|c|}{1969} & \multicolumn{5}{|c|}{1974} & \multicolumn{4}{|c|}{1974} \\
\hline & 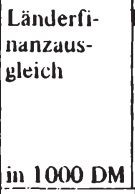 & $\begin{array}{l}\text { Unvertei- } \\
\text { lungseffekt } \\
\text { d.Ergän- } \\
\text { zungszuw. } \\
\text { usw. } \\
\text { in } 1000 \text { DM }\end{array}$ & $\begin{array}{l}\text { Jmvertej- } \\
\text { lungs- } \\
\text { masse } 2 \\
\text { in } 1000 \text { DM }\end{array}$ & $\begin{array}{l}\text { in \% d. } \\
\text { Steuer- } \\
\text { einn. } \\
\text { vor } \\
\text { LFA }\end{array}$ & $\begin{array}{l}\text { Uinvertei- } \\
\text { lung gegen- } \\
\text { über altem } \\
\text { Recht }^{3} \\
\text { in } 1000 \mathrm{DM}\end{array}$ & $\begin{array}{l}\text { Länderfi- } \\
\text { nanzaus- } \\
\text { gleich }\end{array}$ & $\begin{array}{l}\text { Umvertei- } \\
\text { lungseffekt } \\
\text { d.Ergän- } \\
\text { zungszuw. } 4\end{array}$ & $\begin{array}{l}\text { Umvertei- } \\
\text { lungs- } \\
\text { masse I }\end{array}$ & $\begin{array}{l}\text { in \% d. } \\
\text { Steuer- } \\
\text { einn. } \\
\text { nach al- } \\
\text { tem } \\
\text { Recht }\end{array}$ & $\begin{array}{l}\text { Umvert.ge- } \\
\text { genü.d.Ver- } \\
\text { teil.nach } \\
\text { örtl.Auf- } \\
\text { kommen }{ }^{7} \\
\text { in } 1000 \text { DM }\end{array}$ & $\begin{array}{l}\text { Umvert.ef- } \\
\text { fekt des } \\
\text { LFA u.der } \\
\text { Ergänzungs- } \\
\text { zuw. } \\
\text { in } 1000 \text { DM }\end{array}$ & $\begin{array}{l}\text { Uinvertei- } \\
\text { lung:- } \\
\text { masse } 11^{8} \\
\text { in } 1000 \text { DM }\end{array}$ & $\begin{array}{l}\text { in \% d. } \\
\text { Steuer- } \\
\text { einn.b. } \\
\text { Vert.n.d. } \\
\text { kassenm. } \\
\text { örtl.Aufk. }\end{array}$ \\
\hline & 1 & 2 & 3 & 4 & 5 & 6 & 7 & 8 & 9 & 10 & 11 & 12 & 13 \\
\hline 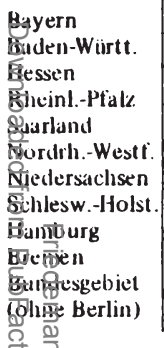 & $\begin{array}{r}+\quad 232900 \\
\cdots \quad 619200 \\
-\quad 624200 \\
+\quad 489100 \\
+\quad 303000 \\
-486400 \\
+\quad 888200 \\
+\quad 520200 \\
-\quad 690600 \\
-\quad 12900 \\
+2433400 \\
-2433300\end{array}$ & $\begin{array}{l}+2680 \\
-41136 \\
-26976 \\
+37248 \\
+30216 \\
\ldots 72600 \\
+61304 \\
+28824 \\
-15600 \\
-\quad 4008 \\
+160272 \\
-160320\end{array}$ & $\begin{array}{l}+\quad 235580 \\
-\quad 660336 \\
-\quad 651176 \\
+\quad 526348 \\
+\quad 333216 \\
-\quad 559000 \\
+\quad 949504 \\
+549024 \\
-706200 \\
-\quad 16908 \\
+2593672 \\
-2593620\end{array}$ & $\begin{array}{r}+3,2 \\
-8,7 \\
-12,8 \\
+25,5 \\
+59,0 \\
-4,1 \\
+22,9 \\
+40,5 \\
-24,3 \\
-2,2 \\
5,6\end{array}$ & 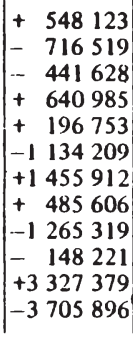 & $\begin{array}{l}+266300 \\
-\quad 614100 \\
-\quad 264800 \\
+\quad 284100 \\
+\quad 194100 \\
-\quad 565100 \\
+\quad 752200 \\
+\quad 328300 \\
-\quad 396300 \\
+\quad 66300 \\
+1891300 \\
-1840300\end{array}$ & $\begin{array}{l}+53584 \\
-117312 \\
-77134 \\
+119319 \\
+29932 \\
-252765 \\
+229900 \\
+93185 \\
-62367 \\
-16341 \\
+525920 \\
-525919\end{array}$ & $\left|\begin{array}{lrr}+ & 868 & 007 \\
-1 & 447 & 931 \\
- & 783 & 562 \\
+1 & 044 & 404 \\
+ & 420 & 785 \\
-1 & 952 & 074 \\
+2 & 438 & 012 \\
+ & 907 & 091 \\
-1 & 723 & 986 \\
- & 98 & 262 \\
+5 & 678 & 299 \\
-6 & 005 & 815\end{array}\right|$ & $\begin{array}{r}+6,6 \\
-10,5 \\
-9,2 \\
+27,8 \\
+37,7 \\
-7,7 \\
+33,9 \\
+34,9 \\
-34,5 \\
-7,5\end{array}$ & $\begin{array}{l}+\quad 785486 \\
-\quad 543996 \\
-\quad 428819 \\
+\quad 546144 \\
+\quad 112330 \\
-1585518 \\
+1927354 \\
+\quad 605550 \\
-1551555 \\
-\quad 251586 \\
+3976864 \\
-4361473\end{array}$ & $\begin{array}{r}+319884 \\
-\quad 731412 \\
-\quad 341934 \\
+403419 \\
+\quad 224032 \\
-\quad 817865 \\
+\quad 982100 \\
+421485 \\
-458667 \\
+\quad 49959 \\
+2400879 \\
6-2349878\end{array}$ & $\mid \begin{array}{llll}+1 & 105 & 370 \\
-1 & 275 & 408 \\
- & 770 & 753 \\
+ & 949 & 563 \\
+ & 336 & 362 \\
-2 & 403 & 383 \\
+2 & 909 & 454 \\
+1 & 027 & 035 \\
-2 & 010 & 222 \\
- & 201 & 627 \\
+6 & 327 & 784 \\
-6 & 661 & 393\end{array}$ & $\begin{array}{r}+8,5 \\
-9,4 \\
-9,1 \\
+24,6 \\
+28,0 \\
-9,4 \\
+43,3 \\
+41,4 \\
38,1 \\
-14,3 \\
7,8\end{array}$ \\
\hline
\end{tabular}

$\stackrel{2}{\circ} \supseteqq$

1) Hihverteilungseffekt der Ergänzungszuweisungen und der Sonderzuweisungen

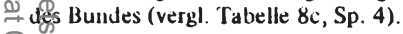

2. Sinume von Spalte 1 und 2.

3) Vergl. Tabelle 9a: Steuereinnahmen der Länder 1974 nach altem Recht

$$
\text { N }{ }^{\infty} \text { (Stand 1969). }
$$

$\leq$. 4 Vergl. Tabelle 8c, Sp. 9

5) Simme von Spalte 5,6 und 7.

$\bar{\Phi}$ 6) Linthält auch die Unverteilungsbeträge, die Berlin zufliebsen.

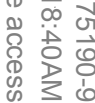

7) Vergl. Tabelle 1, Sp. 9.

8) Summe von Spalte 10 und 11.

Quelle: Berechnet nach

Bundesninisterium der Finanzen, Finanzbericht 1972, a.a.O., S. 191.

Bundesministerium der Finanzen, Finanzbericht 1969, a.a.O., S. 357.

Statistisches Bundesamt, Fachserie L, Reihe 2, Steuerhaushalt von Bund, Ländern und Gemeinden, 4. Vierteljahr und Jahır 1969, S. 30 u. 31.

Sclureiben des Bundesministeriums der Finanzen, Referat VA3 vom 22.9.75 an den Verfasser. 
steuereinnahmen (Struktur des Ländersteuersystems) verändert hat, und

- die Kriterien, nach denen die einer Ebene zustehenden Steuereinnahmen auf die Mitglieder der einzelnen Ebenen verteilt werden, reformiert worden sind. (1 04)

Die Auswirkungen beider Maßnahmenkomplexe auf die Einnahmenposition der einzelnen Länder sollen mit dieser ersten Komponente der Umverteilungsmasse I erfaßt werden. Zu diesem Zweck werden in Tabelle 9a die tatsächlichen Steuereinnahmen der Länder im Jahr 1974 vor Länderfinanzaus gleich mit fiktiven Steuereinnahmen (Spalte 5) verglichen. Diese fiktiven Steuereinnahmen wären 1974 den Ländern zugewiesen worden, wenn weder die Verteilung der Steuerquellen noch die Frage der Verteilungskriterien im Zuge der Finanzreform neu geregelt worden wären.

In Tabelle 9a, Spalte 4 werden die Steuereinnahmen aufgeführt, die den Ländern 1974 zugewiesen worden wären, wenn keine Finanzreform stattgefunden hätte und somit auch 1974 der Rechtszustand des Jahres 1969 geherrscht hätte. Diese Ländersteuereinnahmen 1974 nach altem Recht (Stand 1969) setzen sich zusammen:

- aus dem 1974 anfallenden kassenmäßigen örtlichen Aufkommen aus den Kapitalverkehrsteuern, der Versicherungssteuer und der Wechselsteuer, die bis einschließlich 1969 in Ertragshoheit der Länder standen und durch die Finanzreform auf den Bund übergingen;

- aus dem 1974 anfallenden kassenmäßigen örtlichen Aufkommen aus den Landessteuern gemäß Art. 106, Abs. 2 GG in der Fassung vom 12.5.1969;

- aus $65 \%$ des 1974 anfallenden kassenmäßigen örtlichen Aufkommens aus der Einkommensteuer und der Körperschaftsteuer, die bis zum 31.12. 1969 die einzigen Gemeinschaftsteuern von Bund und Ländern waren.

Diese Steuereinnahmen, die die Länder nach altem Recht im Jahr 1974 er halten hätten, liegen um knapp 3 Mrd. DM über den Steuereinnahmen, die sie 1974 tatsächlich erhalten haben. Um einen Vergleich $\mathrm{zwischen}$ beiden Einnahmenverteilungen durchführen zu können, muß dieser Niveauunterschied ausgeschaltet werden. Deswegen wird die Summe der tatsächlichen Steuereinnahmen der Länder im Jahr 1974 in Höhe von rund $83 \mathrm{Mrd}$. DM so auf die einzelnen Länder verteilt, wie sich die Steuereinnahmen der Länder nach altem Recht auf die einzelnen Länder verteilen. Die auf diese Weise ermittelten fiktiven Steuereinnahmen (Spalte 5) geben an, in welcher Höhe die einzelnen Länder 1974 Steuereinnahmen erzielt hätten,

- wenn weder die Verteilung der Steuerquellen noch die Verteilungskriterien reformiert worden wären,

- aber das Volumen der den Ländern insgesamt zustehenden Steuereinnahmen um knapp $3 \mathrm{Mrd}$. DM gesenkt worden wäre.

Die Differenz zwischen den tatsächlichen (105) und diesen fiktiven Steuereinnahmen der Länder gibt die vollständigen Umverteilungswirkungen dieser beiden wichtigen Maßnahmenkomplexe der Finanzreform von 1969 für das Jahr 1974 wieder.

200 
Tabelle 9a Steuereinnahmen der Länder 1974 nach altem Recht (Stand 1969)

\begin{tabular}{|c|c|c|c|c|c|c|c|c|c|c|}
\hline \multirow[t]{2}{*}{ Land } & \multirow{2}{*}{$\begin{array}{l}\begin{array}{l}\text { Kapitalverkehr } \\
\text { steuern u.a. }\end{array} \\
\text { in } 1000 \mathrm{DM}\end{array}$} & \multirow{2}{*}{\begin{tabular}{|l|}
$\begin{array}{l}\text { übrige Länderr- } \\
\text { dersteuern 2) }\end{array}$ \\
in $1000 \mathrm{DM}$ \\
\end{tabular}} & \multirow{2}{*}{$\begin{array}{l}65 \% \text { der ESt. } \\
\text { und } \mathrm{KSt} .\end{array}$} & \multicolumn{2}{|l|}{$\begin{array}{l}\text { Ländersteuern } \\
\text { insgesamt } 3 \text { ) }\end{array}$} & \multicolumn{3}{|c|}{ fiktive Steuereinnahmen ${ }^{4}$ ) } & \multirow{2}{*}{\begin{tabular}{|l|}
$\begin{array}{l}\text { Umvertei- } \\
\text { lungsmasse }\end{array}$ \\
in $1000 \mathrm{DM}$
\end{tabular}} & \multirow{2}{*}{$\begin{array}{l}\text { prozent. } \\
\text { Veränd. } \\
\text { d. Pro- } \\
\text { Kopf- } \\
\text { Einn. }\end{array}$} \\
\hline & & & & in $1000 \mathrm{DM}$ & in $\%$ & in $1000 \mathrm{DM}$ & $\begin{array}{l}\text { pro } \\
\text { Kopf }\end{array}$ & $\begin{array}{l}\text { in } \% \\
0 \text { Bund }\end{array}$ & & \\
\hline & 1 & 2 & 3 & 4 & $4 a$ & 5 & 6 & 7 & 8 & 9 \\
\hline Bayern & 269442 & 2104328 & 11243066 & 13616836 & 15,83 & 13193883 & 1215,7 & 90,6 & +548123 & $+4,2$ \\
\hline Baden-Württemb. & 201118 & 1798937 & 12190415 & 14190470 & 16,49 & 13743975 & 1487,6 & 110,8 & -716519 & $-5,2$ \\
\hline Hessen & 167022 & 1183205 & 7398011 & 8748238 & 10,17 & 8476424 & 1518,0 & 113,1 & $-\quad 441628$ & $-5,2$ \\
\hline Rheinl.-Pfalz & 25310 & 574461 & 3276551 & 3876322 & 4,51 & 3758965 & 1015,7 & 75,7 & $+\quad 640985$ & $+17,0$ \\
\hline Saarland & 15315 & 180849 & 954784 & 1150948 & 1,34 & 1116854 & 1004,4 & 74,8 & +196753 & $+17,6$ \\
\hline Nordrh.-Westf. & 499865 & 3337750 & 22185038 & 26022653 & 30,25 & 25212568 & 1461,9 & 108,9 & -1134209 & $-4,5$ \\
\hline Niedersachsen & 150007 & 1087498 & 6182354 & 7419859 & 8,62 & 7184540 & 989,7 & 73,7 & +1455912 & $+20,3$ \\
\hline SChlesw.-Holst. & 24565 & 378397 & 2283436 & 2686398 & 3,12 & 2600437 & 1007,9 & 75,1 & +485606 & $+18,7$ \\
\hline Hổmburg & 196603 & 540630 & 4414356 & 5151589 & 5,99 & 4992505 & 2849,6 & 212,3 & -1265319 & $-25,3$ \\
\hline 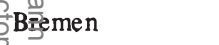 & 27376 & 171567 & 1153796 & 1352739 & 1,57 & 1308553 & 1795,0 & 133,7 & $-\quad 148221$ & $-11,3$ \\
\hline Berlin (West) & 38212 & 431916 & 1343388 & 1813516 & 2,11 & 1758629 & 858,7 & 64,0 & +378517 & $+21,5$ \\
\hline $\begin{array}{l}\text { Bindesgebiet } \\
(\text { einschl.Berlin) } \\
0 \\
0 \\
\infty\end{array}$ & 1614835 & 11789538 & 72625195 & 86029568 & 100,00 & 83347332 & 1342,1 & 100,0 & $\begin{array}{l}+3705896 \\
-3705896\end{array}$ & 4,4 \\
\hline
\end{tabular}

11) Gesellschaftsteuer, Börsenumsatzsteuer, Versicherungssteuer,

$\circ$ Wechselsteuer (Ertragshoheit seit 1.1.1970 beim Bund).

$2 \overrightarrow{5 W}$ Wie nach der Reform von 1969.

(s) Summe der Spalten 1 bis 3.

4) Steuereinnahmen der Länder 1974 , verteilt gemäß den Prozentsätzen der vorstehenden Spalte 4a.
5) Differenz zwischen tatsächlichen Steuereinnahmen vor Länderfinanzausgleich (vergl. Tab. 1, Sp. 5) und fiktiven Steuereinnahmen.

Quelle: Berechnet nach:

Statistisches Bundesamt, Finanzen und Steuern, Reihe 2,

Steuerhaushalt von Bund, Ländern und Gemeinden 1974,

S. $18 \mathrm{ff}$. 


\subsubsection{Der zweite Ansatz zur Ermittlung des Umverteilungseffektes des reformierten Steuerverteilungssystems}

Mit diesem Ansatz wird die in Tabelle 9, Spalte 12 ausgewiesene Umverteilungsmasse II ermittelt. Sie besteht

- aus der Differenz zwischen den tatsächlichen Steuereinnahmen der Länder im Jahr 1974 vor dem Länderfinanzausgleich und dem kassenmäßigen örtlichen Aufkommen der Steuern, deren Ertrag den Ländern seit dem 1.1. 1970 ganz oder teilweise zusteht (106) (Spalte 10);

- aus den Zahlungen im Rahmen des horizontalen Länderfinanzausgleichs im Jahr 1974 (Spalte 11);

- aus dem Umverteilungseffekt der Ergänzungszuweisungen des Jahres 1974 (Spalte 11).

Die Umverteilungsmasse II unterscheidet sich demnach von der Umverteilungsmasse I nur in ihrer ersten Komponente. Während beim ersten Ansatz als Vergleichsverteilung die (fiktiven) Steuereinnahmen der Länder bei unverändertem Recht zugrundegelegt werden, dient beim zweiten Ansatz das kassenmäßige örtliche Aufkommen aus den seit 1970 den Ländern zustehenden Steuern als Vergleichsverteilung. Die Vergleichsverteilung im zweiten Ansatz enthält bereits einen Teil der Auswirkungen der Finanzreform, nämlich die Wirkungen, die von der Neuverteilung der Steuerquellen auf die Einnahmenposition der einzelnen Länder ausgehen. Sie gibt an, welche Steuereinnahmen die einzelnen Länder 1974 erzielt hätten, wenn im Rahmen der Finanzreform zwar eine Neuverteilung der Steuerquellen vorgenommen wor den wäre, die den Ländern insgesamt zustehenden Steuereinnahmen aber nach wie vor ausschließlich gemäß dem kassenmäßigen örtlichen Aufkommen auf die einzelnen Länder verteilt worden wären. Die in Spalte 10 aus gewiesene Komponente der Umverteilungsmasse II ist also ausschließlich auf die durch die Finanzreform eingeführten, vom kassenmäßigen örtlichen Aufkommen gelösten Verteilungskriterien zurückzuführen.

\subsection{Interpretation und Beurteilung der Ergebnisse}

Im Vergleich zu der horizontalen Steuerverteilung, die sich ohne Finanzreform ergeben hätte, werden 1974 vom Steuerverteilungssystem rund 5, 7 Mrd. DM zugunsten der steuerschwachen Länder umverteilt. Die gesamte Umverteilungsmasse beträgt $7 \%$ der Ländersteuereinnahmen des Jahres 1974. Diese Umverteilungsmasse I kann

- zu rund $59 \%$ damit erklärt werden, daß durch die Finanzreform von 1969 die Verteilung der Steuerquellen und die Verteilungskriterien der Länder steuereinnahmen neu geregelt worden sind;

- zu rund $32 \%$ mit dem horizontalen Länderfinanzausgleich erklärt werden;

- zu rund $9 \%$ mit dem Umverteilungseffekt der Ergänzungszuweisungen er klärt werden. 
Im Jahr 1969 war der horizontale Länderfinanzausgleich das wichtigste Instrument der Umverteilung von Steuereinnahmen zwischen den Ländern. Aus ihm resultierten etwa $94 \%$ der gesamten Umverteilungsmasse des damaligen Steuerverteilungssystems. Diese Bedeutung hat der Länderfinanzaus gleich durch die Finanzreform verloren. Andere finanzausgleichspolitische Maßnahmen tragen nach der Finanzreform die Hauptlast der Umverteilung von Ländersteuereinnahmen und entlasten so den horizontalen Länderfinanzausgleich. Damit hat die Finanzreform eine wichtige Voraussetzung für eine Intensivierung der Steuerkraftnivellierung $\mathrm{zw}$ ischen den Ländern geschaffen. $(107,108)$

Beim zweiten Ansatz zur Berechnung der Umverteilungswirkung des Steuerverteilungssystems dient das kassenmäßige örtliche Aufkommen der Steuern, deren Ertrag seit dem 1.1.1970 den Ländern ganz oder teilweise zusteht, als Vergleichsverteilung. In diesem Fall werden rund 6, 3 Mrd. DM oder 7,8\% der gesamten Steuereinnahmen der Länder (ohne Gemeinden) zugunsten der steuerschwachen Länder umverteilt. Diese Umverteilungsmasse II wird verursacht

- zu rund $63 \%$ durch die Zerlegung der Lohn- und der Körperschaftsteuer sowie die Verteilung des Länderanteils an der Umsatzsteuer gemäß $\subseteq 2$ des Finanzausgleichsgesetzes;

- zu rund $29 \%$ durch den Länderfinanzausgleich;

- zu rund $8 \%$ durch die Gewährung der Ergänzungszuweisungen.

Die Umverteilungsmasse II ist um etwa 650 Mill. DM größer als die Umverteilungsmasse I. Dieser Unterschied kann folgendermaßen erklärt werden:

Wäre im Zuge der Finanzreform von 1969 lediglich die oben dargestellte Neuverteilung der Steuerquellen (109) erfolgt, das kassenmäßige örtliche Aufkommen aber als alleiniges Steuerverteilungskriterium beibehalten worden, (110) hätten sich die Steuerkraftunterschiede zwischen den Ländern vergrößert. Die finanzschwachen Länder hätten in diesem Fall rund 650 Mill. DM weniger, die finanzstarken Länder dementsprechend mehr Steuereinnahmen erhalten, als ihnen bei unverändertem Rechtszustand zugestanden hätten. Für den relativ starken Umverteilungseffekt des Steuerverteilungssystems nach der Finanzreform kann man demnach keineswegs die Neuverteilung der Steuerquellen im Rahmen der Finanzreform verantwortlich machen. Vielmehr kommt er allein dadurch zustande, daß mit der Finanzreform von 1969 andere Verteilungskriterien als das des kassenmäßigen örtlichen Aufkommens eingeführt wurden.

Durch die hier diskutierten Maßnahmen der Finanzreform von 1969 ist die Umverteilungswirksamkeit des Steuerverteilungssystems erhöht worden. Gegenüber der horizontalen Steuerverteilung nach altem Recht werden 1974 vom Steuerverteilungssystem $7 \%$ der Ländersteuereinnahmen umverteilt, während die Umverteilungsmasse im letzten Jahr vor Inkraftreten der Finanzreform nur 5, 6 \% der Ländersteuereinnahmen beiträgt. Die Umverteilungs wirksamkeit ist damit um 1,4 Prozentpunkte oder $25 \%$ angestiegen. Ohne Finanzreform von 1969 hätte - dieselbe Umverteilungswirksamkeit wie 1969 
unterstellt - das Steuerverteilungssystem im Rechnungsjahr 1974 rund 4,7 Mrd. DM zugunsten der steuerschwachen Länder umverteilt. Die Kombination von Neuverteilung der Steuerquellen und Einführung neuer Verteilungskriterien im Zuge der Finanzreform bringt also den steuerschwachen Ländern auf Kosten der steuerstarken Länder einen Gewinn in Höhe von rund 1 Mrd. DM.

Diese Erhöhung des Umverteilungseffektes des Steuerverteilungssystems durch die Finanzreform ist aus regionalpolitischer Sicht positiv zu beurteilen. Doch reicht sie - wie oben ge zeigt worden ist (111) - nicht aus, um eine genügend starke Nivellierung der Steuerkraftunterschiede zwischen den Ländern zu bewirken.

IX. Die Verteilung der Zuschüsse des Bundes für Investitionen der Länder und ihrer Gemeinden im Jahr 1974

In dieser Arbeit werden die Verteilung der Steuereinnahmen der Länder und die Verteilung der Zuweisungen des Bundes auf die untergeordneten Gebiets körperschaften als finanzpolitische Instrumente der Regionalpolitik aufge faßt. Dabei kommt der Verteilung der Steuereinnahmen auf die einzelnen Länder eine passive regionalpolitische Funktion zu. (112) Sie soll so vorgenommen werden, daß von ihr keine ballungsfördernden Tendenzen ausgehen und sich die automatischen Stabilisatoren des räumlichen Differenzierungs prozesses relativ frei entfalten können. Dazu ist erforderlich, daß ein regionales Steuerkraftgefälle, das parallel zum regionalen Wirtschaftskraftgefälle verläuft, möglichst weitgehend vermieden wird. Unter diesem Gesichtspunkt ist bisher der Proze $\beta$ der Steuerverteilung auf die einzelnen Länder in fünf Stufen untersucht und hinsichtlich seiner räumlichen Auswirkungen beurteilt worden.

Der regionalen Verteilung der Zuweisungen des Bundes wird dagegen eine aktive regionalpolitische Aufgabe zugewiesen.(112) Die Zuweisungen sollen so auf die einzelnen Länder und Gemeinden verteilt werden, daß regionalpolitisch erwünschte Entwicklungen in Gang gesetzt und gefördert werden. Der gewünschte direkte Einfluß auf die Raumstruktur kann von der Verteilung der Zuweisungen nur dann ausgehen, wenn sie über die bloße Steuerkraftnivellierung hinausgeht und gezielt regionale Einnahmenunterschiede pro Einwohner verursacht.

An dieser Konzeption wird in diesem Abschnitt die tatsächliche regionale Verteilung der Zuschüsse des Bundes für Investitionen der Länder und ihrer Gemeinden (113) im Jahr 1974 gemessen, wodurch eine regionalpolitische Beurteilung der Zuweisungspraxis der Bundesregierung in jenem Jahr möglich wird. Außerdem soll herausgefunden werden, ob der Bund eine bestimmte Konzeption bei der Verteilung seiner Investitionszuschüsse im Jahr 1974 verfolgt und um welche es sich gegebenenfalls handelt. Dazu werden verschiedene fiktive Verteilungen der Investitionszuschüsse mit ihrer tatsächlichen Verteilung auf die Länder verglichen. 
Die konkreten Fragestellungen lauten:

Wie stark weicht die tatsächliche Verteilung der Investitionszuschüsse des Bundes auf die zehn Bundesländer (ohne Berlin) im Jahr 1974 von einer Verteilung $a b$, die sich ergeben hätte, wenn der Bund die Zuweisungssumme

- gemäß dem Anteil der einzelnen Bundesländer am kassenmäßigen örtlichen Gesamtaufkommen der Ländersteuereinnahmen;

- gemäß dem Anteil der einzelnen Bundesländer am Bruttoinlandsprodukt;

- gemäß dem Anteil der einzelnen Bundesländer an der Einwohnerzahl des Bundes gebietes;

- gemäß den Grundsätzen des Bundesraumordnungsprogramms

verteilt hätte?

1. Die regionale Verteilung der Investitionszuschüsse des Bundes gemä $\beta$ dem kassenmäßigen örtlichen Steueraufkommen der Länder im Jahr 1974

\subsection{Die regionalpolitische Beurteilung dieser Vergleichsverteilung}

In Tabelle 10a wird die tatsächliche Verteilung der Investitionszuschüsse des Bundes im Jahr 1974 (Spalte 1) mit einer fiktiven Verteilung (Spalte 2) verglichen. Die fiktive Verteilung gibt an, wie der Bund seine Zuschüsse für Investitionen der Länder und ihrer Gemeinden im Jahr 1974 hätte verteilen müssen, wenn er das kassenmäßige örtliche Steueraufkommen der Länder als Verteilungskriterium benutzt hätte. Die Differenz zwischen der tatsächlichen und der fiktiven Verteilung ergibt die Werte der Spalte 3. An ihnen kann abgelesen werden, welche Länder in welchem Ausmaß mehr bzw. weniger Zuschüsse für Investitionen erhalten, als ihnen aufgrund ihres kassenmäßigen örtlichen Steueraufkommens zustehen. Um wieviel Prozent jedem Land, gemessen an dieser Vergleichsverteilung, "zu viel" oder "zu wenig" Investitionszuweisungen zufließen, weisen die Anteilsquotienten (114) der Spalte 6 aus.

Durch die Verteilung der Investitionszuschüsse gemäß dem kassenmäßigen örtlichen Steueraufkommen der Länder wird das regionale Steuerkraftgefälle, das auf der ersten Stufe des Steuerverteilungsprozesses existiert, (115) auf die Zuschüsse des Bundes für Investitionen übertragen. Da die Länder, die auf der ersten Stufe des Steuerverteilungsprozesses steuerstark sind, zugleich auch eine überdurchschnittliche Wirtschaftskraft und einen hohen Agglomerationsgrad aufweisen, erhalten die verdichteten Wohlstandsregionen pro Einwohner wesentlich höhere Investitionszuschüsse als die schwach agglomerierten, wirtschaftsschwachen Länder. Diese Verteilung der Investitionszuschüsse verstärkt das regionale Steuerkraftgefälle, das auch nach der Gewährung der Ergänzungszuweisungen noch zugunsten der wirtschaftsstarken Länder besteht. (116) Ein Teil des Nivellierungseffektes der finanzausgleichs politischen Maßnahmen der Stufen 2 bis 5 wird also durch die Verteilung der Investitionszuschüsse gemäß dem kassenmäßigen örtlichen Aufkommen der 
Tabelle 10a Die Verteilung der Investitionszuschüsse des Bundes auf die einzelnen Länder gemäß ihrem kassenmäßigen örtlichen Aufkommen im Jahr 1974

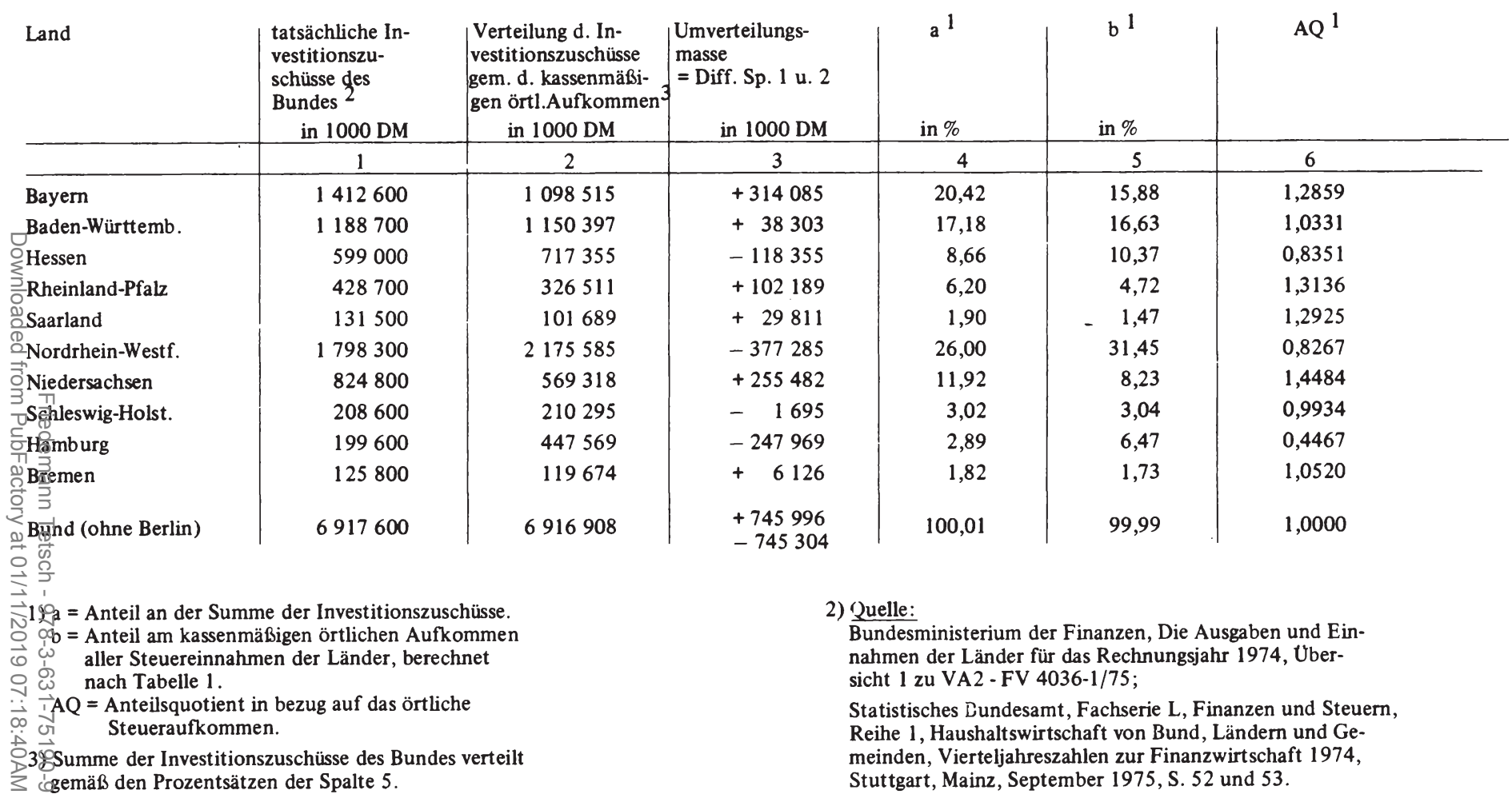


Ländersteuereinnahmen kompensiert, wodurch der Vorsprung der wirtschaftsstarken Länder im Attrahierungswettbewerb um mobile Ressourcen gegenüber den steuer - und wirtschaftsschwachen Ländern ausgedehnt wird. Von dieser Verteilung der Investitionszuschüsse des Bundes auf die einzelnen Länder würden außerordentlich starke ballungsfördernde Tendenzen ausgehen, weswegen sie aus regionalpolitischer Sicht höchst unerwünscht ist.

\subsection{Interpretation und Beurteilung der Ergebnisse}

Die tatsächlichen Investitionszuweisungen des Bundes an die einzelnen Länder im Jahr 1974 weichen stark von diesen fiktiven Zuweisungen ab (Spalte 3). Die Verteilung der Investitionszuschüsse auf die einzelnen Länder ist also keinesfalls am kassenmäßigen örtlichen Steueraufkommen der Länder orientiert. Damit ist aber noch nicht gesagt, daß die tatsächliche Verteilung regionalpolitisch positiver als diese fiktive Verteilung der Investitionszuschüs se $\mathrm{zu}$ beurteilen ist.

Betrachtet man die Vorzeichen der Umverteilungsbeträge jedes einzelnen Landes (Spalte 3) und die entsprechenden Anteilsquotienten (Spalte 6), ergibt sich folgendes Bild:

- Die vier steuer - und wirtschaftsschwachen Länder Bayern, Rheinland-Pfalz, Saarland und Niedersachsen erhalten rund 30 - $45 \%$ mehr Investitionszu schüsse vom Bund, als ihrem Anteil am kassenmäßigen örtlichen Aufkommen entspricht. Die Investitionszuweisungen an die wirtschafts - und steuerstarken Länder Hessen und Nordrhein-Westfalen liegen dagegen um fast $20 \%$, die an Hamburg um $55 \%$ unter denen, die ihnen bei einer Verteilung gemäß ihrem kassenmäßigen örtlichen Aufkommen zugestanden hätten. Im Fall dieser Länder weichen also die tatsächlichen Investitionszuweisungen des Bundes in regionalpolitisch erwünschter Richtung von den fiktiven $\mathrm{Zu}$ weisungsbeträgen ab.

- Genau das Gegenteil gilt jedoch für die Investitionszuweisungen des Bundes an Baden-Württemberg, Bremen und Schleswig-Holstein. Die Investitionszuschüsse an die beiden steuer- und wirtschaftsstarken Länder lie gen rund 3 - $5 \%$ über, die an Schleswig-Holstein geringfügig unter denen, die sie bei der aus regionalpolitischer Sicht schon unerwünschten Verteilung gemäß dem kassenmäßigen örtlichen Aufkommen erhalten hätten. In diesen Fällen ist die tatsächliche Verteilung der Investitionszuschüsse des Bundes im Jahr 1974 noch negativer zu beurteilen als die fiktive Verteilung gemäß dem kassenmäßigen örtlichen Steueraufkommen.

2. Die regionale Verteilung der Investitionszuschüsse des Bundes gemäß dem Anteil der Länder am Bruttoinlandsprodukt im Jahr 1974

2.1. Die regionalpolitische Beurteilung dieser Vergleichsverteilung

In Tabelle $10 \mathrm{~b}$ werden die Investitionszuschüsse des Bundes an die Länder des Jahres 1974 so auf die einzelnen Länder verteilt, wie es ihrem Anteil 
Tabelle 10b Die Verteilung der Investitionszuschüsse des Bundes auf die einzelnen Länder gemäß ihrem Anteil am Bruttoinlandsprodukt im Jahr 1974

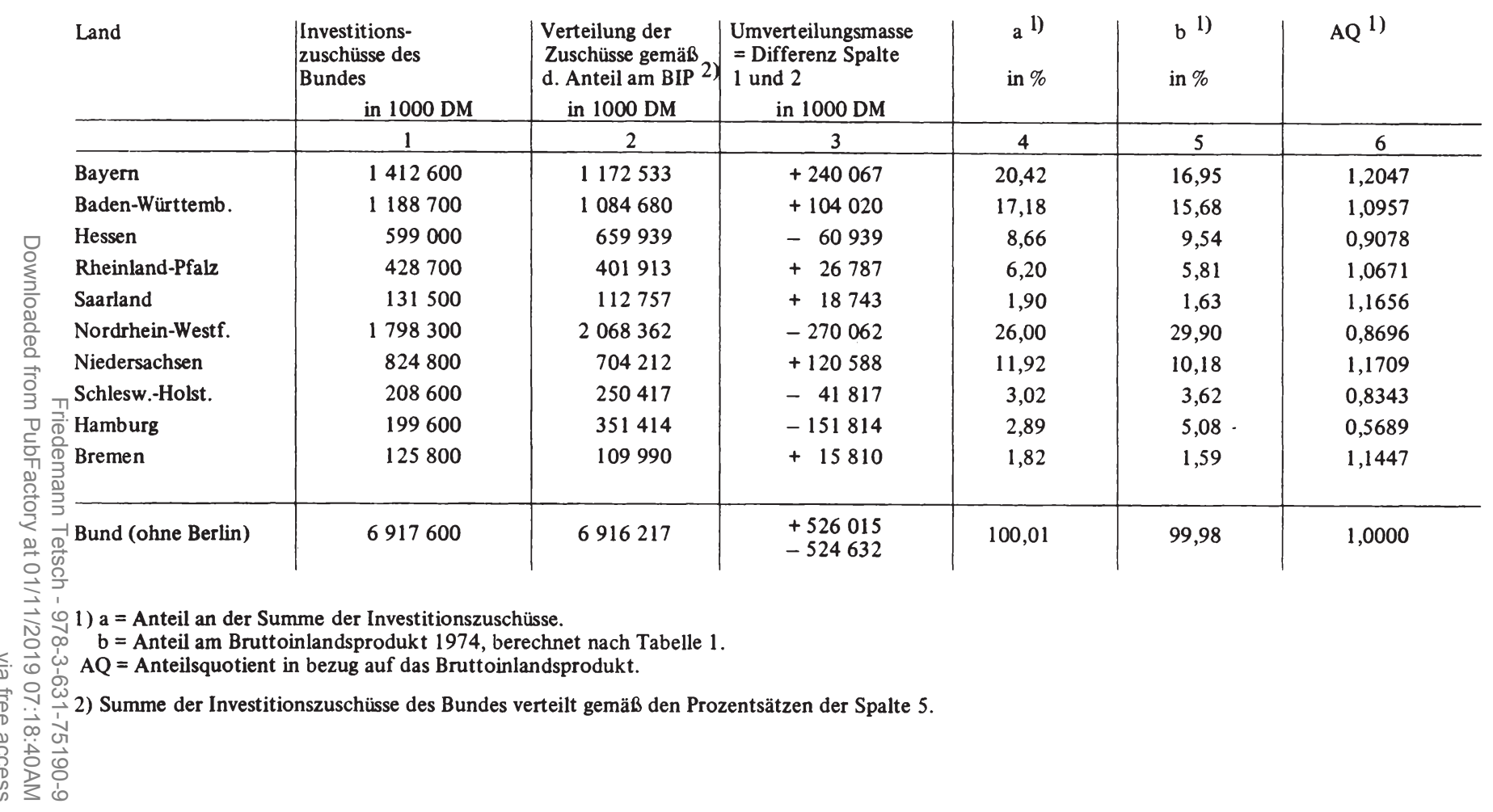


am Bruttoinlandsprodukt entspricht (Spalte 2). Die Verwendung des regionalen Bruttoinlandsprodukts als Verteilungsmaßstab der Investitionszuschüsse bietet sich dem Bund dann an, wenn er den lokalen Finanzbedarf der Länder als ausschlaggebende Größe für die Bemessung ihrer Einnahmen ansieht. (117) Die Regionen, in denen die privaten Wirtschaftssubjekte pro Einwohner die höchste Nachfrage nach Infrastrukturleistungen entfalten, müßten demnach auch die höchsten Investitionszuschüsse pro Einwohner zugewiesen bekommen.

Die räumlichen Auswirkungen einer solchen nachfrageorientierten Zuweisungspraxis sind mit denen vergleichbar, die bei einer Verteilung der Investitionszuschüsse gemäß dem kassenmäßigen örtlichen Steueraufkommen entstehen. Die Regionen, die bereits in der Vergangenheit dank ihrer überdurchschnittlichen Standortqualitäten in starkem Maße mobile Ressourcen attrahiert haben, werden finanziell in die Lage versetzt, die ballungsbedingte Verschlechterung ihrer Standortqualitäten zu verhindern und unter Umständen den in ihnen ansässigen Wirtschaftssubjekten zusätzliche Standortvorteile in Form externer Ersparnisse zu bieten. Die Verteilung der Investitionszuschüsse gemäß den regionalen Bruttoinlandsprodukten wäre damit eine wichtige Ursache für die sich selbst verstärkenden Tendenzen des räumlichen Differenzierungsprozesses. (118)

\subsection{Interpretation und Beurteilung der Ergebnisse}

Die tatsächliche Verteilung der Investitionszuschüsse des Bundes auf die einzelnen Länder im Jahr 1974 entspricht auch dieser fiktiven Verteilung nicht.

- Die Länder Bayern, Saarland, Rheinland-Pfalz und Niedersachsen erhalten 1974 tatsächlich höhere Investitionszuweisungen vom Bund, als sie bei einer Verteilung gemäß ihrem Bruttoinlandsprodukt bekommen hätten. Für die wirtschaftsstarken Länder Hessen, Nordrhein-Westfalen und Hamburg gilt das Umgekehrte. Allerdings sind die regionalpolitisch erwünschten Abweichungen der tatsächlichen Zuweisungen von den fiktiven Zuweisungen dieser Länder erheblich kleiner als im Fall der Verteilung gemäß dem kassenmäßigen örtlichen Aufkommen der Ländersteuereinnahmen.

- Als unvereinbar mit den regionalpolitischen Zielvorstellunge der Bundesregierung (119) müssen dagegen die Investitionszuschüsse des Bundes im Jahr 1974 an Baden-Württemberg, Bremen und Schleswig-Holstein bezeichnet werden. Das Bundesland mit dem geringsten Bruttoinlandsprodukt pro Kopf erhält Zuweisungen, die noch um $17 \%$ unter denjenigen lie gen, die ihm bei einer Verteilung gemäß den regionalen Bruttoinlandsprodukten zugewiesen worden wären. Die Investitionszuweisungen an BadenWürttemberg und Bremen, die schon bei einer Verteilung gemäß dem Anteil dieser Länder am Bruttoinlandsprodukt ballungsfördernd wirken würden, liegen tatsächlich noch $10 \%$ bzw. $14 \%$ über diesen fiktiven Zuweisungen. 
3. Die regionale Verteilung der Investitionszuschüsse des Bundes gemäß der Einwohnerzahl der Länder im Jahr 1974

3.1. Die regionalpolitische Beurteilung dieser Vergleichsverteilung

In Tabelle $10 \mathrm{c}$ werden die Investitionszuschüsse des Bundes an die Länder im Jahr 1974 nach der Einwohnerzahl der Länder verteilt (Spalte 2). Mit der Entscheidung für die tatsächliche Einwohnerzahl der Länder als Verteilungsschlüssel seiner Investitionszuschüsse verzichtet der Bund darauf, etwaige regionale Unterschiede in der marktwirksamen Nachfrage nach öfentlichen Leistungen bei der Ausstattung der Länder mit Finanzmitteln zu berücksichtigen. Damit wendet sich der Bund vom Konzept des lokalen Finanzbedarfs als Grundlage der Einnahmenverteilung ab. Vielmehr will er mit gleich hohen Zuweisungsbeträgen pro Einwohner die Länder, unabhängig von ihrer Größe und Wirtschaftskraft, in die Lage versetzen, auf gesamtwirtschaftlich bedeutenden Gebieten den in ihnen ansässigen Wirtschaftssubjekten annähernd gleich hohe Leistungen pro Kopf anzubieten. Dabei nimmt der Bund bewußt in Kauf, daß das reale Leistungsangebot der stark agglomerierten Länder unter den Durchschnitt sinkt, wenn auf den geförderten Gebieten ballungsbedingte Kostensteigerungen auftreten.

Diese Konzeption für die Verteilung der Investitionszuschüsse des Bundes an die Länder entspricht derjenigen, die in dieser Arbeit für die Verteilung der Steue reinnahmen der Länder vorgeschlagen worden ist. (120) Ihre Anwendung gewährleistet zwar, daß sich die Gegenkräfte der räumlichen Konzentration wirtschaftlicher Aktivitäten (121) in den Wirtschafts rechnungen der privaten Wirtschaftssubjekte bemerkbar machen und bremst somit die räumlichen Konzentrationstendenzen. Die Verteilung der Investitionszuschüs se des Bundes nach der Einwohnerzahl der Länder stattet die zurückgebliebenen Länder jedoch nicht in der Weise mit Finanzmitteln aus, daß sie ihr infrastrukturelles Defizit ausgleichen und ihren Einkommensrückstand ge genüber den Wohlstandsregionen aufholen können. Deshalb kann diese Verteilung der Investitionszuschüsse aus regionalpolitischer Sicht nur bedingt positiv eingeschätzt werden.

\subsection{Interpretation und Beurteilung der Ergebnisse}

Von den bisher untersuchten Vergleichsverteilungen nähert sich die Verteilung gemäß der Einwohnerzahl am stärksten der tatsächlichen Verteilung der Investitionszuschüsse des Bundes im Jahr 1974 an.

- Vier Länder, nämlich Rheinland-Pfalz, Saarland, Niedersachsen und Hamburg, erhalten in einer Höhe Zuweisungen für Investitionen vom Bund, die in etwa ihrem Anteil an der Einwohnerzahl des Bundesgebiets entspricht (Spalte 6).

- Die Investitionszuweisungen an Bayern betragen rund $113 \%$, die an Hes sen und Nordrhein-Westfalen rund $93 \%$ bzw. $91 \%$ des im Bundesdurchschnitt gewährten Zuweisungsbetrages. Sie weichen damit in der regional210 
Tabelle 10c Die Verteilung der Investitionszuschüsse des Bundes auf die einzelnen Länder gemäß ihrer

Einwohnerzahl im Jahr 1974

\begin{tabular}{|c|c|c|c|c|c|c|c|}
\hline & Land & $\begin{array}{l}\text { Investitions- } \\
\text { zuschüsse des } \\
\text { Bundes } \\
\quad \text { in } 1000 \mathrm{DM}\end{array}$ & $\begin{array}{l}\text { Verteilung d. } \\
\text { Zuschüsse nach } \\
\text { d. Einwohnerzahl 1) } \\
\quad \text { in } 1000 \text { DM }\end{array}$ & $\begin{array}{l}\text { Umverteilungs- } \\
\text { masse } \\
=\text { Diff. Sp. } 1 \text { u. } 2 \\
\text { in } 1000 \mathrm{DM}\end{array}$ & $\begin{array}{l}a^{2)} \\
\text { in } \%\end{array}$ & $\begin{array}{l}b^{2)} \\
\text { in } \%\end{array}$ & $A Q^{2)}$ \\
\hline & & 1 & 2 & \begin{tabular}{|l|}
3 \\
\end{tabular} & 4 & 5 & 6 \\
\hline & Bayern & 1412600 & 1250702 & +161898 & 20,42 & 18,08 & 1,1294 \\
\hline 밍 & Baden-Württemb. & 1188700 & 1064619 & +124081 & 17,18 & 15,39 & 1,1163 \\
\hline$\leqq$ & Hessen & 599000 & 643337 & -44337 & 8,66 & 9,30 & 0,9312 \\
\hline ర్లి & Rheinland-Pfalz & 428700 & 426124 & +2576 & 6,20 & 6,16 & 1,0065 \\
\hline$\frac{0}{\mathbb{1}}$ & Saarland & 131500 & 127976 & $+\quad 3524$ & 1,90 & 1,85 & 1,0270 \\
\hline $\overrightarrow{\overrightarrow{0}}$ & Nordrhein-Westf. & 1798300 & 1986043 & -187743 & 26,00 & 28,71 & 0,9056 \\
\hline$\frac{0}{3} \pi$ & Niedersachsen & 824800 & 837030 & -12230 & 11,92 & 12,10 & 0,9851 \\
\hline 류. & Schlesw.-Holstein & 208600 & 297457 & -88857 & 3,02 & 4,30 & 0,7023 \\
\hline 뀨 & Hamburg & 199600 & 200610 & $-\quad 1010$ & 2,89 & 2,90 & 0,9966 \\
\hline 帝 引 & Bremen & 125800 & 83703 & +42097 & 1,82 & 1,21 & 1,5041 \\
\hline 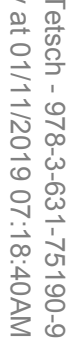 & $\begin{array}{l}\text { Bund (ohne Berlin) } \\
\text { 1) Gleicher Pro-Kop } \\
\text { 2) } a=\text { Anteil an der } \\
b=\text { Anteil an der } \\
A Q=\text { Anteilsquoti }\end{array}$ & $\begin{array}{l}\text { ag für jedes Bund } \\
\text { isungssumme. } \\
\text { ohnerzahl (Stand } \\
\text { bezug auf die Ein }\end{array}$ & 974). & $\begin{array}{r}+334176 \\
-334177\end{array}$ & 100,01 & 100,00 & 1,0000 \\
\hline
\end{tabular}


politisch erwünschten Richtung von der Vergleichsverteilung ab.

- Schon die Verteilung der Investitionszuweisungen nach der Einwohnerzahl kann regionalpolitisch nicht voll befriedigen. Erst recht müssen dann aber die Abweichungen der tatsächlichen von den fiktiven Investitionszuschüssen des Bundes im Fall der Länder Baden-Württemberg, Bremen und Schleswig-Holstein als unvereinbar mit dem hier zugrundeliegenden regionalpolitischen Zielsystem bezeichnet werden.

Baden-Württemberg fließen 1974 rund 125 Mill. DM oder $12 \%$, Bremen sogar rund $50 \%$ (= $42 \mathrm{Mill}$. DM) mehr Zuschüsse des Bundes für Investitionen zu, als ihnen nach ihrer Einwohnerzahl zustehen. Dieser regionalpolitisch unerwünschten Begünstigung zweier wirtschaftsstarker Bundesländer steht die Benachteiligung des wirtschaftsschwächsten aller Bundesländer gegenüber. Die Investitionszuschüsse des Bundes an SchleswigHolstein erreichen 1974 nur $70 \%$ des Bundesdurchschnitts und liegen damit um 89 Mill. DM unter dem Zuweisungsbetrag, der Schleswig-Holstein nach seiner Einwohnerzahl zusteht.

Damit kommt man zu folgender Beurteilung der tatsächlichen Verteilung der Investitionszuschüsse des Bundes an die Länder für das Jahr 1974:

Auch dann, wenn man sich aus regionalpolitischer Sicht mit einer regionalen Verteilung der Investitionszuschüsse nach der Einwohnerzahl zufrieden gibt, muß man einen Konflikt zwischen der Zuweisungspraxis des Bundes im Jahr 1974 und dem regionalpolitischen Zielsystem in den Fällen von drei Bundesländern feststellen. Fordert man dagegen eine regionale Verteilung der Investitionszuschüsse, die als Instrument der Regionalpolitik zur Verringerung der regionalen Wohlstandsunterschiede beitragen kann, dann mu $\beta$ die Zuweisungspraxis des Bundes im Jahr 1974 in sieben von zehn Fällen als regionalpolitisch unbefriedigend und damit zielinkonform beurteilt werden.

4. Die regionale Verteilung der Investitionszuschüsse des Bundes gemäß den Grundsätzen des Bundes raumordnungsprogramms im Jahr 1974

4.1. Die regionalpolitische Beurteilung dieser Vergleichsverteilung

In Tabelle $10 \mathrm{~d}$ wird eine regionale Verteilung der Investitionszuschüsse des Bundes entwickelt, die mit dem hier vertretenen regionalpolitischen Zielsystem voll vereinbar ist und deshalb als regionalpolitisch wünschenswerte Verteilung apostrophiert wird. Danach weist der Bund allen Ländern mit unterdurchschnittlichem Bruttoinlandsprodukt pro Einwohner überdurchschnittlich hohe, allen Ländern mit überdurchschnittlichem Bruttoinlandsprodukt pro Einwohner unterdurchschnittlich hohe Zuweisungsbeträge zu. Mit die sem Zuweisungsverfahren soll erreicht werden, daß die in der wirtschaftlichen Entwicklung zurückgebliebenen Regionen absolut höhere Leistungen pro Einwohner, insbesondere auf dem Gebiet der Infrastruktur, anbieten können, als die wirtschaftsstarken Länder. 
Durch diese Umkehrung des regionalen Einnahmen- und Leistungsgefälles zugunsten der wirtschaftsschwachen Länder wird deren Attraktionskraft im Verhältnis zu den über Jahrzehnte hinweg finanzstarken Ländern erhöht. Dadurch können unter Umständen Unternehmen und Arbeitskräfte dazu veranlaßt werden, in den bisher wirtschaftsschwachen Ländern ansässig zu bleiben oder sich gar in ihnen anzusiedeln.

Die hier entwickelte fiktive Verteilung der Investitionszuschüsse des Bundes geht von der Überlegung aus, daß die einzelnen Bundesländer umso höhere Zuweisungen für Investitionszwecke und damit für attraktivitätsfördernde Maßnahm€ī erhalten sollten, je weiter sie unter dem bundesdurchschnittlichen Bruttoinlandsprodukt liegen und umso weniger Investitionszuschüsse bekommen sollten, je weiter sie nach oben vom Durchschnitt abweichen. Um eine mechanische Regelung der Zuweisungsberechnung anzuwenden, werden die Pro-Kopf-Beträge folgendermaßen ermittelt:

Die wirtschaftsschwachen Bundesländer erhalten Zuweisungen pro Einwohner, die um den Prozentsatz über dem Bundesdurchschnitt liegen, um den ihr Bruttoinlandsprodukt pro Einwohner unter dem Bundesdurchschnitt liegt. Für die wirtschaftsstarken Bundesländer gilt das Umgekehrte. Ein Land wie Hamburg, dessen Bruttoinlandsprodukt pro Kopf $175 \%$ des Bundesdurchschnitts beträgt, erhält danach Investitionszuschüsse in Höhe von nur $25 \%$ des bundesdurchschnittlichen Zuweisungsbetrages.

Man kann die so ermittelte fiktive Verteilung der Investitionszuschüsse des Bundes an die Länder als Minimum dessen bezeichnen, was zur Realisierung der oben skizzierten regionalpolitischen Konzeption und damit der Ziele des Bundesraumordnungsprogramms erforderlich ist. (122) Wären die Investitionszuweisungen des Bundes tatsächlich gemäß dieser fiktiven Verteilung den einzelnen Ländern gewährt worden, könnte man daraus jedoch nur schließen, daß der Bund mit diesem finanzausgleichspolitischen Instrument in die regionalpolitisch erwünschte Richtung wirkt. Eine Aussage darüber, ob die Begünstigung der wirtschaftsschwachen gegenüber den wirtschaftsstarken Ländern quantitativ ausreicht, um die Beharrungskraft der gewachsenen Raumstruktur (123) zu brechen und die regionalen Einkommensdiskrepanzen spürbar zu verringern, ist nicht möglich.

\subsection{Interpretation und Beurteilung der Ergebnisse}

Gemessen an der regionalpolitisch wünschenswerten Verteilung der Investitionszuweisungen des Bundes (Spalte 6) fällt das Urteil über die tatsächliche Verteilung der Zuschüsse des Bundes für Investitionen im Jahr 1974 negativ aus.

- Die Zuschüsse des Bundes für Investitionen an die vier wirtschaftsschwachen Länder Rheinland-Pfalz, Saarland, Niedersachsen und SchleswigHolstein liegen 1974 insgesamt um rund 317 Mill. DM unter dem Zuweisungsbetrag, der ihnen nach dem hier vorgelegten Minimalvorschlag gewährt werden sollte. Dabei wiegt besonders schwer, daß ausgerechnet 
Tabelle 10d Die Verteilung der Investitionszuschüsse des Bundes auf die einzelnen Länder gemäß den Grundsätzen des Bundesraumordnungsprogramms im Jahr 1974

\begin{tabular}{|c|c|c|c|c|c|c|c|c|c|c|}
\hline \multirow{2}{*}{ Land } & \multicolumn{4}{|c|}{ BIP 1974 (pro Kopf) } & \multicolumn{5}{|c|}{ wünschenswerte Zuweisungsbeträge 1) } & \multirow{2}{*}{$\begin{array}{l}\text { Umverteilungsmasse } \\
=\text { Diff. tats. u.wün- } \\
\text { schensw. Zuweisungen } \\
\text { in } 1000 \text { DM }\end{array}$} \\
\hline & in DM & $\begin{array}{l}\text { in } \% \text { des } \\
\rho \text { Bund }\end{array}$ & $\begin{array}{l}\text { Rang- } \\
\text { zahl }\end{array}$ & $\begin{array}{l}\text { prozent. } \\
\text { Abweichung } \\
\text { v. } 0\end{array}$ & $\begin{array}{l}\text { pro Kopf } \\
\text { in DM 2) }\end{array}$ & $\begin{array}{l}\text { insgesamt } \\
\text { in } 1000 \mathrm{DM}\end{array}$ & in $\%$ & $\mathrm{AQ}^{3)}$ & $\begin{array}{l}\text { Rang- } \\
\text { zahl }\end{array}$ & \\
\hline & 1 & 2 & 3 & 4 & 5 & 6 & 7 & 8 & 9 & 10 \\
\hline Bayern & 15017 & 93,8 & 7 & -6 & 122,15 & 1.325 .450 & 19,16 & 1,0597 & 5 & +87150 \\
\hline Baden-Württemb. & 16316 & 101,9 & 5 & +2 & 112,95 & 1.043 .432 & 15,08 & 0,9799 & 6 & +145268 \\
\hline Bessen & 16434 & 102,6 & 4 & +3 & 111,80 & 624.068 & 9,02 & 0,9699 & 7 & -25068 \\
\hline Rheinland-Pfalz & 15116 & 94,4 & 6 & -6 & 122,15 & 451.466 & 6,53 & 1,0600 & 4 & -22766 \\
\hline gaarland & 14155 & 88,4 & 8 & -12 & 129,05 & 142.987 & 2,07 & 1,1189 & 3 & -11487 \\
\hline Rordrhein-Westf. & 16681 & 104,2 & 3 & +4 & 110,65 & 1.906 .500 & 27,56 & 0,9599 & 8 & -108200 \\
\hline Biedersachsen & 13476 & 84,2 & 9 & -16 & 133,65 & 970.700 & 14,03 & 1,1595 & 2 & -145900 \\
\hline Şchieswig-Holst. & 13458 & 84,1 & 10 & -16 & 133,65 & 345.218 & 4,99 & 1,1605 & 1 & -136618 \\
\hline Hargburg & 28036 & 175,1 & 1 & +75 & 28,85 & 50.286 & 0,73 & 0,2517 & 10 & +149314 \\
\hline $\begin{array}{l}\text { Bre } \\
\text { Bren } \\
0\end{array}$ & 21010 & 131,2 & 2 & +31 & 79,55 & 57.833 & 0,84 & 0,6942 & 9 & +67967 \\
\hline 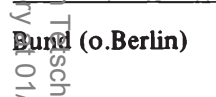 & 16010 & 100,0 & & & 115,25 & 6.917 .940 & 100,01 & & & $\begin{array}{r}+449699 \\
-450039\end{array}$ \\
\hline
\end{tabular}

$\overrightarrow{10}$ Bje Höhe der Investitionszuschüsse richtet sich nach dem Ausmaß der BIP-Abweichung vom Bundesdurchschnitt.

. 2) durchschnittlicher Zuweisungsbetrag plus bzw. minus prozentualer Abweichung des BIP vom Bundesdurchschnitt

Bêispiel: Bayern $=6 \%$ von $115,25 \mathrm{DM}=6,90 \quad$ Baden-Württemberg $=2 \%$ vom $115,25 \mathrm{DM}=2,30 \mathrm{DM}$
离
$122,15=115,25+6,90$
当 $\mathrm{A} Q \mathrm{Q}=$ Anteilsquotient in bezug auf die Wohnbevölkerung.
贾

$112,95=115,25-2,30$ 
die von den beiden wirtschaftsschwächsten Ländern Niedersachsen und Schleswig-Holstein empfangenen Zuweisungen um rund 280 Mill. DM niedriger sind, als die für beide Länder berechneten Mindestzuweisungen.

- Auf der anderen Seite fließen den drei wirtschaftsstarken Ländern BadenWürttemberg, Hamburg und Bremen insgesamt rund $363 \mathrm{Mill}$. DM mehr Investitionszuschüsse $\mathrm{zu}$, als die regionalpolitisch zieladäquate Verteilung erlaubt. Damit werden die beiden wirtschafts - und steuerstärksten Bundesländer Hamburg und Bremen auch durch diese finanzausgleichspolitische Maßnahme des Bundes begünstigt.

- Nur zwei wirtschaftsstarken Bundesländern gewährt der Bund weniger, nur einem wirtschaftsschwachen Land mehr Investitionszuweisungen, als dieser Minimalvorschlag vorsieht.

Die Berechnungen der Tabelle $10 \mathrm{~d}$ zeigen insgesamt, daß die Bundesregierung im Jahr 1974 ihre Zuschüsse für Investitionen der Länder und Gemeinden nicht konsequent als Instrument zum Abbau der regionalen Wohlstandsunterschiede einsetzt. In einigen Fällen verletzt sie die von ihr selbst im Bundesraumordnungsprogramm aufgestellten regionalpolitischen Ziele, in anderen Fällen verfolgt sie diese nur halbherzig. Sie nutzt damit nicht die regionalpolitischen Möglichkeiten, die dieses finanzausgleichspolitische Instrument grundsätzlich bietet.

X. Die Gesamtfinanzmasse der Länder und ihrer Gemeinden in der Bundes republik Deutschland im Jahr 1974

Der durch die Finanzreform von 1969 geschaffene Prozeß der Einnahmenverteilung auf die einzelnen Länder ist mit der regionalen Verteilung der Zuschüsse des Bundes für Investitionen der untergeordneten Gebietskörperschaften abgeschlossen. Deshalb kann an dieser Stelle der Untersuchung das finanzielle Gesamtergebnis dieses Systems der Einnahmenverteilung für das Jahr 1974 berechnet werden. Darunter sind die Gesamteinnahmen zu verstehen, die den einzelnen Ländern und ihren Gemeinden im Jahr 1974 zur Erfüllung ihrer öffentlichen Aufgaben zur Verfügung stehen. Sie werden hier als Gesamtfinanzmasse der Länder und ihrer Gemeinden bezeichnet.

\section{Die regionalpolitische Bedeutung der Gesamtfinanzmasse}

Die regionalpolitische Bedeutung der Höhe der Gesamtfinanzmasse pro Einwohner ist im theoretischen Teil dieser Arbeit ausführlich dargestellt worden. (124) Die Gesamtfinanzmasse bestimmt von der finanziellen Seite her den wirtschaftspolitischen Handlungsspielraum und insbesondere die Attraktionskraft der einzelnen Länder und ihrer Gemeinden auf mobile Ressourcen. Je höher die Pro-Kopf-Einnahmen einer Gebietskörperschaft am Ende des Prozesses der Einnahmenverteilung sind, desto größer ist der Mobilitätsanteil an ihren Einnahmen und desto mehr Finanzmittel kann sie pro Einwohner für attraktivitätsfördernde Zwecke einsetzen. Die Gesamtfinanzmasse pro Kopf 
kann deshalb als Indikator für die Möglichkeiten der Länder dienen, den in ihnen ansässigen Wirtschaftssubjekten günstige Standortbedingungen zu schaffen und auf diese Weise die Raumstruktur zu ihren Gunsten zu beeinflussen.

In diesem Abschnitt sollen diejenigen Einnahmenunterschiede und damit die regionalen Unterschiede in den Ausgaben - und Attrahierungsmöglichkeiten der Länder und ihrer Gemeinden herausgearbeitet werden, die ausschlie $\beta$ lich aus dem 1969 geschaffenen System der Einnahmenverteilung resultieren. Deshalb müssen die Auswirkungen regionaler Steuerbelastungsunterschiede auf die Pro-Kopf-Einnahmen der Länder und ihrer Gemeinden eliminiert werden. Dies geschieht, indem statt der Ist-Steuereinnahmen der Gemeinden ihre Steuerkraftwerte verwendet werden.

\section{Die Zusammensetzung der Gesamtfinanzmasse}

Die Gesamtfinanzmasse eines Landes besteht aus der Landesfinanzmasse und der Gemeindefinanzmasse. (125) Die Landesfinanzmasse umfaßt die Steuereinnahmen des jeweiligen Landes abzüglich der Zuweisungen des Landes an den Lastenausgleichsfonds, die Ausgleichszuweisungen (+) bzw. Aus gleichsbeiträge (-) im Rahmen des Länderfinanzausgleichs, die Ergänzungs zuweisungen sowie die Investitionszuweisungen des Bundes an die Länder. Die Gemeindefinanzmasse besteht aus der Realsteuerkraft der Gemeinden abzüglich der Gewerbesteuerumlage, den Einnahmen der Gemeinden aus dem Gemeindeanteil an der Einkommensteuer sowie den Investitionszuweisungen des Bundes an die Gemeinden. Als quantitativ weniger bedeutende Elemente gehören systematisch die Einnahmen der Gemeinden aus ihrem Erwerbsvermögen und ihre "sonstigen Steuern und steuerähnlichen Einnahmen" zu der Finanzmasse, mit der sie ihre eigenen Aufgaben im engeren Sinne wahrnehmen können.

Nicht zur Gesamtfinanzmasse der Länder gehören die "laufenden Zuweisungen" des Bundes an die Länder und Gemeinden. Bei diesen Zuweisungen handelt es sich überwiegend um Finanzmittel, die lediglich die Haushalte der Länder und Gemeinden durchlaufen. (126) Der Bund bedient sich bei der Erfüllung seiner zentralstaatlichen Aufgaben der technischen Hilfe der untergeordneten Gebietskörperschaften, so z. B. bei der Abwicklung von Trans ferzahlungen an private Haushalte und Unternehmen. Diese Sozialleistungen und Subventionen machen den überwiegenden Teil der "laufenden Zuweisungen" des Bundes an Länder und Gemeinden aus: Wohngeld, Ausbildungsförde rung, Graduiertenförderung, Gasölbetriebsbeihilfe, Wiedergutmachung ge mäß dem Bundesentschädigungsgesetz usw.. (127) Die als "laufende Zuweisungen" den Ländern und Gemeinden zufließenden Finanzierungsmittel ste hen diesen also nicht zur Finanzierung ihrer eigenen Aufgaben im engeren Sinne zur Verfügung. Diese Mittel können deshalb von den untergeordneten Gebietskörperschaften nicht nach eigenen Vorstellungen zur Attrahierung mobiler Ressourcen eingesetzt werden.

Damit ist aber keineswegs gesagt, daß diese Zahlungen an private Wirtschaftssubjekte die Raumstruktur unbeeinflußt lassen. Die konkreten Raum- 
wirkungen dieser Geldleistungen werden jedoch weitgehend von den ausgabenpolitischen Entscheidungen des Zentralstaates und nicht von denjenigen der untergeordneten Gebietskörperschaften bestimmt. Mit der Festlegung des Kreises der Begünstigten und der Bemessungsgrundlage in den entspre chenden Geldleistungsgesetzen entscheidet der Bund implizit über die regionale Verteilung dieser Zahlungen, wobei unter bestimmten Bedingungen nicht einmal die Zustimmung des Bundesrates erforderlich ist. (128) Der Bund trifft somit in der Regel unbewußt die Entscheidung darüber, in welcher Richtung und in welchem Ausmaß in den einzelnen Regionen der Zuführungs effekt durch diese Zahlungen vom Entzugseffekt durch den Beitrag der einzelnen Regionen zur Finanzierung dieser Geldleistungen abweicht. Aus diesem Grund werden die Mittel, die zur Finanzierung der Geldleistungen dienen und als "laufende Zuweisungen" die Haushalte der untergeordneten Gebietskörperschaften lediglich durchlaufen, hier zu den direkten Einflußmöglichkeiten des Zentralstaates auf die Raumstruktur (129) und nicht zum Attrahierungspotential der Länder und Gemeinden gezählt.

Eine Ausnahme zum eben Gesagten stellen die Bundesergänzungszuweisungen dar. Sie sind der wichtigste Posten der "laufenden Zuweisungen", mit dem der Bund den finanziellen Spielraum der Länder und ihrer Gemeinden zur Erfüllung ihrer spezifischen Aufgaben erweitert und werden deshalb auch zur Gesamtfinanzmasse der Länder hinzugerechnet.

\section{Die Berechnung der Gesamtfinanzmasse}

Da es bei der hier untersuchten Frage nur auf die Ermittlung der Gesamtfinanzmasse eines Landes, nicht aber auf die Trennung in Landes- und Gemeindefinanzmasse ankommt, konnten einige Bestandteile der Gesamtfinanzmasse im Rechengang zusammengefaßt werden.

So beinhaltet der Posten "Finanzkraft nach Länderfinanzausgleich" die Steuereinnahmen der Länder, die Steuerkraft ihrer Gemeinden sowie die positiven bzw. negativen Ausgleichszahlungen im Rahmen des Länderfinanzausgleichs. Von der Finanzkraft der einzelnen Länder und ihrer Gemeinden werden die Zuschüsse zum Lastenausgleichsfonds abgezogen. Die Differenz beider Posten ergibt die "den Ländern und ihren Gemeinden verbleibenden Steuereinnahmen" (Spalte 3). Zu ihnen werden die Ergänzungszuweisungen und die In vestitionszuweisungen des Bundes addiert. Die letzteren umfassen sowohl die Investitionszuschüsse des Bundes an die Länder als auch die an die $\mathrm{Ge}-$ meinden, die grundsätzlich über die Haushalte der Länder laufen. (130)

Die sich in Spalte 9 ergebende Summe stellt noch nicht vollständig die Gesamtfinanzmasse der Länder dar. Es fehlen noch die "sonstigen Steuern und steuerähnlichen Einnahmen der Gemeinden", wozu im wesentlichen der Zuschlag zur Grunderwerbsteuer und die örtlichen Aufwand - und Verbrauch steuern (131) gehören, und die Einnahmen der Gemeinden aus ihrem Erwerbsvermögen. Darunter sind die Überschüsse der wirtschaftlichen Unternehmen und die Erträge des allgemeinen Kapital- und Grundvermögens der Gemeinden zu verstehen. Diese beiden Bestandteile der Gesamtfinanzmasse lassen 
sich jedoch nicht ohne Schwierigkeiten in die Rechnung einbeziehen.

Bei den "sonstigen Steuern und steuerähnlichen Einnahmen" existieren zwischen den Ländern Steuerbelastungsunterschiede (132), die nicht eliminiert werden können. Besonders gravierend ist dieser Tatbestand im Fall der Hansestadt Hamburg, die als einziges Bundesland (133) keinen Zuschlag zur Grunderwerbsteuer erhebt (134) und deswegen nur etwa 13 Prozent der bundesdurchschnittlichen Einnahmen aus "sonstigen Steuern" aufweist. Deshalb werden diese Einnahmen hier nicht in die Berechnung der Gesamtfinanzmas se einbezogen.

Bei den Einnahmen der Gemeinden aus ihrem Erwerbsvermögen liegt weniger ein methodisches, als vielmehr ein statistisches Problem vor. Die neuesten verfügbaren Zahlen stammen aus dem Jahr 1972. Da für die einzelnen Länder keine Ist-Zahlen über die Nettoeinnahmen ihrer Gemeinden aus dem Erwerbsvermögen für das Jahr 1974 vorliegen, bleibt auch dieser Bestandteil der Gesamtfinanzmasse der Länder unberücksichtigt. (135)

\section{Interpretation und Beurteilung der Ergebnisse}

Über die finanzielle Situation der einzelnen Länder und ihrer Gemeinden nach Abschlu $\beta$ des hier untersuchten Prozesses der Einnahmenverteilung gibt Tabelle 11 in den Spalten 9 - 12 Auskunft.

\subsection{Die Streuung der Pro-Kopf-Einnahmen}

Die Pro-Kopf-Einnahmen der einzelnen Länder und ihrer Gemeinden (136) streuen schwächer um den Durchschnitt, als das nach der Gewährung der Ergänzungszuweisungen durch den Bund der Fall ist. (137) Dank der Bundes zuschüsse für Investitionen nähern sich die Einnahmenpositionen aller finanzschwachen Länder mit Ausnahme derjenigen von Schleswig-Holstein von unten, die Einnahmenpositionen der finanzstarken Länder (Ausnahme: BadenWürttemberg und Bremen) von oben dem Bundesdurchschnitt an (Spalte 11). Deswegen ist der Variationskoeffizient für die Gesamtfinanzmasse mit 0,160 noch geringfügig niedriger als der Variationskoeffizient für die Einnahmenverteilung nach Gewährung der Ergänzungszuweisungen, der 0,168 beträgt.

\subsection{Das regionale Gefälle in der Finanzkraft}

Die Abschwächung der regionalen Finanzkraftunterschiede auf der sechsten Stufe des Prozesses der Einnahmenverteilung verhindert aber nicht, daß auch nach der Verteilung der Bundeszuschüsse für Investitionen der Länder und ihrer Gemeinden im Jahr 1974 ein regionales Finanzkraftgefälle zugunsten der wirtschaftsstarken Bundesländer besteht:

- Die beiden Bundesländer mit der höchsten Wirtschaftskraft, Hamburg und Bremen, weisen auch mit Abstand die größte Finanzkraft auf. Ihre Ge- 
Cabelle 11 Die Gesamtfinanzmasse der Länder und ihrer Gemeinden im Jahr 1974

\begin{tabular}{|c|c|c|c|c|c|c|c|c|c|c|c|c|}
\hline \multirow[t]{3}{*}{ and } & \multirow{2}{*}{\begin{tabular}{|l} 
Finanzkraft \\
nach LFA 1
\end{tabular}} & \multirow{2}{*}{\begin{tabular}{|l}
$\begin{array}{l}\text { Zuschüsse } z . \\
\text { Lastenaus- } \\
\text { zleichsfonds } 2\end{array}$ \\
in $1000 \mathrm{DM}$
\end{tabular}} & \multicolumn{2}{|c|}{$\begin{array}{l}\text { den Ländern verblei- } \\
\text { bende Steuereinnah- } \\
\text { men3 }\end{array}$} & \multicolumn{2}{|c|}{$\begin{array}{l}\text { Ergänzungszuweisun- } \\
\text { gen des Bundes } 4\end{array}$} & \multicolumn{2}{|c|}{$\begin{array}{l}\text { Investitionszuschüsse } \\
\text { des Bundes6 }\end{array}$} & \multicolumn{4}{|c|}{ Gesamtfinanzmasse 7} \\
\hline & & & in $1000 \mathrm{DM}$ & bro Kopf ${ }^{5}$ & in $1000 \mathrm{DM}$ & bro Kopf & 5 in $1000 \mathrm{DM}$ & pro Kopfs & in $1000 \mathrm{DM}$ & pro Kopf5 & 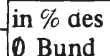 & $\begin{array}{l}\text { in \% d.finanz- } \\
\text { schwächst.Land. }\end{array}$ \\
\hline & $\frac{1}{1}$ & $\frac{10}{2}$ & $\frac{1000 \mathrm{DM}}{3}$ & $\frac{4}{4}$ & $\frac{10}{5}$ & $\begin{array}{l}\text { pro kopr } \\
6\end{array}$ & $\frac{1000 \mathrm{M}}{7}$ & $\begin{array}{l}\text { pro nopl- } \\
\end{array}$ & in 1000 Din & \begin{tabular}{|c|} 
pronopl \\
10 \\
\end{tabular} & $\frac{11}{11}$ & \\
\hline 3ayern & 17965006 & 208200 & 17756806 & $1.636,9$ & 163400 & 15,1 & 1412600 & 130,2 & 19332806 & $1.782,2$ & 95,8 & 101,6 \\
\hline Baalen-Württ. & 16390038 & 204200 & 16185838 & $1.752,1$ & - & - & 1188700 & 128,7 & 17374538 & $1.880,8$ & 101,1 & 107,3 \\
\hline $\mathrm{Hej}$ & 10072639 & 142700 & 9929939 & $1.779,6$ & - & - & 599000 & 107,3 & 10528939 & $1.886,9$ & 101,4 & 107,6 \\
\hline Rheineinl.-Pfalz & 5963457 & 53500 & 5909957 & $1.599,0$ & 154400 & 41,8 & 428700 & 116,0 & 6493057 & $1.756,8$ & 94,5 & 100,2 \\
\hline Nog्ädrh.-Westf. & 30845425 & 382100 & 30463325 & $1.768,6$ & - & - & 1798300 & 104,4 & 32261625 & $1.873,0$ & 100,7 & 106,8 \\
\hline Niedefsachsen & 11747864 & 116300 & 11631564 & $1.601,7$ & 276600 & 38,1 & 824800 & 113,6 & 12732964 & $1.753,4$ & 94,3 & 100,0 \\
\hline 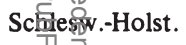 & 4304152 & 41100 & 4263052 & $1.651,1$ & 111700 & 43,3 & 208600 & 80,8 & 4583352 & $1.775,1$ & 95,4 & 101,2 \\
\hline Hathboung & 4466687 & 74900 & 4391787 & $2.521,1$ & - & - & 199600 & 114,6 & 4591387 & $2.635,7$ & 141,7 & 150,3 \\
\hline Brêtem & 1603462 & 17600 & 1585862 & $2.184,4$ & - & - & 125800 & 173,3 & 1711662 & $2.357,7$ & 126,8 & 134,5 \\
\hline $\begin{array}{l}\text { Bundesgebiet } \\
\text { (ohme Berlin) }\end{array}$ & 105197851 & 1251000 & 103946851 & $1.732,2$ & 749600 & 12,5 & 6917600 & 115,3 & 111614051 & $1.860,0$ & 100,0 & - \\
\hline
\end{tabular}

Vacjiationskoeffizient für die Gesamtfinanzmasse 0,160.

\#) $\nabla$ eigl. Tabelle $7 \mathrm{~b}$.

(2) Y Y trgl.Bundesministerium der Finanzen, Die Ausgaben und Einnahmen

ڤै der Länder für das Rechnungsjahr 1974, Ubersicht 1 zu VA2 - FV 4036 - 1/75.

(3) Bifferenz zwischen Spalte 1 und Spalte 2.

4) Vergl. Tabelle 8 a.

5) Einwohnerzahlen Stand 30.6.1974.
6) Vergl. Tabelle $10 \mathrm{a}$.

7) Summe der Spalte 3, 5 und 7.

Quelle: Berechnet nach:

Bundesministerium der Finanzen, VA2,

Die Finanzen der Länder im Rechnungsjahr 1974, Bonn, Juli 1975, Ubersicht 2 und

Schreiben des Bundesministeriums der Finanzen, Referat VA3 vom 22.9.75 an den Verfasser. 
samtfinanzmasse pro Einwohner liegt $50 \%$ bzw. $35 \%$ über derjenigen der finanzschwächsten Bundesländer Rheinland-Pfalz und Niedersachsen (Spalte 12).

- Die wirtschaftsstarken Flächenstaaten verfügen über rund $7 \%$ mehr Einnahmen pro Einwohner als die beiden finanzschwächsten Bundesländer.

- Aus der Gruppe der wirtschafts - und finanzschwachen Länder hebt sich lediglich das Saarland ein wenig ab, dem $103 \%$ der Pro-Kopf-Einnahmen des finanzschwächsten Bundeslandes zur Erfüllung seiner Aufgaben zur Verfügung stehen.

Auch wenn man nicht über die Tatsache des Finanzkraftgefälles zugunsten der wirtschaftsstarken Länder an sich erstaunt ist, so muß doch das Ausmaß des Finanzkraftvorsprungs, den die beiden Stadtstaaten am Ende des Prozesses der Einnahmenverteilung vor allen anderen Bundesländern besitzen, überraschen.

\subsection{Der Einfluß der horizontalen Einnahmenverteilung des Jahres 1974} auf die Raumstruktur

Die Analyse der finanziellen Situation der einzelnen Länder und ihrer Gemeinden nach Abschluß des Prozesses der Einnahmenverteilung erlaubt folgende regionalpolitische Schlußfolgerungen:

- Auch nach der Finanzreform von 1969 schwächt die Verteilung der Einnahmen auf die einzelnen Länder und ihre Gemeinden die Gegenkräfte des räumlichen Differenzierungsprozesses, indem sie den wirtschaftsstarken und hochverdichteten Bundesländern finanziell die Kompensation ballungsbedingter Kostensteigerungen bei der öffentlichen Leistungserstellung ermöglicht.

- Die Finanzreform von 1969 verhindert nicht, daß die horizontale Einnahmenverteilung im Jahr 1974 direkt die regionalen Wirtschaftskraftunterschiede in der Bundesrepublik Deutschland verstärkt, indem sie mindestens einigen der wirtschaftsstarken Länder größere Attrahierungsmöglichkeiten im Vergleich zu den anderen Ländern verschaff.

- Das System der horizontalen Einnahmenverteilung ist auch nach der Finanzreform noch weit davon entfernt, als Instrument der Regionalpolitik zum "Abbau großräumiger Disparitäten zwischen den Gebietseinheiten"(1 38) beizutragen. Ohne die Weiterentwicklung des Systems der horizontalen Einnahmenverteilung zu einem solchen System besteht aber für den Bund immer die Gefahr, daß regionalpolitisch positive Raumwirkungen, die er mit einer regional gezielten Verteilung seiner Infrastrukturprojekte und öfentlichen Aufträge erreichen kann, (139) durch die geringen Attrahierungsmöglichkeiten der wirtschaftsschwachen Regionen kompensiert oder gar überkompensiert werden.

Mit der Ermittlung der Gesamtfinanzmasse ist die Untersuchung über die Auswirkungen der Finanzreform von 1969 auf die Einnahmenposition der einzelnen 
Länder abgeschlossen. Außer der bisher untersuchten Neuregelung der horizontalen Einnahmenverteilung auf Länderebene hat die Finanzreform aber auch eine Neuregelung der horizontalen Einnahmenverteilung auf Gemeinde ebene gebracht. Dieser Teil der Finanzreform wird im folgenden Kapitel untersucht. 
Friedemann Tetsch - 978-3-631-75190-9

Downloaded from PubFactory at 01/11/2019 07:18:40AM

via free access 


\section{DIE NEUORDNUNG DER HORIZONTALEN EINNAHMENVERTEILUNG AUF GEMEINDEE BENE DURCH DIE FINANZREFORM VON 1969}

\section{Das Gemeindesteuersystem vor der Finanzreform von 1969}

Vor der Gemeindefinanzreform von 1969 war das kommunale Steuersystem in der Bundesrepublik Deutschland als gebundenes Trennsystem ausgestaltet. Die Gemeinden verfügten über eigene Steuerquellen, deren Ertrag den einzelnen Gemeinden gemäß dem örtlichen. Aufkommen zustand.

Das Gesetz zur Änderung und Ergänzung von Art. 106 GG vom 24. Dezember 1956 (BGBl. I S. 1077) garantierte den Gemeinden in ihrer Gesamtheit das Aufkommen aus den Realsteuern. (140) Die einzelnen Gemeinden wurden gemäß ihrem örtlichen Aufkommen an den Realsteuereinnahmen beteiligt, doch wurde das örtliche Aufkommen durch zwei Maßnahmen modifiziert. Einmal wurden die Realsteuereinnahmen, die grundsätzlich dem Finanzamt am Sitzort des steuerpflichtigen Unternehmens zuflossen, auf die Gemeinden der Betriebsstätten zerlegt. Diese Zerlegung der Gewerbesteuer war obligatorisch und bundeseinheitlich geregelt. Zum anderen führten die meisten Länder einen Gewerbesteuerausgleich zwischen Wohn- und Betriebsge meinden durch. Mit diesem Ausgleich, der der ausschließlichen Landesgesetzgebung unterstand, wurden die Wohnortgemeinden von pendelnden Arbeitskräften am Gewerbesteueraufkommen der Gemeinden, in denen die Pendler ihren Arbeitsplatz hatten, beteiligt.(141) Das Recht, die Hebesätze für die Realsteuern festzusetzen, war grundsätzlich "eine Angelegenheit der ausschließlichen Landesgesetzgebung". (142) Die Länder überließen ihren Gemeinden jedoch dieses Hebesatzrecht, so daß die Gemeinden defacto eine begrenzte Steuergesetzgebungshoheit besaßen.

Die zweite Steuerquelle der Gemeinden neben den Realsteuern waren die "sonstigen" Gemeindesteuern. (143) Sie waren zwar als "Steuern mit örtlich bedingtem Wirkungskreis" nach Art. 106, Abs. 2 GG a.F. verfassungsrechtlich Landessteuern, wurden aber von den Ländern ihren Gemeinden in Ertragshoheit übertragen.

Das finanzielle Gewicht der einzelnen Komponenten des kommunalen Steuersystems war recht unterschiedlich. In den letzten Jahren vor Inkrafttreten der Finanzreform flossen von den eigenen Steuereinnahmen der Gemeinden etwa

- $15 \%$ aus der Grundsteuer A und B,

- $80 \%$ aus der Gewerbesteuer nach Ertrag und Kapital und der Lohnsummensteuer und

- $5 \%$ aus den sonstigen Gemeindesteuern. (144)

Man kann demnach von einer Dominanz der Gewerbesteuer im kommunalen Steuersystem vor der Finanzreform von 1969 sprechen.

Die Finanzwissenschaft hat eine Reihe von allgemein akzeptierten Kriterien entwickelt, mit denen beurteilt werden kann, ob sich eine bestimmte Steuer als Element des Gemeindesteuersystems eignet. Danach sollte eine Steuer, 
die den Gemeinden in Ertragshoheit überlassen wird, vor allem folgenden Anforderungen genügen (145):

- dem Prinzip der örtlichen Radizierbarkeit;

Der Kreis der Nutznießer des kommunalen Leistungsangebots soll soweit wie möglich identisch sein mit dem Kreis der Träger der kommunalen Steuerlast.

- dem Prinzip der Fühlbarkeit;

Die Gemeindesteuer soll einen möglichst großen Kreis der Gemeindebürger fühlbar belasten, um das Interesse der Gemeindebürger an den kommunalen Selbstverwaltungsaufgaben und an der Kontrolle ihrer gewählten Vertreter im Gemeinderat zu erhöhen.

- dem Grundsatz der geringen Konjunkturreagibilität;

Das Aufkommen aus der Gemeindesteuer soll möglichst geringe Schwankungen im Konjunkturzyklus aufweisen, damit die Gemeinden nicht zu einer prozyklischen Finanzpolitik verleitet werden.

- dem Grundsatz der geringen Streuung;

Diese Anforderung an eine Gemeindesteuer bezieht sich sowohl auf den horizontalen als auch auf den vertikalen Aspekt (146) der Streuung des Steueraufkommens pro Einwohner.

a) Zwischen "Gemeinden von etwa gleicher Größe [sollen] die lokalen Unterschiede im Steueraufkommen pro Kopf gering"(147) sein. In einer etwas schärferen Formulierung kann man fordern, daß "die Steueraufkommen innerhalb gleicher Gemeindegrößenklasse pro Einwohner gleich hoch sein sollen".(148)

b) Zwischen Gemeinden verschiedener Größenklassen sollen sich die Unterschiede im Steue raufkommen pro Kopf "in - vom Finanzbedarf her bestimmten - angemessenen Grenzen"(149) halten. (150)

- dem Grundsatz der Parallelität von Gemeindesteueraufkommen und allge meinem Wirtschaftswachstum.

Danach soll das Aufkommen aus den Gemeindesteuern mittel- oder langfristig nicht schwächer wachsen als das Sozialprodukt.

Die quantitativ bedeutendste Komponente des kommunalen Steuersystems vor der Finanzreform, die Gewerbesteuer, genügt keinem dieser Kriterien einer adäquaten Gemeindesteuer in befriedigender Weise. Deswegen fällt ihre Beurteilung und damit das Urteil über das gesamte kommunale Steuersystem denkbar ungünstig aus. (151) Aus regionalpolitischer Sicht sind besonders die negativen räumlichen Auswirkungen der Dominanz der Gewerbesteuer im kommunalen Steuersystem hervorzuheben. Sie führte einmal sowohl vertikal als auch horizontal zu großen Steuerkraftunterschieden $\mathbf{z w i -}$ schen den Gemeinden und war damit die entscheidende Ursache für das ballungsfördernde Steuerkraftgefälle zugunsten der wirtschaftsstarken und stark agglomerierten Regionen. Zum anderen war sie verantwortlich für das ein- 
seitige Interesse der Gemeinden an der Ansiedlung von Gewerbebetrieben, die auf diese Weise die lokalen Steuerbemessungsgrundlagen und damit ihre Steuerkraft zu erhöhen versuchten. (152) Durch diese auf Gewerbebetriebe ausgerichtete, einnahmenorientierte Ausgabenpolitik der Gemeinden wurden häufig andere wichtige Anforderungen an eine befriedigende Siedlungs struktur (z. B. Wohn- und Freizeitwert, Umweltschutz) grob vernachlässigt.

Zusammenfassend kann man sagen, daß sich die "Reformbedürftigkeit des Gemeindesteuersystems ... aus dem Übergewicht der Gewerbesteuer unter den eigenen Steuereinnahmen der Gemeinden"(153) ergab. Diese Einseitigkeit des Gemeindesteuersystems abzubauen, war ein wesentliches Ziel der Gemeindefinanzreform von 1969 .

\section{Die Ziele der Gemeindefinanzreform von 1969}

Aus der Beurteilung des Gemeindesteuersystems anhand der oben aufgezählten Kriterien für adäquate Gemeindesteuern ergaben sich unmittelbar die Ziele einer Reform des kommunalen Steuersystems. Der Bundeskanzler und die Ministerpräsidenten der Länder beauftragten am 20. März 1964 die Kommission für die Finanzreform, Vorschläge für eine Neıordnung des gemeindlichen Steuersystems auszuarbeiten. Diese Neuordnung sollte, die Ziele verfolgen,

- "die finanzielle Selbstverantwortung der Gemeinden zu stärken", (154)

- "die Konjunkturabhängigkeit der gemeindlichen Haushaltswirtschaft zu verringern", (154)

- "die gemeindlichen Steuerkraftunterschiede zu mildern"(154) und

- "eine sinnvolle Raumordnung zu fördern".(154)

Diese Ziele einer Reform des Gemeindesteuersystems wurden auch von der Bundesregierung bei der Ausarbeitung ihrer eigenen Reformvorschläge übernommen. (155)

Diese beiden letzten Elemente dieses Zielsystems - Milderung der gemeindlichen Steuerkraftunterschiede und Förderung einer sinnvollen Raumordnung stehen nicht auf gleicher Ebene, sondern in einem Ziel-Mittel-Verhältnis zueinander. Sie bilden gemeinsam das regionalpolitische Ziel der Gemeindefinanzreform, weswegen sich die weitere Untersuchung im wesentlichen auf sie beschränkt.

Die Formulierung des regionalpolitischen Ziels im Auftrag an die Finanzreformkommission ist wenig aussagefähig und damit inhaltsleer, wenn nicht zugleich drei wichtige Fragen geklärt werden:

- Soll nur die horizontale Streuung des Steueraufkommens pro Einwohner (bei gleicher Steueranspannung) abgeschwächt werden?

- Oder sollen auch die Steuerkraftunterschiede zwischen den Gemeinden verschiedener Größe abgebaut werden?

- In welchem Ausmaß sollen die horizontalen und gegebenenfalls auch die 
vertikalen Steuerkraftunterschiede durch die Gemeindefinanzreform verringert werden?

Antworten auf diese Frage lassen sich einigen Aussagen der Bundesregierung entnehmen. So vertritt die Bundesregierung folgende Zielvorstellung: "Die Reform des Gemeindesteuersystems soll die ungerechtfertigten Steuer kraftunterschiede $\mathrm{zw}$ ischen gewerbesteuerschwachen und gewerbesteuerstarken Gemeinden verringern, dabei aber die durch den höheren Ausgabebedarf zentraler Orte begründeten Steuerkraftuntèrschiede $\mathrm{zw}$ ischen kleineren und größeren Gemeinden berücksichtigen.

Die vorgenommenen Sondererhebungen über die Auswirkungen der Gemeindefinanzreform (auf der Grundlage der Statistik für 1965) zeigen, daß dieses Ziel durch die Regelungen des Gemeindefinanzreformgesetzes und die Aufhebung des Gewerbesteuerausgleichs zwischen Betriebs- und Wohngemeinden erreicht wird. "(156) Darüberhinaus zeigen diese Sondererhebungen, daß sich die "Annäherung der Steuerkraftunterschiede ... überwiegend auf den Ausgleich zwischen Gemeinden der gleichen Größenklasse [beschränkt]. Die Steuerkraftunterschiede von Größenklasse zu Größenklasse werden durch die Reform nur wenig verändert. "(157)

Diesen Aussagen der Bundesregierung lassen sich zur Frage der horizontalen Streuung der gemeindlichen Steuerkraft folgende Zielvorstellungen entnehmen:

- Die vor der Gemeindefinanzreform bestehenden Steuerkraftunterschiede zwischen Gemeinden der gleichen Größenklasse werden von der Bundesre gierung als ungerechtfertigt groß empfunden.

- Die Gemeindefinanzreform soll deshalb die horizontale Streuung der ge meindlichen Steuerkraft abschwächen, aber nicht vollständig beseitigen oder gar in ihr Gegenteil umkehren. (158)

- Über das Ausmaß, in dem die Steuerkraftunterschiede zwischen gewerbesteuerstarken und gewerbesteuerschwachen Gemeinden der gleichen GröBenklasse abgebaut werden sollen, sagt die Bundesregierung nichts aus.

Für die Frage der vertikalen Streuung ergeben sich aus der oben zitierten Stellungnahme der Bundesregierung die folgenden Konsequenzen:

- Die Bundesregierung hält die vor der Finanzreform bestehenden vertikalen Steuerkraftunterschiede für gerechtfertigt und wünschenswert. Deshalb soll die Gemeindefinanzreform die bestehende Staffelung der Steuerkraft mit wachsender Gemeindegröße nicht verändern. Das Ziel der Gemeindefinanzreform, "die gemeindlichen Steuerkraftunterschiede zu mildern", bezieht sich also ausdrücklich nur auf die Steuerkraftunterschiede zwischen Gemeinden der gleichen Größenklasse. (159)

- Die Steuerkraftunterschiede zwischen Gemeinden unterschiedlicher Größe, die vor der Gemeindefinanzreform existieren und durch die Reform nicht angetastet werden sollen, werden von der Bundesregierung mit dem "höheren Finanzbedarf zentraler Orte" begründet. Sie werden also als korrektes Abbild der Kostenbelastung der größeren Gemeinden betrachtet, die 
durch ihr zentralörtliches Dienstleistungsangebot zugunsten der Einwohner ihres Umlandes verursacht wird.

- Diese Kostenbelastung infolge der Ertrags-spillouts zugunsten des Umlandes versucht die Bundesregierung pauschal abzugelten, indem sie die Steuereinnahmen der Gemeinden pro Einwohner nach der Gemeindegröße staffelt. (160)

- Um die von ihr erwünschte Konstanz der vertikalen Streuung zu erreichen, hält die Bundesregierung den Wegfall des Gewerbesteuerausgleichs zwischen Wohn- und Betriebsgemeinden für unbedingt erforderlich.

Diese von der Bundesregierung mit der Gemeindefinanzreform verfolgten regionalpolitischen Ziele stehen im Mittelpunkt der weiter unten folgenden empirischen Untersuchung. In ihr werden im ersten Teil die Auswirkungen der Gemeindefinanzreform von 1969 auf die vertikale Streuung der gemeindlichen Steuerkraft und im zweiten Teil ihre Auswirkungen auf die horizontale Streuung der gemeindlichen Steuerkraft für das Jahr 1974 analysiert. In beiden Fällen ist die Fragestellung eine doppelte:

- In einem ersten Schritt wird zu ermitteln versucht, ob die Maßnahmen der Bundesregierung tatsächlich die von ihr erwünschten und prognostizierten Ergebnisse erbracht haben, ob also die vertikale Streuung der gemeindlichen Steuerkraft unverändert geblieben und ihre horizontale Streuung abgeschwächt worden ist?

- In einem zweiten Schritt werden die tatsächlichen Ergebnisse der Gemeindefinanzreform an den hier zugrundegelegten regionalpolitischen Zie len (161) gemessen. Damit wird nach der regionalpolitischen Zieladäquanz der Maßnahmen der Gemeindefinanzreform gefragt. Die Ergebnisse die ser Überlegungen geben zugleich Hinweise darauf, ob die von der Bundesregie rung mit der Gemeindefinanzreform verfolgten Ziele mit dem regionalpolitischen Zielsystem übereinstimmen, das sie im Bundesraumordnungsprogramm vom 30.4.1975 aufgestellt hat. (162)

Bevor jedoch mit der empirischen Untersuchung dieser Fragen begonnen werden kann, müssen noch kurz die Maßnahmen, mit denen die Ziele der Gemeindefinanzreform erreicht werden sollen, dargestellt werden.

III. Die Maßnahmen der Gemeindefinanzreform von 1969

Das eigentliche Ziel der Gemeindefinanzreform von 1969 ist die Verbesserung der Struktur des kommunalen Steuersystems. (163) Diese Strukturre form umfaßt drei Maßnahmenkomplexe:

- die Beteiligung der Gemeinden am Aufkommen aus der Einkommensteuer,

- die Beteiligung von Bund und Ländern am Gewerbesteueraufkommen der Gemeinden in Form einer Gewerbesteuerumlage und

- den Wegfall des Gewerbesteuerausgleichs zwischen Betriebs - und Wohngemeinden. 
1. Die Beteiligung der Gemeinden am Aufkommen aus der Einkommensteuer

Durch die Finanzreform von 1969 werden die Gemeinden in den Steuerver bund für die Einkommensteuer einbezogen. Nach Art. 106, Abs. 5 GG in der Fassung vom 12.5.1969 erhalten die Gemeinden "einen Anteil an dem Aufkommen der Einkommensteuer, der von den Ländern an ihre Gemeinden auf der Grundlage der Einkommensteuerleistungen ihrer Einwohner weiterzuleiten ist." Die Höhe des Gemeindeanteils an der Einkommensteuer und die Kriterien, nach denen er auf die einzelnen Gemeinden verteilt wird, bestimmt das Gemeindefinanzreformgesetz vom 8. September 1969. Danach erhalten die Gemeinden eines Landes insgesamt $14 \%$ des Aufkommens aus der Lohnsteuer und der veranlagten Einkommensteuer, das ihrem Land nach der Zerlegung zusteht. $(164,165)$

Der den Gemeinden eines Landes insgesamt zustehende Anteil an der Einkommensteuer wird nach sogenannten Schlüssel- oder Anteilszahlen, die im Rahmen der alle drei Jahre durchgeführten Einkommen- und Lohnsteuer statistik ermittelt werden, auf die einzelnen Gemeinden verteilt. (166) "Bei der Ermittlung der Anteilszahlen werden nur die Steuerbeträge berücksichtigt, die auf zu versteuernde Einkommensbeträge bis zu einem bestimmten Höchstbetrag entfallen, um auszuschließen, daß durch die Anrechnung der vollen Steuerbeträge aus den Spitzeneinkommen für einzelne Gemeinden über mäßige Steuereinnahmen entstehen. "(167) Die Schlüsselzahl für eine einzelne Gemeinde wird berechnet, indem die Einkommensteuerzahlungen der Einwohner dieser Gemeinde, die aus einem bestimmten Bereich der Einkommensteuerbemessungs grundlage stammen, zum Einkommensteueraufkommen des gesamten Landes aus diesem Bereich der Bemessungsgrundlage in $\mathrm{Be}-$ ziehung gesetzt werden. Diese dem Verteilungsschlüssel des Gemeindeanteils "zugrunde zu legenden Höchstbeträge bilden das Kernstück des Gemeindefinanzreformgesetzes. "(168)

Das Pro-Kopf-Aufkommen aus der Einkommensteuer streut zwischen den Gemeinden horizontal und vertikal umso weniger, je niedriger die Höchstbeträge (Sockelbeträge) festgelegt werden. (169) Dieser Einfluß der Höchstbeträge auf das Steuerkraftgefälle zwischen den Gemeinden ließ $₫ 3$, Abs. 2 des Gemeindefinanz reformgesetzes, in dem der Sockelbetrag festgelegt wird, zu der "im Gesetzgebungsverfahren am meisten umstrittene[n] Bestimmung"(1 70) werden. Für die Jahre 1970 und 1971 schreibt das Gemeindefinanzreformgesetz als Höchstbeträge 8.000 DM zu versteuernden Einkommensbetrag für Ledige und 16.000 DM zu versteuernden Einkommensbetrag für Verheiratete vor. Danach werden also die einzelnen Gemeinden an $14 \%$ des Einkommensteueraufkommens ihres Landes nach Zerlegung gemäß ihrem jeweiligen Anteil am Einkommensteueraufkommen aus dem Linearbereich der Bemessungsgrundlage (Bereich der indirekten Progression) beteiligt.

Der Entwurf für das Gemeindefinanzreformgesetz sah für die Zeit nach dem 1.1.1971 eine Verdoppelung der Höchstbeträge auf 16.000/32.000 DM vor. Doch noch vor Verabschiedung des Gemeindefinanzreformgesetzes im Bundestag einigte sich die damalige Regierungskoalition darauf, ab 1.1.1972 
Höchstbeträge in Höhe von 80.000/160.000 DM versteuerndes Einkommen anzuwenden. Diese Erhöhung der Sockelbeträge sollte "nach Auffassung der Sozialdemokratischen Bundestagsfraktion ... eine Steuerkraftumverteilung zu Lasten der größeren Gemeinden verhindern",(171) "die größeren Gemeinden mit ihren höheren Investitionsaufgaben stärker"(172) am Gemeindeanteil an der Einkommensteuer beteiligen und somit dem "höheren Finanzbedarf je Einwohner in den Großstädten bei der Aufteilung des Einkommensteueranteils stärker Rechnung .. tragen"(173).

Dieser Verteilungsschlüssel für den Gemeindeanteil an der Einkommensteuer, der in $\$ 3$, Abs. 2 des Gemeindefinanzreformgesetzes verankert ist, kam nicht zur Anwendung. Die Ergebnisse statistischer Sondererhebungen zeigten, daß eine Erhöhung des Sockelbetrages auf 80.000/160.000 DM die mit der Gemeindefinanzreform angestrebte Milderung der Steuerkraftunterschiede $\mathrm{zw}$ ischen den Gemeinden weitgehend verhinderte. Deswegen hatten auch die Länder Bayern, Niedersachsen und Rheinland-Pfalz angekündigt, sie wollten den Gewerbesteuerausgleich zwischen Betriebs - und Wohngemeinden für die Jahre 1970 und 1971 nur aussetzen, bei Höchstbeträgen von 80.000/ 160. $000 \mathrm{DM}$ jedoch wieder einführen. (174)

Diese Sachlage veranlaßte den Bundesgesetzgeber, mit dem Gesetz zur Änderung des Gemeindefinanzreformgesetzes vom 27. Dezember 1971 (175) die Höchstbeträge endgültig auf zu versteuernde Einkommensbeträge von 16.000/ 32. 000 DM festzusetzen. Damit entscheiden seit dem 1.1.1972 die Einkommensteuerzahlungen der Einwohner einer Gemeinde, die aus diesem Bereich der Einkommensteuerbemessungsgrundlage stammen, über die Höhe, in der die entsprechende Gemeinde an $14 \%$ des Einkommensteueraufkommens ihres Landes nach der Zerlegung beteiligt wird.

2. Die Beteiligung von Bund und Ländern am Gewerbesteueraufkommen der Gemeinden in Form einer Gewerbesteuerumlage

Die Finanzreform von 1969 schafft die Möglichkeit, daß "Bund und Länder . . durch eine Umlage an dem Aufkommen der Gewerbesteuer beteiligt werden"(176) können. Von dieser Kann-Vorschrift macht das Gemeindefinanzreformgesetz Gebrauch. Es sieht vor, daß die Gemeinden einen Teil ihres Gewerbesteueraufkommens in Form einer Umlage an Bund und Länder abzutreten haben. (177) Die Gewerbesteuerumlage beträgt für jede einzelne Gemeinde $120 \%$ der Grundbeträge (178) der Gewerbesteuer nach Ertrag und Kapital. (179) Das Aufkommen der Gemeinden aus der Lohnsummensteuer wird nicht zur Berechnung der Gewerbesteuerumlage herangezogen. Da die Gewerbesteuerumlage auf der Basis der Grundbeträge, nicht aber auf der Basis des Ist-Aufkommens aus der Gewerbesteuer berechnet wird, wirken sich Hebesatzänderungen der Gemeinden nicht auf die Höhe der von ihnen abzuführenden Gewerbesteue rumlage aus.

Die Beteiligung von Bund und Ländern am Gewerbesteueraufkommen dient dem Ausgleich des Einnahmenverlustes, der ihnen durch die Beteiligung der Gemeinden an der Einkommensteuer entsteht. Die Gewerbesteuerumlage 
soll den Gemeinden $40 \%$ ihres Ist-Aufkommens aus der Gewerbesteuer entziehen. Dies ist dann der Fall, wenn eine Gemeinde keine Lohnsummensteuer erhebt und für die Gewerbeertragsteuer und Gewerbekapitalsteuer Hebesätze von jeweils $300 \%$ anwendet. (180) Damit ist die Gewerbesteuerumlage so be messen, daß sie die Einnahmenerhöhung der Gemeinden (Einnahmenverlust von Bund und Ländern) infolge der Beteiligung der Gemeinden an der Einkommensteuer nicht vollständig ausgleicht. Auf diese Weise wird die mit der Gemeindefinanzreform angestrebte Verstärkung der kommunalen Finanzmasse erreicht. (181)

3. Die Aufhebung des Gewerbesteuerausgleichs zwischen Wohn- und Betriebsgemeinden

Nach der Auffassung der Bundesregierung entfällt "durch die Beteiligung der Gemeinden an den Steuerleistungen ihrer Einwohner .. das bisherige Bedürfnis nach Gewerbesteuerausgleichsleistungen zwischen Betriebs - und Wohngemeinden. "(182) Der Bundesgesetzgeber ging bei der Verabschiedung des Gemeindefinanzreformgesetzes und insbesondere bei der Festsetzung der Gewerbesteuerumlage in Höhe von $40 \%$ des Gewerbesteueraufkommens (183) davon aus, daß die Länder den der ausschließlichen Landesgesetzgebung unterstehenden Gewerbesteuerausgleich zum 1.1.1970 aufheben würden. Denn "ohne diese kompensierende Maßnahme würden sich zu starke Einbußen bei den gewerbesteuerstarken Gemeinden ergeben. "(184) Die Beseitigung des Gewerbesteuerausgleichs erschien dem Bundesgesetzgeber in erster Linie erforderlich, um eine Abschwächung des zwischen großen und kleinen Gemeinden existierenden Steuerkraftgefälles durch die Gemeindefinanzreform zu verhindern. Darüberhinaus sollte diese Maßnahme aber auch die Nivellierung der horizontalen Steuerkraftunterschiede in Grenzen halten.

Ohne Zugeständnisse der Länder in der Frage des Gewerbesteuerausgleichs wäre das Gemeindefinanzreformgesetz in der vorliegenden Fassung vom Bundestag nicht verabschiedet worden. Deshalb haben die Länder noch vor Verabschiedung des Gesetzes die Beseitigung des Gewerbesteuerausgleichs zwischen Betriebs- und Wohngemeinden in Aussicht gestellt (185) und ihn nach Verabschiedung des Gesetzes tatsächlich aufgehoben.(186)

IV. Die Auswirkung der Gemeindefinanzreform von 1969 auf die vertikale Streuung der Steuerkraft der Gemeinden im Jahr 1974

1. Die Verände rung der vertikalen Streuung der Steuerkraft der Gemeinden im Jahr 1974 durch die Gemeindefinanzreform unter Vernachlässigung des Gewerbesteuerausgleichs zwischen Wohn- und Betriebsgemeinden

\subsection{Das methodische Vorgehen}

In diesem Abschnitt der empirischen Untersuchung soll ermittelt werden, ob und gegebenenfalls in welchem Ausmaß die vertikale Streuung der Steuerkraft der Gemeinden im Jahr 1974 durch die oben beschriebenen Maßnahmen der 
Gemeindefinanzreform verändert wird. Um diese Auswirkungen der Gemeindefinanzreform zu berechnen, muß die tatsächliche Verteilung der kommunalen Steuerkraft (187) auf die einzelnen Gemeindegrößenklassen im Jahr 1974 mit einer fiktiven Verteilung der Steuerkraft vergleichen werden. (188) Die fiktive Verteilung muß angeben, wie sich im Jahr 1974 die Steuerkraft der Gemeinden auf die einzelnen Größenklassen verteilt hätte, wenn 1969 keine Gemeindefinanzreform durchgeführt worden wäre und somit das kommunale Steuersystem des Jahres 1974 dieselbe Struktur wie das des Jahres 1969 besitzen würde. Die vertikale Verteilung der kommunalen Steuerkraft ohne Finanzreform wäre 1974 bestimmt worden

- von der Verteilung der Realsteuerkraft der Gemeinden auf die einzelnen Größenklassen im Jahr 1974 und

- von dem vertikalen Umverteilungseffekt des Gewerbesteuerausgleichs zwischen Wohn- und Betriebsgemeinden, der ohne Gemeindefinanzreform auch im Jahr 1974 durchgeführt worden wäre.

Da der Gewerbesteuerausgleich seit dem 1.1.1970 nicht mehr durchgeführt wird, existieren auch keine statistischen Unterlagen über den Umverteilungseffekt, den er $1974 \mathrm{zwischen} \mathrm{den} \mathrm{Gemeinden} \mathrm{verschiedener} \mathrm{Größenklassen}$ bewirkt hätte. Deswegen kann die vertikale Steuerkraftverteilung, die 1974 ohne Gemeindefinanzreform vorzufinden gewesen wäre, nicht mit eindeutiger Sicherheit berechnet werden. Nur über die Verteilung der Realsteuerkraft der Gemeinden auf die einzelnen Größenklassen liegen für 1974 statistische Daten vor. Deshalb wird diese Verteilung auf einer ersten Stufe der empirischen Untersuchung als Annäherung an die vertikale Steuerkraftverteilung ohne Finanzreform im Jahr 1974 betrachtet und als Vergleichsverteilung für die tatsächliche Verteilung der gemeindlichen Steuerkraft auf die einzelnen Größenklassen des Jahres 1974 benutzt. Die Diskrepanz zwischen der vertikalen Verteilung der gemeindlichen Steuerkraft und der der Realsteuerkraft kann, mit der oben gemachten Einschränkung, als Auswirkung der Gemeindefinanzreform auf das Steuerkraftgefälle zwischen Gemeinden unterschiedlicher Größe bezeichnet werden.

Diese Diskrepanz erlaubt damit vorläufige Aussagen über

- die Verstärkung der kommunalen Finanzkraft durch die Gemeindefinanzreform und ihre Verteilung auf die einzelnen Größenklassen,

- den Abbau von Steuerkraftunterschieden zwischen Gemeinden verschiedener Größenklassen durch die Gemeindefinanzreform (vertikaler Nivellierungseffekt),

- die durch die Gemeindefinanzreform bewirkte Steuerkraftverschiebung zwischen den Gemeindegrößenklassen (vertikaler Umverteilungseffekt).

Diese Fragen werden anschließend in den Tabellen 12 a - 12c untersucht.

1.2. Die Verstärkung der Finanzkraft der Gemeinden im Jahr 1974 durch die Gemeindefinanzreform

Ein Ziel der Gemeindefinanzreform von 1969 ist die Verstärkung der Finanz- 
kraft der Gemeinden. Dieses Ziel soll dadurch erreicht werden, daß den Gemeinden im Zuge der Gewerbesteuerumlage weniger Finanzmittel entzogen werden, als ihnen in Form des Gemeindeanteils an der Einkommensteuer zugeführt werden. (189) Wie Tabelle 12a zeigt, wird dieses quantitative Ziel der Gemeindefinanzreform erreicht. Im Jahr 1974 übersteigt der Gemeindeanteil an der Einkommensteuer die Gewerbesteuerumlage der Gemeinden um 6,56 Mrd. DM (Spalte 6). Damit bewirkt die Gemeindefinanzreform, daß die tatsächliche Steuerkraft der Gemeinden um 36,5\% über derjenigen liegt, die sie ohne Finanzreform im Jahr 1974 aufzuweisen gehabt hätten. (190)

Über die Verteilung der zusätzlichen Steuereinnahmen der Gemeinden auf die einzelnen Größenklassen gibt Tabelle 12b in Spalte 14 nähere Auskunft. Die gemeindliche Steuerkraft der einzelnen Größenklassen wird durch die Gemeindefinanzreform ziemlich gleichmäßig angehoben. Lediglich für drei Gemeindegrößenklassen weicht der reformbedingte Anstieg der kommunalen Steuerkraft auffällig von der durchschnittlichen Steuerkraftverstärkung ab. Überdurchschnittlich steigt mit jeweils rund $45 \%$ die Steuerkraft der Gemeinden mit weniger als 3.000 Einwohnern und der Gemeinden mit 200. 000 bis unter 500.000 Einwohnern. Dagegen liegt die tatsächliche Steuerkraft der Gemeinden der obersten Größenklasse nur um 31,5\% über ihrer Realsteuerkraft. Die Gemeinden mit mehr als 500.000 Einwohnern erfahren also durch die Gemeindefinanzreform im Durchschnitt eine weit unterdurchschnittliche Verstärkung ihrer Finanzkraft im Jahr 1974.

In diesen Abweichungen der reformbedingten Steuerkraftverstärkung dreier Gemeindegrößenklassen von der durchschnittlichen Steuerkraftverstärkung schlägt sich der Einfluß der Strukturreform des kommunalen Steuersystems (191) auf die vertikale Streuung der kommunalen Steuerkraft nieder. Dieser Einfluß der Strukturreform wird uns im folgenden eingehender beschäftigen.

1.3. Die Abschwächung der Steuerkraftunterschiede zwischen den Gemeinden unterschiedlicher Größenklassen im Jahr 1974 durch die Gemeinde finanzreform von 1969

Der Nivellierungseffekt der Gemeindefinanzreform wird deutlich, wenn man die vertikale Streuung der tatsächlichen Steuerkraft der Gemeinden (Tabelle 12b, Spalte 9) mit der vertikalen Streuung der Realsteuerkraft (Tabelle 12b, Spalte 2) vergleicht.

Danach läßt die Gemeindefinanzreform die relative Steuerkraftposition der Gemeinden von sechs Größenklassen so gut wie unverändert. Nur für drei Größenklassen weicht die relative durchschnittliche Steuerkraft nach der Gemeindefinanzreform bemerkenswert von ihrer relativen durchschnittlichen Realsteuerkraft des Jahres 1974 ab. Bei diesen Größenklassen handelt es sich um jene, deren Gemeinden durch die Gemeindefinanzreform eine über - bzw. unterdurchschnittliche Verstärkung ihrer Finanzkraft erfahren. Durch die Gemeindefinanzreform wird die durchschnittliche Steuerkraft der 
Tabelle 12a Die Steuerkraft der Gemeinden der Bundesrepublik Deutschland nach Gemeindegrößenklassen im Jahr 1974

\begin{tabular}{|c|c|c|c|c|c|c|c|}
\hline \multicolumn{2}{|c|}{ Gemeindegrößenklassen } & $\begin{array}{l}\text { Einwohner } \\
\text { am } 30.6 .74 \\
\text { in } 1000 \\
\end{array}$ & $\begin{array}{l}\text { Realsteuer- } \\
\text { kraft } 1 \text { ) } \\
\text { in } 1000 \mathrm{DM} \\
\end{array}$ & $\begin{array}{l}\text { Gewerbesteuer- } \\
\text { umlage } \\
\text { in } 1000 \mathrm{DM}\end{array}$ & $\begin{array}{l}\text { Gemeindeanteil an } \\
\text { d.Einkommensteuer } \\
\text { in } 1000 \mathrm{DM}\end{array}$ & $\begin{array}{l}\text { Gemeindliche } \\
\text { Steuerkraft } \\
\text { in } 1000 \mathrm{DM}\end{array}$ & $\begin{array}{l}\text { Verstärkung } \\
\text { d.Steuerkraft } 3 \text { ) } \\
\text { in } 1000 \mathrm{DM}\end{array}$ \\
\hline & & \begin{tabular}{|l|}
1 \\
\end{tabular} & 2 & 3 & 4 & 5 & 6 \\
\hline $0-<$ & 3.000 & 8178 & 1260148 & 461239 & 1028711 & 1827701 & 567472 \\
\hline $3.000-<$ & 5.000 & 3604 & 748767 & 296573 & 578334 & 1030528 & 281761 \\
\hline $5.000-<$ & 10.000 & 6900 & 1607562 & 664815 & 1256904 & 2199651 & 592089 \\
\hline $10.000-<$ & 20.000 & 8157 & 2054667 & 835114 & 1591757 & 2811310 & 756643 \\
\hline $20.000-<$ & 50.000 & 9315 & 2742429 & 1123482 & 2088889 & 3707836 & 965407 \\
\hline $50.000-<$ & 100.000 & 5472 & .1830931 & 781675 & 1434266 & 2483522 & 652591 \\
\hline $100.000-<$ & 200.000 & 4743 & 1653457 & 650455 & 1253385 & 2256387 & 602930 \\
\hline $200.000-<$ & 500.000 & 4888 & 1605121 & 658365 & 1388779 & 2335535 & 730414 \\
\hline$\geq$ & $500.000^{4)}$ & 10786 & 4487407 & 1836317 & 3250469 & 5901560 & 1414152 \\
\hline insgesamt & & 62043 & 17990489 & 7308035 & 13871494 & 24554030 & 6563459 \\
\hline
\end{tabular}

1) Grundbeträge der Grundsteuer A und B sowie der Gewerbesteuer nach Ertrag und Kapital, multipliziert mit bundeseinheitlichen (fiktiven) Hebesätzen.

2) Realsteuerkraft + Gemeindeanteil an der Einkommensteuer ./. Gewerbesteuerumlage.

3) Gemeindeanteil an der Einkommensteuer ./. Gewerbesteuerumlage.

4) Einschließlich Hamburg, Bremen und Berlin.

Quelle: Berechnet nach

Statistisches Bundesamt, Finanzen und Steuern, Reihe 9, Realsteuervergleich 1974, Stuttgart, Mainz,

Dezember 1975, S. 24 und 106. 
Tabelle 12b Die vertikale Streuung der Steuerkraft der Gemeinden im Jahr 1974

\begin{tabular}{|c|c|c|c|c|c|c|c|c|c|c|c|c|c|c|c|c|c|c|}
\hline \multicolumn{2}{|c|}{$\begin{array}{l}\text { Gemeindegrößen- } \\
\text { klassen }\end{array}$} & \multicolumn{3}{|c|}{ Realsteuerkraft } & \multirow{2}{*}{$\begin{array}{l}\text { Gewerbe- } \\
\text { steuer- } \\
\text { lumlage } \\
\text { |nro Kopf }\end{array}$} & \multicolumn{3}{|c|}{$\begin{array}{l}\text { Gemeindeanteil an } \\
\text { d.Einkommensteuer }\end{array}$} & \multicolumn{3}{|c|}{$\begin{array}{l}\text { Gemeindliche } \\
\text { Steuerkraft }\end{array}$} & \multicolumn{4}{|c|}{ Verstärkung der Steuerkraft } & \multicolumn{3}{|c|}{$\begin{array}{l}\text { Steuereinnahmen der } \\
\text { Gemeinden } 1974 \text { (Ist) }\end{array}$} \\
\hline & & $\begin{array}{l}\text { pro } \\
\text { Kopf }\end{array}$ & $a^{1)}$ & $b^{1)}$ & & \begin{tabular}{|l} 
pro \\
Kopf
\end{tabular} & $a^{1)}$ & $b^{1)}$ & \begin{tabular}{|l|} 
pro \\
Kopf
\end{tabular} & $a^{1)}$ & $b^{1)}$ & $\begin{array}{l}\text { pro } \\
\text { Kopf }\end{array}$ & $a^{1)}$ & $i^{1)}$ & $\begin{array}{l}\text { in \% der } \\
\text { Realst.-Kraft }\end{array}$ & \begin{tabular}{|l|} 
pro \\
Kopf
\end{tabular} & $a^{1)}$ & $b^{1)}$ \\
\hline & & 1 & 2 & 3 & 4 & 5 & 6 & 7 & 8 & 9 & 10 & 11 & 12 & 13 & 14 & 15 & 16 & 17 \\
\hline $0-<$ & 3.000 & 154,1 & 53,1 & 100,0 & 56,4 & 125,8 & 56,3 & 100,0 & 223,5 & 56,5 & 100,0 & 69,4 & 65,6 & 100,0 & 45,0 & 256,2 & 50,2 & 100,0 \\
\hline $3.000-<$ & 5.000 & 207,8 & 71,7 & 134,8 & 82,3 & 50,5 & 71,8 & 127,6 & 85,9 & 72,2 & 127,9 & 78,2 & 73,9 & 112,7 & 37,6 & 327,5 & 64,2 & 127,8 \\
\hline $5.000-<$ & 10.000 & 233,0 & 80,3 & 151,2 & 96,4 & 182,2 & 81,5 & 144,8 & 318,8 & 80,5 & 142,6 & 85,8 & 81,1 & 123,6 & 36,8 & 363,0 & 71,2 & 141,7 \\
\hline $10.000-<$ & 20.000 & 251,9 & 86,9 & 163,5 & 102,4 & 195,1 & 87,3 & 155,1 & 344,6 & 87,1 & 154,2 & 92,8 & 87,7 & 133,7 & 36,8 & 396,4 & 77,7 & 154,7 \\
\hline $20.000-<$ & 50.000 & 294,4 & 101,5 & 191,0 & 120,6 & 224,3 & 100,3 & 178,3 & 398,1 & 100,6 & 178,1 & 103,6 & 97,9 & 149,3 & 35,2 & 476,4 & 93,4 & 185,9 \\
\hline $50.000-<$ & 100.000 & 334,61 & 115,4 & 217,1 & 142,9 & 262,1 & 117,2 & 208,3 & 453,9 & 114,7 & 203,1 & 119,3 & 112,8 & 171,9 & 35,7 & 576,2 & 113,0 & 224,9 \\
\hline त्فे $00.000-<$ & 200.000 & 348,61 & 120,2 & 226,2 & 137,1 & 264,3 & 118,2 & 210,1 & 475,7 & 120,2 & 212,8 & 127,1 & 120,1 & 183,1 & 36,5 & 641,7 & 125,8 & 250,5 \\
\hline $00.000-<$ & 500.000 & 328,4 & 113,2 & 213,1 & 134,7 & 284,1 & 127,1 & 225,8 & 477,8 & 120,7 & 213,8 & 149,4 & 141,2 & 215,3 & 45,5 & 666,4 & 130,6 & 260,1 \\
\hline$y_{-1}^{3} \quad \leq$ & $500.000^{2)}$ & 416,0 & 143,4 & 270,0 & 170,3 & 301,4 & 134,8 & 239,6 & 547,2 & 138,3 & 244,8 & 131,1 & 123,9 & 188,9 & 31,5 & 810,7 & 158,9 & 316,4 \\
\hline ginsgesamt & & 290,01 & 100,0 & 188,2 & 117,8 & 223,6 & 100,0 & 177,7 & 395,8 & 100,0 & 177,1 & 105,8 & 100,0 & 152,4 & 36,5 & 510,1 & 100,0 & 199,1 \\
\hline
\end{tabular}

d) $\mathrm{a}=$ in \% des Bundesdurchschnitts

$\mathrm{b}=$ in \% der kleinsten Größenklasse.

$\vec{z}$ 어

ه $\overrightarrow{\dot{\phi}}$ Variationskoeffizienten:

مै $\dot{0}$ हो) für die Realsteuerkraft 0,264

(8) für die gemeindliche Steuerkraft 0,252

C) für die Ist-Steuereinnahmen der Gemeinden 0,340
2) Einschließlich Hamburg, Bremen und Berlin (West).

Quelle: Berechnet nach

Statistisches Bundesamt,

Finanzen und Steuern, Reihe 9 ,

Realsteuervergleich 1974,

Stuttgart, Mainz, Dezember 1975

S. 22, 23, 24 und 106. 
Gemeinden mit weniger als 3.000 Einwohnern von $53,1 \%$ auf $56,5 \%$ des Bundesdurchschnitts angehoben, die der Gemeinden mit mehr als 500. 000 Einwohnern sinkt dagegen infolge der Strukturreform von 143,4 \% auf 138,3\% des Bundesdurchschnitts. Die Gemeindefinanzreform scheint also die vertikale Streuung der kommunalen Steuerkraft pro Kopf abzuschwächen. Diesem Nivellierungseffekt wirkt jedoch entgegen, daß die durchschnittliche Steuerkraft der Gemeinden mit 200.000 bis unter 500.000 Einwohnern durch die Strukturreform des kommunalen Steuersystems auf 120, $7 \%$ des Bundesdurchschnitts gegenüber $113,2 \%$ ohne Reform von 1969 ansteigt.

Diese Stärkung der relativen Steuerkraftposition der Gemeinden der zweitobersten Größenklasse verhindert nicht nur einen vertikalen Nivellierungseffekt der Gemeindefinanzreform. Gleichzeitig kommt auf diese Weise eine von der untersten bis zu obersten Größenklasse durchgängige Staffelung der gemeindlichen Steuerkraft pro Einwohner zustande. Ohne Gemeindefinanzreform wäre dagegen die Staffelung der Steuerkraft pro Einwohner bei der zweitobersten Größenklasse durchbrochen worden, deren Gemeinden im Durchschnitt eine geringere Realsteuerkraft pro Einwohner aufweisen als die Gemeinden der nächstunteren Größenklasse. Mit dieser Korrektur wird die Eignung der Staffelung der Steuerkraft pro Kopf nach der Gemeindegröße als Instrument zur Abgeltung von Spillover-Effekten verbessert. (192)

Der Vergleich der Variationskoeffizienten für die gemeindliche Steuerkraft pro Kopf und für die Realsteuerkraft pro Kopf der einzelnen Größenklassen zeigt das geringe Ausmaß des vertikalen Nivellierungseffektes der Gemeindefinanzreform. Für die Realsteuerkraft beträgt der Variationskoeffizient im Jahr 1974 0,264, für die gemeindliche Steuerkraft des Jahres 1974 nur geringfügig weniger, nämlich 0,252 .

Die Gemeindefinanzreform von 1969 hat nur eine minimale Abschwächung der Steuerkraftunterschiede zwischen den Gemeinden unterschiedlicher GröBe bewirkt. Damit scheint also das von der Bundesregierung mit der Reform verfolgte Ziel, die vertikale Streuung der gemeindlichen Steuerkraft unverändert zu lassen, weitgehend verwirklicht worden zu sein. Dieses vorläufige Ergebnis der Untersuchung muß aber weiter unten (193) durch die Berücksichtigung des Nivellierungseffektes des Gewerbesteuerausgleichs ergänzt und möglicherweise modifiziert werden. Außerdem sagt die Feststellung, daß dieses Ziel der Gemeindefinanzreform tatsächlich erreicht zu sein scheint, noch nichts über die Vereinbarkeit des angestrebten und erreichten Zustandes mit dem regionalpolitischen Zielsystem aus. Auch die regionalpolitische Beurteilung der vertikalen Streuung der gemeindlichen Steuerkraft des Jahres 1974 als politisch gewolltes Ergebnis der Gemeindefinanzreform erfolgt weiter unten. (194)

1.4. Die Umverteilung der Steuerkraft zwischen den Gemeinden unterschiedlicher Größe im Jahr 1974 durch die Gemeindefinanzreform von 1969

Ein vertikaler Umverteilungseffekt der Gemeindefinanzreform liegt dann vor, wenn die den Gemeinden insgesamt zur Verfügung stehende Finanzmasse des 
Tabelle 12c Die Umverteilungswirkung der Gemeindefinanzreform für das Jahr 1974 ohne Berücksichtigung des Gewerbesteuerausgleichs

\begin{tabular}{|c|c|c|c|c|c|c|}
\hline \multirow{2}{*}{$\begin{array}{l}\text { Gemeindegrößen- } \\
\text { klassen }\end{array}$} & \multicolumn{2}{|c|}{ Realsteuerkraft 1974} & \multirow{2}{*}{$\begin{array}{l}\text { fiktive Verteilung } \\
\text { d.gemeindl. Steuer- } \\
\text { kraft 2) }\end{array}$} & \multirow{2}{*}{\begin{tabular}{|c|}
$\mid \begin{array}{l}\text { tats. Verteilung } \\
\text { der gemeindlichen } \\
\text { Steuerkraft }\end{array}$ \\
in $1000 \mathrm{D} \mathrm{M}$ \\
\end{tabular}} & \multicolumn{2}{|c|}{ (Umverteilungsmasse 3) } \\
\hline & in $1000 \mathrm{DM}$ & a1) & & & in $1000 \mathrm{DM}$ & b1) \\
\hline$\square \quad 0-<3.000$ & 1260148 & 7,00 & 1718782 & 1827701 & +108919 & +6.3 \\
\hline$\sum 3.000-<\quad 5.000$ & 748767 & 4,16 & 1021448 & 1030528 & +9080 & $+0,9$ \\
\hline $5.000-<10.000$ & 1607562 & 8,94 & 2195130 & 2199651 & +4521 & $+0,2$ \\
\hline $0.000-<20.000$ & 2054667 & 11,42 & 2804070 & 2811310 & +7240 & $+0,3$ \\
\hline $20.000-<\quad 50.000$ & 2742429 & 15,24 & 3742034 & 3707836 & -34198 & $-0,9$ \\
\hline$\$ 0.900-<100.000$ & 1830931 & 10,18 & 2499600 & 2483522 & -16078 & $-0,6$ \\
\hline 190त्रि00-<200.000 & 1653457 & 9,19 & 2256515 & 2256387 & $-\quad 128$ & 0,0 \\
\hline ते & 6092528 & 33,87 & 8316450 & 8237095 & -79355 & $-1,0$ \\
\hline $\begin{array}{l}\text { ingsgesamt } \\
\text { nactipichtlich: }\end{array}$ & 17990489 & 100,00 & 24554030 & 24554030 & $\begin{array}{l}+129760 \\
-129759\end{array}$ & ${ }_{-0,5}^{+}$ \\
\hline $200.000-<500.000$ & 1605121 & 8,92 & 2190219 & 2335535 & +145316 & $+6,6$ \\
\hline $\overrightarrow{\vec{N}} \varphi \geq 500.000$ & 4487407 & 24,94 & 6123775 & 5901560 & -222215 & $-3,6$ \\
\hline $\begin{array}{l}\text { irasgesamt } \\
\circ \infty\end{array}$ & 17990489 & 99,99 & 24551573 & 24554030 & $\begin{array}{r}+275076 \\
-272619\end{array}$ & $+1,1$ \\
\hline
\end{tabular}

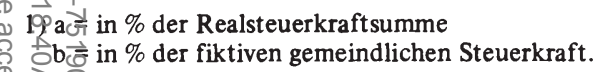

( ) Demeindliche Steuerkraftsumme in Höhe von 24,554 Mrd. DM wird gemäß den Prozentsätzen aus Spalte 2 auf die einzelnen Größenklassen verteilt.

3) Differenz zwischen Spalte 4 und Spalte 3. 
Jahres 1974 tatsächlich anders auf die einzelnen Größenklassen verteilt ist, als dies ohne die Reform der Struktur des Gemeindesteuersystems von 1969 der Fall gewesen wäre. In Höhe der Differenz der tatsächlichen und der fiktiven Verteilung der kommunalen Steuerkraft findet durch die Gemeindefinanzreform eine Steuerkraftumverteilung statt. Ihrer Berechnung dient die Tabelle 12c, wobei wiederum der Umverteilungseffekt des Gewerbesteuerausgleichs zwischen Wohn- und Betriebsgemeinden vernachlässigt wird.

Der Umverteilungseffekt der Gemeindefinanzreform kann nicht durch eine direkte Gegenüberstellung der tatsächlichen Steuerkraft der einzelnen Ge meindegrößenklassen und ihrer Realsteuerkraft ermittelt werden. Die Finanzreform von 1969 verändert ja nicht nur die Struktur des kommunalen Steuersystems, sondern sorgt zugleich für eine nicht unerhebliche Erhöhung der gesamten Steuerkraft der Gemeinden. Dieser Niveaueffekt der Gemeindefinanzreform muß eliminiert werden, wenn man den durch die Strukturreform des kommunalen Steuersystems bewirkten Umverteilungseffekt berechnen will. Dies geschieht für das Jahr 1974 in Tabelle 12c in der Weise, daß die Summe der gemeindlichen Steuerkraft in Höhe von 24,55 Mrd. DM so auf die einzelnen Größenklassen verteilt wird, wie sich die Realsteuerkraftsumme des Jahres 1974 auf die einzelnen Größenklassen verteilt. (195) Diese fiktiven Steuerkraftwerte geben an, in welcher Höhe 1974 bei gleicher Steueranspannung in den einzelnen Größenklassen Steuereinnahmen angefallen wären, wenn im Zuge der Gemeindefinanzreform ausschließlich eine für alle Größenklassen prozentual gleich starke Erhöhung der Steuerkraft um 36, 5 \% vorgenommen worden wäre. Die Abweichung zwischen den fiktiven und den tatsächlichen Steuerkraftwerten der einzelnen Größenklassen resultiert daraus, daß dank der Strukturreform des kommunalen Steuersystems die Steuerkraftverstärkung der einzelnen Größenklassen vom Durchschnittssatz von $36,5 \%$ abweicht.

Durch die Reform der Struktur des kommunalen Steuersystems werden im Jahr 1974 rund 130 Mill. DM oder 0,5\% der gesamten kommunalen Steuerkraft zugunsten der Gemeinden mit weniger als 20.000 Einwohnern umverteilt (Spalte 5). Quantitativ bedeutend ist diese Steuerkraftumverteilung allerdings nur für die Gemeinden der untersten Größenklasse. Ihre tatsächliche Steuerkraft ist um 109 Mill. DM oder 6, 3 \% größer als die Steuerkraft, die sie bei ausschließlicher Finanzkraftverstärkung um 36,5\% aufweisen würden. Den begünstigten Gemeinden stehen die Gemeinden mit mehr als 20.000 Einwohnern gegenüber. Ihre Steuerkraft liegt 1974 um rund 130 Mill. DM unter derjenigen, die sie bei unveränderter Struktur des kommunalen Steuersystems besitzen würden. Nach diesen Berechnungen ist also das Ziel der Gemeindefinanzreform, eine Steuerkraftumverteilung zwischen den Gemeindegrößenklassen möglichst zu vermeiden, weitgehend erreicht worden.

In Tabelle 12c sind die beiden obersten Größenklassen zu einer einzigen GröBenklasse mit Gemeinden mit mehr als 200.000 Einwohnern zusammengefaßt worden. Dadurch wird ein wichtiger Umverteilungseffekt der Strukturreform verdeckt. Dank der Beteiligung der Gemeinden an der Einkommensteuer bei gleichzeitigem Entzug eines quantitativ geringeren Teils ihres 
Gewerbesteueraufkommens liegt die tatsächliche Steuerkraft der Gemeinden mit 200. 000 bis unter 500.000 Einwohnern rund 145 Mill. DM oder 6,6\% über der Steuerkraft, die sie 1974 ohne Strukturreform aber mit Finanzkraftverstärkung aufweisen würden. Dieser Umverteilungseffekt der Gemeindefinanzreform stärkt damit die Einnahmenposition einer Gruppe von Großstädten, erweitert ihre Attrahierungsmöglichkeiten und fördert die Zuwanderung mobiler Ressourcen in diese Städte, wodurch die Entwicklungschancen ländlicher Gebiete und der in ihnen liegenden Kleinstädte u. U. weiter vermindert werden.

Bei der Untersuchung des Nivellierungs - und des Umverteilungseffektes der Gemeindefinanzreform ist bisher die vertikale Verteilung der Realsteuer kraft des Jahres 1974 mit der Steuerkraftverteilung gleichgesetzt worden, die sich 1974 ohne Strukturreform des kommunalen Steuersystems ergeben hätte. Dabei wird vernachlässigt, daß ohne eine strukturelle Verbesserung des kommunalen Steuersystems im Jahr 1969 auch im Jahr 1974 ein Gewerbesteuerausgleich zwischen Wohn - und Betriebsgemeinden durchgeführt worden wäre. Wenn auch das genaue Ausmaß des vertikalen Umverteilungseffektes eines solchen Gewerbesteuerausgleichs für das Jahr 1974 unbekannt ist, kann doch soviel gesagt werden: Auch 1974 hätte der Gewerbesteuerausgleich eine Umverteilung von Gewerbesteuereinnahmen zugunsten der Gemeinden der unteren Größenklassen bewirkt. Die vertikale Streuung der Steuerkraft der Gemeinden im Jahr 1974 wäre demnach ohne Gemeindefinanzreform von 1969 geringer als die vertikale Streuung der Realsteuerkraft 1974. Das legt die Vermutung nahe, daß die hier ausgewiesene geringfügige Steuerkraftumverteilung und Abschwächung der vertikalen Steuerkraftunterschiede nicht auf die Strukturreform des Gemeindesteuersystems, sondern vornehmlich auf die Vernachlässigung des Gewerbesteuerausgleichs zurückzuführen sind. Ließe sich der vertikale Umverteilungseffekt eines Gewerbesteuerausgleichs für das Jahr 1974 abschätzen, käme man möglicherweise zu dem entgegengesetzten Ergebnis. Dann würde sich u. U. zeigen, daß gerade durch die Gemeindefinanzreform eine Steuerkraftumverteilung zu Lasten der Gemeinden der unteren Größenklassen stattfindet und somit die vertikalen Steuerkraftunterschiede verstärkt werdēn.

Im folgenden wird der Versuch unternommen, den Umverteilungseffekt eines Gewerbesteuerausgleichs zwischen Wohn- und Betriebsgemeinden für das Jahr 1974 abzuschätzen, um eine quantitative Vorstellung über die tatsächlichen Auswirkungen der Gemeindefinanzreform von 1969 auf die vertikale Streuung der kommunalen Steuerkraft zu gewinnen.

2. Die Veränderung der vertikalen Streuung der Steuerkraft der Gemeinden im Jahr 1974 durch die Gemeindefinanzreform unter Berücksichtigung des Gewerbesteuerausgleichs zwischen Wohn- und Betriebsgemeinden

2.1. Der fiktive Gewerbesteuerausgleich zwischen Wohn- und Betriebsge meinden im Jahr 1974

Um abzuschätzen, welchen vertikalen Umverteilungseffekt der Gewerbesteuerausgleich zwischen Wohn- und Betriebsgemeinden bewirkt hätte, wenn er auch 
1974 durchgeführt worden wäre, müssen einige Annahmen über das vermutliche Ausgleichsvolumen und dessen Verteilung auf die einzelnen Gemeindegrößenklassen gemacht werden. Dazu sind einige Vorüberlegungen erforderlich.

2.1.1. Bestimmungsfaktoren des Volumens des Gewerbesteuerausgleichs zwischen Wohn- und Betriebsgemeinden

Bis zum 31.12.1969 hatte die Gemeinde, in der ein Arbeitnehmer mit Wohnsitz in einer anderen Gemeinde beschäftigt war, der Wohnsitzgemeinde einen Gewerbesteuerausgleichszuschuß zu überweisen. Diese Ausgleichszahlung der Betriebsgemeinde an die Wohngemeinde betrug grundsätzlich $50 \%$ des Gewerbesteueraufkommens pro Arbeitnehmer in der Betriebsgemeinde, wobei bei der Berechnung des Gewerbesteueraufkommens landeseinheitliche Hebesätze zugrunde gelegt wurden. In dieser Höhe wurden die Wohngemeinden aber nur dann am Gewerbesteueraufkommen der Betriebsgemeinden beteiligt, wenn der Ausgleichszuschuß einen länderweise unterschiedlich hohen Höchstbetrag nicht überschritt. Waren dagegen die $50 \%$ des Gewerbesteueraufkommens pro Arbeitnehmer der Betriebsgemeinde größer als der Höchstbetrag, erhielt die Wohngemeinde für jeden Pendler lediglich den Höchstbe trag als Ausgleichszahlung und damit weniger als die Hälfte des Gewerbesteueraufkommens pro Arbeitnehmer der Betriebsgemeinde. (196)

Die Existenz der Höchstbeträge für die Gewerbesteuerausgleichszahlungen besitzt nun einige Bedeutung für die Frage, welches Ausgleichsvolumen für das Jahr 1974 angenommen werden darf. Bei konstantem Höchstbetrag steigen nämlich im Verlauf der wirtschaftlichen Entwicklung die Ausgleichsbeträge zugunsten der Wohngemeinden schwächer als das Gewerbesteueraufkommen der Betriebsgemeinden. Sobald das Gewerbesteueraufkommen pro Arbeitnehmer der Betriebsgemeinden doppelt so groß wie der Höchstbetrag ist, partizipieren ja die Wohngemeinden nicht mehr an den Zuwächsen des Gewerbesteueraufkommens. Setzt man eine Konstanz aller anderen Bestimmungsfaktoren des Volumens des Gewerbesteuerausgleichs voraus, so folgt aus diesem Zusammenhang, daß bei konstanten Höchstbeträgen langfristig der Anteil der Gewerbesteuerausgleichszahlungen am Gewerbesteueraufkommen zurückgeht. Dieser Effekt der Höchstbeträge läßt sich indessen dadurch abschwächen oder gar aufheben, daß regelmäßig die Höchstbeträge der Aufkommensentwicklung der Gewerbesteuer angepaßt werden. Diese Konsequenz haben die Länder in den 50er und 60er Jahren mehrfach gezogen. (197)

Als weiterer Faktor, der das Volumen des Gewerbesteuerausgleichs und seinen Anteil am Gewerbesteueraufkommen langfristig beeinflußt, müssen Änderungen der kommunalen Gebietsgliederung betrachtet werden. Werden im Zuge einer kommunalen Gebietsreform zahlreiche kleine re Vorortgemeinden in größere Städte eingemeindet, wird das Volumen des Gewerbe steuerausgleichs tendenziell reduziert. Im Fall der Eingemeindung der Wohnsitz - in die Betriebsgemeinde werden ja aus interkommunalen Arbeitskräfte bewegungen intrakommunale Wanderungen, so daß die Notwendigkeit eines Gewerbesteue raus gleichs entfällt. 
Ein dritter wichtiger Bestimmungsfaktor des Volumen des Gewerbesteuerausgleichs ist in der räumlichen Verteilung der Arbeitsplätze und ihrer langfristigen Entwicklung zu sehen. Befindet sich die Wirtschaft eines Landes in einem Prozeß zunehmender, sich selbst verstärkender räumlicher Konzentration wirtschaftlicher Aktivitäten, so wächst das Arbeitsplatzangebot in bereits stark agglomerierten und hoch industrialisierten Regionen (Betriebsgemeinden) stärker als in den ländlichen, schwach industrialisierten Regionen (Wohngemeinden). Durch ein solches regional unterschiedliches Anwachsen des Arbeitsplatzangebots steigt die Zahl der Arbeitskräfte, die in die Ballungsgebiete (Wachstumszentren) pendeln. Dadurch nimmt das Volumen des Gewerbesteuerausgleichs absolut und relativ zu.

Über den konkreten Einfluß, den diese drei Faktoren auf das Volumen des Gewerbesteuerausgleichs und dessen Anteil am Gewerbesteueraufkommen in den letzten Jahren ausgeübt hätten, können hier nur Vermutungen angestellt werden. So ist dem Augenschein nach die räumliche Konzentration der Arbeitsplätze in der Bundesrepublik in den letzten zehn Jahren nicht geringer geworden, so daß auch der Pendlerstrom nicht an Gewicht verloren haben dürfte. Außerdem kann man wohl annehmen, daß die Länder die von ihnen für Gewerbesteuerausgleichszahlungen festgesetzten Höchstbeträge in den letzten Jahren ausreichend an die Entwicklung des Gewerbesteueraufkommens angepaßt hätten. Beides spricht dafür, daß ein Gewerbesteuerausgleich im Jahr 1974 mindestens dasselbe relative Volumen wie in den letzten Jahren vor Inkrafttreten der Gemeindefinanzreform erreicht hätte. Ein gegenläufiger Einfluß kann dagegen der in den letzten Jahren weit fortgeschrittenen kommunalen Gebiets reform zugesprochen werden. Dieser Einfluß hätte möglicherweise eine leichte Verringerung des Anteils des Ausgleichsvolumens am Gewerbesteueraufkommen bewirkt, vielleicht aber auch nur die entgegengesetzte Wirkung einer verstärkten räumlichen Konzentration der Arbeitsplätze kompensiert.

2.1.2. Annahmen über Volumen und Struktur des fiktiven Gewerbesteuer ausgleichs des Jahres 1974

Weil hier nicht eindeutig entschieden werden kann, ob das Volumen des Gewerbesteuerausgleichs 1974 einen größeren, kleineren oder denselben Anteil am Gewerbesteueraufkommen wie im verwendeten Vergleichsjahr er reicht hätte, sind zwei Varianten berechnet worden. In der ersten Variante wird angenommen, daß die Höchstbeträge für die Gewerbesteuerausgleichs zahlungen laufend angepaßt worden wären und daß sich die anderen beiden Bestimmungsfaktoren in ihrem Einfluß auf das relative Volumen des Gewerbesteuerausgleichs weitgehend neutralisiert hätten. Deswegen wird in Variante I das Volumen des Gewerbesteuerausgleichs 1974 mit dem Anteil an der Realsteuerkraftsumme angesetzt, den es im zugrundegelegten Vergleichsjahr aufweist. In der zweiten Variante wird dagegen unterstellt, daß die Höchstbeträge nicht ausreichend angepaßt worden wären und/oder der Einfluß der kommunalen Gebietsreform sehr stark gewesen wäre. Deshalb wird das Volumen des Gewerbesteuerausgleichs mit 1 Prozent der Real- 
steuerkraftsumme des Jahres 1974 und damit erheblich niedriger festgesetzt, als es im Vergleichsjahr war. In beiden Varianten wird außerdem davon aus gegangen, daß sich die für das Jahr 1974 unterstellte Gewerbesteueraus gleichsmasse so auf die einzelnen Gemeindegrößenklassen verteilt, wie sich die Ausgleichsmasse des Vergleichsjahres auf die Größenklassen verteilt. Damit wird vorausgesetzt, daß sich Richtung und Struktur der Pendlerwanderung in den letzten Jahren kaum verändert haben. Nach wie vor sind es dieselben Wohnorte, aus denen Arbeitskräfte in die selben Betriebsorte pendeln.

Die für das Jahr 1974 berechneten fiktiven Gewerbesteuerausgleichszahlungen können demnach deswegen von den Zahlungen, die in einem Gewerbesteuerausgleich 1974 ohne Gemeindefinanzreform tatsächlich geleistet worden wären, abweichen, weil

- die hier gemachten Annahmen über das Volumen des Gewerbesteuerausgleichs 1974 und/oder

- die Annahme über die Verteilung des geschätzten Ausgleichsvolumens auf die einzelnen Größenklassen

nicht der Wirklichkeit entsprechen. Diese beiden Fehlerquellen verlangen, daß die Ergebnisse der anschließenden Berechnung mit großer Vorsicht interpretiert werden.

Als Grundlage der Schätzung des fiktiven Gewerbesteuerausgleichs 1974 dienen Daten einer steuerstatistischen Sonderuntersuchung des Statistischen Bundesamtes über die "Auswirkungen der geplanten Gemeindefinanzreform"(198), die sich auf das Jahr 1965 beziehen. Nur für dieses Vergleichsjahr liegen Daten vor, die die erforderliche Größenklassengliederung aufweisen und auch die Ausgleichsbeträge der Stadtstaaten und des Saarlandes an Gemeinden anderer Bundesländer enthalten. (199) Im Jahr 1965 beträgt das Volumen des Gewerbesteuerausgleichs zwischen Wohn- und Betriebsgemeinden rund 230 Mill. DM oder 2,25\% der Realsteuerkraftsumme der Gemeinden. Die Verteilung dieser Ausgleichsmasse auf die einzelnen Gemeindegrößenklassen wird in Tabelle $13 a$ in den Spalten 1 und 2 angegeben. Entsprechend dieser Verteilung werden auch die für das Jahr 1974 geschätzten Gewerbesteuerausgleichsmassen auf die einzelnen Größenklassen aufgeteilt.

2.2. Die vertikale Verteilung der Steuerkraft der Gemeinden im Jahr 1974 ohne Gemeindefinanzreform von 1969

Nach den Überlegungen des letzten Abschnitts ist es nun möglich, in Tabelle 13a die Verteilung der kommunalen Steuerkraft auf die einzelnen Gemeindegrößenklassen zu berechnen, die sich vermutlich im Jahr 1974 ohne Gemeindefinanzreform ergeben hätte. Je nach dem unterstellten Volumen des Gewerbesteuerausgleichs erhält man eine andere vertikale Verteilung der kommunalen Steuerkraft. 
2.2.1. Die vertikale Streuung der kommunalen Steuerkraft im Jahr 1974 unter Berücksichtigung des Gewerbesteuerausgleichs in der Variante I

Mit Variante I des Gewerbesteuerausgleichs 1974 wird unterstellt, daß das Ausgleichsvolumen mit 2,25\% der Realsteuerkraftsumme dasselbe relative Gewicht besessen hätte, wie im Vergleichsjahr 1965. Trifft diese Annahme zu, wären 1974 rund 400 Mill. DM durch den Gewerbesteuerausgleich zugunsten der Gemeinden mit weniger als 10.000 Einwohnern umverteilt worden. Die geschätzte Verteilung dieser Ausgleichsmasse wird in Tabelle 13a, Spalte 3 aufgeführt. Durch Addition der fiktiven Gewerbesteuerausgleichssalden einer jeden Gemeindegrößenklasse (Spalte 3) und ihrer tatsächlichen Realsteuerkraft im Jahr 1974 erhält man die kommunale Steuerkraft, die sich 1974 unter den gemachten Annahmen ohne Gemeindefinanzreform in den einzelnen Gemeindegrößenklassen eingestellt hätte (Spalte 5). Diese Verteilung der kommunalen Steuerkraft ohne Gemeindefinanzreform weist eine wesentlich geringere vertikale Streuung auf als die Verteilung der Realsteuerkraft des Jahres 1974. Die Pro-Kopf-Werte der Realsteuerkraft ohne fiktiven Gewerbesteuerausgleich schwanken $z$ wischen $53,1 \%$ für die Gemeinden der untersten und 134, 0 \% für die Gemeinden der obersten Größenklasse um den Bundesdurchschnitt (Spalte 14). Die Realsteuerkraft pro Kopf beträgt damit in der obersten Größenklasse durchschnittlich 252,2 \% derjenigen der untersten Größenklasse (Spalte 15). Durch den Gewerbesteuerausgleich in der Variante I verringert sich die Schwankungsbreite der Steuerkraftwerte pro Kopf erheblich. Nach dem Gewerbesteuerausgleich liegen die Steuerkraftwerte pro Kopf nur noch zwischen 66,8 \% und 129,8\% des Bundesdurchschnitts (Spalte 7). Die durchschnittliche Steuerkraft der Gemeinden der obersten GröBenklasse beträgt nur noch 194, 3 \% derjenigen der Gemeinden der untersten Größenklasse. Der Gewerbesteuerausgleich in der Variante I bewirkt, daß der Variationskoeffizient von 0,259 für die Realsteuerkraft pro Kopf auf 0,207 für die fiktive Steuerkraft pro Kopf fällt.

2.2.2. Die vertikale Streuung der kommunalen Steuerkraft im Jahr 1974 unter Berücksichtigung des fiktiven Gewerbesteuerausgleichs in der Variante II

Weniger stark ist annahmegemäß der Umverteilungseffekt des Gewerbesteuerausgleichs in der Variante II. Mit ihr wird angenommen, daß das Ausgleichsvolumen von 2,25\% im Jahr 1965 auf 1,0\% der Realsteuerkraftsumme der Gemeinden im Jahr 1974 gesunken wäre. Spalte 4 in Tabelle 13a zeigt, welche Gewerbesteuerausgleichszahlungen unter den hier gemachten Annahmen im Jahr 1974 auf die einzelnen Größenklassen entfallen wären. Addiert man diese fiktiven Gewerbesteuerausgleichssalden und die tatsächliche Realsteuerkraft der einzelnen Gemeindengrößenklassen, bekommt man die fiktiven Steuerkraftwerte aus Spalte 9. Infolge des unterstellten geringeren Volumens des Gewerbesteuerausgleichs 1974 ist die vertikale Streuung dieser fiktiven Steuerkraftwerte pro Kopf (Spalte 11) wesentlich größer als bei Variante I 
Tabelle 13a Die vertikale Verteilung der Steuerkraft der Gemeinden im Jahr 1974 ohne Gemeindefinanzreform und unter Berücksichtigung des Gewerbesteuerausgleichs

\begin{tabular}{|c|c|c|c|c|c|c|c|c|c|c|c|c|c|c|c|c|}
\hline \multirow{3}{*}{\multicolumn{2}{|c|}{$\begin{array}{l}\text { Gemeindegrößen- } \\
\text { klassen }\end{array}$}} & \multicolumn{2}{|c|}{$\begin{array}{l}\text { Saldo des Gewerbe- } \\
\text { steuerausgleichs } \\
1965\end{array}$} & \multicolumn{2}{|c|}{$\begin{array}{l}\text { fiktiver (hochge- } \\
\text { rechn.) Saldo des } \\
\text { Gewerbesteueraus- } \\
\text { gleichs } 1974\end{array}$} & \multicolumn{4}{|c|}{$\begin{array}{l}\text { Realsteuerkraft } 1974 \text { und fikt. } \\
\text { Gewerbesteuerausgleich } \\
\text { Variante I }\end{array}$} & \multicolumn{4}{|c|}{$\begin{array}{l}\text { Realsteuerkraft } 1974 \text { und fikti- } \\
\text { ver Gewerbesteuerausgleich } \\
\text { Variante II }\end{array}$} & \multicolumn{3}{|c|}{ Realsteuerkraft $1974^{4}$} \\
\hline & & in $1000 \mathrm{DM}$ & $\mathrm{a}^{1}$ & $\begin{array}{l}\text { Variante } \\
\text { in } 1000 \mathrm{DM} \\
\end{array}$ & $\begin{array}{l}\text { Variante } \mathrm{II}^{3} \\
\text { in } 1000 \mathrm{DM}\end{array}$ & in $1000 \mathrm{DM}$ & pro & $b^{1}$ & $c^{1}$ & in $1000 \mathrm{DM}$ & pro & $\mathrm{b}^{1}$ & $c^{1}$ & proop & $\mathrm{b}^{1}$ & $c^{1}$ \\
\hline & & 1 & 2 & 3 & 4 & 5 & 6 & 7 & 8 & 9 & 10 & 11 & 12 & 13 & 14 & 15 \\
\hline$\square \quad 0-<$ & 3000 & +186453 & 80,31 & +325084 & +144482 & 1585232 & 193,8 & 66,8 & 100,0 & 1404630 & 171,8 & 59,2 & 100,0 & 154,1 & 53,1 & 100,0 \\
\hline \$ $000-<$ & 5000 & +30339 & 13,07 & +52905 & +23513 & 801672 & 222,4 & 76,7 & 114,8 & 772280 & 214,3 & 73,9 & 124,7 & 207,8 & 71,7 & 134,8 \\
\hline 5్ర000-< & 10000 & +15368 & $\underline{6,62}$ & +26797 & +11910 & 1634359 & 236,9 & 81,7 & 122,2 & 1619472 & 234,7 & 80,9 & 136,6 & 233,0 & 80,3 & 151,2 \\
\hline $1 థ 000-<$ & 20000 & -11530 & $\overline{5,03}$ & -20361 & $-\quad 9049$ & 2034306 & 249,4 & 86,0 & 128,7 & 2045618 & 250,8 & 86,5 & 146,0 & 251,9 & 86,9 & 163,5 \\
\hline $20000-<$ & 50000 & -35213 & 15,36 & -62176 & -27633 & 2680254 & 287,7 & 99,2 & 148,5 & 2714796 & 291,4 & 100,5 & 169,6 & 294,4 & 101,5 & 191,0 \\
\hline $58000-<$ & 100000 & -42413 & 18,50 & -74885 & -33282 & 1756046 & 320,9 & 110,7 & 165,6 & 1797649 & 328,5 & 113,3 & 191,2 & 334,6 & 115,4 & 217,1 \\
\hline $100000-<$ & 200000 & -32224 & 14,06 & - 56913 & -25295 & 1596544 & 336,6 & 116,1 & 173,7 & 1628162 & 343,3 & 118,4 & 199,8 & 348,6 & 120,2 & 226,2 \\
\hline 웅 $\frac{0}{0} \geq$ & 200000 & $\{-107878$ & 47,06 & -190492 & -84663 & 5902036 & 376,5 & 129,8 & 194,3 & 6007865 & 383,3 & 132,2 & 223,1 & 388,7 & 134,0 & 252,2 \\
\hline ins恼es & & $\begin{array}{l}+232160 \\
-229258^{6}\end{array}$ & $\begin{array}{r}100,00 \\
100,01\end{array}$ & $\begin{array}{l}+404786 \\
-404826\end{array}$ & $\left|\begin{array}{l}+179905 \\
-179922\end{array}\right|$ & 17990449 & 290,0 & 100,0 & 149,6 & 17990472 & 290,0 & 100,0 & 168,8 & 290,0 & 100,0 & 188,2 \\
\hline
\end{tabular}

1) $\underline{\mathrm{a}}=$ 'Anteil an der Gewerbesteuerausgleichsmasse $\overline{\mathrm{b}}=$ in $\%$ des Bundesdurchschnitts

$\mathcal{C}=$ in $\%$ der untersten Größenklasse

ㄱ. $\mathrm{Q}=$ in \% der Realsteuerkraft incl. Gewerbesteuerausgleich.

(2) Die hochgerechnete Ausgleichsmasse beträgt wie 1965 2,25\% der Realsteuerkraftsumme $(2,25 \%$ von $17990489=404786)$. Sie wird auf die einzelnen

Größenklassen gemäß deren Anteil an der Ausgleichsmasse 1965 verteilt.

(8) Bienhochgerechnete Ausgleichsmasse beträgt nur $1 \%$ der Realsteuerkraftsumme ( $1 \%$ von $17990489=179$ 905). Sie wird wie bei Variante I verteilt.
4) Vergl. Tabelle 12b, Spalten 1 - 3.

5) Einschließlich Hamburg, Bremen und Berlin.

6) Die Gewerbesteuerausgleichsmasse 1965 beträgt rund 2,25\% der Realsteuerkraftsumme des Jahres 1965.

Qudlle: Berechnet nach

Hansen, Andreas, Auswirkungen der geplanten Gemeindefinanzreform, Ergebnis der steuerstatistischen Sonderuntersuchungen, in: Wirtschaft und Statistik, hrsg. vom Statistischen Bundesamt, Jg. 1969, Heft 5 (Mai); Stuttgart, Mainz, S. 245 - 252, hier: S. 247, Tab. 1; und

Statistisches Bundesamt, Realsteuervergleich 1974, a.a.O. 
und nur noch wenig geringer als die vertikale Streuung der Realsteuerkraft pro Kopf (Spalte 14). Durch den Gewerbesteuerausgleich der Variante II fällt der Variationskoeffizient lediglich von 0,259 auf 0,236.

Mit den Berechnungen der Tabelle 13a ist diejenige Verteilung der kommunalen Steuerkraft auf die einzelnen Größenklassen geschätzt worden, die sich im Jahr 1974 vermutlich ergeben hätte, wenn 1969 weder eine Reform der Struktur des kommunalen Steuersystems noch eine Aufstockung der Finanzkraft der Gemeinden verwirklicht worden wäre. Damit ist die Grundlage geschaffen, den vertikalen Umverteilungs - und Nivellierungseffekt der Gemeindefinanzreform von 1969 zutreffender abzuschätzen, als dies durch den bloßen Vergleich der hochgerechneten Realsteuerkraft mit der gemeindlichen Steuerkraft des Jahres 1974 (200) möglich ist.

2. 3. Der Umverteilungs - und Nivellierungseffekt der Gemeindefinanzreform bei Berücksichtigung des fiktiven Gewerbesteuerausgleichs 1974 in der Variante I

In Tabelle $13 \mathrm{~b}$ werden der Umverteilungs - und der Nivellierungseffekt der Strukturreform des kommunalen Steuersystems für das Jahr 1974 unter der Annahme eines Gewerbesteuerausgleichs in der Variante I berechnet. Zu diesem Zweck muß wieder der Niveaueffekt der Gemeindefinanzreform eliminiert werden. (201) Deshalb wird die Summe der kommunalen Steuerkraft des Jahres 1974 in Höhe von 24,55 Mrḍ. DM so auf die einzelnen Größenklas sen verteilt, wie sich die Steuerkraft der Gemeinden 1974 ohne Gemeindefinanzreform und mit fiktivem Gewerbesteuerausgleich in der Variante I verteilt hätte. (202) Auf diese Weise erhält man diejenige vertikale Verteilung der kommunalen Steuerkraft, die sich 1974 eingestellt hätte, wenn 1969 keine Strukturreform, sondern ausschließlich eine Finanzkraftverstärkung um $36,5 \%$ durchgeführt worden wäre. Die Differenz zwischen diesen fiktiven Steuerkraftwerten der Spalte 3 und der tatsächlichen gemeindlichen Steuerkraft (Spalte 7) zeigt, in welchem Umfang die Strukturreform des kommunalen Steuersystems im Jahr 1974 eine Steuerkraftumverteilung zwischen den Gemeinden verschiedener Größenklassen bewirkt.

Unter der Voraussetzung, daß 1974 ein Gewerbesteuerausgleich in der Variante I durchgeführt worden wäre, verursacht die Gemeindefinanzreform von 1969 eine vertikale Steuerkraftumverteilung in Höhe von rund $430 \mathrm{Mill}$. DM oder 1, $8 \%$ der Steuerkraftsumme. Diese reformbedingte Steuerkraftumverteilung stärkt aber nicht die Steuerkraftposition der Gemeinden der unteren Größenklassen, sondern geht vielmehr zu ihren Lasten. Die Gemeinden mit weniger als 10.000 Einwohnern weisen danach 1974 eine tatsächliche Steuerkraft auf, die um insgesamt $430 \mathrm{Mill}$. DM niedriger liegt als die Steuerkraft, die sie bei ausschließlicher Finanzkraftverstärkung besessen hätten. Dagegen verfügen 1974 alle Gemeinden mit mehr als 10.000 Einwohnern über eine um 430 Mill. DM höhere Steuerkraft, als ohne Strukturreform des kommunalen Steuersystems der Fall gewesen wäre. Damit würde die Gemeindefinanzreform zu einer erheblichen Verschärfung der vertikalen Streuung der kom- 
Tabelle 13b Die Umverteilungswirkung der Gemeindefinanzreform für das Jahr 1974 unter Berücksichtigung des fiktiven Gewerbesteuerausgleichs 1974 in der Variante I

\begin{tabular}{|c|c|c|c|c|c|c|c|c|c|c|c|c|c|}
\hline & \multicolumn{2}{|c|}{$\begin{array}{l}\text { Realsteuerkraft } \\
1974 \text { und fiktiver Ge- } \\
\text { werbesteuerausgleich } \\
\text { Variante I }\end{array}$} & \multicolumn{4}{|c|}{$\begin{array}{l}\text { fiktive Verteilung der gemeindlichen } \\
\text { Steuerkraft } 1 \text { ) }\end{array}$} & \multicolumn{4}{|c|}{$\begin{array}{l}\text { tatsächliche gemeindliche } \\
\text { Steuerkraft }\end{array}$} & \multicolumn{2}{|c|}{ (Umverteilungsmasse ${ }^{3 \text { ) }}$} \\
\hline & & $\begin{array}{l}\text { Variante I } \\
\text { in } 1000 \mathrm{DM}\end{array}$ & in $\%$ & in $1000 \mathrm{DM}$ & $\begin{array}{l}\text { pro } \\
\text { Kopf }\end{array}$ & $\mathrm{a}^{2)}$ & $b^{2)}$ & in $1000 \mathrm{DM}$ & $\begin{array}{l}\text { pro } \\
\text { Kopf }\end{array}$ & $a^{2)}$ & $b^{2)}$ & in $1000 \mathrm{DM}$ & $c^{2)}$ \\
\hline $\bar{F}$ & & 1 & 2 & 3 & 4 & 5 & 6 & 7 & 8 & 9 & 10 & 11 & 12 \\
\hline $0-<$ & 3.000 & 1585232 & 8,81 & 2163210 & 264,5 & 66,8 & 100,0 & 1827701 & 223,5 & 56,5 & 100,0 & -335509 & $-15,5$ \\
\hline $3.000-<$ & 5.000 & 801672 & 4,46 & 1095110 & 303,9 & 76,8 & 114,9 & 1030528 & 285,9 & 72,2 & 127,9 & - 64582 & $-5,9$ \\
\hline Dे $5.000-<$ & 10.000 & 1634359 & 9,08 & 2229506 & 323,1 & 81,6 & 122,2 & 2199651 & 318,8 & 80,5 & 142,6 & -29855 & $-1,3$ \\
\hline$\frac{C}{2} 10.000-<$ & 20.000 & 2034306 & 11,31 & 2777061 & 340,5 & 86,0 & 128,7 & 2811310 & 344,6 & 87,1 & 154,2 & +34249 & $+1,2$ \\
\hline $20,000-<$ & 50.000 & 2680254 & 14,90 & 3658550 & 392,8 & 99,2 & 148,5 & 3707836 & 398,1 & 100,6 & 178,1 & +49286 & $+1,3$ \\
\hline $50.000-<$ & 100.000 & 1756046 & 9,76 & 2396473 & 438,0 & 110,7 & 165,6 & 2483522 & 453,9 & 114,7 & 203,1 & +87049 & $+3,6$ \\
\hline $100.000-<$ & 200.000 & 1596544 & 8,87 & 2177942 & 459,2 & 116,0 & 173,6 & 2256387 & 475,7 & 120,2 & 212,8 & +78445 & $+3,6$ \\
\hline 党 & $200.000^{4}$ & 5902036 & 32,81 & 8056177 & 514,0 & 129,9 & 194,3 & 8237095 & 525,5 & 132,8 & 235,1 & +180918 & $+2,2$ \\
\hline \multicolumn{2}{|l|}{ 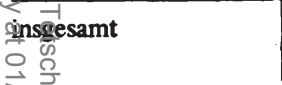 } & 17990449 & 100,00 & 24554029 & 395,8 & 100,0 & 149,6 & 24554030 & 395,8 & 100,0 & 177,1 & $\begin{array}{l}-429946 \\
+429947\end{array}$ & $+1,8$ \\
\hline
\end{tabular}

Ferteilung der Steuerkraftsumme des Jahres 1974 in Höhe von 24,554 Mrd. DM auf die einzelnen Größenklassen gemäß den Anteilswerten aus Spalte 2.

2) $\mathrm{a}_{0}^{\infty}=$ in \% des Bundesdurchschnitts

$\mathrm{b}=$ in \% der untersten Größenklasse

政= in \% der Werte aus Spalte 3.

(3) Differenz zwischen tatsächlicher gemeindlicher Steuerkraft und der Steuerkraft, die die Gemeinden ohne Strukturreform des kommunalen Steuersystems, gber bei Finanzkraftverstärkung aufweisen würden (Werte aus Spalte 3).

正) Einschließlich Hamburg, Bremen und Berlin.

Variationskoeffizienten: a) für die fiktive gemeindliche Steuerkraft 0,207

b) für die tatsächliche gemeindliche Steuerkraft 0,248 . 
munalen Steuerkraft pro Kopf führen. Ohne Gemeindefinanzreform hätten die Steuerkraftwerte pro Kopf 1974 vermutlich zwischen 66, $8 \%$ und 129, $9 \%$ des Bundesdurchschnitts (Spalte 5) gelegen, nach Durchführung der Gemeindefinanzreform liegen sie dagegen tatsächlich zwischen 56,5\% und $132,8 \%$ des Bundesdurchschnitts (Spalte 9). Durch die Gemeindefinanzreform erhöht sich der Variationskoeffizient von 0,207 auf 0,248.

Dieses erhebliche Ausmaß des durch die Gemeindefinanzreform bedingten Steuerkraftumverteilungs - und -differenzierungseffektes hängt von dem hier unterstellten Volumen des fiktiven Gewerbesteuerausgleichs zwischen Wohnund Betriebsgemeinden im Jahr 1974 ab. Die folgenden Berechnungen werden zeigen, ob auch bei Annahme des quantitativ geringeren Gewerbesteuerausgleichs in der Variante II noch festgestellt werden kann, daß durch die Gemeindefinanzreform das Steuerkraftgefälle zwischen den Gemeinden unterschiedlicher Größe verstärkt wird.

2.4. Der Umverteilungs - und Nivellierungseffekt der Gemeindefinanzreform bei Berücksichtigung des fiktiven Gewerbesteuerausgleichs 1974 in der Variante II

In Tabelle $13 \mathrm{c}$ wird berechnet, welchen Einfluß die Gemeindefinanzreform im Jahr 1974 auf die vertikale Streuung der kommunalen Steuerkraft pro Kopf ausübt, wenn man einen Gewerbesteuerausgleich zwischen Wohn- und Betriebsgemeinden in der Variante II zugrundelegt. (203) Auch unter dieser Voraussetzung bewirkt die Strukturreform des kommunalen Steuersystems von 1969 eine Steuerkraftumverteilung zu Lasten der kleinen Gemeinden und verschärft damit das vertikale Steuerkraftgefälle zwischen den Gemeinden. Gegenüber der Steuerkraftverteilung, die 1974 bei ausschließlicher Finanzkraftverstärkung entstanden wäre, verlieren die Gemeinden der drei unteren Größenklassen durch die Strukturreform eine Steuerkraftsumme in Höhe von rund 123 Mill. DM oder 0,5\% der gesamten kommunalen Steuerkraft (Spalte 11). Für die vertikale Verteilung der Steuerkraft ohne Strukturreform (Spalte 8 ) ergibt sich ein Variationskoeffizient von 0,236 gegenüber einem Wert von 0,248 für die vertikale Verteilung der tatsächlichen gemeindlichen Steuerkraft des Jahres 1974.

\subsection{Zusammenfassung der Untersuchungsergebnisse}

Die Einbeziehung des Gewerbesteuerausgleichs in die Untersuchung über den Einfluß der Gemeindefinanzreform auf die vertikale Streuung der kommunalen Steuerkraft erlaubt somit folgendes Fazit:

Unterstellt man, daß im Jahr 1974 ohne Gemeindefinanzreform ein Gewerbesteuerausgleich mit einem Volumen von 1 - 2,25\% der Realsteuerkraftsumme durchgeführt worden wäre, kann die Aussage, daß die Gemeindefinanzreform das vertikale Steuerkraftgefälle zwischen den Gemeinden geringfügig abschwächt, (204) nicht mehr aufrecht erhalten werden. Vielmehr sind im 
Tabelle 13c Die Umverteilungswirkung der Gemeindefinanzreform für das Jahr 1974 unter Berücksichtigung des fiktiven Gewerbesteuerausgleichs 1974 in der Variante II

\begin{tabular}{|c|c|c|c|c|c|c|c|c|c|c|c|c|c|}
\hline \multirow{2}{*}{\multicolumn{2}{|c|}{$\begin{array}{l}\text { Geme indegrößen- } \\
\text { klassen }\end{array}$}} & \multicolumn{2}{|c|}{$\begin{array}{l}\text { Realsteuerkraft } 1974 \\
\text { und fiktiver Gewerbe- } \\
\text { steuerausgleich } \\
\text { Variante II } \\
\text { in 1000 DM | in \% }\end{array}$} & \multicolumn{4}{|c|}{$\begin{array}{l}\text { fiktive Verteilung der gemeindlichen } \\
\text { Steuerkraft } 1 \text { ) }\end{array}$} & \multicolumn{4}{|c|}{$\begin{array}{l}\text { tatsächliche gemeindliche } \\
\text { Steuerkraft }\end{array}$} & \multicolumn{2}{|c|}{ Umverteilungsmasse ${ }^{3)}$} \\
\hline & & 1 & 2 & 3 & 4 & 5 & 6 & 7 & 8 & 9 & 10 & 11 & 12 \\
\hline $0-<$ & 3.000 & 1404630 & 7,81 & 1917670 & 234,5 & 59,2 & 100,0 & 1827701 & 223,5 & 56,5 & 100,0 & -89969 & $-4,7$ \\
\hline $3.000-<$ & 5.000 & 772280 & 4,29 & 1053368 & 292,3 & 73,9 & 124,6 & 1030528 & 285,9 & 72,2 & 127,9 & -22840 & $-2,2$ \\
\hline $5.000-<$ & 10.000 & 1619472 & 9,00 & 2209863 & 320,3 & 80,9 & 136,6 & 2199651 & 318,8 & 80,5 & 142,6 & -10212 & $-0,5$ \\
\hline $10.000-<$ & 20.000 & 2045618 & 11,37 & 2791793 & 342,3 & 86,5 & 146,0 & 2811310 & 344,6 & 87,1 & 154,2 & +19517 & $+0,7$ \\
\hline $20.000-<$ & 50.000 & 2714796 & 15,09 & 3705203 & 397,8 & 100,5 & 169,6 & 3707836 & 398,1 & 100,6 & 178,1 & +2633 & $+0,1$ \\
\hline $50.000-<1$ & 100.000 & 1797649 & 9,99 & 2452948 & 448,3 & 113,3 & 191,2 & 2483522 & 453,9 & 114,7 & 203,1 & +30574 & $+1,2$ \\
\hline $700.000-<$ & 200.000 & 1628162 & 9,05 & 2222140 & 468,5 & 118,4 & 199,8 & 2256387 & 475,7 & 120,2 & 212,8 & +34247 & $+1,5$ \\
\hline$\quad \geq$ & $\left.200.000^{4}\right)$ & 6007865 & 33,40 & 8201046 & 523,2 & 132,2 & 223,1 & 8237095 & 525,5 & 132,8 & 235,1 & +36049 & $+0,4$ \\
\hline insgesamt & & 17990472 & 100,00 & 24554031 & 395,8 & 100,0 & 168,8 & 24554030 & 395,8 & 100,0 & 177,1 & $\begin{array}{l}-123021 \\
+123020\end{array}$ & $\overline{+} 0,5$ \\
\hline
\end{tabular}

() Verteilung der Steuerkraftsumme des Jahres 1974 in Höhe von 24,554 Mrd. DM auf die einzelnen Größenklassen gemäß den Anteilswerten aus Spalte 2.

2) $\mathrm{a}=$ in $\%$ des Bundesdurchschnitts

$\mathrm{b}=$ in \% der untersten Größenklasse

$\mathrm{c}=$ in \% der Werte aus Spalte 3.

3) Differenz zwischen tatsächlicher gemeindlicher Steuerkraft und der Steuerkraft, die die Gemeinden ohne Struktur-

जr reform des kommunalen Steuersystems, aber bei Finanzkraftverstärkung aufweisen würden (Werte aus Spalte 3).

$\overrightarrow{4})$ einschließlich Hamburg, Bremen und Berlin.

Wariationskoeffizienten: a) für die fiktive gemeindliche Steuerkraft 0,236

b) für die tatsächliche gemeindliche Steuerkraft 0,248. 
Jahr 1974 die tatsächlichen Steuerkraftunterschiede zwischen den Gemeinden unterschiedlicher Größenklasse mit einiger Sicherheit größer, als sie ohne Gemeindefinanzreform von 1969 gewesen wären. Durch die Strukturre form des kommunalen Steuersystems wird den Gemeinden mit weniger als 10. 000 Einwohnern eine Steuerkraftsumme in Höhe von 100 - 400 Mill. DM entzogen und den Gemeinden mit mehr als 10.000 Einwohnern zugewiesen. Dieser Umverteilungseffekt zugunsten der großen Gemeinden und der daraus resultie rende Steuerkraftdifferenzierungseffekt der Gemeindefinanzreform sind umso höher zu veranschlagen, je größer das Volumen des Gewerbesteuerausgleichs zwischen Wohn- und Betriebsgemeinden im Jahr 1974 gewesen wäre. Man kann also keineswegs davon sprechen, daß das von der Bundesregierung angestrebte Ziel der Reform, die Konstanz des vertikalen Steuerkraftgefälles, mit den Maßnahmen der Gemeindefinanzreform von 1969 auch erreicht worden ist.

Nachdem diese Frage mit einiger Sicherheit beantwortet worden ist, wird nun nach der Vereinbarkeit dieses Ergebnisses der Gemeindefinanzreform mit dem hier zugrundegelegten regionalpolitischen Zielsystem gefragt.

2.6. Die regionalpolitische Beurteilung der Auswirkungen der Gemeindefinanzreform auf die vertikale Streuung der kommunalen Steuerkraft

Ohne Gemeindefinanzreform von 1969 hätte die Steuerkraft pro Kopf der Ge meinden mit mehr als 200.000 Einwohnern vermutlich zwischen $194-223 \%$ der Steuerkraft der Gemeinden mit weniger als 3.000 Einwohnern betragen. (205) Es ist ein erklärtes Ziel der Gemeindefinanzreform, Steuerkraftunterschiede zwischen Gemeinden unterschiedlicher Größe in einem solchen Ausmaß aufrecht zu erhalten. Als Rechtfertigung für diese vertikalen Steuerkraftunterschiede von mindestens $100 \%$ dient die hohe Kostenbelastung der großen Gemeinden durch ihr zentralörtliches Leistungsangebot zugunsten der Einwohner ihres Umlandes. (206)

Diese Begründung muß dann akzeptiert werden, wenn mindestens $50 \%$ aller Ausgaben der Gemeinden mit mehr als 200. 000 Einwohnern von Einwohnern ihres Umlandes verursacht werden und diesen in irgendeiner Form Nutzen stiften. Setzt man voraus, daß jeder auswärtige Benutzer einer kommunalen Einrichtung der großstädtischen Kommune dieselben Kosten verursacht wie ein einheimischer Benutzer, (207) so müßte jeder zweite Benutzer der kommunalen Einrichtungen in den Großstädten der obersten Größenklasse aus Umlandgemeinden stammen. Ob die Annahme einer solchen Benutzerquote realistisch und haltbar ist, muß wohl bezweifelt werden. (208) Dabei ist noch nicht einmal berücksichtigt, daß neben den Ertrags-spillouts der Großstädte zugunsten ihres Umlandes auch Ertrags-spillins zugunsten der Großstädte existieren. (209) Bezieht man diese in die Überlegung ein, müßte der Anteil auswärtiger Benutzer an der Gesamtzahl der Benutzer der zentralörtlichen Einrichtungen noch über $50 \%$ liegen, um ein Steuerkraftverhältnis von $1: 2$ $z$ wischen Gemeinden der untersten und der obersten Größenklasse zu rechtfertigen. "Auch wenn genaue Unterlagen darüber fehlen, um wieviel der Aus- 
gabebedarf in den großen Gemeinden durch Übernahme von zentralen Funktionen ansteigt, ist mit Sicherheit anzunehmen, daß die Zunahme der Steuerkraft über die Erhöhung des Finanzbedarfs hinausgeht. "(210) Diese Aussage, die sich auf die vertikale Steuerkraftverteilung vor Inkrafttreten der Gemeindefinanzreform bezieht, gilt auch für die vertikale Verteilung der kommunalen Steuerkraft, die sich 1974 ohne Gemeindefinanzreform ergeben hätte.

Grobe Schätzungen lassen eher vermuten, daß die Gemeinden der oberen Größenklasse etwa $20-25 \%$ ihrer Finanzmittel für ein zentralörtliches Leistungsangebot einsetzen müssen. (211) Würde diese Vermutung zutreffen, so wird damit eine Pro-Kopf-Steuerkraft der Gemeinden mit mehr als 200. 000 Einwohnern in Höhe von $140-150 \%$ der Steuerkraft der kleinsten Gemeinden gerechtfertigt. (212) Liegt die tatsächliche Steuerkraft der Gemeinden der obersten Größenklassen nun über diesem Steuerkraftniveau, so führt dies zu folgenden Konsequenzen für die Raumstruktur:

- Die Großstädte verfügen über Mittel, mit denen sie ballungsbedingte Kostensteigerungen ihrer Leistungserstellung auffangen und ballungsbedingte Nachfrage nach öffentlichen Leistungen befriedigen können. Durch diese Steuerkraftverteilung wird verhindert, daß sich die Standortbedingungen in den Ballungsgebieten automatisch verschlechtern und daß sich der Ballungsproze $\beta$ verlangsamt. (213)

- Deckt die Steuerkraft pro Kopf, die den großen Gemeinden zugewiesen wird, mehr als den zentralörtlichen und spezifisch ballungsbedingten Finanzbedarf, so wirkt diese Steuerkraftausstattung direkt ballungsverstärkend. Die großen Gemeinden verfügen in diesem Fall über Mittel, mit denen sie ihre Standortqualitäten im Vergleich zu kleineren Gemeinden weiter verbessern und somit ihre Attraktionskraft auf mobile Ressourcen stärken können. (213)

Das vertikale Steuerkraftgefälle, das 1974 ohne Gemeindefinanzreform bestanden hätte, bringt unter dem Vorwand der Abgeltung von Ertrags-spillouts eine Überdotierung der großen Gemeinden mit sich. Es hätte deshalb auf jeden Fall verhindert, daß sich der räumliche Konzentrationsprozeß automatisch abschwächt. Darüberhinaus ist sogar anzunehmen, daß es den Vorsprung der großen Gemeinden im Attrahierungswettbewerb um mobile Ressourcen vergrößert und damit unmittelbar den Ballungsproze $\beta$ verstärkt hätte. Damit kann festgestellt werden, daß schon das Ziel der Gemeindefinanzreform, die vertikale Streuung der kommunalen Steuerkraft unverändert zu lassen, nicht mit den hier vertretenen regionalpolitischen Zielen vereinbar ist.

Noch stärker kollidiert mit diesen regionalpolitischen Zielvorstellungen das tatsächliche Ergebnis der Gemeindefinanzreform. Denn der ballungsfördernde Effekt der vertikalen Steuerkraftverteilung vor bzw. ohne Gemeindefinanzreform wird durch die Strukturreform des kommunalen Steuersystems von 1969 noch verstärkt, indem diese die Steuerkraftposition der Gemeinden mit mehr als 200.000 Einwohnern auf $235 \%$ (Tabelle 13b, Spalte 10), die der Gemeinden mit mehr als 500.000 Einwohnern auf $245 \%$ (Tabelle $12 \mathrm{~b}$, Spalte 10) der Steuerkraft pro Kopf der kleinsten Gemeinden erhöht. Damit ist das 
kommunale Steuersystem nach der Gemeindefinanzreform eine mindestens ebenso gewichtige, wenn nicht noch gewichtigere Ursache für die sich selbst verstärkenden Tendenzen des räumlichen Differenzierungsprozesses, als es das kommunale Steuersystem vor der Gemeindefinanzreform von 1969 gewesen ist. (214)

3. Die Beteiligung der Gemeinden am Aufkommen aus der Umsatzsteuer ein Vorschlag zur Reform des Gemeindesteuersystems

3.1. Die regionalpolitisch wünschenswerte Neuordnung des kommunalen Steuersystems

Die Bundesregierung proklamiert in ihrem Bundesraumordnungsprogramm vom 30.4.1975 den "Abbau großräumiger Disparitäten"(215) und die Schaffung und Erhaltung "gleichwertige[r] Lebensbedingungen in allen Teilen des Bundesgebiets"(216) als Ziele ihrer Raumordnungspolitik. Sie will dem Wachstumsdruck in den Ballungsgebieten entgegenwirken und die Abwanderung aus ländlichen Gebieten verhindern. (217) Als ein wichtiges Instrument zur Erreichung ihrer regionalpolitischen Ziele schlägt sie vor, die der öffentlichen Hand zur Verfügung stehenden Finanzmittel mit Vorrang den abwanderungs gefährdeten Gebieten zuzuweisen. (218)

Diese Entwicklungsfunktion kann das durch die Finanzreform von 1969 ge schaffene Gemeindesteuersystem nicht erfüllen. Im Gegenteil: Es sichert den stark verdichteten Regionen bei gleicher Steueranspannung pro Kopf wesentlich höhere Steuereinnahmen und damit Ausgabemöglichkeiten als den ländlichen, abwanderungsgefährdeten Gebieten und steht damit in direktem Widerspruch zu den von der Bundesregierung vertretenen Vorstellungen über Ziele und Instrumente einer wünschenswerten Regionalpolitik.

Aus diesem Grund wird hier eine Reform des gegenwärtigen kommunalen Steuersystem für erforderlich gehalten. Diese Reform sollte darin bestehen, die gesamte Gewerbesteuer zu beseitigen (219) und als Ersatz für den Ausfall von Gewerbesteuereinnahmen den Gemeinden einen Teil des Umsatzsteueraufkommens zuzuweisen. Als Zeitpunkt für die Durchführung der Reform bietet sich die noch ausstehende Harmonisierung der Mehrwertsteuersätze zwischen den Mitgliedsländern der Europäischen Gemeinschaft an. Diese Harmonisierung wird zu einer Anhebung der Mehrwertsteuersätze in der Bundesrepublik führen und kann so den Steuerverlust ausgleichen, der dem Bund und den Ländern durch die vorgeschlagene Reform des kommunalen Steuersystems entsteht. Die Kombination von Harmonisierung der Mehrwertsteuersätze und Abschaffung der Gewerbesteuer hat zugleich den Vorteil, unerwünschte Preis- und Verteilungseffekte, die eine isolierte Erhöhung der Mehrwertsteuersätze mit sich bringt, zu vermeiden oder in Grenzen zu halten. Diese Wirkung beruht darauf, daß mit der Gewerbesteuer eine Kostensteuer entfallen soll, wodurch den entlasteten Unternehmen Preissenkungsspielräume verschafft werden. (220) 
Der Gemeindeanteil an der Umsatzsteuer kann nicht nach dem kassenmäßigen örtlichen Aufkommen aus der Umsatzsteuer auf die einzelnen Gemeinden verteilt werden. Das kassenmäßige örtliche Umsatzsteueraufkommen eignet sich schon auf Länderebene nicht als Verteilungskriterium (221) und würde erst recht zwischen den Gemeinden zu überaus großen Steuerkraftunterschieden führen. Desweiteren bietet sich an, den Gemeinden das örtliche Mehrwertsteueraufkommen der letzten Stufe zuzuweisen. Doch bestehen auch für diese Lösung begründete Zweifel, ob durch sie die Steuerkraftunterschiede $z$ wischen den Gemeinden auf ein vertretbares Maß reduziert werden können. (222) Um einen möglichst weitgehenden Abbau der kommunalen Steuerkraftunterschiede zu erreichen, wird hier vorgeschlagen, den Gemeindeanteil an der Umsatzsteuer nach der tatsächlichen Einwohnerzahl auf die einzelnen Gemeinden zu verteilen. Im folgenden wird untersucht, wie sich diese Reform des kommunalen Steuersystems im Jahr 1974 auf die Einnahmenposition der nach Größenklassen gegliederten Gemeinden ausgewirkt hätte.

3.2. Der Umverteilungs - und Nivellierungseffekt einer Beteiligung der Ge meinden an der Umsatzsteuer gemäß ihrer Einwohnerzahl

Die Steuereinnahmen, die die Gemeinden der einzelnen Größenklassen nach dieser Reform des kommunalen Steuersystems im Jahr 1974 erhalten hätten (Tabelle 14, Spalte 4), setzen sich zusammen aus

- ihren Einnahmen aus den Grundsteuern (Spalte 1),

- ihren Einnahmen aus dem Gemeindeanteil an der Umsatzsteuer (Spalte 2) und

- ihren Einnahmen aus dem Gemeindeanteil an der Einkommensteuer (Spalte 3 ).

Von diesen drei Komponenten können die erste und die dritte der amtlichen Statistik entnommen werden, während die zweite berechnet werden muß.

Im Jahr 1974 betragen die Einnahmen aus der Gewerbesteuer nach Ertrag, Kapital und Lohnsumme 21.567,1 Mill. DM. Davon fließen den Gemeinden nach Abzug der Gewerbesteuerumlage insgesamt 14.259,4 Mill. DM endgültig zu. In dieser Höhe wären die Gemeinden im Jahr 1974 am erhöhten Aufkommen aus der Umsatzsteuer durch die Reform des Gemeindesteuersystems beteiligt. Jeder einzelnen Gemeinde würde pro Einwohner ein Betrag in Höhe von 229,83 DM zufließen. Durch Multiplikation dieses Pro-Kopf-Betrages mit der Zahl der Einwohner in jeder Gemeindegrößenklasse erhält man die vertikale Verteilung des fiktiven Gemeindeanteils an der Umsatzsteuer für das Jahr 1974.

Durch eine Beteiligung der Gemeinden an der Umsatzsteuer gemäß ihrer Einwohnerzahl und gleichzeitiger Abschaffung der Gewerbesteuer wären im Jahr 1974 rund 3 Mrd. DM oder 9,6\% der tatsächlichen kommunalen Steuereinnahmen umverteilt worden (Spalte 9). Die Reform hätte in Höhe dieses Betrages die Einnahmenposition der Gemeinden mit weniger als 50.000 Einwohnern gestärkt, und zwar prozentual umso mehr, je kleiner sie sind. Mit rund 
Tabelle 14 Die Beteiligung der Gemeinden an der Umsatzsteuer gemäß ihrer Einwohnerzahl für das Jahr 1974

\begin{tabular}{|c|c|c|c|c|c|c|c|c|c|c|}
\hline \multirow[t]{2}{*}{$\begin{array}{l}\text { Gemeindegrößen- } \\
\text { klassen }\end{array}$} & \multirow{2}{*}{$\begin{array}{l}\begin{array}{l}\text { Grundsteuer- } \\
\text { aufkommen }\end{array} \\
\text { in } 1000 \mathrm{DM} \\
\end{array}$} & \multirow{2}{*}{$\begin{array}{l}\begin{array}{l}\text { Gemeindean- } \\
\text { teil a.d. Um } \\
\text { satzsteuer } 2 \text { ) }\end{array} \\
\text { in } 1000 \mathrm{DM} \\
\end{array}$} & \multirow{2}{*}{$\begin{array}{l}\text { Gemeindean- } \\
\text { teil a.d. } \\
\text { Eink.steuer } \\
\text { in } 1000 \mathrm{DM}\end{array}$} & \multicolumn{4}{|c|}{$\begin{array}{l}\text { fiktive Steuereinnahmen } \\
\text { der Gemeinden 3) }\end{array}$} & \multirow{2}{*}{\begin{tabular}{|l} 
tatsächliche \\
$\begin{array}{l}\text { Steuerein- } \\
\text { nahmen }\end{array}$ \\
in $1000 \mathrm{DM}$ \\
\end{tabular}} & \multicolumn{2}{|c|}{ Umverteilungsmasse 4) } \\
\hline & & & & in $1000 \mathrm{DM}$ & pro Kopf & $\mathrm{a}^{1)}$ & $\mathrm{b}^{1)}$ & & in $1000 \mathrm{DM}$ & $c^{1)}$ \\
\hline & 1 & 2 & \begin{tabular}{|c|}
3 \\
\end{tabular} & \begin{tabular}{|l|}
4 \\
\end{tabular} & 5 & 6 & 7 & \begin{tabular}{|l|}
8 \\
\end{tabular} & 9 & 10 \\
\hline 3.000 & 385600 & 1879550 & 1028800 & 3293950 & 402,8 & 79,0 & 100,0 & 2095000 & +1198950 & $+57,2$ \\
\hline $3.000-<\quad 5.000$ & 153900 & 828307 & 578300 & 1560507 & 433,0 & 84,9 & 107,5 & 1180300 & +380207 & $+32,2$ \\
\hline $5.000-<10.000$ & 290900 & 1585827 & 1256900 & 3133627 & 454,1 & 89,0 & 112,7 & 2504800 & +628827 & $+25,1$ \\
\hline $10.000-<20.000$ & 344200 & 1874723 & 1591700 & 3810623 & 467,2 & 91,6 & 116,0 & 3232900 & +577723 & $+17,9$ \\
\hline $20.000-<50.000$ & 450500 & 2140866 & 2088900 & 4680266 & 502,4 & 98,5 & 124,7 & 4437500 & +242766 & $+5,5$ \\
\hline $50.000-<100.000$ & 307200 & 1257630 & 1434200 & 2999030 & 548,1 & 107,4 & 136,1 & 3152900 & $-\quad 153870$ & $-4,9$ \\
\hline $100.000-<200.000$ & 299200 & 1090084 & 1253200 & 2642484 & 557,1 & 109,2 & 138,3 & 3042900 & -400416 & $-13,2$ \\
\hline $200.000-<500.000$ & 331300 & 1123409 & 1388600 & 2843309 & 581,7 & 114,0 & 144,4 & 3257000 & -413691 & $-12,7$ \\
\hline$\geq 500.000$ & 954300 & 2478946 & 3250600 & 6683846 & 619,7 & 121,5 & 153,8 & 8744100 & -2060254 & $-23,6$ \\
\hline Ins & 3517100 & 14259342 & 13871200 & 31647642 & 510,1 & 100,0 & 126,6 & 31647400 & $\begin{array}{l}+3028473 \\
-3028231\end{array}$ & $+9,6$ \\
\hline
\end{tabular}

Variationskoeffizienten für die fiktiven Steuereinnahmen: 0,136.

1) $\mathrm{a}=$ in \% des Bundesdurchschnitts

$\mathrm{b}=$ in \% der untersten Größenklasse

$c=$ in \% der tatsächlichen Steuereinnahmen der Gemeinden.

Quelle: Berechnet nach

Statistisches Bundesamt, Finanzen und Steuern,

Reihe 9, Realsteuervergleich 1974,

a.a.O., S. 22 f.

2) 1974 betrug das Gewerbesteueraufkommen insgesamt 21 567,1 Mill. DM. Nach Abzug der Gewerbesteuerumlage verblieben den Gemeinden 14 259,4 Mill. DM. In Höhe dieses Betrages werden sie hier gemäß ihrer Einwohnerzahl an der um 21,6 Mrd. DM aufgestockten Umsatzsteuer beteiligt. Pro Einwohner erhalten die Gemeinden demnach 229,83 DM.

3) Summe von Grundsteueraufkommen, Gemeindeanteil an der Umsatzsteuer und Gemeindeanteil an der Einkommensteuer.

4) fiktive Steuereinnahmen der Gemeinden ./. tatsächliche Steuereinnahmen der Gemeinden (Differenz zwischen Spalte 4 und 8). 
2 Mrd. DM oder 23,6 \% ihrer tatsächlichen Steuereinnahmen des Jahres 1974 hätten die Gemeinden mit mehr als 500.000 Einwohnern absolut und relativ den stärksten Einnahmenverlust durch die Reform hinzunehmen.

Infolge der Richtung und des Ausmaßes dieses Umverteilungseffektes käme es zu einem starken Abbau der 1974 bestehenden Steuerkraftunterschiede zwischen den Gemeinden verschiedener Größenklassen. Nach der Reform lägen die Pro-Kopf-Werte der kommunalen Steuereinnahmen zwischen 79, $0 \%$ und $121,5 \%$ des Bundesdurchschnitts (Spalte 6), während ohne Reform die Steuerkraft der kleinsten Gemeinden $56,5 \%$, die der größten Gemeinden $138,3 \%$ des Bundesdurchschnitts beträgt (Tabelle 12b, Spalte 9). Das Ausmaß des Nivellierungseffektes dieser Reformmaßnahmen zeigt sich wieder an der Veränderung des Variationskoeffizienten: Für die fiktiven Steuereinnahmen liegt er mit 0,136 um fast $50 \%$ unter demjenigen für die tatsächliche gemeindliche Steuerkraft des Jahres 1974.

Die hier vorgeschlagene Reformmaßnahme würde dafür sorgen, daß die Gemeinden der obersten Größenklasse 1974 im Durchschnitt nur noch über rund $54 \%$ höhere Steuereinnahmen pro Kopf bei gleicher Steueranspannung verfügen könnten (Spalte 7) als die Gemeinden der untersten Größenklasse. Damit wäre ein vertikales Steuerkraftgefälle realisiert, das mit großer Wahrscheinlichkeit wesentlich besser der Kostenbelastung der großen Gemeinden durch ihr Umland entspricht als das gegenwärtig bestehende Steuerkraftgefälle. (223) Auf diese Weise könnten eine Überdotierung der großen Gemeinden und die daraus resultierenden ballungsfördernden Wirkungen des kommunalen Steuersystems weitgehend verhindert werden.

\section{Zusammenfassung der Ergebnisse}

Mit diesem Vorschlag zur Reform des bestehenden Gemeindesteuersystems ist die Untersuchung über die Auswirkungen der Gemeindefinanzreform von 1969 auf die vertikale Streuung der kommunalen Steuerkraft abgeschlossen. In einer verkürzten Darstellung, sozusagen "auf einen Blick", werden die Ergebnisse dieser Untersuchung in Tabelle 15 zusammengefaßt. Zu diesem Zweck sind die Variationskoeffizienten für die vertikale Streuung verschiedener Steuerkraftwerte des Jahres 1974 zusammengestellt. An der Veränderung der Variationskoeffizienten oberhalb des Trennungsstriches läßt sich der Nivellierungseffekt der Gemeindefinanzreform ablesen, wenn man den Gewerbesteuerausgleich zwischen Wohn- und Betriebsgemeinden vernachlässigt. Darüberhinaus wird noch einmal die steuerkraftnivellierende Wirkung der hier vorgeschlagenen Reform des Gemeindesteuersystems deutlich. Die Entwicklung der Variationskoeffizienten unterhalb des Trennungsstriches gibt darüber Auskunft, in welcher Weise sich die Strukturreform des kommunalen Steuersystems von 1969 unter Berücksichtigung des Gewerbesteuerausgleichs auf die vertikale Streuung der kommunalen Steuerkraft auswirkt. 
Tabelle 15 Die Auswirkung der Gemeindefinanzreform auf die vertikale Streuung der gemeindlichen Steuerkraftwerte pro Einwohner im Jahr 1974

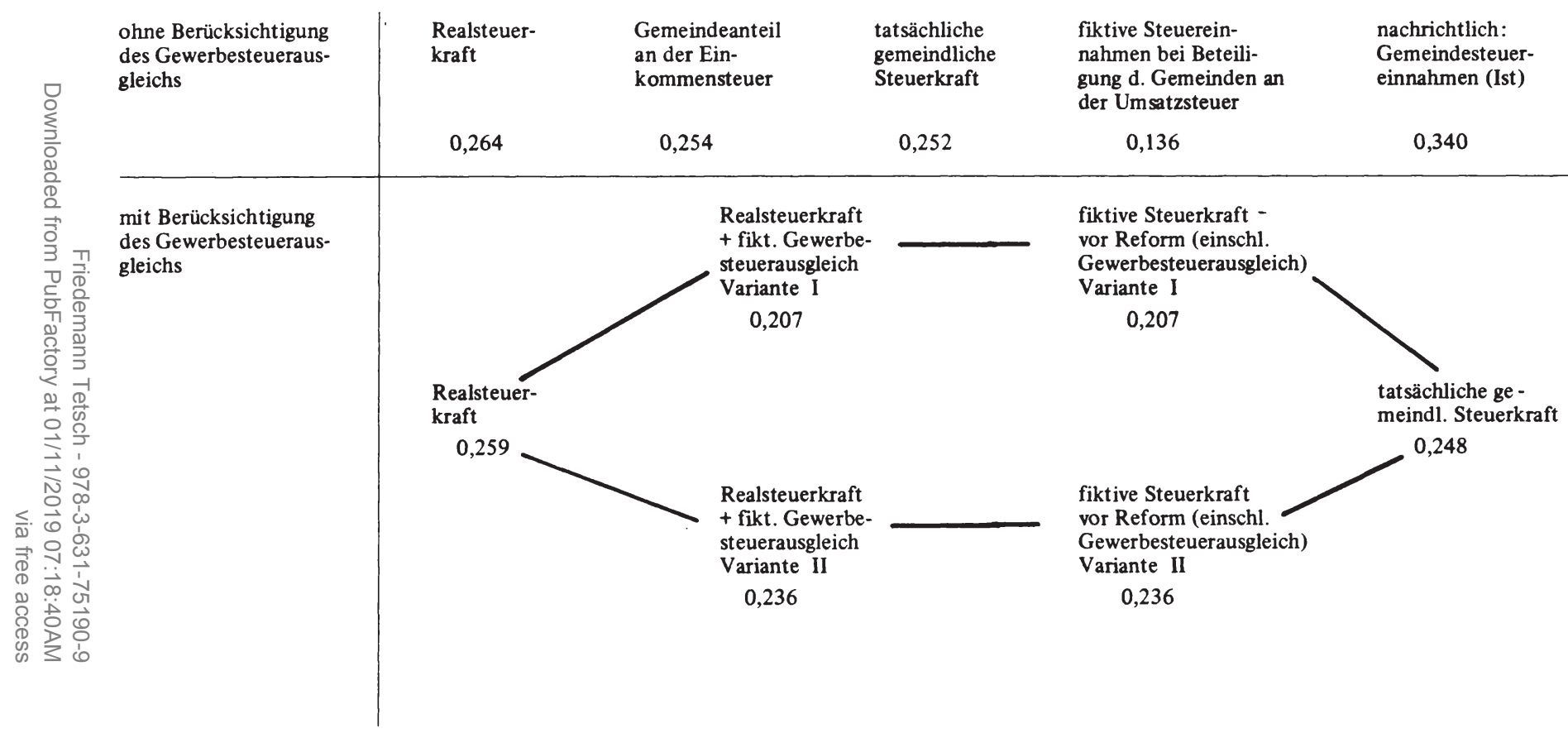


V. Die Auswirkung der Gemeindefinanzreform von 1969 auf die horizontale Streuung der Steuerkraft der Gemeinden im Jahr 1974

Eines der wichtigsten Ziele der Gemeindefinanzreform von 1969 besteht darin, die Steuerkraftunterschiede zwischen den Gemeinden, und zwar ausschließlich zwischen den Gemeinden gleicher Größenklasse, zu mildern. (224) In diesem Abschnitt der Arbeit wird zu ermitteln versucht, ob und gegebenenfalls in welchem Ausmaß dieses Ziel durch die Strukturreform des kommunalen Steuersystems realisiert wird. Zur.Beantwortung dieser Frage werden zwei Ansätze gewählt, die sich ergänzen und ein möglichst umfassendes Bild vom horizontalen Nivellierungseffekt der Gemeindefinanzreform liefern sollen:

- Als erstes wird untersucht, in welcher Weise sich im Jahr 1974 die Steuerkraftunterschiede $z$ wischen den einzelnen Gemeinden derselben Größenklasse als Folge der Gemeindefinanzreform verändern. Diese Untersuchung wird also auf der Basis der Steuerkraftwerte der einzelnen Gemeinden durchgeführt, wobei die Gemeinden nach Größenklassen gegliedert sind.

- Anschließend wird die Ebene der Landkreise und der kreisfreien Städte und damit eine regionale Gliederung der Gemeinden als Untersuchungsbasis gewählt. In diesem Teil der Untersuchung wird danach gefragt, wie sich die Gemeindefinanzreform auf die Unterschiede in der kommunalen Steuerkraft $z w i s c h e n$ den einzelnen Landkreisen bzw. den einzelnen kreisfreien Städten in der Bundesrepublik Deutschland im Jahr 1974 auswirkt.

Als Indikator für das Ausmaß der horizontalen Streuung der kommunalen Steuerkraft werden jeweils zwei Meßzahlen benutzt. Die erste Meßzahl ist der Variationskoeffizient. In ihn gehen die Abweichungen der Steuerkraftwerte aller Gemeinden einer Größenklasse bzw, aller Landkreise (kreisfreien Städte) eines Landes vom jeweiligen Gruppendurchschnitt ein. Er hat damit den Vorteil, die horizontale Streuung der kommunalen Steuerkraft umfassend und exakt zu messen. Als zweite Meßzahl wird die Relation zwischen der Steuerkraft der steuerstärksten und derjenigen der steuerschwächsten $\mathrm{Ge}$ bietskörperschaft in der jeweils gewählten Gliederung angeben. Dieser Indikator mißt die horizontale Streuung der kommunalen Steuerkraft und ihre reformbedingte Veränderung nur sehr grob. Er hat aber den Vorteil, anschaulich zu sein und ein Bild von dem Steuerkraftgefälle zu vermitteln, das zwischen den Gemeinden gleicher Größenklasse bzw. zwischen den gewählten regionalen Einheiten ohne Gemeindefinanzreform vermutlich bestanden hätte und nach Durchführung der Gemeindefinanzreform tatsächlich existiert.

Der horizontale Nivellierungseffekt der Gemeindefinanzreform wird ermittelt, indem die Meßzahlen für diejenige horizontale Streuung der Steuerkraft, die 1974 ohne Gemeindefinanzreform vorzufinden gewesen wäre, mit den Meßzahlen für die horizontale Streuung der tatsächlichen kommunalen Steuerkraft des Jahres 1974 verglichen werden. Auch hier besteht die Schwierigkeit darin, die fiktive horizontale Streuung der kommunalen Steuerkraft ohne Gemeindefinanzreform zu berechnen oder halbwegs zuverlässig zu schätzen. 
Diese Schwierigkeit resultiert daraus, daß der bis zum 31.12 .1969 praktizierte Gewerbesteuerausgleich auch innerhalb der einzelnen GemeindegröBenklassen eine Steuerkraftumverteilung zugunsten der gewerbesteuerschwachen Wohngemeinden bewirkt und dieser horizontale Nivellierungseffekt mit der Abschaffung des Gewerbesteuerausgleichs entfällt.

1. Der Einfluß der Gemeindefinanzreform von 1969 auf die Streuung der Steuerkraft der Gemeinden gleicher Größenklasse im Jahr 1974

1.1. Das methodische Vorgehen

In diesem Teil der Untersuchung wird versucht, auf der Basis der Steuerkraftwerte der einzelnen Gemeinden den horizontalen Nivellierungseffekt der Gemeindefinanzreform für das Jahr $1974 \mathrm{zu}$ berechnen. Um diesen $\mathrm{Ef}$ fekt vollständig zu erfassen, müßten unter Einbeziehung aller Gemeinden der Bundesrepublik für jede einzelne Größenklasse der Variationskoeffizient für die Realsteuerkraft und der für die gemeindliche Steuerkraft ermittelt werden. Dazu ist erforderlich, daß für jede einzelne der 12.150 Gemeinden der Bundesrepublik des Jahres 1974 (225) die Abweichung sowohl ihrer Realsteuerkraft pro Einwohner als auch die ihrer gemeindlichen Steuerkraft pro Einwohner vom jeweiligen Durchschnittswert ihrer Größenklasse festgestellt wird. Der damit verbundene Arbeitsaufwand ist so groß, daß er hier nicht bewältigt werden konnte. Deshalb umfaßt die hier durchgeführte Untersuchung, deren Ergebnisse in Tabelle 16 a zusammengestellt sind, nicht alle Gemeinden der Bundesrepublik, sondern beschränkt sich auf die 1.173 Gemeinden des Landes Schleswig-Holstein. (225) Die Ergebnisse dieser Untersuchung haben damit einen beschränkten Aussagewert. Sie zeigen bestenfalls, wie sich im Jahr 1974 die Gemeindefinanzreform von 1969 auf die horizontale Streuung der Steuerkraft der Gemeinden in Schleswig-Holstein auswirkt. Vor allem aus diesem Grund wird die Untersuchung über den Einfluß der Gemeindefinanzreform auf die horizontale Streuung der kommunalen Steuerkraft auch auf die Landkreise und kreisfreien Städte ausgedehnt. Auf diese Weise können alle Gemeinden der Bundesrepublik, wenn auch nur zu Landkreisen zusammengefaßt, in die Untersuchung einbezogen werden.

Die Ergebnisse dieser Untersuchung müssen noch aus einem weiteren Grund relativiert werden. Als Vergleichsverteilung für die horizontale Verteilung der tatsächlichen gemeindlichen Steuerkraft des Jahres 1974 dient die horizontale Verteilung der Realsteuerkraft des Jahres 1974. Die Realsteuerkraftwerte der einzelnen Gemeinden entsprechen aber nicht den Steuerkraftwerten, die sie im Jahr 1974 ohne Gemeindefinanzreform aufgewiesen hätten. Denn ohne Gemeindefinanzreform von 1969 wäre ja auch im Jahr 1974 ein Gewer besteuerausgleich $\mathrm{zw}$ ischen Wohn- und Betriebsgemeinden durchgeführt worden, der auch innerhalb der einzelnen Gemeindegrößenklassen die Steuerkraftunterschiede abgeschwächt hätte. Die Variationskoeffizienten der einzelnen Größenklassen für die fiktive kommunale Steuerkraft ohne Gemeindefinanzreform wären deshalb 1974 kleiner gewesen als die Variationskoeffizienten für die Realsteuerkraft der Gemeinden. Man kann also nicht die gesamte Differenz 
Tabelle 16a Die Streuung der Steuerkraft der Gemeinden gleicher Größenklasse in Schleswig-Holstein in den Jahren 1974 und 1965

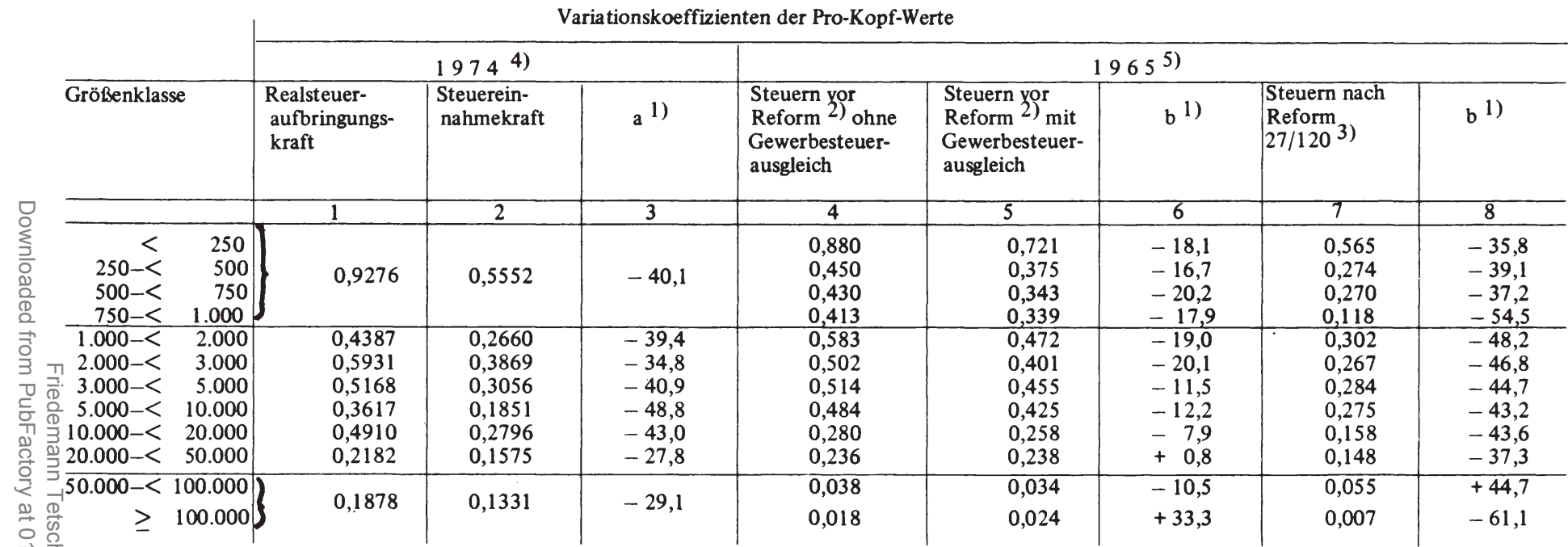

1) $\mathrm{a}=$ prozentuale Veränderung gegenüber den

Variationskoeffizienten der Realsteueraufbringungskraft

$b=$ prozentuale Veränderung gegenüber den Variationskoeffizienten der Steuern vor Reform ohne Gewerbesteuerausgleich

2) Realsteueraufkommen einschließlich Lohnsummensteuer (Ist-Werte), keine Steuerkraft werte wie 1974.
3) Realsteueraufkommen einschl. Lohnsummensteuer + Gemeindeanteil an der Einkommensteuer in Höhe von $27 \%$ des Aufkommens aus dem Linearbereich der Einkommensteuerbemessungsgrundlage ./. Gewerbesteuerumlage in Höhe von $120 \%$ der Grundbeträge.

4) Quelle: Berechnet nach den Steuerkraftwerten pro Einwohner jeder einzelnen Gemeinde Schleswig-Holsteins, in: Statistische Berichte des Statistischen Landesamtes Schleswig-Holstein, Realsteuervergleich in SchleswigHolstein 1974, Kiel, Oktober 1975.

5) Quelle: Ubernommen aus: Zwilling, Ernst, Untersuchungen zu einem rationalen Steuersystem der Gemeinden, Meisenheim am Glan 1971, Tabelle 23. 
zwischen den Variationskoeffizienten der Realsteuerkraft und der gemeindlichen Steuerkraft jeder einzelnen Gemeindegrößenklasse auf die Gemeindefinanzreform zurückführen.

Um die tatsächliche Wirkung der Gemeindefinanzreform auf die horizontalen Steuerkraftunterschiede zwischen den Gemeinden wenigstens annäherungsweise zu erhalten, muß der Teil der Differenz zwischen den beiden für jede Größenklasse zu vergleichenden Variationskoeffizienten geschätzt werden, der mit dem Wegfall des horizontalen Nivellierungseffektes des Gewerbesteuerausgleichs zu erklären ist. Nur die dann noch verbleibende Differenz zwischen den Variationskoeffizienten läßt sich als Auswirkung der Gemeindefinanzreform auf die horizontale Streuung der Steuerkraft interpretieren. Für die Schätzung des horizontalen Nivellierungseffektes, der im Jahr 1974 von einem fiktiven Gewerbesteuerausgleich in Schleswig-Holstein ausgegangen wäre, werden Berechnungen herangezogen, die Zwilling für das Jahr 1965 durchgeführt hat. (226) Die Ergebnisse jener Untersuchung werden in Tabelle 16a denen der Untersuchung für das Jahr 1974 gegenübergestellt.

Die von Zwilling für die "Steuern vor Reform ohne Gewerbesteuerausgleich" (Spalte 4) und für die "Steuern nach Reform" (Spalte 7) ermittelten Variationskoeffizienten sind aus einer Reihe von Gründen nur begrenzt mit den für 1974 errechneten Variationskoeffizienten (Spalte 1 und 2) vergleichbar. Zwilling hat im Gegensatz zum Verfasser nicht die horizontale Streuung der kommunalen Steuerkraftwerte, sondern die horizontale Streuung der kommunalen IstSteuereinnahmen pro Kopf der Gemeinden Schleswig-Holsteins untersucht, so daß sich in seinen Variationskoeffizienten auch der Einfluß lokaler Hebesatzunterschiede niederschlägt. Außerdem hat Zwilling ein kommunales Steuersystem nach der Reform unterstellt, das in dieser Form nicht verwirklicht worden ist. Desweiteren ist in der Untersuchung $\mathrm{Zwillings} \mathrm{die} \mathrm{Größen-}$ klasseneinteilung differenzierter als in der für das Jahr 1974 durchgeführten Untersuchung. Unterschiede zwischen den Ergebnissen beider Untersuchungen erklären sich schließlich auch daraus, daß zwischen 1965 und 1974 in Schleswig-Holstein eine kommunale Gebiets reform durchgeführt wurde, in deren Verlauf sich die Zahl der Gemeinden von 1.377 (227) auf 1.173 verringert hat.

Trotz dieser unzureichenden Vergleichbarkeit der für 1965 und für 1974 berechneten Variationskoeffizienten hat die Untersuchung Zwillings für die Frage nach dem tatsächlichen horizontalen Nivellierungseffekt der Gemeindefinanzreform von 1969 einige Bedeutung. Zwilling ermittelt nämlich für jede Gemeindegrößenklasse den Variationskoeffizienten für das Realsteuerauf kommen pro Kopf ohne und den für das Realsteueraufkommen pro Kopf mit Berücksichtigung des Gewerbesteuerausgleichs. In der Differenz zwischen diesen beiden Variationskoeffizienten (Spalte 6) schlägt sich der horizontale Nivellie rungseffekt des Gewerbesteuerausgleichs für Schleswig-Holstein im Jahr 1965 nieder. Dieses Ergebnis der Untersuchung von Zwilling bietet nun einen Anhaltspunkt dafür, wie stark die Variationskoeffizienten der einzelnen Gemeindegrößenklassen in Schleswig-Holstein vermutlich reduziert worden wären, wenn auch im Jahr 1974 ein Gewerbesteuerausgleich zwischen Wohn - und Betriebsgemeinden durchgeführt worden wäre. Damit läßt sich 
eine vorsichtige Schätzung wagen, welcher Teil der für 1974 festgestellten Differenz $\mathrm{zw}$ ischen dem Variationskoeffizienten für die Realsteuerkraft und dem für die gemeindliche Steuerkraft auf den Wegfall des Gewerbesteueraus gleichs und welcher Teil auf die Gemeindefinanzreform von 1969 zurückzuführen ist.

\subsection{Interpretation und Beurteilung der Ergebnisse}

Die Untersuchung über den Einfluß der Gemeindefinanzreform von 1969 auf die horizontale Streuung der kommunalen Steuerkraft in Schleswig-Holstein im Jahr 1974 bringt zwei wichtige Ergebnisse:

- Mit steigender Gemeindegrößenklasse nimmt der Variationskoeffizient für die Steuereinnahmekraft (228) ebenso wie der Variationskoeffizient für die Realsteueraufbringungskraft (228) tendenziell ab. Die Steuerkraftunterschiede zwischen etwa gleich großen Gemeinden sind also umso gröBer, je kleiner die Gemeinden sind. An diesem Tatbestand hat auch die Gemeindefinanzreform von 1969 nichts geändert.

- Die Variationskoeffizienten für die Steuereinnahmekraft liegen erheblich unter denen für die Realsteueraufbringungskraft. Die Abweichung zwischen den beiden Streuungsmaßen beträgt etwa $30-40 \%$. Auffällig ist dabei, daß sich nur die Variationskoeffizienten für die beiden oberen Gemeindegrößenklassen um weniger als $30 \%$ voneinander unterscheiden. Die Ge meindefinanzreform von 1969 scheint also eine beachtliche Abschwächung der horizontalen Steuerkraftunterschiede zwischen den Gemeinden Schles wig-Holsteins zu bewirken.

Die von Zwilling berechneten Variationskoeffizienten weichen zwar im einzelnen z. T. stark von den entsprechenden Variationskoeffizienten des Jahres $1974 \mathrm{ab}$. In ihrer Tendenz bestätigen sie jedoch beide Ergebnisse der für 1974 durchgeführten Untersuchung. Für die hier behandelte Frage des horizontalen Nivellierungseffektes der Gemeindefinanzreform sind insbesondere Zwillings Berechnungen über den horizontalen Nivellierungseffekt des Gewerbesteuerausgleichs im Jahr 1965 von Bedeutung. In jenem Jahr reduziert der Gewerbesteuerausgleich in Schleswig-Holstein die horizontale Streuung der kommunalen Steuerkraft in allen Größenklassen mit Gemeinden mit weniger als 20.000 Einwo'inern um etwa 10 - $20 \%$ (Spalte 6). Faßt man die Gemeinden mit mehr als 20.000 Einwohnern zu zwei Größenklassen zusammen, wie dies 1974 gescheilen ist, so werden die horizontalen Steuerkraftunterschiede zwischen diesen Gemeinden durch den Gewerbesteuerausgleich 1965 so gut wie gar nicht verändert.

Auf dieses Ergebnis kann sich die Schätzung des horizontalen Nivellierungseffektes eines fiktiven Gewerbesteuerausgleichs 1974 stützen. Hier wird angenommen, daß der horizontale Nivellierungseffekt des Gewerbesteueraus gleichs 1974 vor allem in den unteren Größenklassen schwächer gewesen wäre als im Jahr 1965. Diese Annahme kann damit begründet werden, daß die kommunale Gebietsreform in Schleswig-Holstein in erster Linie zu einem Zusam- 
menschluß von Gemeinden etwa gleicher Größe aus den unteren Größenklas sen geführt hat. (229) Dadurch werden interkommunale Arbeitskräftewanderungen zu intrakommunalen Arbeitskräftewanderungen, so daß sich das Volumen der Gewerbesteuerausgleichszahlungen zwischen den Gemeinden derselben Größenklasse verringert. Konkret wird geschätzt, daß ein Gewerbesteuerausgleich in Schleswig-Holstein im Jahr 1974 die horizontale Streuung der kommunalen Steuerkraft in den unteren und mittleren Gemeindegrößenklassen um etwa $10 \%$, dagegen in den beiden oberen Größenklassen über haupt nicht reduziert hätte.

Wenn diese Vermutung halbwegs realistisch ist, dann kann etwa ein Viertel der für 1974 ermittelten Differenz zwischen den Variationskoeffizieñten der Realsteue raufbringungskraft und der Steuereinnahmekraft, mit Ausnahme der beiden oberen Größenklassen, mit dem Wegfall des Gewerbesteueraus gleichs erklärt werden. Drei Viertel dieser Differenz (230) können demnach als Auswirkung der Gemeindefinanzreform auf die horizontale Streuung der kommunalen Steuerkraft interpretiert werden.

Es sprechen demnach gute Gründe dafür, daß die Gemeindefinanzreform von 1969 die horizontale Streuung der kommunalen Steuerkraft in allen Gemeindegrößenklassen in Schleswig-Holstein um jeweils etwa $30 \%$ abschwächt. Man kann also davon sprechen, daß das mit der Gemeindefinanzreform von 1969 angestrebte Ziel, die Milderung der Steuerkraftunterschiede zwischen Gemeinden der gleichen Größenklasse, wenigstens für Schleswig-Holstein, erreicht worden ist.

Darüberhinaus stellt sich die Frage nach der regionalpolitischen Zieladäquanz der Gemeindefinanzreform unter dem Aspekt der horizontalen Streuung der kommunalen Steuerkraft. Steuerkraftunterschiede zwischen Gemeinden der gleichen Größenklasse sind nicht mit dem im Grundgesetz verankerten Grundsatz der Einheitlichkeit der Lebensverhältnisse vereinbar und tragen zu einer Verstärkung der regionalen Wohlstandsunterschiede bei. Deshalb wird hier ein vollständiger Abbau der horizontalen Steuerkraftunterschiede für erforderlich erachtet. (231) Gemessen an dieser Zielvorstellung, erscheint die Abschwächung der horizontalen Streuung der kommunalen Steuerkraft durch die Gemeindefinanzreform um etwa $30 \%$ als völlig unzureichend. Auch nach der Gemeindefinanzreform existieren zwischen den Gemeinden derselben Größenklasse noch unvertretbar große Steuerkraftunterschiede. Dies wird besonders deutlich, wenn man die in jeder einzelnen Größenklasse Schles wig-Holsteins im Jahr 1974 vorzufindenden Extremwerte für die Steueraufbringungskraft der Gemeinden zueinander in Beziehung setzt (Tabelle 16b, Spalte 4). Die Gemeindefinanzreform von 1969 kann damit nicht verhindern, daß die horizontale Verteilung der kommunalen Steuerkraft in Schleswig-Holstein auch noch im Jahr 1974 den räumlichen Differenzierungsprozeß verstärkt. (232) Durch die Maßnahmen der Gemeindefinanzreform werden lediglich diese regionalpolitisch unerwünschten Wirkungen der horizontalen Steuerkraftverteilung abgeschwächt und dies auch nur zu einem relativ geringen Teil. 
2. Der Einfluß der Gemeindefinanzreform von 1969 auf die Streuung der kommunalen Steuerkraft der Landkreise und der kreisfreien Städte im Jahr 1974

2.1. Das methodische Vorgehen

Alle bisher gemachten Aussagen über den Einfluß der Gemeindefinanzreform von 1969 auf die horizontale Streuung der kommunalen Steuerkraft gelten strenggenommen ausschließlich für Schleswig-Holstein. Diese Beschränkung des Aussagewertes der Untersuchung soll in diesem Abschnitt weitgehend beseitigt werden. Deshalb wird die Untersuchung über den horizontalen Nivellierungseffekt der Gemeindefinanzreform auf das gesamte Bundesgebiet ausgedehnt, womit alle Gemeinden der Bundesrepublik erfaßt werden. Um den damit verbundenen Arbeitsaufwand in Grenzen zu halten, wird diese Untersuchung auf der Ebene der Landkreise und der kreisfreien Städte durchgeführt. Die Auswirkung der Gemeindefinanzreform auf die horizontale Streuung der kommunalen Steuerkraft wird in erster Linie wiederum an der Differenz zwischen den Variationskoeffizienten für die Realsteuerkraft und für die gemeindliche Steuerkraft abgelesen.

\subsubsection{Die Berechnung der Streuungsmaße}

Bei der Berechnung dieser Variationskoeffizienten wurde länderweise vorgegangen. Für jeden einzelnen Landkreis eines Bundeslandes wurde die Abweichung der Realsteuerkraft pro Kopf und der gemeindlichen Steuerkraft pro Kopf seiner Gemeinden von der durchschnittlichen Realsteuerkraft bzw. gemeindlichen Steuerkraft aller kreisangehörigen Gemeinden des jeweiligen Bundeslandes festgestellt. Ebenso wurde mit den Steuerkraftwerten der einzelnen kreisfreien Städte eines jeden Bundeslandes verfahren. Auf der Basis dieser Abweichungen vom jeweiligen Landescurchschnitt wurden für die einzelnen Bundesländer die Variationskoeffizienten für die Realsteuerkraft und für die gemeindliche Steuerkraft errechnet. Die Differenz zwischen beiden Variationskoeffizienten zeigt an, in welchem Ausmaß die Gemeindefinanzreform die Streuung der kommunalen Steuerkraft der Landkreise bzw, der kreisfreien Städte eines Landes im Jahr 1974 verändert. Für alle 267 Landkreise des Bundesgebiets wurden außerdem die Abweichungen der Realsteuerkraft pro Kopf bzw. der gemeindlichen Steuerkraft pro Kopf ihrer Gemeinden vom jeweiligen Durchschnittswert aller kreisangehörigen Gemeinden des Bundesgebiets ermittelt. Mit Hilfe dieser Abweichungen vom jeweiligen Bundesdurchschnitt wurden dann die Variationskoeffizienten für die Realsteuerkraft und für die gemeindliche Steuerkraft der zu Landkreisen zusammengefaßten Gemeinden für das gesamte Bundesgebiet berechnet. Nach demselben Verfahren sind die Variationskoeffizienten für alle 104 kreisfreien Städte des Bundesgebiets (einschließlich Hamburg, Bremen und Berlin) zustandegekommen. Diese in der untersten Zeile der Tabelle $17 \mathrm{a}$ angegebenen Variations koeffizienten besitzen von allen hier berechneten den umfassendsten Aussagewert. In der Differenz zwischen dem für die Realsteuerkraft und dem für die 
Tabelle 16b Der Einfluß der Gemeindefinanzreform von 1969 auf die horizontale Streuung der Steuerkraft der Gemeinden gleicher Größenklassen in Schleswig-Holstein im Jahr 1974

\begin{tabular}{|c|c|c|c|c|c|}
\hline \multirow{2}{*}{\multicolumn{2}{|c|}{$\begin{array}{l}\text { Gemeindegrößen- } \\
\text { klassen }\end{array}$}} & \multicolumn{2}{|c|}{ Realsteueraufbringungskraft } & \multicolumn{2}{|l|}{ Steuereinnahmekraft } \\
\hline & & pro Kopf & a & pro Kopf & a \\
\hline \multirow{3}{*}{$0-<1000$} & & 1 & 2 & 3 & 4 \\
\hline & b & $\begin{array}{l}2.913,90 \\
\text { (Lieth) }\end{array}$ & \multirow{2}{*}{$25.628,0$} & $\begin{array}{l}1.905,73 \\
\text { (Lieth) }\end{array}$ & \multirow{2}{*}{$2.959,7$} \\
\hline & $c^{1}$ & $\begin{array}{c}11,37 \\
\text { (Sierksrade) }\end{array}$ & & $\begin{array}{c}64,39 \\
\text { (Kolkerheide) }\end{array}$ & \\
\hline \multirow{2}{*}{$1000-<2000$} & b & $\begin{array}{c}426,81 \\
\text { (Busdorf) }\end{array}$ & \multirow{2}{*}{$1.060,7$} & $\begin{array}{c}571,48 \\
\text { (Kampen) }\end{array}$ & \multirow{2}{*}{$1.220,3$} \\
\hline & c & $\begin{array}{c}40,24 \\
\text { (Lohe-Föhrden) }\end{array}$ & & $\begin{array}{c}46,83 \\
\text { (Lohe-Föhrden) }\end{array}$ & \\
\hline \multirow{2}{*}{$2000-<3000$} & b & $\begin{array}{c}760,37 \\
\text { (Helgoland) } \\
\end{array}$ & \multirow{2}{*}{$1.021,5$} & $\begin{array}{c}836,46 \\
\text { (Helgoland) }\end{array}$ & \multirow{2}{*}{432,8} \\
\hline & c & $\begin{array}{c}74,44 \\
\text { (Dassendorf) }\end{array}$ & & $\begin{array}{l}193,26 \\
\text { (Wrist) }\end{array}$ & \\
\hline \multirow{2}{*}{$3000-<5000$} & b & $\begin{array}{c}678,10 \\
\text { (Hohenwestedt) }\end{array}$ & \multirow{2}{*}{$1.186,9$} & $\begin{array}{c}636,63 \\
\text { (Hohenwestedt) }\end{array}$ & \multirow{2}{*}{431,4} \\
\hline & c & $\begin{array}{c}57,13 \\
\text { (Rickling) } \\
\end{array}$ & & $\begin{array}{c}147,56 \\
\text { (Rickling) }\end{array}$ & \\
\hline \multirow{2}{*}{$5000-<10000$} & b & $\begin{array}{c}542,24 \\
\text { (Wahlstedt, Stadt) }\end{array}$ & \multirow{2}{*}{576,8} & $\begin{array}{c}499,32 \\
\text { (Wahlstedt, Stadt) }\end{array}$ & \multirow{2}{*}{217,1} \\
\hline & c & $\begin{array}{c}94,01 \\
\text { (Glücksburg, Stadt) } \\
\end{array}$ & & $\begin{array}{c}229,95 \\
\text { (Tangstedt) }\end{array}$ & \\
\hline \multirow{2}{*}{$10000-<20000$} & b & $\begin{array}{c}809,28 \\
\text { (Bad Segeberg) } \\
\end{array}$ & \multirow{2}{*}{591,8} & $\begin{array}{c}751,21 \\
\text { (Bad Segeberg) } \\
\end{array}$ & \multirow{2}{*}{317,0} \\
\hline & c & $\begin{array}{c}136,76 \\
\text { (Stockelsdorf) }\end{array}$ & & $\begin{array}{c}237,01 \\
\text { (Henstedt-Ulzburg) }\end{array}$ & \\
\hline \multirow{2}{*}{$20000-<50000$} & b & $\begin{array}{c}473,08 \\
\text { (Geesthacht) }\end{array}$ & \multirow{2}{*}{203,2} & $\begin{array}{r}612,76 \\
\text { (Wedel) } \\
\end{array}$ & \multirow{2}{*}{165,0} \\
\hline & c & $\begin{array}{c}232,79 \\
\text { (Eckernförde) }\end{array}$ & & $\begin{array}{c}371,31 \\
\text { (Eckernförde) }\end{array}$ & \\
\hline \multirow{2}{*}{$\geq 50000$} & $\mathrm{~b}$ & $\begin{array}{r}485,55 \\
\text { (Lübeck) } \\
\end{array}$ & \multirow{2}{*}{174,5} & $\begin{array}{r}614,29 \\
(\mathrm{Kiel}) \\
\end{array}$ & \multirow{2}{*}{140,2} \\
\hline & c & $\begin{array}{l}278,27 \\
\text { (Flensburg) }\end{array}$ & & $\begin{array}{c}438,19 \\
\text { (Flensburg) }\end{array}$ & \\
\hline
\end{tabular}

1) Eine Gemeinde (Norderfriedrichskoog) weist eine Realsteueraufbringungskraft von null DM auf.

$\mathrm{a}=$ Steuerkraft der steuerstärksten Gemeinde in \% der Steuerkraft der steuerschwächsten Gemeinde der jeweiligen Größenklasse.

$\mathrm{b}=$ steuerstärkste Gemeinde.

$\mathrm{c}=$ steuerschwächste Gemeinde.

Quelle: Berechnet nach

Statistische Berichte des Statistischen Landesamtes Schleswig-Holstein,

Realsteuervergleich in Schleswig-Holstein 1974, Kiel, Oktober 1975. 
gemeindliche Steuerkraft berechneten Variationskoeffizienten schlägt sich der Einfluß der Gemeindefinanzreform auf die Streuung der kommunalen Steuerkraft aller Landkreise und aller kreisfreien Städte des Bundesgebiets nieder.

In Tabelle $17 \mathrm{~b}$ ist ein zweiter Indikator verwendet worden, um den Einflu $\beta$ der Gemeindefinanzreform auf das horizontale Steuerkraftgefälle in der Bundesrepublik zu messen. Dieses Streuungsmaß dient zur Ergänzung der Variationskoeffizienten, da es sehr anschaulich ist. Für jedes einzelne Bundesland sind die Landkreise mit der höchsten Realsteuerkraft pro Kopf und mit der höchsten gemeindlichen Steuerkraft pro Kopf den Landkreisen mit den niedrigsten Steuerkraftwerten gegenübergestellt. Das Verhältnis zwischen dem Steuerkraftwert des reichsten und dem Steuerkraftwert des ärmsten Landkreises vermittelt einen Einblick in das regionale Steuerkraftgefälle innerhalb der einzelnen Bundesländer, das ohne Gemeindefinanzreform vorzufinden gewesen wäre und nach der Gemeindefinanzreform tatsächlich besteht. An der Differenz zwischen dieser Relation für die Realsteuerkraft und für die gemeindliche Steuerkraft zeigt sich der Einfluß der Gemeindefinanzreform auf das regionale Gefälle der kommunalen Steuerkraft in den einzelnen Bundesländern. Für die kreisfreien Städte der einzelnen Länder sind dieselben Steuerkraftrelationen berechnet worden. Um das intraregionale Steuerkraftgefälle noch deutlicher zu machen, ist schließlich der Steuerkraftwert der reichsten kreisfreien Stadt eines Landes mit dem Steuerkraftwert seines ärmsten Landkreises in Beziehung gesetzt worden (Tabelle 17b, Spalte 9 und 10). In der untersten Zeile der Tabelle $17 \mathrm{~b}$ sind wieder die entsprechenden Werte für das gesamte Bundesgebiet angegeben.

\subsubsection{Relativierung der Untersuchungsergebnisse}

Auch auf der Ebene der Landkreise und der kreisfreien Städte gibt die Realsteuerkraft nicht die Steuerkraftposition an, die die zu Landkreisen zusammengefaßten Gemeinden bzw. die kreisfreien Städte 1974 ohne Gemeindefinanzreform von 1969 erreicht hätten. Der Gewerbesteuerausgleich, der 1974 ohne Gemeindefinanzreform durchgeführt worden wäre, hätte zu einer Abweichung zwischen der Steuerkraft ohne Reform und der Realsteuerkraft der Landkreise bzw. der kreisfreien Städte geführt. Über Richtung und Aus maß dieser Abweichung müssen einige Überlegungen angestellt wèrden, damit die in den Tabellen $17 \mathrm{a}$ und $17 \mathrm{~b}$ zusammengestellten Ergebnisse dieser Untersuchung angemessen interpretiert werden können.

Im Rahmen eines Gewerbesteuerausgleichs zwischen Wohn- und Betriebsgemeinden im Jahr 1974 hätten Gemeinden eines Landkreises Ausgleichszahlungen an Gemeinden desselben Landkreises leisten müssen. Diese intraregionalen Ausgleichszahlungen hätten keine Abweichung der Steuerkraft eines Landkreises ohne Reform von seiner Realsteuerkraft bewirkt und wären damit ohne Einfluß auf die horizontale Streuung der Steuerkraft der Landkreise geblieben. Anders verhält es sich mit den Ausgleichszahlungen, die von kreisangehörigen Gemeinden eines Landkreises an solche eines anderen Landkrei- 
ses und die von kreisfreien Städten an kreisangehörige Gemeinden gegangen wären. Diese interregionalen Ausgleichszahlungen hätten 1974 dafür gesorgt, daß die Steuerkraft der Landkreise ohne Reform von ihrer Realsteuerkraft abgewichen wäre. Nimmt man an, daß die gewerbesteuerschwachen, stark agrarisch strukturierten Landkreise pro Einwohner höhere Gewerbesteuerausgleichszahlungen von den kreisfreien Städten erhalten hätten als die gewerbesteuerstarken Landkreise, (233) so hätte der Gewerbesteuerausgleich 1974 auch auf Kreisebene die Steuerkraftunterschiede abgeschwächt. Ein Teil der für 1974 für die Landkreise festgestellten Differenz zwischen den Variationskoeffizienten der Realsteuerkraft und der gemeindlichen Steuerkraft muß also mit dem Wegfall des horizontalen Nivellierungseffekts des Gewerbesteuerausgleichs erklärt werden. Doch muß das Ausmaß dieses horizontalen Nivellierungseffektes als ziemlich gering eingeschätzt werden, da ja der intraregionale Teil der Gewerbesteuerausgleichszahlungen die Streuung der Steuerkraft der Landkreise unverändert läßt und sich die interregionalen Ausgleichszahlungen pro Kopf zwischen den Landkreisen nicht allzu sehr unterscheiden dürften. Deshalb wird hier davon ausgegangen, daß die Variationskoeffizienten für die Realsteuerkraft nur minimal von denen für die Steuerkraft ohne Gemeindefinanzreform abweichen und somit ein ziemlich genaues Bild von der horizontalen Streuung der Steuerkraft der Landkreise wiedergeben, die sich 1974 ohne Gemeindefinanzreform eingestellt hätte.

Für die Streuung der Steuerkraft der kreisfreien Städte hätte ein Gewerbe steuerausgleich 1974 vermutlich eine wesentlich größere Bedeutung als für die Landkreise. Die kreisfreien Städte hätten 1974 in geringem Umfang an andere kreisfreie Städte und in einem erheblichen Umfang an kreisangehörige Gemeinden Gewerbesteuerausgleichszahlungen zu entrichten. Dabei hätten die gewerbesteuerstärksten kreisfreien Städte, deren großes Arbeits platzangebot viele Arbeitskräfte aus den umliegenden Landkreisen anzieht, pro Einwohner höhere (negative) Gewerbesteuerausgleichssalden aufgewie sen als die gewerbesteuerschwachen kreisfreien Städte. Somit hätte ein Ge werbesteuerausgleich im Jahr 1974 vermutlich zu einer relativ starken $\mathrm{Ab}$ schwächung der Steuerkraftunterschiede zwischen den kreisfreien Städten geführt. Ihr Ausmaß wäre mit Sicherheit größer gewesen als im Fall der Landkreise. Für die kreisfreien Städte kann also vermutet werden, daß ein nicht zu vernachlässigender Teil der Differenz zwischen dem Variationskoeffizienten für die Realsteuerkraft und dem für die gemeindliche Steuerkraft auf den Wegfall des Gewerbesteuerausgleichs zurückgeführt werden muß.

\subsection{Interpretation und Beurteilung der Ergebnisse}

Der Einfluß der Gemeindefinanzreform von 1969 auf die horizontale Streuung der kommunalen Steuerkraft läßt sich am besten den in Tabelle 17a zusammengestellten Ergebnissen der Untersuchung entnehmen.

In den einzelnen Bundesländern liegen die Variationskoeffizienten für die Steuerkraft der zu Landkreisen zusammengefaßten Gemeinden um etwa 20 - 
Tabelle 17a Der Einfluß der Gemeindefinanzreform auf die horizontale Streuung der kommunalen Steuerkraft im Jahr 1974 auf der Ebene der Landkreise und der kreisfreien Städte

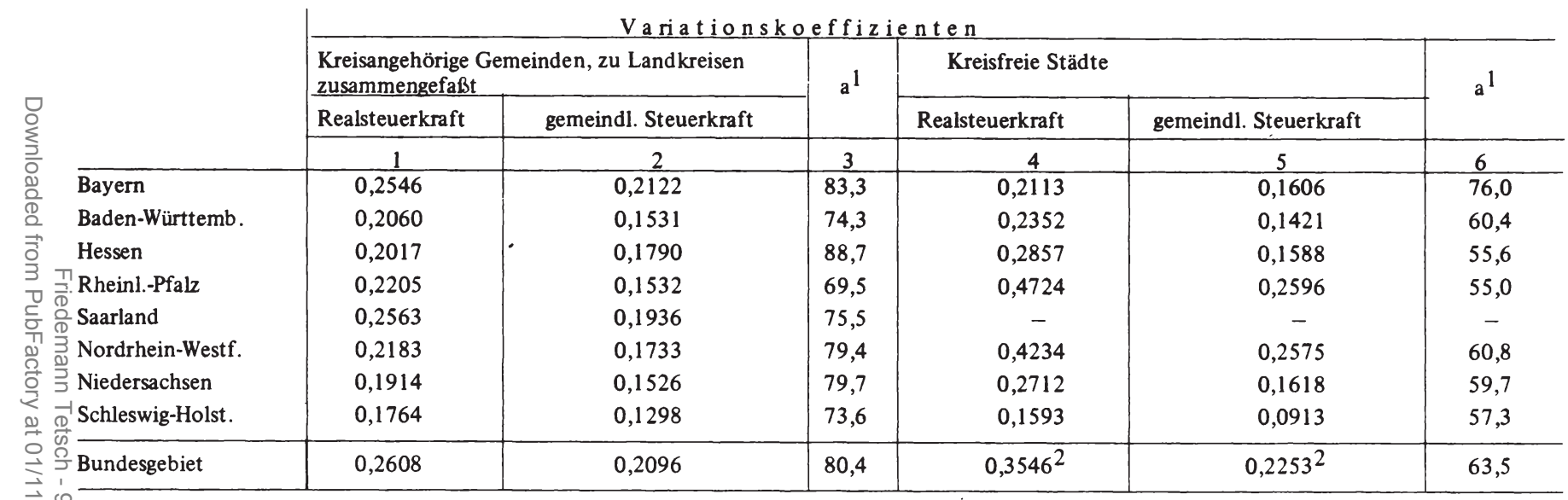

1) Variationskoeffizient für die gemeindliche Steuerkraft in \% des Variationskoeffizienten für die Realsteuerkraft.

2) Einschließlich Hamburg, Bremen und Berlin.

Quelle: Berechnet nach

Statistisches Bundesamt, Finanzen und Steuern, Reihe 9, Realsteuervergleich 1974,

Stuttgart, Mainz, Dezember 1975, S. 78 - 99. 
$30 \%$ unter den Variationskoeffizienten für die Realsteuerkraft (Spalte 3). (234) Die Variationskoeffizienten für die Realsteuerkraft können als nahezu identisch mit denen für die fiktive Steuerkraft der Landkreise ohne Gemeindefinanreform angesehen werden. Folglich bedeutet die festgestellte Differenz, daß die Gemeindefinanzreform von 1969 die horizontale Streuung der kommunalen Steuerkraft der Landkreise in den einzelnen Bundesländern im Jahr 1974 um 20 - $30 \%$ abschwächt. Für Schleswig-Holstein beträgt der horizontale Nivellierungseffekt der Gemeindefinanzreform auf der Ebene der Landkreise rund $26 \%$. Dieser Wert entspricht ziemlich genau demjenigen, der für Schleswig-Holstein auf der Basis von Gemeindewerten berechnet worden ist. (235)

Die horizontale Streuung der kommunalen Steuerkraft aller Landkreise des Bundesgebiets ist als Folge der Gemeindefinanzreform um $20 \%$ geringer, als sie vermutlich ohne Gemeindefinanzreform gewesen wäre.

Die Variationskoeffizienten für die gemeindliche Steuerkraft der kreisfreien Städte weichen in den einzelnen Ländern wesentlich stärker von den Variations koeffizienten für die Realsteuerkraft ab, als dies bei den Landkreisen der Fall ist. Sie liegen in allen Bundesländern mit Ausnahme Bayerns $40-45 \%$ unter denen für die Realsteuerkraft der kreisfreien Städte (Spalte 6). Hier wird vermutet, daß ein nicht unwesentlicher Teil dieser Differenz nicht als Auswirkung der Gemeindefinanzreform interpretiert werden darf, sondern mit dem Wegfall des Gewerbesteuerausgleichs zu erklären ist. Über das Aus maß, mit dem der horizontale Nivellierungseffekt eines Gewerbesteueraus gleichs für das Jahr 1974 angesetzt werden könnte, liegen keine statistisch gesicherten Anhaltspunkte vor. Doch wird man sicherlich auch in diesem Fall höchstens ein Viertel der festgestellten Differenzen zwischen den Variationskoeffizienten mit dem Wegfall des Gewerbesteuerausgleichs erklären können. (236) Unter dieser Annahme kann man aus den vorliegenden Untersuchungsergebnissen den Schluß ziehen, daß die Gemeindefinanzreform im Jahr 1974 mehr als $30 \%$ und weniger als $40 \%$ der horizontalen Streuung der kommunalen Steuerkraft der kreisfreien Städte beseitigt. Damit ist der horizontale Nivellierungseffekt der Gemeindefinanzreform in Bezug auf die kreisfreien Städte stärker als hinsichtlich der Landkreise.

Für das gesamte Bundesgebiet beträgt der Variationskoeffizient für die gemeindliche Steuerkraft der kreisfreien Städte 63,5 \% desjenigen für die Realsteuerkraft. Unter Berücksichtigung des horizontalen Nivellierungseffektes eines Gewerbesteuerausgleichs kann man feststellen, daß die Gemeindefinanzreform von 1969 die horizontale Streuung der Steuerkraft der kreisfreien Städte der Bundesrepublik im Jahr 1974 um rund $30 \%$ verringert.

Damit bestätigt diese Untersuchung im wesentlichen die für Schleswig-Holstein auf der Basis von Gemeindewerten gefundenen Ergebnisse. Aus regionalpolitischer Sicht müssen deshalb die für jedes einzelne Bundesland und für das gesamte Bundesgebiet ermittelten Auswirkungen der Gemeindefinanzreform auf die horizontale Streuung der kommunalen Steuerkraft ebenso negativ beurteilt werden wie im Fall der auf Schleswig-Holstein beschränkten Unter suchung. Die Gemeindefinanzreform von 1969 schwächt zwar die regional- 
politisch unerwünschten Unterschiede in der kommunalen Steuerkraft der Landkreise bzw. der kreisfreien Städte ab, doch ist dieser horizontale Nivellierungseffekt quantitativ völlig unzureichend. Auch nach Durchführung der Gemeindefinanzreform existiert in jedem einzelnen Bundesland und im ge samten Bundesgebiet ein ausgesprochen starkes regionales Steuerkraftgefälle. Darüber gibt Tabelle 17b Auskunft.

In dem Bundesland mit dem geringsten regionalen Steuerkraftgefälle (Schles wig-Holstein) (237) verfügt 1974 der steuerstärkste Landkreis über 60, $3 \%$ höhere Steuereinnahmen pro Kopf als der steuerschwächste Landkreis. In Bayern, dem Land mit dem stärksten regionalen Steuerkraftgefälle, (237) beläuft sich der Steuerkraftvorsprung des steuerstärksten gegenüber dem steuerschwächsten Landkreis auf $176,7 \%$ (Spalte 4). Betrachtet man das gesamte Bundesgebiet, so sind die auch nach der Gemeindefinanzreform existierenden regionalen Steuerkraftunterschiede noch bedenklicher. Die Steuerkraft des reichsten Landkreises in der Bundesrepublik beträgt 328, 7 \% derjenigen des ärmsten Landkreises.

Aus regionalpolitischer Sicht haben alle Landkreise bzw. die in ihnen zusammengefaßten Gemeinden für ihre Einwohner grundsätzlich die gleichen Aufgaben zu erfüllen, die man mit den Begriffen der Versorgungs- und der Entwicklungsfunktion bezeichnen kann. Das Gemeindesteuersystem der Bundesrepublik Deutschland berücksichtigt diese Sachlage nicht. Es sorgt vielmehr dafür, daß einige Landkreise die Versorgungs- und Entwicklungsfunktion bes ser als andere Landkreise ausüben können und bewirkt damit regionale Unterschiede in der Attraktionskraft der untergeordneten Gebietskörperschaften.

Ebenso ungünstig wie im Fall der Landkreise sieht die Steuerkraftverteilung auf die einzelnen kreisfreien Städte in den einzelnen Bundesländern und im gesamten Bundesgebiet aus. Die Steuerkraft der reichsten kreisfreien Stadt liegt im Jahr 1974 zwischen 24, 5 \% (Schleswig-Holstein) und 216, 8 \% (Nordrhein-Westfalen) über der Steuerkraft der ärmsten kreisfreien Stadt des jeweiligen Bundeslandes (Spalte 8).

Bisher sind die Gruppe der Landkreise und die Gruppe der kreisfreien Städte getrennt untersucht worden. Vergleicht man nun die Steuerkraft der reichsten kreisfreien Stadt mit der Steuerkraft des ärmsten Landkreises, ergibt sich eine erhebliche Verschärfung des regionalen Steuerkraftgefälles sowohl in den einzelnen Bundesländern als auch auf der Ebene des Bundesgebiets. Diese Steuerkraftrelation reicht 1974 von $177,8 \%$ in Schleswig-Holstein bis $418,4 \%$ in Rheinland-Pfalz. Die steuerstärkste kreisfreie Stadt des Bundesgebiets verfügt trotz der Gemeindefinanzreform über eine Steuerkraft, die um 458, 7 \% über derjenigen des steuerschwächsten Landkreises der Bundesrepublik liegt (Spalte 10).

Aus regionalpolitischer Sicht muß man davon ausgehen, daß die kreisfreien Städte weitgehend dieselben Aufgaben für ihre Einwohner zu erfüllen haben wie die Landkreise. Höhere Steuereinnahmen pro Einwohner sind nur dann gerechtfertigt, wenn die kreisfreien Städte die Einwohner der umliegenden Landkreise mit öffentlichen Leistungen versorgen. Man kann unterstellen, 
Tabelle 17b Der Einfluß der Gemeindefinanzreform auf die horizontale Streuung der kommunalen Steuerkraft im Jahr 1974 auf der Ebene der Landkreise und der kreisfreien Städte

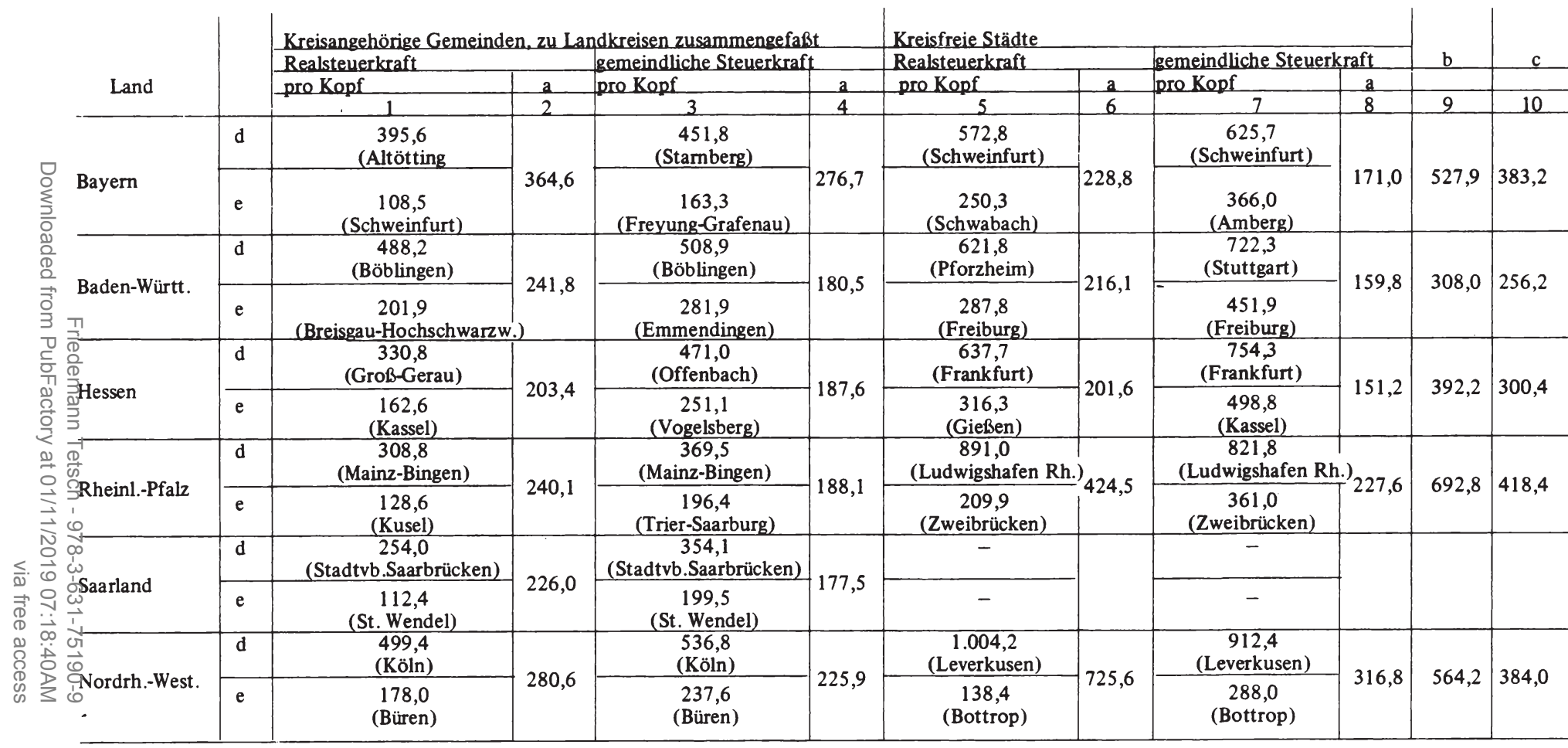


noch Tabelle 17 b Der Einfluß der Gemeindefinanzreform auf die horizontale Streuung der kommunalen Steuerkraft im Jahr 1974 auf der Ebene der Landkreise und der kreisfreien Städte

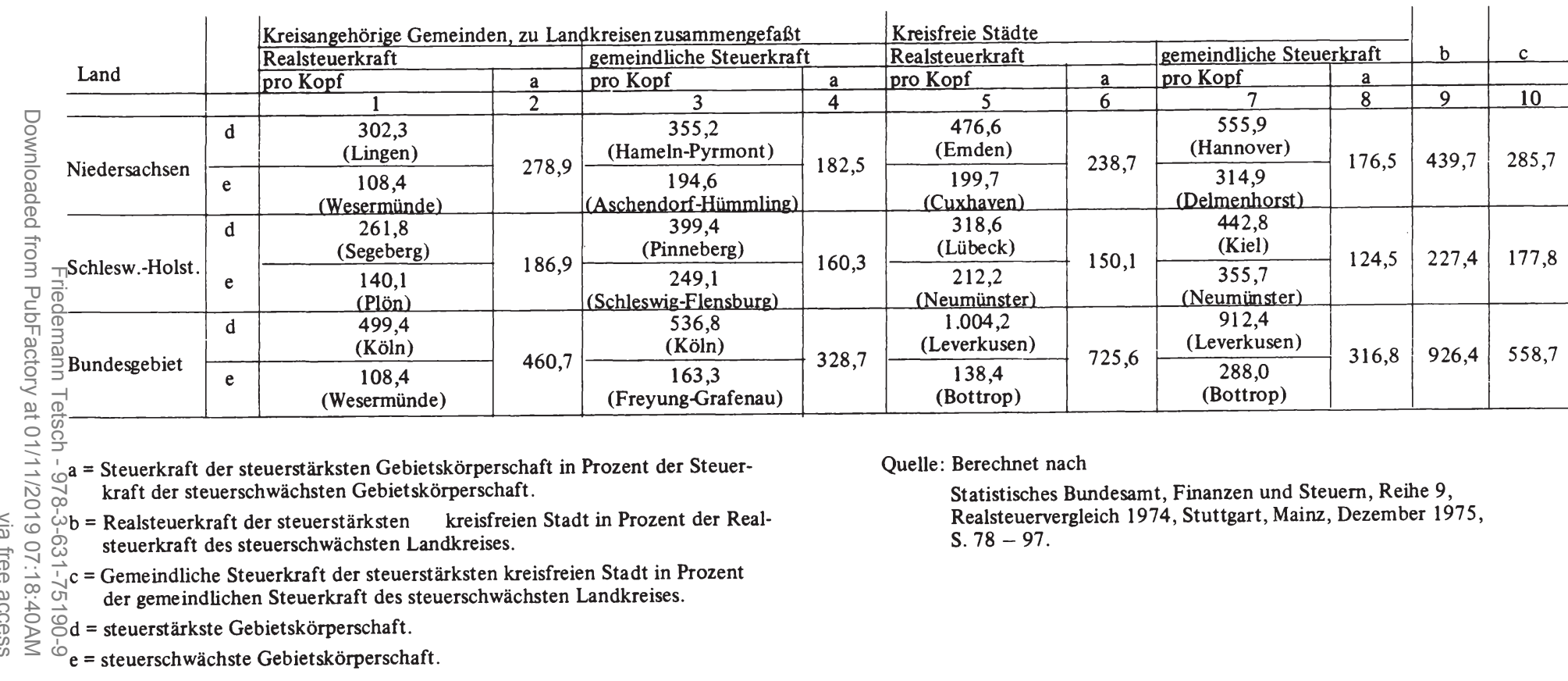


daß dieser Fall für die meisten kreisfreien Städte zutrifft. Über diese durch Ertrags-spillouts gerechtfertigten Steuerkraftunterschiede gehen aber die tatsächlichen Steuerkraftunterschiede zwischen Landkreisen und kreisfreien Städten weit hinaus.

Zusammenfassend kann man feststellen:

Auch nach der Gemeindefinanzreform verursacht das kommunale Steuersystem der Bundesrepublik enol me regionale Steuerkraftunterschiede

- innerhalb der Gruppe der I andkreise,

- innerhalb der Gruppe der $\mathrm{k}$ eisfreien Städte und

- zwischen den kreisfreien Stadten und den Landkreisen.

Das Gemeindesteuersystem verstärkt damit den räumlichen Differenzierungs prozeß innerhalb der einzelnen Bundesländer und innerhalb des gesamten Bundesgebietes und wirkt direkt ballungsfördernd. Die Gemeindefinanzreform von 1969 hat lediglich bewirkt, daß diese regionalpolitisch unerwünschten Effekte des kommunalen Steuersystems nicht mehr ganz so stark sind, wie sie ohne Reform gewesen wären.

VI. Die Aufstockung der kommunalen Steuerkraft durch Finanzzuweisungen von Bund und Ländern

Im letzten Abschnitt ist untersucht worden, welche Raumwirkungen von den Vorschriften über die Verteilung der den Gemeinden insgesamt zustehenden Steuereinnahmen auf die einzelnen Gemeinden ausgehen. Diese isolierte Betrachtung der horizontalen Verteilung der kommunalen Steuereinnahmen führt zu dem Ergebnis, daß das kommunale Steuersystem die großen Gemeinden und wirtschaftsstarken Regionen mit weit überdurchschnittlich hohen Steuer einnahmen pro Kopf (bei einheitlicher Steueranspannung) ausstattet und des halb die regionalen Steuerkraft- und Wirtschaftskraftunterschiede tendenziell verstärkt.

Die Ausgestaltung des kommunalen Steuersystems ist aber nicht das einzige Mittel, mit dem die übergeordneten Gebietskörperschaften (Bund und Länder) die Einnahmenpositionen und damit die Attrahierungsmöglichkeiten der einzelnen lokalen (regionalen) Gebietskörperschaften beeinflussen können. Daneben besitzen sie die Möglichkeit, durch die Gewährung von Finanzzuweisungen direkt die Einnahmenposition der einzelnen Gemeinden und Gemeinde verbände zu bestimmen. Die regionale Verteilung der Finanzmasse, die für Finanzzuweisungen an die Gemeinden und Gemeindeverbände zur Verfügung steht, (238) ist ein Instrument, mit dem Richtung und Ausmaß der nach der Steuerverteilung bestehenden kommunalen Einnahmekraftunterschiede wirksam verändert werden können. In der Bundesrepublik Deutschland werden den Gemeinden und Gemeindeverbänden in einem solchen Umfang Finanzzu weisungen gewährt, (239) daß der davon ausgehende Einfluß auf die Raumstruktur nicht vernachlässigt werden darf. Will man die räumlichen Auswirkungen ermitteln, die von der Ausstattung der lokalen (regionalen) Gebietskörperschaf ten mit Finanzmitteln in der Bundesrepublik ausgehen, darf man nicht bei der 
Analyse der Raumwirkungen des kommun: Zusätzlich muß man wenigstens noch die 1 weisungen von Bund und Ländern an die $G_{1}$ in die Untersuchung einbeziehen. en Steuersystems stehenbleiben. gionale Verteilung der Finanzzuneinden und Gemeindeverbände

Im Rahmen dieser Arbeit interessieren in oesondere zwei Fragen:

- Welchen Einfluß übt der vertikale Gemє ndefinanzausgleich auf die Raumstruktur aus? Verstärkt er die ballungs örderndı n Effekte, die vom kommunalen Steuersystem ausgehen oder wirkt er di ssen regionalpolitisch unerwünschten Effekten entgegen?

- In welcher Weise beeinflußt das kommunale Einnahmensystem der Bundesrepublik Deutschland, bestehend aus dem Gemeindesteuersystem und dem vertikalen Gemeindefinanzausgleich, die räumliche Verteilung der Ressourcen? Verfügen die Regionen mit überdurchschnittlicher Wirtschafts - und Steuerkraft auch nach Durchführung des vertikalen Gemeindefinanzausgleichs über absolut höhere Einnahmen pro Kopf als wirtschafts schwache Regionen oder ist den letzteren durch politische Entscheidung ein Finanzkraftvorsprung gegenüber den ersteren verschafft worden?

Die beiden Fragestellungen werden anschließend auf der Ebene der einzelnen Bundesländer und überwiegend bezogen auf das Jahr 1974 behandelt.

1. Die räumlichen Auswirkungen des Finanzausgleichs zwischen Ländern (Bund) und Gemeinden (Gemeindeverbänden) im Jahr 1974

1.1. Die regionalpolitisch erwünschte Verteilung der Finanzzuweisungen von Bund und Ländern an Gemeinden und Gemeindeverbände

Die Raumwirkungen der Verteilung der Finanzzuweisungen an die Gemeinden und Gemeindeverbände werden mit Hilfe derselben Überlegungen ermittelt, die auch im Zusammenhang mit der regionalen Verteilung der Steuereinnahmen und der Verteilung der Investitionszuweisungen des Bundes an die Länder angestellt worden sind. (240) Als Indikator für den Einfluß, der vom vertikalen Gemeindefinanzausgleich auf die Raumstruktur ausgeht, dient die absolute Höhe der Pro-Kopf-Zuweisungen, die den einzelnen Gemeinden (Gemeindeverbänden) zufließen. Erhält eine Gemeinde überdurchschnittlich hohe Zuweisungen pro Einwohner, wird sie damit finanziell in die Lage versetzt, pro Einwohner absolut höhere zusätzliche Leistungen anzubieten als Gemeinden mit unterdu rchschnittlich hohen Pro-Kopf-Zuweisungen. Handelt es sich bei den Gemeinden mit überdurchschnittlich hohen Pro-Kopf-Zuweisungen um Gemeinden mit überdurchschnittlicher Steuer- und Wirtschaftskraft, verstärkt die Verteilung der vertikalen Ausgleichszahlungen die ballungsfördernden Effekte des kommunalen Steuersystems. Dagegen wirkt die Verteilung der Finanzzuweisungen an die Gemeinden (Gemeindeverbände) den Ballungstendenzen entgegen, wenn Gemeinden mit unterdurchschnittlicher Steuer- und Wirtschaftskraft pro Einwohner überdurchschnittlich hohe Pro-Kopf-Zuweisungen erhalten, während sich steuer - und wirtschaftsstarke 
Gemeinden mit unterdurchschnittlichen Pro-Kopf-Zuweisungen zufrieden geben müssen. (241)

Aus dem Vorstehenden ergeben sich unmittelbar Kriterien, mit denen die tatsächliche Verteilung der Finanzzuweisungen an die Gemeinden (Gemeindeverbände) auf ihre Vereinbarkeit mit den hier zugrundegelegten regionalpolitischen Zielen geprüft werden kann. Eine Verteilung der für Finanzzuweisungen bereitstehenden Finanzmasse nach der Einwohnerzahl der Gemeinden (Regionen) ist aus regionalpolitischer Sicht nur bedingt positiv zu beurteilen. Sie verhindert zwar, daß die stark agglomerierten Regionen mit ihrer überdurchschnittlichen Wirtschafts - und Steuerkraft auch noch überdurchschnittlich hohe Fro-Kopf-Zuweisungen erhalten und damit trotz ballungsbedingter Kostensteigerungen der öffentlichen Leistungserstellung genauso viel oder gar absolut höhere zusätzliche Leistungen pro Einwohner anbieten können als wirtschafts - und steuerschwache Regionen. Eine Verteilung der kommunalen $F$ inanzausgleichsmasse nach der Einwohnerzahl verringert jedoch nicht den pro Einwohner existierenden absoluten Einnahmenrückstand der wirtschafts - und steuerschwachen Gemeinden (Regionen) gegenüber den Wohlstands und Ballungsregionen. Den ersteren ist es damit auch nicht möglich, durch absolut höhere zusätzliche Ausgaben pro Kopf den durch die Steuerkraftverteilung bedingten absoluten Abstand im (Infrastruktur-) Leistungsangebot pro Einwohner gegenüber den letzteren aufzuholen. Deswegen muß aus regionalpolitischer Sicht eine Verteilung der kommunalen Ausgleichsmasse gefordert werden, durch die die steuer- und wirtschaftsschwachen Regionen überdurchschnittlich hohe, die steuer- und wirtschaftsstarken Regionen unterdurchschnittlich hohe Pro-Kopf-Zuweisungen erhalten.(242) Nur einer solchen Verteilung der Zuweisungen an die Gemeinden (Gemeindeverbände) kann eine ballungsbremsende Wirkung, durch die die ballungsverstärkenden Effekte des kommunalen Steuersystems wenigstens teilweise kompensiert werden, zugesprochen werden. Demzufolge werden die anschließend ermittelten tatsächlichen Verteilungen der Finanzzuweisungen von Bund und Ländern an die Gemeinden und Gemeindeverbände dann als regionalpolitisch zielkonform be urteilt, wenn die steuerschwachen (wirtschaftsschwachen) Gemeinden und Regionen mindestens und die steuerstarken (wirtschaftsstarken) Gemeinden und Regionen höchstens durchschnittlich hohe Pro-Kopf-Zuweisungen erhalten.

\subsection{Das methodische Vorgehen}

Die tatsächliche Verteilung der Finanzzuweisungen von Bund und Ländern an die Gemeinden und Gemeindeverbände wird für das Jahr 1974 in den Tabellen $18 \mathrm{a}-18 \mathrm{f}$ und 19a - 19g ermittelt. Die Finanzzuweisungen werden unterglie dert in "allgemeine Zuweisungen, Erstattungen von Verwaltungs - und Betriebsausgaben, Zuweisungen und Zuschüsse für laufende Zwecke, Zinseinnahmen, Schuldendiensthilfen" und "Zuweisungen und Zuschüsse für Investitionen und Investitionsförderungsmaßnahmen", wobei die entsprechenden Zuweisungen von Land und Bund $z u$ jeweils einem Posten zusammengefaßt sind. Die Bereinigung der "allgemeinen Zuweisungen usw." von denjenigen Zuweisungen, die lediglich die Gemeindehaushalte durchlaufen und deswegen von den Gemein- 
den nicht zur Attrahierung von Ressourcen eingesetzt werden können, (243) ist aus statistischen Gründen nicht möglich.

Die räumlichen Auswirkungen des vertikalen Gemeindefinanzausgleichs im Jahr 1974 werden in einem ersten Ansatz auf der Basis der Gliederung der Gemeinden nach Größenklassen untersucht. Für die zu Größenklassen zu sammengefaßten Gemeinden werden die Pro-Kopf-Werte der Steuereinnahmekraft, der allgemeinen Finanzzuweisungen usw., der Investitionszuweisungen, der gesamten Finanzzuweisungen und der Finanzkraft berechnet. Die Gliederung der Gemeinden nach Größenklassen erlaubt jedoch nur vorläufige und relativ vage Aussagen über den Einfluß des vertikalen Gemeindefinanzausgleichs auf die Raumstruktur.

Einmal ist es nämlich nicht möglich, die für die Zuweisungen und die Finanzkraft berechneten Pro-Kopf-Werte der kreisfreien Städte mit den entsprechenden Pro-Kopf-Werten der kreisangehörigen Gemeinden zu vergleichen. Dies liegt daran, daß die kreisfreien Städte auch solche Zuweisungen erhalten, die im Fall der kreisangehörigen Gemeinden deren Gemeindeverbänden zufließen und von diesen zur Erfüllung kommunaler Aufgaben in ihrem Kreisgebiet eingesetzt werden. Bei einer Gliederung nach Gemeindegrößenklassen können die Raumwirkungen des vertikalen Gemeindefinanzausgleichs also nur getrennt für die Gruppe der kreisfreien Städte und für die Gruppe der kreisangehörigen Gemeinden aufgezeigt werden.

$\mathrm{Zu}$ diesem Problem der mangelnden Vergleichbarkeit der Daten kommt noch die Schwierigkeit, die Verteilung der Zuweisungen auf die einzelnen Gemeindegrößenklassen auf ihre regionalpolitische Zieladäquanz zu prüfen. Betrachten wir z. B. den Fall, daß die kreisangehörigen Gemeinden eines Landes mit mehr als 50.000 Einwohnern im Durchschnitt überdurchschnittlich hohe Pro-Kopf-Zuweisungen, die Gemeinden mit weniger als 3.000 Einwohnern unterdurchschnittliche und damit absolut geringe re Pro-Kopf-Zuweisungen als die großen Gemeinden erhalten. Das hohe Niveau der Zuweisungen an die Gemeinden mit mehr als 50.000 Einwohnern kann dadurch verursacht werden, daß im Rahmen einer Regionalpolitik der dezentralen Schwerpunktbildung (244) den in schwach strukturierten Regionen liegenden Gemeinden dieser Größenklasse weit überdurchschnittliche, dagegen den in Ballungs regionen liegenden Gemeinden dieser Größenklasse weit unterdurchschnittliche Zuweisungen pro Einwohner zufließen. Eine solche Verteilung der $\mathrm{Zu}-$ weisungen von Bund und Ländern an die Gemeinden wäre aber aus regionalpolitischer Sicht keinesfalls negativ zu bewerten. Überdurchschnittlich hohe Pro-Kopf-Zuweisungen für große Gemeinden sind nur dann in jedem Fall mit dem hier zugrundegelegten regionalpolitischen Zielsystem unvereinbar, wenn die begünstigten Gemeinden zugleich in wirtschaftsstarken, hochverdichteten Regionen liegen.

Aus diesen beiden Gründen wird als zweiter Ansatz für die Untersuchung der Raumwirkungen des vertikalen Gemeindefinanzausgleichs die regionale Glie derung gewählt. Die Finanzzuweisungen von Bund und Land an alle Gemeinden eines Landkreises werden zusammengefaßt und mit den Finanzzuweisungen von Land und Bund an den entsprechenden Gemeindeverband addiert. Die - 
se Summe der Zuweisungen an den einzelnen Landkreis gibt an, in welchem Umfang im Rahmen des vertikalen Gemeindefinanzausgleichs der einzelnen als Landkreis abgegrenzten Region Finanzmittel zur Erfüllung der öffentlichen Aufgaben zur Verfügung gestellt werden. Diese Zuweisungen an die Landkreise sind vollständig vergleichbar mit den Zuweisungen an die als kreisfreie Städte abgegrenzten Regionen.

In die Untersuchung über die räumlichen Auswirkungen des vertikalen Gemeindefinanzausgleichs und des kommunalen Finanzsystems in der Bundesrepublik Deutschland können nicht alle acht in Frage kommenden Flächenstaaten der Bundes republik einbezogen werden, da die dafür erforderlichen Daten nicht verfügbar sind. Für Baden-Württemberg liegen weder Daten über die Verteilung der Zuweisungen auf die nach Gemeindegrößenklassen gegliederten Gemeinden vor, noch können die veröffentlichten Angaben über die Zuweisungen an die einzelnen Landkreise Baden-Württembergs verwendet werden, da sie auch die Zuweisungen der kreisangehörigen Gemeinden an den jeweiligen Gemeindeverband, also die Kreisumlage enthalten, was zu einer erheblichen Doppelzählung führt. (245) Für Niedersachsen liegt nur die regionale Gliederung der Zuweisungen, nicht aber die nach Gemeindegrößenklassen vor. Dagegen existieren für Schleswig-Holstein für das Jahr 1974 nur Angaben über die Verteilung der Finanzzuweisungen an die zu Größenklassen zusammengefaßten Gemeinden. Deswegen ist für dieses Bundes land zusätzlich die regionale Verteilung der Finanzzuweisungen für das Jahr 1975 ermittelt und in Tabelle $19 \mathrm{~g}$ angegeben worden.

\subsection{Interpretation und Beurteilung der Ergebnisse}

1.3.1. Die Verteilung der Finanzzuweisungen von Bund und Ländern auf die einzelnen Gemeindegrößenklassen im Jahr 1974

Die Verteilung der Finanzzuweisungen von Bund und Ländern auf die zu Gemeindegrößenklassen zusammengefaßten Gemeinden soll hier nicht für alle einzelnen der erfaßten sechs Bundesländer getrennt interpretiert und beurteilt werden, um den Umfang der Arbeit nicht ungebührlich auszuweiten. Vielmehr sollen nur die wichtigsten Tendenzen komprimiert in thesenhafter Form wiedergegeben werden. Dabei wird in Kauf genommen, daß auf eine Reihe wichtiger und interessanter Unterschiede in der Verteilung der vertikalen Ausgleichszahlungen zwischen den einzelnen Bundesländern nicht eingegangen werden kann. Sie aus den Tabellen $18 \mathrm{a}-18 \mathrm{f}$ zu entnehmen, bleibt dem interessierten Leser überlassen.

Die Untersuchung über die Verteilung der Finanzzuweisungen von Bund und Ländern auf die einzelnen Gemeindegrößenklassen bringt im wesentlichen folgende Ergebnisse:

- Hinsichtlich des vertikalen Gemeindefinanzausgleichs können die sechs hier untersuchten Bundesländer in zwei Gruppen eingeteilt werden, wobei die Verteilung der vertikalen Ausgleichszahlungen zwischen den einzelnen Mitgliedern der jeweiligen Gruppen relativ große Ähnlichkeit aufweist. Die 
erste Gruppe umfaßt Hessen und Rheinland-Pfalz (Tabelle 18a und $18 \mathrm{~b}$ ), die zweite Gruppe besteht aus den Ländern Nordrhein-Westfalen, Bayern, Saarland und Schleswig-Holstein (Tabelle 18c - 18f).

- In Hessen und Rheinland-Pfalz erhalten im Jahr 1974 die steuerstärksten kreisfreien Städte, die in der Regel auch die größte Einwohnerzahl aufweisen, absolut höhere Zuweisungen pro Einwohner als die steuerschwächeren und kleineren kreisfreien Städte (Spalte 7 und 8 in Tabelle 18a und 18b). In Rheinland-Pfalz ist dies sowohl auf die Verteilung der allgemeinen Zuweisungen als auch auf die Verteilung der Investitionszuweisungen, in Hessen in erster Linie auf die Verteilung der Investitionszuweisungen zurückzuführen. Der vertikale Gemeindefinanzausgleich vergrößert damit in diesen beiden Ländern den absoluten Einnahmekraftvorsprung, den die großen und stark industrialisierten kreisfreien Städte gegenüber den kleineren und steuerschwächeren kreisfreien Städten bereits nach der Verteilung der kommunalen Steuereinnahmen besitzen. Damit trägt der vertikale Gemeindefinanzausgleich 1974 dazu bei, daß die steuerstärksten kreisfreien Städte ihren durch die Steuerkraftverteilung gegebenen Vorsprung im Attrahierungswettbewerb um mobile Ressourcen gegenüber den anderen kreisfreien Städten trotz ballungsbedingt höherer Kosten ihrer Leistungserstellung aufrecht erhalten oder gar noch ausweiten können.

Für die kreisangehörigen Gemeinden ergibt sich 1974 in beiden Ländern ein ähnliches Bild wie für die kreisfreien Städte: Mit steigender Gemeindegrößenklasse und damit wachsender Steuereinnahmekraft pro Einwohner nimmt tendenziell auch der Zuweisungsbetrag zu, den die zu Gemeindegrößenklassen zusammengefaßten Gemeinden im Durchschnitt pro Einwohner von Land und Bund erhalten. Diese Aussage gilt für beide Zuweisungsarten, wobei die positive Korrelation zwischen Pro-Kopf-Zuweisung und Gemeindegrößenklasse bei den Investitionszuweisungen stärker als bei den allgemeinen Zuweisungen ist. Insgesamt fließen den kreisangehörigen Gemeinden der obersten Größenklasse in Hessen 186,0\%, denjenigen in Rheinland-Pfalz sogar 250,9\% der Zuweisungen zu, die ihnen nach ihrer Einwohnerzahl zustehen.

Dank des vertikalen Gemeindefinanzausgleichs können also die großen kreis angehörigen Gemeinden in Hessen und Rheinland-Pfalz trotz eventuell höherer Kosten der Leistungserstellung genauso viel oder mehr öffentliche Leistungen pro Einwohner zusätzlich anbieten als die kleinen Gemeinden. Im Vergleich zu den kleinen Gemeinden werden dadurch die großen Gemeinden noch attraktiver für mobile Ressourcen, als sie dies bereits nach der Verteilung der kommunalen Steuereinnahmen sind.

Sollte die Mehrzahl der kreisangehörigen Gemeinden der obersten Größenklassen in Hessen und in Rheinland-Pfalz in Ballungsregionen mit hoher Wirtschaftskraft liegen, so schwächt diese Verteilung der Finanzzuweisungen von Land und Bund an die Gemeinden 1974 die automatischen Stabilisatoren des Ballungsprozesses und trägt möglicherweise noch unmittelbar zu einer Verstärkung der Ballungstendenzen in diesen beiden Ländern bei. Andererseits ist es aber auch denkbar, daß gerade denjenigen kreisangehörigen Gemeinden der obersten Größenklasse weit überdurchschnittliche Pro- 
Tabelle 18a Die Finanzkraft der kreisfreien Städte und der kreisangehörigen Gemeinden in Hessen im Jahr 1974

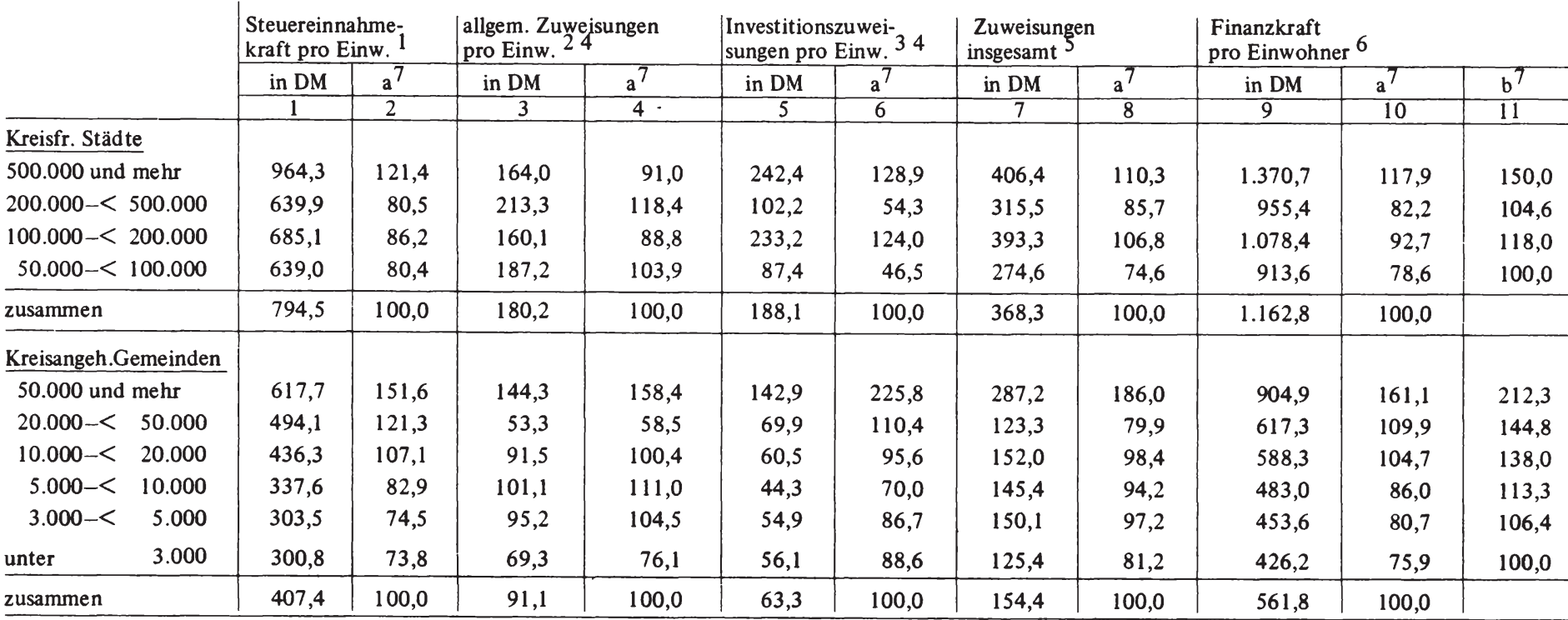

1) Quelle: Berechnet nach

Statistisches Bundesamt, Fachserie L, Finanzen und Steuern, Realsteuervergleich 1974, Stuttgart, Mainz, Dezember 1975 , S. $32-65$.

4) Quelle: Berechnet nach

Hessisches Statistisches Landesamt, Anlage zum Schreiben an den Verfasser vom 20.8.1975, VII 1 - Az.: 77g 231/75,

Tgb.-Nr. 978 und Anlage zum Schreiben an den Verfasser vom 24.9.1975, VII 1 - Az.: 77g 231/75, Tgb.-Nr. 1114.
2) Allgemeine Zuweisungen, Erstattungen von Verwaltungs- und Betriebsausgaber Zuweisungen und Zuschüsse für laufende Zwecke, Zinseinnahmen, Schuldendiensthilfen vom Land.

3) Zuweisungen und Zuschüsse für Investitionen und Investitionsförderungsmaßnahmen von Land und Bund.

5) Summe der Werte aus Spalte 3 und 5.

6) Summe der Werte aus Spalte 1, 3 und 5.

7) $\mathrm{a}=$ in $\%$ des jeweiligen Landesdurchschnitts $\mathrm{b}=$ in \% der jeweils untersten Größenklasse. 
Tabelle 18b Die Finanzkraft der kreisfreien Städte und der kreisangehörigen Gemeinden in Rheinland-Pfalz im Jahr 1974

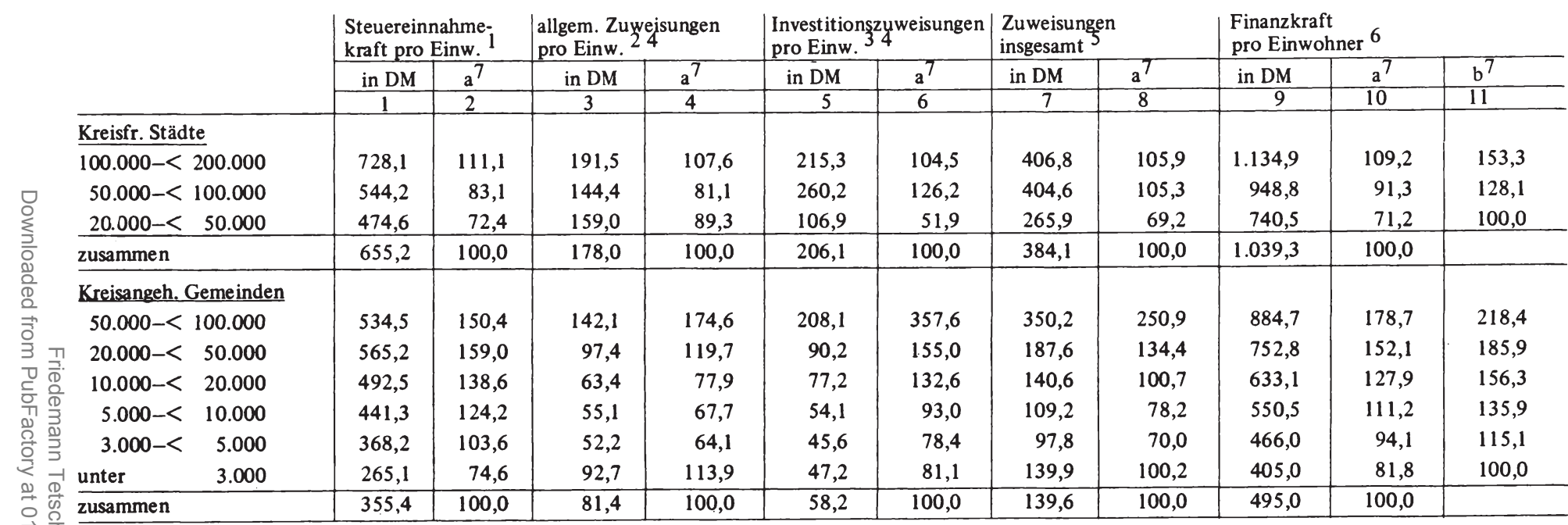

1) Quelle: Berechnet nach

Statistisches Landesamt Rheinland-Pfalz,

Statistische Berichte, Realsteuervergleich 1974, Bad Ems, September 1975, S. 3.

4) Quelle: Berechnet nach

Statistisches Landesamt Rheinland-Pfalz,

Statistische Berichte, Die kassenmäßigen Ausgaben und

Einnahmen der Gemeinden und Gemeindeverbände 1974,

Ergebnisse der vierteljährlichen Gemeindefinanzstatistik,

Bad Ems, August 1975, S. 8 f.
2) Allgemeine Zuweisungen und Zuweisungen für laufende Zwecke von Land und Bund.

3) Zuweisungen und Zuschüsse für Investitionen und Investitionsförderungsmaßnahmen von Land und Bund.

5) Summe der Spalten 3 und 5.

6) Summe der Spalten 1, 3 und 5.

7) $\mathrm{a}=$ in $\%$ des jeweiligen Landesdurchschnitts $\mathrm{b}=$ in \% der jeweils untersten Größenklasse. 
Kopf-Beträge von Land und Bund zugewiesen werden, die in ländlichen $\mathrm{Ab}$ wanderungsgebieten liegen. Die hier nachgewiesene Begünstigung der Ge meinden dieser Größenklasse im Rahmen des vertikalen Gemeindefinanzausgleichs wäre dann regionalpolitisch weit weniger ungünstig zu beurteilen als im ersten Fall. Auch wenn einiges für die erste Vermutung spricht, ist doch eine endgültige Beurteilung der räumlichen Auswirkungen des vertikalen Gemeindefinanzausgleichs in Hessen und Rheinland-Pfalz im Jahr 1974 erst auf der Basis der regionalen Gliederung der Gemeinden möglich.

- Die Verteilung der Finanzzuweisungen auf die nach Größenklassen gegliederten kreisfreien Städte in Nordrhein-Westfalen und Schleswig-Holstein im Jahr 1974 verfolgt offensichtlich das Ziel, die absoluten Einnahmekraftunterschiede $z w$ ischen den kreisfreien Städten zu verringern. Die Größenklassen mit den im Durchschnitt steuerschwächsten Gemeinden erhalten in beiden Ländern pro Einwohner höhere Zuweisungen als die Größenklassen, deren Gemeinden im Durchschnitt die höchste Steuereinnahmekraft pro Einwohner aufweisen (Spalte 7 und 8 in Tabelle 18c und 18e). Diese regionalpolitisch erwünschte Abschwächung der absoluten Einnahmekraftunterschiede pro Einwohner zwischen den kreisfreien Städten kommt in Nordrhein-Westfalen in erster Linie durch die Verteilung der allgemeinen Zuweisungen, dagegen in Schleswig-Holstein durch die Verteilung beider Zuweisungsarten zustande.

Im Gegensatz zu Nordrhein-Westfalen und Schleswig-Holstein werden in Bayern (246) die kreisfreien Städte mit der im Durchschnitt höchsten Steuereinnahmekraft pro Einwohner auch noch mit den höchsten Zuweisungen pro Einwohner ausgestattet (Spalte 7 und 8 in Tabelle 18d). Regionalpolitisch besonders bedenklich ist dabei, daß ausgerechnet die kreisfreien Städte mit mehr als 500.000 Einwohnern von allen kreisfreien Städten sowohl die höchsten allgemeinen Zuweisungen pro Einwohner als auch die höchsten Investitionszuweisungen pro Einwohner zugewiesen bekommen. Dadurch können die Gemeinden dieser Größenklasse mindestens ebenso hohe, wenn nicht gar höhere zusätzliche Leistungen pro Einwohner anbieten als die anderen kreisfreien Städte. In Bayern stärkt also der vertikale Gemeindefinanzausgleich im Jahr 1974 die Attraktionskraft der größten und steuerkräftigsten kreisfreien Städte im Vergleich zu den kleineren und steuerschwächeren Städten und wirkt somit tendenziell ballungsfördernd. Hinsichtlich der Verteilung der Finanzzuweisungen auf die nach Größenklassen gegliederten kreisfreien Städte im Jahr 1974 müßte Bayern mit Hessen und Rheinland-Pfalz zu einer Gruppe zusammengefaßt werden. Da jedoch die Verteilung der Zuweisungen auf die zu Größenklassen zusammengefaßten kreisangehörigen Gemeinden Bayerns in starkem Maße mit derjenigen der Länder Nordrhein-Westfalen, Schleswig-Holstein und Saarland übereinstimmt, wird Bayern der hier besprochenen zweiten Ländergruppe zugerechnet. (247)

In allen vier zur zweiten Gruppe zusammengefaßten Ländern schwächt die Verteilung der Finanzzuweisungen an die kreisangehörigen Gemeinden die absoluten Einnahmekraftunterschiede pro Einwohner ab, die nach der Verteilung der kommunalen Steuereinnahmen bestehen. In Nordrhein-Westfalen erhalten die kreisangehörigen Gemeinden mit weniger als 20.000 Einwohnern, 
Tabelle 18c Die Finanzkraft der kreisfreien Städte und der kreisangehörigen Gemeinden in Nordrhein-Westfalen im Jahr $1974^{1}$

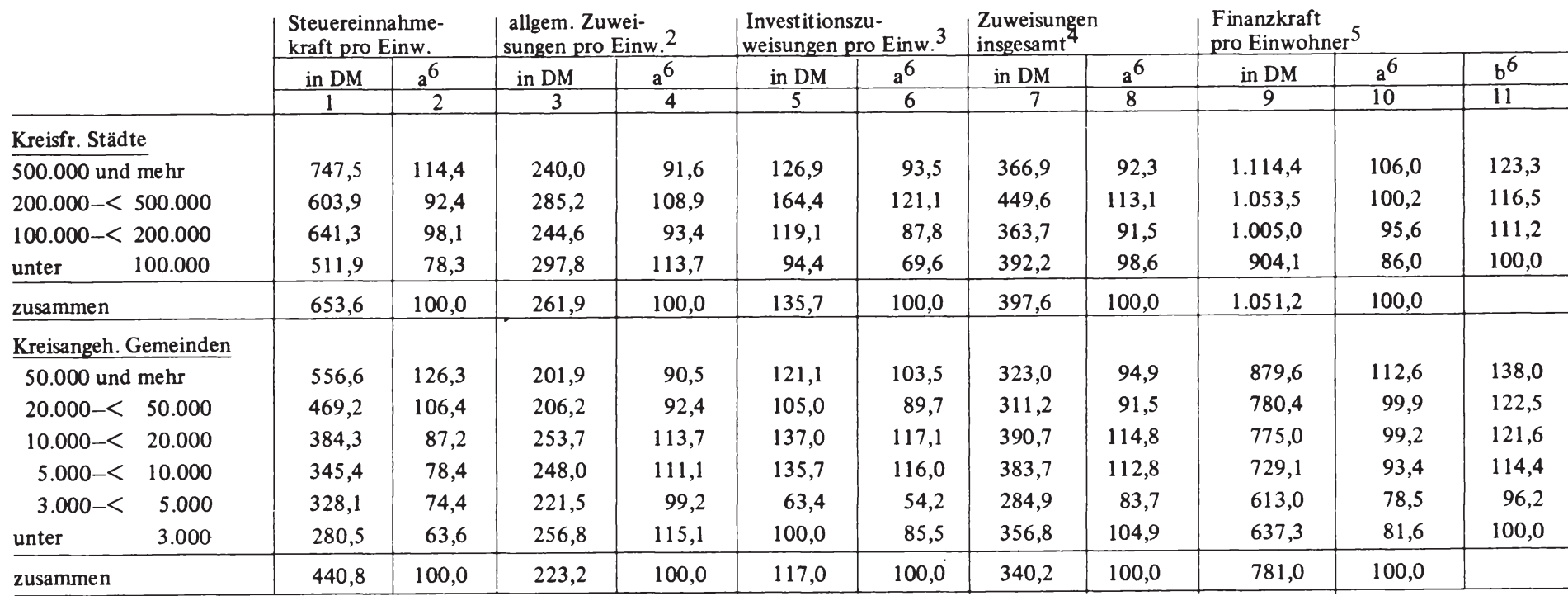

1) Quelle: Berechnet nach

Landesamt für Datenverarbeitung und Statistik NordrheinWestfalen, Statistische Berichte, Die Gemeindefinanzen in Nordrhein-Westfalen 1974, Ergebnisse der vierteljährlichen

Kassenstatistik, Düsseldorf, September 1975, S. 40 f und

S. $12 \mathrm{f}$.

2) Allgemeine Zuweisungen, Erstattungen von Verwaltungs-und Betriebsausgaben, Zuweisungen und Zuschüsse für laufende Zwecke, Zinseneinnahmen, Schuldendiensthhilfen von Land und Bund.
3) Zuweisungen und Zuschüsse für Investitonen und Investitionsförderungsmaßnahmen von Land und Bund.

4) Summe der Werte der Spalten 3 und 5.

5) Summe der Werte der Spalten 1, 3 und 5.

6) $\mathrm{a}=$ in \% des jeweiligen Landesdurchschnitts $\mathrm{b}=$ in \% der jeweils untersten Größenklasse. 
Tabelle. 18d Die Finanzkraft der kreisfreien Städte und der kreisangehörigen Gemeinden in Bayern im Jahr 1974

\begin{tabular}{|c|c|c|c|c|c|c|c|c|c|c|c|}
\hline & \multicolumn{2}{|c|}{$\begin{array}{l}\text { Steuereinnahme- } \\
\text { kraft pro Einw. }\end{array}$} & \multicolumn{2}{|c|}{$\begin{array}{l}\text { allgem. Zuw exisungen } \\
\text { pro Einw.2 } 4\end{array}$} & \multicolumn{2}{|c|}{$\begin{array}{l}\text { Investitionszuwei- } \\
\text { sungen pro Einw. } 34\end{array}$} & \multicolumn{2}{|c|}{$\begin{array}{l}\text { Zuweisungen } \\
\text { insgesamt }\end{array}$} & \multicolumn{3}{|c|}{$\begin{array}{l}\text { Finanzkraft } \\
\text { pro Einwohner } 6\end{array}$} \\
\hline & in DM & $a^{7}$ & in DM & $a^{7}$ & in DM & $a^{7}$ & in DM & $a^{7}$ & in DM & $a^{7}$ & $b^{7}$ \\
\hline & 1 & 2 & 3 & 4 & 5 & 6 & 7 & 8 & 9 & 10 & 11 \\
\hline Kreisfr. Städte & & & & & & & & & & & \\
\hline 500.000 und mehr & 733,1 & 109,0 & 218,1 & 107,8 & 150,7 & 109,0 & 368,8 & 108,3 & $1.101,9$ & 108,8 & 124,9 \\
\hline $200.000-<500.000$ & 590,0 & 87,7 & 185,6 & 91,7 & 33,9 & 24,5 & 219,5 & 64,5 & 809,5 & 79,9 & 91,7 \\
\hline $100.000-<200.000$ & 597,5 & 88,8 & 198,1 & 97,9 & 96,5 & 69,8 & 294,6 & 86,5 & 892,1 & 88,1 & 101,1 \\
\hline $50.000-<100.000$ & 655,5 & 97,5 & 177,4 & 87,7 & 165,5 & 119,8 & 342,9 & 100,7 & 998,4 & 98,6 & 113,2 \\
\hline $20.000-<50.000$ & 546,6 & 81,3 & 178,9 & 88,4 & 156,8 & 113,5 & 335,7 & 98,6 & 882,3 & 87,1 & 100,0 \\
\hline zusammen & 672,5 & 100,0 & 202,3 & 100,0 & 138,2 & 100,0 & 340,5 & 100,0 & $1.013,0$ & 100,0 & \\
\hline Kreisangeh. Gemeinden & & & & & & & & & & & \\
\hline $20.000-<50.000$ & 579,3 & 153,7 & 109,9 & 85,7 & 99,0 & 86,8 & 208,9 & 86,3 & 788,2 & 127,3 & 149,3 \\
\hline $10.000-<20.000$ & 517,4 & 137,3 & 92,6 & 72,2 & 108,5 & 95,2 & 201,1 & 83,0 & 718,5 & 116,1 & 136,1 \\
\hline $5.000-<10.000$ & 452,5 & 120,1 & 107,9 & 84,2 & 134,2 & 117,7 & 242,1 & 100,0 & 694,6 & 112,2 & 131,6 \\
\hline $3.000-<\quad 5.000$ & 362,1 & 96,1 & 131,0 & 102,2 & 128,4 & 112,6 & 259,4 & 107,1 & 621,5 & 100,4 & 117,7 \\
\hline unter & 271,5 & 72,1 & 152,5 & 119,0 & 103,9 & 91,1 & 256,4 & 105,9 & 527,9 & 85,3 & 100,0 \\
\hline zusammen & 376,8 & 100,0 & 128,2 & 100,0 & 114,0 & 100,0 & 242,2 & 100,0 & 619,0 & 100,0 & \\
\hline
\end{tabular}

1) Quelle: Berechnet nach

Statistisches Bundesamt, Finanzen und Steuern, Reihe 9 ,

Realsteuervergleich 1974, Stuttgart, Mainz, Dezember 1975, S. $34 \mathrm{ff}$.

4) Quelle: Berechnet nach

Bayerisches Statistisches Landesamt, Anlagen zum Schreiben an den Verfasser vom 6.5.1977, Nr. VI/A/1-2736.
2) Allgemeine Zuweisungen und Zuweisungen für laufende Zwecke von Bund und Land.

3) Investitionszuschüsse von Bund und Land.

5) Summe der Werte aus Spalte 3 und 5.

6) Summe der Werte aus Spalte 1,3 und 5.

7) $\mathrm{a}=$ in $\%$ des Landesdurchschnitts

$\mathrm{b}=$ in \% der untersten Größenklasse. 
Tabelle 18e Die Finanzkraft der kreisfreien Städte und der kreisangehörigen Gemeinden in Schleswig-Holstein im Jahr 1974

\begin{tabular}{|c|c|c|c|c|c|c|c|c|c|c|c|c|}
\hline & & \multicolumn{2}{|c|}{$\begin{array}{l}\text { Steuereinnahme- } \\
\text { kraft pro Einw. }\end{array}$} & \multicolumn{2}{|c|}{$\begin{array}{l}\text { allgem. Zuweisungen } \\
\text { pro Einw. } 24\end{array}$} & \multicolumn{2}{|c|}{$\begin{array}{l}\text { Investitionszuwei- } \\
\text { sungen pro Einw. } 34\end{array}$} & \multicolumn{2}{|c|}{$\begin{array}{l}\text { Zuweisungen } \\
\text { insgesamt }\end{array}$} & \multicolumn{3}{|c|}{$\begin{array}{l}\text { Finanzkraft } \\
\text { pro Einwohner } 6\end{array}$} \\
\hline & & in DM & $a^{7}$ & in DM & $a^{7}$ & in $\mathrm{DM}$ & $a^{7}$ & in $\mathrm{DM}$ & $a^{7}$ & in $\mathrm{DM}$ & $a^{7}$ & $b^{7}$ \\
\hline & & 1 & $\frac{a}{2}$ & 3 & 4 & 5 & 6 & 7 & 8 & 9 & 10 & 11 \\
\hline & \multicolumn{12}{|l|}{ Kreisfr. Städte } \\
\hline & $\begin{array}{c}200.000-<300.000 \\
\text { Kiel }\end{array}$ & 614,3 & 107,8 & 161,0 & 83,1 & 64,7 & 76,9 & 225,7 & 81,2 & 840,0 & 99,1 & 83,5 \\
\hline & Lübeck & 603,5 & 105,9 & 185,3 & 95,7 & 67,8 & 80,6 & 253,1 & 91,1 & 856,6 & 101,0 & 85,2 \\
\hline 8 & $50.000-<100.000$ & & & & & & & & & & & \\
\hline & Flensburg & 438,2 & 76,9 & 189,2 & 97,7 & 76,6 & 91,1 & 265,8 & 95,7 & 704,0 & 83,0 & 70,0 \\
\hline $\bar{d}$ & Neumïnster & 487,0 & 85,5 & 322,3 & 166,4 & 196,2 & 233,3 & 518,5 & 186,6 & $1.005,5$ & 118,6 & 100,0 \\
\hline & zusammen & 569,9 & 100,0 & 193,7 & 100,0 & 84,1 & 100,0 & 277,8 & 100,0 & 847,7 & 100,0 & \\
\hline$\frac{0}{3} \pi$ & Kreisangeh. Gemeinden & & & & & & & & & & & \\
\hline 등 & 20.000 und mehr & 495,8 & $1.37,1$ & 104,9 & 72,8 & 114,0 & 124,2 & 218,9 & 92,8 & 714,7 & 119,6 & 143,3 \\
\hline T⿱一兀) & $10.000-<20.000$ & 415,7 & 114,9 & 128,3 & 89,1 & 101,7 & 110,8 & 230,0 & 97,5 & 645,7 & 108,1 & 129,5 \\
\hline 苋 & $5.000-<10.000$ & 367,5 & 101,6 & 141,5 & 98,3 & 94,9 & 103,4 & 236,4 & 100,3 & 603,9 & 101,1 & 121,1 \\
\hline$\frac{3}{21}$ & $3.000-<\quad 5.000$ & 329,4 & 91,1 & 142,9 & 99,2 & 109,7 & 119,5 & 252,6 & 107,1 & 582,0 & 97,4 & 116,7 \\
\hline$\stackrel{\frac{D}{0}}{0}$ & Inter & 253,3 & 70,0 & 178,3 & 123,8 & 67,1 & 73,1 & 245,4 & 104,1 & 498,7 & 83,5 & 100,0 \\
\hline ऐ学 & usammen & 361,7 & 100,0 & 144,0 & 100,0 & 91,8 & 100,0 & 235,8 & 100,0 & 597,5 & 100,0 & \\
\hline
\end{tabular}

) Quelle: Berechnet nach

Statistische Berichte des Statistischen Landesamtes Schleswig-

Holstein, Realsteuervergleich 1974, Kiel, Oktober 1975, S. 14 f.

t) Quelle: Berechnet nach

Statistische Berichte des Statistischen Landesamtes Schleswig-

Holstein, Die Gemeindefinanzen in Schleswig-Holstein im Jahre 1974, Teil 2, Kiel, September 1975, S. 4 f.
2) Allgemeine Zuweisungen, Erstattungen von Verwaltungs- und Betriebsausgaben, Zuweisungen und Zuschüsse für laufende Zwecke, Zinseinnahmen, Schuldendiensthilfen von Land und Bund.

3) Zuweisungen und Zuschüsse für Investitionen und Investitionsförderungsmaßnahmen von Land und Bund.

5) Summe der Werte aus Spalte 3 und 5.

6) Summe der Werte aus Spalte 1, 3 und 5.

7) $\mathrm{a}=$ in $\%$ des jeweiligen Landesdurchschnitts $\mathrm{b}=$ in $\%$ der jeweils untersten Größenklasse. 


\begin{tabular}{|c|c|c|c|c|c|c|c|c|c|c|c|}
\hline & \multicolumn{2}{|c|}{$\begin{array}{l}\text { Steuereinnahme- } \\
\text { kraft pro Einw. }\end{array}$} & \multicolumn{2}{|c|}{$\begin{array}{l}\text { allgem. Zuweisungen } \\
\text { pro Einw. } 24\end{array}$} & \multicolumn{2}{|c|}{$\mid \begin{array}{l}\text { Investitionszu- } \\
\text { weisungen pro Einw. } 34\end{array}$} & \multicolumn{2}{|c|}{$\begin{array}{l}\text { Zuweisungen } \\
\text { insgesamt }\end{array}$} & \multicolumn{3}{|c|}{$\begin{array}{l}\text { Finanzkraft } \\
\text { pro Einwohner } 6\end{array}$} \\
\hline & in DM & $a^{7}$ & in $\mathrm{DM}$ & $a^{7}$ & in DM & $a^{7}$ & in DM & $a^{7}$ & in DM & $a^{7}$ & $b^{7}$ \\
\hline & 1 & 2 & 3 & 4 & 5 & 6 & 7 & 8 & 9 & 10 & 11 \\
\hline jeme inden & & & & & & & & & & & \\
\hline 00.000 und mehr & 408,2 & 113,8 & 210,3 & 110,5 & 40,3 & 64,8 & 250,6 & 99,2 & 658,8 & 107,8 & 87,1 \\
\hline $50.000-<100.000$ & 403,4 & 112,4 & 310,7 & 163,3 & 105,0 & 168,8 & 415,7 & 164,6 & 819,1 & 134,0 & 108,2 \\
\hline $20.000-<50.000$ & 426,7 & 118,9 & 133,2 & 70,0 & 50,4 & 81,0 & 183,6 & 72,7 & 610,3 & 99,8 & 80,7 \\
\hline $10.000-<$ & 233,4 & 65,1 & 213,3 & 112,1 & 77,5 & 124,6 & 290,8 & 115,2 & 524,2 & 85,8 & 69,3 \\
\hline $5.000-<$ & 443,8 & 123,7 & 235,1 & 123,5 & 77,9 & 125,2 & 313,0 & 124,0 & 756,8 & 123,8 & 100,0 \\
\hline usammen & 358,8 & 100,0 & 190,3 & 100,0 & 62,2 & 100,0 & 252,5 & 100,0 & 611,3 & 100,0 & \\
\hline
\end{tabular}

1) Quelle: Berechnet nach

Statistisches Bundesamt, Fachserie L, Finanzen und Steuem, Reihe 9, Realsteuervergleich 1974, Stuttgart, Mainz

Dezember 1975, S. 34 f., S. 38 f., S. 42 f., S. 56 ff., S. 62 f., S. $64 \mathrm{f}$.

4) Quelle: Berechnet nach

Statistisches Amt des Saarlandes, Statistische Berichte, Kommunale Finanzen 1974, Saarbrücken, Januar 1977.
2) Allgemeine Zuweisungen, Erstattungen von Verwaltungs- und Betriebsausgaben, Zuweisungen und Zuschüsse für laufende Zwecke, Zinseinnahmen und Schuldendiensthilfen von Land und Bund.

3) Zuweisungen und Zuschüsse für Investitionen und Investitionsförderungsmaßnahmen von Land und Bund.

5) Summe der Werte aus Spalte 3 und 5.

6) Summe der Werte aus Spalte 1, 3 und 5.

7) $\mathrm{a}=$ in $\%$ des Landesdurchschnitts

$\mathrm{b}=$ in \% der untersten Größenklasse. 
in Bayern und Schleswig-Holste in diejenigen mit weniger als 10.000 Einwohnern überdurchschnittlich hohe und damit absolut höhere Pro-Kopf-Zuweisungen als die kreisangehörigen Gemeinden mit mehr als $20.000 \mathrm{bzw}$. mit mehr als 10.000 Einwohnern. Diese Abschwächung der absoluten Einnahmekraftunterschiede pro Einwohner zwischen den kreisangehörigen Gemeinden unterschiedlicher Größe ist in erster Linie mit der Verteilung der allgemeinen Zuweisungen von Land und Bund zu erklären. In allen vier Bundesländern ist die Höhe der allgemeinen Zuweisungen pro Kopf relativ stark negativ mit der Gemeindegrößenklasse und/oder mit der kommunalen Steuereinnahmekraft pro Einwohner korreliert. Allerdings läßt sich auch bei der Verteilung der Investitionszuweisungen keine eindeutige Begünstigung der großen und/oder steuerstarken kreisangehörigen Gemeinden feststellen. (248)

Zusammenfassend kann man festhalten: In Nordrhein-Westfalen, SchleswigHolstein und dem Saarland verringert der vertikale Gemeindefinanzausgleich die durch das kommunale Steuersystem bedingten absoluten Einnahmekraftunterschiede pro Einwohner sowohl zwischen den kreisfreien Städten verschiedener Größenklasse als auch zwischen den kreisangehörigen Gemeinden unterschiedlicher Größe. In Bayern gilt dies dagegen nur für die zu Gemeindegrößenklassen zusammengefaßten kreisangehörigen Gemeinden. Damit spricht einiges für die Vermutung, daß in diesen vier Ländern der vertikale Gemeindefinanzausgleich im Jahr 1974 den ballungsfördernden Effekten des vertikalen Steuerkraftgefälles entgegenwirkt. Ob und gegebenenfalls in welchem Ausmaß dies tatsächlich der Fall ist, kann allerdings mit größerer Sicherheit erst festgestellt werden, wenn die Verteilung der Zuweisungen von Bund und Land auf die als Landkreise und kreisfreie Städte abgegrenzten regionalen Einheiten ermittelt worden ist.

1.3.2. Die Verteilung der Finanzzuweisungen von Bund und Ländern auf die einzelnen Landkreise und kreisfreien Städte im Jahr 1974

In diesem Abschnitt sollen die räumlichen Auswirkungen des vertikalen Ge meindefinanzausgleichs im Jahr 1974 ermittelt und im Hinblick auf ihre re gionalpolitische Zieladäquanz beurteilt werden. Zu diesem Zweck werden die als Landkreise und als kreisfreie Städte abgegrenzten Regionen der einzelnen Länder in steuerschwache und steuerstarke Regionen eingeteilt. Als steuerstark gelten die Regionen, deren Steuereinnahmekraft $100 \%$ und mehr der landesdurchschnittlichen Steuereinnahmekraft beträgt. Regionen mit einer Steuereinnahmekraft von weniger als $100 \%$ des Landesdurchschnitts werden als steuerschwach bezeichnet. Entsprechend den Überlegungen über die regionalpolitisch wünschenswerte Verteilung der Zuweisungen von Bund und Ländern auf die einzelnen Landkreise und kreisfreien Städte (249) wird hier gefragt, wieviel steuerstarke Regionen 1974 im Rahmen des vertikalen Gemeindefinanzausgleichs durchschnittliche oder unterdurchschnittliche Finanzzuweisungen pro Einwohner erhalten haben. Gleichfalls wird die Zahl der steuerschwachen Regionen ermittelt, denen durchschnittliche oder überdurchschnittliche Finanzzuweisungen pro Einwohner zufließen. Auf diese Weise kann festgestellt werden, in wieviel Fällen der vertikale Gemeindefinanzausgleich 1974 in die regionalpolitisch erwünschte Richtung wirkt. Ebenso 
läßt sich diesen Zahlen ein Hinweis darüber entnehmen, ob die regionalpolitisch erwünschte oder die zielinkonforme Wirkung des vertikalen Gemeindefinanzausgleichs überwiegt.

In den Fällen, in denen steuerstarke Regionen überdurchschnittlich hohe und steuerschwache Regionen unterdurchschnittlich hohe Pro-Kopf-Zuweisungen erhalten, bewirkt der vertikale Gemeindefinanzausgleich eine Vergrößerung der absoluten Einnahmekraftunterschiede zwischen den Regionen. Diese Wirkung der regionalen Verteilung der Finanzzuweisungen von Bund und Ländern verstärkt tendenziell die regionalen Wohlstandsunterschiede und wird deshalb als regionalpolitisch unerwünscht bewertet.

Dieselben Fragen wie für die Verteilung der Gesamtfinanzzuweisungen werden auch für die Verteilung der allgemeinen Zuweisungen und für die Verteilung der Investitionszuweisungen getrennt untersucht. Mit der Ermittlung der Zahl der Fälle, in denen die Verteilung der allgemeinen Zuweisungen und die Verteilung der Investitionszuweisungen zielkonform bzw. zielinkonform ist, wird ein tieferer Einblick in die Verteilungspraxis der Finanzzuweisungen gegeben. Dadurch kann man möglicherweise Ansatzpunkte für eine Umgestaltung des vertikalen Gemeindefinanzausgleichs zu einem wirksamen regionalpolitischen Instrument gewinnen.

Die bisher gestellten Fragen erlauben lediglich Antworten über die Wirkungsrichtung des vertikalen Gemeindefinanzausgleichs. Damit ist aber nichts darüber gesagt, ob in den Fällen, in denen der vertikale Finanzausgleich in die erwünschte Richtung wirkt, diese Wirkung auch stark genug ist, um die ballungsfördernden Effekte des regionalen Steuereinnahmekraftgefälles vollständig zu neutralisieren. Um Hinweise auf die Wirkungsstärke des vertikalen Gemeindefinanzausgleichs zu bekommen, ist außerdem ermittelt worden, wieviel steuerstarke Regionen nach Verteilung der Finanzzuweisungen eine durchschnittliche oder unterdurchschnittliche Finanzkraft und wieviel steuerschwache Regionen nach Verteilung der Finanzzuweisungen eine durchschnittliche oder überdurchschnittliche Finanzkraft besitzen. In diesen Fällen ist der ballungshemmende Effekt des vertikalen Gemeindefinanzausgleichs eindeutig stark genug, um die ballungsfördernden Effekte des regionalen Steuerkraftgefälles auszugleichen. Durch den vertikalen Gemeindefinanzausgleich werden in diesen Fällen steuer- und wirtschaftsschwache Regionen mit absolut höheren Pro-Kopf-Einnahmen ausgestattet als einige steuer- und wirtschaftsstarke Regionen. Die ersteren erhalten auf diese Weise die Möglichkeit, ihren Entwicklungsrückstand gegenüber diesen steuer - und wirtschafts starken Regionen langfristig aufzuholen.

Die vorstehend skizzierten Fragen sollen im folgenden mit Hilfe der Tabellen 19a - 19g beantwortet werden. Die vereinfachten Ergebnisse der Untersuchung sind in Tabelle 20 zusammengestellt.

1.3.2.1. Die räumlichen Auswirkungen des vertikalen Gemeindefinanzausgleichs in Hessen im Jahr 1974

Hessen besteht im Jahr 1974 aus neun steuerstarken und 21 steuerschwachen 
Regionen. Von den steuerstarken Regionen, also den sechs kreisfreien Städten sowie den Landkreisen Groß-Gerau, Hochtaunus und Offenbach, erhalten sieben Regionen unterdurchschnittlich hohe Zuweisungen pro Kopf von Land und Bund. Doch ausgerechnet die Regionen, die den Kern des Ballungsraumes Rhein/Main bilden und hinsichtlich der Steuerkraft an der ersten bzw. dritten Stelle der Regionen Hessens stehen, werden mit weit überdurchschnittlich hohen Zuweisungen pro Einwohner bedacht. Frankfurt bekommt mit einer Steuerkraft von 182, $8 \%$ des Landesdurchschnitts auch noch $\mathrm{Zu}-$ weisungen pro Einwohner in Höhe von $112,4 \%$ des Landesdurchschnitts, Of fenbach (Stadt) bei einer Steuerkraft von 133,6 \% des Landesdurchschnitts sogar Zuweisungen pro Einwohner in Höhe von $159,8 \%$ des Landesdurchschnitts (Tabelle 19a, Spalte 2 und 8).

Von den steuerschwachen Regionen - es sind dies ausschließlich Landkreise weisen nur acht Regionen durchschnittlich oder überdurchschnittlich hohe Zuweisungen pro Einwohner von Land und Bund auf. Diese Gruppe der steuerschwachen Regionen mit wenigstens durchschnittlich hohen Pro-Kopf-Zuweisungen umfaßt sechs von sieben Landkreisen des Regierungsbezirks Kassel. Aus dem Regierungsbezirk Darmstadt werden lediglich zwei steuerschwache Regionen mit überdurchschnittlich hohen Zuweisungen pro Einwohner aus gestattet. Im Fall der Landkreise des Regierungsbezirks Kassel fließen die öffentlichen Finanzmittel in überdurchschnittlicher Höhe in eine Region, die als Gebietseinheit 13 im Bundesraumordnungsprogramm zu einer Förderregion erklärt worden ist. (250) In diesem Fall entspricht also die Verteilung der Finanzzuweisungen von Land und Bund in Hessen den regionalpolitischen Zielvorstellungen.

Insgesamt 13 steuerschwachen Regionen - 12 von ihnen gehören zum Regierungsbezirk Darmstadt - werden im Rahmen des vertikalen Gemeindefinanzausgleichs in Hessen $1974 \mathrm{z}$. T. erheblich unterdurchschnittlich hohe Finanzzuweisungen pro Einwohner von Land und Bund gewährt. Unter diesen benachteiligten Regionen befinden sich solche mit weit unterdurchschnittlicher Wirtschafts - und Steuerkraft wie die Landkreise Darmstadt, Dieburg, Gießen, Odenwaldkreis, Vogelsbergkreis und Wetzlar, deren Steuerkraft zwischen 60 und $75 \%$ des Landesdurchschnitts liegt (Tabelle 19a, Spalte 2). Einige dieser im Rahmen des vertikalen Gemeindefinanzausgleichs benachteiligten Landkreise bilden die Gebietseinheit 21 des Bundesraumordnungsprogramms, die wegen ihrer "besonderen Strukturschwächen" als Förderregion ausgewiesen ist. (251)

Der vertikale Gemeindefinanzausgleich in Hessen wirkt 1974 nur im Fall des Regierungsbezirks Kassel in die regionalpolitisch erwünschte Richtung. In der Mehrzahl der Regionen führt er jedoch dazu, daß die nach der Verteilung der kommunalen Steuereinnahmen bestehenden absoluten Einnahmekraftrückstände der steuerschwachen Regionen (Landkreise) gegenüber den steuerstarken Regionen (kreisfreien Städten) größer werden. Durch den vertikalen Gemeindefinanzausgleich steigt die Einnahmekraft der kreisfreien Städte pro Einwohner um 368, 3 DM oder $101,8 \%$ des Landesdurchschnitts, die der Landkreise insgesamt um 359, 4 DM oder 99, 4 \% des Landesdurchschnitts. 
Tabelle 19 a Die Finanzkraft der Gemeinden und Gemeindeverbände in Hessen im Jahr 1974

\begin{tabular}{|c|c|c|c|c|c|c|c|c|c|c|c|}
\hline & \multicolumn{2}{|c|}{$\mid \begin{array}{l}\text { Steuerkraft } \\
\text { pro Einw. } 1\end{array}$} & \multicolumn{2}{|c|}{$\begin{array}{l}\text { pllgem.Zuweis. } \\
\text { pro Einw. } 44\end{array}$} & \multicolumn{2}{|c|}{$\begin{array}{l}\text { Invest.-Zuwsg. } \\
\text { pro Einw. }{ }^{34} \text {. }\end{array}$} & \multicolumn{2}{|c|}{$\begin{array}{l}\text { Zuweisungen } \\
\text { insgesamt }\end{array}$} & \multicolumn{3}{|c|}{$\begin{array}{l}\text { Finanzkraft } \\
\text { pro Einwohner } 6\end{array}$} \\
\hline & in DM & $a^{7}$ & in $\mathrm{DM}$ & $a^{7}$ & in $\mathrm{DM}$ & $a^{7}$ & in $\mathrm{DM}$ & $a^{7}$ & in $\mathrm{DM}$ & $a^{7}$ & $b^{7}$ \\
\hline & 1 & 2 & 3 & 4 & 5 & 6 & 7 & 8 & 9 & 10 & 11 \\
\hline \multicolumn{12}{|l|}{ Kreisfr. Städte: } \\
\hline Darmstadt & 575,0 & 139,3 & 119,4 & 54,1 & 116,2 & 82,5 & 235,6 & 65,1 & 810,6 & 104,7 & 138,9 \\
\hline Frankfurt & 754,3 & 182,8 & 164,0 & 74,2 & 242,4 & 172,2 & 406,4 & 112,4 & $1.160,7$ & 149,9 & 199,0 \\
\hline Gießen & 537,5 & 130,2 & 187,2 & 84,7 & 87,4 & 62,0 & 274,6 & 75,9 & 812,1 & 104,9 & 139,2 \\
\hline Offenbach & 551,4 & 133,6 & 207,6 & 94,0 & 370,3 & 263,0 & 577,9 & 159,8 & $1.129,3$ & 145,8 & 193,6 \\
\hline Wiesbaden & 549,5 & 133,1 & 203,8 & 92,3 & 78,9 & 56,0 & 282,7 & 78,2 & 832,2 & 107,5 & 142,6 \\
\hline Kassel & 498,8 & 120,9 & 224,6 & 101,7 & 130,1 & 92,4 & 354,7 & 98,1 & 853,5 & 110,2 & 146,3 \\
\hline \multicolumn{12}{|l|}{ Landkreise: } \\
\hline \multicolumn{12}{|l|}{ RB Darmstadt } \\
\hline$\overline{\text { Bergstraße }}$ & 320,4 & 77,6 & 235,9 & 106,8 & 52,5 & 37,3 & 288,4 & 79,7 & 608,8 & 78,6 & 104,4 \\
\hline Darmstadt & 309,8 & 75,1 & 213,9 & 96,8 & 59,7 & 42,4 & 273,6 & 75,6 & 583,4 & 75,3 & 100,0 \\
\hline Dieburg & 296,6 & 71,9 & 248,1 & 112,3 & 89,7 & 63,7 & 337,8 & 93,3 & 634,4 & 81,9 & 108,7 \\
\hline Dillkreis & 361,1 & 87,5 & 164,6 & 74,5 & 153,6 & 109,1 & 318,2 & 88,0 & 679,3 & 87,7 & 116,4 \\
\hline Gießen & 284,3 & 68,9 & 249,8 & 113,1 & 74,9 & 53,2 & 324,7 & 89,8 & 609,0 & 78,6 & 104,4 \\
\hline Groß-Gerau & 438,3 & 106,2 & 182,2 & 82,5 & 85,1 & 60,4 & 267,3 & 73,9 & 705,6 & 91,1 & 120,9 \\
\hline Hochtaunus & 438,0 & 106,1 & 172,5 & 78,1 & 164,4 & 116,8 & 336,9 & 93,1 & 774,9 & 100,1 & 132,8 \\
\hline Limburg-Weilburg & 278,7 & 67,5 & 308,2 & 139,5 & 140,4 & 99,7 & 448,6 & 124,0 & 727,3 & 93,9 & 124,7 \\
\hline Main-Kinzig & 351,6 & 85,2 & 223,8 & 101,3 & 86,7 & 61,6 & 310,5 & 85,8 & 662,1 & 85,5 & 113,5 \\
\hline Main-Taunus & 381,5 & 92,4 & 253,8 & 114,9 & 84,3 & 60,0 & 338,1 & 93,5 & 719,6 & 92,9 & 123,3 \\
\hline Odenwaldkreis & 299,8 & 72,6 & 228,2 & 103,3 & 119,7 & 85,0 & 347,9 & 96,2 & 647,7 & 83,6 & 111,0 \\
\hline Offenbach & 471,0 & 114,1 & 157,3 & 71,2 & 59,5 & 42,3 & 216,8 & 60,0 & 687,8 & 88,8 & 117,9 \\
\hline Rheingaukreis & 374,3 & 90,7 & 175,9 & 79,6 & 171,9 & 122,1 & 347,8 & 96,2 & 722,1 & 93,2 & 123,8 \\
\hline Untertaunus & 280,1 & 67,9 & 286,8 & 129,8 & 125,8 & 89,3 & 412,6 & 114,1 & 692,7 & 89,4 & 118,7 \\
\hline Vogelsbergkreis & 251,1 & 60,8 & 269,2 & 121,9 & 90,5 & 64,3 & 359,7 & 99,4 & 610,8 & 78,9 & 104,7 \\
\hline Wetteraukreis & 348,2 & 84,4 & 229,9 & 104,1 & 73,6 & 52,3 & 303,5 & 83,9 & 651,7 & 84,2 & 111,7 \\
\hline Wetzlar & 309,0 & 74,9 & 170,4 & 77,1 & 120,7 & 85,7 & 291,1 & 80,5 & 600,1 & 77,5 & 102,9 \\
\hline \multicolumn{12}{|l|}{ RB Kassel } \\
\hline$\overline{\text { Fulda }}$ & 275,6 & 66,8 & 347,4 & 157,3 & 310,1 & 220,2 & 657,5 & 181,8 & 933,1 & 120,5 & 159,9 \\
\hline Hersfeld-Rotenburg & 272,9 & 66,1 & 237,6 & 107,6 & 250,3 & 177,8 & 487,9 & 134,9 & 760,8 & 98,2 & 130,4 \\
\hline Kassel & 261,7 & 63,4 & 288,0 & 130,4 & 172,8 & 122,7 & 460,8 & 127,4 & 722,5 & 93,3 & 123,8 \\
\hline Marburg-Biedenkopf & 326,9 & 79,2 & 218,8 & 99,0 & 95,6 & 67,9 & 314,4 & 86,9 & 641,3 & 82,8 & 109,9 \\
\hline Schwalm-Eder & 293,0 & 71,0 & 285,9 & 129,4 & 140,7 & 99,9 & 426,6 & 117,9 & 719,6 & 92,9 & 123,3 \\
\hline Waldeck-Frankenberg & 272,7 & 66,1 & 254,5 & 115,2 & 180,4 & 128,1 & 434,9 & 120,2 & 707,6 & 91,4 & 121,3 \\
\hline Werra-Meißner & 278,0 & 67,4 & 294,0 & 133,1 & 264,8 & 188,1 & 558,8 & 154,5 & 836,8 & 108,1 & 143,4 \\
\hline Hessen & 412,7 & 100,0 & 220,9 & 100,0 & 140,8 & 100,0 & 361,7 & 100,0 & 774,4 & 100,0 & \\
\hline Kreisfr. Städte & 636,7 & 154,3 & 180,2 & 81,6 & 188,1 & 133,6 & 368,3 & 101,8 & $1.005,0$ & 129,8 & \\
\hline Landkreise & 333,5 & 80,8 & 235,3 & 106,5 & 124,1 & 88,1 & 359,4 & 99,4 & 692,9 & 89,5 & \\
\hline
\end{tabular}


Anmerkungen zu Tabelle 19a

1) Quelle: Berechnet nach

Statistisches Bundesamt, Finanzen und Steuern, Reihe 9, Realsteuervergleich 1974, Stuttgart, Mainz, Dezember 1975, S. $80 \mathrm{ff}$.

2) Allgemeine Zuweisungen, Erstattungen von Verwaltungs- und Betriebsausgaben vom Land an Gemeinden und Gemeindeverbände.

3) Zuschüsse für Investitionen und Investitionsförderungsmaßnahmen von Land und Bund an Gemeinden und Gemeindeverbände.

4) Quelle: Berechnet nach

Hessisches Statistisches Landesamt, Anlage zum Schreiben an den Verfasser vom 24.9.1975, Abt.: VII 1 - Az.: 77g 231/75, Tgb.-Nr. 1114.

5) Summe der Werte aus Spalte 3 und 5.

6) Summe der Werte aus Spalte 1, 3 und 5.

7) $\mathrm{a}=$ in $\%$ des Landesdurchschnitts

$\mathrm{b}=$ in \% des finanzschwächsten Landkreises. 
Dieser Tatbestand wirkt sich besonders deswegen negativ auf die Raumstruktur in Hessen aus, weil ausgerechnet in die Region mit der höchsten Wirtschaftskraft und dem höchsten Agglomerationsgrad Hessens weit überdurchschnittliche Zuweisungen pro Einwohner fließen. Der absolute Einnahmekraftvorsprung pro Einwohner der kreisfreien Städte Frankfurt und Offenbach vergrößert sich damit gegenüber allen Landkreisen, mit Ausnahme derjenigen des Regierungsbezirks Kassel, und auch gegenüber den anderen kreisfreien Städten. Im Ballungsraum Frankfurt/Offenbach können dank des vertikalen Gemeindefinanzausgleichs 1974 absolut höhere öffentliche Leistungen pro Einwohner zusätzlich angeboten werden als in der Mehrzahl der Regionen mit sowieso schon weit unterdurchschnittlichem Niveau des öffentlichen Leistungs angebots. Die Attraktivität dieses Ballungsraumes auf mobile Ressourcen steigt, die Abwanderung von Unternehmen und Arbeitskräften aus diesem Raum in schwächer agglomerierte Regionen wird verhindert.

Dieser ballungsfördernde Effekt des vertikalen Gemeindefinanzausgleichs in Hessen im Jahr 1974 ist vor allem das Resultat der regionalen Verteilung der Investitionszuweisungen. Von den steuerstarken Regionen werden drei Regionen mit weit überdurchschnittlichen Investitionszuweisungen pro Einwohner von Land und Bund ausgestattet. Die kreisfreien Städte Frankfurt und Offenbach erhalten pro Einwohner Investitionszuweisungen in Höhe von $172,2 \%$ und 263,0 \% des Landesdurchschnitts, ihr Nachbarkreis Hochtaunus in Höhe von $116,8 \%$ des Landesdurchschnitts. Dagegen liegen bei zwölf Landkreisen - sie gehören wiederum mit einer Ausnahme zum Regierungsbezirk Darmstadt - die Investitionszuweisungen pro Einwohner unter dem Landes durchschnitt, teilweise sogar weiter unter dem Landesdurchschnitt, als ihre Steuerkraft. Während die kreisfreien Städte insgesamt pro Einwohner 188,1 DM oder 133,6 \% des Landesdurchschnitts als Investitionszuweisungen bekommen, gehen nur 124,1 DM oder 88,1 \% des Landesdurchschnitts in dieser Form an die Landkreise. In Hessen scheint 1974 die regionale Verteilung der Investitionszuweisungen sehr stark an der aktuellen Nachfrage nach Infrastrukturleistungen ausgerichtet zu sein und dient damit vorwiegend der Engpaßbeseitigung in den Ballungsgebieten. Lediglich im Fall der strukturschwachen Regionen des Regierungsbezirks Kassel wird dieses finanzausgleichspolitische Instrument zielkonform als Instrument der Regionalpolitik eingesetzt. Dadurch wird sogar erreicht, daß zwei steuerschwache Regionen, nämlich Fulda und der Werra-Meißner-Kreis, nach Durchführung des vertikalen Gemeindefinanzausgleichs auf eine überdurchschnittlich hohe Finanzkraft pro Kopf kommen.

1.3.2.2. Die räumlichen Auswirkungen des vertikalen Gemeindefinanzaus gleichs in Rheinland-Pfalz im Jahr 1974

Rheinland-Pfalz besteht im Jahr 1974 aus zwölf steuerstarken Regionen, von denen elf kreisfreie Städte sind, und 24 steuerschwachen Regionen, unter denen sich nur eine kreisfreie Stadt befindet. Nur sieben steuerstarke und zehn steuerschwache Regionen erhalten 1974 in einer Höhe Finanzzuweisungen pro Einwohner, die als regionalpolitisch zielkonform beurteilt werden 
kann. Zu den im Rahmen des vertikalen Gemeindefinanzausgleichs begünstigten steuerschwachen Regionen gehören die vier Landkreise des Regierungsbezirks Trier. Sie stehen am unteren Ende der Rangfolge nach der Steuereinnahmekraft pro Einwohner und sind im Bundes raumordnungsprogramm vom 30.4.1975 wegen ihrer "besonderen Strukturschwächen" als Gebietseinheit 19 zu Fördergebieten deklariert worden. (252) Fünf steuerstarken Regionen werden $z$. T. weit überdurchschnittlich hohe Finanzzuweisungen pro Kopf von Land und Bund gewährt. Unter ihnen befinden sich mit den kreisfreien Städten Ludwigshafen, Koblenz und Worms drei der vier steuerstärksten Regionen des Landes. Die Zuweisungen an diese in Verdichtungsgebieten entlang des Rheins liegenden kreisfreien Städte betragen 141,4\%, 120,2\% und $115,2 \%$ der im Landesdurchschnitt gezahlten Zuweisungen (Tabelle 19b, Spalte 8). Die Mehrzahl der steuerschwachen Regionen (14 von 24) muß sich mit z. T. weit unterdurchschnittlichen Finanzzuweisungen pro Kopf zufrieden geben. Bei diesen handelt es sich vor allem um die Landkreise der Regierungsbezirke Koblenz und Rheinhessen-Pfalz, deren Steuerkraft und Wirtschaftskraft pro Einwohner überwiegend weit unter dem Landesdurchschnitt liegen. Die meisten dieser im Rahmen des vertikalen Gemeindefinanzaus gleichs in Rheinland-Pfalz 1974 benachteiligten Regionen sind als "Schwerpunkträume mit besonderen Strukturschwächen" (Gebietseinheiten 20 und 27) im Bundesraumordnungsprogramm vom 30.4.1975 als förderungswürdige Regionen ausgewiesen. (252)

In Rheinland-Pfalz führt der vertikale Gemeindefinanzausgleich im Jahr 1974 dazu, daß die absoluten Einnahmekraftunterschiede, die nach der Steuerverteilung zugunsten der steuer- und wirtschaftsstarken Regionen (kreisfreien Städte) bestehen, vergrößert werden. Dies gilt insbesondere für die bereits steuer- und wirtschaftskraftstärksten der kreisfreien Städte. Insgesamt werden den kreisfreien Städten pro Einwohner Finanzzuweisungen von Land und Bund in Höhe von 384,1 DM oder $113,3 \%$ des Landesdurchschnitts gewährt. Die Landkreise erhalten dagegen nur Zuweisungen pro Einwohner in Höhe von $316,1 \mathrm{DM}$ oder 93,3\% des Landesdurchschnitts. Mit dieser regionalen Verteilung der Finanzausgleichsmasse verstärken Land und Bund im Jahr 1974 direkt die ballungsfördernden Wirkungen, die vom regionalen Steuereinnahmekraftgefälle in Rheinland-Pfalz ausgehen. (253)

Während die regionale Verteilung der allgemeinen Zuweisungen auf die steuerstarken Regionen (kreisfreien Städte) noch den regionalpolitischen Anforderungen entspricht, kann man dies von ihrer Verteilung auf die steuerschwachen Regionen (Landkreise) nicht sagen. Immerhin erhalten elf von 24 steuerschwachen Regionen unterdurchschnittlich hohe allgemeine Finanzzuweisungen pro Einwohner. Unter ihnen sind ausgesprochen steuerschwache Landkreise wie der Rhein-Lahn-Kreis, der Westerwaldkreis, Ahrweiler, Altenkirchen, Alzey-Worms oder Ludwigshafen, deren Steuereinnahmekraft zwischen 73 und $85 \%$ des Landesdurchschnitts liegt.

Noch stärker als die Verteilung der allgemeinen Finanzzuweisungen bestimmt die Verteilung der Investitionszuweisungen die ballungsfördernde Wirkung des vertikalen Gemeindefinanzausgleichs in Rheinland-Pfalz. (254) Im Jahr 1974 erhalten sieben von zwölf steuerstarken Regionen, unter ihnen 
Tabelle 19b Die Finanzkraft der Gemeinden und Gemeindeverbände in Rheinland-Pfalz im Jahr 1974

\begin{tabular}{|c|c|c|c|c|c|c|c|c|c|c|c|}
\hline & \multicolumn{2}{|c|}{$\left[\begin{array}{c}\text { Steuereinn.- } \\
\text { kraft pro Einw }\end{array}\right.$} & \multicolumn{2}{|c|}{$\begin{array}{l}\text { allgem.Zuwsg. } \\
\text { pro Einw. }\end{array}$} & \multicolumn{2}{|c|}{$\begin{array}{l}\text { Invest.-Zuwss. } \\
\text { pro Einw. } 3\end{array}$} & \multicolumn{2}{|c|}{$\begin{array}{l}\text { Zuweisungen } \\
\text { insgesamt }\end{array}$} & \multicolumn{3}{|c|}{$\begin{array}{l}\text { Finanzkraft } \\
\text { pro Einwohner }\end{array}$} \\
\hline & in DM & $a^{6}$ & in DM & $a^{6}$ & in DM & $a^{6}$ & in $\mathrm{DM}$ & $a^{6}$ & in $\mathrm{DM}$ & $a^{6}$ & $b^{6}$ \\
\hline & 1 & 2 & 3 & 4 & 5 & 6 & 7 & 8 & 9 & 10 & 11 \\
\hline \multicolumn{12}{|l|}{ Kreisfr. Städte: } \\
\hline Koblenz & 604,7 & 137,8 & 134,2 & 62,0 & 273,2 & 222,8 & 407,4 & 120,2 & $1.012,1$ & 130,2 & 187,4 \\
\hline Trier & 487,4 & 111,1 & 284,6 & 131,6 & 319,4 & 260,5 & 604,0 & 178,2 & $1.091,4$ & 140,4 & 202,1 \\
\hline Frankenthal (Pf.) & 518,2 & 118,1 & 114,4 & 52,9 & 81,0 & 66,1 & 195,4 & 57,7 & 713,6 & 91,8 & 132,1 \\
\hline Kaiserslautern & 482,6 & 110,0 & 211,5 & 97,8 & 128,3 & 104,6 & 339,8 & 100,3 & 822,4 & 105,8 & 152,3 \\
\hline Landau i.d.Pf. & 499,2 & 113,8 & 142,5 & 65,9 & 31,2 & 25,4 & 173,7 & 51,3 & 672,9 & 86,5 & 124,6 \\
\hline Ludwigshafen a.Rh. & $1.147,0$ & 261,5 & 205,5 & 95,0 & 273,6 & 223,2 & 479,1 & 141,4 & $1.626,1$ & 209,1 & 301,1 \\
\hline Mainz & 679,1 & 154,8 & 152,9 & 70,7 & 112,8 & 92,0 & 265,7 & 78,4 & 944,8 & 121,5 & 175,0 \\
\hline Neustadt a.d.Wstr. & 451,3 & 102,9 & 200,3 & 92,6 & 341,0 & 278,1 & 541,3 & 159,7 & 992,6 & 127,6 & 183,8 \\
\hline Pirmasens & 571,4 & 130,2 & 95,4 & 44,1 & 201,4 & 164,3 & 296,8 & 87,6 & 868,2 & 111,7 & 160,8 \\
\hline Speyer & 443,6 & 101,1 & 93,1 & 43,0 & 32,1 & 26,2 & 125,2 & 36,9 & 568,8 & 73,1 & 105,3 \\
\hline Worms & 587,0 & 133,8 & 142,2 & 65,7 & 248,3 & 202,5 & 390,5 & 115,2 & 977,5 & 125,7 & 181,0 \\
\hline Zweibrücken & 434,5 & 99,0 & 308,3 & 142,5 & 306,3 & 249,8 & 614,6 & 181,4 & $1.049,1$ & 134,9 & 194,3 \\
\hline \multicolumn{12}{|l|}{ Landkreise: } \\
\hline \multicolumn{12}{|l|}{ RB Koblenz } \\
\hline Ahrweiler & 373,0 & 85,0 & 189,5 & 87,6 & 108,2 & 88,3 & 297,7 & 87,8 & 670,7 & 86,3 & 124,2 \\
\hline Altenkirchen (Ww.) & 324,3 & 73,9 & 211,8 & 97,9 & 95,9 & 78,2 & 307,7 & 90,8 & 632,0 & 81,3 & 117,0 \\
\hline Bad Kreuznach & 407,7 & 92,9 & 239,1 & 110,5 & 69,0 & 56,3 & 308,1 & 90,9 & 715,8 & 92,1 & 132,6 \\
\hline Birkenfeld & 417,7 & 95,2 & 280,4 & 129,6 & 59,2 & 48,3 & 339,6 & 100,2 & 757,3 & 97,4 & 140,2 \\
\hline Cochem-Zell & 341,3 & 77,8 & 257,3 & 119,0 & 105,9 & 86,4 & 363,2 & 107,2 & 704,5 & 90,6 & 130,5 \\
\hline Mayen-Koblenz & 397,8 & 90,7 & 160,1 & 74,0 & 76,1 & 62,1 & 236,2 & 69,7 & 634,0 & 81,5 & 117,4 \\
\hline Neuwied & 424,1 & 96,7 & 246,1 & 113,8 & 140,2 & 114,4 & 386,3 & 114,0 & 810,4 & 104,2 & 150,1 \\
\hline Rhein-Hunsrück & 310,1 & 70,7 & 274,0 & 126,7 & 180,5 & 147,2 & 454,5 & 134,1 & 764,6 & 98,3 & 141,6 \\
\hline Rhein-Lahn-Kreis & 341,1 & 77,8 & 199,6 & 92,3 & 81,3 & 66,3 & 280,9 & 82,9 & 622,0 & 80,0 & 115,2 \\
\hline Westerwaldkreis & 374,6 & 85,4 & 210,9 & 97,5 & 78,5 & 64,0 & 289,4 & 85,4 & 664,0 & 85,4 & 123,0 \\
\hline \multicolumn{12}{|l|}{ RB Trier } \\
\hline Bernkastel-Wittlich & 324,3 & 73,9 & 205,8 & 95,1 & 293,3 & 239,2 & 499,1 & 147,3 & 823,4 & 105,9 & 152,5 \\
\hline Bitburg-Prüm & 282,5 & 64,4 & 470,5 & 217,5 & 124,1 & 101,2 & 594,6 & 175,4 & 877,1 & 112,8 & 162,4 \\
\hline Daun & 271,6 & 61,9 & 258,6 & 119,6 & 78,5 & 64,0 & 337,1 & 99,5 & 608,7 & 78,3 & 112,7 \\
\hline Trier-Saarburg & 242,0 & 55,2 & 312,4 & 144,4 & 103,6 & 84,5 & 416,0 & 122,8 & 658,0 & 84,6 & 121,9 \\
\hline
\end{tabular}


Tabelle 19b Die Finanzkraft der Gemeinden und Gemeindeverbände in Rheinland-Pfalz im Jahr 1974

\begin{tabular}{|c|c|c|c|c|c|c|c|c|c|c|c|}
\hline & \multicolumn{2}{|c|}{$\begin{array}{l}\text { Steuereinn.- } \\
\text { kraft pro Einw }\end{array}$} & \multicolumn{4}{|c|}{\begin{tabular}{|l} 
allgem.Zuwsg. Invest.-Zuwss. \\
pro Einw.
\end{tabular}} & \multicolumn{2}{|c|}{$\begin{array}{l}\text { Zuweisungen } \\
\text { insgesamt }\end{array}$} & \multicolumn{3}{|c|}{$\begin{array}{l}\text { Finanzkraft } \\
\text { pro Einwohner }\end{array}$} \\
\hline & in DM & $a^{6}$ & in DM & $a^{6}$ & in $\mathrm{DM}$ & $a^{6}$ & in DM & $a^{6}$ & in DM & $a^{6}$ & $b^{6}$ \\
\hline & 1 & 2 & 3 & 4 & 5 & 6 & 7 & 8 & 9 & 10 & 11 \\
\hline RB Rheinhessen-Pfalz & & & & & & & & & & & \\
\hline Alzey-Worms & 332,2 & 75,7 & 198,0 & 91,5 & 30,7 & 25,0 & 228,7 & 67,5 & 560,9 & 72,1 & 103,9 \\
\hline Bad Dürkheim & 379,4 & 86,4 & 137,2 & 63,4 & 48,4 & 39,5 & 185,6 & 54,8 & 565,0 & 72,7 & 104,6 \\
\hline Donnersbergkreis & 311,8 & 71,1 & 274,7 & 127,0 & 94,1 & 76,8 & 368,8 & 108,8 & 680,6 & 87,5 & 126,0 \\
\hline Germersheim & 399,1 & 91,0 & 146,1 & 67,5 & 127,5 & 104,0 & 273,6 & 80,7 & 672,7 & 86,5 & 124,6 \\
\hline Kaiserslautern & 287,9 & 65,6 & 291,6 & 134,8 & 21,6 & 17,6 & 313,2 & 92,4 & 601,1 & 77,3 & 111,3 \\
\hline Kusel & 264,2 & 60,2 & 253,8 & 117,3 & 22,0 & 17,9 & 275,8 & 81,4 & 540,0 & 69,4 & 100,0 \\
\hline Landau-Bad Bergzabern & 337,5 & 76,9 & 250,3 & 115,7 & 42,7 & 34,8 & 293,0 & 86,5 & 630,5 & 81,1 & 116,8 \\
\hline Ludwigshafen & 354,5 & 80,8 & 150,2 & 69,4 & 38,3 & 31,2 & 188,5 & 55,6 & 543,0 & 69,8 & 100,6 \\
\hline Mainz-Bingen & 481,0 & 109,6 & 183,4 & 84,8 & 80,3 & 65,5 & 263,7 & 77,8 & 744,7 & 95,8 & 137,9 \\
\hline Pirmasens & 316,2 & 72,1 & 193,4 & 89,4 & 69,5 & 56,7 & 262,9 & 77,6 & 579,1 & 74,5 & 107,2 \\
\hline Rheinland-Pfalz & 438,7 & 100,0 & 216,3 & 100,0 & 122,6 & 100,0 & 338,9 & 100,0 & 777,6 & 100,0 & \\
\hline $\begin{array}{l}\text { Kreisfr. Städte } \\
\text { Landkreise }\end{array}$ & $\begin{array}{l}655,2 \\
355,4\end{array}$ & $\begin{array}{r}149,4 \\
81,0\end{array}$ & $\begin{array}{l}178,0 \\
225,6\end{array}$ & $\begin{array}{r}82,3 \\
104,3\end{array}$ & $\begin{array}{r}206,1 \\
90,5\end{array}$ & $\begin{array}{r}168,1 \\
73,8\end{array}$ & 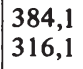 & $\begin{array}{r}113,3 \\
93,3\end{array}$ & $\begin{array}{r}1.039,3 \\
671,5\end{array}$ & $\begin{array}{r}133,7 \\
86,4\end{array}$ & \\
\hline
\end{tabular}

1) Quelle: Berechnet nach

Statistische Berichte des Statistischen Landesamtes Rheinland-Pfalz, Realsteuervergleich 1974, Bad Ems, September 1975, S. 7.

2) Allgemeine Zuweisungen und Zuweisungen für laufende Zwecke von Land und Bund an Gemeinden und Gemeindeverbände.

Quelle: Berechnet nach

Statistische Berichte des Statistischen Landesamtes Rheinland-Pfalz, Die kassenmäßigen Ausgaben und Einnahmen der Gemeinden und Gemeindeverbände 1974, Ergebnisse der vierteljährlichen Gemeindefinanzstatistik, Bad Ems, August 1975, S. 92.

3) Zuweisungen für Investitionen von Land und Bund an Gemeinden mit 3.000 und mehr Einwohnern, Verbandsgemeinden und Kreise.

Quelle: Berechnet nach

Statistisches Landesamt Rheinland-Pfalz, Anlage zum Schreiben vom 30.10.1975 an den Verfasser, Az: 41 329/Ly/Kr.

4) Summe der Werte aus Spalte 3 und 5.

5) Summe der Werte aus Spalte 1, 3 und 5.

6) $\mathrm{a}=$ in \% des Landesdurchschnitts

$\mathrm{b}=$ in \% des finanzschwächsten Landkreises. 
die kreisfreien Städte Ludwigshafen, Koblenz, Worms und Kaiserslautern, weit überdurchschnittliche Investitionszuweisungen pro Kopf. Auf der anderen Seite werden 18 von 24 steuerschwachen Regionen bei der Verteilung der Investitionszuweisungen stark benachteiligt. Sie bekommen nicht nur weniger Investitionszuweisungen als ihrer Einwohnerzahl entspricht, in vielen Fällen liegt ihr Zuweisungsbetrag pro Einwohner noch weiter unter dem Durchschnitt als ihre Steuereinnahmekraft pro Einwohner.

Angesichts dieser Verteilungen der vertikalen Finanzausgleichszahlungen in Rheinland-Pfalz ist auch nicht verwunderlich, daß nur wenige der steuerstarken Regionen nach Durchführung des vertikalen Gemeindefinanzausgleichs eine unterdurchschnittliche und nur wenige der steuerschwachen Regionen eine überdurchschnittliche Finanzkraft aufweisen. Bei den vier steuerstarken Regionen mit durchschnittlicher oder unterdurchschnittlicher Finanzkraft handelt es sich um solche, die schon zu den ärmsten der Gruppe der steu erstarken Regionen gehören (Frankenthal, Landau, Speyer, Mainz-Bingen). Ihr absoluter Einnahmekraftrückstand pro Einwohner gegenüber den reichsten kreisfreien Städten wird durch den vertikalen Gemeindefinanzausgleich vergrößert. Unter den vier steuerschwachen Regionen mit überdurchschnitt licher Finanzkraft (kreisfreie Stadt Zweibrücken, Landkreise Neuwied, Bernkastel-Wittlich und Bitburg-Prüm) sind nur zwei, die durch den vertikalen Gemeindefinanzausgleich von einer weit unterdurchschnittlichen Steuerkraft pro Einwohner auf eine überdurchschnittliche Finanzkraft pro Einwohner angehoben werden. Dies ist aus regionalpolitischer Sicht die einzige uneingeschränkt positiv zu beurteilende Wirkung des vertikalen Gemeindefinanzaus gleichs in Rheinland-Pfalz im Jahr 1974.

Damit hat die Untersuchung der regionalen Verteilung der Finanzzuweisungen für die Länder Hessen und Rheinland-Pfalz die im Zusammenhang mit der Verteilung der Zuweisungen auf die einzelnen Gemeindegrößenklassen geäußerte Vermutung über den tendenziell ballungsfördernden Effekt des vertikalen Gemeindefinanzausgleichs in diesen beiden Ländern (255) bestätigt und konkretisiert.

1.3.2.3. Die räumlichen Auswirkungen des vertikalen Gemeindefinanzausgleichs in Nordrhein-Westfalen im Jahr 1974

Nordrhein-Westfalen besteht 1974 aus 82 als Landkreise und kreisfreie Städte abgegrenzten Regionen, von denen 28 steuerstark und 54 steuerschwach sind. Im Rahmen des vertikalen Gemeindefinanzausgleichs erhalten 24 steuerstarke Regionen insgesamt Finanzzuweisungen pro Einwohner von Land und Bund, die $100 \%$ oder weniger des Landesdurchschnitts betragen. 44 von 54 steuerschwachen Regionen werden durchschnittlich oder überdurchschnittlich hohe Pro-Kopf-Zuweisungen gewährt. In der Mehrzahl der Regionen wirkt also der vertikale Gemeindefinanzausgleich in Nordrhein-Westfalen im Jahr 1974 in die regionalpolitisch gewünschte Richtung. Ein Blick auf die Spalten 8 und 2 der Tabelle'19c zeigt zudem, daß die regionalpolitisch erwünschten Abweichungen der gesamten Finanzzuweisungen pro Einwohner vom Landesdurch- 
schnitt tendenziell umso größer sind, je stärker die Steuereinnahmekraft der einzelnen Regionen vom Landesdurchschnitt (in die entgegengesetzte Richtung) abweicht.

Lediglich vier steuerstarke Regionen erhalten überdurchschnittlich hohe $\mathrm{Ge}$ samtzuweisungen pro Einwohner. Bei ihnen handelt es sich um die kreisfreien Städte Duisburg, Mühlheim/Ruhr, Bonn und Dortmund. In diesen Fällen übt also der vertikale Gemeindefinanzausgleich in Nordrhein-Westfalen im Jahr 1974 direkt ballungsverstärkende Wirkungen aus. Von den steuerschwachen Regionen müssen sich 1974 zehn mit unterdurchschnittlichen Gesamtzuweisungen pro Einwohner zufrieden geben. Da es sich bei ihnen jedoch in der Mehrzahl um solche handelt, die aus der Gruppe der steuerschwachen Regionen noch die höchste Steuereinnahmekraft pro Einwohner besitzen, ist ihre Benachteiligung im Rahmen des vertikalen Gemeindefinanzausgleichs regionalpolitisch weniger negativ zu beurteilen als die Begünstigung der vier kreisfreien Städte.

Der regionalpolitisch günstige Effekt des vertikalen Gemeindefinanzausgleichs in Nordrhein-Westfalen beruht in erster Linie auf der Verteilung der allgemeinen Finanzzuweisungen, durch die in der überwiegenden Zahl der Regionen die absoluten Einnahmekraftunterschiede pro Einwohner verringert werden. Dagegen tritt bei der Verteilung der Investitionszuweisungen eine relativ starke Abweichung von der regionalpolitisch erwünschten Verteilung auf. Immerhin sieben der steuerstarken und 23 der steuerschwachen Regionen erhalten überdurchschnittliche bzw. unterdurchschnittliche Investitionszuweisungen pro Einwohner. Zu den bei der Verteilung der Investitionszuweisungen begünstigten Regionen gehören mit den kreisfreien Städten Duisburg, Krefeld, Leverkusen, Mühlheim und Bonn solche, die bereits eine hohe Steuereinnahmekraft pro Einwohner besitzen und im Ballungsgebiet entlang des Niederrheins liegen. Bei der Verteilung der Investitionszuweisungen benachteiligt werden vor allem einige steuerschwache kreisfreie Städte im Norden des Ruhrgebiets und steuerschwache Landkreise wie Geldern, Moers und Rees. Zwar gehen mit einiger Wahrscheinlichkeit auch von der regionalen Verteilung der Investitionszuweisungen in Nordrhein-Westfalen insgesamt ballungshemmende Wirkungen aus. Doch scheint sie 1974 relativ stark an der regionalen Verteilung der aktuellen Nachfrage (lokaler Bedarf) nach Infrastrukturleistungen orientiert zu sein, so daß sie in der Gefahr steht, den regionalpolitischen Zielen zuwiderzulaufen.

Der vertikale Gemeindefinanzausgleich in Nordrhein-Westfalen wirkt 1974 insgesamt nicht nur in die regionalpolitisch erwünschte Richtung, sein ballungshemmender Einfluß scheint auch eine beachtliche Stärke zu besitzen. Von den 28 steuerstarken Regionen weisen nach Durchführung des vertikalen Gemeindefinanzausgleichs immerhin 14 eine durchschnittliche oder unterdurchschnittliche Finanzkraft auf. In 16 der 54 steuerschwachen Regionen erhöht der vertikale Gemeindefinanzausgleich die Einnahmenposition in einem solchen Ausmaß, daß die Finanzkraft über dem Landesdurchschnitt liegt. In diesen Fällen reicht also der vertikale Finanzausgleich aus, um die ballungsfördernden Effekte des regionalen Steuerkraftgefälles vollständig zu kompensieren oder gar überzukompensieren. Auf diesen Tatbestand wird weiter unten zurückzukommen sein. 
Tabelle 19 c Die Finanzkraft der Gemeinden und Gemeindeverbände in Nordrhein-Westfalen im Jahr $1974^{1}$

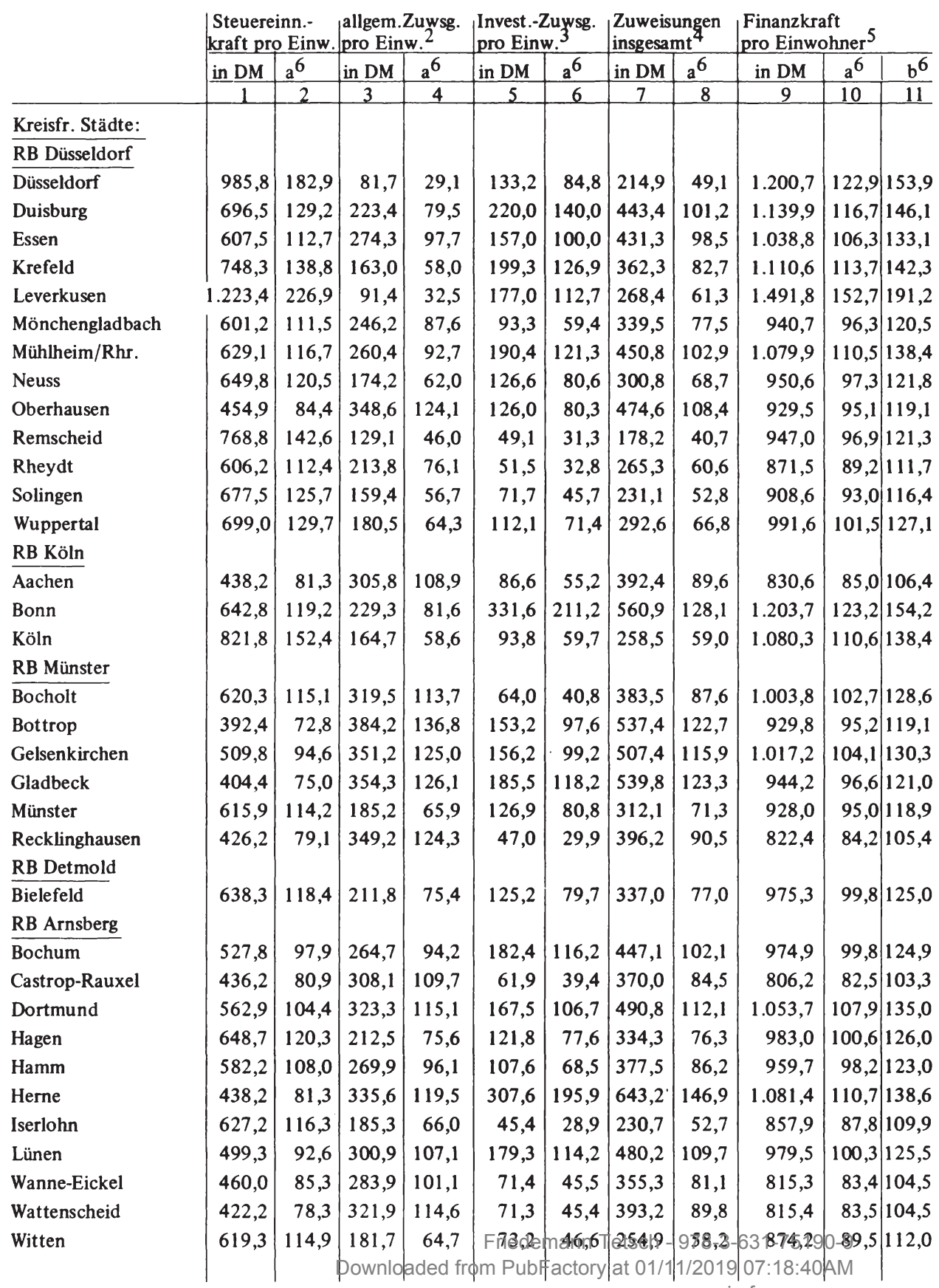


noch Tabelle $19 \mathrm{c}$

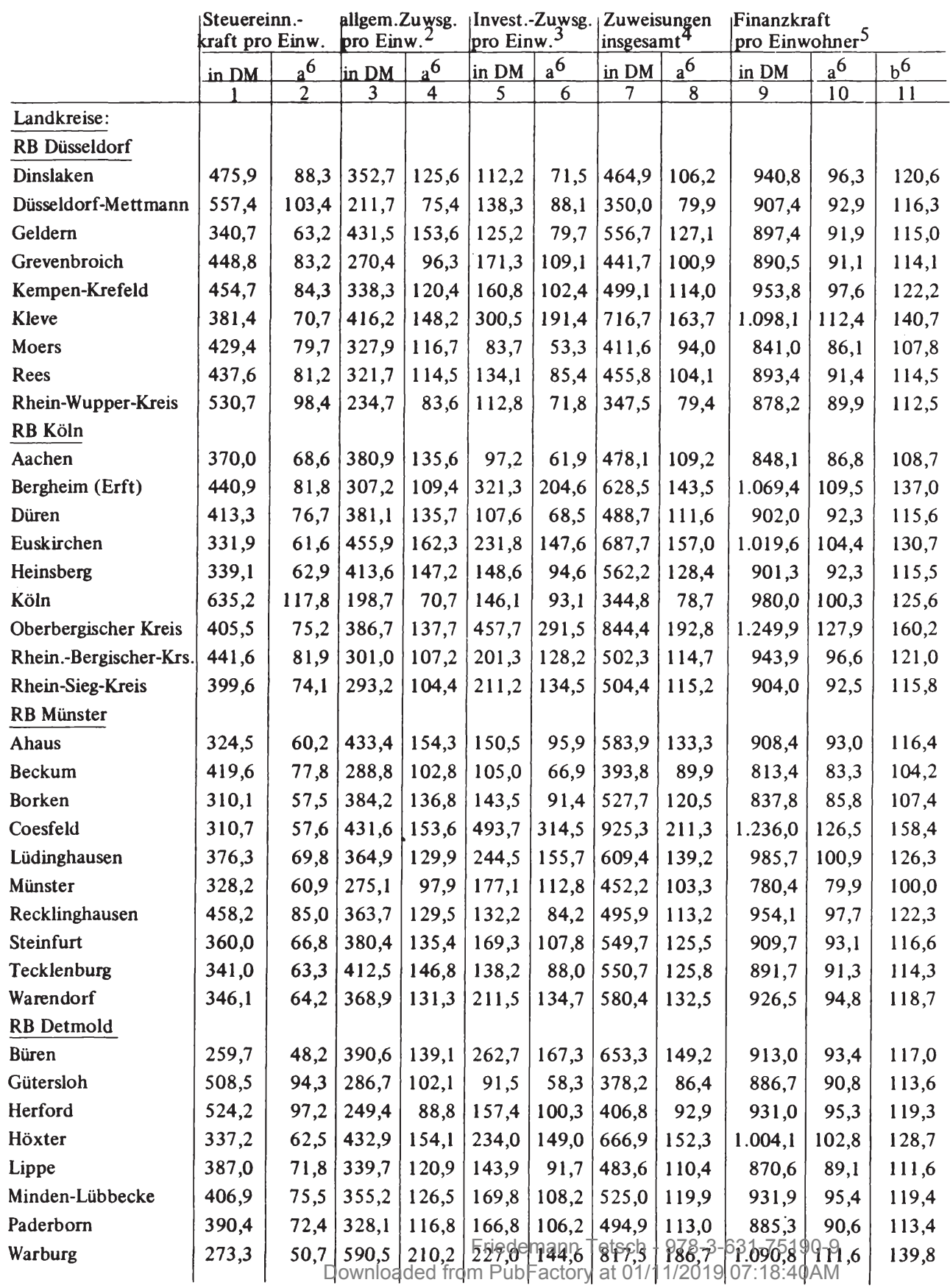


noch Tabelle $19 \mathrm{c}$

\begin{tabular}{|c|c|c|c|c|c|c|c|c|c|c|c|}
\hline & \multicolumn{2}{|c|}{$\begin{array}{l}\text { Steuereinn.- } \\
\text { kraft pro Einw. }\end{array}$} & \multicolumn{2}{|c|}{$\begin{array}{l}\text { allgem.Zuwsg. } \\
\text { pro Einw. } 2\end{array}$} & \multicolumn{2}{|c|}{$\begin{array}{l}\text { Invest.-Zuwsg. } \\
\text { pro Einw. }\end{array}$} & \multicolumn{2}{|c|}{$\begin{array}{l}\text { Zuweisungen } \\
\text { insgesamt }^{4}\end{array}$} & \multicolumn{3}{|c|}{$\begin{array}{l}\text { Finanzkraft } \\
\text { pro Einwohner }\end{array}$} \\
\hline & in DM & $a^{6}$ & in DM & $a^{6}$ & in DM & $a^{6}$ & in DM & $a^{6}$ & in DM & $a^{6}$ & $b^{6}$ \\
\hline & 1 & 2 & 3 & 4 & 5 & 6 & 7 & 8 & 9 & 10 & 11 \\
\hline \multicolumn{12}{|l|}{ RB Arnsberg } \\
\hline$\overline{\text { Arnsberg }}$ & 474,6 & 88,0 & 285,3 & 101,6 & 187,9 & 119,7 & 473,2 & 108,1 & 947,8 & 97,0 & 121,5 \\
\hline Brilon & 355,6 & 66,0 & 370,3 & 131,8 & 380,7 & 242,5 & 751,0 & 171,5 & $1.106,6$ & 113,3 & 141,8 \\
\hline Ennepe-Ruhr-Kreis & 576,5 & 106,9 & 259,4 & 92,3 & 100,0 & 63,7 & 359,4 & 82,1 & 935,9 & 95,8 & 119,9 \\
\hline Iserlohn & 554,6 & 102,9 & 234,2 & 83,4 & 88,6 & 56,4 & 322,8 & 73,7 & 877,4 & 89,8 & 112,4 \\
\hline Lippstadt & 383,4 & 71,1 & 272,7 & 97,1 & 266,1 & 169,5 & 538,8 & 123,0 & 922,2 & 94,4 & 118,2 \\
\hline Lüdenscheid & 632,6 & 117,3 & 240,1 & 85,5 & 134,8 & 85,9 & 374,9 & 85,6 & $1.007,5$ & 103,1 & 129,1 \\
\hline Meschede & 381,8 & 70,8 & 335,3 & 119,4 & 297,6 & 189,6 & 632,9 & 144,5 & $1.014,7$ & 103,9 & 130,0 \\
\hline Olpe & 409,5 & 76,0 & 324,8 & 115,6 & 303,4 & 193,2 & 628,2 & 143,5 & $1.037,7$ & 106,2 & 133,0 \\
\hline Siegen & 581,4 & 107,8 & 241,7 & 86,0 & 183,7 & 117,0 & 425,4 & 97,1 & $1.006,8$ & 103,1 & 129,0 \\
\hline Soest & 347,9 & 64,5 & 403,5 & 143,6 & 196,5 & 125,2 & 600,0 & 137,0 & 947,9 & 97,0 & 121,5 \\
\hline Unna & 403,5 & 74,8 & 360,0 & 128,2 & 170,2 & 108,4 & 530,2 & 121,1 & 933,7 & 95,6 & 119,6 \\
\hline Wittgenstein & 348,2 & 64,6 & 378,3 & 134,7 & 289,6 & 184,4 & 667,9 & 152,5 & $1.016,1$ & 104,0 & 130,2 \\
\hline Nordrhein-Westfalen & 539,1 & 100,0 & $280,9^{8}$ & 100,0 & $157,0^{8}$ & 100,0 & 437,9 & 100,0 & 977,0 & 100,0 & \\
\hline Kreisfr. Städte & 653,6 & 121,2 & 232,4 & 82,7 & 142,3 & 90,6 & 374,7 & 85,6 & $1.028,3$ & 105,3 & \\
\hline Landkreise $^{7}$ & 440,8 & 81,8 & 322,5 & 114,8 & 169,5 & 108,0 & 492,0 & 112,4 & 932,8 & 95,5 & \\
\hline
\end{tabular}

1) Quelle: Berechnet nach

Landesamt für Datenverarbeitung und Statistik Nordrhein-Westfalen, Statistische Berichte, Die Gemeindefinanzen in Nordrhein-Westfalen 1974, Ergebnisse der vierteljährlichen Kassenstatistik, Düsseldorf, September 1975, S. 44 f. und S. 16 - 39.

2) Zuweisungen und Zuschüsse vom Land (Verwaltungshaushalt) an Gemeinden und Gemeindeverbände.

3) Zuweisungen und Zuschüsse für Investitionen und Investitionsförderungsmaßnahmen von Land und Bund an Gemeinden und Gemeindeverbände.

4) Summe der Werte aus Spalte 3 und 5.

5) Summe der Werte aus Spalte 1, 3 und 5.

6) $\mathrm{a}=$ in $\%$ des Landesdurchschnitts

$\mathrm{b}=$ in \% des finanzschwächsten Landkreises.

7) Landkreise: kreisangehörige Gemeinden, Ämter und Kreise.

8) Ohne Zuweisungen an Landschaftsverbände. 
1.3.2.4. Die räumlichen Auswirkungen des vertikalen Gemeindefinanzaus gleichs in Bayern im Jahr 1974

In Bayern werden im Jahr 1974 von 36 steuerstarken Regionen insgesamt 29 Regionen mit durchschnittlich oder unterdurchschnittlich hohen Zuweisungen pro Einwohner ausgestattet. Zu diesen 29 Regionen mit höchstens durchschnittlich hohen Pro-Kopf-Zuweisungen gehören alle Großstädte Bayerns, also auch die Zentren der drei Verdichtungsräume Bayerns, (256) München, Nürnberg und Augsburg. Dagegen erhalten 36 von den 60 steuerschwachen Regionen Bayerns höhere Zuweisungen, als ihnen bei einer Verteilung der Finanzausgleichsmasse nach der Einwohnerzahl zustehen. Diese Begünstigung der Mehrzahl der steuerschwachen Regionen Bayerns bei der Verteilung der Finanzzuweisungen von Land und Bund ist aus regionalpolitischer Sicht besonders deswegen positiv zu beurteilen, weil unter den begünstigten Regionen fast alle Landkreise der Regierungsbezirke Niederbayern, Oberpfalz und Oberfranken sind. Diese Regionen entlang der Grenze zur Tschechoslowakei weisen die geringste Steuer-und Wirtschaftskraft pro Einwohner in Bayern auf und sind wegen ihrer Strukturschwächen in der Erwerbs - und Infrastruktur als Gebietseinheiten 22, 32 und 33 im Bundesraumordnungsprogramm vom 30.4.1975 zu Fördergebieten erklärt worden. (257) Außerdem muß hervorgehoben werden, daß die Zuweisungen pro Einwohner an die einzelnen Landkreise dieser drei peripher gelegenen Regierungsbezirke tendenziell umso weiter über dem Landesdurchschnitt liegen, je weiter ihre Steuereinnahmekraft pro Einwohner nach unten vom Landesdurchschnitt abweicht. In diesen Fällen entspricht also die tatsächliche regionale Vertei lung der Finanzzuweisungen von Land und Bund der regionalpolitisch wünschenswerten Verteilung. (258) Der vertikale Gemeindefinanzausgleich ver ringert die absoluten Einnahmekraftunterschiede zwischen diesen Regionen und den steuerstarken Wohlstands - und Ballungsregionen des Landes und be wirkt damit eine Abschwächung der räumlichen Differenzierungstendenzen. Dank dieser regionalen Verteilung der Finanzzuweisungen erreichen immerhin sieben Landkreise dieser strukturschwachen Regie rungsbezirke eine mindestens durchschnittlich hohe Finanzkraft pro Einwohner, so daß sie höhere Aus gaben für attraktivitätsfördernde Zwecke pro Einwohner tätigen können als eine ganze Reihe von wesentlich steuer- und wirtschaftsstärkeren Regionen.

Diese positive Beurteilung der Wirkungsrichtung und -stärke des vertikalen Gemeindefinanzausgleichs in Bayern im Jahr $1974 \mathrm{mu} \beta$ allerdings in einem nicht unwesentlichen Punkt eingeschränkt werden: Von den steuerstarken Regionen mit unterdurchschnittlich hohen Pro-Kopf-Zuweisungen fließen ausge rechnet München und Nürnberg mit 95,2 \% bzw. 93,4\% des Landesdurchschnitts die höchsten Pro-Kopf-Zuweisungen zu (Spalte 8 in Tabelle 19d). Die beiden Zentren der größten Verdichtungsgebiete Bayerns erhalten damit 1974 höhere Zuweisungen pro Einwohner als 19 kreisfreie Städte und 27 Landkreise. Gegenüber diesen Regionen wird also die Attraktionskraft Münchens und Nürnbergs gestärkt. Außerdem wird dadurch verhindert, daß wenigstens einige Landkreise der steuer- und wirtschaftsschwachen Regierungsbezirke Nie derbayern, Oberpfalz und Oberfranken eine Finanzkraft pro Einwohner er- 
Tabelle 19 d Die Finanzkraft der Gemeinden und Gemeindeverbände in Bayern im Jahr 1974

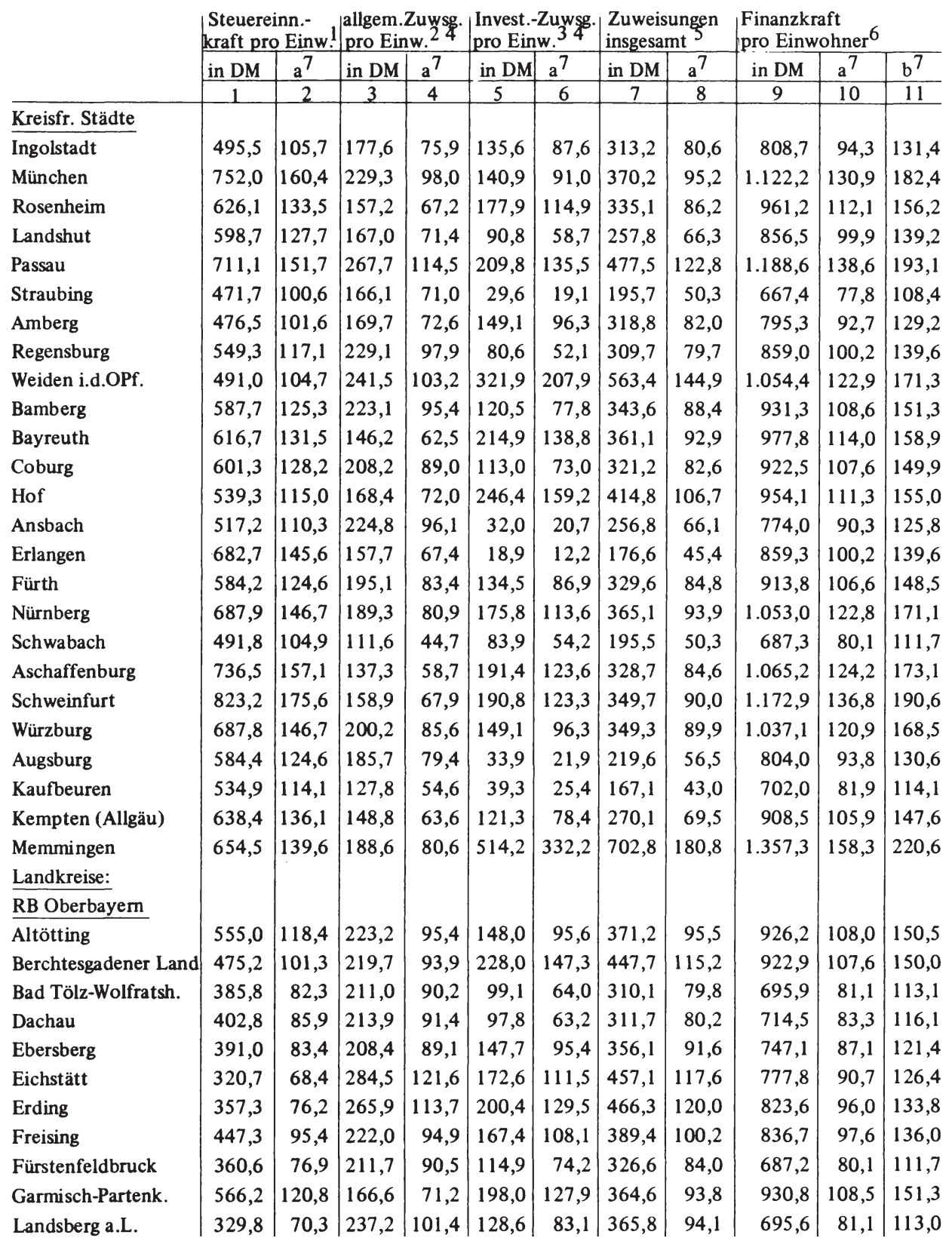


noch Tabelle $19 \mathrm{~d}$

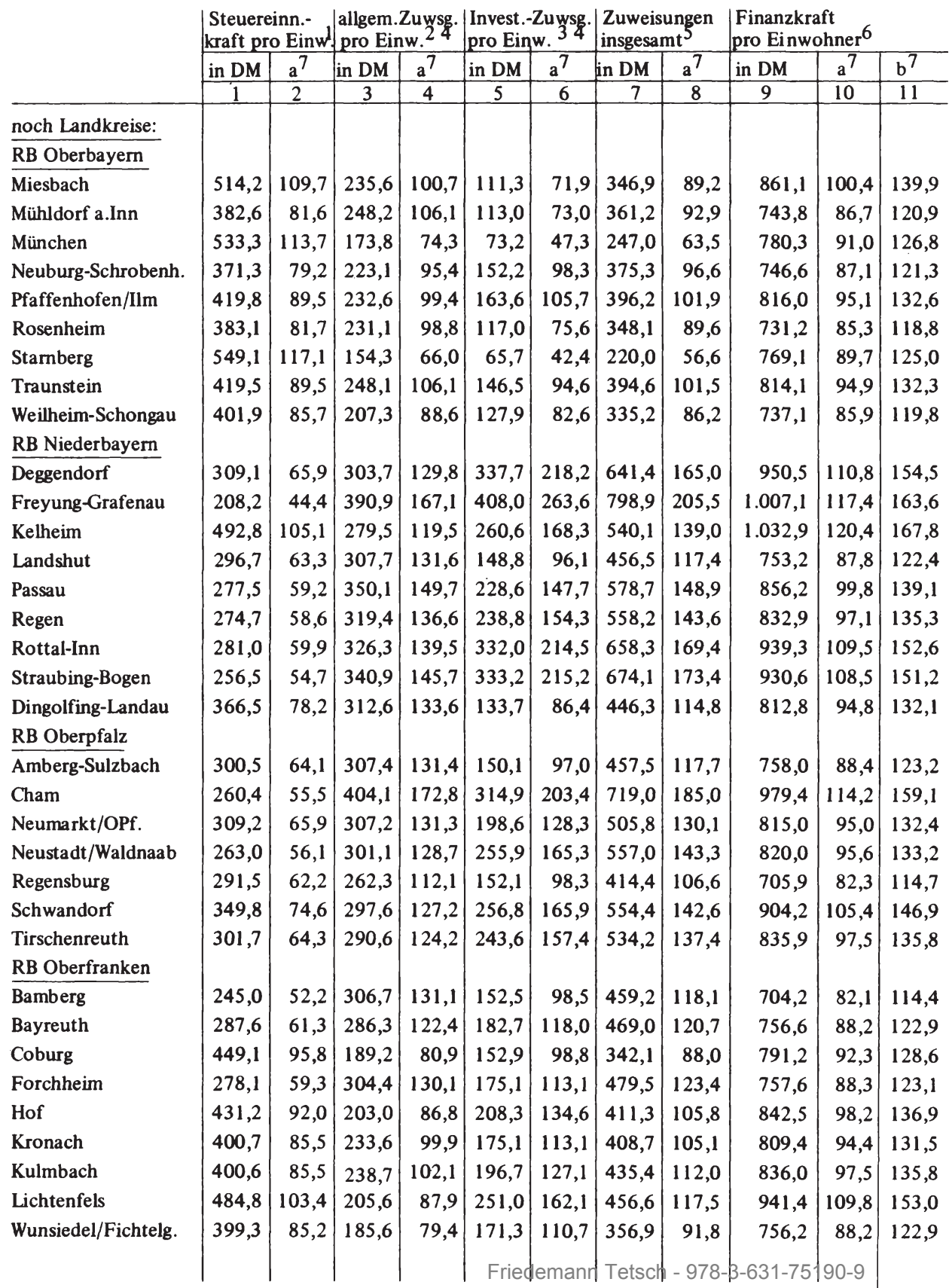


noch Tabelle $19 \mathrm{~d}$

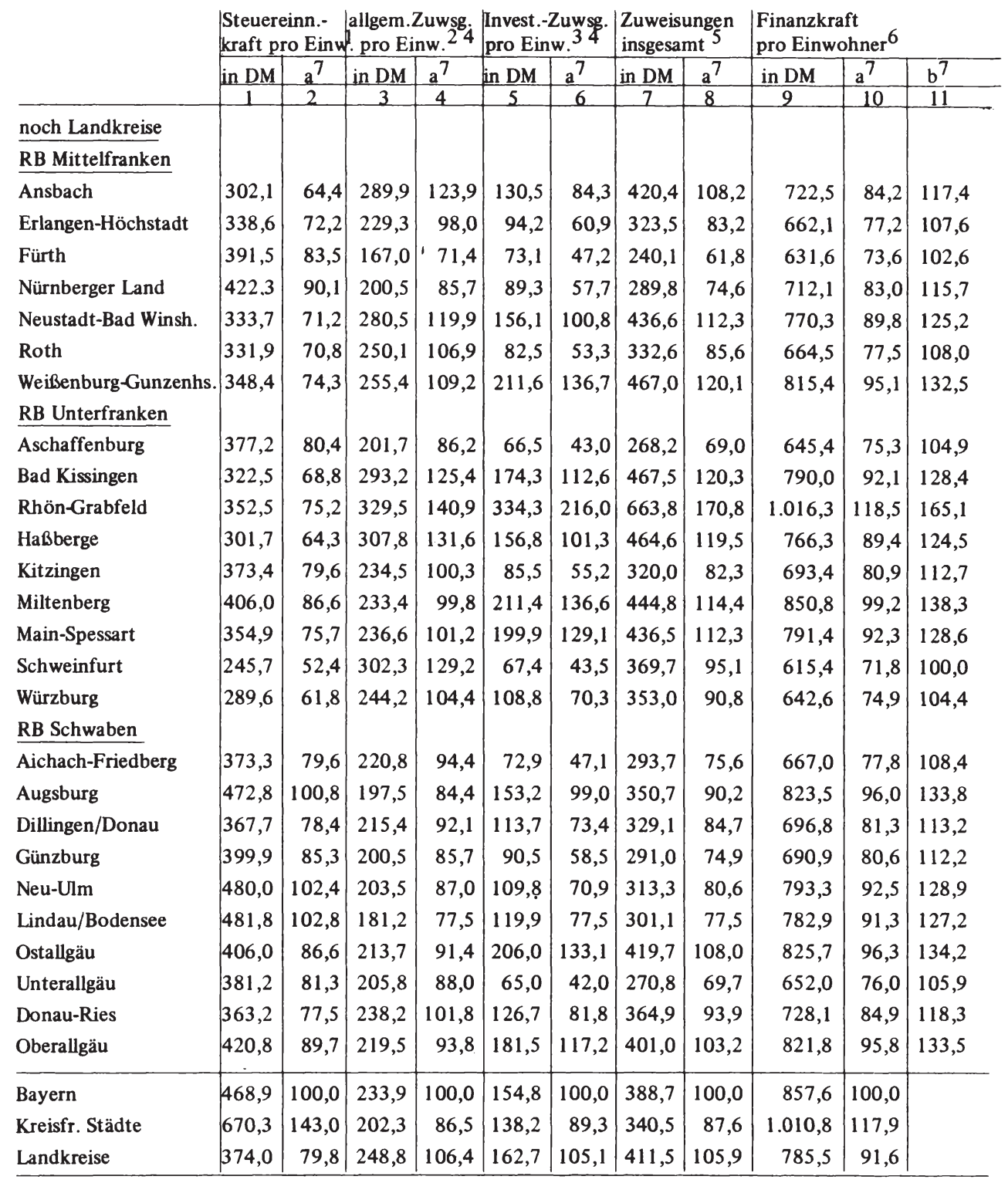




\section{Anmerkungen zu Tabelle $19 \mathrm{~d}$}

1) Quelle: Berechnet nach

Bayerisches Statistisches Landesamt, Statistische Berichte, Staatliche und kommunale Steuern und andere Ergebnisse der vierteljährlichen Finanzstatistiken sowie Realsteuervergleich in Bayern 1974, München, August 1975, S. 39 ff.

2) Allgemeine Zuweisungen und Zuschüsse für laufende Zwecke von Bund und Land an Gemeinden und Gemeindeverbände.

3) Zuweisungen und Zuschüsse für Investitionen von Bund und Land an Gemeinden und Gemeindeverbände.

4) Quelle: Berechnet nach

Bayerisches Statistisches Landesamt, Anlagen zum Schreiben an den Verfasser vom 6.5.1977, Nr. VI/A/1-2736.

5) Summe der Werte aus Spalte 3 und 5.

6) Summe der Werte aus Spalte 1, 3 und 5.

7) $\mathrm{a}=$ in \% des Landesdurchschnitts

$\mathrm{b}=$ in \% des finanzschwächsten Landkreises. 
reichen, die über derjenigen der Ballungszentren liegt. Wegen dieser Ausstattung der beiden Ballungszentren München und Nürnberg mit beinahe durchschnittlich hohen Finanzzuweisungen pro Einwohner muß wohl der ballungs bremsende Effekt des vertikalen Gemeindefinanzausgleichs in Bayern 1974 als relativ gering eingeschätzt werden. Jedenfalls kann man nicht ohne wei teres davon sprechen, daß in Bayern der vertikale Gemeindefinanzausgleich im Jahr 1974 zielgerecht als Instrument der Regionalpolitik eingesetzt wird.

1.3.2.5. Die räumlichen Auswirkungen des vertikalen Gemeindefinanzausgleichs in Niedersachsen im Jahr 1974

Vieles von dem, was über Wirkungsrichtung und -stärke des vertikalen Gemeindefinanzausgleichs in Bayern für das Jahr 1974 gesagt worden ist, gilt entsprechend auch für Niedersachsen:

- Den meisten steuerstarken Regionen werden 1974 in Niedersachsen unterdurchschnittlich hohe, den meisten der steuerschwachen Regionen überdurchschnittlich hohe Pro-Kopf-Zuweisungen zugewiesen (vgl. Tabelle 20 ).

- Beinahe alle Landkreise der Regierungsbezirke Lüneburg, Osnabrück, Aurich und des Verwaltungsbezirks Oldenburg werden mit überdurchschnittlich hohen Zuweisungen pro Einwohner ausgestattet, wobei der Zuweisungsbetrag pro Einwohner tendenziell umso höher ist, je niedriger die regionale Steuereinnahmekraft pro Kopf ist. Diese begünstigten Regionen sind durch ihre Schwächen in der Erwerbs- und Infrastruktur gekennzeichnet und werden im Bundesraumordnungsprogramm als Gebietseinheiten 4, 5, 6 und 7 als Fördergebiete ausgewiesen. (259)

- Alle kreisfreien Städte mit Ausnahme von Cuxhaven und Wilhelmshaven müssen sich dagegen mit unterdurchschnittlich hohen Zuweisungen pro Einwohner zufrieden geben. Wie in Bayern erhält allerdings auch in Niedersachsen die am stärksten verdichtete Region mehr Zuweisungen pro Einwohner als alle anderen steuerstarken Regionen mit unterdurchschnittlichen Pro-Kopf-Zuweisungen. Trotz der höchsten Steuereinnahmekraft pro Einwohner in Höhe von 193,2 \% des Landesdurchschnitts betragen die Zuweisungen pro Einwohner an Hannover $91,6 \%$ des Landesdurchschnitts (Spalte 8 in Tabelle 19e).

- Dadurch liegen die Pro-Kopf-Zuweisungen an Hannover im Jahr 1974 über den Pro-Kopf-Zuweisungen von Bund und Land an sieben kreisfreie Städte und sieben Landkreise. Gegenüber diesen Regionen vergrößert sich also der absolute Einnahmekraftvorsprung, den die kreisfreie Stadt Hannover bereits nach der Steuerverteilung besitzt.

- Insgesamt wirkt der vertikale Gemeindefinanzausgleich in Niedersachsen im Jahr 1974 den ballungsfördernden Effekten der regionalen Steuerkraftverteilung entgegen und bremst, isoliert betrachtet, mit einiger Wahrscheinlichkeit den räumlichen Differenzierungsprozeß. 
- Der regionalpolitisch erwünschte Effekt der regionalen Verteilung der Finanzzuweisungen muß für das Jahr 1974 für Niedersachsen stärker

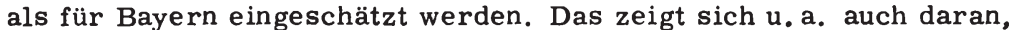
daß fünf von 14 steuerstarken Regionen nach der Verteilung der Finanzzuweisungen unterdurchschnittlich hohe, zehn von 44 steuerschwachen Regionen überdurchschnittlich hohe Einnahmen pro Einwohner (bei gleicher Steueranspannung) zur Verfügung haben.

- Besonders positiv zu bewerten ist, daß die meisten der steuerschwachen Regionen mit überdurchschnittlich hoher Finanzkraft pro Einwohner eine ausgesprochen niedrige Steuereinnahmekraft pro Einwohner besitzen und in den strukturschwachen Problemgebieten Niedersachsens liegen. Allerdings sorgen die relativ hohen Pro-Kopf-Zuweisungen an die kreisfreie Stadt Hannover dafür, daß 1974 nur eine einzige Region - der steuerschwache Landkreis Lüneburg - eine höhere Finanzkraft pro Einwohner als das Ballungs gebiet Hannover erreicht.

\subsubsection{Die räumlichen Auswirkungen des vertikalen Gemeindefinanzaus -} gleichs im Saarland im Jahr 1974

Die Verteilung der Finanzzuweisungen auf die einzelnen Regionen des Saarlandes im Jahr 1974 ergibt kein einheitliches Bild (Tabelle 19f). Zwar erhalten die beiden steuerstarken Regionen (Stadtverband Saarbrücken, Saar-PfalzKreis) unterdurchschnittlich hohe Zuweisungen, zwei steuerschwache Regionen (Merzig-Wadern, Neunkirchen) überdurchschnittlich hohe Zuweisungen pro Einwohner. Dagegen liegen die Gesamtzuweisungen, die den beiden anderen steuerschwachen Regionen (Saarlouis, St. Wendel) zufließen, unter dem Landesdurchschnitt.

Durch den vertikalen Gemeindefinanzausgleich wird 1974 der absolute Einnahmekraftrückstand zweier steuerschwacher Regionen (Merzig-Wadern, Neunkirchen) gegenüber der steuerstärksten Region des Saarlandes (Stadtverband Saarbrücken) verringert. Für die beiden Landkreise St. Wendel und Saarlouis bewirkt dagegen der vertikale Gemeindefinanzausgleich, daß sich der absolute Rückstand ihrer Einnahmekraft gegenüber dem Stadtverband Saarbrücken leicht bzw. erheblich vergrößert (Tabelle 19f, Spalte 7). In diesen beiden Fällen wird also der ballungsfördernde Effekt des regionalen Steuereinnahmekraftgefälles durch die Verteilung der Finanzzuweisungen verstärkt.

Insgesamt dürfte wohl der ballungsbremsende Effekt des vertikalen Gemeindefinanzausgleichs im Saarland 1974 stärker als sein ballungsfördernder Effekt sein.

1.3.2.7. Die räumlichen Auswirkungen des vertikalen Gemeindefinanzaus gleichs in Schleswig-Holstein im Jahr 1975

Die regionale Verteilung der Finanzzuweisungen von Land und Bund an die 
Tabelle 19 e Die Finanzkraft der Gemeinden und Gemeindeverbände in Niedersachsen im Jahr 1974

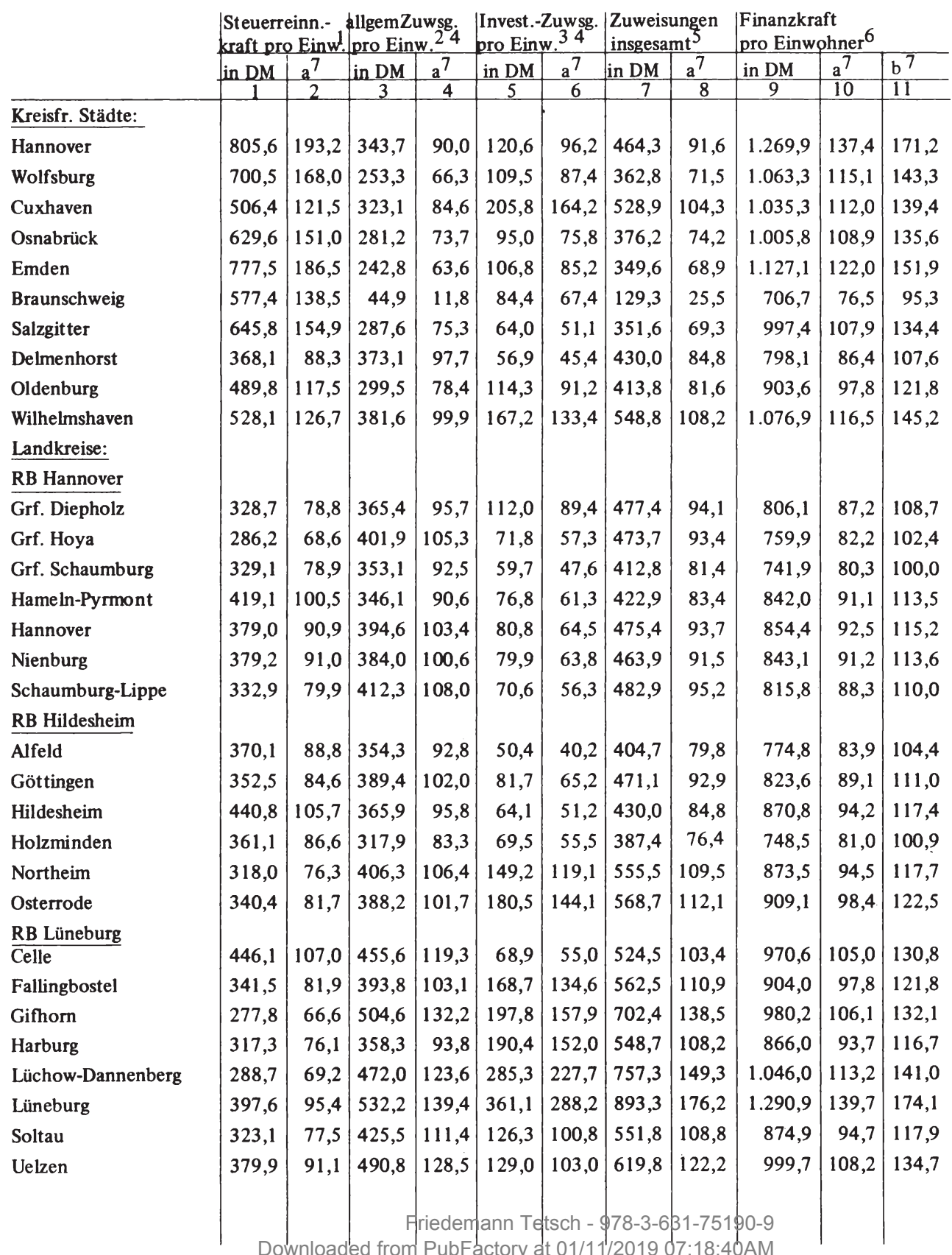


noch Tabelle $19 \mathrm{e}$

\begin{tabular}{|c|c|c|c|c|c|c|c|c|c|c|c|}
\hline & \multicolumn{2}{|c|}{$\begin{array}{l}\text { Steuereinn.- } \\
\text { kraft pro Einw }\end{array}$} & \multicolumn{2}{|c|}{$\begin{array}{l}\text { allgem.Zuwsg. } \\
\text { pro Einw. } 24\end{array}$} & \multicolumn{2}{|c|}{$\mid \begin{array}{l}\text { Invest.-Zuwsg. } \\
\text { pro Einw. } 34\end{array}$} & \multicolumn{2}{|c|}{$\begin{array}{l}\text { Zuweisungen } \\
\text { insgesamt }\end{array}$} & \multicolumn{3}{|c|}{$\begin{array}{l}\text { Finanzkraft } \\
\text { pro Einwohner } 6\end{array}$} \\
\hline & in DM & $a^{7}$ & in DM & $a^{7}$ & in DM & $a^{7}$ & in $\mathrm{DM}$ & $a^{7}$ & in $\mathrm{DM}$ & $a^{7}$ & $b^{7}$ \\
\hline & 1 & 2 & 3 & 4 & 5 & 6 & 7 & 8 & 9 & 10 & 11 \\
\hline \multicolumn{12}{|l|}{ noch Landkreise: } \\
\hline \multicolumn{12}{|l|}{ RB Stade } \\
\hline Bremervörde & 295,8 & 71,0 & 503,4 & 131,8 & 160,7 & 128,3 & 664,1 & 131,0 & 959,9 & 103,9 & 129,4 \\
\hline Land Hadeln & 242,3 & 58,1 & 488,2 & 127,9 & 156,0 & 124,5 & 644,2 & 127,0 & 886,5 & 95,9 & 119,5 \\
\hline Osterholz & 252,1 & 60,5 & 385,1 & 100,9 & 118,9 & 94,9 & 504,0 & 99,4 & 756,1 & 81,8 & 101,9 \\
\hline Rotenburg & 284,5 & 68,2 & 421,3 & 110,3 & 127,2 & 101,5 & 548,5 & 108,2 & 833,0 & 90,2 & 112,3 \\
\hline Stade & 387,3 & 92,9 & 349,5 & 91,5 & 156,4 & 124,8 & 505,9 & 99,8 & 893,2 & 96,7 & 120,4 \\
\hline Verden & 361,2 & 86,6 & 359,2 & 94,1 & 98,3 & 78,5 & 457,5 & 90,2 & 818,7 & 88,6 & 110,4 \\
\hline Wesermünde & 225,3 & 54,0 & 407,2 & 106,7 & 177,4 & 141,6 & 584,6 & 115,3 & 809,9 & 87,7 & 109,2 \\
\hline \multicolumn{12}{|l|}{$\underline{\text { RB Osnabrück }}$} \\
\hline Aschendorf-Hümmling & 236,5 & 56,7 & 605,3 & 158,5 & 235,6 & 188,0 & 840,9 & 165,8 & $1.077,4$ & 116,6 & 145,2 \\
\hline Grf. Bentheim & 355,9 & 85,4 & 434,3 & 113,8 & 129,9 & 103,7 & 564,2 & 111,3 & 920,1 & 99,6 & 124,0 \\
\hline Lingen & 388,6 & 93,2 & 533,7 & 139,8 & 131,5 & 104,9 & 665,2 & 131,2 & $1.053,8$ & 114,0 & 142,0 \\
\hline Meppen & 278,4 & 66,8 & 492,5 & 129,0 & 107,1 & 85,5 & 599,6 & 118,2 & 878,0 & 95,0 & 118,3 \\
\hline Osnabrück & 313,6 & 75,2 & 420,2 & 110,1 & 100,0 & 79,8 & 520,2 & 102,6 & 833,8 & 90,2 & 112,4 \\
\hline \multicolumn{12}{|l|}{ RB Aurich } \\
\hline Aurich & 281,6 & 67,5 & 469,9 & 123,1 & 163,3 & 130,3 & 633,2 & 124,9 & 914,8 & 99,0 & 123,3 \\
\hline Leer & 272,0 & 65,2 & 494,9 & 129,6 & 143,3 & 114,4 & 638,2 & 125,9 & 910,2 & 98,5 & 122,7 \\
\hline Norden & 274,0 & 65,7 & 466,5 & 122,2 & 209,0 & 166,8 & 675,5 & 133,2 & 949,5 & 102,8 & 128,0 \\
\hline Wittmund & 245,6 & 58,9 & 455,2 & 119,2 & 180,3 & 143,9 & 635,5 & 125,3 & 881,1 & 95,4 & 118,8 \\
\hline \multicolumn{12}{|l|}{ Verw.Bez. Braunschweig } \\
\hline Gandersheim & 401,1 & 96,2 & 375,0 & 98,2 & 99,7 & 79,6 & 474,7 & 93,6 & 875,8 & 94,8 & 118,0 \\
\hline Goslar & 421,5 & 101,1 & 355,9 & 93,2 & 128,0 & 102,2 & 483,9 & 95,4 & 905,4 & 98,0 & 122,0 \\
\hline Helmstedt & 393,1 & 94,3 & 402,1 & 105,3 & 285,5 & 227,9 & 687,6 & 135,6 & $1.080,7$ & 117,0 & 145,7 \\
\hline Wolfenbüttel & 391,9 & 94,0 & 394,8 & 103,4 & 101,5 & 81,0 & 496,3 & 97,9 & 888,2 & 96,1 & 119,7 \\
\hline Peine & 380,3 & 91,2 & 377,3 & 98,8 & 82,3 & 65,7 & 459,6 & 90,6 & 839,9 & 90,9 & 113,2 \\
\hline \multicolumn{12}{|l|}{ Verw.Bez. Oldenburg } \\
\hline Ammerland & 275,1 & 66,0 & 527,4 & 138,1 & 230,0 & 183,6 & 757,4 & 149,4 & $1.032,5$ & 111,7 & 139,2 \\
\hline Cloppenburg & 249,0 & 59,7 & 461,5 & 120,9 & 123,2 & 98,3 & 584,7 & 115,3 & 833,7 & 90,2 & 112,4 \\
\hline Friesland & 297,9 & 71,5 & 389,0 & 101,9 & 109,3 & 87,2 & 498,3 & 98,3 & 796,2 & 86,2 & 107,3 \\
\hline Oldenburg & 273,1 & 65,5 & 394,9 & 103,4 & 135,5 & 108,1 & 530,4 & 104,6 & 803,5 & 87,0 & 108,3 \\
\hline Vechta & 304,6 & 73,1 & 367,0 & 96,1 & 141,4 & 112,8 & 508,4 & 100,3 & 813,0 & 88,0 & 110,0 \\
\hline Wesermarsch & 449,7 & 107,9 & 384,2 & 100,6 & 241,3 & 192,6 & 625,5 & 123,3 & $1.075,2$ & 116,4 & 144,9 \\
\hline Niedersachsen & 416,9 & 100,0 & 381,8 & 100,0 & 125,3 & 100,0 & 507,1 & 100,0 & 924,0 & 100,0 & \\
\hline Kreisfr. Städte & 659,2 & 158,1 & 274,4 & 71,9 & 109,7 & 87,5 & 384,1 & 75,7 & $1.043,3$ & 112,9 & \\
\hline Landkreise & 344,1 & 82,5 & 414,3 & 108,5 & 130,0 & 103,8 & 544,3 & 107,3 & 888,4 & 96,1 & \\
\hline
\end{tabular}




\section{Anmerkungen zu Tabelle $19 \mathrm{e}$}

1) Quelle: Berechnet nach

Niedersächsisches Landesverwaltungsamt - Statistik -, Statistische Berichte, Realsteuern und Realsteuerhebesätze 1974, Hannover, Oktober 1975. S. 16 f.

2) Zuweisungen und Zuschüsse für laufende Zwecke, einschließlich Zinseinnahmen, Schuldendiensthilfen und Erstattungen von Verwaltungs- und Betriebsausgaben von öffentlichen und anderen Bereichen (ohne von Gemeinden/Gemeindeverbänden) an Gemeinden und Gemeindeverbände.

3) Zuweisungen und Zuschüsse für Investitionen von öffentlichen und anderen Bereichen (ohne von Gemeinden/Gemeindeverbänden) an Gemeinden und Gemeindeverbände.

4) Quelle: Berechnet nach

Niedersächsisches Landesverwaltungsamt - Statistik -, Statistische Berichte, Die Gemeindefinanzen für das Jahr 1974 in Niedersachsen, Ergebnisse der vierteljährlichen Kassenstatistik, Hannover, August 1975, S. 10 - 21.

5) Summe der Werte aus Spalte 3 und 5.

6) Summe der Werte aus Spalte 1, 3 und 5.

7) $\mathrm{a}=$ in \% des Landesdurchschnitts

$\mathrm{b}=$ in \% des finanzschwächsten Landkreises. 
Tabelle 19 f Die Finanzkraft der Gemeinden und Gemeindeverbände im Saarland im Jahr 1974

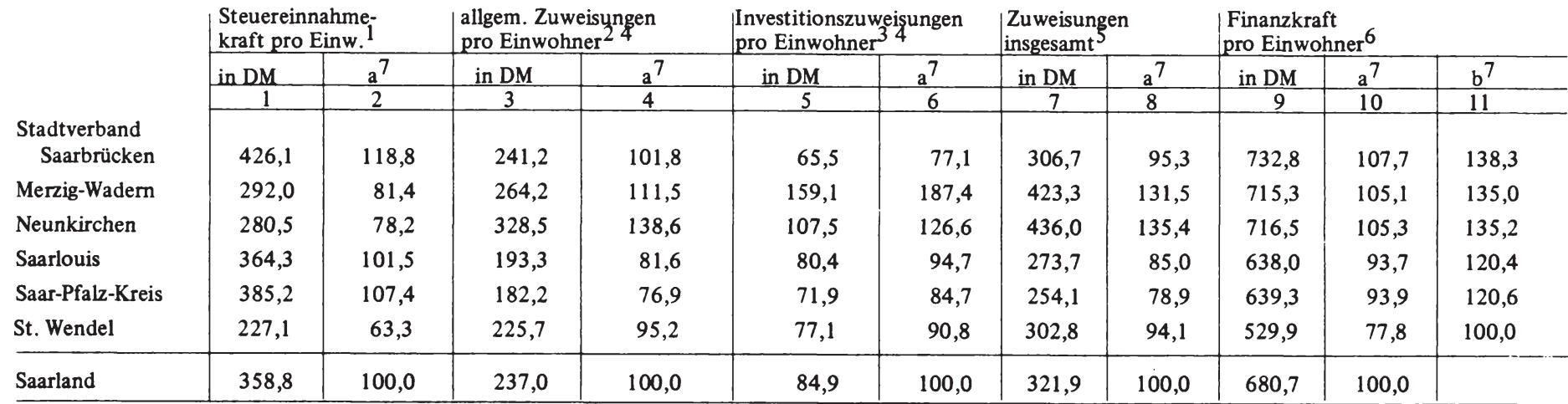

\section{1) Quelle: Berechnet nach}

Statistisches Bundesamt, Fachserie L, Finanzen und Steuern, Reihe 9, Realsteuervergleich 1974, Stuttgart, Mainz, Dezember 1975, S. 96 f.

2) Allgemeine Zuweisungen, Erstattungen von Verwaltungs- und Betriebsausgaben, Zuweisungen und Zuschüsse für laufende Zwecke, Zinseinnahmen, Schuldendiensthilfen von Land und Bund an Gemeinden und Gemeindeverbände.

3) Zuweisungen und Zuschüsse für Investitionen und Investitionsförderungsmaßnahmen von Land und Bund an Gemeinden und Gemeindeverbände.

4) Quelle: Berechnet nach

Statistisches Amt des Saarlandes, Statistische Berichte, Kommunale Finanzen 1974, Saarbrücken, Januar 1977.

5) Summe der Werte aus Spalte 3 und 5.

6) Summe der Werte aus Spalte 1, 3 und 5.

7) $\mathrm{a}=$ in $\%$ des Landesdurchschnitts

$\mathrm{b}=$ in \% des finanzschwächsten Landkreises. 
Gemeinden und Gemeindeverbände deckt sich 1975 in Schleswig-Holstein weitgehend mit der regionalpolitisch wünschenswerten Verteilung der Zuweisungen. Nur eine kreisfreie Stadt (Neumünster) und ein Landkreis (Hzgt. Lauenburg) erhalten mehr bzw. weniger Zuweisungen, als sie bei einer zielgerechten Verteilung der Finanzausgleichsmasse bekommen hätten (Tabelle 19g, Spalte 7 und 8). Den beiden steuerstärksten Regionen (Kiel und Lübeck) flieBen mit 75,6\% bzw. 73,2\% des Landesdurchschnitts 1975 die niedrigsten Zuweisungen pro Kopf aller Regionen Schleswig-Holsteins zu. Dagegen werden die drei steuerschwächsten Regionen des Landes (Schleswig-Flensburg, Nordfriesland und Plön) mit den höchsten Pro-Kopf-Zuweisungen ausgestattet. Sie erhalten Zuweisungen pro Einwohner in Höhe von 125,4 \%, 120,3\% und $122,9 \%$ des Landesdurchschnitts. Damit wirkt der vertikale Gemeindefinanzausgleich 1975 in Schleswig-Holstein dem ballungsfördernden Effekt des regionalen Steuerkraftgefälles auch in quantitativ beachtlicher Stärke entgegen. $\mathrm{Ob}$ der vertikale Gemeindefinanzausgleich allerdings ausreicht, die ballungsfördernde Wirkung des kommunalen Steuersystems auszugleichen oder gar überzukompensieren, kann erst beurteilt werden, wenn Richtung und Ausmaß des regionalen Einnahmekraftgefälles, das nach der Verteilung der Zuweisungen besteht, untersucht werden. Bevor dazu übergegangen wird, sollen die Ergebnisse der Untersuchung über die Raumwirkungen des vertikalen Gemeindefinanzausgleichs kurz zusammengefaßt werden.

\subsubsection{Zusammenfassung der Ergebnisse}

Die Ergebnisse der vorstehenden Untersuchung über den räumlichen Einfluß des vertikalen Gemeindefinanzausgleichs 1974 (bzw. 1975) können in einigen Thesen zusammengefaßt werden:

- Die Raumwirkungen des vertikalen Gemeindefinanzausgleichs unterscheiden sich von Bundesland zu Bundesland. Sie müssen deshalb für jedes einzelne Bundesland gesondert ermittelt werden. Allerdings lassen sich zwischen den einzelnen Ländern Ähnlichkeiten feststellen, die eine Gruppenbildung erlauben.

- In fünf der hier untersuchten Bundesländer - es handelt sich um Nordrhein-Westfalen, Bayern, Niedersachsen, Saarland und Schleswig-Holstein - wirkt der vertikale Gemeindefinanzausgleich - in jeweils unter schiedlicher Stärke - tendenziell dem ballungsfördernden Effekt des regionalen Steuerkraftgefälles entgegen. Er schwächt damit - isoliert be trachtet - den räumlichen Differenzierungsprozeß ab.

- In den beiden anderen hier untersuchten Bundesländern (Hessen und Rheinland-Pfalz) vergrößert er dagegen die absoluten Einnahmekraftunterschiede $z$ wischen den steuerstarken und den steuerschwachen Regionen und wirkt damit in Richtung einer Verstärkung der regionalen Wirtschafts kraftunterschiede und der Ballungstendenzen.

- In allen sieben Bundesländern entspricht die regionale Verteilung der allgemeinen Zuweisungen stärker den regionalpolitischen Anforderungen als 
Tabelle $19 \mathrm{~g}$ Die Finanzkraft der Gemeinden und Gemeindeverbände in Schleswig-Holstein im Jahr 1975

\begin{tabular}{|c|c|c|c|c|c|c|c|c|c|c|c|}
\hline & \multicolumn{4}{|c|}{$\begin{array}{l}\text { Steuereinn. } \\
\text { kraft pro Einwpro Einw. } 24 \text {. }\end{array}$} & \multicolumn{2}{|c|}{$\begin{array}{l}\text { Invest.-Zuwsg. } \\
\text { pro Einw. } 34 .\end{array}$} & \multicolumn{2}{|c|}{$\begin{array}{l}\text { Zuweisungen } \\
\text { insgesamt }^{5}\end{array}$} & \multicolumn{3}{|c|}{$\begin{array}{l}\text { Finanzkraft } \\
\text { pro Einwohner } 6\end{array}$} \\
\hline & in DM & $a^{7}$ & in $\mathrm{DM}$ & $a^{7}$ & in DM & $a^{7}$ & in DM & $a^{7}$ & in $\mathrm{DM}$ & $a^{7}$ & $b^{7}$ \\
\hline & 1 & 2 & 3 & 4 & 5 & 6 & \begin{tabular}{|l|}
7 \\
\end{tabular} & 8 & 9 & 10 & 11 \\
\hline \multicolumn{12}{|l|}{ Kreisfr. Städte: } \\
\hline$\overline{\text { Flensburg }}$ & 452,9 & 106,3 & 167,1 & 72,1 & 144,1 & 86,7 & 311,2 & 78,2 & 764,1 & 92,7 & 113,7 \\
\hline Kiel & 604,0 & 141,8 & 146,6 & 63,2 & 154,6 & 93,0 & 301,2 & 75,6 & 905,2 & 109,8 & 134,7 \\
\hline Lübeck & 595,2 & 139,7 & 214,2 & 92,4 & 77,1 & 46,4 & 291,3 & 73,2 & 886,5 & 107,5 & 131,9 \\
\hline Neumünster & 494,4 & 116,0 & 234,6 & 101,2 & 317,2 & 190,7 & 551,8 & 138,6 & $1.046,2$ & 126,9 & 155,7 \\
\hline \multicolumn{12}{|l|}{ Landkreise: } \\
\hline Dithmarschen & 355,7 & 83,5 & 318,3 & 137,3 & 322,0 & 193,6 & 640,3 & 160,8 & 996,0 & 120,8 & 148,2 \\
\hline Hzgt. Lauenburg & 366,1 & 85,9 & 217,1 & 93,6 & 88,8 & 53,4 & 305,9 & 76,8 & 672,0 & 81,5 & 100,0 \\
\hline Nordfriesland & 329,5 & 77,3 & 319,8 & 137,9 & 159,4 & 95,9 & 479,2 & 120,3 & 808,7 & 98,1 & 120,3 \\
\hline Ostholstein & 342,0 & 80,3 & 248,6 & 107,2 & 169,7 & 102,0 & 418,3 & 105,0 & 760,3 & 92,2 & 113,1 \\
\hline Pinneberg & 485,8 & 114,0 & 159,4 & 68,7 & 142,9 & 85,9 & 302,3 & 75,9 & 788,1 & 95,6 & 117,3 \\
\hline Plön & 331,7 & 77,8 & 281,6 & 121,4 & 207,8 & 125,0 & 489,4 & 122,9 & 821,1 & 99,6 & 122,2 \\
\hline Rendsburg-Eckernförde & 337,2 & 79,1 & 260,3 & 112,2 & 208,5 & 125,4 & 468,8 & 117,7 & 806,0 & 97,8 & 119,9 \\
\hline Schleswig-Flensburg & 292,0 & 68,5 & 334,3 & 144,2 & 164,9 & 99,2 & 499,2 & 125,4 & 791,2 & 96,0 & 117,7 \\
\hline Segeberg & 415,0 & 97,4 & 233,4 & 100,6 & 197,6 & 118,8 & 431,0 & 108,2 & 846,0 & 102,6 & 125,9 \\
\hline Steinburg & 380,3 & 89,3 & 246,0 & 106,1 & 152,0 & 91,4 & 398,0 & 100,0 & 778,3 & 94,4 & 115,8 \\
\hline Stormarn & 447,0 & 104,9 & 183,5 & 79,1 & 120,3 & 72,3 & 303,8 & 76,3 & 750,8 & 91,1 & 111,7 \\
\hline Schleswig-Holstein & 426,1 & 100,0 & 231,9 & 100,0 & 166,3 & 100,0 & 398,2 & 100,0 & 824,3 & 100,0 & \\
\hline Kreisfr. Städte & 566,1 & 132,9 & 183,9 & 79,3 & 146,9 & 88,3 & 330,8 & 83,1 & 896,9 & 108,8 & \\
\hline Landkreise & 376,6 & 88,4 & 248,8 & 107,3 & 173,1 & 104,1 & 421,9 & 106,0 & 798,5 & 96,9 & \\
\hline
\end{tabular}

1) Quelle: Berechnet nach

Statistisches Landesamt Schleswig-Holstein, Statistische Berichte, Realsteuervergleich in

Schleswig-Holstein 1975, Kiel, Januar 1977, S. 10 und 14.

2) Allgemeine Zuweisungen, Erstattungen von Verwaltungs- und Betriebsausgaben, Zuweisungen und Zuschüsse für laufende Zwecke, Zinseinnahmen, Schuldendiensthilfen von Land und Bund an Gemeinden, Ämter und Gemeindeverbände.

3) Zuweisungen und Zuschüsse für Investitionen und Investitionsförderungsmaßnahmen von Land und Bund an Gemeinden, Ämter und Gemeindeverbände.

4) Quelle: Berechnet nach

unveröffentlichten Angaben des Statistischen Landesamtes Schleswig-Holstein. Vierteljahresstatistik der Kommunalfinanzen, 1. - 4. Vierteljahr 1975, Az.: 21-137/75.

5) Summe der Werte aus Spalte 3 und 5.

6) Summe der Werte aus Spalte 1, 3 und 5.

7) $\mathrm{a}=$ in $\%$ des Landesdurchschnitts

$\mathrm{b}=$ in \% des finanzschwächsten Landkreises. 
die regionale Verteilung der Investitionszuweisungen. Diese scheint relativ stark an der regionalen Verteilung der aktuellen Nachfrage nach Infrastrukturleistungen orientiert zu sein und begünstigt dadurch tendenziell die wirtschaftsstarken, stark verdichteten Regionen.

- In keinem der untersuchten Bundesländer erreicht eine nennenswerte Zahl von steuerschwachen, ländlichen Regionen dank des vertikalen Gemeindefinanzausgleichs eine höhere Finanzkraft pro Einwohner als die steuerstärksten und stark agglomerierten Regionen des Landes. Am oberen Ende der Rangfolge nach der Einnahmekraft pro Einwohner stehen auch nach der Verteilung der Finanzzuweisungen überwiegend die Zentren der Ballungsgebiete und tauchen nur vereinzelt Landkreise aus schwach strukturierten Gebieten auf.

2. Die räumlichen Auswirkungen der regionalen Verteilung der kommunalen Gesamteinnahmen im Jahr 1974

Abschließend soll untersucht werden, ob die regionale Verteilung der den Gemeinden insgesamt zur Verfügung gestellten Einnahmen den räumlichen Differenzierungsproze $\beta$ verstärkt oder den räumlichen Konzentrationstendenzen entgegenwirkt.

Wenn der vertikale Gemeindefinanzausgleich die absoluten Einnahmekraftunterschiede vergrößert, die nach der Verteilung der kommunalen Steuereinnahmen zwischen den Regionen bestehen, so wirkt er isoliert betrachtet ballungsfördernd. In diesem Fall werden auch von der Verteilung der gesamten kommunalen Finanzmasse die räumlichen Konzentrationstendenzen verstärkt. Da die absoluten Finanzkraftvorsprünge der wirtschaftsstarken Regionen gegenüber den wirtschaftsschwachen Regionen größer als die absoluten Steuerkraftvorsprünge sind, ist der ballungsfördernde Effekt der Finanzkraftverteilung stärker als der der Steuerkraftverteilung.

Etwas schwieriger ist die Beurteilung der Raumwirkungen des kommunalen Einnahmensystems, wenn der vertikale Gemeindefinanzausgleich den ballungsfördernden Effekten des regionalen Steuerkraftgefälles entgegenwirkt.

Die erste Möglichkeit besteht darin, daß auch nach der Verteilung der Finanzzuweisungen ein regionales Einnahmekraftgefälle zugunsten der wirtschafts und steuerstarken Regionen, also in erster Linie zugunsten der kreisfreien Städte, existiert. Ob dieses regionale Finanzkraftgefälle ballungsfördernd wirkt, hängt von dem Ausmaß ab, in dem die wirtschaftsstarken Regionen mit höheren Einnahmen pro Kopf als die wirtschaftsschwachen Regionen aus gestattet werden. In der Regel stellen die wirtschaftsstarken Regionen (kreisfreien Städte) den Einwohnern der umliegenden wirtschaftsschwächeren Regionen zentralörtliche Leistungen zur Verfügung, wodurch sie kostenmäßig belastet werden. Im Umfang dieser Kostenbelastung aus ihrem zentralörtlichen Leistungsangebot kann ein regionales Finanzkraftgefälle zugunsten der wirtschaftsstarken Regionen gerechtfertigt werden, ohne daß regionalpolitisch negative Wirkungen auf die Raumstruktur befürchtet werden müssen. 
Tabelle 20 Die Verteilung der Finapzzuweisungen von Bund und Ländern und der Finanzkraft auf steuerstarke und steuerschwache Regionen im Jahr 1974

Anzahl der Regionen

\begin{tabular}{|c|c|c|c|c|c|c|c|}
\hline & \multicolumn{7}{|c|}{ Anzahl der Regionen } \\
\hline & $\begin{array}{l}\text { Nordrhein- } \\
\text { Westfalen }\end{array}$ & $\begin{array}{l}\text { Rheinland- } \\
\text { Pfalz }\end{array}$ & $\begin{array}{l}\text { Saar- } \\
\text { land }\end{array}$ & Hessen & Bayern & $\begin{array}{l}\text { Nieder- } \\
\text { sachsen }\end{array}$ & $\begin{array}{c}\text { Schleswig } \\
\text { Holstein }\end{array}$ \\
\hline Regionen insgesamt & 82 & 36 & 6 & 30 & 96 & 58 & 15 \\
\hline $\begin{array}{l}\text { Steuerstarke Regionen } \\
\text { (100\% und mehr des Landesdurchschnitts) } \\
\text { mit durchschnittl. u. unterdurchschnittl. } \\
\text { Gesamtzuweisungen } \\
\text { mit überdurchschnittl. Gesamtzuweisungen }\end{array}$ & $\begin{array}{c}24 \\
4\end{array}$ & $\begin{array}{l}7 \\
5\end{array}$ & $\begin{array}{l}2 \\
-\end{array}$ & $\begin{array}{l}7 \\
2\end{array}$ & $\begin{array}{c}29 \\
7\end{array}$ & $\begin{array}{c}10 \\
4\end{array}$ & $\begin{array}{l}5 \\
1\end{array}$ \\
\hline $\begin{array}{l}\text { mit durchschnittl. u. unterdurchschnittl. } \\
\text { allgemeinen Zuweisungen } \\
\text { mit überdurchschnittl. allgem. Zuweis. }\end{array}$ & $\begin{array}{c}26 \\
2\end{array}$ & $\begin{array}{c}11 \\
1\end{array}$ & $\begin{array}{l}1 \\
1\end{array}$ & $\begin{array}{l}8 \\
1\end{array}$ & $\begin{array}{c}32 \\
4\end{array}$ & $\begin{array}{c}12 \\
2\end{array}$ & $\begin{array}{l}5 \\
1\end{array}$ \\
\hline $\begin{array}{l}\text { mit durchschnittl. u. unterdurchschnittl. } \\
\text { Investitionszuweisungen } \\
\text { mit überdurchschnittl. Investitionszuw. }\end{array}$ & $\begin{array}{c}21 \\
7 \\
\end{array}$ & $\begin{array}{l}5 \\
7 \\
\end{array}$ & $\stackrel{2}{-}$ & $\begin{array}{l}6 \\
3\end{array}$ & $\begin{array}{l}23 \\
13\end{array}$ & $\begin{array}{c}10 \\
4\end{array}$ & $\begin{array}{l}5 \\
1 \\
\end{array}$ \\
\hline $\begin{array}{l}\text { mit durchschnittl. u. unterdurchschnittl. } \\
\text { Finanzkraft } \\
\text { mit überdurchschnittl. Finanzkraft }\end{array}$ & $\begin{array}{l}14 \\
14\end{array}$ & $\begin{array}{l}4 \\
8\end{array}$ & $\begin{array}{l}1 \\
1\end{array}$ & $\begin{array}{l}3 \\
6\end{array}$ & $\begin{array}{l}15 \\
21\end{array}$ & $\begin{array}{l}5 \\
9\end{array}$ & $\begin{array}{l}3 \\
3\end{array}$ \\
\hline $\begin{array}{l}\text { Steuerschwache Regionen } \\
\text { (weniger als } 100 \% \text { des Landesdurchschnitts) } \\
\text { mit durchschnittl. u. überdurchschnittl. } \\
\text { Gesamtzuweisungen } \\
\text { mit unterdurchschnittl. Gesamtzuweis. }\end{array}$ & $\begin{array}{l}44 \\
10\end{array}$ & $\begin{array}{l}10 \\
14\end{array}$ & $\begin{array}{l}2 \\
2\end{array}$ & $\begin{array}{c}8 \\
13\end{array}$ & $\begin{array}{l}36 \\
24\end{array}$ & $\begin{array}{l}28 \\
16\end{array}$ & $\begin{array}{l}8 \\
1\end{array}$ \\
\hline $\begin{array}{l}\text { mit durchschnittl. u. überdurchschnittl. } \\
\text { allgemeinen Zuweisungen } \\
\text { mit unterdurchschnittl. allgem. Zuweis. }\end{array}$ & $\begin{array}{c}48 \\
6\end{array}$ & $\begin{array}{l}13 \\
11\end{array}$ & $\begin{array}{l}2 \\
2\end{array}$ & $\begin{array}{c}16 \\
5\end{array}$ & $\begin{array}{l}38 \\
22\end{array}$ & $\begin{array}{l}33 \\
11\end{array}$ & $\begin{array}{l}8 \\
1\end{array}$ \\
\hline $\begin{array}{l}\text { mit durchschnittl. u. überdurchschnittl. } \\
\text { Investitionszuweisungen } \\
\text { mit unterdurchschnittl. Investitionszuw. }\end{array}$ & $\begin{array}{l}31 \\
23\end{array}$ & $\begin{array}{c}6 \\
18\end{array}$ & $\begin{array}{l}2 \\
2\end{array}$ & $\begin{array}{c}9 \\
12\end{array}$ & $\begin{array}{l}30 \\
30\end{array}$ & $\begin{array}{l}25 \\
19\end{array}$ & $\begin{array}{l}5 \\
4\end{array}$ \\
\hline $\begin{array}{l}\text { mit durchschnittl. u. überdurchschnittl. } \\
\text { Finanzkraft } \\
\text { mit unterdurchschnittl. Finanzkraft }\end{array}$ & $\begin{array}{l}16 \\
38\end{array}$ & $\begin{array}{c}4 \\
20\end{array}$ & $\begin{array}{l}2 \\
2\end{array}$ & $\begin{array}{c}2 \\
19\end{array}$ & $\begin{array}{c}8 \\
52\end{array}$ & $\begin{array}{l}10 \\
34\end{array}$ & $\begin{array}{l}2 \\
7\end{array}$ \\
\hline
\end{tabular}

1) Schleswig-Holstein: 1975. 
Wird ein regionales Finanzkraftgefälle im Ausmaß der Kostenbelastung aus dem zentralörtlichen Leistungsangebot realisiert, können sich die automatischen Stabilisatoren des räumlichen Differenzierungsprozesses vollständig auswirken. Allerdings werden durch eine solche regionale Finanzkraftverteilung die in der Entwicklung zurückgebliebenen Regionen nicht in die Lage versetzt, ihr infrastrukturelles Defizit zu beseitigen und damit ihren Entwicklungsrückstand gegenüber den stark verdichteten Wohlstandsregionen langfristig aufzuholen. Für eine aktive regionale Entwicklungspolitik, von der auch Deglomerationstendenzen ausgelöst werden sollen, reicht also diese regionale Finanzkraftverteilung nicht aus. (260) Sind die Finanzkraftunterschiede $z$ wischen wirtschaftsstarken und wirtschaftsschwachen Regionen jedoch größer als durch das zentralörtliche Leistungsangebot der wirtschafts starken Regionen gerechtfertigt ist, verhindert das regionale Finanzkraftgefälle eine automatische Abschwächung der Ballungstendenzen oder wirkt direkt ballungsverstärkend.

Über das Ausmaß, in dem die wirtschaftsstarken Regionen (kreisfreien Städte) durch Einwohner umliegender Landkreise kostenmäßig belastet werden, liegen keine empirisch gesicherten Hinweise vor. Hier kann nur vermutet werden, daß die mit der Abgeltung von Nettoertrags-spillouts zu rechtfertigenden Einnahmekraftunterschiede zwischen wirtschaftsstarken und wirtschaftsschwachen Regionen wesentlich kleiner sind als die zwischen großen und kleinen Gemeinden und etwa 10 Prozent nicht übersteigen dürften.

Die zweite Möglichkeit besteht darin, daß durch den vertikalen Gemeindefinanzausgleich ein regionales Finanzkraftgefälle geschaffen wird, das entgegengesetzt zum regionalen Gefälle der Wirtschafts - und Steuerkraft verläuft. Nur in diesen Fällen kann man der regionalen Verteilung der kommunalen Gesamteinnahmen Wirkungen zusprechen, durch die die regionalen Wirtschaftskraftunterschiede langfristig abgebaut werden können.

Mit Hilfe dieser Vorüberlegungen lassen sich folgende Aussagen über die Raumwirkungen der Verteilung der kommunalen Gesamteinnahmen in den hier untersuchten Bundesländern machen:

- Nach Durchführung des vertikalen Gemeindefinanzausgleichs weisen in Hessen 1974 alle sechs kreisfreien Städte eine überdurchschnittlich hohe, 19 von 21 steuerschwachen Regionen eine unterdurchschnittlich hohe Finanzkraft pro Kopf auf. Die Finanzkraft pro Einwohner der beiden kreisfreien Städte Frankfurt und Offenbach beläuft sich auf 199, $0 \%$ und 193,6 \% der Finanzkraft pro Kopf des finanzschwächsten Landkreises (Darmstadt) (Tabelle 19a, Spalte 11).

Diese auch nach Durchführung des vertikalen Gemeindefinanzausgleichs bestehenden Einnahmekraftunterschiede zwischen dem Ballungs raum Rhein/Main und den ländlichen Regionen Hessens kann man wohl kaum damit rechtfertigen, daß Frankfurt, Offenbach oder auch Wiesbaden und Darmstadt in diesem Ausmaß die Einwohner ihres engeren Umlandes oder gar der Landkreise Bergstraße, Vogelsbergkreis oder Marburg-Biedenkopf mit zentralörtlichen Leistungen versorgen. 
Durch den vertikalen Gemeindefinanzausgleich nimmt der absolute Einnahmekraftvorsprung der kreisfreien Städte insgesamt und insbesondere der des Ballungskerns Frankfurt/Offenbach zu. Deshalb muß die Verteilung der kommunalen Gesamteinnahmen regionalpolitisch noch ungünstiger als die der kommunalen Steuereinnahmen beurteilt werden.

- In Rheinland-Pfalz besitzen acht der steuerstärksten Regionen nach Durchführung des vertikalen Gemeindefinanzausgleichs eine überdurchschnitt lich hohe, zwanzig der steuerschwachen Regionen eine unterdurchschnittliche Finanzkraft pro Einwohner. Die drei steuerstärksten Regionen des Landes - Ludwigshafen (Stadt), Mainz und Koblenz - besitzen 1974 eine Finanzkraft pro Einwohner, die $301,1 \%, 175,0 \%$ und 187, $4 \%$ der Finanzkraft des finanzschwächsten Landkreises des Landes (Kusel) beträgt (Tabelle 19b, Spalte 11). Nach Verteilung der Finanzzuweisungen existiert also in Rheinland-Pfalz 1974 ein regionales Finanzkraftgefälle zugunsten der wirtschafts - und steuerstarken Regionen, durch das der räumliche Differenzierungsproze $ß$ verstärkt wird.

Da durch den vertikalen Gemeindefinanzausgleich 1974 die absoluten Einnahmekraftvorsprünge der wirtschafts - und steuerstarken Regionen gegenüber den wirtschafts - und steuerschwachen Regionen ansteigen, muß der ballungsfördernde Effekt des regionalen Finanzkraftgefälles in Rheinland-Pfalz 1974 als noch stärker als der des regionalen Steuerkraftgefälles eingeschätzt werden.

- In Nordrhein-Westfalen weisen 14 steuerstarke Regionen (unter ihnen die steuerstärksten) auch nach der Verteilung der Finanzzuweisungen eine überdurchschnittliche, 38 steuerschwache Regionen eine unterdu rchschnittliche Finanzkraft pro Einwohner auf. Die Zentren der Ballungsregion entlang des Rheins - Düsseldorf, Krefeld, Leverkusen, Bonn und Köln - verfügen über eine Finanzkraft pro Kopf in Höhe von 153,9 \%, 142, $3 \%, 191,2 \%$, $154,2 \%$ bzw. 138,4\% der Finanzkraft pro Kopf des finanzschwächsten Landkreises (Münster) Tabelle 19c, Spalte 11). Diese Finanzkraftvorsprünge der wirtschaftsstärksten Region(enł Nordrhein-Westfalens dürften wohl erheblich über ihre Kostenbelastung durch Einwohner der wirtschaftsschwächeren Regionen hinausgehen.

Der vertikale Gemeindefinanzausgleich in Nordrhein-Westfalen verhindert 1974 nicht, daß parallel zum regionalen Wirtschaftskraftgefälle ein Finanzkraftgefälle verläuft. Damit werden auch durch die Verteilung der kommunalen Gesamteinnahmen die räumlichen Ballungstendenzen verstärkt oder wenigstens die stabilisierenden Wirkungen der Nachteile der Enge verhindert. Da jedoch die absoluten Einnahmekraftvorsprünge der wirtschaftsstarken Ballungsregionen gegenüber den wirtschaftsschwachen Regionen durch den vertikalen Gemeindefinanzausgleich verringert werden, wirkt das regionale Finanzkraftgefälle weniger stark ballungsfördernd als das regionale Steuerkraftgefälle.

Dazu trägt auch bei, daß 14 der 28 steuerstarken Regionen infolge des vertikalen Gemeindefinanzausgleichs eine unterdurchschnittlich hohe und 16 der 54 steuerschwachen Regionen eine überdurchschnittlich hohe Finanz- 
kraft pro Einwohner erhalten. Aus regionalpolitischer Sicht ist dabei besonders zu begrüßen, daß zu dieser letzten Gruppe solche Regionen wie Kleve, Euskirchen, Coesfeld, Lüdinghausen, Höxter, Warburg, Brilon, Meschede, Olpe und Wittgenstein gehören, deren Steuereinnahmekraft zwischen 50 und $76 \%$ des Landesdurchschnitts liegt. Damit ist in Nordrhein-Westfalen die Parallelität von regionalem Wirtschaftskraftgefälle und regionalem Einnahmekraftgefälle durchbrochen.

Wenn auch die regionale Verteilung der kommunalen Gesamteinnahmen in Nordrhein-Westfalen 1974 aus regionalpolitischer Sicht noch nicht ganz befriedigen kann, so sorgt sie mit einiger Wahrscheinlichkeit dafür, daß in einigen Fällen die regionalen Wirtschaftskraftunterschiede nicht noch vergrößert werden und ist somit wesentlich positiver als die Verteilung der kommunalen Steuereinnahmen zu beurteilen.

- Trotz der weitgehend zielkonformen Verteilung der Finanzzuweisungen von Land und Bund an die Gemeinden und Gemeindeverbände existiert in Bayern 1974 ein ausgesprochen starkes regionales Finanzkraftgefälle zugunsten der steuer- und wirtschaftsstärksten Regionen des Landes. Von 36 steuerstarken Regionen besitzen 21 auch eine überdurchschnittlich hohe Finanzkraft pro Einwohner. Zu ihnen gehören auch München und Nürnberg, deren Finanzkraft pro Einwohner 182, 4 \% bzw. 171,1 \% derjenigen des finanzschwächsten Landkreises (Schweinfurt) beträgt (Tabelle 19d, Spalte 11). Nur acht der 60 steuerschwachen Regionen weisen nach der Verteilung der Finanzzuweisungen eine überdurchschnittlich hohe Finanzkraft pro Einwohner auf. Zwar liegen sie sämtlich im strukturschwachen Zonenrandgebiet Bayerns, doch liegt auch ihre Finanzkraft pro Einwohner wenn auch $\mathrm{z}$. T. nur geringfügig - unter der der beiden Ballungszentren München und Nürnberg.

In Bayern trägt also das kommunale Finanzsystem 1974 mit einiger Wahrscheinlichkeit zu einer Verstärkung der regional Wirtschaftskraftunterschiede und räumlichen Ballungstendenzen bei. Allerdings ist dank des vertikalen Gemeindefinanzausgleichs dieser ballungsverstärkende Effekt schwächer als der des kommunalen Steuersystems.

- Auch in Niedersachsen kann im Jahr 1974 die regionale Verteilung der kommunalen Gesamteinnahmen aus regionalpolitischer Sicht nicht befriedigen. Neun steuerstarke Regionen besitzen auch nach der Verteilung der Zuweisungen überdurchschnittliche Pro-Kopf-Einnahmen. An ihrer Spitze steht die kreisfreie Stadt Hannover mit 171,2 \% der Finanzkraft pro Einwohner des finanzschwächsten Landkreises (Grfsch. Schaumburg). Allerdings können zehn steuerschwache Landkreise, die vorwiegend in ländlichen Problemgebieten liegen, nach Durchführung des vertikalen Gemeindefinanzausgleichs über z. T. erheblich über dem Durchschnitt liegende ProKopf-Einnahmen verfügen. Diese Regionen sind 1974 finanziell nicht schlechter als die meisten steuer- und wirtschaftsstarken Regionen des Landes gestellt.

Gegenüber der Mehrzahl der Landkreise besitzen jedoch Hannover und die meisten anderen kreisfreien Städte Finanzkraftvorsprünge pro Einwohner 
in einem solchen Ausmaß, daß sie ballungsbedingte Kostensteigerungen ihrer Leistungserstellung auffangen und in vielen Fällen auch absolut höhere öffentliche Leistungen pro Einwohner als die ländlichen Regionen anbieten können.

- Im Saarland sorgt der vertikale Gemeindefinanzausgleich dafür, daß zwei steuerschwache Regionen (Merzig-Wadern, Neunkirchen) mit nur geringfügig weniger Einnahmen pro Einwohner ausgestattet werden, als die steuer - und wirtschaftsstärkste Region (Stadtverband Saarbrücken). Da gegen verfügt die Region mit der geringsten Steuereinnahmekraft des Landes (St. Wendel) auch nach der Verteilung der Zuweisungen über die mit Abstand niedrigste Einnahmekraft pro Einwohner. Im Saarland existiert 1974 also kein Einnahmekraftgefälle mehr, das durchgehend parallel zum regionalen Wirtschaftskraftgefälle verläuft. Die regionale Verteilung der kommunalen Gesamteinnahmen trägt mit einiger Wahrscheinlichkeit im Saarland dazu bei, daß sich die automatischen Stabilisatoren des räumlichen Konzentrationsprozesses weitgehend auswirken können und die regionalen Wirtschaftskraftunterschiede nicht noch größer werden.

- Die regionale Verteilung der den Gemeinden insgesamt zustehenden Einnahmen kann in Schleswig-Holstein für das Jahr 1975 aus regionalpolitischer Sicht beinahe ebenso günstig wie für das Saarland beurteilt werden. Zwar existiert auch in Schleswig-Holstein ein regionales Finanzkraftgefälle zugunsten der wirtschafts - und steuerstärksten Regionen des Landes (Kiel, Lübeck, Neumünster). Doch sind die Finanzkraftvorsprünge insbe sondere von Kiel und Lübeck gegenüber den meisten Landkreisen so gering, daß sie bestenfalls zur Abgeltung der Kostenbelastung aus ihrem zentralörtlichen Leistungsangebot ausreichen. Ein finanzieller Spielraum zur Beseitigung der Nachteile der Enge wird beiden einzigen Verdichtungs räumen Schleswig-Holsteins (261) durch diese Verteilung der kommunalen Gesamteinnahmen im Jahr 1975 kaum verschafft. Ein steuer- und wirtschaftsschwacher Landkreis (Dithmarschen) kann sogar dank des vertikalen Gemeindefinanzausgleichs über höhere Pro-Kopf-Einnahmen verfügen als Kiel und Lübeck.

Der regionalen Verteilung der kommunalen Gesamteinnahmen in Schleswig-Holstein kann man also ebenso wie der im Saarland bescheinigen, daß von ihr in den beiden Untersuchungsjahren keine regionalpolitisch unerwünschten Wirkungen auf die Raumstruktur ausgehen. Sie reicht jedoch in beiden Ländern nicht aus, um die Standortbedingungen und Lebensverhältnisse in den zurückgebliebenen ländlichen Regionen im Vergleich zu den stark verdichteten Wohlstandsregionen zu verbessern und damit unmittelbar einen Beitrag zur Verringerung der regionalen Wohlstandsunterschiede in beiden Ländern zu leisten. Deshalb können die räumlichen Auswirkungen des kommunalen Finanzsystems in Schleswig-Holstein und dem Saarland nur bedingt als regionalpolitisch zielkonform beurteilt werden.

Damit ist die empirische Untersuchung über die räumlichen Auswirkungen, die von der finanziellen Ausstattung der Gemeinden und Gemeindeverbände durch Bund und Länder ausgehen, abgeschlossen. Es hat sich gezeigt, daß 
auch unter Einbeziehung der Maßnahmen des vertikalen Gemeindefinanzaus gleichs in die Untersuchung von der Verteilung der kommunalen Finanzmasse auf die einzelnen Gemeinden und Regionen (länderweise verschieden star ke) ballungsfördernde Wirkungen oder - wie im Fall der Länder SchleswigHolstein und Saarland - keine deglomerierenden, also regionalpolitisch er wünschten Wirkungen ausgehen. Dabei ist regionalpolitisch besonders bedenklich, daß in zwei untersuchten Ländern - nämlich Hessen und RheinlandPfalz - die regionalpolitisch unerwünschten Effekte der Einnahmenverteilung nach Durchführung des vertikalen Gemeindefinanzausgleichs stärker sind als vor seiner Durchführung.

VII. Politische Schlußfolgerungen für das kommunale Einnahmensystem

Die empirische Untersuchung über die räumlichen Auswirkungen des kommunalen Einnahmensystems in der Bundesrepublik Deutschland im Jahr 1974 hat im wesentlichen folgende Ergebnisse gebracht:

- Die Verteilung der kommunalen Steuereinnahmen führt zwischen Gemeinden unterschiedlicher Größe, zwischen Gemeinden derselben Größenklas se und zwischen den einzelnen als Landkreise und kreisfreie Städte abgegrenzten Regionen zu Steuerkraftunterschieden, die den räumlichen Differenzierungsprozeß verstärken.

- Die Gemeindefinanzreform von 1969 hat - wenn man den Wegfall des Ge werbesteuerausgleichs zwischen Wohn- und Betriebsgemeinden berücksichtigt - die vertikalen Steuerkraftunterschiede eher verstärkt und die horizontalen Steuerkraftunterschiede aus regionalpolitischer Sicht nur unzureichend abgeschwächt.

- Die Verteilung der Finanzzuweisungen von Bund und Ländern an die Ge meinden und Gemeindeverbände wirkt im Jahr 1974 in fünf der sieben untersuchten Bundesländer dem ballungsfördernden Effekt des regionalen Steuerkraftgefälles entgegen, in den beiden anderen Bundesländern vergrößert sie dagegen die absoluten Einnahmekraftvorsprünge der wirtschaftsstarken gegenüber den wirtschaftsschwachen Regionen.

- In allen untersuchten Bundesländern entspricht die regionale Verteilung der allgemeinen Finanzzuweisungen weitaus eher den regionalpolitischen Anforderungen als die regionale Verteilung der Investitionszuwei sungen.

- In allen untersuchten Bundesländern existiert auch nach der Durchführung des vertikalen Gemeindefinanzausgleichs ein regionales Einnahmekraftgefälle, das überwiegend - wenn auch nicht durchgehend - parallel zum regionalen Wirtschaftskraftgefälle verläuft. Nur in zwei Bundesländern ist das regionale Finanzkraftgefälle zugunsten der wirtschaftsstarken Regionen so schwach, daß von ihm mit einiger Wahrscheinlichkeit keine regionalpolitisch unerwünschten Wirkungen auf die Raumstruktur ausgehen.

Angesichts dieser Ergebnisse stellt sich die Frage, ob aus regionalpolitischer Sicht einer der drei kommunalen Einnahmearten - eigenen Steuerein- 
nahmen, allgemeinen Finanzzuweisungen und Investitionszuweisungen - der Vorzug vor den anderen zu geben ist und in welchem größenmäßigen Verhältnis sie zueinander stehen sollten.

1. Eigene Steuereinnahmen als Bestandteil des kommunalen Einnahmensystems

Eigene Steuereinnahmen entsprechen weitestgehend dem Grundsatz der kommunalen Selbstverwaltung, da ihre Verwendung grundsätzlich in das freie Ermessen der einzelnen Gemeinden gestellt ist. Dabei spielt es keine Rolle, ob den Gemeinden der gesamte Ertrag einer Steuer überlassen wird oder ob sie in Höhe eines bestimmten Prozentsatzes am Ertrag aus Gemeinschaftsteuern beteiligt werden. Gegenüber den Einnahmen aus Finanzzuweisungen weisen die Einnahmen aus eigenen Steuern den Vorteil auf, daß in ihrem Fall die Gemeinden einen gesetzlich festgesetzten Anspruch auf Einnahmen in einer bestimmten Höhe besitzen. Zwar unterliegt die Höhe der den Gemeinden zustehenden Steuereinnahmen grundsätzlich der Entscheidung des Bundesgesetzgebers. Doch ist für eine Steuerrechtsänderung, durch die die Steuereinnahmen der Gemeinden beeinträchtigt werden, in der Bundesrepublik eine politische Übereinstimmung zwischen dem Bund und den Ländern erforderlich. (262) Dadurch werden in der Verfassungswirklichkeit häufige Änderungen der Steuerverteilungsvorschriften zulasten der Gemeinden erschwert. Aus diesem Grund können die Gemeinden mit einer kontinuierlichen Entwicklung ihrer Einnahmen aus dieser Quelle rechnen, (263) womit diese Einnahmeart den Gemeinden langfristige Dispositionsmöglichkeiten bietet.

Steuern, deren örtliches Aufkommen sowohl vertikal als auch horizontal zwischen den Gemeinden gar nicht oder nur schwach streut und die zugleich den allgemeinen Steuergrundsätzen entsprechen, (264) sind nur schwer vorstellbar (265) oder relativ unergiebig. (266) Die Einführung von Verteilungsschlüsseln für den Gemeindeanteil an den Gemeinschaftsteuern, durch die die Steuerkraftunterschiede zwischen den Gemeinden in regionalpolitisch vertretbaren Grenzen gehalten werden, scheiterte bisher in der Bundesrepublik am politischen Widerstand der um ihren Besitzstand fürchtenden wirtschaftsstarken Gemeinden und Regionen. Dies haben die Diskussion über die Vorschläge zur Gemeindefinanzreform und die tatsächlichen Ergebnisse der Gemeindefinanzreform von 1969 eindeutig belegt. (267) Aus regionalpolitischer Sicht stehen damit den oben aufgeführten Vorteilen einer Ausstattung der Kommunen mit eigenen Steuereinnahmen die erheblichen Nachteile einer unerwünscht großen regionalen Streuung der kommunalen Steuerkraft gegenüber.

2. Allgemeine Finanzzuweisungen als Bestandteil des kommunalen Einnahmensystems

Die allgemeinen Finanzzuwei sungen unterscheiden sich hinsichtlich des Freiheitsgrades, den die Gemeinden bei der Verwendung dieser Einnahmen be- 
sitzen, nicht von den Einnahmen aus eigenen Steuern. Allerdings müssen die Gemeinden bei dieser Einnahmenart häufiger mit diskretionären Ände rungen des Einnahmenvolumens und der Verteilungsvorschriften rechnen, als dies bei eigenen Steuereinnahmen der Fall ist. Dies liegt daran, daß die Höhe der für allgemeine Finanzzuweisungen zur Verfügung stehenden Finanzausgleichsmasse und die Verteilung dieser Ausgleichsmasse der ausschließlichen Landesgesetzgebung unterliegen, (268) also ein Einigungszwang zwischen mehreren Entscheidungsträgern nicht besteht. Dieser Tatbestand bewirkt, daß die langfristigen Dispositionsmöglichkeiten der einzelnen Gemeinden umso geringer sind, je höher der Anteil der allgemeinen Zuweisungen an ihren Gesamteinnahmen ist.

Diesem Nachteil gegenüber einer Ausstattung mit eigenen Steuereinnahmen steht aus regionalpolitischer Sicht éin bedeutender Vorteil der Ausstattung der Kommunen mit allgemeinen Finanzzuweisungen gegenüber. Die Verteilung dieser kommunalen Einnahmen bezweckt und - wie die empirische Untersuchung zeigt - erreicht auch weitgehend, daß die nach der Verteilung der Steue reinnahmen bestehenden absoluten Einnahmekraftunterschiede zwischen den wirtschaftsstarken und wirtschaftsschwachen Gemeinden (Regionen) abgeschwächt werden. Diese Einnahmeart weist also in der Bundesrepublik aus regionalpolitischer Sicht die günstigste regionale Verteilung auf. Allerdings enthalten auch die Regelungen über die Verteilung der allgemeinen Finanzzuweisungen Elemente, durch die die angestrebte Abschwächung der kommunalen Einnahmekraftunterschiede in relativ engen Grenzen gehalten wird. Die wichtigsten Bestimmungen, die den Nivellierungseffekt der Verteilung der allgemeinen Zuweisungen begrenzen, betreffen die Verteilung der Schlüsselzuweisungen, die den überwiegenden Teil der allgemeinen Finanzzuweisungen ausmachen. $\mathrm{Zu}$ ihnen gehören vor allem

- die Verwendung eines Gemeindegrößenansatzes ("veredelte" Einwohnerzahl) bei der Ermittlung der Bedarfsmeßzahl,

- die Verwendung von Neben- bzw. Ergänzungsansätzen bei der Ermittlung der Bedarfsmeßzahl,

- die Verwendung von zu niedrig angesetzten fiktiven Hebesätzen (Nivellierungssätzen) bei der Ermittlung der Steuerkraftmeßzahl,

- der nur teilweise Ausgleich der (positiven) Differenz zwischen Bedarfs meßzahl und Steuerkraftmeßzahl (Existenz von Ausschüttungsquoten kleiner als $100 \%$ ). (269)

Diesen Regelungen, die länderweise z. T. stark voneinander abweichen, ist es zuzuschreiben, da $\beta$ die Verteilung der allgemeinen Finanzzuweisungen in Rheinland-Pfalz und Hessen im Jahr 1974 die regionalen Einnahmekraftunterschiede nur unzureichend abschwächt, ja sie in einigen Fällen sogar noch verstärkt und damit nur bedingt den regionalpolitischen Anforderungen entspricht. In Schleswig-Holstein wird dagegen auf die Verwendung eines Gemeindegrößenansatzes verzichtet, was zu einer starken negativen Korrelation zwischen der Höhe der den einzelnen Gemeinden und Regionen gewährten allgemeinen Zuweisungen pro Einwohner und der kommunalen Steuereinnahmekraft pro Einwohner führt. (270) 
3. Spezielle Finanzzuweisungen als Bestandteil des kommunalen Einnahmensystems

Die Gewährung spezieller Zuweisungen bietet den übergeordneten Gebiets körperschaften grundsätzlich die größten Möglichkeiten, auf die Ausgabenpolitik der Gemeinden und Gemeindeverbände Einfluß zu nehmen und damit das räumlich koordinierte Zielsystem gegen die räumlich unkoordinierten Zielsysteme zur Geltung zu bringen. Dieser aus regionalpolitischer Sicht erwünschte Instrumentalcharakter der speziellen Finanzzuweisungen wird damit erkauft, daß die Gemeinden die Verwendung der ihnen zufließenden Mittel bestenfalls innerhalb vorgeschriebener Verwendungsbereiche frei entscheiden können. (271) Vielfach ist ihnen sogar der einzelne Verwendungs zweck (das einzelne Projekt) zwingend vorgeschrieben, (272) so daß ihre Entscheidungsfreiheit lediglich in der Annahme oder Ablehnung der speziellen Finanzzuweisungen besteht. (273)

Die empirische Untersuchung der regionalen Verteilung der Investitionszuweisungen macht deutlich, daß Bund und Länder im Jahr 1974 die regionalpolitischen Möglichkeiten, die ihnen die Gewährung von Investitionszuweisungen an Gemeinden und Gemeindeverbände bietet, nicht oder nur in unbefriedigendem Maße genutzt haben. In Nordrhein-Westfalen, Bayern, Niedersachsen, Schleswig-Holstein und dem Saarland muß die regionale Verteilung der Investitionszuweisungen regionalpolitisch weniger günstig beurteilt werden als die der allgemeinen Zuweisungen (einschließlich der Zuweisungen für laufende Zwecke). In Hessen und Rheinland-Pfalz verletzt die regionale Verteilung der Investitionszuweisungen unmittelbar die regionalpolitischen Ziele.

Die Ursachen für diese regionalpolitisch unbefriedigende Verteilung der Investitionszuweisungen liegen in den für diese Zuweisungsart angewandten Zuweisungstechniken. In der Bundesrepublik wird der größte Teil der für Investitionszuweisungen bereitstehenden Mittel entweder als sogenannte Adhoc-Zuweisungen oder als sogenannte Ermessenszuweisungen vergeben. Im ersten Fall werden die Förderbeträge für einzelne Investitionsprojekte für namentlich genannte Gemeinden in den Haushaltsplan des entsprechenden Landes aufgenommen und vom Landesgesetzgeber beschlossen. Im zweiten Fall wird ein bestimmter für Investitionszuweisungen vorgesehener Betrag global in den Landeshaushaltsplan eingestellt. Seine konkrete Verwendung wird im Verlauf des Vollzugs des Haushaltsplans fallweise von den zuständigen Verwaltungsinstanzen entschieden, hängt also vom Ermessen der Landesverwaltung ab. (274) In vielen Fällen werden diese Ad-hoc-oder Ermessenszuweisungen nur dann gewährt, wenn sich die empfangende Kommune in Höhe eines bestimmten Prozentsatzes an den Investitionskosten beteiligt. (275) $\mathrm{Ob}$ eine Gemeinde überhaupt und in welcher Höhe sie gegebenenfalls Investitionszuweisungen erhält, hängt unter diesen Umständen unter anderem ab

- von ihrem Informationsstand über die Möglichkeiten, Investitionshilfen zu bekommen,

- von der Schnelligkeit, mit der sie ihren Investitionsbedarf anmeldet ("Windhundverfahren"), 
- von der Lautstärke und dem politischen Druck, mit dem sie Investitionshilfen fordert (Investitionszuweisungen als "Stöhn - und Jammerprämien"),

- von (partei-)politischen und/oder persönlichen Beziehungen zwischen den einzelnen Vergabestellen und den einzelnen Gemeinden ("Klinkenputzen"),

- von der Steuerkraft der Gemeinde und damit ihrer finanziellen Möglichkeit zur Eigenbeteiligung. (276)

Bei den in der Bundesrepublik vorwiegend angewandten Verteilungstechniken entscheiden zu einem großen Teil Faktoren über die regionale Verteilung der Investitionszuweisungen, die in keinerlei Beziehung zu den angestrebten regionalpolitischen Zielen stehen. Deshalb kommt es zu einer zufälligen, regionalpolitisch unkontrollierten und unkontrollierbaren Verteilung der Investitionszuweisungen, die in vielen $F$ ällen den regionalpolitischen Zielen direkt zuwiderläuft. Die Abhängigkeit der Gemeinden vom diskretionären Ermessen der Vergabeinstanz bewirkt außerdem, daß die Aufgaben- und Ausgabenplanung der Gemeinden einer umso größeren Unsicherheit unterliegen, je stärker sie auf Investitionszuweisungen nach diesen Zuweisungstechniken angewiesen sind.

\section{Konzeptionen der Reform des kommunalen Einnahmensystems}

Aus der vorstehenden Gegenüberstellung der Vor - und Nachteile der einzelnen kommunalen Einnahmearten lassen sich allerdings noch nicht automatisch Aussagen über die wünschenswerte Struktur der kommunalen Einnahmen und damit über die Richtung einer Reform des kommunalen Einnahmensystems ableiten. Für die Ableitung konkreter Reformvorschläge ist einmal entscheidend, welche gesellschaftspolitischen Auffassungen, insbesondere über Inhalt und Bedeutung der kommunalen Selbstverwaltung, den Überlegungen zugrundeliegen. Zum anderen kommt es darauf an, wie man die politischen Widerstände, die der Verwirklichung der einzelnen Reformvorschläge entgegenstehen, einschätzt. Unter diesen Gesichtspunkten sind zwei Grundsatzpositionen denkbar. Im ersten Fall geht man davon aus, daß

- die Einnahmen der Kommunen aus eigenen Steuern und aus allgemeinen Finanzzuweisungen aus der Sicht der kommunalen Selbstverwaltungsidee relativ gleichwertig sind,

- die Investitionszuweisungen von Bund und Ländern an die Gemeinden ein unentbehrliches Instrument zur Realisierung des räumlich koordinierten Zielsystems der Regionalpolitik sind und

- die Bestimmungen des vertikalen Gemeindefinanzausgleichs politisch leichter in die regionalpolitisch erwünschte Richtung verändert werden können als die Regelungen des kommunalen Steuersystems.

In diesem Fall wird man einmal die Eliminierung der Bestimmungen fordern, die den Ausgleichseffekt der Verteilung der Schlüsselzuweisungen in Grenzen halten. Zum anderen wird man vorschlagen, die Verteilung der für Investitionszuweisungen zur Verfügung stehenden Finanzmittel in eine mittel- 
oder langfristige Aufgabenplanung einzubetten, (277) an verbindlichen Raumordnungsplänen auszurichten und damit der freien Ermessensentscheidung der Verwaltung zu entziehen. Gedacht werden könnte z. B. an eine gesetzlich geregelte Verteilung der zur Disposition stehenden Finanzmassen, bei der die Anspruchsvoraussetzungen (z. B. Zugehörigkeit zu bestimmten Regionen) und die Verteilungsschlüssel (z. B. Abstand der regionalen Wirtschaftskraft vom Durchschnitt) unter regionalpolitischen Gesichtspunkten eindeutig festgelegt werden. Unter diesen Voraussetzungen wäre es regionalpolitisch erwünscht, den Anteil der (zielkonform verteilten) Finanzzuweisungen an den Gesamteinnahmen der Kommunen zu erhöhen.

$\mathrm{Zu}$ anderen wirtschaftspolitischen Empfehlungen gelangt man dagegeiī, wenn man

- den Einnahmen der Kommunen aus eigenen Steuern aus Gründen der kommunalen Selbstverantwortung grundsätzlich Vorrang vor Einnahmen aus Zuweisungen von übergeordneten Gebietskörperschaften einräumt und/oder

- die politischen und technischen Schwierigkeiten, die einer regionalpolitisch zielkonformen Umgestaltung des vertikalen Gemeindefinanzausgleichs entgegenstehen, höher einschätzt als die Widerstände gegen eine zielgerechte Verteilung der kommunalen Steuereinnahmen.

Unter diesen Prämissen müßten die konkreten Reformbemühungen in erster Linie darauf gerichtet sein, Verteilungsschlüssel für die kommunalen Steuereinnahmen zu entwickeln und durchzusetzen, durch die regionalpolitisch unerwünschte Steuerkraftunterschiede $z$ wischen den Gemeinden und Regionen verhindert werden. In diesem Fall wäre aus regionalpolitischer Sicht ein möglichst hoher Anteil der (zielgerecht verteilten) kommunalen Steuereinnahmen und ein möglichst geringer Anteil der Investitionszuweisungen an den kommunalen Gesamteinnahmen zu fordern.

Eine eindeutige Entscheidung zugunsten einer der beiden Konzeptionen und damit zugunsten einer bestimmten Zusammensetzung der kommunalen Einnahmen kann nicht getroffen werden. (278) Allerdings hat wohl die vorstehende Diskussion eines deutlich gemacht: Für die regionalpolitische Beurteilung eines konkreten kommunalen Einnahmensystems ist weniger die Art der kommunalen Einnahmen und damit die qualitative Struktur des Einnahmensystems ausschlaggebend, als vielmehr die Verteilung der kommunalen Finanzmasse auf die einzelnen Gemeinden und Regionen. Eine Reform des kommunalen Einnahmensystems, durch die ballungsfördernde Effekte der Ausstattung der Kommunen mit Finanzmitteln wenigstens verhindert werden sollen, hat deshalb in erster Linie an den Vorschriften und Techniken der Verteilung der kommunalen Einnahmen - der Steuereinnahmen ebenso wie der Finanzzuweisungen - anzusetzen. Welche Richtung dabei im einzelnen einzuschlagen ist, wurde im Verlauf dieser Arbeit an verschiedenen Stellen hérausgearbeitet. 
Friedemann Tetsch - 978-3-631-75190-9

Downloaded from PubFactory at 01/11/2019 07:18:40AM

via free access 
(1) Vergl. Brösse, U., Raumordnungspolitik, Berlin, New York 1975 , S. $5 \mathrm{f}$.

(2) Vergl. Lauschmann, E., Grundlagen einer Theorie der Regionalpolitik, 2. Auflage, Veröffentlichungen der Akademie für Raumforschung und Landesplanung, Taschenbücher zur Raumplanung, Bd. 2, Hannover 1973 , S. 1.

(3) Vergl. Brösse, U., Raumordnungspolitik, a.a. O., S. 57 ff.

(4) Witzmann, K., Raumordnungspolitik, regionale Wirtschaftspolitik und Finanzpolitik, in: Finanzpolitik als Gegenstand der Regionalplanung, Forschungsberichte der Landesarbeitsgemeinschaft Bayern der Akademie für Raumforschung und Landesplanung, Bd. 45, Hannover 1969, S. 89 - 100, hier: S. 90.

(5) Vergl. Brösse, U., Ziele in der Regionalpolitik und in der Raumordnungspolitik, Zielforschung und Probleme der Realisierung von Zielen, Berlin 1972, S. 33.

(6) Jürgensen, H. , Antinomien in der Regionalpolitik, in: Jahrbuch für Sozialwissenschaft, 14. Jg. (1963), S. 401 - 413, hier: S. 401 Anmerkung 1

(7) Vergl. Jürgensen, H. , Antinomien in der Regionalpolitik, a. a. O. , S. 401 .

(8) Schneider, H.K., Über die Notwendigkeit regionaler Wirtschaftspolitik, in: Beiträge zur Regionalpolitik, hrsg. v. H. K. Schneider, Schriften des Vereins für Socialpolitik, N. F. Bd. 41, Berlin 1968, S. 3 - 17, hier: S. 4

(9) Lauschmann, E., Grundlagen einer Theorie der Regionalpolitik, a. a. O., S. 1 .

(10) Vergl. Voigt, F. u. a., Wirtschaftliche Entleerungsgebiete in Industrieländern, Ein Beitrag zur Theorie der Raumwirtschaft und der Regionalpolitik für die BRD, Forschungsberichte des Landes Nordrhein-Westfalen, Nr. 2061, Köln, Opladen 1969, S. 159.

Voigt und Mitarbeiter verwenden für wirtschaftspolitische Maßnahmen mit unbeabsichtigten Auswirkungen auf die Raumstruktur den Begriff "passive Regionalpolitik". Strenggenommen müßten danach alle wirtschaftspolitischen Maßnahmen zur "passiven Regionalpolitik" gerechnet werden, denn "da jede Tätigkeit an einem bestimmten Orte in der Fläche vollzogen werden muß und die Fläche nicht vollkommen homogen ist, wird auch jede wirtschaftspolitische Maßnahme das vorhandene Standortgefüge der Volkswirtschaft beeinflussen." (Schnyder, J.S. , Öffentliche Finanzen als Mittel der Regionalpolitik, Dissertation, Reinheim/ Odw. 1967, S. 115.) 
(11) Vergl. Brösse, U., Ziele in der Regionalpolitik..., a. a. O., S. 88 ff.

(12) Vergl. Lauschmann, E., Grundlagen einer Theorie der Regionalpolitik, a. a. O., S. 259 .

(13) Vergl. Brösse, U., Ziele in der Regionalpolitik..., a. a. O., S. $90 f$.

(14) Der Begriff "Ressourcen" wird in einem sehr weiten Sinn verstanden. Er umfaßt alle natürlichen, menschlichen und gesellschaftlich bedingten Ressourcen als "Bausteine menschlichen Wohlstandes".

(Brösse, U., Ziele in der Regionalpolitik..., a. a. O., S. 93 f.)

(15) Vergl. Brösse, U., Ziele in der Regionalpolitik..., a. a. O., S. 91.

(16) Mit dem Begriff "arme Region" wird in dieser Arbeit ein Teilraum bezeichnet, dessen Wirtschaftskraft, z. B. als Bruttoinlandsprodukt pro Einwohner gemessen, unter dem gesamträumlichen Durchschnitt liegt. Das Umgekehrte gilt für sogenannte "reiche Regionen".

(17) Vergl. Brösse, U., Ziele in der Regionalpolitik..., a. a. O., S. 92.

(18) Grundgesetz für die Bundesrepublik Deutschland vom 23. Mai 1949, Art. 30 .

(19) Ebenda, Art. 28, Abs. 2.

(20) Brösse, U., Ziele in der Regionalpolitik...., a. a. O., S. 93.

(21) Schneider, H.K., Über die Notwendigkeit regionaler Wirtschaftspolitik, a. a. O., S. 4.

(22) Vergl. dazu Giersch, H., Das ökonomische Grundproblem der Regionalpolitik, in: Jahrbuch für Sozialwissenschaft, 14. Jg. (1963), S. 386 400, hier: S. 388.

(23) Schneider, H. K. , Über die Notwendigkeit regionaler Wirtschaftspolitik, a. a. O., S. 4 .

(24) Siehe z.B. Kommission der Europäischen Gemeinschaften, Die regionale Entwicklung in der Gemeinschaft, Analytische Bilanz, o. O., 1971; oder

Gemeinschaftsveröffentlichung der Statistischen Landesämter, Das Bruttoinlandsprodukt der kreisfreien Städte und Landkreise 1970 und 1972, Volkswirtschaftliche Gesamtrechhungen der Länder, Heft 6 , Stuttgart 1975.

(25) Vergl. Spieß, L., Der Finanzausgleich im Lichte volkswirtschaftlicher Ziele, Ansätze zu einer Theorie des Finanzausgleichs als wirtschaftspolitisches Steuemungsinstrument im Bundesstaate, Dissertation, Freiburg i. Br. 1973, S. 126; und Lösch, A., Die räumliche Ordnung der Wirtschaft, 3. unveränderte Auflage mit einem Vorwort von W. Stolper, Stuttgart 1962, S. 170.

(26) Vergl. Grundgesetz für die Bundesrepublik Deutschland vom 23. Mai 1949, Art. 72, Abs. 2, Nr. 3 und Art. 106, Abs. 3, Nr. 2. 
(27) Schneider, H.K. , Über die Notwendigkeit regionaler Wirtschaftspolitik, a. a.O., S. 5 .

(28) Vergl. Spie ß, L., Der Finanzausgleich im Lichte volkswirtschaftlicher Ziele, a.a. O., S. 157.

(29) Biehl, D., u. a., Bestimmungsgründe des regionalen Entwicklungspotentials, Infrastruktur, Agglomeration und sektorale Wirtschaftsstruktur, Kieler Studien, Nr. 133, hrsg. v. H. Giersch, Tübingen 1975, S. 3 f.

(30) Vergl. Biehl, D., u. a., Zur regionalen Einkommensverteilung in der Europäischen Wirtschaftsgemeinschaft, in: Die Weltwirtschaft, Halbjahresschrift des Instituts für Weltwirtschaft an der Universität Kiel, hrsg. v. H. Giersch, Heft 1, Kiel 1972, S. $64-78$.

(31) Giersch, H., Das ökonomische Grundproblem der Regionalpolitik, a. a. O. , S. 387 .

(32) Besonders brisant wirken diese regionalen Einkommensunterschiede, wenn sie mit religiösen und/oder ethnischen Unterschieden $\mathrm{zwischen}$ den Regionen zusammenfallen.

(33) Horstmann, K. , Horizontale Mobilität, in: Handbuch der empirischen Sozialforschung II, hrsg. v. R. König, Stuttgart 1969, S. 43 - 60, ins besondere S. $51 \mathrm{ff}$.

(34) Jürgensen, H. , Private und soziale Kosten, in: Probleme der normativen Ökonomie und der wirtschaftspolitischen Beratung, hrsg. v. E.v. Beckerath U. H. Giersch in Verbindung mit H. Lampert, Berlin 1963, S. 245 - 266, insbesondere S. 247.

(35) Hansmeyer fordert deshalb als Ziel der Regionalpolitik sogar die "Erhaltung des Wirtschaftsraumes als "Kulturlandschaft". (Hansmeyer, $\mathrm{K}-\mathrm{H}$., Ziele und Träger regionaler Wirtschaftspolitik, in: Beiträge zur Regionalpolitik, hrsg. v. H.K. Schneider, a.a. O., S. $36-60$, hier: S. 42 .

(36) Vergl. Hansmeyer, K. -H., Ziele und Träger regionaler Wirtschafts politik, a. a. O., S. 41.

(37) Vergl. Pawlowsky, P., Räumliche externe Effekte lokaler öffentlicher Leistungen im föderativen Staat, Dissertation, Basel 1972, S. 29 ff.

(38) Cairncross, A., u. a., Wirtschaftspolitik für Europa, Wege nach vorn, München, Zürich 1974, S. $76 \mathrm{f}$.

(39) Vergl. Biehl, D., u. a., Bestimmungsgründe des regionalen Entwicklungspotentials, a. a. O., S. 3.

(40) Vergl. Littmann, K., Finanzpolitik, răumliche Gleichgewichte und Optima, Kreislauftheoretische Betrachtungen über die Wirkungen der staatlichen Aktivität auf die räumliche Faktorverteilung, in: Kommunale Finanzen und Finanzausgleich, hrsg. v. H. Timm und H. Jecht, Schriften des Vereins für Socialpolitik, N.F. Band 32, Berlin 1964, S. $61-113$, hier: S. $74 \mathrm{ff}$. 
(41) Vergl. Storbeck, D., Die wirtschaftliche Problematik der Raumordnung, Eine Untersuchung über Notwendigkeit, Ziele und Mittel der Raumordnung im System der Marktwirtschaft, Berlin 1959, S. $119 \mathrm{ff}$.

(42) Vergl. Schnyder, J.S., Öffentliche Finanzen als Mittel der Regionalpolitik, a.a.O., S. 110.

(43) Giersch, H. , Das ökonomische Grundproblem der Regionalpolitik, a.a. O. , S. 387 .

(44) Vergl. ebenda, S. $393 \mathrm{ff}$.

(45) Biehl, D., u. a., Bestimmungsgründe des regionalen Entwicklungs potentials, a. a. O., S. 14.

(46) Vergl. ebenda, S. $14 \mathrm{f}$.

(47) Als dritte Eigenschaft müssen Potentialfaktoren einen möglichst hohen Grad an Polyvalenz aufweisen, also möglichst vielseitig verwendbar sein. (Biehl, D., u.a., Bestimmungsgründe..., a.a. O., S. 20 f.)

(48) Ebenda, S. $21 \mathrm{f}$.

(49) Ebenda, S. 18.

(50) Ebenda, S. 32.

(51) Vergl. ebenda, S. 22.

(52) Vergl. ebenda, S. 22 und 30.

(53) Ebenda, S. 28.

(54) Ebenda, S. 28.

(55) Ebenda, S. 32.

(56) Diese Auffassung vertreten auch Biehl und Mitarbeiter (vergl. Bestimmungsgründe..., a. a. O., S. 161). Dadurch aber, daß die von ihnen identifizierten Engpaßfaktoren Infrastruktur, Agglomeration und sektorale Wirtschaftsstruktur durch regionalpolitische Maßnahmen in den Förderregionen der Gemeinschaftsaufgabe "Verbesserung der regionalen Wirtschaftsstruktur" ausgebaut werden sollen, verlieren diese Faktoren ihren Potentialfaktorcharakter. Sie werden zu mobilen, politisch gestaltbaren Faktoren. Biehl und Mitarbeiter geben damit ihre mittelfristige Sicht zugunsten des langfristigen Zeithorizonts auf.

(57) Hier ist z. B. an die enormen Kosten einer intensiven Nutzung des Bodens in mehreren Ebenen, der Reinhaltung der natürlichen Umwelt von Schadstoffen oder der Bewältigung klimatischer Probleme in Sibirien oder den Tropen gedacht.

(58) Es muß noch einmal nachdrücklich betont werden, daß dies nur für den gewählten mittelfristigen Zeithorizont gilt.

(59) Vergl. oben, S. 32. 
(60) Vergl. Giersch, H., Das ökonomische Grundproblem der Regionalpolitik, a. a. O., S. 394 .

(61) Ebenda, S. 391 f.

(62) Biehl, D., u.a., Bestimmungsgründe..., a.a. O., S. 9.

(63) Ebenda, S. 9.

(64) Vergl. Siebert, H., Zur interregionalen Verteilung neuen technischen Wissens, in: Zeitschrift für die gesamte Staatswissenschaft, hrsg. v. Fr. Böhm, u.a., Bd. 123, Tübingen 1967, S. $231-263$.

(65) Die erste Bedingung sind regionale Unterschiede in der relativen Aus stattung der Regionen mit Produktionsfaktoren.

(66) Vergl. Rose, K. , Theorie der Außenwirtschaft, 5. durchgesehene Auflage, München 1974, S. $276 \mathrm{ff}$.

(67) Vergl. Giersch, H. , Aufgaben der Strukturpolitik, in: Hamburger Jahrbuch für Wirtschafts - und Gesellschaftspolitik, Tübingen 1964, S. 61 - 90.

(68) Lauschmann, E., Grundlagen einer Theorie der Regionalpolitik, a. a. O., S. 265.

(69) Vergl. ebenda, S. $295 \mathrm{ff}$.

(70) Vergl. Schneider, H.K., Über die Notwendigkeit regionaler Wirtschaftspolitik, a. a. O., S. 5 f.

(71) Vergl. Biehl, D., u. a., Bestimmungsgründe..., a.a. O., S. 162 ff.

(72) Vergl. Storbeck, D., Die wirtschaftliche Problematik der Raumordnung, a. a. O., S. $129 \mathrm{ff}$.

(73) Bundesregierung der Bundesrepublik Deutschland, Raumordnungsprogramm für die großräumige Entwicklung des Bundesgebiets (Bundesraumordnungsprogramm), Bundestagsdrucksache 7/3584, April 1975, S. 6 .

(74) Ebenda, S. 8.

(75) Ebenda, S. 7.

(76) Ebenda, S. 8.

(77) Ebenda, S. 8.

(78) Vergl. Doerig, H. -U., Der staatliche Einfluß auf die regionale Verteilung von Bevölkerung und Wirtschaft - unter besonderer Berücksichtigung der zentral - und gliedstaatlichen Industriestrukturpolitik im Kanton St. Gallen, Struktur - und regionalwirtschaftliche Studien des Schweizerischen Instituts für Außenwirtschafts - und Marktforschung an der Hochschule St. Gallen für Wirtschafts-und Sozialwissenschaften, Bd. 2, Zürich, St. Gallen 1968, S. 53 ff.

(79) Brösse, U., Raumordnungspolitik, a. a. O., S. 65 ff. 
(80) Bundesraumordnungsprogramm, a. a. O., S. 42.

(81) Voigt, F., u. a., Wirtschaftliche Entleerungsgebiete in den Industrieländern, a.a.O., S. 18.

(82) Lösch, A., Die räumliche Ordnung der Wirtschaft, a. a. O., S. 10 und S. 170 .

(83) Vergl. ebenda, S. $169 \mathrm{ff}$.

(84) Vergl. Töpfer, K., Regionalpolitik und Standortentscheidung, Die Beeinflussung privater Pläne, dargestellt an der unternehmerischen Standortentscheidung, Beiträge zur Raumplanung, hrsg. vom Zentralinstitut für Raumplanung an der Universität Münster, Bd. 6, Bielefeld 1969, S. $43 \mathrm{ff}$.

(85) Vergl. Brösse, U., Ziele in der Regionalpolitik..., a. a. O., S. 136 ff, insbesondere S. $142 \mathrm{ff}$.

(86) Vergl. Jochimsen, R., Theorie der Infrastruktur, Grundlagen der marktwirtschaftlichen Entwicklung, Tübingen 1966, S. $150 \mathrm{ff}$.

(87) Vergl. ebenda, S. 151.

(88) Vergl. Lösch, A., Die räumliche Ordnung der Wirtschaft, a. a. O. , S. $47 \mathrm{ff}$.

(89) "Entscheidend ist, daß wir sie [die natürlichen Daten, F. T.] auch gedanklich nicht ausschalten dürfen." (Miksch, L., Zur Theorie des räumlichen Gleichgewichts, Sonderdruck aus: Weltwirtschaftliches Archiv, Zeitschrift des Instituts für Weltwirtschaft an der Universität Kiel, hrsg. v. F. Baade, Bd. 66, Hamburg 1951, S. 17.)

(90) Lösch, A., Die räumliche Ordnung der Wirtschaft, a. a. O., S. 181.

(91) Ebenda, S. 181.

(92) Vergl. ebenda, S. $141 \mathrm{f}$.

(93) Ebenda, S. 141.

(94) Vergl. ebenda, S. $144 \mathrm{f}$.

(95) Vergl. Voigt, F., u. a., Wirtschaftliche Entleerungsgebiete in den Industrieländern, a. a. O., S. 52 ff.

(96) Unter "Hauptstadt" muß jeder Sitz politischer Entscheidungsträger, also z. B. Burgen, Fürsten- und Bischofssitze, Residenzstädte, Sitze von regionalen, nationalen und supranationalen Regierungen subsumiert werden.

(97) Lösch, A., Die räumliche Ordnung der Wirtschaft, a. a. O., S. 238.

(98) Vergl. ebenda, S. 53.

(99) Vergl. Voigt, F., u. a., Wirtschaftliche Entleerungsgebiete in den Industrieländern, a. a. O., S. 21 ff. 
(100) Vergl. Miksch, L., Zur Theorie des räumlichen Gleichgewichts, a. a. O. , S. 12 ff.

(101) Vergl. Schneider, E., Einführung in die Wirtschaftstheorie, II. Teil, Wirtschaftspläne und wirtschaftliches Gleichgewicht in der Verkehrswirtschaft, 9. durchgesehene Auflage, Tübingen 1964, S. $77 \mathrm{ff}$.

(102) Voigt, F., u.a., Wirtschaftliche Entlee rungsgebiete in den Industrie ländern, a. a. O., S. 25.

(103) Vergl. ebenda, S. 22 f.

(104) Miksch, L., Zur Theorie des räumlichen Gleichgewichts, a. a. O. , S. $21 \mathrm{f}$.

(105) Lösch, A., Die räumliche Ordnung der Wirtschaft, a, a. O. , S. 183.

(106) Vergl. Miksch, L., Zur Theorie des räumlichen Gleichgewichts, a. a. O., S. $21 \mathrm{f}$.

(107) Vergl. Böventer, E. v., Die Struktur der Landschaft, Versuch einer Synthese und Weiterentwicklung der Modelle J.H. von Thünens, W. Christallers und A. Löschs, in: Optimales Wachstum und Optimale Standortverteilung, Schriften des Vereins für Socialpolitik, N. F., Bd. 27, Berlin 1962, S. 77 - 133, hier: S. 80.

(108) Vergl. Littmann, K., u. a., Die Gestaltung des kommunalen Finanzsystems unter raumordnungspolitischen Gesichtspunkten, Veröffentlichungen der Akademie für Raumforschung und Landesplanung, Abhandlungen Bd. 50, Hannover 1968, S. 20.

(109) Vergl. Schneider, H. K., Über die Notwendigkeit regionaler Wirtschaftspolitik, a. a. O., S. 12.

(110) Schnyder, J.S., Öffentliche Finanzen als Mittel der Regionalpolitik, a. a. O., S. 100 .

(111) Vergl. Schneider, H.K., Über die Notwendigkeit regionaler Wirtschaftspolitik, a. a. O., S. $12 \mathrm{f}$.

(112) Vergl. Jochimsen, R. Theorie der Infrastruktur, a, a. O., S. 60; und Schnyder, J.S., Öffentliche Finanzen als Mittel der Regionalpolitik, a. a. O., S. 93 .

(113) Vergl. Lösch, A., Die räumliche Ordnung der Wirtschaft, a.a. O., S. $148 \mathrm{ff}$.

(114) Ebenda, S. 150.

(115) Definition der externen Effekte: siehe Seite $58 \mathrm{f}$.

(116) Schneider, H.K., Modelle für die Regionalpolitik, in: Beiträge zur Regionalpolitik, a.a.O., S. $63-85$, hier: S. 81.

(117) Jochimsen, R., Theorie der Infrastruktur, a. a. O., S. 64.

(118) Schnyder, J.S., Öffentliche Finanzen als Mittel der Regionalpolitik, a. a. O., S. 95 . 
(119) Vergl. Jochimsen, R., Theorie der Infrastruktur, a. a. O., S. 68 ff. und

Schneider, H. K. , Über die Notwendigkeit regionaler Wirtschaftspolitik, a. a. O., S. $12 \mathrm{ff}$.

(120) Vergl. Pawlowsky, P., Räumliche externe Effekte ..., a. a. O., S. 16 ff.

(121) Vergl. ebenda, S. $16 \mathrm{ff}$.

(122) Vergl. Böventer, E. v., Die Struktur der Landschaft, a.a. O. , S. 80.

(123) Vergl. Schneider, H. K., Modelle für die Regionalpolitik, a. a. O., S. $80 \mathrm{f}$.

(124) Töpfer, K., Regionalpolitik und Standortentscheidung, a.a. O., S. 37.

(125) Giersch zählt weitere Vorteile des räumlichen Verbunds auf: Neben Ersparnissen an Kommunikationskosten auch solche an Fracht-, Verladeund Lagerungskosten, weiterhin die Möglichkeiten der Verwertung von Abfallenergie und von verderblichen Nebenprodukten. (Vergl. Giersch, H., Das ökonomische Grundproblem der Regionalpolitik, a.a. O., S.398.)

(126) Im Gegensatz zu 'traditionellen' Dienstleistungen! (Vergl. Biehl, D. , u. a., Zur regionalen Einkommensverteilung ...., a. a. O., S. 78.)

(127) Vergl. Isenberg, G., Kräfte und Gegenkräfte im Ballungsproze, , in: Die öfentliche Verwaltung, Zeitschrift für Verwaltungsrecht und Verwaltungspolitik, Heft 21/22 (16. Jg.), Stuttgart 1963, S. 807 - 811, hier: S. 808

(128) Vergl. Lauschmann, E., Grundlagen einer Theorie der Regionalpolitik, a. a.O., S. 43 .

(129) Vergl. ebenda, S. 51.

(130) Vergl. zum Begriff der Infrastruktur z. B. Frey, R. , Infrastruktur, Grundlagen der Planung öffentlicher Investitionen, Hand- und Lehrbücher aus dem Gebiet der Sozialwissenschaften, hrsg. v. E. Salin und G. Schmölders, Tübingen 1970; und

Jochimsen, R., Theorie der Infrastruktur, a. a. O., S. $99 \mathrm{ff}$.

(131) Töpfer, K., Regionalpolitik und Standortentscheidung, a. a. O., S. 111.

(132) Vergl. Frey, R., Infrastruktur, a.a. O., S. $70 \mathrm{ff}$.

(133) Vergl. Töpfer, K., Regionalpolitik und Standortentscheidung, a. a. O. , S. $110 \mathrm{f}$.; und

Biehl, D., u. a., Bestimmungsgründe ..., a. a. O., S. 46.

(134) Vergl. Frey, R., Infrastruktur, a. a. O., S. $30 \mathrm{f}$.

(135) Die Nutzung von Infrastruktureinrichtungen durch nicht ortsansässige Wirtschaftssubjekte ist zwar oft möglich, verursacht diesen aber höhere Geld- und Zeitkosten als den ortsansässigen Wirtschaftssubjekten.

(136) Vergl. Bundesregierung, Bundesraumordnungsprogramm, a. a. O. , S. 15; und 
Voigt, F., u. a., Wirtschaftliche Entleerungsgebiete ..., a. a. O., S. $110 \mathrm{ff}$.

(137) Dies ist vor allem in Staaten der Fall, in denen das Mehrheitswahlrecht praktiziert wird. In Staaten mit Verhältniswahlrecht ist die Chance bzw. die Gefahr des Machtwechsels (aus Regierungssicht) relativ gering. (Vergl. Hermens, F.A., Verfassungslehre, Demokratie und Frieden, Bd. 7, Veröffentlichungen des Forschungsinstituts für Politische Wis senschaft und Europäische Fragen der Universität zu Köln, 2. Auflage, Köln, Opladen 1968, insbesondere S. 291 ff.)

(138) Vergl. Brösse, U., Ziele in der Regionalpolitik ..., a.a. O., S. $150 \mathrm{ff}$.

(139) Vergl. ebenda, S. $165 \mathrm{f}$.

(140) Dieses Ziel der Zentralregierung erklärt auch ihre Präferenz für kurzfristig wirkende Maßnahmen, deren Wirkungen noch vor der nächsten Wahl anfallen. Dies ist aber bei Infrastrukturmaßnahmen in Ballungs gebieten eher zu erwarten als bei Infrastrukturmaßnahmen in schwach agglomerierten Regionen.

Vergl. oben, Seite $38 \mathrm{f}$.; und

Spieß, L., Der Finanzausgleich im Lichte volkswirtschaftlicher Ziele, a. a. O., S. 78 .

(141) Vergl. Littmann, K., Finanzpolitik, räumliche Gleichgewichte und Optima, a. a. O., S. $91 \mathrm{ff}$.

(142) Gesetz über die Grundsätze des Haushaltsrechts des Bundes und der Länder (Haushaltsgrundsätzegesetz) vom 19. August 1969 (BGBl. I S. 1273), $\$ 6$.

(143) Voigt, F., u. a., Wirtschaftliche Entleerungsgebiete in Industrieländern, a. a. O., S. 71.

(144) Vergl. Siebert, H., Zur interregionalen Verteilung neuen technischen Wissens, a. a. O., S. 232.

(145) Ebenda, S. 233.

(146) Vergl. Voigt, F., u.a., Wirtschaftliche Entleerungsgebiete in Indu strieländern, a.a. O., S. $56 \mathrm{f}$.

(147) Vergl. Siebert, H., Zur interregionalen Verteilung neuen technischen Wissens, a.a.O., S. 234.

(148) Vergl. ebenda, S. $235 \mathrm{ff}$.

(149) Diese Aussage beruht in erster Linie auf theoretischen Überlegungen (vergl. insbesondere unten, S. $75 \mathrm{ff}$ ). Sie wird gestützt durch die Beobachtung von

- relativ großen Produktivitätsunterschieden zwischen Ballungs räumen und ländlichen Regionen,

- im Vergleich zu den regionalen Produktivitätsunterschieden geringeren regionalen Unterschieden im Lohnniveau, 
- unterdurchschnittlichen Arbeitslosenquoten in den Ballungsregionen bei gleichzeitig z. T. weit überdurchschnittlich hohen Arbeitslosenquoten in den peripheren (ländlichen) Regionen.

Ein empirischer Nachweis des behaupteten regionalen Gewinngefälles liegt meines Wissens allerdings noch nicht in befriedigender Weise vor.

(150) Vergl. Voigt, F., u. a., Wirtschaftliche Entleerungsgebiete in Indu strieländern, a.a. O., S. $58 \mathrm{ff}$.; und

Siebert, H., Zur interregionalen Verteilung ..., a. a. O., S. $240 \mathrm{ff}$.

(151) Siebert, H. , Zur interregionalen Verteilung ..., a. a. O., S. 248.

(152) Vergl. Biehl, D., u. a., Bestimmungsgründe ..., a.a. O., S. 32.

(153) Vergl. Storbeck, D., Die wirtschaftliche Problematik der Raumordnung, a. a. O., S. $57 \mathrm{ff}$.

(154) Vergl. Giersch, H., Das ökonomische Grundproblem der Regionalpolitik, a. a. O., S. 396.

(155) Böventer, E. v., Die Struktur der Landschaft, a. a. O., S. 125.

(156) Auch hier ist eine umfassende und vollständige Darstellung weder be absichtigt, noch möglich.

(157) Vergl. Isenberg, G. , Kräfte und Gegenkräfte im Ballungsprozeß, a. a. O. , S. 808 .

(158) Brösse, U., Ziele in der Regionalpolitik ..., a. a. O. , S. 107.

(159) Zum Preis von null Geldeinheiten ist das mengenmäßige Angebot größer als die mengenmäßige Nachfrage nach diesen Gütern.

(160) Vergl. Storbeck, D., Die wirtschaftliche Problematik der Raumordnung, a. a. O., S. 61 und S. 70.

(161) Gedacht ist hierbei u. a. an die Starrheit, teilweise sogar Irreversibilität der Verwaltungsgrenzen lokaler und regionaler Gebietskörperschaften (s. Schwierigkeiten der kommunalen Gebietsreform und der Neugliederung des Bundesgebiets in leistungsfähigere Länder), die die Effizienz und Zieladäquanz der öffentlichen Aktivitäten (z. B. Unterversorgung mit öffentlichen Leistungen, unwirtschaftliches Konkurrenzdenken, Vernachlässigung grenzenüberschreitender Probleme) beeinträchtigt.

(162) Vergl. Brösse, U., Ziele in der Regionalpolitik ..., a. a. O., S. 106 ff.

(163) Vergl. Spieß, L., Der Finanzausgleich im Lichte volkswirtschaftlicher Ziele, a.a. O., S. 97 f.

(164) Vergl. zur Existenz automatischer Stabilisatoren und ihrer Außerkraftsetzung durch die öffentlichen Hände:

Lösch, A., Die räumliche Ordnung der Wirtschaft, a. a. O., S. 51, Anmerkung (1); und

Storbeck, D., Die wirtschaftliche Problematik der Raumordnung, a.a.O., S. 154 . 
Diese beiden Autoren führen als Beispiele an: Verhinderung der Bodenspekulation, Mietpreisbindung und Förderung des Wohnungsbaus mit öffentlichen Mitteln auch und gerade in den Ballungsgebieten.

(165) Storbeck, D., Die wirtschaftliche Problematik der Raumordnung, a.a.O., S. 64 .

(166) Vergl. Töpfer, K. , Regionalpolitik und Standortentscheidung, a.a. O., S. 42 .

(167) Vergl. z. B. Giersch, H., Das ökonomische Grundproblem der Re gionalpolitik, a. a. O., S. 396.

(168) Vergl. Böventer, E. v., Die Struktur der Landschaft, a.a. O., S. $127 \mathrm{ff}$.

(169) Vergl. Lösch, A., Die räumliche Ordnung der Wirtschaft, a. a. O., S. 51, Anmerkung 1 .

(170) Biehl, D., u. a., Bestimmungsgründe ..., a.a. O., S. 51.

(171) Vergl. Töpfer, K., Regionalpolitik und Standortentscheidung, a.a. O., S. 33 .

(172) Vergl. Giersch, H., Aufgaben der Strukturpolitik, a.a. O., S. 85.

(173) Man kann diesen Tatbestand auch als "Nicht-Anwendbarkeit des Marginalprinzips bei der Standortwahl" bezeichnen. (Vergl. Böventer, E. v., Die Struktur der Landschaft, a.a. O., S. $127 \mathrm{ff.)}$

(174) Vergl. Storbeck, D., Die wirtschaftliche Problematik der Raumordnung, a. a. O., S. 66.

(175) Giersch, H., Aufgaben der Strukturpolitik, a.a. O., S. 85.

(176) Vergl. Jochimsen, R., Theorie der Infrastruktur, a.a. O., S. $47 \mathrm{f}$.

(177) Miksch, L., Zur Theorie des räumlichen Gleichgewichts, a. a. O. . S. 18 .

(178) Vergl. Töpfer, K., Regionalpolitik und Standortentscheidung, a. a. O., S. $51 \mathrm{ff}$.

(179) Ebenda, S. 63.

(180) Ebenda, S. $62 \mathrm{f}$.

(181) Vergl. ebenda, S. $66 \mathrm{f}$; und

Schneider, H.K. , Über die Notwendigkeit regionaler Wirtschaftspolitik, a. a.O., S. 16, Anmerkung 14.

(182) Töpfer, K., Regionalpolitik und Standortentscheidung, a.a. O., S. 66.

(183) Vergl. ebenda, S. $43 \mathrm{ff}$.

(184) Kosten und Unsicherheit der Informationen sind umso niedriger, je besser das Kommunikationsnetz ausgebaut ist, je größer die standortsuchenden Unternehmen sind und/oder je aktiver der Staat auf dem Gebiet der Regionalpolitik agiert. Die Leistungsfähigkeit von Sender, 
Empfänger und Transportweg der für die Standortentscheidung relevanten Informationen wird aber wohl in der Zukunft zunehmen.

(185) Vergl. Giersch, H., Beschäftigungspolitik ohne Geldillusion, in: Die Weltwirtschaft, Halbjahresschrift des Instituts für Weltwirtschaft an der Universität Kiel, hrsg. v. H. Giersch, Heft 2, Tübingen 1972, S. $127-135$, hier: S. 129.

(186) Das Reallohn-Arbeitsproduktivitäts-Verhältnis ist eine andere Bezeichnung für die betrieblichè, regionale oder volkswirtschaftliche Lohnquote:

$\frac{W}{Y}=\frac{l \cdot L}{P \cdot Y}=\frac{\frac{1}{P}}{\frac{Y}{L} r}$

$\frac{\mathrm{W}}{\mathrm{Y}}=$ Lohnquote

$\frac{1}{\mathrm{P}}$ - Reallohn

$\frac{Y r}{L}=$ Arbeitsproduktivität
$W=$ Lohnsumme

$Y=$ nominelle Wertschöpfung

$1=$ Nominallohnsatz

$\mathrm{L}=$ eingesetzte Menge des Faktors Arbeit (Zahl der Arbeitsstunden)

$P=$ Preisniveau

$\mathrm{Yr}=$ reale (preisbereinigte) Wertschöpfung

Vergl. Krelle, W., Verteilungstheorie, Wiesbaden 1962 , S. $67 \mathrm{f}$.

(187) Vergl. Giersch, H., Beschäftigungspolitik ohne Geldillusion, a.a. O., insbesondere S. $128 \mathrm{ff}$.

(188) Vergl. auch Brösse, U., Raumordnungspolitik, a.a. O., S. 137.

(189) Vergl. Biehl, D., u. a., Zur regionalen Einkommensverteilung .... a. a. O., S. $72 \mathrm{ff}$.

(190) Vergl. Giersch, H., Beschäftigungspolitik ohne Geldillusion, a. a. O., S. 130 .

(191) Cairncross, A., u. a., Wirtschaftspolitik für Europa, a.a. O., S. 77.

(192) Biehl, D., u. a., Bestimmungsgründe ..., a.a. O., S. 5.

(193) Vergl. Spieß, L., Der Finanzausgleich im Lichte volkswirtschaftlicher Ziele, a.a. O., S. $83 \mathrm{f}$.

(194) Ein Instrument zur Beeinflussung des regionalen Nominallohnniveaus sind z. B. staatliche Lohnsubventionen.

(195) Vergl. Brösse, U., Raumordnungspolitik, a. a. O., S. 67 ff.

(196) Vergl. Doerig, H. -U., Der staatliche Einfluß auf die regionale Verteilung ..., a. a. O., S. $53 \mathrm{ff}$.

(197) Vergl. Ehrlicher, W., u. a., Kommunaler Finanzausgleich und Raumordnung, Veröffentlichungen der Akademie für Raumforschung und Landesplanung, Abhandlungen, Bd. 51, Hannover 1967, S. $10 \mathrm{f}$.

(198) Brösse, U., Raumordnungspolitik, a. a. O., S. 80. 
(199) Vergl. Voigt, F., u.a., Wirtschaftliche Entleerungsgebiete in Industrieländern, a. a. O., S. 63.

(200) Vergl. Albers, W., Art. Finanzausgleich (III) Deutschland, in: Handwörte rbuch der Sozialwissenschaften, hrsg. v. E.v. Beckerath u. a., 3. Bd., Göttingen 1961, S. 553 - 573, hier: S. 558.

(201) Vergl. Littmann, K., Finanzpolitik, räumliche Gleichgewichte und Optima, a. a. O., S. 64.

(202) Im Gegensatz zur "passiven Reaktion" der Kommunen auf raumwirtschaftliche Daten, die durch den Ablauf des räumlichen Differenzierungsprozesses in der Vergangenheit gesetzt worden sind.

Vérgl. Littmann, K., Finanzpolitik ..., a.a. O., S. 77 f; und

Voigt, F., u.a., Wirtschaftliche Entleerungsgebiete ..., a. a. O., S. $68 \mathrm{f}$.

(203) Littmann, K., Finanzpolitik ..., a. a. O., S. 79.

(204) Ebenda, S. 90.

(205) Vergl. oben, S. $26 \mathrm{f}$.

(206) Vergl. Kloten, N., Steuerpolitik als regionale Strukturpolitik, in: Archiv für Kommunalwissenschaften, hrsg. v. Verein für Kommunalwissenschaften e. V. u.a., 1. Halbjahresband 1964, Stuttgart 1964, S. 41 56 , hier: S. 49.

(207) Vergl. ebenda, S. $47 \mathrm{f}$.

(208) Steuereinnahmen der Gemeinden (pro Einwohner) bei regional unterschiedsloser Steueranspannung.

(209) Vergl. Albers, W., Finanzzuweisungen und Standortverteilung, in: Kommunale Finanzen und Finanzausgleich, a. a. O., S. 253 - 286, hier: S. $267 \mathrm{f}$.

(210) Vergl. z. B. Kloten, N., Steuerpolitik als regionale Strukturpolitik, a. a. O., S. $47 \mathrm{f}$; und

Littmann, K., Finanzpolitik ..., a. a. O., S. 78.

(211) Die Struktur des kommunalen Steuersystems in der Bundesrepbulik Deutschland 1969 und 1974

\begin{tabular}{lcc} 
& 1969 (in \%) & 1974 (in \%) \\
\hline Grundsteuer A & 2,4 & 1,3 \\
Grundsteuer B & 11,4 & 9,5 \\
Gewerbesteuer (netto) & 81,7 & 43,5 \\
Gemeindeanteil an der Einkommensteuer & - & 41,9 \\
Zuschlag zur Grunderwerbssteuer & 2,9 & 2,5 \\
sonstige Gemeindesteuern & 1,6 & 1,3 \\
\hline & 100,0 & 100,0
\end{tabular}

Quelle: Berechnet nach

Statistisches Bundesamt, Fachserie L, Finanzen und Steuern, 
Reihe 2, Steuerhaushalt von Bund, Ländern und Gemeinden, 4. Vierteljahr und Jahr 1969, Stuttgart, Mainz, Mai 1970, S. $30 \mathrm{f} ; 1974, \mathrm{~S} .22 \mathrm{f}$.

(212) Vergl. oben, S. $75 \mathrm{ff}$.

(213) Vergl. Egner, E., Art. Raumwirtschaftspolitik, in: Handwörterbuch der Sozialwissenschaften, hrsg. v. E. v. Beckerath, Bd. 8, Göttingen, Tübingen 1964, S. 694 - 704, hier: S. 699 f.

(214) Vergl. Doerig, H. -U., Der staatliche Einfluß ..., a. a. O., S. $61 \mathrm{ff}$.

(215) Vergl, Brösse, U., Raumordnungspolitik, a.a. O., S. 90 ff.

(216) Vergl. Zimmermann, H., Öffentliche Ausgaben und regionale Wirtschaftsentwicklung, Veröffentlichungen der List Gesellschaft e. V., Bd. 61, Basel, Tübingen 1970, S. $76 \mathrm{ff}$.

(217) Zimmermann, H., Öffentliche Ausgaben und regionale Wirtschaftsentwicklung, a. a. O., S. 77.

(218) Vergl. ebenda, S. $220 \mathrm{f}$.

(219) Littmann, K., Finanzpolitik ..., a. a. O., S. 83.

(220) Auch Frey hält "eine eindeutige Trennung in Infrastrukturproduktivund -konsumtivinvestitionen nicht [für] möglich."

(Frey, R., Infrastruktur, a.a. O., S. 20). In seinen theoretischen Überlegungen über die Wirkungen der Infrastruktur trennt jedoch auch er die Produktivinfrastruktur von der Konsumtivinfrastruktur.

(221) Vergl. u. a. Littmann, K., Finanzpolitik ..., a. a. O., S. 79 ff; Albers, W., Finanzzuweisungen und Standortverteilung, a.a. O., S. $264 \mathrm{ff}$; und Zimmermann, H., Öffentliche Ausgaben ..., a. a. O., S. 76 ff.

(222) Die unmittelbaren Zahlungen umfassen Transferzahlungen (Sozialleistungen und Subventionen) und Käufe staatlicher bzw. kommunaler Inputs. (Vergl. Zimmermann, H., Öffentliche Ausgaben ...., a.a. O., S. 78).

(223) Sie werden im folgenden meistens als Infrastrukturleistungen bezeichnet.

(224) Die Leistungsabgabe der Kommunen an private Haushalte muß weiter aufgegliedert werden in Leistungen zugunsten von Rentnerhaushalten, Arbeitnehmerhaushalten und Unternehmerhaushalten, da ein bestimmtes haushaltsorientiertes Leistungsangebot in unterschiedlichem Ausmaß das Verhalten dieser drei Gruppen von Haushalten beeinflussen kann. (Vergl. Littmann, K., Finanzpolitik .... a. a. O., S. 85).

(225) Vergl. Littmann, K. , Finanzpolitik ..., a. a. O., S. 79 ff; und Albers, W., Art. Standortwirkungen der staatswirtschaftlichen Tätigkeit, in: Handwörterbuch der Wirtschaftswissenschaft (HdWW), zugleich Neuauflage des "Handwörterbuch der Sozialwissenschaften", hrsg. v. W. Albers u. a., Stichwort Sozialismus bis Steuern II, Stuttgart, Tübingen 1977 , S. 212 - 223, hier: S. $212 \mathrm{ff}$. 
(226) Vergl. Albers, W., Der Einfluß des Finanzausgleichs auf regionale Wettbewerbsbedingungen und Produktionsstandorte, in: Gestaltungs probleme der Weltwirtschaft, Festschrift aus Anlaß des 70. Geburtstags von A. Predöhl, hrsg. v. H. Jürgensen, Göttingen 1964, S. 462 491, hier: S. 483 ff.

(227) Vergl. Littmann, K., Finanzpolitik ..., a.a. O., S. 79 f.

(228) Eine Kreditaufnahme zur Deckung des Einnahmeausfalls ist annahmegemäß ausgeschlossen.

(229) Positive externe Ėrsparnisse einer kommunalen Aktivität sind dann gegeben, wenn die Kostensenkung (Nutzenerhöhung), die durch eine be stImmte kommunale Leistung bewirkt wird, größer ist als die Kostenerhöhung (Nutzeneinbuße), die durch die zur Finanzierung der Leistung e rhobenen Steuern verursacht wird. (Vergl. Littmann, K., Finanzpolitik ..., a. a. O., S. 65 ff.).

(230) Vergl. Albers, W., Art. Standortwirkungen der staatswirtschaftlichen Tätigkeit, a.a. O., S. 213.

(231) Bereits die Erhöhung der Steuerzahllast, die die Unternehmen zu einer Überwälzung auf die Abnehmer zwingt und ein regionales Preisgefälle auslöst, ist standortwirksam.

(232) Vergl. Albers, W., Der Einfluß des Finanzausgleichs ..., a. a. O. , S. 485 .

(233) Diese Bedingung wird weiter unten diskutiert.

(234) Hervorhebung vom Verfasser dieser Arbeit.

(235) Zimmermann, H., Öffentliche Ausgaben ..., a. a. O., S. 236.

(236) Diese Annahmen für die Diskussion der Wirksamkeit von Strukturvariationen werden auch von Littmann implizit (vergl. Littmann, K., Finanzpolitik ...., a. a. O.) und von Albers explizit (vergl. Albers, W., Finanzzuweisungen und Standortverteilung, a.a.O., S. 264) gemacht.

(237) Vergl. Albers, W., Finanzzuweisungen und Standortverteilung, a. a. O., S. 269 .

(238) Das Umgekehrte gilt für die Haushalte.

(239) Vergl. oben, S. $56 \mathrm{ff}$.

(240) Vergl. Töpfer, K., Regionalpolitik und Standortentscheidung, a. a. O. , S. $107 \mathrm{ff}$.

(241) Vergl. Littmann, K., Finanzpolitik ..., a. a. O., S. 82.

(242) Wie dies Voigt tut. Vergl. Voigt, F., u. a., Wirtschaftliche Entleerungs gebiete ..., a. a. O., S. 66 .

(243) Vergl. Littmann, K., Finanzpolitik ..., a. a. O., S. 82.

(244) Vergl. Voigt, F., u.a., Wirtschaftliche Entleerungsgebiete ..., a. a. O., S. 66 . 
(245) Vergl. Albers, W., Art. Standortwirkungen der staatswirtsch aftlichen Tätigkeit, a.a.O., S. 213.

(246) Die steuerliche Entlastung führt entweder indirekt (Preisgefälle) oder direkt (vergl. S. 83) zu einer Verbesserung der Gewinnsituation am Ort der geringeren Steuerbelastung. Dadurch erweitert sich der Selbstfinanzierungsspielraum der bereits ansässigen Unternehmen und für wenigstens einige standortsuchende Unternehmen kann diese Gemeinde ein geeigneter Standort werden. Ob ein bisher gegebener Gewinnrückstand gegenüber anderen Standorten in ein Gewinngefälle zugunsten dieser Gemeinde umgewandelt wird, hängt vom Ausmaß der steuerlichen Entlastung ab.

(247) Albers, W., Der Einfluß des Finanzausgleichs ..., a. a. O., S. 485.

(248) Vergl. Albers, W., Finanzzuweisungen und Standortverteilung, a. a. O., S. 269 .

(249) Albers, W., Der Einfluß des Finanzausgleichs ..., a. a. O., S. 486.

(250) Vergl. Kloten, N., Steuerpolitik ..., a.a. O., S. 50; und Zimmermann, H., Öffentliche Ausgaben..., a. a.O., S. 83.

(251) Es handelt sich hierbei um dieselbe Problematik, wie sie im Zusammenhang mit konjunkturpolitisch motivierten Steuererleichterungen gemäß $₫ 26,3$ und $₫ 27,2$ (Investitionsbonus) des Gesetzes zur Förderung der Stabilität und des Wachstums der Wirtschaft vom 8. Juni 1967 (BGBl. I S. $582 \mathrm{ff}$ ) auftritt.

(252) Kloten, N., Steuerpolitik ..., a. a. O., S. 52.

(253) Albers, W., Art. Standortwirkungen der staatswirtschaftlichen Tätigkeit, a.a.O., S. 222.

(254) Da die Käufe staatlicher Inputs nicht so sehr durch ihre Struktur, als vielmehr durch ihre regionale Verteilung auf die Raumstruktur wirken, werden sie erst im Zusammenhang mit dem raumwirtschaftlichen Einfluß des Zentralstaates behandelt.

(255) Töpfer, K., Regionalpolitik und Standortentscheidung, a. a. O., S. 107.

(256) Vergl. unten, S. $98 \mathrm{f}$.

(257) Vergl. Albers, W. und Friaul, K. H., Art. Subventionen, in: Staats lexikon, hrsg. v. d. Görres-Gesellschaft, 6. völlig neu bearbeitete und erweiterte Auflage, 11. Bd., 3. Ergänzungsband, Freiburg i. Br. 1970, Sp. $414-429$.

(258) Vergl. Zimmermann, H., Öffentliche Ausgaben ..., a. a. O., S. 83.

(259) Vergl. die unterstellten Annahmen auf Seite 87.

(260) Vergl. Brösse, U., Raumordnungspolitik, a. a. O., S. $107 \mathrm{f}$.

(261) Vergl. oben, Seite 55 f.

(262) Töpfer, K., Regionalpolitik und Standortentscheidung, a.a. O., S. 108. 
(263) Töpfer, K., Regionalpolitik und Standortentscheidung, a.a. O., S. 110.

(264) Brösse unterscheidet Bodennutzungs -, Siedlungsstruktur-, Wachstums -, Anreiz-, Einkommens-, Versorgungs -, Mobilitäts - sowie Stabilisierungs - und Selbsterzeugungseffekte von Infrastrukturmaßnahmen. (Vergl. Brösse, U., Raumordnungspolitik, a.a. O., S. 119 ff.)

(265) Frey, R., Infrastruktur, a. a. O., S. 50.

(266) Ebenda, S. 55.

(267) Vergl. auch Biehl, D., u. a., Bestimmungsgründe ..., a. a. O., S. 45 f; und

Töpfer, K., Regionalpolitik und Standortentscheidung, a. a. O., S. $110 \mathrm{ff}$.

(268) Vergl. Frey, R., Infrastruktur, a. a. O., S. 32 f.

(269) Voigt, F., u. a., Wirtschaftliche Entleerungsgebiete ..., a. a. O., S. $172 \mathrm{f}$.

(270) Vergl. Brösse, U., Raumordnungspolitik, a. a. O., S. 135 f.

(271) Vergl, unten, Seite $98 \mathrm{f}$.

(272) Vergl, oben, Seite 29.

(273) Littmann, K., Finanzpolitik, räumliche Gleichgewichte und Optima, a. a. O., S. 84 .

(274) Ebenda, S. 83.

(275) Albers, W., Der Einfluß des Finanzausgleichs ..., a. a. O., S. 486.

(276) Vergl. Töpfer, K., Regionalpolitik und Standortentscheidung, a. a. O., S. 112 .

(277) Vergl. Brösse, U., Raumordnungspolitik, a.a. O., S. 122.

(278) Vergl. Doerig, H. -U., Der staatliche Einfluß ..., a. a. O., S. 66.

(279) Vergl. Brösse, U., Raumordnungspolitik, a.a. O., S. 137.

(280) Vergl. Zimmermann, H., Öffentliche Ausgaben ..., a. a. O., S. 81 und Seite 249.

(281) Vergl. Littmann, K., Finanzpolitik, räumliche Gleichgewichte und Optima, a. a. O., S. 85.

(282) Biehl, D., u.a., Bestimmungsgründe ..., a. a. O., S. 47.

(283) Kloten, N., Steuerpolitik als regionale Strukturpolitik, a. a. O., S. 52.

(284) Kreditfinanzierung ist annahmegemäß ausgeschlossen.

(285) Vergl. Albers, W., Art. Standortwirkungen der staatswirtschaftlichen Tätigkeit, a. a. O., S. 213 und S. 222.

(286) Vergl. oben, Seite 86.

(287) Vergl. Boeventer, E.v., Die Struktur der Landschaft, a. a. O., S. 131. 
(288) Nicht zum finanzpolitischen Instrumentarium im engeren Sinn zählt die Informationspolitik. Sie hat dafür zu sorgen, daß die von der Kommune geschaffenen langfristigen Standortvorteile und gebotenen Anfangshilfen den standortsuchenden Investoren bekannt werden. Dies ist eine wichtige Bedingung für das Wirksamwerden der Standortvorteile. (Vergl. Töpfer, K., Regionalpolitik und Standortentscheidung, a. a. O. , S. $120 \mathrm{f}$.)

(289) Nicht an der relativen, sondern an der absoluten Höhe der Ausgaben für attraktivitätsfördernde Zwecke kann die Einflußmöglichkeit der einzelnen Gemeinden auf die Raumstruktur abgelesen werden.

(290) Hier wird noch angenommen, daß das Angebot infrastruktureller Leistungen proportional mit steigenden Infrastrukturausgaben zunimmt, also die Kosten der Leistungserstellung pro Outputeinheit konstant bleiben. Weiter unten wird berücksichtigt, daß sich die Kosten der Leistungserstellung pro Outputeinheit mit steigender Gemeindegröße verändern können. Höhere Infrastrukturausgaben sind dann u. U. erfor derlich, um das bisherige Leistungsangebot aufrecht zu erhalten.

(291) Vergl. Brösse, U., Raumordnungspolitik, a.a. O., S. 182.

(292) Vergl. Kloten, N., Standortwirkungen kommunaler Besteuerungsformen, in: Kommunale Finanzen und Finanzausgleich, a. a. O., S. 121 171 , hier: S. 146.

(293) Vergl. Albers, W., Finanzzuweisungen und Standortverteilung, a. a. O., S. 274, Anmerkung 16.

(294) $\mathrm{Zu}$ diesen primär haushaltsorientierten Aktivitäten gehören sicherlich solche auf dem Gebiet der inneren Sicherheit und Ordnung, der Verund Entsorgung der Gemeindeeinwohner, aber auch Transferzahlungen an die einkommensschwächsten Haushalte. Zusammensetzung dieser Pflichtaufgaben und der zu ihrer Erfüllung erforderliche Finanzaufwand hängen' aber auch vom Entwicklungsstand der jeweiligen Gesellschaft ab. Im Zeitverlauf wird sich eine Erhöhung des Finanzbedarfs für diese Aufgaben ergeben, die aber geringer als das allgemeine Wachstum sein dürfte.

(295) Kloten, N., Standortwirkungen kommunaler Besteuerungsformen, a. a. O., S. 146.

(296) Vergl. Voigt, F., u.a., Wirtschaftliche Entleerungsgebiete in Industrieländern, a. a. O., S. 140.

(297) Vergl. ebenda, S. 69.

(298) Vergl. Albers, W., Finanzzuweisungen und Standortverteilung, a. a. O., S. 274, Anmerkung 16.

(299) Im Zusammenhang mit den Attrahierungsmöglichkeiten der Gemeinden durch Variation ihrer Ausgabenstruktur (vergl. oben, S. 91 ff.) wurde Parallelverhalten der übrigen Gemeinden für unwahrscheinlich eingeschätzt. Die hier diskutierte Beziehung zwischen absoluter Steuer- 
kraft und Ausgabenstruktur bringt dafür die Erklärung: Um ihre unternehmensorientierten Leistungen oder direkten Zahlungen zu erhöhen, muß eine Gemeinde ihre haushaltsorientierten Leistungen und/oder Zahlungen entweder absolut einschränken oder aber, was realistischer ist, sie muß darauf verzichten, etwaige wachstumsbedingte Steuermehreinnahmen für diese Zwecke zu verwenden. Gemeinden mit sehr niedriger Steuerkraft, die nicht einmal das Mindestniveau kommunaler Aktivität finanzieren können, sind dazu nicht in der Lage.

Nur Gemeinden mit einer hohen Steuerkraft können die grundsätzlich den Kommunen zur Verfügung stehenden Attrahierungsmöglichkeiten auf der Ausgabenseite ihres Budgets wahrnehmen. Nur solche Gemeinden können ihre wachstumsbedingten Steuermehreinnahmen schwergewichtig zum Ausbau der Infrastruktur nutzen, und nur solche Gemeinden können ihre Ausgabenstruktur entsprechend anpassen, wenn eine andere steuerstarke Gemeinde eine aktive Attrahierungspolitik betreibt. Hier liegt die "faktische Unterlegenheit deglomerierter [damit steuerschwacher, F.T.] Räume, etwaige fiskalische Operationsmöglichkeiten zu nutzen" (Littmann, K., Finanzpolitik ...., a. a. O., S. 103) begründet.

(300) Wissenschaftlicher Beirat beim Bundesministerium der Finanzen, Gutachten zum Gemeindesteuersystem und zur Gemeindesteuerreform in der Bundesrepublik Deutschland, Schriftenreihe des Bundesministeriums der Finanzen, Heft 10, Bonn 1968, S. 22.

(301) Kloten, N., Standortwirkungen kommunaler Besteuerungsformen, a. a. O. , S. 147.

(302) Ebenda, S. 146.

(303) Ehrlicher, W., u. a., Kommunaler Finanzausgleich und Raumordnung, a. a. O., S. 5 .

(304) Vergl. Albers, W., Art. Standortwirkungen der staatswirtschaftlichen Tätigkeit, a. a. O., S. 212.

(305) Vergl. oben, S. $48 \mathrm{f}$.

(306) Z. B. als Bruttoinlandsprodukt oder als Sozialprodukt pro Einwohner gemessen.

(307) Vergl. für viele: Wissenschaftlicher Beirat beim Bundesministerium der Finanzen, Gutachten zum Gemeindesteuersystem ..., a. a. O., S. 16 und S. 22; und Voigt, F., u. a., Wirtschaftliche Entleerungsgebiete ..., a. a. O., S. 141 .

(308) Ehrlicher, W., u. a., Kommunaler Finanzausgleich und Raumordnung, a. a. O., S. 12 .

(309) Die Ausgaben der öffentlichen Haushalte für Investitionen und Investitions förderungsmaßnahmen 1972 (in \%): 
\begin{tabular}{ccccc} 
Bund Länder (ohne Stadtstaaten) & Gemeinden & Stadtstaaten & insges. \\
\hline 28,2 & 20,5 & 46,1 & 5,2 & 100,0
\end{tabular}

Quelle: Berechnet nach

Statistisches Bundesamt (Hrsg.), Statistisches Jahrbuch 1975 für die Bundes republik Deutschland, Stuttgart, Mainz, August 1975, S. 406.

(310) Vergl. oben, Seite $61 \mathrm{ff}$.

(311) Ohne Finanzzuweisungen von übergeordneten Gebietskörperschaften.

(312) Vergl. oben, Seite $84 \mathrm{ff}$.

(313) Vergl, oben, Seite $98 \mathrm{f}$.

(314) Vergl. Kloten, N., Standortwirkungen kommunaler Besteuerungsformen, a. a. O., S. 141; und

Albers, W., Art. Standortwirkungen der staatswirtschaftlichen Tätigkeit, a.a. O., S. 222.

(315) Vergl. Albers, W., Art. Standortwirkungen ..., a.a. O., S. 213 f.

(316) Vergl. Voigt, F., u. a., Wirtschaftliche Entleerungsgebiete ..., a. a. O., S. $140 \mathrm{f}$;

Zwilling, E., Untersuchungen zu einem rationalen Steuersystem der Gemeinden, Meisenheim am Glan 1971, S. 35 f; und

Flämig, Ch., Gemeindefinanzen und kommunale Wirtschaftsentwicklungsplanung, Baden-Baden 1974, S. $33 \mathrm{f}$.

(317) Zwilling, E., Untersuchungen zu einem rationalen Steuersystem .... a. a. O., S. 35 .

(318) Zimmermann, H., Öffentliche Ausgaben ..., a. a. O., S. 115.

(319) Vergl. Albers, W., Art. Standortwirkungen der staatswirtschaftlichen Tätigkeit, a.a. O., S. 215 f.

(320) Dieser'Fall ist "praktisch ohne Bedeutung, theoretisch allerdings von einigem Interesse". (Littmann, K., Finanzpolitik, räumliche Gleichgewichte und Optima, a.a. O., S. 94.)

(321) Vergl. Albers, W., Art. Standortwirkungen der staatswirtschaftlichen Tätigkeit, a.a. O., S. 216.

(322) Littmann, K., Finanzpolitik, räumliche Gleichgewichte und Optima, a. a. O., S. 91 .

(323) Ebenda, S. 94.

(324) Diese beiden Bezeichnungen werden hier anders verstanden, als dies in der Literatur sonst gebräuchlich ist. Üblicherweise wird die Verteilung von Zahlungen $\mathrm{zwischen}$ öfentlichem und privatem Sektor auf die einzelnen Regionen (oder Personen) als "Zahlungsinzidenz" oder "formale Inzidenz" bezeichnet. Die Verteilung der Steuertraglast bzw. die Verteilung der Begünstigung durch Staatsausgaben nach Abschluß aller Marktprozesse wird "effektive Inzidenz" bzw. "Nutzeninzidenz" 
genannt. (Vergl. Wittmann, W., Bundesstaatlicher Finanzausgleich: Eine Globalbilanz, in: Zeitfragen der schweizerischen Wirtschaft und Politik, hrsg. v. Redressement National, Nr. 101, Zürich 1971, S. 9 ff.) Dieses Vorgehen erscheint aber nur dann sinnvoll, wenn die staatlichen Maßnahmen ausschließlich als monetäre Leistungsströme wirken (Steuern und Transferzahlungen). Von Infrastrukturmaßnahmen gehen dagegen sowohl reale als auch monetäre Leistungsströme zum privaten Sektor. Ihrer Unterscheidung dienen hier die Begriffe "Nutzeninzidenz" und "Zahlungsinzidenz".

(325) Vergl. Littmann, K., Finanzpolitik, räumliche Gleichgewichte und Optima, a. a. O. , S. $94 \mathrm{f}$; und

Albers, W., Art. Standortwirkungen der staatswirtschaftlichen Tätigkeit, a. a. O., S. 216.

(326) Zimmermann, H., Öffentliche Ausgaben ..., a.a. O., S. 115.

(327) Vergl. Littmann, K., Finanzpolitik, räumliche Gleichgewichte und Optima, a. a. O., S. 96 f; und

Albers, W., Art. Standortwirkungen der staatswirtschaftlichen Tätigkeit, a.a. O., S. 216.

(328) Vergl. Zimmermann, H., Öffentliche Ausgaben ..., a. a. O., S. 102 ff; und

Wittmann, W., Bundesstaatlicher Finanzausgleich ...., a.a. O., S. $25 \mathrm{ff}$.

(329) Vergl. Littmann, K., Finanzpolitik, räumliche Gleichgewichte und Optima, a. a. O., S. 96 f.

(330) Vergl. oben, S. $98 \mathrm{ff}$.

(331) Vergl. z. B. Brösse, U., Raumordnungspolitik, a. a. O., S. 182 f; Storbeck, D., Die wirtschaftliche Problematik ..., a. a. O., S. 79; und Ehrlicher, W., Kommunaler Finanzausgleich .... a. a. O., S. 1.

(332) Vergl. Albers, W., Art. Standortwirkungen der staatswirtschaftlichen Tätigkeit, a.a. O., S. $215 \mathrm{f}$.

(333) Vergl. Heckt, W., Die Entwicklung des bundesstaatlichen Finanzaus gleichs in der Bundesrepublik Deutschland, hrsg. v. Institut Finanzen und Steuern, Heft 103, Bonn 19̀73, S. 69.

(334) Am Aufkommen dieser Steuern partizipieren Gebietskörperschaften verschiedener Ebenen des Föderativstaates.

(335) Für die BRD: Vergl. Grundgesetz für die Bundesrepublik Deutschland vom 23. Mai 1949, BGBl. S. 1., \$\$ 28,2 und 30.

(336) Vergl. Flämig, Ch., Gemeindefinanzen und kommunale Wirtschafts entwicklungsplanung, a. a. O., S. $23 \mathrm{f}$; und Klein, F., Die Finanz- und Haushaltsreform, Schriften der Bundes zentrale für politische Bildung, Bonn 1969, S. $25 \mathrm{f}$.

(337) Vergl. Heckt, W., Die Entwicklung des bundesstaatlichen Finanzaus - 
gleichs ..., a. a. O., S. 31 .

(338) In der Bundesrepublik gelten bei Fragen des Finanzausgleichs die Gemeinden verfassungsrechtlich als Teile ihres jeweiligen Landes (Vergl. Grundgesetz, Art. 106,9). Deshalb werden die Interessen der Gemeinden bei den Verhandlungen über die Verteilung der der öffentlichen Hand zur Verfügung stehenden Einnahmen von den Ländern wahrgenommen. Sind Länder und Gemeinden am Ertrag derselben Steuer( $n$ ) betei ligt, ist es möglich, daß die Länder in einen Konflikt zwischen eige nem Interesse und Interessen ihrer Gemeinden geraten.

(339) Vergl. oben, Seite $79 \mathrm{ff}$.

(340) Vergl. Ehrlicher, W., Kommunaler Finanzausgleich und Raumordnung, a.a.O., S. 12 .

(341) Diese Zusammenhänge gelten nicht nur für die Teilstaaten, sondern ebenso für den Gesamtstaat, der mit anderen Staaten auf internationaler Ebene um mobile Ressourcen wetteifert. "Die Regierungen [der Staaten der Europäischen Gemeinschaften, F.T.] werden sich weiter in finanziellen Zugeständnissen überbieten, um die eigene Industrieansiedlung zu forcieren; und sie werden weiterhin eher bei öfentlichen Investitionen sparen, die zur Steigerung des Lebensstandards und zur Verbesserung der Lebensqualität beitragen als bei solchen, die die Wettbewerbsfähigkeit der Industrie erhöhen" (Cairncross, A. , u. a. , Wirtschaftspolitik für Europa, a. a. O., S. 64).

(342) Vergl. oben, Seite $26 \mathrm{f}$.

(343) Vergl. Schäfer, F., Bundesstaatliche Ordnung als politisches Prinzip, in: Aus Politik und Zeitgeschichte, Beilage zur Wochenzeitung "Das Parlament", hrsg. v. der Bundeszentrale für politische Bildung, Bonn, April 1975, S. 4 und 20.

(344) Korrekterweise müßte man von "nachgeordneten" Gebietskörperschaf ten sprechen. Da jedoch der Begriff "untergeordnete Gebietskörperschaft" geläufiger ist, wird er hier beibehalten.

(345) Klein, F., Die Finanzreform zwischen Bund, Ländern und Gemeinden, in: Aus Politik und Zeitgeschichte, Beilage zur Wochenzeitung "Das Parlament", hrsg. v. der Bundeszentrale für politische Bildung, Bonn 1969 , S. 5 .

(346) Vergl. Haller, H., Wandlungen in den Problemen föderativer Staats wirtschaften, in: Finanzarchiv, hrsg. v. F. Neumark, N. F. 27, Heft $1-2$, Tübingen 1968, S. $269 \mathrm{f}$.

(347) Wagener, F., Aufgaben und Gliederung der Länder im neuen Jahrzehnt, in: Die Öffentliche Verwaltung, Zeitschrift für Verwaltungsrecht und Verwaltungspolitik, 23. Jg., Heft 5/6, Stuttgart 1970, S. 159.

(348) Vergl. Haller, H., Wandlungen in den Problemen ..., a. a. O., S. $269 \mathrm{f}$.

(349) Wissenschaftlicher Beirat beim Bundesministerium der Finanzen, Gutachten zum Gemeindesteuersystem ..., a. a. O., S. 11. 
(350) Dieses Argument gilt gleichermaßen für Teilstaaten. Die einzelnen Bundesländer stehen infolge unterschiedlicher Topographie, Wirtschafts - und Bevölkerungsstruktur, Agglomerationsgrad u.v. m. regionsspezifischen Problemen und regional unterschiedlichen Anforderungen ihrer Einwohner gegenüber.

(351) Neumann, M. , Zur ökonomischen Theorie des Föderalismus, in: Kyklos, Internationale Zeitschrift für Sozialwissenschaften, hrsg. v. G. Bombach, Vol. XXIV, Basel 1971, S. 496.

(352) Fischer-Menshausen, H. , Einige Bemerkungen zur Diskussion über die Finanzreform, in: Wirtschaftsdienst, Wirtschaftspolitische Monatszeitschrift, hrsg. v. Hamburgischen Welt-Wirtschafts-Archiv, 48. Jg. , Heft 9, Hamburg 1968, S. 498 - 511, hier: 508.

(353) Ehrlicher z. B. verneint ein solches Recht, denn die Wirtschafts- und Steuerkraft einer untergeordneten Gebietskörperschaft hängen sehr stark von finanzpolitischen Entscheidungen der Vergangenheit ab. Ungleiche Startbedingungen, die als Folge einer unzulänglichen Finanzpolitik in der Vergangenheit entstanden sind, sollten nicht noch sanktioniert und verewigt werden. (Vergl. Ehrlicher, W., u. a., Kommunaler Finanzausgleich und Raumordnung, a.a. O., S. 74).

(354) Vergl. oben, S. $28 \mathrm{ff}$.

(355) Vergl, oben, S. $98 \mathrm{ff}$.

(356) Vergl. Haller, H., Finanzpolitik, Grundlagen und Hauptprobleme, 4. durchgesehene und verbesserte Auflage, Tübingen 1968, S. $235 \mathrm{ff}$.

(357) Vergl. für die Bundesrepublik Deutschland: Albers, W., Art. Standortwirkungen der staatswirtschaftlichen Tätigkeit, a. a. O., S. 217, Tab. 2; und unten, Tab. $1-4$.

(358) Die Untersuchungen zur Reform des Gemeindesteuersystems in der BRD haben gezeigt, daß es auch so gut wie unmöglich ist, Steuern zu finden, deren örtliches Aufkommen sowohl vertikal als auch horizontal zwischen den Gemeinden nur gering streut. (Vergl. Zwilling, E., Untersuchungen zu einem rationalen Steuersystem ...., a. a. O., Tab. 15; und

Albers, W., Die regionalpolitische Bedeutung des Finanzausgleichs, III. Kapitel in: Möglichkeiten wirtschaftlicher Schwerpunktbildung in Schleswig-Holstein, hrsg. v. d. Gesellschaft für Regionale Strukturentwicklung e.V., 1. Bd. : Hauptgutachten, unter Mitwirkung von K. -H. Hansmeyer, W. Albers, H. Jürgensen, K. Mackscheidt und H. Zimmermann, unveröffentlichtes Manuskript, Bonn 1969, S. 169 - 244, hier: S. $196 \mathrm{ff}$, insbesondere: S. 206.)

(359) Vergl. Albers, W., Art. Standortwirkungen ..., a. a. O., S. 216 f.

(360) Haller, H., Finanzpolitik, a. a. O., S. 269. 
(361) Heckt, W., Die Entwicklung des bundesstaatlichen Finanzausgleichs..., a. a. O., S. 69 .

(362) Vergl. Albers, W., Finanzzuweisungen und Standortverteilung, a. a. O. , S. $254 \mathrm{ff}$.

(363) Vergl. Zeitel, G. , Probleme des Steuerverbundes, in: Archiv für Kommunalwissenschaften, hrsg. v. Verein für Kommunalwissenschaften e. V. u. a., 5. Jg. , Stuttgart 1966, S. 222.

(364) Fischer-Menshausen, H., Einige Bemerkungen zur Diskussion über die Finanzreform, a. a. O., S. 509.

(365) Albers, W., Die regionalpolitische Bedeutung des Finanzausgleichs, a. a. O., S. 170 .

(366) Die Erfahrung in der Bundesrepublik mit dem Länderfinanzausgleich vor der Finanzreform bestätigt diese Vermutung. So lag z. B. 1966 die Steuerkraft der finanzschwachen Bundesländer nach Durchführung des Finanzausgleichs jeweils rund 10 Prozent unter dem Bundesdurchschnitt. Diese Finanzausstattung sichert weder gleichmäßige öffentliche Leistungen im Raum, noch "werden die finanzschwachen Länder in die Lage versetzt, ihren Abstand vom Durchschnitt durch überdurchschnittliche öffentliche Leistungen zu verringern. Das aber müßte das Ziel einer ausgewogenen Regionalpolitik sein." (Albers, W., Die regionalpolitische Bedeutung des Finanzausgleichs, a.a. O., S. 175 und Tab. 14).

(367) Vergl. Haller, H., Finanzpolitik, a. a. O., S. 266 ff; und Zeitel, G., Probleme des Steuerverbunds, a. a. O., S. $228 \mathrm{ff}$.

(368) Wissenschaftlicher Beirat beim Bundesministerium der Finanzen, Gutachten zum Gemeindesteuersystem ..., a. a. O., S. 13.

(369) Vergl. Haller, H., Finanzpolitik, a. a. O., S. 269.

(370) Vergl. für die Bundesrepublik: Grundgesetz i.d.F. v. 12.5.1969, Art. 105, Abs. 2.

(371) Art. 105, Abs. 3 des Grundgesetzes i.d.F. v. 12.5.1969 lautet: "Bundesgesetze über Steuern, deren Aufkommen den Ländern oder den Gemeinden (Gemeindeverbänden) ganz oder zum Teil zufließt, bedürfen der Zustimmung des Bundesrates."

(372) Zeitel, G., Probleme des Steuerverbundes, a.a. O., S. 235.

(373) Vergl. Grundgesetz für die Bundesrepublik Deutschland vom 23. Mai 1949, i.d. F. vom 12. Mai 1969, Art. 105 und Art. 106, Abs. 6.

(374) Vergl. Albers, W., Finanzzuweisungen und Standortverteilung, a. a. O., S. 255 .

(375) Fischer-Menshausen, H., Einige Bemerkungen zur Diskussion über die Finanzreform, a. a. O., S. 509.

(376) Ebenda, S. 509. 
(377) So auch: Heckt, W., Die Entwicklung des bundesstaatlichen Finanzausgleichs ..., a. a. O., S. $68 \mathrm{ff}$; und

Haller, H., Finanzpolitik, a.a. O., S. 274 f.

(378) Vergl. Albers, W., Die regionalpolitische Bedeutung des Finanzausgleichs, a. a. O., S. 182 .

(379) Haller, H., Finanzpolitik, a. a. O., S. 272.

(380) Ob eine solche "Umverteilungsillusion" überhaupt und in welcher Intensität sie gegebenenfalls vorliegt, hängt insbesondere davon ab, wie kompliziert die im konkreten Fall gewählten Verteilungsschlüssel sind und in welchem Zustand sich die finanzstatistischen Unterlagen befinden.

(381) So auch: Haller, H., Finanzpolitik, a.a. O., S. 272 ff;

Fischer-Menshausen, H., Einige Bemerkungen zur Diskussion über die Finanzreform, a.a.O., S. $508 \mathrm{f}$; und

Heckt, W., Die Entwicklung des bundesstaatlichen Finanzausgleichs ... , a. a. O., S. 69 .

(382) Littmann, K. , Finanzpolitik, räumliche Gleichgewichte und Optima, a. a. O., S. 62 .

(383) Ebenda, S. 106.

(384) Vergl. Albers, W., Finanzzuweisungen und Standortverteilung, a. a. O., S. 275 .

(385) Vergl. Albers, W., Finanzzuweisungen und Standortverteilung, a. a. O. , S. $275 \mathrm{f}$.

(386) Littmann, K. , Finanzpolitik, räumliche Gleichgewichte und Optima, a. a. O., S. 106.

(387) Vergl. Heckt, W., Die Entwicklung des bundesstaatlichen Finanzaus gleichs..., a. a. O., S. 6.

(388) Stein, O., Art. Bedarf und Bedürfnis, in: Handwörterbuch der Sozialwissenschaften, hrsg. v. E.v. Beckerath u.a., 1. Bd., Tübingen, Göttingen 1956, S. 707 - 718, hier: S. 709.

(389) Littmann, K. u. a., Die Gestaltung des kommunalen Finanzsystems.... a. a. O., S. 24 .

(390) Spieß, L., Der Finanzausgleich im Lichte ..., a. a. O., S. 148.

(391) Vergl. Littmann, K., Finanzpolitik, räumliche Gleichgewichte und Optima, a. a. O., S. 98; und

Brösse, U., Raumordnungspolitik, a. a. O., S. $144 \mathrm{ff}$.

(392) Vergl. Spieß, L., Der Finanzausgleich im Lichte ..., a. a. O., S. 148.

(393) Vergl. dazu z.B. :

Albers, W., Die regionalpolitische Bedeutung des Finanzausgleichs, a. a. O., S. $196 \mathrm{ff}$; 
Albers, W., Finanzzuweisungen und Standortverteilung, a. a. O. , S. $277 \mathrm{ff}$; ders., Der Einfluß des Finanzausgleichs .... a. a. O., S. 478;

Ehrlicher, W., u.a., Kommunaler Finanzausgleich und Raumordnung, a. a. O., S. 27 f. und S. 41 f.;

Voigtländer, H., Die raumordnungspolitische Problematik des Finanzausgleichs zwischen Land und Gemeinden (Gemeindeverbänden) in Schleswig-Holstein, Dissertation, Hamburg 1969, S. 128 ff.

(394) Ehrlicher, W., u. a., Kommunaler Finanzausgleich und Raumordnung, a. a. O., S. 28 .

(395) Albers, W., Finanzzuweisungen und Standortverteilung, a. a. O., S. 278.

(396) Vergl. oben, Seite $66 \mathrm{ff}$.

(397) Vergl. oben, Seite $68 \mathrm{ff}$.

(398) Littmann, K., u. a., Die Gestaltung des kommunalen Finanzsystems..., a. a. O., S. 27 .

(399) Vergl. Voigtländer, H., Die raumordnungspolitische Problematik ..., a. a. O., S. $129 \mathrm{f}$.

(400) Diese These kann folgendermaßen plausibel gemacht werden: Wenn die Menschen zu arm sind, um sich ein Auto leisten zu können, brauchen sie keine gutausgebauten Straßen. Müssen sie den ganzen Tag schwer arbeiten, um ihren Lebensunterhalt notdürfitig zu sichern, fehlt ihnen die Freizeit, um Theater, Schwimmbäder u.a. zu nutzen. Befinden sich in der Nähe des Wohnortes keine Arbeitsplätze außerhalb der Landwirtschaft, für die hochqualifizierte Arbeitskräfte benötigt werden, braucht man seinen Kindern auch keine gute Schulausbildung angedeihen zu lassen. Infolge der Armut der Menschen werden pro Einwohner wenig öffentliche Leistungen nachgefragt, so daß die Gemeinde nur einen geringen lokalen Finanzbedarf aufweist.

(401) Haller, H., Wandlungen in den Problemen föderativer Staatswirtschaften, a. a. O., S. 267.

(402) Littmann, K., u. a., Die Gestaltung des kommunalen Finanzsystems..., a. a. O., S. 26 .

(403) Wittmann geht davon aus, daß die "Menschen in den Agglomerationen .. naturgemä $\beta$ auf ein höheres $M a ß$ an Staatsleistungen angewiesen [sind] als die Leute in ländlichen Regionen. " Deshalb postuliert er den "Grundsatz einer den regionalen und lokalen Verhältnissen angemessenen Versorgung mit Staatsleistungen." (Wittmann, W. , Bundesstaatlicher Finanzausgleich: Eine Globalbilanz, a.a. O., S. 4 und 5.)

(404) Vergl. Voigt, F., u.a., Wirtschaftliche Entleerungsgebiete ..., a. a. O., S. 171 .

(405) Werden die Einnahmenunterschiede mit regionalen Unterschieden der Nachfrage nach öffentlichen Leistungen begründet, liegt wieder ein Zirkelschluß vor: Wegen der geringen Wirtschaftskraft einer Region 
ist die regionale Nachfrage nach öffentlichen Leistungen gering. Deswegen erhält die Region unterdurchschnittliche Einnahmen pro Kopf. Damit kann sie nur unterdurchschnittlich hohe Leistungen pro Kopf anbieten, wodurch sie auch in der Zukunft wirtschaftsschwach bleibt. Armut wird mit Armut begründet.

(406) Vergl. Littmann, K., u. a., Die Gestaltung des kommunalen Finanzsystems ..., a.a. O., S. $24 \mathrm{f}$.

(407) Vergl. oben, Seite $67 \mathrm{f}$.

(408) Vergl. oben, Seite $68 \mathrm{ff}$.

(409) Vergl. Albers, W., Die regionalpolitische Bedeutung des Finanzausgleichs, a. a. O., S. 198.

(410) Vergl. Littmann, K., u. a., Die Gestaltung des kommunalen Finanzsystems ..., a. a. O., S. 28.

(411) Ehrlicher, W., u. a., Kommunaler Finanzausgleich und Raumordnung, a.a.O., S. 42 .

(412) Vergl. Littmann, K., u. a., Die Gestaltung des kommunalen Finanzsystems ..., a. a. O., S. $28 \mathrm{f}$.

(413) Ebenda, S. 29.

(414) Vergl. oben, Seite 115 f.

(415) Diese Bedingung sieht auch Littmann. (Littmann, K., u. a., Die Gestaltung des kommunalen Finanzsystems ..., a. a. O., S. 49)

(416) Littmann, K., u.a., Die Gestaltung des kommunalen Finanzsystems ..., a. a.O., S. 61 .

(417) Vergl, oben, Seite 114

(418) Albers, W., Der Einfluß des Finanzausgleichs ..., a. a. O., S. 478.

(419) Vergl. Brösse, U., Raumordnungspolitik, a. a. O., S. 69 f.

(420) Vergl. oben, Seite 59; und

Pawlowsky, P., Räumliche externe Effekte ..., a. a. O., S. $20 \mathrm{ff}$.

(421) Littmann, K., Finanzpolitik, räumliche Gleichgewichte und Optima, a. a. O., S. 86 .

(422) Schneppe, F., Raumbedeutsame Wirkungen des kommunalen Finanzausgleichs in Niedersachsen, Veröffentlichungen der Akademie für Raumforschung und Landesplanung, Beiträge, Bd. 2., Hannover 1968 , S. 84 .

(423) Vergl. Voigtländer, H., Die raumordnungspolitische Problematik..., a. a. O., S. $132 \mathrm{f}$.

(424) Vergl. Hansmeyer, K. -H., Interkommunaler Finanzausgleich, in: Archiv für Kommunalwissenschaften, 5. Jg. , Stuttgart 1966, S. 261 284, hier: S. 272 ff; und 
Pawlowsky, P., Räumliche externe Effekte ..., a.a. O., S. $113 \mathrm{f}$.

(425) Pawlowsky, P., Räumliche externe Effekte ..., a. a. O., S. 115.

(426) So auch:

Voigtländer, H., Die raumordnungspolitische Problematik des Finanzausgleichs ..., a. a. O., S. 133; und

Ehrlicher, W., u.a., Kommunaler Finanzausgleich und Raumordnung, a. a. O., S. 41 .

(427) Eine weitere Möglichkeit der Behandlung von Spillover-Effekten ist mehr ein Problem der Aufgabenverteilung als der Einnahmenverteilung und wird deshalb hier nicht dargestellt. Es handelt sich dabei um institutionelle Änderungen der föderativen Struktur: Durch Zusammenschluß mehrerer Gemeinden zu unitarischen Großgemeinden oder zu föderativ organisierten Samtgemeinden sowie durch Übertragung der mit Ertrags-spillouts verbundenen Aufgaben auf eine höhere bundesstaatliche Ebene können die externen Effekte der kommunalen Tätigkeit in interne Effekte kommunaler bzw. staatlicher Tätigkeit umgewandelt werden. (Vergl. Pawlowsky, P., Räumliche externe Effekte ..., a. a. O., S. $121 \mathrm{ff}$. und Frey, R., Infrastruktur, a. a. O., S. $100 \mathrm{f}$.)

(428) Vergl, oben, Seite $28 \mathrm{ff}$.

(429) Vergl. z.B. Littmann, K., Finanzpolitik, räumliche Gleichgewichte und Optima, a. a. O., S. 93 und S. 98;

Voigt, F., u. a., Wirtschaftliche Entleerungs gebiete ..., a. a. O., S. $171 \mathrm{ff}$; und

Brösse, U., Raumordnungspolitik, a.a. O., S. 144 ff. u. S. 182 f.

(430) Vergl. Ehrlicher, W., u. a., Kommunaler Finanzausgleich und Raumordnung, a. a. O., S. 71 ; und

Spie ß, L., Der Finanzausgleich im Lichte ..., a. a. O., S. 2 ff.

(431) Vergl. Albers, W., Finanzzuweisungen und Standortverteilung, a. a. O., S. 262 ;

Littmann, K., u. a., Die Gestaltung des kommunalen Finanzsystems..., a.a.O., S. 1 ;

Doerig, H. -U., Der staatliche Einfluß auf die regionale Verteilung .... a. a. O., S. 57 ; und

Schnyder, J.S., Öffentliche Finanzen als Mittel der Regionalpolitik, a. a. O., S. 115.

(432) Vergl. Haller, H. , Finanzpolitik, a. a. O., S. 267 f.; und ders., Wandlungen in den Problemen ..., a. a. O., S. 268.

(433) Wissenschaftlicher Beirat beim Bundesministerium der Finanzen, Gutachten zum Gemeindesteuersystem ..., a. a. O., S. 12.

(434) Dasselbe gilt ạch für die Teilstaaten eines Bundesstaates.

(435) Dies gilt sowohl für Spillover-Effekte, die von Teilstaaten verursacht, als auch für diejenigen, die von zentralörtlichen Gemeinden bewirkt werden. 
(436) Vergl. Spieß, L., Der Finanzausgleich im Lichte ..., a. a. O. , S. 145.

(437) Vergl. Littmann, K., Finanzpolitik, räumliche Gleichgewichte und Optima, a.a.O., S. 86 f.

(438) Vergl. oben, Seite $125 \mathrm{f}$.

(439) Vergl. Littmann, K., u. a., Die Gestaltung des kommunalen Finanzsystems ..., a. a. O., S. $61 \mathrm{ff}$.

(440) Vergl. Ehrlicher, W., u. a., Kommunaler Finanzausgleich und Raumordnung, a. a. O., S. $77 \mathrm{ff}$.; und

Spie B, L., Der Finanzausgleich im Lichte ..., a. a. O., S. $102 \mathrm{ff}$.

(441) Durch Nichtberücksichtigung der regionalen Unterschiede in der Nachfrage nach öffentlichen Leistungen.

(442) Durch Nichtberücksichtigung der ballungsbedingten Kostensteigerungen der Erstellung öffentlicher Leistungen.

(443) Vergl. unten, Seite 137, Anmerkung 14.

(444) Dazu ist z. B. eine örtliche Schwerpunktbildung erforderlich. 
(1) Vergl, oben, Seite $98 \mathrm{ff}$.

(2) Vergl, oben, Seite $28 \mathrm{ff}$.

(3) Kamp, M.E., u.a., Das optimale Finanzsystem, Vorlesungen über Finanzwissenschaft, Heft 2, 2, völlig neubearbeitete und stark erweiterte Auflage, Bonn 1969, S. 45.

Zur Finanzverfassung gehören neben den Regelungen des Finanzausgleichs außerdem noch diejenigen der Finanzverwaltung, der Finanzrechtsprechung, des Haushaltswesens, der Rechnungslegung und -prüfung sowie des Schuldenwesens. (Vergl. ebenda, S. $44 \mathrm{f}$.)

(4) Bundesministerium der Finanzen (Hrsg.), Finanzbericht 1970, Die volkswirtschaftlichen Grundlagen und die wichtigsten finanzwirtschaftlichen Probleme des Haushaltsplans der Bundesrepublik Deutschland für das Rechnungsjahr 1970, abgeschlossen am 13.2.1970, Bonn-Bad Godesberg, S. 161 .

(5) Albers, W., Art. Finanzausgleich (III) Deutschland, a. a. O., S. 553.

(6) $\mathrm{Zu}$ den Überlegungen über die Systematik des Finanzausgleichs vergl. z. B. :

Albers, W., Art. Finanzausgleich (III) Deutschland, a. a. O., S. 553 ff.; Kamp, M.E., u. a., Das optimale Finanzsystem, a. a. O. , S. 45-85; Kolms, H., Finanzwissenschaft, Bd. IV, Berlin 1964, S. 141 - 152; Brösse, U., Raumordnungspolitik, a.a. O., S. $182-189$.

(7) Kolms, H., Finanzwissenschaft, Bd. IV, a. a. O., S. 142.

(8) Heckt, W., Die Entwicklung des bundesstaatlichen Finanzausgleichs..., a. a. O., S. 51 .

(9) Ebenda, S. 25.

(10) Finanzbericht 1970, a. a. O., S. 162.

(11) Vergl. Kolms, H., Finanzwissenschaft, Bd. IV, a.a. O., S. 144.

(12) Kamp, M.E., u.a., Das optimale Finanzsystem, a.a. O., S. 49.

(13) Die aus dieser Entscheidung resultierende Verteilung der Steuereinnahmen auf die verschiedenen Bundesstaatsebenen wird im folgenden "vertikale Steuerverteilung" genannt.

(14) Die so entstehende Verteilung der Steuereinnahmen auf die einzelnen Mitglieder einer Ebene heißt weiterhin "horizontale Steuerverteilung".

(15) Die Finanzreform umfaßt im wesentlichen folgende Gesetze:

a) Einundzwanzigstes Gesetz zur Änderung des Grundgesetzes (Finanzreformgesetz) vom 12. Mai 1969, BGBl. I S. $359 \mathrm{ff}$.

b) Zweiundzwanzigstes Gesetz zur Änderung des Grundgesetzes (Gesetz zur Erweiterung der Gesetzgebungszuständigkeit des Bundes) vom 12. Mai 1969, BGBl. I S. 363 . 
Als Ausführungsgesetze:

c) Gesetz über die Gemeinschaftsaufgabe

- "Ausbau und Neubau von wissenschaftlichen Hochschulen" (Hochschulbauförderungsgesetz) vom 1. September 1969, BGBl. I S. $1556 \mathrm{ff}$.

- "Verbesserung der regionalen Wirtschaftsstruktur" vom 6. Oktober 1969, BGBl. I S. $1861 \mathrm{ff}$.

- "Verbesserung der Agrarstruktur und des Küstenschutzes" vom 3. September 1969, BGBl. I S. $1573 \mathrm{ff}$.

d) Gesetz zur Neuordnung der Gemeindefinanzen (Gemeindefinanzreformgesetz) vom 8. September 1969, BGBl. I S. $1587 \mathrm{ff}$.

e) Gesetz über den Finanzausgleich zwischen Bund und Ländern vom 28. August 1969, BGBl. I S. $1432 \mathrm{ff}$.

f) Neufassung des Gesetzes über die Steuerberechtigung und die Zerlegung bei der Einkommensteuer und der Körperschaftsteuer (Zerlegungsgesetz) vom 25. Februar 1971, BGBl. I S. $145 \mathrm{ff}$.

Im weiteren Sinne:

g) - Gemeindeverkehrsfinanzierungsgesetz vom 18. März 1971, BGBl. I S. $239 \mathrm{ff}$.

- Krankenhaussicherungsgesetz vom 29. Juni 1972, BGB1. I S. $1009 \mathrm{ff}$.

- Städtebauförderungsgesetz vom 27. Juli 1971, BGBl. I S. 1125 ff.

(16) Vergl. außer den unter Anmerkung 15 aufgeführten Gesetzen z. B. : Klein, F., Die Finanzreform zwischen Bund, Ländern und Gemeinden, a. a. O.;

Obert, G., Eine zeitgemäße Finanzverfassung, Verwirklichung der Finanzreform - Grundlage für eine wirksame Erfüllung der öffentlichen Aufgaben, in: Bulletin des Presse- und Informationsamtes der Bundesregie rung, Nr. 65, Bonn, Mai 1969, S. 555 - 558;

Heckt, W., Die Entwicklung des bundesstaatlichen Finanzausgleichs ..., a. a. O., S. 42 ff.;

Stotz, M., Die Entwicklung und der gegenwärtige Stand des Finanzausgleichs in der Bundesrepublik Deutschland verglichen mit den Finanzausgleichssystemen in anderen Ländern, Dissertation, Stuttgart 1972, S. 54 - 94 und S. 129 - 172;

Bundesministerium der Finanzen (BMF) (Hrsg.), Finanzbericht 1968 , abgeschlossen am 10.10.1967, S. 209 - 218;

ders., Finanzbericht 1969, abgeschlossen am 5.10.1968, S. 195 - 206; ders., Finanzbericht 1970, abgeschlossen am 13.2.1970, S. 161 - 184; ders., Finanzbericht 1971, abgeschlossen am 10.9.1970, S. 161 - 187; ders., Finanzbericht 1972, abgeschlossen am 30.9.1971, S. $179-193$.

(17) Fragen der vertikalen Steuerverteilung werden nur insoweit in die Untersuchung einbezogen, als von ihnen Auswirkungen auf die horizontale Steuerverteilung ausgehen, was freilich in starkem Maße der Fall sein kann. 
(18) 1969 erhielten die Länder $65 \%$, der Bund $35 \%$ des Aufkommens der Einkommen- und Körperschaftsteuer. (Vergl. Klein, F., Die Finanzund Haushaltsreform, a. a. O., S. 17).

(19) Vergl. Grundgesetz, Art. 106 und 107 in der Fassung vom 23.12. 1955 (BGBl. I S. 817) und vom 24.12.1956 (BGBl. I S. 1077).

(20) Vergl. Grundgesetz, Art. 106 und 107 in der Neufassung vom 12. 5.1969 (Finanzreformgesetz); und Finanzbericht 1970, a. a. O., S. 163 und $170 \mathrm{f}$.

(21) Das Aufkommen der Lohnsteuer und der veranlagten Einkommensteuer steht Bund und Ländern nur insoweit je zur Hälfte $\mathrm{zu}$, als es nicht den Gemeinden zugewiesen ist. Beim derzeit geltenden Gemeindeanteil in Höhe von $14 \%$ des Einkommensteueraufkommens erhalten demnach Bund und Länder je $43 \%$.

(22) Heckt, W., Die Entwicklung des bundesstaatlichen Finanzausgleichs ..., a. a. O., S. 55 .

(23) Gesellschaftsteuer, Wertpapiersteuer, Börsenumsatzsteuer.

(24) Klein, F., Die Finanz- und Haushaltsreform, a. a. O., S. 18.

(25) Finanzbericht 1970, a. a. O., S. 169.

(26) Diese Möglichkeit der Zerlegung wurde mit dem Zerlegungsgesetz vom 29.3.1952 (BGBl. I S. 225) wahrgenommen. Aus Gründen der Verwaltungsvereinfachung wurde das Zerlegungsgesetz aber schon ab 1.1.1955 wieder aufgehoben ( $\$ 15$ des Länderfinanzausgleichsgesetzes $v$. 27.4.1955, BGBl. I S. 199). (Vergl. Heckt, W., Die Entwicklung des bundesstaatlichen Finanzausgleichs ..., a. a. O., S. $34 \mathrm{f}$. und 41 ).

(27) Vergl. Kommission für die Finanzreform, Gutachten über die Finanzre form in der Bundesrepublik Deutschland, 2. Auflage, Stuttgart 1966 , S. 2 f., Tz. 9;

Entwurf eines .... Gesetzes zur Änderung und Ergänzung des Grundgesetzes (Finanzreformgesetz) vom 30. April 1968, Bundestagsdrucksache $\mathrm{V} / 2861$, Bonn 1968, S. 36, Tz. 155;

Heckt, W., Die Entwicklung des bundesstaatlichen ..., a. a. O., S. 43.

(28) Klein, F., Das Finanzreformprogramm der Bundesregierung, in: Bulletin des Presse - und Informationsamtes der Bundesregierung, Nr. 83, Bonn, August 1967, S. 713 - 719, hier: S. 718 .

(29) Klein, F., Die Finanzreform Bund/Länder, in: Bulletin des Presse- und Informationsamtes der Bundesregierung, Nr. 34, Bonn, März 1968, S. 270 - 276, hier: S. 270.

(30) Ebenda, S. 271.

(31) Vergl. Entwurf des Finanzreformgesetzes, Bundestagsdrucksache V/2861, 7, S. 8.

(32) Nach dem Entwurf des Finanzreformgesetzes sollte im Gegensatz zum 
Finanzreformprogramm die Einfuhrumsatzsteuer ausschließlich dem Bund zustehen (Vergl. $\$ 6$ des Entwurfs ...).

(33) Vergl, zu ihrer Beurteilung: oben Seite $114 \mathrm{ff}$.

(34) Finanzbericht 1970 , a. a. O., S. 169.

(35) Vergl. Klein, F., Die Finanzreform zwischen Bund, Ländern und Gemeinden, a. a. O., S. 13.

(36) Vergl. Grundgesetz, Art. 107 in der Fassung vom 12.5.1969; und Finanzbericht 1970, a. a. O., S. $170 \mathrm{f}$.

(37) Wäre der Entwurf des Finanzreformgesetzes nicht auf den Widerstand des Bundestages gestoßen, sondern verwirklicht worden, hätte sich weitgehend diese horizontale Verteilung der Ländersteuereinnahmen gemäß dem kassenmäßigen örtlichen Aufkommen ergeben. Lediglich die $37 \%$ des Einfuhrumsatzsteueraufkommens wären nicht den einzelnen Ländern überlassen worden.

(38) Der Variationskoeffizient ist definiert als das Verhältnis von Standardabweichung $(\sigma)$ und arithmetischem Mittel $(\mu)$ einer Verteilung. Da er eine dimensionslose Zahl ist, sagt der Variationskoeffizient einer Verteilung nur etwas im Vergleich mit dem Variationskoeffizienten einer anderen Verteilung aus.

(39) Vergl. oben, S. $141 \mathrm{ff}$.

(40) Vergl, oben, S. $100 \mathrm{ff}$.

(41) Bayern und Berlin fallen etwas aus dieser Einteilung heraus. Bayern steht zwischen der Gruppe der steuerschwachen und der der steuerstarken Länder, muß aber noch zur ersteren gerechnet werden. Die Steuerkraft Berlins liegt noch um rund $10 \%$ unter der der steuerschwachen Bundesländer.

(42) "Die Finanzreform ist mit der Neufassung des Art. 107 GG ... dem Ziel einer gleichmäßigen finanziellen Ausstattung der Länder nähergekommen. Dieses Ziel wurde aber nicht voll erreicht." (Klein, F., Die Finanzund Haushalts reform, a.a. O., S. 21.)

(43) Vergl. dazu: Albers, W., Die regionalpolitische Bedeutung des Finanzausgleichs, a. a. O., S. $178 \mathrm{ff}$; und Klein, F., Die Finanz- und Haushaltsreform, a. a. O., S. 20 f.

(44) Vergl. die "Neufassung des Gesetzes über die Steuerberechtigung und die Zerlegung bei der Einkommensteuer und der Körperschaftsteuer (Zerlegungsgesetz)" vom 25.2.1971, BGBl. I S. $145 \mathrm{ff}$.

(45) Entwurf eines ....Gesetzes zur Änderung und Ergänzung des Grundgesetzes (Finanzreformgesetz), a. a. O., S. 35, Tz. 150.

(46) Vergl. Gemeindefinanzreformgesetz, $₫ 1$.

(47) Die Schlußfolgerung von Daten aus dem Jahr 1974 auf den Zustand vor 1970 läßt sich vertreten, wenn man davon ausgeht, daß sich höchstens 
das Ausmaß, kaum aber die Richtung der Arbeitskräftewanderungen in den letzten 10 bis $20 \mathrm{Jahren}$ verändert hat.

(48) Nordrhein-Westfalen hat also brutto 232,8 Mill. DM an Bayern zu entrichten. Insgesamt muß es Brutto-Zahlungen in Höhe von 1, $34 \mathrm{Mrd}$. DM an die anderen Länder leisten.

(49) Nordrhein-Westfalen erhält also von Bayern brutto 103 Mill. DM. Die von Nordrhein-Westfalen insgesamt empfangenen Zerlegungsbeträge sind 716 Mill. DM kleiner als die insgesamt zu leistenden Zerlegungszahlungen.

(50) Hamburg hätte also brutto 24,4 Mill. DM von Bayern zu empfan En und 70, 4 Mill. DM an Bayern abzuführen. Daraus resultiert eine Nettozahlung in Höhe von 46 Mill. DM an Bayern. Das sind 4,9\% des gesamten Zerlegungssaldos von Hamburg in Höhe von -939 Mill. DM.

(51) Vergl. Pawlowsky, P., Räumliche externe Effekte ..., a. a. O., S. 26 f.

(52) Über das Ausmaß dieses Kosten-spillouts für das letzte Jahr vor der Finanzreform kann man nur spekulieren: 1969 betrug das Lohnsteueraufkommen in der BRD mit 27 Mrd. DM rund $38 \%$ desjenigen des Jahres 1974. Da 1974 der Kosten-spillout zugunsten der Ballungsgebiete (bzw. ihrer Länder) etwa 1,5 Mrd. DM betragen hätte, kann man ihn für 1969 mit etwa 570 Mill. DM ansetzen, unveränderte Pendlerwanderungen vorausgesetzt. Die Länder erhielten $196965 \%$ des Lohnsteueraufkommens. Deshalb kann man vermuten, daß die Länder, in denen die fünf großen Ballungszentren liegen, 1969 etwa 370 Mill. DM Lohnsteuern von Einwohnern ihrer ländlichen Nachbarländer erhalten haben.

(53) Vergl. oben, Seite $100 \mathrm{f}$.

(54) Vergl, oben, Seite $146 \mathrm{f}$.

(55) Mehrwertsteuer und Einfuhrumsatzsteuer ohne Investitionssteuer. In Zukunft wird nur noch vom "Länderanteil an der Umsatzsteuer" gesprochen.

(56) Vergl. oben, Seite 140

(57) Dieses Gesetz wird im folgenden "Finanzausgleichsgesetz" genannt.

(58) Vergl. Grundgesetz, Art. 107, Abs. 1;

Gesetz über den Finanzausgleich zwischen Bund und Ländern vom 28. 8. 1969, BGB1. I S. 1432 ff, § 2; und

Finanzbericht 1970, a. a. O., S. $173 \mathrm{f}$.

(59) Einkommensteuer, Körperschaftsteuer und Gewerbesteuerumlage.

(60) Den einzelnen Ländern sind in Spalte $237 \%$ ihres kassenmäßigen örtlichen Aufkommens zugewiesen worden.

(61) Hierbei macht das Saarland dank seiner hohen kassenmäßigen Einnahmen aus der Einfuhrumsatzsteuer eine Ausnahme. 
(62) Die große Streuung des kassenmäßigen örtlichen Aufkommens der Umsatzsteuer erklärt sich wiederum in erster Linie mit steuertechnischen Bestimmungen. Die Mehrwertsteuer wird in der BRD an das Finanzamt abgeführt, das für den Wohnsitz des Unternehmers bzw. den Sitzort des Unternehmens zuständig ist. Die Einfuhrumsatzsteuer geht an das Finanzamt, das für den Ort des Grenzübertritts des besteuerten Gutes zuständig ist. Nicht die regionale Verteilung des Verbrauchs, sondern die regionale Verteilung der Unternehmenssitze und der Grenzübergänge bestimmt also die Höhe des kassenmäßigen örtlichen Aufkommens. (Vergl. Umsatzsteuergesetz (Mehrwertsteuer) vom 29. Mai 1967, BGBl. I S. 545 ff; und

Hartmann und Metzenmacher, Umsatzsteuergesetz (Mehrwertsteuer), Kommentar, 6. Auflage, Loseblatt-Sammlung, Berlin o. J., UStG-Erläute rungen $₫ 18, S .45$.

(63) Eine sinnvolle Beurteilung des Variationskoeffizienten ist also nur möglich, wenn gleichzeitig berücksichtigt wird, welche Länder nach oben und welche Länder nach unten vom Durchschnitt abweichen.

(64) Vergl, oben, Seite $146 \mathrm{f}$.

(65) Vergl, oben, Seite $146 \mathrm{f}$.

(66) Vergl, oben, Seite 143.

(67) Als einziges steuerschwaches Bundesland würde Rheinland-Pfalz durch eine Verteilung des Länderanteils an der Körperschaftsteuer nach der Einwohnerzahl weniger Körperschaftsteuereinnahmen erhalten, als ihm nach geltendem Recht zustehen.

(68) Allgemeine Definition des Anteilsquotienten: Anteil der Region an der untersuchten Größe geteilt durch Anteil der Region an einer Basis-(Bezugs-)Größe.

Vergl. Zimmermann, H., Öffentliche Ausgaben ..., a. a. O., S. $100 \mathrm{ff}$; und Lauschmann, E., Grundlagen einer Theorie der Regionalpolitik, a. a. O., S. $130 \mathrm{f}$.

(69) Einkommensteuergesetz in der Neufassung vom 1. Dezember 1971 (EStG 1971), §43, Abs. 1 .

(70) Ebenda, $\$ 44$, Abs. 5.

(71) Vergl. oben, Seite 158.

(72) Hamburg und Bremen besitzen weitaus größere Steuerkraftvorsprünge.

(73) Vergl. oben, Seite $146 \mathrm{f}$.

(74) BGBl. I S. $1432 \mathrm{ff}$.

(75) Finanzbericht 1970, a. a. O., S. 173.

(76) Berlin nimmt wegen seiner staats rechtlichen Sonderstellung nicht am Länderfinanzausgleich teil, sondern erhält aus der Bundeskasse Finanzzuweisungen (Bundeshilfe). (Vergl. Finanzbericht 1970, a. a. O., S. 171 und $185 \mathrm{ff}$; und 
Stotz, M., Die Entwicklung und der gegenwärtige Stand ..., a. a. O. , S. 35.)

(77) Vergl. Gesetz über den Finanzausgleich zwischen Bund und Ländern vom 28. August 1969, $\$ \$ 4-6$.

(78) Bei $S<0,92$ A: $\quad Z=1,0(0,92 A-S)+0,375(A-0,92 A)$. Bei $0,92 \mathrm{~A}<\mathrm{S}<\mathrm{A}: \quad \mathrm{Z}=0,375(\mathrm{~A}-\mathrm{S})$.

Vergl. Stotz, M., Die Entwicklung und der gegenwärtige Stand des Finanzausgleiches ..., a.a. O., S. $86 \mathrm{ff}$.

(79) Bei 1,0 A $\leq \leq \leq 1,02$ A : $B=0$.

Bei 1, $02 \quad A<S \leq 1,1 \quad A: B=0,7$ (S -1,02 A).

Bei $\quad S>1,1 \mathrm{~A} \quad: \mathrm{B}=1,0(\mathrm{~S}-1,1 \mathrm{~A})+0,7(1,1 \mathrm{~A}-1,02 \mathrm{~A})$

(80) Von der Spanne zwischen $102 \%$ und $110 \%$ ihrer Ausgleichsmeßzahl verbleiben ihnen $30 \%$, das sind 2, 4 Prozentpunkte.

(81) Vergl. Finanzausgleichsgesetz vom 28. August 1969, $\$ 10$.

(82) Vergl. ebenda, $₫ 7$, Abs. 3 und 4.

(83) Vergl. ebenda, $₫ 9$ Abs. 2.

(84) Vergl. ebenda, $₫ 8$, Abs. 5.

(85) Vergl. ebenda, $₫ 9$, Abs. 3.

(86) Finanzbericht 1970, a. a. O., S. 175.

(87) Zur Diskussion dieses Arguments: Vergl. oben, Seite $120 \mathrm{ff}$.

(88) Vergl. oben, Seite $125 \mathrm{f}$.

(89) Vergl. oben, Seite $181 \mathrm{ff}$.

(90) Vergl. Grundgesetz, Art. 107, Abs. 2.

(91) Vergl. Finanzausgleichsgesetz, $\$ \$ 4 \mathrm{ff}$.

(92) Vergl. z. B. das Gesetz zur Regelung des Finanzausgleichs (Finanzausgleichsgesetz - FAG) in der Fassung vom 10. Mai 1972 des Landes Hes sen, GVBl. I S. $110 \mathrm{ff}, \S 1$, Abs. 2.

Die Ausführungsbestimmungen zu diesem Finanzausgleichsgesetz des Landes Hessen für das Ausgleichsjahr 1974, legen fest, daß die Gemeinden Hessens in Höhe von $23 \%$ am Länderanteil aller Gemeinschaftsteuern nach Abzug der Zahlungen im Länderfinanzausgleich beteiligt werden.

(93) Vergl. Heckt, W., Die Leistungen der Länder für den gemeindlichen Finanzausgleich, Institut Finanzen und Steuern, Heft 105, Bonn 1974, S. $16 \mathrm{f}$.

(94) Vergl. oben, Seite 182 .

(95) Vergl. oben, Seite $100 \mathrm{f}$.

(96) Vergl. oben, Seite $137 \mathrm{f}$.

(97) Vergl. Finanzbericht 1969, a. a. O., S. 356 f. 
(98) Grundgesetz, Art. 107, Abs. 2.

(99) Bundesministerium der Finanzen (Hrsg.), Finanzbericht 1973, abgeschlossen am 15. 3.1973, Bonn-Bad Godesberg, S. 212.

(100) Vergl. Bundesministerium der Finanzen (Hrsg.), Finanzbericht 1975 , abgeschlossen am 15.8.1974, Bonn-Bad Godesberg, S. 122.

(101) Vergl, oben, Seite $125 \mathrm{f}$.

(102) Vergl. Bundesministerium der Finanzen (Hrsg.), Finanzbericht 1974, abgeschlossen am 20.9.1973, Bonn-Bad Godesberg, S. $175 \mathrm{f}$.

(103) Vergl. oben, Seite $184 \mathrm{ff}$. und Seite 195.

(104) Vergl. oben, Seite $140 \mathrm{ff}$.

(105) Vergl. Tabelle 1, Spalte 6.

(106) Diese Differenz ist oben durch die Zerlegung der Lohnsteuer, die Zerlegung der Körperschaftsteuer und die Verteilung des Länderanteils an der Umsatzsteuer gemäß $\$ 2$ des Finanzausgleichsgesetzes erklärt worden. (Vergl. oben, Seite 149 ff.)

(107) Vergl. Heckt, W., Die Entwicklung des bundesstaatlichen Finanzausgleichs ...., a. a. O., S. $62 \mathrm{f}$.

(108) Ohne den Umverteilungseffekt, der von der Finanzreform von 1969 ausgeht, hätte der Länderfinanzausgleich 1974 ein Volumen von etwa $5 \mathrm{Mrd}$. DM aufweisen müssen. Die Erfahrungen mit dem Länderfinanzausgleich vor der Finanzreform sprechen dafür, daß eine offen ausgewiesene Umverteilungsmasse in dieser Höhe auf den erbitterten Widerstand der ausgleichspflichtigen Länder gestoßen wäre.

(109) Vergl. oben, Seite 141.

(110) Dies ist die Vergleichsverteilung beim zweiten Berechnungsansatz.

(111) Vergl. oben, Seite $193 \mathrm{f}$.

(112) Vergl. oben, Seite 134.

(113) Die Investitionszuweisungen des Bundes umfassen im wesentlichen: - "Finanzhilfen für besonders bedeutsame Investitionen der Länder und Gemeinden (Gemeindeveribände)", die der Bund nach Art. 104a, Abs. 4 GG den Ländern gewähren kann. Zu ihnen gehören im einzelnen:

a) Zuweisungen zur Krankenhausfinanzierung nach dem Krankenhaus sicherungs gesetz vom 29.6.1972 (BGB1. I S. $1009 \mathrm{ff}$ )

b) Zuweisungen für den kommunalen Straßenbau und den öffentlichen Personennahverkehr nach dem Gemeindeverkehrsfinanzierungs gesetz vom 18.3.1971 (BGB1. I S. $239 \mathrm{ff}$ );

c) Zuweisungen zur Förderung des Städtebaus nach dem Städtebauförderungs gesetz vom 27.7.1971 (BGBl. I S. $1125 \mathrm{ff}$ );

- Zuweisungen zur Durchführung der Gemeinschaftsaufgaben

a) Aus- und Neubau von wissenschaftlichen Hochschulen, 
b) Verbesserung der regionalen Wirtschaftsstruktur,

c) Verbesserung der Agrarstruktur und des Küstenschutzes nach Art. 91 a des Grundgesetzes.

(114) Vergl. oben, Seite 176 , Anmerkung 68.

(115) Vergl. Tabelle 1, Spalte 4.

(116) Vergl. Tabelle $8 \mathrm{a}$ und $8 \mathrm{~b}$.

(117) Vergl. oben, Seite $117 \mathrm{ff}$.

(118) Vergl. oben, Seite $61 \mathrm{ff}$.

(119) Vergl. oben, Seite $45 \mathrm{ff}$.

(120) Vergl. oben, Seite 134.

(121) Vergl. oben, Seite $66 \mathrm{ff}$.

(122) Diese fiktive Verteilung der Investitionszuschüsse wird deshalb im folgenden kurz "Minimalvorschlag" genannt.

(123) Vergl. oben, Seite $72 \mathrm{ff}$.

(124) Vergl. oben, Seite $98 \mathrm{ff}$.

(125) Vergl. Heckt, W., Die Leistungen der Länder für den gemeindlichen Finanzausgleich, a. a. O., S. $16 \mathrm{ff}$.

(126) Vergl: ebenda, S. 11.

(127) Vergl. Bundesministerium der Finanzen, Referat VA2, Finanzielle Leistungen des Bundes an die Länder nach den Haushaltsplänen der Länder 1974 und 1975, Schreiben an den Verfasser vom 19.8.1975.

(128) Vergl. Grundgesetz i.d.F. vom 12.5.1969, Art. 104a, Abs. 3.

(129) Vergl. oben, Seite $105 \mathrm{ff}$.

(130) Vergl. Bundesministerium der Finanzen, Referat VA2, Schreiben an den Verfasser vom 19.8.1975.

(131) Getränkesteuer, Schankerlaubnissteuer, Vergnügungssteuer, Hundesteuer usw. .

(132) Nach Art. 105, Abs. 2a GG haben die Länder die Gesetzgebungskompetenz über die örtlichen Verbrauch- und Aufwandsteuern.

(133) Außer Berlin.

(134) Vergl. Statistisches Bundesamt, Fachserie L, Finanzen und Steuern, Reihe 2, Steuerhaushalt von Bund, Ländern und Gemeinden 1974, Stuttgart, Mainz, August 1975, S. 22 und 23.

(135) Die Vernachlässigung dieser beiden Bestandteile der Gesamtfinanzmasse der Länder verfälscht das Gesamtergebnis nur geringfügig, denn quantitativ sind sie unbedeutend. Die "sonstigen Steuern und steuerähnlichen Einnahmen" der Gemeinden betragen 1974 pro Ein- 
wohner des Bundesgebietes 20,3 DM bei Extremwerten von 2,6 DM pro Kopf für Hamburg und 29,8 DM pro Kopf für Rheinland-Pfalz. (Berechnet nach: Statistisches Bundesamt, Finanzen und Steuern, Reihe 2, Steuerhaushalt von Bund, Ländern und Gemeinden 1974, a. a. O. , S. 20 und 21. ) Die Einnahmen aus dem Erwerbsvermögen erreichten 1972 bundesdurchschnittlich 18,4 DM pro Kopf und streuten zwischen 12, 3 DM pro Kopf (Nordrhein-Westfalen) und 30,7 DM pro Kopf (Rheinland-Pfalz). (Berechnet nach: Statistisches Bundesamt, Finanzen und Steuern, Reihe 1, Kommunalfinanzen 1972, Stuttgart, Mainz, Juni 1975, S. 226 f. und S. 238, )

(136) Bei einheitlicher Steue ranspannung.

(137) Vergl. Tabelle $8 \mathrm{~b}$, Spalte 5.

(138) Bundesraumordnungsprogramm vom 30.4.1975, a. a. O., S. 6.

(139) Vergl. oben, Seite $107 \mathrm{f}$.

(140) Grundsteuer A und B, Gewerbesteuer nach Ertrag und Kapital und Lohnsummensteuer.

(141) Vergl. Albers, W., Art. Finanzausgleich (III) Deutschland, a. a. O. , S. 569 ; und

Ehrlicher, W., u. a., Kommunaler Finanzausgleich und Raumordnung, a.a.O., S. $64 \mathrm{ff}$.

(142) Klein, F., Die Finanz- und Haushaltsreform, a. a. O., S. 34.

(143) Zuschlag zur Grunderwerbsteuer, Getränkesteuer, Schankerlaubnis steuer, Vergnügungssteuer, Hundesteuer u. a..

(144) Vergl. Zwilling, E., Untersuchungen zu einem rationalen Steuersystem der Gemeinden, a. a. O., Tabelle 8; und oben, Seite 80, Anmerkung 211.

(145) Vergl. z. B. Wissenschaftlicher Beirat beim Bundesministerium der Finanzen, Gutachten zum Gemeindesteuersystem ...., a. a. O., S. 14 ff; Zwilling, E., Untersuchungen zu einem rationalen Steuersystem der Gemeinden, a. a. O., S. $71 \mathrm{ff}$; und

Zeitel, G., Die zweckmäßige Struktur des kommunalen Steuersystems, in: Kommunale Finanzen und Finanzausgleich, a. a. O. , S. $173-218$, hier: S. $178 \mathrm{ff}$.

(146) Die Begriffe "horizontal" und "vertikal" bezeichnen hier einen anderen Tatbestand als auf Seite 137 . Während es dort um die Verteilung der Steuereinnahmen auf Gebietskörperschaften der gleichen oder verschiedener Ebenen ging, dient hier die Gemeindegröße als Unterscheidungs merkmal. Bei der horizontalen Steuerverteilung auf Gemeindeebene wird also unterschieden $\mathrm{zwischen}$ horizontalen und vertikalen Steuer kraftunterschieden.

(147) Wissenschaftlicher Beirat beim Bundesministerium der Finanzen, Gutachten zum Gemeindesteuersystem ..., a. a. O., S. 16. 
(148) Zwilling, E., Untersuchungen zu einem rationalen Steuersystem der Gemeinden, a.a. O., S. 83.

(149) Wissenschaftlicher Beirat beim Bundesministerium der Finanzen, Gutachten zum Gemeindesteuersystem ..., a. a. O., S. 17.

(150) Nach Ansicht des Verfassers sollten aus regionalpolitischen Gründen alle Gemeinden unabhängig von ihrer Größe mit gleich hohen Steuereinnahmen pro Einwohner ausgestattet werden.

Vergl. oben, Seite $120 \mathrm{ff}$, insbesondere Seite $131 \mathrm{ff}$;

vergl. auch Littmanns Kritik am "Finanzbedarf" als Steuerverteilungs kriterium, oben, Seite $118 \mathrm{f}$.

(151) Vergl. zur Beurteilung des kommunalen Steuersystems vor der Finanzreform z. B. :

Kommission für die Finanzreform, Gutachten über die Finanzreform in der Bundesrepublik Deutschland, a. a. O., S. $97 \mathrm{ff}$;

Wissenschaftlicher Beirat beim Bundesministerium der Finanzen, Gutachten zum Gemeindesteuersystem ..., a. a. O., S. 20 ff;

Entwurf eines .... Gesetzes zur Änderung und Ergänzung des Grundgesetzes (Finanzreformgesetz), a. a. O., S. $42 \mathrm{ff}$;

Heckt, W., Die Ziele der Gemeindefinanzreform, in: Bulletin des

Presse- und Informationsamtes der Bundesregierung, Nr. 25, Bonn, Februar 1968, S. 197 - 201, hier: S. 198 f.

(152) Vergl, oben, Seite $79 \mathrm{ff}$.

(153) Heckt, W., Die Ziele der Gemeindefinanzreform, a. a. O., S. 198.

(154) Kommission für die Finanzreform, Gutachten über die Finanzreform in der Bundesrepublik Deutschland, a. a. O., S. 3, Tz. 10.

(155) Vergl. Heckt, W., Die Ziele der Gemeindefinanzreform, a. a. O., S. 197.

(156) Finanzbericht 1970, a. a. O., S. 181.

(157) Ebenda, S. 182 .

(158) Dies fordert auch die Kommission für die Finanzreform. (Vergl. ihr Gutachten über die Finanzreform in der Bundesrepublik Deutschland, a. a. O., S. 90 f.)

(159) Vergl. Görgens, H. , Ergebnis und Bedeutung der Finanzreform, in: WWI-Mitteilungen, Zeitschrift des Wirtschaftswissenschaftlichen Instituts der Gewerkschaften, 23. Jg. , Heft 3, Düsseldorf, März 1970, S. 70 - 78, hier: S. 75; und

Hansen, A. , Auswirkungen der geplanten Gemeindefinanzreform,Ergebnis der steuerstatistischen Sonderuntersuchungen, in: Wirtschaft und Statistik, hrsg. v. Statistischen Bundesamt, Jg. 1969, Heft 5, Stuttgart, Mainz 1969, S. 245 - 252, hier: S. 248.

(160) Vergl. die Einwände des Verfassers gegen diese Methode der Abgeltung von Spillover-Effekten, oben, Seite 129.

(161) Vergl. oben, Seite $28 \mathrm{ff}$. 
(162) Vergl, oben, Seite $45 \mathrm{ff}$.

(163) Vergl. Klein, F., Die Finanzreform zwischen Bund, Ländern und Gemeinden, a. a. O., S. $18 \mathrm{f}$.

(164) Vergl. Gemeindefinanzreformgesetz vom 8. September 1969, a. a. O., $\$ 1$.

(165) Vergl, die Einnahmengewinne bzw. -verluste, die den Gemeinden der einzelnen Länder aus der Zerlegung der Lohnsteuer entstehen (Tabelle 2).

(166) Vergl. Gemeindefinanzreformgesetz vom 8. September 1969, a. a. O., $\S 3$.

(167) Finanzbericht 1970, a. a. O., S. 180.

(168) Elsner, H., Schüler, M., Das Gemeindefinanzreformgesetz, Einführung in die Gemeindefinanzreform und Erläuterungen zum Gemeindefinanzreformgesetz, Hannover 1970, S. 71.

(169) Vergl. Hansen, A., Auswirkungen der geplanten Gemeindefinanzre form, a. a. O., S. $250 \mathrm{ff}$.

(170) Elsner, H., Schüler, M., Das Gemeindefinanzreformgesetz, a. a. O., S. 96 .

(171) Ebenda, S. 72 .

(172) Finanzbericht 1970, a. a. O., S. 180.

(173) Heckt, W., Die Gemeindefinanzreform, in: Bulletin des Presse- und Informationsamtes der Bundesregierung, Nr. 17, Bonn, Februar 1969, S. 133 - 139, hier: S. 135 .

(174) Vergl. Elsner, H., Schüler, M., Das Gemeindefinanzreformgesetz, a. a. O., S. 103. Diese drei Bundesländer hoben tatsächlich den Gewerbesteuerausgleich nicht auf, sondern setzten lediglich seinen Vollzug für die Jahre 1970 und 1971 aus. Erst nach der endgültigen Festsetzung der Höchstbeträge auf 16.000/32.000 DM im (Bundes-)Gesetz zur Änderung des Gemeindefinanzreformgesetzes vom 27.12.1971 beseitigten auch sie mittels eines Landesgesetzes den Gewerbesteueraus gleich endgültig (vergl. unten, Anhang I).

(175) Bundesgesetzblatt, Teil I, S. 2157, Art. 1.

(176) Grundgesetz in der Fassung vom 12.5.1969, Art. 106, Abs. 6.

(177) Vergl. Gemeindefinanzreformgesetz vom 8. September 1969, a. a. O., $\S 6$, Abs. 1.

(178) Ist-Aufkommen der jeweiligen Gemeinde aus der Gewerbesteuer vom Ertrag und vom Kapital, geteilt durch die tatsächlich angewandten Hebesätze der Gemeinden und multipliziert mit 100.

(179) Vergl. Gemeindefinanzreformgesetz vom 8. September 1969, a.a. O., $\S 6$, Abs. 2 . 
(180) Vergl. Elsner, H., Schüler, M., Das Gemeindefinanzreformgesetz, a. a. O., S. $76 \mathrm{ff}$.

(181) Vergl. ebenda, S. 69.

(182) Finanzbericht 1970, a. a. O., S. 181.

(183) Die SPD-Bundestagsfraktion plädierte für eine Gewerbesteuerumlage in Höhe von $30 \%$. Bei Verwirklichung dieser Lösung und gleichzeitigem Wegfall des Gewerbesteuerausgleichs hätte sich eher eine Verstärkung als eine Abschwächung des kommunalen Steuerkraftgefälles eingestellt. Deswegen lehnten die Lander die Aufhebung des Gewerbesteuerausgleichs in diesem Fall ab. (Vergl. Heckt, W., Die Gemeindefinanzreform, a. a. O., S. 136; und Elsner, H., Schüler, M., Das Gemeindefinanzreformgesetz, a.a. O., S. 77).

(184) Begründung des Gemeindefinanzreformgesetzes, Bundestagsdrucksache $\mathrm{V} / 3876$, S. 6 .

(185) Vergl. Finanzbericht 1970, a. a. O., S. 181.

(186) Nachweis des Wegfalls des Gewerbesteuerausgleichs zwischen Betriebsund Wohngemeinden siehe unten, Anhang I.

(187) Kommunale Steuerkraft - Steuereinnahmen der Gemeinden bei einheitlicher Steueranspannung (gleichen Hebesätzen) in absoluten Werten.

(188) Die Notwendigkeit, Steuerkraftwerte zu verwenden, wird oben begründet. Vergl. oben, Seite 216.

(189) Vergl. oben, Seite $229 \mathrm{f}$.

(190) Mit der Aussage, daß das quantitative Ziel der Gemeindefinanzreform erreicht worden ist, wird nicht zugleich behauptet, daß die Gemeinden seit dem 1.1.1970 insgesamt ausreichend mit Finanzmitteln ausgestattet seien. Diese Frage wird hier nicht behandelt.

(191) Vergl. oben, Seite $227 \mathrm{ff}$.

(192) Vergl. die grundsätzlichen Einwände gegen diese Methode der Abgeltung von Spillover-Effekten, oben, Seite 129.

(193) Vergl. unten, Seite $238 \mathrm{ff}$.

(194) Vergl. unten, Seite $248 \mathrm{ff}$.

(195) Also gemäß den Prozentsätzen aus Spalte 2 der Tabelle 12c.

(196) Vergl. Ehrlicher, W., u. a., Kommunaler Finanzausgleich und Raumordnung, a. a. O., S. $64 \mathrm{ff}$.

(197) Vergl. Hansmeyer, K. -H. , Interkommunaler Finanzausgleich, a. a. O. , S. 268.

(198) Vergl. Hansen, A., Auswirkungen der geplanten Gemeindefinanzreform, a. a. O., S. 247 . 
(199) Die Stadtstaaten sowie das Saarland führten nur mit den Gemeinden ihrer Nachbarländer einen Gewerbesteuerausgleich durch. (Vergl. Ehrlicher, W., u. a., Kommunaler Finanzausgleich und Raumordnung, a.a. O., S. 64, Anmerkung 36.)

(200) Vergl. oben, Seite $232 \mathrm{ff}$.

(201) Vergl. oben, Seite 237.

(202) Also gemäß den Prozentsätzen aus Spalte 2 der Tabelle $13 \mathrm{~b}$.

(203) Die Berechnung der fiktiven gemeindlichen Steuerkraftwerte der einzelnen Größenklassen und der Umverteilungsmasse erfolgt analog zu der Berechnung in Tabelle 13b (vergl, oben, Seite $242 \mathrm{ff}$.).

(204) Vergl, oben, Seite 235.

(205) Vergl. Tabelle $13 \mathrm{~b}$, Spalte 6 und Tabelle 13c, Spalte 6.

(206) Vergl. oben, Seite $225 \mathrm{f}$.

(207) Diese Annahme trifft wahrscheinlich für etliche Einrichtungen nicht einmal zu. Eine Kommune errichtet und unterhält eine öffentliche Einrichtung in erster Linie, um ihre eigenen Einwohner mit öffentlichen Leistungen zu versorgen. Da viele dieser Einrichtungen in hohem Grade unteilbar sind, können sie von den Einwohnern des zentralen Ortes nicht ausgelastet werden. In dieser Situation sind die Grenzkosten, die durch die Benutzung der Einrichtung durch Einwohner des Umlandes entstehen, beinahe null oder doch wesentlich geringer als die Durchschnittskosten der öffentlichen Leistungserstellung.

(208) Die Benutzerquoten für einige zentralörtliche Einrichtungen hat Schneppe auf der Grundlage statistischer Daten geschätzt. (Vergl. Schneppe, F., Raumbedeutsame Wirkungen des kommunalen Finanzausgleichs in Nie dersachsen, a. a. O., S. $38 \mathrm{ff.}$ )

(209) Vergl, oben, Seite 128.

(210) Albers, W., Die regionalpolitische Bedeutung des Finanzausgleichs, a. a. O., S. 198.

(211) Vergl. Albers, W., Art. Standortwirkungen der staatswirtschaftlichen Tätigkeit, a.a. O., S. $220 \mathrm{f}$.

(212) Es muß nachdrücklich betont werden, daß das hier als vertretbar bezeichnete vertikale Steuerkraftgefälle zwischen großen und kleinen Gemeinden lediglich auf Schätzungen bzw. dem Augenschein basiert. Um konkretere Anhaltspunkte zu erhalten, bedarf es intensiver empirischer Untersuchungen über die Inanspruchnahme zentralörtlicher Einrichtungen durch Einwohner des Umlandes und der dadurch verursachten Kosten.

(213) Vergl. oben, Seite $125 \mathrm{f}$.

(214) Diese Beurteilung der Auswirkungen der Gemeindefinanzreform auf die vertikale Verteilung der kommunalen Steuerkraft wird von anderen 
Autoren nicht geteilt. So konstatiert z. B. Flämig eine leichte "Verminderung des Steuerkraftgefälles von den größeren zu den kleineren Gemeinden" durch die Gemeindefinanzreform, deren Ausmaß etwa der in dieser Arbeit ermittelten reformbedingten Steuerkraftnivellierung bei Vernachlässigung des Gewerbesteuerausgleichs entspricht (vergl. oben, S. 232 ff.) Diese (nicht zutreffend eingeschätzte) Wirkung der Gemeindefinanzreform kritisiert Flämig mit folgenden Worten: "So löblich auf den ersten Blick eine Einebnung des Steuerkraftgefälles auch sein mag, so wenig vermögen diese Ergebnisse der Finanzreform bei näherer Betrachtung zu befriedigen. Angesichts der immensen Aufgaben, die gerade die großen Städte und die zentralen Orte für die nächste Zukunft zu erfüllen haben, .... stellt sich die Frage, ob der in der Bundesrepublik nicht erst seit der Finanzreform offenkundige Trend zur Angleichung der Finanzkraftunterschiede in Abhängigkeit von der Gemeindegrößenklasse nicht ein Maß erreicht hat, das eine Korrektur im Denkansatz erforderlich macht." (Flämig, Ch., Gemeindefinanzen und kommunale Wirtschaftsentwicklungsplanung, a.a. O., S. 89.) Damit befürwortet Flämig noch größere Steuerkraftunterschiede zwischen Gemeinden unterschiedlicher Größenklassen, als sie ohnehin schon existieren. Eine solche vertikale Verteilung der kommunalen Steuerkraft würde den räumlichen Ballungstendenzen weitere Nahrung geben.

(215) Bundesraumordnungsprogramm vom 30.4.1975, a.a. O., S. 3.

(216) Ebenda, S. 4.

(217) Vergl.ebenda, S. 8.

(218) Vergl. ebenda, S. 35.

(219) Eine teilweise oder vollständige Beseitigung der Gewerbesteuer befür worten auch:

Kommission für die Finanzreform, Gutachten über die Finanzreform in der Bundesrepublik Deutschland, a. a. O., S. 96 ff;

Entwurf eines .... Gesetzes zur Änderung und Ergänzung des Grundgesetzes, a. a. O., S. 45;

Wissenschaftlicher Beirat beim Bundesministerium der Finanzen, Gutachten zum Gemeindesteuersystem ..., a. a. O., S. $34 \mathrm{ff}$;

Littmann, K., u. a., Die Gestaltung des kommunalen Finanzsystems ..., a. a. O., S. $57 \mathrm{ff}$.

(220) Vergl. Heckt, W., Die Ziele der Gemeindefinanzreform, a.a. O., S. 199.

(221) Vergl, oben, Seite $165 \mathrm{ff}$.

(222) Dieser Zweifel wird durch eine Untersuchung von Zwilling gestützt, deren Gegenstand allerdings eine Steuer auf die Brutto-Umsätze der letzten Stufe, nicht aber eine Steuer auf die Wertschöpfung der letzten Stufe ist. Die von Zwilling untersuchte Endverbrauchsumsatzsteuer weist sowohl in vertikaler als auch in horizontaler Hinsicht eine nur 
unwesentlich geringere Streuung ihres Pro-Kopf-Aufkommens auf als die Gewerbesteuer. (Vergl. Zwilling, E., Untersuchungen zu einem rationalen Steue rsystem ..., a. a. O., S. 128 ff und Tab. 15.)

$\mathrm{Zu}$ einem anderen Ergebnis kommt dagegen Oberhauser: "Sowohl zwischen den Stadtkreisen als auch zwischen den Landkreisen aller drei Bundesländer würde die Einführung einer Einzelhandelsumsatzsteuer zu einer z. T. erheblichen Verminderung der Streuung des Steuerauf kommens gegenüber der Gewerbesteuer führen". (Oberhauser, A., Material zur regionalen Streuung des Aufkommens einer Einzelhandelsumsatzsteuer, in: Kommunale Finanzen und Finanzausgleich, a. a. O. , S. 219 - 239, hier: S. 223.)

Diéses Ergebnis hat z. B. den Wissenschaftlichen Beirat beim Bundesministerium der Finanzen veranlaßt, in seinem oben angegebenen Gutachten vorzuschlagen, den Gemeinden die Ertragshoheit über die Gewerbesteuer zu entziehen und ihnen das örtliche Mehrwertsteueraufkommen der letzten Stufe zuzuweisen. Da die Untersuchung Oberhausers lediglich auf Kreisebene durchgeführt wurde, ist sie allerdings bedeutend weniger aussagefähig als die auf Gemeindewerten basierende Untersuchung von Zwilling.

(223) Vergl. oben, Seite 249.

(224) Vergl. oben, Seite 225 f.

(225) Vergl. Statistisches Bundesamt, Finanzen und Steuern, Reihe 9, Realsteuervergleich 1974, Stuttgart, Mainz, Dezember 1975, S. 105.

(226) Vergl. Zwilling, E., Untersuchungen zu einem rationalen Steuersystem der Gemeinden, a. a. O., Tabelle 23.

(227) Ebenda, Tabelle 15.

(228) Lokale Steuerbelastungsunterschiede sind dadurch eliminiert worden, daß die gewogenen Durchschnittshebesätze des Landes angewandt worden sind.

(229) Die Zahl der Gemeinden in den einzelnen Größenklassen hat sich in Schleswig-Holstein zwischen 1965 und 1974 folgendermaßen verändert:

Zahl der Gemeinden in Schleswig-Holstein

\begin{tabular}{|c|c|c|}
\hline & am 30.6.1965 & am 30.6 .1974 \\
\hline $0-<1.000$ & $1076=77,5 \%$ & $853=72,7 \%$ \\
\hline $1.000-<2.000$ & $166=12,0 \%$ & $154-13,1 \%$ \\
\hline $2.000-<3.000$ & $25=1,8 \%$ & $40=3,4 \%$ \\
\hline $3.000-<5.000$ & $48=3,5 \%$ & $40=3,4 \%$ \\
\hline $5.000-<10.000$ & $37=2,7 \%$ & $3,4 \%$ \\
\hline $10.000-<20.000$ & $21=1,5 \%$ & $29=2,5 \%$ \\
\hline $20.000-<50.000$ & $11=0,8 \%$ & $12=1,0 \%$ \\
\hline$\geqslant 50.000$ & $4=0.3 \%$ & $5=0,4 \%$ \\
\hline insgesamt & $1388=100,1 \%$ & $1173=99,9 \%$ \\
\hline
\end{tabular}


Statistisches Bundesamt, Finanzen und Steuern, Reihe 9, Realsteuervergleich 1965, Stuttgart, Mainz, September 1966, S. 46; Statistisches Landesamt Schleswig-Holstein, Realsteuervergleich in Schleswig-Holstein 1974, Kiel, Oktober 1975, S. 12.

(230) Für die beiden oberen Größenklassen die gesamte Differenz.

(231) Vergl. oben, Seite 132 f. und Seite 224.

(232) Vergl, oben, Seite $100 \mathrm{f}$.

(233) Die gewerbesteuerstarken Landkreise bieten ihren Einwohnern in der Regel ausreichende Arbeitsmöglichkeiten, so daß diese nur in geringem Umfang in kreisfreie Städte einpendeln müssen.

(234) Ausnahme: Hessen.

(235) Vergl. oben, Seite 260.

(236) Vergl. oben, Seite 260.

(237) Vergl. auch Tabelle $17 \mathrm{a}$, Spalte 2.

(238) Im folgenden "vertikaler Gemeindefinanzausgleich" genannt.

(239) Das Volumen des vertikalen Gemeindefinanzausgleichs in der Bundes republik Deutschland im Jahr 1974 (in Mill. DM):

Allgemeine und laufende Zuweisungen und Zuschüsse, Schuldendiensthilfen an Gemeinden (Gv.): vom Bund $1.257,9$ von Ländern $\frac{15.731,9}{16.989,8}$

Zuweisungen und Zuschüsse für Investitionen an Gemeinden (Gv.):

vom Bund $1.601,6$ von Ländern

Quelle: Statistisches Bundesamt, Fachserie L, Finanzen und Steuern, Reihe 1, Haushaltswirtschaft von Bund, Ländern und Gemeinden, Vierteljahreszahlen zur Finanzwirtschaft, 4. Vierteljahr 1974, Stuttgart, Mainz, September 1975, S. 50 - 53.

(240) Vergl, oben, Seite $98 \mathrm{ff}$. und Seite $204 \mathrm{ff}$.

(241) Es muß an dieser Stelle ausdrücklich davor gewarnt werden, dem vertikalen Finanzausgleich ballungsbremsende Wirkungen zuzusprechen, wenn durch ihn die relativen Finanzkraftunterschiede geringer ausfallen als die relativen Steuerkraftunterschiede. Die relative Einnahmenposition einer steuerstarken Gemeinde (Region) kann sich auch dann verschlechtern, wenn sie pro Einwohner überdurchschnittlich hohe ProKopf-Zuweisungen erhält. Ebenso kann sich die relative Einnahmenposition einer steuerschwachen Gemeinde trotz unterdurchschnittlich hoher Pro-Kopf-Zuweisungen verbessern. (Vergl. dazu das Beispiel der kreisfreien Stadt Frankfurt: Zuweisungen insgesamt 406,4 DM = 
$112,4 \%$ des Landesdurchschnitts und des Landkreises Dieburg: Zuweisungen insgesamt $337,8 \mathrm{DM}=93,3 \%$ des Landesdurchschnitts in Tabelle 19a.)

Unterschiede zwischen den Steuer-bzw. Finanzkraftrelationen zweier Einnahmenverteilungen lassen nur dann eindeutige Aussagen über Unterschiede in den Raumwirkungen der beiden Einnahmenverteilungen $\mathrm{zu}$, wenn in beiden Fällen das Volumen der Verteilungsmasse gleich groß ist und damit den Verschiebungen in den Relationen auch gleichgerichtete Veränderungen der absoluten Werte entsprechen. Dies war im bisherigen Verlauf der Untersuchung in der Regel der Fall. Mit der Einbeziehung des vertikalen Gemeindefinanzausgleichs in die Untersuchung ändert sich nun aber das Volumen der kommunalen Finanzmasse. Ob die regionale Verteilung der kommunalen Finanzkraft mehr oder weniger stark ballungsfördernd wirkt als die Verteilung der volumensmäßig kleineren Gemeindesteuereinnahmen kann nicht durch Vergleich der Finanzkraftrelation mit der Steuerkraftrelation festgestellt werden. Vielmehr muß ermittelt werden, ob durch den vertikalen Gemeindefinanzausgleich der absolute Einnahmenvorsprung (pro Einwohner) der steuerstarken Gemeinden (Regionen) gegenüber den steuerschwachen größer oder kleiner geworden ist.

(242) Vergl. dazu die oben gemachten Ausführungen über die regionalpolitische Funktion der Zuweisungen der übergeordneten an die untergeordneten Gebietskörperschaften (oben, S. 133 f.) und über die Verteilung der Investitionszuweisungen des Bundes an die Länder im Jahr 1974 (oben Seite $204 \mathrm{ff}$ ).

(243) Vergl. oben, Seite $216 \mathrm{f}$.

(244) Vergl. oben, Seite 78.

(245) Vergl. Statistisches Landesamt Baden-Württemberg, Statistische Berichte, Gemeindefinanzen im Rechnungsjahr 1974, Ergebnisse der vierteljährlichen Kassenstatistik, Stuttgart, Dezember 1975, S. 2, 4 und 6.

(246) Das Saarland besitzt keine kreisfreien Städte.

(247) Außerdem bringt die weiter unten durchgeführte Untersuchung der re gionalen Verteilung der Zuweisungen von Land und Bund an die Gemeinden und Gemeindeverbände eine relativ große Übereinstimmung zwischen den einzelnen Ländern dieser zweiten Gruppe zutage.

(248) Dies gilt am wenigsten für Schleswig-Holstein.

(249) Vergl, oben, Seite $271 \mathrm{f}$.

(250) Vergl. Bundesraumordnungsprogramm, a.a. O., S. 38.

(251) Ebenda, Seite 38.

(252) Ebenda, Seite 38.

(253) Dabei muß jedoch bedacht werden, daß für die einzelnen als Landkreise abgegrenzten Regionen lediglich Angaben über die Investitionszuweisun- 
gen an die Kreisverwaltungen, Verbandsgemeinden und kreisangehörigen Gemeinden mit 3.000 und mehr Einwohnern zur Verfügung stehen. Dadurch werden die Investitionszuweisungen an die einzelnen Landkrei se insgesamt um 68.675.000 DM = 25,7 DM pro Einwohner zu niedrig ausgewiesen. Folglich erhalten die Landkreise in Rheinland-Pfalz ins gesamt Zuweisungen für Investitionen in Höhe von 116,2 DM und Gesamtzuweisungen in Höhe von 341,8 DM pro Einwohner. (Vergl. Statistisches Landesamt Rheinland-Pfalz, Statistische Berichte, Die kassenmäßigen Ausgaben und Einnahmen der Gemeinden und Gemeindever bände 1974, Ergebnisse der vierteljährlichen Gemeindefinanzstatistik, Bad Ems, August 1975, S. 9. ) An der Wirkungsrichtung des vertikalen Gemeindefinanzausgleichs in Rheinland-Pfalz ändert sich also auch dann nicht viel, wenn man die Investitionszuweisungen an die Gemeinden mit weniger als 3.000 Einwohnern berücksichtigt.

(254) Auch bei Berücksichtigung der Investitionszuweisungen an die Gemeinden mit weniger als 3.000 Einwohnern.

(255) Vergl. oben, Seite $275 \mathrm{f}$.

(256) Gemäß Beschluß der Ministerkonferenz für Raumordnung vom 21.11. 1968. (Vergl. Bundesraumordnungsprogramm vom 30.4.1975, a.a. O., S. 13.)

(257) Vergl. Bundesraumordnungsprogramm vom 30.4 .1975 , a.a. O., S. 38. (258) Vergl. oben, Seite $271 \mathrm{f}$.

(259) Vergl. Bundesraumordnungsprogramm vom 30.4.1975, a.a. O., S. 38. (260) Vergl. oben, Seite $133 \mathrm{ff}$. und Seite $204 \mathrm{ff}$.

(261) Vergl. Bundesraumordnungsprogramm vom 30.4.1975, a.a. O., S. 13.

(262) Vergl. Grundgesetz i.d.F. vom 12.5.1969, Art. 105, Abs. 3.

(263) Abgesehen von konjunkturell bedingten Schwankungen.

(264) Kopfsteuern verletzen eklatant die allgemeinen Steuergrundsätze und scheiden damit von vornherein aus den Überlegungen aus.

(265) Vergl, oben, Seite $112 \mathrm{f}$.

(266) Dies gilt für die Kraftfahrzeugsteuer.

(267) Vergl. oben, Seite $246 \mathrm{f}$. und Seite $255 \mathrm{ff}$.

(268) Vergl. Grundgesetz i.d.F. vom 12.5.1969, Art. 106, Abs. 7 und die Finanzausgleichsgesetze der einzelnen Bundesländer.

(269) Vergl. dazu Ehrlicher, W., u. a., Kommunaler Finanzausgleich und Raumordnung, a. a. O., S. $22 \mathrm{ff}$;

Schneppe, F., Raumbedeutsame Wirkungen des kommunalen Finanzausgleichs in Niedersachsen, a. a. O., S. $50 \mathrm{ff}$.;

Institut "Finanzen und Steuern" e. V., Der kommunale Finanzausgleich in der Bundesrepublik Deutschland - Eine kritische Gesamtdarstellung, Heft 97, Bonn 1971, S. $27 \mathrm{ff}$. 
(270) Vergl. oben, Tabelle 18 e und Tabelle $19 \mathrm{~g}$.

(271) Dies gilt in der Regel für diejenigen speziellen Zuweisungen, die nach Schlüsseln verteilt werden und zur Finanzierung laufender Aufgaben dienen.

(272) Dies gilt für die meisten Investitionszuweisungen.

(273) Auf die Möglichkeit der Kommunen, Eigenmittel durch Investitionszuweisungen zu substituieren und sich damit einen Freiheitsraum zu erhalten, kann hier nicht eingegangen werden. (Vergl. dazu Spie $\beta$, L. , Der Finanzausgleich im Lichte volkswirtschaftlicher Ziele, a. a. O., S. 16 ff.)

(274) Vergl. Ehrlicher, W., u. a., Kommunaler Finanzausgleich und Raumordnung, a. a. O., S. $55 \mathrm{ff}$.

(275) Vergl. ebenda, S. 61.

(276) Vergl. dazu u. a. : Albers, W., Finanzzuweisungen und Standortverteilung, a. a. O., S. $283 \mathrm{f}$.;

Ehrlicher, W., u. a., Kommunaler Finanzausgleich und Raumordnung, a. a. O., S. 59 ff.;

Voigtländer, H., Die raumordnungspolitische Problematik des Finanzausgleichs ..., a.a. O., S. $188 \mathrm{ff}$.

(277) Das setzt selbstverständlich voraus, daß eindeutige Prioritäten gesetzt und Nutzen-Kosten-Analysen für die verschiedenen Handlungsalternativen durchgeführt werden.

(278) In der Diskussion über die Reform des kommunalen Einnahmensystems werden Maßnahmen aus beiden Konzeptionen gefordert. Vergl. Albers, W., Finanzzuweisungen und Standortverteilung, a.a. O., S. 279 f. und S. $283 \mathrm{f.}$;

Ehrlicher, W., u. a., Kommunaler Finanzausgleich und Raumordnung, a. a. O., S. $72 \mathrm{ff}$.;

Littmann, K., u. a, , Die Gestaltung des kommunalen Finanzsystems ..., a. a. O., S. $48 \mathrm{ff}$. 
Friedemann Tetsch - 978-3-631-75190-9

Downloaded from PubFactory at 01/11/2019 07:18:40AM

via free access 
a) Bücher und Aufsätze

ALBERS, W., Art. Finanzausgleich (III) Deutschland, in: Handwörterbuch der Sozialwissenschaften, hrsg. v. E. v. Beckerath u. a., 3. Bd., Göttingen 1961, S. 553 - 573.

derselbe, Finanzzuweisungen und Standortverteilung, in: Kommunale Finanzen und Finanzausgleich, hrsg. v. H. Timm und H. Jecht, Schriften des Vereins für Socialpolitik, N.F. Band 32, Berlin 1964, S. $253-286$.

derselbe, Art. Standortwirkungen der staatswirtschaftlichen Tätigkeit, in: Handwörterbuch der Wirtschaftswissenschaft (HdWW), zugleich Neuauflage des "Handwörterbuch der Sozialwissenschaften", hrsg. v. W. Albers u.a., Stichwort Sozialismus bis Steuern II, Stuttgart, Tübingen 1977, S. $212-223$.

derselbe, Der Einfluß des Finanzausgleichs auf regionale Wettbewerbsbedingungen und Produktionsstandorte, in: Gestaltungsprobleme der Weltwirtschaft, Festschrift aus Anlaß des 70. Geburtstags von A. Predöhl, hrsg. v. H. Jürgensen, Göttingen 1964, S. 462 - 491.

derselbe, Die regionalpolitische Bedeutung des Finanzausgleichs, III. Kapitel in: Möglichkeiten wirtschaftlicher Schwerpunktbildung in SchleswigHolstein, hrsg. v. der Gesellschaft für Regionale Strukturentwicklung e. V., 1. Band: Hauptgutachten, unter Mitwirkung von K. -H. Hansmeyer, W. Albers, H. Jürgensen, K. Mackscheidt und H. Zimmermann, unveröffentlichtes Manuskript, Bonn 1969, S. 169 - 244.

ALBERS, W. und FRIAUL, K.H. , Art. Subventionen, in: Staatslexikon, hrsg. v. d. Görres-Gesellschaft, 6. völlig neu bearbeitete und erweiterte Auflage, 11. Bd., 3. Ergänzungsband, Freiburg i. Br. 1970, Sp. 414 429.

BIEHL, D., u. a., Bestimmungsgründe des regionalen Entwicklungspotentials, Infrastruktur, Agglomeration und sektorale Wirtschaftsstruktur, Kieler Studien, Nr. 133, hrsg. v. H. Giersch, Tübingen 1975.

derselbe, Zur regionalen Einkommensverteilung in der Europäischen Wirtschaftsgemeinschaft, in: Die Weltwirtschaft, Halbjahresschrift des Instituts für Weltwirtschaft an der Universität Kiel, hrsg. v. H. Giersch, Heft 1, Tübingen 1972 , S. $64-78$.

BÖVENTER, E. v., Die Struktur der Landschaft, Versuch einer Synthese und Weiterentwicklung der Modelle J.H. von Thünens, W. Christallers und A. Löschs, in: Optimales Wachstum und Optimale Standortverteilung, Schriften des Vereins für Socialpolitik, N. F., Bd. 27, Berlin 1962 , S. $77-133$.

BRÖSSE, U., Raumordnungspolitik, Berlin, New York 1975. 
BRÖSSE, U., Ziele in der Regionalpolitik und in der Raumordnungspolitik, Zielforschung und Probleme der Realisierung von Zielen, Berlin 1972.

CAIRNCROSS, A., u.a., Wirtschaftspolitik für Europa, Wege nach vorn, München, Zürich 1974.

DAHMS, W., Gemeindefinanzreform 1970, in: Statistische Monatshefte Schleswig-Holstein, hrsg. v. Statistischen Landesamt Schleswig-Holstein, 23. Jg. . Heft 4, Kiel 1971, S. $64-67$.

DOERIG, H. -U., Der staatliche Einfluß auf die regionale Verteilung von Bevölkerung und Wirtschaft - unter besonderer Berücksichtigung der zentral- und gliedstaatlichen Industriestrukturpolitik im Kanton St. Gallen, Struktur - und regionalwirtschaftliche Studien des Schweizerischen Instituts für Außenwirtschafts- und Marktforschung an der Hochschule St. Gallen für Wirtschafts - und Sozialwissenschaften, Bd. 2, Zürich, St. Gallen 1968.

EGNER, E., Art. Raumwirtschaftspolitik, in: Handwörterbuch der Sozialwissenschaften, hrsg. von E. v. Beckerath, Bd. 8, Göttingen, Tübingen 1964, S. $694-704$.

EHRLICHER, W., u. a., Kommunaler Finanzausgleich und Raumordnung, Veröffentlichungen der Akademie für Raumforschung und Landesplanung, Abhandlungen, Bd. 51, Hannover 1967.

ELSNER, H. u. SCHÜLER, M., Das Gemeindefin anzreformgesetz, Einführung in die Gemeindefinanzreform und Erläuterungen zum Gemeindefinanzreformgesetz, Hannover 1970.

FISCHER-MENSHAUSEN, H., Einige Bemerkungen zur Diskussion über die Finanzreform, in: Wirtschaftsdienst, Wirtschaftspolitische Monats zeitschrift, hrsg. v. Hamburgischen Welt-Wirtschafts-Archiv, 48. Jg. , Heft 9, Hamburg 1968, S. 498 - 511.

FLÄMIG, Ch., Gemeindefinanzen und kommunale Wirtschaftsentwicklungs planung, Baden-Baden 1974.

FREY, R., Infrastruktur, Grundlagen der Planung öffentlicher Investitionen, Hand- und Lehrbücher aus dem Gebiet der Sozialwissenschaften, hrsg. v. E. Salin und G. Schmölders, Tübingen 1970.

GIERSCH, H. , Das ökonomische Grundproblem der Regionalpolitik, in: Jahrbuch für Sozialwissenschaft, 14. Jg., Göttingen 1963, S. $386-400$.

derselbe, Aufgaben der Strukturpolitik, in: Hamburger Jahrbuch für Wirtschafts- und Gesellschaftspolitik, Tübingen 1964, S. 61 - 90.

derselbe, Beschäftigungspolitik ohne Geldillusion, in: Die Weltwirtschaft, Halbjahresschrift des Instituts für Weltwirtschaft an der Universität Kiel, hrsg. v. H. Giersch, Heft 2, Tübingen 1972, S. $127-135$.

GÖRGENS, H. , Ergebnis und Bedeutung der Finanzreform, in: WWI-Mitteilungen, Zeitschrift des Wirtschaftswissenschaftlichen Instituts der Gewerkschaften, 23. Jg., Heft 3, Düsseldorf, März 1970, S. 70 - 78. 
HALLER, H., Wandlungen in den Problemen föderativer Staatswirtschaften, in: Finanzarchiv, hrsg. v. F. Neumark, N. F. 27, Heft 1-2, Tübingen 1968.

derselbe, Finanzpolitik, Grundlagen und Hauptprobleme, 4. durchgesehene und verbesserte Auflage, Tübingen 1968.

HANSEN, A., Auswirkungen der geplanten Gemeindefinanzreform, Ergebnis der steuerstatistischen Sonderuntersuchungen, in: Wirtschaft und Statistik, hrsg. v. Statistischen Bundesamt, Jg. 1969, Heft 5, Stuttgart, Mainz 1969, S. 245 - 252.

HANSMEYER, K. -H. , Interkommunaler Finanzausgleich, in: Archiv für Kommunalwissenschaften, 5. Jg., Stuttgart 1966, S. 261 - 284.

derselbe, Ziele und Träger regionaler Wirtschaftspolitik, in: Beiträge zur Regionalpolitik, hrsg. v. H.K. Schneider, Schriften des Vereins für Socialpolitik, N. F. Bd. 41, Berlin 1968, S. $36-60$.

HARTMANN und METZENMACHER, Umsatzsteuergesetz (Mehrwertsteuer), Kommentar, 6. Auflage, Loseblatt-Sammlung, Berlin o.J.

HECKT, W., Die Entwicklung des bundesstaatlichen Finanzausgleichs in der Bundesrepublik Deutschland, hrsg. v. Institut Finanzen und Steuern, Heft 103, Bonn 1973.

derselbe, Die Leistungen der Länder für den gemeindlichen Finanzausgleich, Institut Finanzen und Steuern (Hrsg.), Heft 105, Bonn 1974.

derselbe, Die Ziele der Gemeindefinanzreform, in: Bulletin des Presse- und Informationsamtes der Bundesregierung, $\mathrm{Nr}$. 25, Bonn, Februar 1968, S. $197-201$.

derselbe, Die Gemeindefinanzreform, in: Bulletin des Presse - und Informationsamtes der Bundesregierung, Nr. 17, Bonn, Februar 1969, S. 133 139.

HERMENS, F.A., Verfassungslehre, Demokratie und Frieden, Bd. 7, Veröffentlichungen des Forschungsinstituts für Politische Wissenschaft und Europäische Fragen der Universität zu Köln, 2. Auflage, Köln, Opladen 1968.

HORSTMANN, K., Horizontale Mobilität, in: Handbuch der empirischen Sozialforschung II, hrsg. v. R. König, Stuttgart 1969, S. 43 - 60 .

Institut Finanzen und Steuern, Die wichtigsten Vorschläge zur Finanzreform, Eine vergleichende Übersicht, $\mathrm{Nr} .107$, Bonn 1968.

dasselbe, Der kommunale Finanzausgleich in der Bundesrepublik Deutschland - Eine kritische Gesamtdarstellung, Heft 97, Bonn 1971.

ISENBERG, G. , Kräfte und Gegenkräfte im Ballungsprozeß, in: Die öffentliche Verwaltung, Zeitschrift für Verwaltungsrecht und Verwaltungs politik, Heft $21 / 22$ (16. Jg.), Stuttgart 1963, S. 807 - 811. 
JOCHIMSEN, R., Theorie der Infrastruktur, Grundlagen der marktwirtschaftlichen Entwicklung, Tübingen 1966.

JÜRGENSEN, H. , Antinomien in der Regionalpolitik, in: Jahrbuch für Sozialwissenschaft, 14. Jg., Göttingen 1963, S. 401 - 413.

derselbe, Private und soziale Kosten, in: Probleme der normativen Ökonomie und der wirtschaftspolitischen Beratung, hrsg. v. E. v. Beckerath und H. Giersch in Verbindung mit H. Lampert, Berlin 1963, S. 245 266.

KAMP, M.E., u. a., Das optimale Finanzsystem, Vorlesungen über Finanzwissenschaft, Heft 2, 2, völlig neubearbeitete und stark erweiterte Auflage, Bonn 1969.

KLEIN, F., Die Finanz- und Haushaltsreform, Schriften der Bundeszentrale für politische Bildung, Bonn 1969.

derselbe, Die Finanzreform zwischen Bund, Ländern und Gemeinden, in: Aus Politik und Zeitgeschichte, Beilage zur Wochenzeitung "Das Parlament", hrsg. v. der Bundeszentrale für politische Bildung, Bonn 1969.

derselbe, Das Finanzreformprogramm der Bundesregierung, in: Bulletin des Presse- und Informationsamtes der Bundesregierung, Nr. 83, Bonn, August 1967, S. $713-719$.

derselbe, Die Finanzreform Bund/Länder, in: Bulletin des Presse- und Informationsamtes der Bundesregierung, Nr. 34, Bonn, Mainz 1968, S. $270-276$.

KLOTEN, N., Steuerpolitik als regionale Strukturpolitik, in: Archiv für Kommunalwissenschaften, hrsg. v. Verein für Kommunalwissenschaf ten e. V. u. a., Halbjahresband 1964, Stuttgart 1964, S. 41 - 56.

derselbe, Standortwirkungen kommunaler Besteuerungsformen, in: Kommunale Finanzen und Finanzausgleich, hrsg. v. H. Timm und H. Jecht, Schriften des Vereins für Socialpolitik, N. F. Band 32, Berlin 1964, S. 121 171.

KOLMS, H., Finanzwissenschaft, Bd. IV, Berlin 1964.

Kommission der Europäischen Gemeinschaften, Die regionale Entwicklung in der Gemeinschaft, Analytische Bilanz, o. O., 1971.

Kommission für die Finanzreform, Gutachten über die Finanzreform in der Bundesrepublik Deutschland, 2. Auflage, Stuttgart 1966.

KRELLE, W., Verteilungstheorie, Wiesbaden 1962.

LAUSCHMANN, E., Grundlagen einer Theorie der Regionalpolitik, 2. Auflage, Veröffentlichungen der Akademie für Raumforschung und Landesplanung, Taschenbücher zur Raumplanung, Bd. 2, Hannover 1973.

LAUX, E., Kommunale Selbstverwaltung im Staat der siebziger Jahre, in: Archiv für Kommunalwissenschaften, hrsg. v. Verein für Kommunalwissenschaften e. V. u. a., 9. Jg., II. Halbjahresband, Stuttgart 1970, S. $217-239$. 
LITTMANN, K. , Finanzpolitik, räumliche Gleichgewichte und Optima, Kreislauftheoretische Betrachtungen über die Wirkungen der staatlichen Aktivität auf die räumliche Faktorverteilung, in: Kommunale Finanzen und Finanzausgleich, hrsg. v. H. Timm und H. Jecht, Schriften des Vereins für Socialpolitik, N. F. Band 32, Berlin 1964, S. 61-113.

LITTMANN, K., u. a., Die Gestaltung des kommunalen Finanzsystems unter raumordnungspolitischen Gesichtspunkten, Veröffentlichungen der Akademie für Raumforschung und Landesplanung, Abhandlungen Bd. 50, Hannover 1968.

LÖSCH, A., Die räumliche Ordnung der Wirtschaft, 3. unveränderte Auflage mit einem Vorwort von W. Stolper, Stuttgart 1962.

MIKSCH, L., Zur Theorie des räumlichen Gleichgewichts, Sonderdruck aus: Weltwirtschaftliches Archiv, Zeitschrift des Instituts für Weltwirtschaft an der Universität Kiel, hrsg. v. F. Baade, Bd. 66, Hamburg 1951.

MÜNSCHER, A. und KREIBICH, V., Das Gemeindefinanzreformgesetz als Instrument der Raumentwicklung - Regionale Mobilität und der Anteil der Gemeinden an der Einkommensteuer, in: Informationen zur Raumentwicklung, hrsg. v. d. Bundesanstalt für Landeskunde und Raumforschung, Heft 10/11, Bonn-Bad Godesberg 1974, S. $417-425$.

NEUMANN, M., Zur ökonomischen Theorie des Föderalismus, in: Kylos, Internationale Zeitschrift für Sozialwissenschaften, hrsg. v. G. Bombach, Vol XXIV, Basel 1971.

OBERHAUSER, A., Material zur regionalen Streuung des Aufkommens einer Einzelhandelsumsatzsteuer, in: Kommunale Finanzen und Finanzausgleich, a. a. O., S. $219-239$.

OBERT, G., Eine zeitgemäße Finanzverfassung, Verwirklichung der Finanzreform - Grundlage für eine wirksame Erfüllung der öffentlichen Aufgaben, in: Bulletin des Presse - und Informationsamtes der Bundesregie rung, Nr. 65, Bonn, Mai 1969, S. 555 - 558.

PAWLOWSKY, P. , Räumliche externe Effekte lokaler öffentlicher Leistungen im föderativen Staat, Dissertation, Basel 1972.

ROSE, K., Theorie der Außenwirtschaft, 5. durchgesehene Auflage, München 1974.

SIEBERT, H. , Zur interregionalen Verteilung neuen technischen Wissens, in: Zeitschrift für die gesamte Staatswissenschaft, hrsg. v. Fr. Böhm, u. a., Bd. 123, Tübingen 1967, S. $231-263$.

SPIESS, L., Der Finanzausgleich im Lichte volkswirtschaftlicher Ziele, Ansätze zu einer Theorie des Finanzausgleichs als wirtschaftspolitisches Steuerungsinstrument im Bundesstaate, Dissertation, Freiburg i. Br. 1973.

SCHÄFER, F., Bundesstaatliche Ordnung als politisches Prinzip, in: Aus 
Politik und Zeitgeschichte, Beilage zur Wochenzeitung "Das Parlament", hrsg. v. der Bundeszentrale für politische Bildung, Bonn, April 1975.

SCHNEIDER, H.K. , Über die Notwendigkeit regionaler Wirtschaftspolitik, in: Beiträge zur Regionalpolitik, hrsg. v. H.K. Schneider, Schriften des Vereins für Socialpolitik, N. F. Bd. 41, Berlin 1968, S. $3-17$.

derselbe, Modelle für die Regionalpolitik, in: Beiträge zur Regionalpolitik, a. a. O., S. $63-85$.

SCHNEIDER, E., Einführung in die Wirtschaftstheorie, II. Teil, Wirtschaftspläne und wirtschaftliches Gleichgewicht in der Verkehrswirtschaft, 9. durchgesehene Auflage, Tübingen 1964.

SCHNEPPE, F., Raumbedeutsame Wirkungen des kommunalen Finanzausgleichs in Niedersachsen, Veröffentlichungen der Akademie für Raumforschung und Landesplanung, Beiträge, Bd. 2, Hannover 1968.

SCHNYDER, J.S., Öffentliche Finanzen als Mittel der Regionalpolitik, Dissertation, Reinheim/Odw. 1967.

STEIN, O., Art. Bedarf und Bedürfnis, in: Handwörterbuch der Sozialwissenschaften, hrsg. v. E. v. Beckerath u. a., 1. Bd., Tübingen, Göttingen 1956, S. $707-718$.

STORBECK, D., Die wirtschaftliche Problematik der Raumordnung, Eine Unteršuchung über Notwendigkeit, Ziele und Mittel der Raumordnung im System der Marktwirtschaft, Berlin 1959.

STOTZ, M. , Die Entwicklung und der gegenwärtige Stand des Finanzausgleichs in der Bundesrepublik Deutschland verglichen mit den Finanzausgleichs systemen in anderen Ländern, Dissertation, Stuttgart 1972.

TÖPFER, K., Regionalpolitik und Standortentscheidung, Die Beeinflussung privater Pläne, dargestellt an der unternehmerischen Standortentscheidung, Beiträge zur Raumplanung, hrsg. vom Zentralinstitut für Raumplanung an der Universität Münster, Bd. 6, Bielefeld 1969.

VOIGT, F., u.a., Wirtschaftliche Entleerungsgebiete in Industrieländern, Ein Beitrag zur Theorie der Raumwirtschaft und der Regionalpolitik für die BRD, Forschungsberichte des Landes Nordrhein-Westfalen, Nr. 2061, Köln, Opladen 1969.

VOIGTLÄNDER, H., Die raumordnungspolitische Problematik des Finanzausgleichs zwischen Land und Gemeinden (Gemeindeverbänden) in Schleswig-Holstein, Dissertation, Hamburg 1969.

WAGENER, F., Aufgaben und Gliederung der Länder im neuen Jahrzehnt, in: Die Öffentliche Verwaltung, Zeitschrift für Verwaltungsrecht und Verwaltungspolitik, 23. Jg., Heft 5/6, Stuttgart 1970.

Wissenschaftlicher Beirat beim Bundesministerium der Finanzen, Gutachten zum Gemeindesteuersystem und zur Gemeindesteuerreform in der Bundesrepublik Deutschland, Schriftenreihe des Bundesministeriums der Finanzen, Heft 10, Bonn 1968. 
WITTMANN, W. , Bundesstaatlicher Finanzausgleich: Eine Globalbilanz, in: Zeitfragen der schweizerischen Wirtschaft und Politik, hrsg. v. Redressement National, Nr. 101, Zürich 1971.

derselbe, Einführung in die Finanzwissenschaft, III. Teil, Stuttgart 1972.

WITZMANN, K., Raumordnungspolitik, regionale Wirtschaftspolitik und Finanzpolitik, in: Finanzpolitik als Gegenstand der Regionalplanung, Forschungsberichte der Landesarbeitsgemeinschaft Bayern der Akademie für Raumforschung und Landesplanung, Bd. 45, Hannover 1969 , S. $89-100$.

ZEITEL, G., Probleme des Steuerverbundes, in: Archiv für Kommunalwissenschaften, hrsg. v. Verein für Kommunalwissenschaften e. V. u. a., 5. Jg., Stuttgart 1966.

derselbe, Die zweckmäßige Struktur des kommunalen Steuersystems, in: Kommunale Finanzen und Finanzausgleich, a. a. O., S. $173-218$.

ZIMMERMANN, H. , Öffentliche Ausgaben und regionale Wirtschaftsentwicklung, Veröffentlichungen der List Gesellschaft e. V., Bd. 61, Basel, Tübingen 1970.

ZWILLING, E., Untersuchungen zu einem rationalen Steuersystem der Gemeinden, Meisenheim am Glan 1971.

\section{b) Sonstige}

Bundesministerium der Finanzen (Hrsg.), Finanzbericht 1968, Die volkswirtschaftlichen Grundlagen und die wichtigsten finanzwirtschaftlichen Probleme des Haushaltsplans der Bundesrepublik Deutschland für das Rechnungsjahr 1968, abgeschlossen am 10.10.1967, Bonn-Bad Godesberg.

dasselbe, Finanzbericht 1969, abgeschlossen am 5.10.1968, Bonn-Bad Godesberg.

dasselbe, Finanzbericht 1970, abgeschlossen am 13.2.1970, Bonn-Bad Godesberg.

dasselbe, Finanzbericht 1971, abgeschlossen am 10.9.1971, Bonn-Bad Godesberg.

dasselbe, Finanzbericht 1972, abgeschlossen am 30.9.1971, Bonn-Bad Godesberg.

dasselbe, Finanzbericht 1973, abgeschlossen am 15.3.1973, Bonn-Bad Godesberg.

dasselbe, Finanzbericht 1974, abgeschlossen am 20.9.1973, Bonn-Bad Godesberg.

dasselbe, Finanzbericht 1975, abgeschlossen am 15.8.1974, Bonn-Bad Godesberg. 
Bundesministerium der Finanzen, Referat VA 2, Finanzielle Leistungen des Bundes an die Länder nach den Haushaltsplänen der Länder 1974 und 1975, Schreiben an den Verfasser vom 19.8.1975.

dasselbe, Schnellbrief an die Finanzmintster (Finanzsenatoren) der Länder, betr. Zerlegung der Lohnsteuer und Körperschaftsteuer für das I. IV. Vierteljahr 1974, Bonn, April 1974, Juli 1974, Oktober 1974, Januar 1975.

dasselbe, Die Ausgaben und Einnahmen dèr Länder für das Rechnungsjahr 1974, VA 2 - FV $4036-1 / 75$.

dasselbe, Referat VA 3, Schreiben an den Verfasser vom 22.9.1975.

dasselbe, Referat VA 2, Die Finanzen der Länder im Rechnungsjahr 1974, Bonn, Juli 1975.

Statistisches Bundesamt (Hrsg.), Statistisches Jahrbuch 1975 für die Bundesrepublik Deutschland, Stuttgart, Mainz, August 1975.

dasselbe, Fachserie L, Finanzen und Steuern, Reihe 1, Haushaltswirtschaft von Bund, Ländern und Gemeinden, Vierteljahreszahlen zur Finanzwirtschaft 1974, Stuttgart, Mainz, September 1975.

dasselbe, Fachserie L, Finanzen und Steuern, Reihe 1, Kommunalfinanzen 1972, Stuttgart, Mainz, Juni 1975.

dasselbe, Fachserie L, Finanzen und Steuern, Reihe 2, Steuerhaushalt von Bund, Ländern und Gemeinden, 4. Vierteljahr und Jahr 1969, Stuttgart, Mainz, Mai 1970.

dasselbe, Fachserie L, Finanzen und Steuern, Reihe 2, Steuerhaushalt von Bund, Ländern und Gemeinden 1974, Stuttgart, Mainz, August 1975.

dasselbe, Fachserie L, Finanzen und Steuern, Reihe 9, Realsteuervergleich 1974, Stuttgart, Mainz, Dezember 1975.

dasselbe, Fachserie L, Finanzen und Steuern, Reihe 9, Realsteuervergleich 1965, Stuttgart,Mainz, September 1966.

dasselbe, Statistisches Jahrbuch 1974 für die Bundesrepublik Deutschland, Stuttgart, Mainz 1974.

dasselbe, Schreiben VII B-47/4 - 393 vom 15.9.1976 an den Verfasser.

Statistisches Landesamt Baden-Württemberg, Statistische Berichte, Gemeindefinanzen im Rechnungsjahr 1974, Ergebnisse der vierteljährlichen Kassenstatistik, Stuttgart, Dezember 1975.

Gemeinschaftsveröffentlichung der Statistischen Landesämter, Das Bruttoinlandsprodukt der kreisfreien Städte und Landkreise 1970 und 1972, Volkswirtschaftliche Gesamtrechnungen der Länder, Heft 6, Stuttgart 1975.

Statistisches Landesamt Schleswig-Holstein, Statistische Berichte, Realsteuervergleich in Schleswig-Holstein 1974, Kiel, Oktober 1975. 
Statistisches Landesamt Schleswig-Holstein, Statistische Berichte, Die Gemeindefinanzen in Schleswig-Holstein im Jahre 1974, Teil 2, Kiel, September 1975.

dasselbe, Statistische Berichte, Realsteuervergleich in Schleswig-Holstein 1975, Kiel, Januar 1977.

dasselbe, Unveröffentlichte Angaben aus Vierteljahresstatistik der Kommunalfinanzen, 1. - 4. Vierteljahr 1975, Az. : $21-137 / 75$.

Landesamt für Datenverarbeitung und Statistik Nordrhein-Westfalen, Statistische Berichte, Die Gemeindefinanzen in Nordrhein-Westfalen 1974, Ergebnisse der vierteljährlichen Kassenstatistik, Düsseldorf, September 1975 .

Statistisches Landesamt Rheinland-Pfalz, Statistische Berichte, Realsteuervergleich 1974, Bad Ems, September 1975.

dasselbe, Statistische Berichte, Die kassenmäßigen Ausgaben und Einnahmen der Gemeinden und Gemeindeverbände 1974, Ergebnisse der vierteljährlichen Gemeindefinanzstatistik, Bad Ems, August 1975.

dasselbe, Anlage zum Schreiben vom 30.10.1975 an den Verfasser, Az.: $41329 / \mathrm{Ly} / \mathrm{Kr}$.

Statistisches Amt des Saarlandes, Statistische Berichte, Kommunale Finanzen 1974, Saarbrücken, Januar 1977.

Hessisches Statistisches Landesamt, Anlage zum Schreiben an den Verfasser vom 20.8.1975, VII 1-Az.: 77 g $231 / 75$, Tgb. -Nr. 978.

dasselbe, Anlage zum Schreiben an den Verfasser vom 24.9.1975, VII 1-Az. : 77 g $231 / 75$, Tgb. -Nr. 1114.

Niedersächsisches Landesverwaltungsamt -Statistik-, Statistische Berichte, Realsteuern und Realsteuerhebesätze 1974, Hannover, Oktober 1975.

dasselbe, Die Gemeindefinanzen für das Jahr 1974 in Niedersachsen, Ergebnisse der vierteljährlichen Kassenstatistik, Hannover, August 1975.

Bayerisches Statistisches Landesamt, Statistische Berichte, Staatliche und kommunale Steuern und andere Ergebnisse der vierteljährlichen Finanzstatistiken sowie Realsteuervergleich in Bayern 1974, München, August 1975.

dasselbe, Anlagen zum Schreiben an den Verfasser vom 6.5.1977, Nr. VI/A/ $1-2736$.

Bundesregierung der Bundesrepublik Deutschland, Raumordnungsprogramm für die großräumige Entwicklung des Bundesgebiets (Bundesraumordnungsprogramm), Bundestagsdrucksache 7/3584, April 1975.

Grundgesetz für die Bundesrepublik Deutschland vom 23. Mai 1949.

Entwurf eines ....Gesetzes zur Änderung und Ergänzung des Grundgesetzes (Finanzreformgesetz) vom 30. April 1968, Bundestagsdrucksache V/2861, Bonn 1968. 
Einundzwanzigstes Gesetz zur Änderung des Grundgesetzes (Finanzreformgesetz) vom 12. Mai 1969, BGBl. I S. $359 \mathrm{ff}$.

Zweiundzwanzigstes Gesetz zur Änderung des Grundgesetzes (Gesetz zur Erweiterung der Gesetzgebungszuständigkeit des Bundes) vom 12. Mai 1969, BGBl. I S. 363 .

Gesetz über die Grundsätze des Haushaltsrechts des Bundes und der Länder (Haushaltsgrundsätzegesetz) vom 19. August 1969, BGBl. I S. 1273.

Gesetz zur Förderung der Stabilität und des Wachstums der Wirtschaft vom 8. Juni 1967, BGBl. I S. $582 \mathrm{ff}$.

Gesetz über die Gemeinschaftsaufgabe "Ausbau und Neubau von wissenschaftlichen Hochschulen" (Hochschulbauförderungsgesetz) vom 1. September 1969, BGBl. I S. $1556 \mathrm{ff}$.

Gesetz über die Gemeinschaftsaufgabe "Verbesserung der regionalen Wirtschaftsstruktur" vom 6. Oktober 1969, BGBl. I S. $1861 \mathrm{ff}$.

Gesetz über die Gemeinschaftsaufgabe "Verbesserung der Agrarstruktur und des Küstenschutzes" vom 3. September 1969, BGBl. I S. 1573 ff.

Gesetz zur Neuordnung der Gemeindefinanzen (Gemeindefinanzreformgesetz) vom 8. September 1969, BGBl. I S. $1587 \mathrm{ff}$.

Gesetz über den Finanzausgleich zwischen Bund und Ländern vom 28. August 1969, BGB1. I S. $1432 \mathrm{ff}$.

Neufassung des Gesetzes über die Steuerberechtigung und die Zerlegung bei der Einkommensteuer und der Körperschaftsteuer (Zerlegungsgesetz) vom 25. Februar 1971, BGB1. I S. $145 \mathrm{ff}$.

Gemeindeverkehrsfinanzierungsgesetz vom 18. März 1971, BGBl. I S. 239 ff.

Krankenhaussicherungsgesetz vom 29. Juni 1972, BGBl. I S. $1009 \mathrm{ff}$.

Städtebauförderungsgesetz vom 27. Juli 1971, BGBl. I S. 1125 ff.

Begründung des Gemeindefinanzreformgesetzes, Bundestagsdrucksache V/ 3876.

Gesetz zur Regelung des Finanzausgleichs (Finanzausgleichsgesetz - FAG) in der Fassung vom 10. Mai 1972 des Landes Hessen, GVBl. I S. $110 \mathrm{ff}$.

Umsatzsteuergesetz (Mehrwertsteuer) vom 29. Mai 1967, BGBl. I S. 545 ff. Einkommensteuergesetz in der Neufassung vom 1. Dezember 1971, (EStG $1971)$. 
Nachweis des Wegfalls des Gewerbesteuerausgleichs zwischen Betriebsund Wohngemeinden.

1. Baden-Württemberg:

Gesetz zur Änderung des Gesetzes über den kommunalen Finanzausgleich vom 16. Juni 1970, in: Gesetzblatt für Baden-Württemberg, Jg. 1970, S. $253 \mathrm{ff} ., \S 2$.

2. Hessen:

Fünftes Gesetz zur Änderung des Finanzausgleichsgesetzes vom 16. Dezember 1969, in: Gesetz- und Verordnungsblatt für das Land Hessen, Teil I 1969, S. 320 ff. , Art. 3.

3. Bayern:

a) Gesetz zur Aussetzung des Vollzugs (1) des Gesetzes über die Durchführung des Gewerbesteuerausgleichs zwischen Wohngemeinden und Betriebsgemeinden vom 18. Dezember 1969, in: Bayerisches Gesetzund Verordnungsblatt, S. 398.

b) Gesetz über die Aufhebung (1) des Gesetzes über die Durchführung des Gewerbesteuerausgleichs zwischen Wohngemeinden und Betriebsgemeinden vom 23. Dezember 1971, in: Bayerisches Gesetz- und Verordnungsblatt, S. 475 .

4. Niedersachsen:

a) Drittes Gesetz zur Änderung des Gesetzes über den Finanzausgleich vom 11. Februar 1970, in: Niedersächsisches Gesetz- und Verordnungs blatt, S. $28 \mathrm{ff}$, Art. V.

b) Gesetz über die Aufhebung (1) des Gesetzes über den Gewerbesteuerausgleich zwischen Betriebsgemeinden und Wohngemeinden vom 14. Juli 1972, in: Niedersâchsisches Gesetz- und Verordnungsblatt, S. 386.

5. Rheinland-Pfalz:

a) Landesgesetz zur Änderung des Finanzausgleichsgesetzes vom 26. Februar 1970, in: Gesetz- und Verordnungsblatt für das Land Rheinland-Pfalz, S. 70 ff., Art. 2.

b) Landesgesetz zur Änderung des Finanzausgleichsgesetzes vom 6. Juni 1972, in: Gesetz- und Verordnungsblatt für das Land Rheinland-Pfalz, S. $199 \mathrm{ff}$., Art. 3 .

6. Nordrhein-Westfalen:

Gesetz über die Aufhebung des Gewerbesteuerausgleichs vom 10. März

(1) Hervorhebung vom Verfasser. 
1970, in: Gesetz - und Verordnungsblatt für das Land Nordrhein-Westfalen, S. 602 .

7. Schleswig-Holstein:

Gesetz über den Finanzausgleich in Schleswig-Holstein vom 25. März 1970, in: Gesetz- und Verordnungsblatt für Schleswig-Holstein, S. $50 \mathrm{ff} ., \$ 42$, Abs. 2, Nr. 2. 


\section{FINANZWISSENSCHAFTLICHE SCHRIFTEN}

Band 1 Prof. Dr. Werner Steden: Finanzpolitik und Einkommensverteilung. Ein Wachstums- und Konjunkturmodell der Bundesrepublik Deutschland. (In Vorbereitung)

Band 2 Rainer Hagemann: Kommunale Finanzplanung im föderativen Staat. 173 S., 1976.

Band 3 Klaus Scherer: Maßstäbe zur Beurteilung von konjunkturellen Wirkungen des öffentlichen Haushalts. 242 S., 1977.

Band 4 Brita Steinbach: „Formula Flexibility“ - Kristische Analyse und Vergleich mit diskretionärer Konjunkturpolitik. 370 S., 1977.

Band 5 Hans-Georg Petersen: Personelle Einkommensbesteuerung und Inflation. Eine theoretisch-empirische Analyse der Lohn- und veranlagten Einkommensteuer in der Bundesrepublik Deutschland. 330 S., 1977.

Band 6 Friedemann Tetsch: Raumwirkungen des Finanzsystems der Bundesrepublik Deutschland. Eine Untersuchung der Auswirkungen der Finanzreform von 1969 auf die Einnahmenposition der untergeordneten Gebietskörperschaften und ihrer regionalpolitischen Zieladäquanz. 384 S., 1978.

Band 7 Wilhelm Pfähler: Normative Theorie der fiskalischen Besteuerung. Ein methodologischer und theoretischer Beitrag zur Integration der normativen Besteuerungstheorie in die Wohlfahrtstheorie. 224 S., 1978. 
Friedemann Tetsch - 978-3-631-75190-9

Downloaded from PubFactory at 01/11/2019 07:18:40AM

via free access 